\title{
IUCN Directory of Protected Areas in Oceania
}

\section{Compiled by the}

World Conservation Monitoring Centre

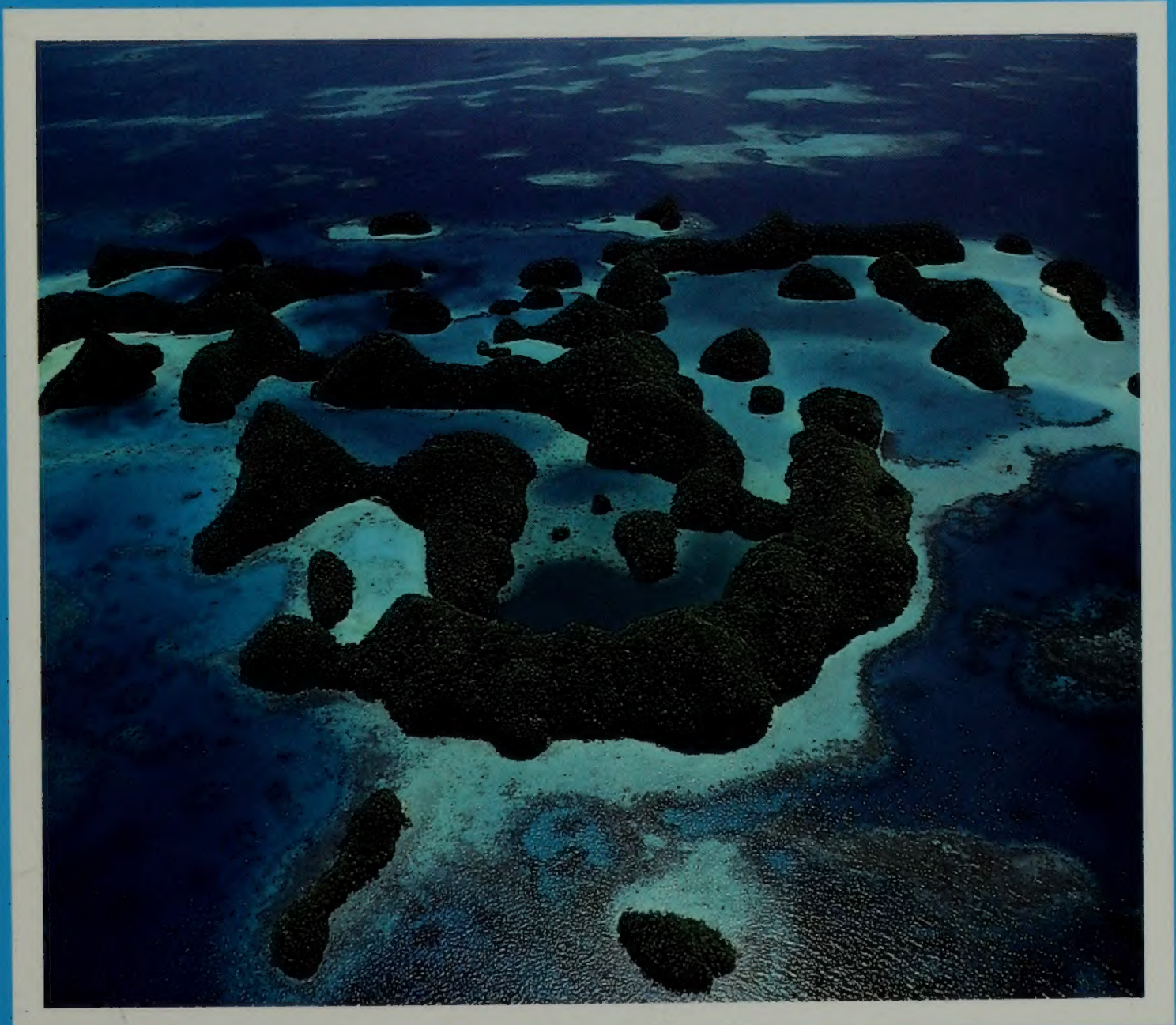

IUCN - The World Conservation Union 
A/N 4019 InCN 1991 


\section{IUCN Directory of Protected Areas \\ in Oceania}




\section{IUCN - THE WORLD CONSERVATION UNION}

Founded in 1948, IUCN - the World Conservation Union - is a membership organisation comprising governments, non-governmental organisations (NGOs), research institutions, and conservation agencies in over 100 countries. The Union's objective is to promote and encourage the protection and sustainable utilisation of living resources.

Several thousand scientists and experts from all continents form part of a network supporting the work of its six Commissions: threatened species, protected areas, ecology, strategy and planning, environmental law, and education and communication. Its thematic programmes include forest conservation, wetlands, marine ecosystems, plants, the Sahel, Antarctica, and population and sustainable development. These activities enable IUCN and its members to develop sound policies and programmes for the conservation of biological diversity and sustainable development of natural resources.

\section{WCMC - THE WORLD CONSERVATION MONITORING CENTRE}

The World Conservation Monitoring Centre (WCMC) is a joint venture between the three partners in the World Conservation Strategy, IUCN - the World Conservation Union, the World Wide Fund for Nature (WWF), and the United Nations Environment Programme (UNEP). Its mission is to support conservation and sustainable development by collecting and analysing global conservation data so that decisions affecting biological resources are based on the best available information.

WCMC has developed a globa! overview database of the world's biological diversity that includes threatened plant and animal species, habitats of conservation concern, critical sites, protected areas of the world, and the utilisation and trade in wildlife species and products. Drawing on this database, WCMC provides an information service to the conservation and development communities, governments and United Nations agencies, scientific institutions, the business and commercial sector, and the media. WCMC produces a wide variety of specialist outputs and reports based on analyses of its data. 


\title{
IUCN Directory of Protected Areas in Oceania
}

\author{
Compiled by
}

\author{
James R. Paine
}

World Conservation Monitoring Centre

in collaboration with the

IUCN Commission on National Parks and Protected Areas

and the

South Pacific Regional Environment Programme 
Published by: IUCN, Gland, Switzerland and Cambridge, UK

Prepared by: The World Conservation Monitoring Centre, Cambridge, UK

Production of this Directory was supported in part by the East-West Center of Honolulu, Hawaii, through a grant to the Center from the John D. and Catherine T. MacArthur Foundation.

A contribution to GEMS - the Global Environment Monitoring System.

Copyright:
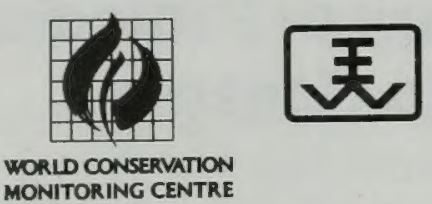
MONITORING CENTRE

(1991) International Union for Conservation of Nature and Natural Resources

Reproduction of this publication for educational or other non-commercial purposes is authorised without prior permission from the copyright holder. Reproduction for resale or other commercial purposes is prohibited without the prior written permission of the copyright holder.

Citation: $\quad$ IUCN (1991). IUCN Directory of Protected Areas in Oceania. Prepared by the World Conservation Monitoring Centre. IUCN, Gland, Switzerland and Cambridge, UK. xxiii +447 pp.

ISBN:

2-8317-0069-8

Compiled by: James R. Paine

Printed by: $\quad$ Page Bros (Norwich) Ltd., UK

Cover photos: $\quad$ Ngerukewid Islands Wildlife Preserve, Republic of Palau.

WWF/IUCN: Douglas Faulkner

Produced by: IUCN Publications Services Unit on desktop publishing equipment purchased through a gift from Mrs Julia Ward

Available from: IUCN Publications Services Unit,

219c Huntingdon Road, Cambridge, CB3 0DL, UK

or

IUCN Communications Unit

Avenue du Mont-Blanc, CH-1196 Gland, Switzerland

The designations of geographical entities in this book, and the presentation of the material, do not imply the expression of any opinion whatsoever on the part of IUCN or WCMC or other participating organisations concerning the legal status of any country, territory, or area, or of its authorities, or concerning the delimitation of its frontiers or boundaries. 


\section{CONTENTS}

Page

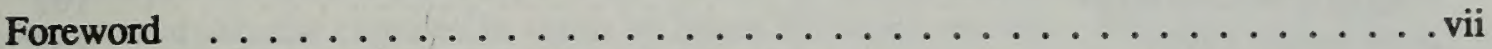

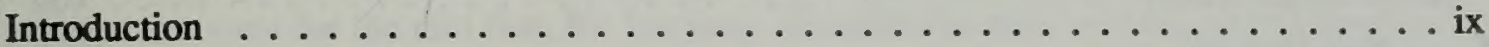

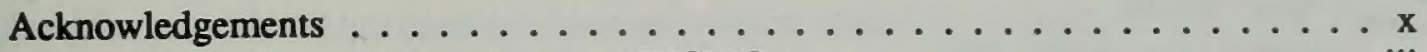

Managing information on protected areas at WCMC $\ldots \ldots \ldots \ldots \ldots$ xiii

Information sheets: guidelines to their contents $\ldots \ldots \ldots \ldots \ldots \ldots \ldots$

Information sheets on protected areas $\ldots \ldots \ldots \ldots \ldots$ xvii

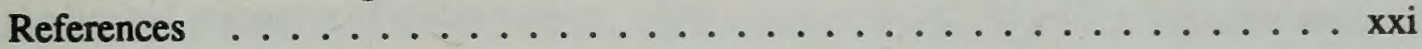

Annex 1: Categories and management objectives of protected areas . . . . . . xxii

Annex 2: IUCN threatened species categories . . . . . . . . . . . . . . . . . . . . . . .

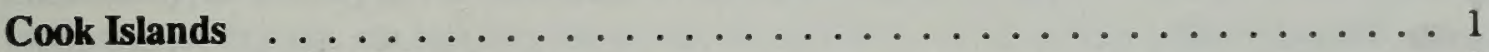

Summary of protected areas $\ldots \ldots \ldots \ldots \ldots \ldots$

Map of protected areas $\ldots \ldots \ldots \ldots \ldots \ldots \ldots$

Information sheets $\ldots \ldots \ldots \ldots \ldots$

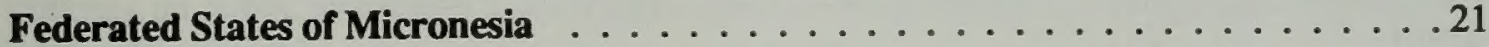

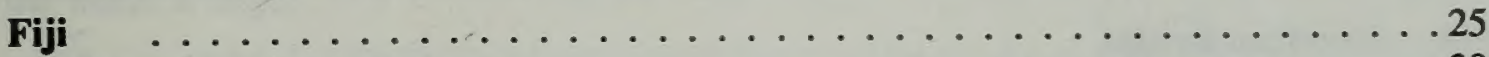

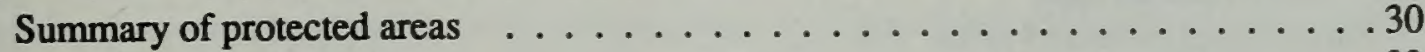

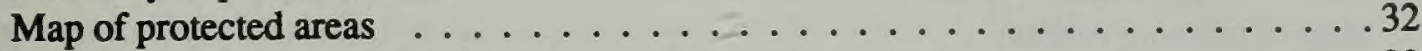

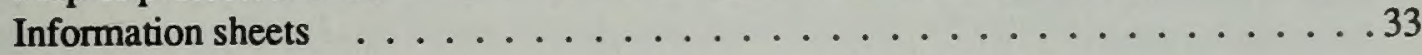

France - French Polynesia . . . . . . . . . . . . . . . . . 45

Summary of protected areas $\ldots \ldots \ldots \ldots \ldots \ldots \ldots \ldots$

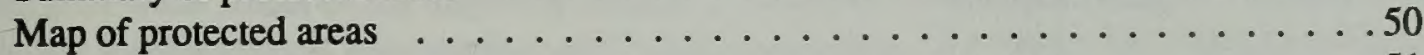

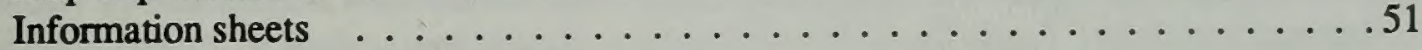

France - New Caledonia . . . . . . . . . . . . . . . . . . . 59

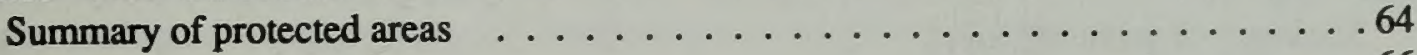

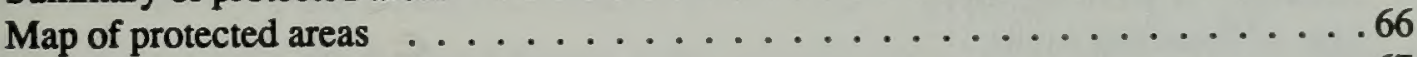

Information sheets $\ldots \ldots \ldots \ldots \ldots \ldots \ldots \ldots \ldots . \ldots \ldots 67$

France - Wallis and Futuna $\ldots \ldots \ldots \ldots \ldots \ldots \ldots$

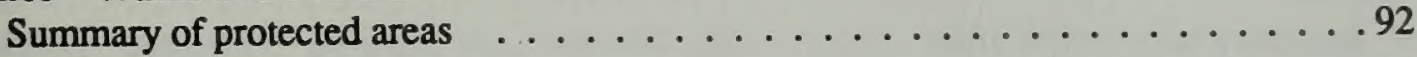

Kiribati, Republic of . . . . . . . . . . . . . . . . . .93

Summary of protected areas $\ldots \ldots \ldots \ldots \ldots \ldots . \ldots \ldots 9$

Map of protected areas $\ldots \ldots \ldots \ldots \ldots \ldots$

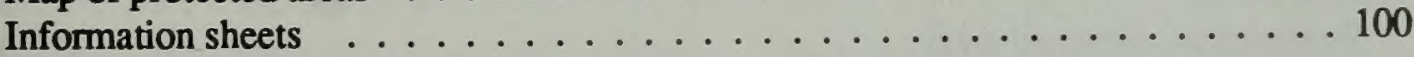

Marshall Islands, Republic of . . . . . . . . . . . . . . . . . . 119

Summary of protected areas . . . . . . . . . . . . . 122

Map of protected areas . . . . . . . . . . . . . . . 123

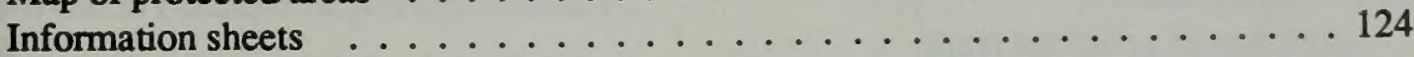

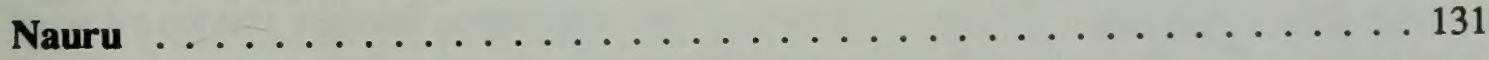

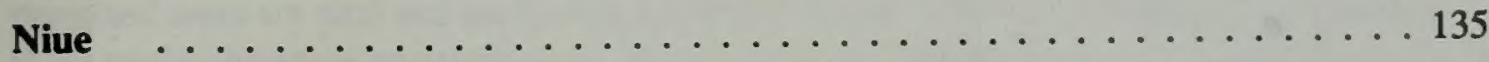

Northern Mariana Islands, Commonwealth of . . . . . . . . . . . . . . . 139

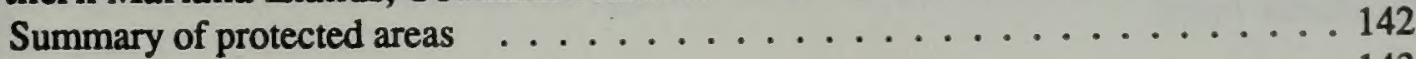

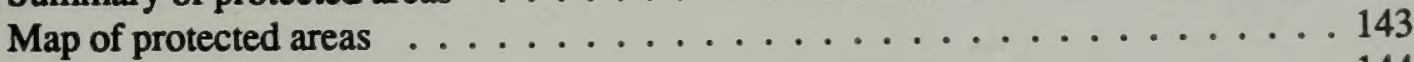

Information sheets $\ldots \ldots \ldots \ldots \ldots \ldots \ldots \ldots \ldots \ldots$ 
Palau, Republic of . . . . . . . . . . . . . . . . . . . 157

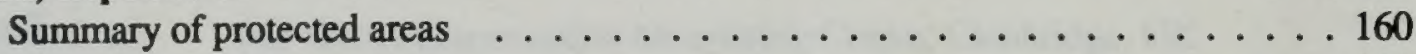

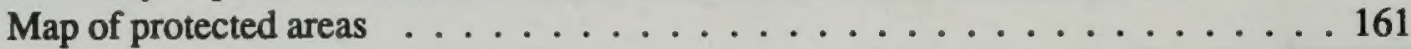

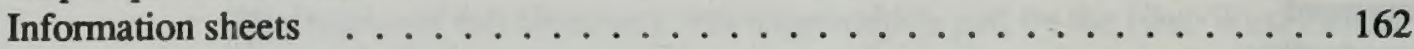

Papua New Guinea . . . . . . . . . . . . . . . . . . . . . 167

Summary of protected areas . . . . . . . . . . . . . 177

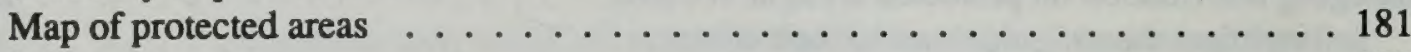

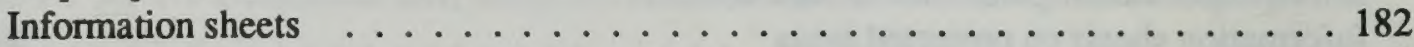

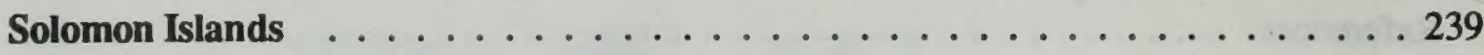

Summary of protected areas . . . . . . . . . . . . . . 247

Tokelau . . . . . . . . . . . . . . . . . . 253

Tonga, Kingdom of . . . . . . . . . . . . . . . . . . . 257

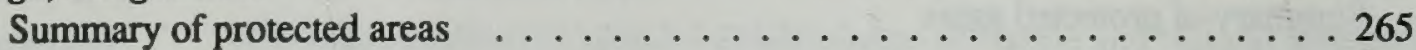

Map of protected areas . . . . . . . . . . . . . . 266

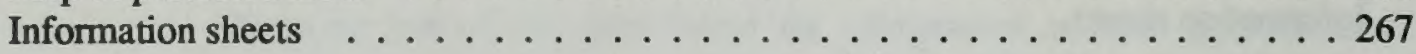

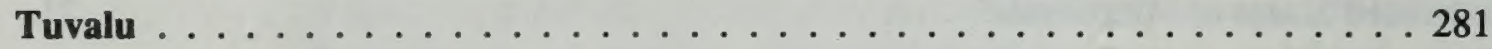

USA - American Samoa . . . . . . . . . . . . . . . . . 285

Summary of protected areas . . . . . . . . . . . . . . . . 290

Map of protected areas . . . . . . . . . . . . . . . . 291

Information sheets . . . . . . . . . . . . . . . . 292

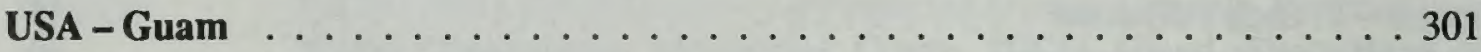

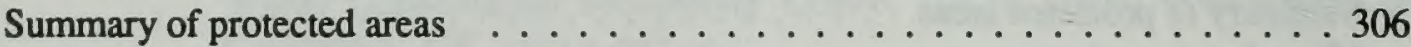

Map of protected areas . . . . . . . . . . . . . . . . . . 307

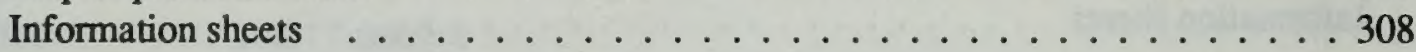

USA - Hawaii . . . . . . . . . . . . . . . . . . . . . . 327

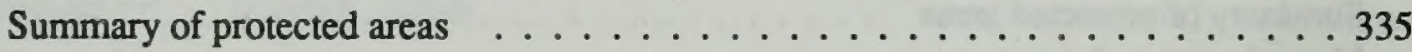

Map of Protected Areas . . . . . . . . . . . . . . . . 338

Information sheets . . . . . . . . . . . . . . . . . . . 339

Vanuatu . . . . . . . . . . . . . . . . . . . 371

Summary of protected areas $\ldots \ldots \ldots \ldots \ldots \ldots \ldots \ldots$

Map of protected areas . . . . . . . . . . . . . . . . 379

Information sheets $\ldots \ldots \ldots \ldots \ldots \ldots \ldots \ldots \ldots \ldots \ldots \ldots \ldots$

Western Samoa . . . . . . . . . . . . . . . . . . . . . . . . . 387

Summary of protected areas $\ldots \ldots \ldots \ldots \ldots \ldots \ldots \ldots$

Map of protected areas . . . . . . . . . . . . . . . . . . . 397

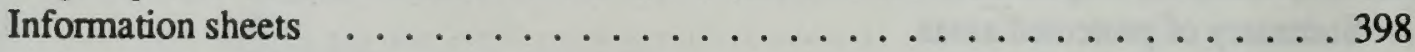

Other Pacific Islands . . . . . . . . . . . . . . . . . . . . . . . . . 407

Summary of protected areas $\ldots \ldots \ldots \ldots \ldots \ldots . \ldots . \ldots 40 . \ldots \ldots$

Map of protected areas . . . . . . . . . . . . . . . . 408

Information sheets $\ldots \ldots \ldots \ldots \ldots \ldots \ldots$. . . . . . . . . . . . . . . .

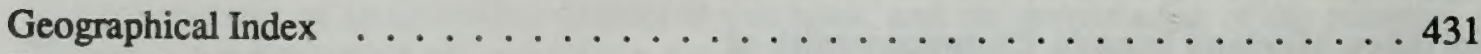

Taxonomic Index . . . . . . . . . . . . . . . . . 435 


\section{FOREWORD}

The islands of the Pacific conjure up visions of warmth, beauty and colour set in a vast ocean ... a paradise captured in words by James Michener and Oscar Hammerstein. This image perhaps accounts for the fact that, for too long, Oceania has been a backwater in the world's conservation priorities. It has considerable conservation needs, but lacks the large animal species which capture public imagination and funding support.

Oceania is blessed with great diversity but saddled with the vulnerability of small islands and the limited resources of micro nations, while many of its people seek a consumer-oriented lifestyle.

Fortunately, in-country government and NGO efforts, backed by regional initiatives and growing international support, are tackling the particular problems which beset conservation in this vast region of scattered islands.

The publication of this IUCN Directory of Protected Areas in Oceania is a positive step in building up public awareness in the Pacific nations and territories, in the Oceania region and in the world at large.

Oceania, as covered by this Directory, extends from its largest land mass in Papua New Guinea in the east to Chile's Isla de Pascua (Easter Island) in the west and from the islands of Hawaii in the north to Australia's Lord Howe Islands and New Zealand's Kermadecs in the south.

Settled initially some 20,000 years ago and subsequently colonised by voyagers across its vast expanse of water, most of the habitable islands of Oceania were occupied by around 1000 AD variously by Melanesian, Micronesian and Polynesian people. Their island homes were diverse. Low coral islands or atolls, coral islands or reefs lifted from the ocean floor, emerging as high atolls on limestone platforms, islands of volcanic origin, and continental islands. Isolated islands saw the evolution of unique flora and fauna with many endemic species.

Traditional constraints on resource use and, in larger areas and surrounding seas, an abundance of natural resources meant that communities lived in relative harmony with their environment.

European "discovery" between the 16th and 18th centuries and then Western colonisation impacted significantly on the situation, with the introduction of alien species, changing patterns of resource use, and exploitation of forests combining to have a devastating impact on many indigenous species and their often small and fragile habitats.

Independence brought a new range of challenges to often tiny nations made up of small island communities across an ocean whose fisheries attracted sometimes destructive fishing techniques from outside the region and whose community-based land tenure systems found it hard to cope with Western concepts of private ownership.

In such a context, regional cooperation and innovative approaches to resource management and protected areas are vital and are having a positive impact, as the Directory shows, with progress in the establishment of protected areas, including some with a distinctive South Pacific character, such as Papua New Guinea's wildlife management areas established and managed by customary land owners. 
In 1975, New Zealand hosted the First South Pacific Conference on National Parks and Reserves in Wellington and in 1976 a key initiative was taken by the South Pacific Forum, the political association of independent Pacific countries. Consultation with other regional bodies, including the South Pacific Commission (SPC), led in 1982 to a decision to set up a South Pacific Regional Environment Programme (SPREP) located with SPC in Noumea, New Caledonia. The small SPREP Secretariat implements a wide-ranging work programme among which the field of protected areas and nature conservation is of particular importance. Related SPREP projects deal with problems of introduced species, bird conservation, and the establishment and effective management of terrestrial and marine protected areas.

The Second South Pacific conference on protected areas was held in Australia in 1979, but, since its establishment, SPREP has taken the lead in organising the two subsequent such conferences at ministerial level, held in Western Samoa in 1985 and Vanuatu in 1989. SPREP works, too, to implement two regional conventions, the Convention on the Conservation of Nature in the South Pacific (Apia Convention) and the Convention for the Protection of the Natural Resources and Environment of the South Pacific Region (SPREP Convention).

While SPREP does not quite cover the whole of the Oceania region dealt with in the Directory, its definition of the South Pacific is wide enough to cover 22 island states or territories across 29 million sq. $\mathrm{km}$ of ocean, approximately the size of Africa.

The most encouraging sign for the future is the confidence the Oceanic states have in SPREP as a coordinating and innovating body working in cooperation with UNEP, IUCN - The World Conservation Union, and other bodies such as the Honolulu-based East-West Center, the World Wide Fund for Nature and other non-governmental organisations.

The publication of this Directory is welcomed by IUCN and its Commission on National Parks and Protected Areas, whose Vice-Chair for Oceania, Iosefatu Reti of Western Samoa, is a former SPREP Coordinator.

The confident hope is that the Directory will encourage the island states and territories to focus even more on the importance of protected areas, working through SPREP's coordinating efforts and with greater support from the world conservation community. Such areas are vital to preserve the biological diversity which is the region's often unique natural heritage and to provide a base for environmentally sensitive tourism which can capitalise on the world's positive image of Oceania as a region of beauty and peace.

P.H.C. Lucas

Chair, IUCN Commission on National Parks and Protected Areas

Wellington, New Zealand 


\section{INTRODUCTION}

Participants at the World National Parks Congress, held in Bali, Indonesia in 1982, recognised that the ready availability of good-quality information on the world's protected areas was essential to a wide range of international organisations, governments, protected area managers, voluntary bodies and individuals. Such information is a prerequisite for assessing the coverage and status of protected areas from regional and global perspectives. Moreover, monitoring protected areas is vital to ensure that those areas designated for conservation of the world's natural resources continue to meet the needs of society.

The World Conservation Monitoring Centre (WCMC) is gradually developing its capabilities as an international centre for information on protected areas. Working in collaboration with the IUCN Commission on National Parks and Protected Areas, the WCMC Protected Areas Data Unit (PADU) is compiling a series of regional protected areas directories, with priority addressed to tropical countries where much of the world's biological diversity is to be found. Past work has been focused on the Neotropical and Afrotropical realms and South Asia, culminating in the publication of protected area directories for each region.

The Action Strategy for Protected Areas in the South Pacific, adopted by the Third South Pacific National Parks and Reserves Conference held in Apia, Western Samoa in 1985, identifies a number of specific activities at national, regional and international levels, which are important steps in the establishment and effective management of protected areas in the region. One of the activities identified for implementation by IUCN was to develop a protected areas database from information collected by governments and other sources, and publish relevant data as a "Directory of South Pacific Region Protected Areas".

A draft directory had, in fact, been prepared prior to the 1985 conference, and was discussed with participants at that meeting. Also, the format of the country reports which participants were asked to present to the Conference was designed with the update of the draft directory in mind. It had been intended that the directory would be revised following the Conference, using the information provided in the country reports and by participants. Unfortunately, however, funds were not available to complete the work at that time.

Since then, the original draft has been extensively revised and up-dated, with the incorporation of much additional material. This has been made possible both by the increased levels of core funding now available to WCMC, and through a collaborative project with the US Fish and Wildlife Service (funded by US-AID). This project led to the preparation of overviews of the protected areas system of ten South Pacific countries, for use as briefing documents for US-AID personnel. This effectively funded revision of the texts for ten countries, carried out in collaboration with appropriate individuals in each of the countries concerned.

The draft overviews, and a revised draft protected areas directory, were presented at the Fourth South Pacific Conference on Nature Conservation and Protected Areas held in Vanuatu in 1989. This led to further review of the text, both as a result of papers presented by participants, and through interaction with a wide range of contacts made at the conference. Presentations were also made at two other Pacific meetings, to ensure people were fully aware of the project, and to stimulate a wider response to appeals for information. These were the US National Park Service workshop, "Interpreting critical issues in resources management" (War in the Pacific National 
Historical Park, Guam, April 1990), and the "Congress on Coastal and Marine Tourism" (East-West Center, Honolulu, May 1990).

This Directory covers the protected areas systems of American Samoa, Commonwealth of the Northern Mariana Islands, Cook Islands, Fiji, Federated States of Micronesia, French Polynesia, Guam, Hawaii, Kiribati, Marshall Islands, New Caledonia, Nauru, Niue, Palau, Papua New Guinea, Solomon Islands, Tokelau, Tonga, Tuvalu, Vanuatu, Wallis and Futuna, Western Samoa and some of the Pacific islands of Australia, Chile, New Zealand and the United States. Summary data are presented for all protected areas known to exist in these countries, although only a limited number of properties are described in detail (largely a reflection of the availability of information, documentation on some sites being non-existent or not easily obtainable).

The Directory is organised into chapters for each country. Each chapter comprises a standard format description of the national protected area system, accompanied by a list of protected areas, and a map of protected areas (for widely scattered islands and atolls a general map depicts the geographical location). In cases where there are no formal protected areas, no list or map is provided. This section is followed by descriptions of individual properties in alphabetical order. Geographical and taxonomic indexes enable easy reference to individual properties and plant or animal species mentioned in the text.

\section{ACKNOWLEDGEMENTS}

This Directory has to a large extent been a cooperative effort, benefiting from a tremendous amount of assistance from within the Pacific region. Many people have contributed to the preparation of the Directory through reviewing or compiling material and providing new information. Their assistance is greatly appreciated. Those who spring to mind in the final hours of its preparation are listed below under respective country chapters. To others, whose contributions may have been overlooked inadvertently in the course of time, sincere apologies are due.

Viane Ali (Fiji); Sebastian Anefal (FSM); Graham Baines (Solomon Islands); Ernest Bani (Vanuatu); Bruce Beehler (Smithsonian Institution); Everett Bishop (Western Samoa); Michael Brooke (Henderson Island); Marcus Chambers (Vanuatu, Papua New Guinea); Richard Chesher (Tonga); Gilbert Child (FAO); Earl of Cranbrooke (Vanuatu); The Reverend Canon Crutwell (Papua New Guinea); Jean-Louis d'Auzon (New Caledonia); Chris Dahl (FSM); Nancy Daschbach (American Samoa); Peter Eaton (Papua New Guinea); Lou Eldredge (Pacific Science Association); Netatua Fifita (Tonga); Gladys Fullman (Fiji); Frederick Green (Guam); Larry Hamilton (East-West Centre); M. Harber (Guam); Bryan Harry (Hawaii); Roger Hicks (Papua New Guinea); Heidi Hirsh (Guam); Erik Holm-Petersen (Tourism Council of the South Pacific); Jack Hopa (Vanuatu); H. Hopkins (Papua New Guinea); Henry Isa (Solomon Islands); Roy Kam (Hawaii); Kelese Kolone (Tuvalu); Guy Kula (Papua New Guinea); L. Lamothe (Papua New Guinea); Annette Lees (Maruia Society); David Lotz (Guam); Harley Manner (Palau, Guam); Anthony Mariano (Guam); George Marshall (Papua New Guinea); Adrian Marshall (Vanuatu); Gerald McCormack (Cook Islands); James Miculka (Guam); Warwick Murray (New Zealand); Audrey Newman (Hawaii); P. Osborne (Papua New Guinea); Demei Otobed (Belau); Sia Paopao (American Samoa); Malcolm Payne (Countryside Commission for Scotland); Sam Pearsall (TNC); Kalati Poai (Western Samoa); Nick Polunin (Papua New Guinea); James Reichel (Northern Marianas); Iosefatu Reti (Western Samoa, SPREP); Guy Salmon (Maruia Society); Elizabeth Schreiber (Kiribati); Birandra Singh (Fiji); Philippe Siu (French Polynesia); 
Neil Stronach (Papua New Guinea); Suliana Suwatibau (Fiji); G. Talagi (Niue); Katino Teeb'aki (Kiribati); Peter Thomas (SPREP); Peter Vaughan (Solomon Islands); Yolande Vernaudon (French Polynesia); Bonnie Vittery (Henderson Island); Dick Watling (Fiji); Neva Wendt (SPREP); Lauren Wenzel (Fiji); Gary Wiles (Guam).

A number of present and previous staff of PADU have been involved in the preparation of this directory. In particular, the preliminary draft presented at the Third South Pacific National Pakes and Reserves Conference was prepared by Jeremy Harrison.

Particular thanks are again due to Jeremy Harrison, in his role of Head of the Protected Areas Data Unit, being a tireless source of advice and support. Michael Green and Sara Day compiled the chapter on Papua New Guinea and Peter Gorbutt compiled the data sheet on J.H. Garrick Memorial Reserve, Fiji. Other past and present members of staff in WCMC who have contributed their expertise by reviewing draft information sheets and providing further information, include Steve Davis, Brian Groombridge, Martin Jenkins, Tim Inskipp and Sue Wells, and Tim Johnson, from the International Council for Bird Preservation. Mike Adam and Gillian Bunting (WCMC), gave generously of their time and patience as they struggled with the cartographical puzzle that scatters such small islands across the immensity of the Pacific. Secretarial support was most ably given by Alison Suter, assisted by Debbie Rothera. Thanks also go to my colleagues Clare Billington and Donald Gordon for their moral support. The support of our colleagues at IUCN headquarters, notably Vitus Fernando and James Thorsell, is also acknowledged.

The final copy was prepared for publication by Barbara Lambert, IUCN Publications Services Unit, and Alison Suter assisted with proof-reading.

The production of this Directory was supported in part by the East-West Center of Honolulu, Hawaii, through a grant to the Center from the John D. and Catherine T. MacArthur Foundation. We are happy to acknowledge the assistance of Larry Hamilton in securing this support.

This Directory is not a final statement and in no way represents a cessation of interest in the Pacific region on the part of WCMC. There will always be new developments in the field of protected areas, perhaps even more so now that both the Apia Convention and the SPREP Convention have entered into force. Thus, there is a continuing need to maintain and update the WCMC files. With this Directory goes a plea for corrections, comments and additional material, in order that WCMC can carry out its mission as effectively as possible. By the same token, WCMC offers an information service that covers an increasingly wide range of topics. All parties, from individuals to government departments, are invited to contact WCMC with their enquiries at the address below.

Notwithstanding the significant contributions of those mentioned above, errors and omissions remain the responsibility of the compiler.

James R. Paine

WCMC Protected Areas Data Unit

219 Huntingdon Road, Cambridge, CB3 ODL, UK

Tel: (0223) 277314

Fax: $\quad$ (0223) 277316

Telex: $\quad 817036$ SCMU G

E-mail: jimp@wcmc.uucp 



\section{MANAGING INFORMATION ON PROTECTED AREAS AT WCMC}

\section{Institutional background}

The IUCN Commission on National Parks and Protected Areas (CNPPA) has been actively involved in the collection and dissemination of information on protected areas ever since it was set up in 1960 to serve as the "leading international, scientific and technical body concerned with the selection, establishment and management of national parks and other protected areas". Over the years CNPPA's information management role increased to the extent that in 1981 it set up the Protected Areas Data Unit to undertake this service. Support for this initiative was forthcoming from the United Nations Environment Programme, as part of its Global Environmental Monitoring Programme. Originally part of the IUCN Conservation Monitoring Centre, PADU is now an integral part of the World Conservation Monitoring Centre, restructured in July 1988 as a joint venture between the three partners in the World Conservation Strategy, namely IUCN - The World Conservation Union, the World Wide Fund for Nature (WWF) and the United Nations Environment Programme (UNEP).

\section{Objectives}

WCMC aims to provide accurate up-to-date information on protected area systems of the world for use by its partners (IUCN, WWF and UNEP) in the support and development of their programmes, other international bodies, governmental and non-governmental organisations, scientists and the general public. Such information covers the entire spectrum of protected areas, from national parks and sanctuaries established under protected areas legislation or customary regimes to forest reserves created under forestry legislation. It also includes privately-owned reserves in which nature is protected.

PADU has an integral relationship with CNPPA. In particular, PADU is responsible to CNPPA for producing the United Nations List of National Parks and Protected Areas $(1982,1985,1990)$, which is periodically generated from its protected areas database currently totalling some 24,000 records. This database, together with supporting documentation, includes comprehensive information on natural sites designated under international conventions and programmes, namely the Convention concerning the Protection of the World Cultural and Natural Heritage (World Heritage Convention), Convention on Wetlands of International Importance especially as Waterfowl Habitat (Ramsar Convention), and Unesco Man and Biosphere Programme. Thus, PADU cooperates closely with the Division of Ecological Sciences, Unesco, in maintaining information on Biosphere Reserves and World Heritage Sites accorded by the MAB Secretariat and World Heritage Committee, respectively. Likewise, it is responsible to the Ramsar Bureau for managing information on Ramsar Wetlands.

\section{Information capture, management and compilation}

Information is collected from official sources, viz. national agencies responsible for administering protected areas, and other sources through a global network of contacts ranging in profession from policy-makers and administrators to land managers and scientists. It is also obtained from published and unpublished literature. Regional CNPPA meetings and other 
relevant scientific and technical meetings provide valuable opportunities for making new contacts and collecting fresh information.

Information, ranging from books, reports, management plans, scientific papers, and maps, is stored as hard copy in manual files. Basic data on individual protected areas are extracted and, after verification, entered in a protected areas database. This computerised database can be used for generating lists of protected areas meeting pre-defined criteria, together with summary statistics, as well as performing more complex tasks. In addition, boundaries of protected areas are gradually being digitised, using a Geographic Information System, in order to be able to generate computerised mapped output. The raw information is also used for compiling information sheets on national protected areas systems (protected areas systems information sheets) and on individual protected areas (protected areas information sheets). These information sheets are compiled according to standard formats developed over the years by PADU in collaboration with CNPPA, details of which are given elsewhere in this directory.

\section{Dissemination of information}

Compiled information is periodically published in the form of regional or thematic directories, with sections on individual countries comprising a protected areas system information sheet, a protected areas list with accompanying map, and a series of protectcd areas information sheets covering at least the more important properties. Prior to releasing or publishing documents, draft material is circulated for review by relevant government agencies and experts to help ensure that compiled information is accurate and comprehensive. Regional and thematic directories published to date are as follows:

IUCN Directory of Neotropical Protected Areas (1982)

IUCN Directory of Afrotropical Protected Areas (1987)

MAB Information System: Biosphere Reserves: Compilation 4 (1986)

MAB Information System: Biosphere Reserves: Compilation 5 (1990)

Directory of Wetlands of International Importance $(1987,1990)$

Protected Landscapes: Experience around the World (1987)

IUCN Directory of South Asian Protected Areas (1990)

Information is also made available to a wide range of users, including international organisations, governments, protected area managers, conservation organisations, commercial companies involved in natural resource exploitation, scientists, and the media and general public. It may be consulted by arrangement. Material may be prepared under contract: for example, PADU regularly provides UNEP with summary data on protected areas for its biennial Environmental Data Report. PADU is experimenting with providing outside users with direct access to its protected areas database. Trials have been ongoing with the US National Park Service since 1986 and it is hoped to be able to extend this service to other users in due course. PADU is also able to disseminate information through the CNPPA Newsletter and Parks magazine. In the case of the latter, PADU has recently assumed responsibility for compiling Clipboard in which world news on protected areas is featured. 


\section{INFORMATION SHEETS \\ GUIDELINES TO THEIR CONTENTS}

\section{INFORMATION SHEETS ON PROTECTED AREAS SYSTEMS}

\section{Country ${ }^{1}$}

- Full name of country or political unit, as used by the United Nations (1982).

\section{Area}

- Area of country or political unit according to the Times Atlas of the World (Seventh Edition, 1986), unless otherwise stated (with full reference). Terrestrial and marine components are distinguished, if appropriate.

\section{Population}

- Population of country or political unit and its rate of natural increase according to the Population Reference Bureau, Washington DC, whose data are based on those of the United Nations Statistical Office. Year of census or estimate is indicated in parentheses. If another source has to be used, it is cited.

\section{GNP}

- Gross national product per capita in US dollars, with year in parentheses, of country or political unit according to the Population Reference Bureau.

\section{Policy and Legislation}

- Information on aspects of the constitution that are relevant to protected areas.

- Details of national policies that relate to nature conservation, particularly with respect to the protection of ecosystems. Policies relating to environmental impact assessments and national/ regional conservation strategies are outlined.

- Brief historical account of national legislation and traditions that relate to the establishment of the protected areas system, with dates and numbers of acts, decrees and ordinances. Legislation covering forestry and other resource sectors is included, in so far as it provides for protected areas establishment. Procedures for the notification and declassification of protected areas are summarised.

- Outline of legal provisions for administering protected areas.

- Legal definitions of national designations of protected areas, together with the names of the authorities legally responsible for their administration, are summarised. National designations are cited in the original language or transliterated, followed in brackets by the English translation as appropriate. Details of activities permitted or prohibited within each type of protected area and penalties for offences are outlined.

${ }^{1}$ In the case of countries with federal systems of government, a single information sheet describes the protected areas system at both federal and state levels, except in the case of geographically disjunct regions. 
- Reviews of protected areas policy and legislation are noted with deficiencies in prevailing provisions highlighted.

\section{International Activities}

- Participation in international conventions and programmes (World Heritage and Ramsar conventions, MAB Programme, UNEP Regional Seas Programme) and regional agreements (African, ASEAN, Beme, FAO Latin American/Caribbean Technical Cooperation Network, South Asian Cooperative Environmental Programme, South Pacific, Western Hemisphere) relevant to habitat protection is summarised, with details of dates of accession or ratification, etc.

- Outline of any cooperative programmes or transfrontier cooperative agreements relevant to protected areas.

\section{Administration and Management}

- All authorities responsible for the administration and management of protected areas are described, including a brief history of their establishment, administrative organisation, staff structure, budget and any training programmes. Authorities responsible for different types of protected areas are clearly distinguished.

- Outline of the role of any advisory boards.

- Cooperative agreements between management authorities and national or foreign universities and institutes, with details of any research underway or completed.

- Details of non-governmental organisations concerned with potected areas, including reference to any national directories of voluntary conservation bodies.

- Effectiveness of protected areas management, noting levels of disturbance and threats to the national network. Attention is drawn to any sites registered as threatened under the World Heritage Convention, or by the IUCN Commission on National Parks and Protected Areas.

\section{Systems Reviews}

- Short account of physical features, biological resources, and land use patterns, including the extent and integrity of major ecosystems. (Appropriate sources of information include IUCN's Plants in Danger: What do we know?, protected areas systems reviews, and wetland and coral reef directories.)

- Brief historical account of nature conservation, so far as it relates to the establishment and expansion of the national protected areas network. Emphasis is given to any systems reviews or comprehensive surveys of biological resources, with details of major recommendations arising from such studies.

- Threats to the protected areas system beyond the control of the management agencies are outlined.

\section{Other Relevant Information (optional)}

- Tourism and other economic benefits of the protected areas system, if applicable.

- Other items, as appropriate. 


\section{Addresses}

- Names and addresses (with telephone, telex and FAX nos, and cable) of authorities responsible for administering protected areas, including the title of the post of the chief executive).

- Names and addresses (with telephone, telex and FAX nos, and cable) of non-governmental organisations, including the title of the post of the chief executive, actively involved in protected areas issues.

\section{References}

- Key references (including all cited works) to the protected areas system, in particular, and nature conservation, in general, are listed. Those not seen by the compiler are marked as "unseen".

\section{Date}

- Date of last extensive "review" and the most recent "update".

\section{INFORMATION SHEETS ON PROTECTED AREAS ${ }^{2}$}

\section{Country}

- Short name of country or political unit, as used by the United Nations (1982).

\section{Name}

- The name of the property or properties (including any collective name, if applicable), as designated in the original language or transliterated. Where appropriate, the English translation is given underneath. In the case of transliteration, standard systems are used.

\section{IUCN Management Category}

- The property is assigned to the most appropriate IUCN management category (see Annex 1) in collaboration with the IUCN Commission on National Parks and Protected Areas.

\section{Biogeographical Province}

- The biogeographical code, followed by the name of the province in brackets (after Udvardy, 1975).

\section{Geographical Location}

- The general location of the property within the country, including province and/or administrative district, proximity to major towns and/or topographical features, and means and ease of access. The location of different units is described, if applicable.

${ }^{2}$ Sheets contain information on individual protected areas or clusters of such properties that form discrete conservation units. "No information" is entered under any heading for which no data are available. 


\section{IUCN Directory of Protected Areas in Oceania}

- The boundary of the property is briefly described, its relation to any significant political boundaries noted, and geographical coordinates are given.

\section{Date and History of Establishment}

- The date of establishment, together with the act, decree or ordinance number of the original and subsequent legislative articles relating to its establishment. Proposed extensions or upgradings are detailed.

- A brief chronological history of previous designations, together with details of subsequent additions (including their sizes in hectares).

- If applicable, dates of inscription as World Heritage Site, Biosphere Reserve, Ramsar Wetland or other appropriate international and regional designations are given.

\section{Area}

- The best estimate of total area in hectares (ha), together with sizes of individually gazetted units, if applicable. If this differs from the total area as notified, the discrepancy is indicated. The extent of terrestrial and marine components is specified, if appropriate.

- Contiguous or otherwise associated protected areas are noted and their sizes given in hectares (ha) in parentheses, including any lying across international borders.

\section{Land Tenure}

- Land ownership (e.g. state, provincial, freehold, private, customary etc.), including sizes or proportions of respective areas if owned by several authorities.

\section{Altitude}

- Maximum and minium altitude in metres (m).

\section{Physical Features}

- General description of abiotic features, covering geology, topography, geomorphology, soils and hydrology.

\section{Climate}

- Seasons, annual precipitation, and maximum and minimum temperatures, with respect to altitude if appropriate. Other outstanding climatic features are noted.

\section{Vegetation}

- Main vegetation types are briefly described, including their approximate coverage and state of preservation. Characteristic species are noted.

- Communities and species of particular interest, including endemic, globally threatened (see Annex 2), economically important and potentially economically important (e.g. crop relatives), and invasive or introduced species. Any nationally threatened species of direct relevance to management are also mentioned.

- References to vegetation descriptions and species inventories are included in the above. 
NB: Names of genera and families are based on Mabberley (1987).

\section{Fauna}

- Mammal, bird, reptile, amphibian, fish and invertebrate faunas are described in relation to the different habitats, with emphasis on dominant, endemic, globally threatened (see Annex 2), economically important, and introduced or re-introduced species of particular interest. Where relevant, information is given on the use certain species make of habitats for breeding, stopover, migration, etc. Population sizes are given in the case of key species, with details of trends over specified periods of time.

- References to species inventories are included in the above.

NB: Scientific nomenclature of species is based on Honacki et al. (1982) for mammals, Moroney et al. (1975) for birds, Frost (1985) for amphibians, Nelson (1984) for fishes and Parker (1982) for invertebrates. The preparation of a taxonomic reference for reptiles is being coordinated by The Association of Systematics Collections.

\section{Cultural Heritage (if relevant)}

- Archaeological features and cultural monuments.

- Ethnic groups and their traditions.

- Historical features.

\section{Local Human Population (if relevant)}

- Size of the human population resident, transhumant or nomadic within the property, together with details of the number and distribution of settlements.

- Livelihoods of local populations are briefly described in relation to any zonation of the property, with details of land use (e.g. numbers of livestock and amount of land under permanent or shifting cultivation).

- Land use is described for the area surrounding the property, particularly as it impinges on the integrity of the property.

\section{Visitors and Visitor Facilities (if relevant)}

- Annual number of visitors, together with proportions of nationals and foreigners for the latest year. Total revenue accruing from tourism is also indicated. Significant trends over specified periods of time are noted.

- Types of accommodation available on site (or nearby), with details of location and amount if it is particularly limited.

- Availability and location of interpretation programmes, including visitor centres, educational facilities and museums.

- Any other recreational facilities of particular interest.

\section{Scientific Research And Facilities}

- A brief historical account of research undertaken, together with details of ongoing studies. Bibliographies, if compiled, are cited.

- Laboratories and other facilities, including accommodation, available to scientisis. 


\section{Conservation Value}

- Geological, scenic, biological, cultural and socio-economic values of the property, and justification for its conservation.

- In the case of World Heritage sites, all natural and cultural criteria are outlined, based on the IUCN evaluation of the nomination submitted to the World Heritage Committee.

\section{Conservation Management}

- A brief history of the conservation of the property, including any reasons for its original establishment where these differ from its present conservation value. Any legal provisions specific to the protection of the property are mentioned, together with details of activities (e.g. hunting, fishing, grazing) specifically permitted or prohibited.

- Administrative structure and management, including location of main facilities (e.g. headquarters).

- Management objectives, as drawn up in the management plan, and their degree of implementation. (The existence or absence of a management plan or "statement of objectives" is noted and, if appropriate, the authority responsible for its implementation.)

- Major management activities (e.g. controlled burning, culling).

- Any system of zonation, including function and size of zones.

- Significant training, interpretative and extension programmes.

- Recommendations, particularly those made in the management plan, for future conservation and management of the property.

\section{Management Constraints}

- Past and current problems are briefly described, such as invasive species, poaching, fire, pollution, disease, agricultural encroachment, impact of tourism, relationship between management authorities and local people, lack of trained manpower or equipment, and proposed developments (e.g. roads, dams), with emphasis on the main types of threat and their extent. Threats from within and outside the property are distinguished.

- If a property is registered as threatened by the IUCN Commission on National Parks and Protected Areas or under any national or international convention (e.g. World Heritage), details are provided.

\section{Staff}

- Numbers of staff allocated to each position and, if applicable, details of voluntary staff for the latest year, with trends if significant.

\section{Budget}

- Annual budget for the latest year (in parentheses) in local currency, and in US dollars for ease of comparison. Capital (e.g. construction of facilities) and recurrent (e.g. salaries) costs are distinguished. Significant trends are noted.

- Financial support from outside sources. 


\section{Local Addresses}

- Names and addresses (with telephone, telex, FAX nos, and cable) of the local authorities responsible for the day-to-day administration and management of the property, including the title of the post of the chief executive (i.e. park warden or equivalent).

- Names and addresses (with telephone, telex, FAX nos. and cable) of any local nongovernmental organisations directly involved in the protection and management of the property, including the title of the post of the chief executive.

\section{References}

- Key references, including management plans, reports, scientific monographs, bibliographies and handbooks, in addition to other scientific papers or popular articles and books specifically about the property. Particularly relevant references not available for consultation are also listed and cited as "unseen".

\section{Date}

- Date of last extensive "review" and the most recent "update".

\section{REFERENCES}

Frost, D.R. Ed. (1985). Amphibian species of the world: a taxonomic and geographical reference. Allen Press and The Association of Systematics Collections, Lawrence, Kansas, USA. $735 \mathrm{pp}$.

Honacki, J.H., Kinman, K.E. and Koeppl, J.W. (1982). Mammal species of the world: a taxonomic and geographic reference. Allen Press and The Association of Systematics Collections, Lawrence, Kansas, USA. 694 pp.

IUCN (1984). Categories and criteria for protected areas. In: McNeely, J.A. and Miller, K.R. (Eds), National Parks, Conservation, and Development. The role of protected areas in sustaining society. Smithsonian Institution Press, Washington. Pp. 47-53.

IUCN (1990). 1990 IUCN Red List of Threatened Animals. IUCN, Gland, Switzerland and Cambridge, UK. 228 pp.

Mabberley, D.J. (1987). The Plant Book. Cambridge University Press, Cambridge. 706 pp.

Morony, J.J. Jr, Bock W.J. and Farrand Jr (1975). Reference list of the birds of the world. American Museum of Natural History, New York. 207 pp.

Nelson, J.S. (1984). Fishes of the World. John Wiley, New York.

Parker, S.P. (1982). Synopsis and classification of living organisms. 2 volumes. Mcgraw Hill, New York.

Udvardy, M.D.F. (1975). A classification of the biogeographical provinces of the world. IUCN Occasional Paper No. 18, Morges, Switzerland. 48 pp.

United Nations (1982). Names of countries and adjectives of nationality. Terminology Bulletin No. 327. 


\section{ANNEX 1 \\ Categories and management objectives of protected areas}

I Scientific Reserve/Strict Nature Reserve: to protect nature and maintain natural processes in an undisturbed state in order to have ecologically representative examples of the natural environment available for scientific study, environmental monitoring, education, and for the maintenance of genetic resources in a dynamic and evolutionary state.

II National Park: to protect natural and scenic areas of national or international significance for scientific, educational and recreational use.

III Natural Monument/Natural Landmark: to protect and preserve nationally significant natural features because of their special interest or unique characteristics.

IV Managed Nature Reserve/Wildlife Sanctuary: to assure the natural conditions necessary to protect nationally significant species, groups of species, biotic communities, or physical features of the environment where these require specific human manipulation for their perpetuation.

V Protected Landscape or Seascape: to maintain nationally significant natural landscapes which are characteristic of the harmonious interaction of man and land while providing opportunities for public enjoyment through recreation and tourism within the normal life style and economic activity of these areas.

VI Resource Reserve: to protect the natural resources of the area for future use and prevent or contain development activities that could affect the resource pending the establishment of objectives which are based upon appropriate knowledge and planning.

VII Natural Biotic Area/Anthropological Reserve: to allow the way of life of societies living in harmony with the environment to continue undisturbed by modern technology.

VIII Multiple-Use Management Area/Managed Resource Area: to provide for the sustained production of water, timber, wildlife, pasture, and outdoor recreation, with the conservation of nature primarily oriented to the support of economic activities (although specific zones may also be designated within these areas to achieve specific conservation objectives).

IX Biosphere Reserve: to conserve for present and future use the diversity and integrity of representative biotic communities of plants and animals within natural ecosystems, and to safeguard the genetic diversity of species on which their continuing evolution depends.

$\mathrm{X}$ World Heritage Site: to protect the natural features for which the area is considered to be of World Heritage quality, and to provide information for world-wide public enlightenment. 


\section{ANNEX 2 \\ IUCN threatened species categories}

Species identified by IUCN as threatened are assigned a category indicating the degree of threat. Definitions are as follows:

(Ex) Extinct: species not definitely located in the wild during the past 50 years.

(E) Endangered: taxa in danger of extinction and whose survival is unlikely if causal factors continue operating.

(V) Vulnerable: taxa believed likely to move into the "Endangered" category in the near future if causal factors continue operating.

(R) Rare: taxa with small world populations that are not at present "Endangered" or "Vulnerable" but are at risk.

(I) Indeterminate: taxa known to be "Endangered", "Vulnerable" or "Rare" but where there is insufficient information to say which of these categories is appropriate.

(K) Insufficiently known: taxa that are suspected, but not definitely known, to belong to any of the above categories because of lack of information.

(T) Threatened: threatened is a general term to denote species which are "Endangered", Vulnerable", "Rare", "Indeterminate" or "Insufficiently known". It is used to identify taxa comprised of several sub-taxa which have differing status categories.

(C) Commercially threatened: taxa not currently threatened with extinction but most or all of whose populations are threatened as a sustainable resource, or will become so unless their exploitation is regulated.

Abridged from IUCN (1990) 


\section{ADDENDUM 1989 Action Strategy for Nature Conservation in the South Pacific}

Readers should be aware that since the completion of this Directory the 1989 Action Strategy for Nature Conservation in the South Pacific has become available. This represents a thorough revision of the 1985 Action Strategy for Protected Areas in the South Pacific Region, referred to throughout the Directory.

The 1989 Strategy was developed and adopted by participants at the Fourth South Pacific Conference on Nature Conservation and Protected Areas, representing 20 of the 27 member countries of SPREP and some 36 international and regional non-government, conservation and development assistance organisations. It was endorsed for adoption within the SPREP Work Programme for 1991/1992 which was due to be have been developed at the SPREP Intergovernmental Meeting in September 1990. The Strategy aims to provide a work programme to help implement the nature conservation and protected area objectives of SPREP's Action Plan for Managing the Natural Resources and Environment of the South Pacific. It also incorporates the views of IUCN's Commission on National Parks and Protected Areas. The Strategy recognises the importance of the human dimension in natural resource conservation, and acknowledges the strong potential of traditional knowledge and custom to assist in the development of sustainable resource use practices appropriate to the special circumstances of the island countries of the South Pacific. The need to consider more flexible protected area categories is recognised with the use of the term "conservation area" as opposed to "protected area".

The Strategy has seven goals, concerned with national strategies for sustainable resource use; establishing representative conservation area systems; promoting the integration of traditional knowledge and resource conservation; fostering links between conservation and tourism; improving public environmental awareness; developing training and education in nature conservation and conservation area management; and promoting regional and international co-operation. Each goal includes a number of objectives under which activities needed at national, regional and international levels are listed.

Specific project suggestions are listed in Appendix 1 of the Strategy for the following countries: American Samoa, Cook Islands, Fiji, Federated States of Micronesia, French Polynesia, Guam, Marshall Islands, New Caledonia, Palau, Papua New Guinea, Solomon Islands, Tokelau, Tonga, Vanuatu and Western Samoa. Regional Programmes for marine turtle and avifauna conservation are given in Appendices 2 and 3, respectively. Readers are urged to acquaint themselves more fully with the goals, objectives and proposed activities by consulting the Strategy.

\section{References}

SPREP (1985). Action strategy for protected areas in the South Pacific Region. South Pacific Commission, Noumea, New Caledonia. 24 pp.

SPREP (1989). Action strategy for nature conservation in the South Pacific. South Pacific Commission, Noumea, New Caledonia. 49 pp. 


\section{COOK ISLANDS}

Area The territorial seas and Exclusive Economic Zone cover nearly 2 million sq. $\mathrm{km}$, whilst total land area is only about 240 sq. $\mathrm{km}$ (Utanga, 1989).

Population 17,463 (SPREP, 1989)

Natural increase: No information

\section{GNP No information}

Policy and Legislation The Cook Islands Act (1915) constitutes the earliest conservation legislation. Sections 356 and 357 cover the acquisition and reservation of land for public purposes, such as recreation. Section 487 provides for the establishment of native reserves to protect sites of historic or scenic interest and sources of water supply. Local Island Counnil Ordinances also make provision for the reservation of land for public purposes. The 1915 Act was effectively superseded by the Conservation Act (1975) which became the principal legislative instrument for the conservation of nature and natural resources, protection of historic sites and the environment, and the establishment of national parks and other protected areas (SPREP, 1985b).

The 1975 Act was largely unused and was repealed and replaced in April 1987 by the 1986-87 Conservation Act. The 1986-87 Act is essentially similar to the 1975 Act, but is equally binding on both government and the public. The principal lifference is that the Conservation Service is established as an independent corporation, whereas previously it was within the Ministry of Internal Affairs and Conservation. The Act, which applies in full only to Rarotonga and Aitutaki, provides for the post of Director of Conservation with wide-ranging powers to protect, conserve, manage and control parks, wildlife, forests, water catchments and resources. Under the Act (Sections 27 and 28), any land, lagoon, reef or island, or portion of the seabed with its superjacent waters, can be declared a national park or reserve. The Director is obliged to prepare a management plan for any national park or reserve declared under the Act and, after approval, to implement it. National parks, as defined in Section 30, are intended for the protection, conservation and management of wildlife and natural features, the encouragement and regulation of the appropriate use, appreciation and enjoyment of the park by the public and the protection of special features, e.g. archaeological sites, water catchments and soil resources. The Act does not, however, define the purpose of reserves. There are also specific provisions for the protection of the coastal zone and Cook Island waters from unauthorised activities. Finally, the Act has provisions for the control of soil erosion, siltation, aggregate extraction, pollution and agricultural encroachment.

As the Conservation Act (1986/87) does not provide adequate protection for the Outer Islands, the Conservation Service, in liaison with each Island Council, has started preparing separate conservation plans for these islands. The Service has proposed developing legal mechanisms under which parks and reserves could be established on native freehold land. The outline concepts include land-leasing and shared-management regimes (McCormack, 1989).

The traditional system of resources management was based on the subdivision of land on high islands with boundaries running along dividing ridges to include entire valleys, alluvial plains, storm ridges on the coastal plain, the beach and lagoons fronting the valley and out to the outer edge of the reef. Such subdivisions, known as ra'hui, and invested with supernatural powers (tapu or taboo), were held by a Sub-Chief (Mataiapo or Rangatira) under a Chief, for members of the tribe. Tribal members were allocated different areas for planting, gathering and fishing. 
In addition, areas within the sub-division could be set aside for exclusive use of the Chief, and comparable prohibitions on removing specific natural resources, such as brilliant plumage required in ceremonies, fruits, trees, ferns or medicinal plants, animals and others. This system was curtailed when all land below mean high water mark was defined as Crown property, and in the Southern Group is largely used today for the control of trespass, and conservation of fruit trees, fruit bats, wildfowl and other game. In contrast, the traditional systems of resource conservation are more intact in the northern atolls, for example Pukapuka. Although there has been some codification of ra'hui as Island Council by-laws, a system of reserved areas for the protection of food plants, fishing grounds, sea birds, coconut crab, and turtles controlled by the community, is essentially traditional. The management of natural resources allows an usually high population to inhabit a relatively small island (Utanga, 1989).

Other legislation affecting protected areas includes the 1966 Local Government Act, which provides for the creation of Island Councils and enables them to regulate the use of any reserve or park under their control. Under the Trochus Act, 1975, three fishing reserves have been established, at Aitutaki, Palmerston and Manuae, respectively, in which unlicensed diving and fishing for trochus shell is prohibited. The Territorial Sea and Exclusive Economic Zone Act, 1979, controls the management, conservation, exploitation and exploration of marine resources within the territorial sea.

International Activities The Cook Islands is not yet party to any of the international conventions or programmes that directly promote the conservation of natural areas, namely the Convention concerning the Protection of the World Cultural and Natural Heritage (World Heritage Convention), Unesco Man and Biosphere Programme and the Convention on Wetlands of International Importance especially as Waterfowl Habitat (Ramsar Convention).

At a regional level, the Cook Islands ratified the 1976 Convention on the Conservation of Nature in the South Pacific on 24 June 1987. Known as the Apia Convention, it entered into force during 1990. The Convention is coordinated by the South Pacific Commission and represents the first attempt within the region to cooperate on environmental matters. Among other measures, it encourages the creation of protected areas to preserve indigenous flora and fauna.

The Cook Islands is also party to the South Pacific Regional Environment Programme (SPREP) and the Convention for the Protection of the Natural Resources and Environment of the South Pacific Region, 1986 (SPREP Convention) was signed on 25 November 1986 and ratified on 9 September 1987. The Convention entered into force during August 1990. Article 14 calls upon the parties to take all appropriate measures to protect rare or fragile ecosystems and threatened or endangered flora and fauna through the establishment of protected areas and the regulation of activities likely to have an adverse effect on the species, ecosystems and biological processes being protected. However, as this provision only applies to the Convention area, which by definition is open ocean, it is most likely to assist with the establishment of marine reserves and the conservation of marine species.

Other international and regional conventions concerning environmental protection to which the Cook Islands is party are reviewed by Venkatesh et al. (1983).

Administration and Management The 1986-87 Conservation Act is administered by the Conservation Service. The Conservation Service is run by a Council appointed by the Minister of Conservation. The Director, responsible for administration of the Service, is the Chairman of the Council (G. McCormack, pers. comm., 1989). The function of the Conservation Service is to promote the conservation of the environment for the use and enjoyment of present and future 
generations. Within the Conservation Act there are specific regulations concerning some aspects of the environment, but there are also provisions under which the Conservation Service can establish additional regulations (McCormack, 1989).

Systems Reviews The Cook Islands are extremely remote oceanic islands, lying approximately $3,000 \mathrm{~km}$ north-east from the nearest major land mass, namely New Zealand, and are defined by statute as all islands lying between $08^{\circ} \mathrm{S}$ and $23^{\circ} \mathrm{S}$ and $156^{\circ} \mathrm{W}$ and $167^{\circ} \mathrm{W}$. It is divided geographically into a Northern Group, comprising atolls, and a Southern Group, mainly comprising high volcanic islands, but also Manuae, an atoll and Takutea, which is a sand cay. The depths of the surrounding ocean, reaching $1,300-1,500 \mathrm{~m}$, precluded the formation of land bridges during glacial periods. The islands are also remotely located on a biological diversity gradient which diminishes west from continental land masses, and both north and south away from the equator. These biogeographical dimensions have contributed to distinctive ecosystems, which are also shaped by annual periodic climatic effects, and episodic events such as drought, inundation and cyclones, but the principal influence on biological diversity is the physical structure of the Cook Islands. The Cook Islands, however, have a long history of human habitation and consequently much of the natural environment has been modified, especially on coastal flats (Dahl, 1980a).

Vegetation varies from montane rain forest on Rarotonga (Merlin, 1985), through lowland limestone rain forest on Mauke, beach forest on atolls and reef islets, to scrub and grassland formations. Freshwater marsh is found on Mangaia, Rarotonga, Mauke, Mitiaro and Atiu, whilst tidal salt marsh is restricted to Ngatangiia Harbour, Rarotonga (Dahl, 1980a). Natural vegetation on coastal flats has been largely modified by man (Stoddart, 1975c) and lowland forest has been almost totally destroyed (Davis et al., 1986). However, upland forest above $250 \mathrm{~m}$ remains largely intact (Sykes, 1983) and the foresi cover of deep valley heads and sharp ridges and peaks appears to be pristine (Philipson, 1971). Coastal vegetation on Rarotonga has been heavily modified and burning has spread to such a degree that valleys are covered by introduced grasses and weeds. Hills near the sea mostly support Gleichenia thickets or forest (G. McCormack, pers. comm., 1989). The mainland and reef island vegetation of Aitutaki is described by Stoddart (1975b and 1975c).

All Cook Islands feature coral formations, which are frequently fringing and lagoon reefs. Within the southern Cooks, windward and leeward atoll reefs are restricted to Manuae and Palmerston, whilst barrier reefs are found only at Aitutaki (Dahl, 1980b). UNEP/IUCN (1988) provides a brief summary of each island's reefs, and more detailed accounts for Aitutaki, Manihiki, Ngatangiia Harbour and Muri Lagoon, Pukapuka and Suwarrow Atoll National Park. Crossland (1928) and Dana (1898) gave early descriptions of the fringing reefs around Rarotonga and more recent work has been carried out by, for example, Dahl (1980b), Gauss (1982), Lewis et al. (1980) and Stoddart (1972 and 1975a; 1975b; 1975c).

Proposals to designate protected areas in the central uplands of Rarotonga date back to the 19th century, but Suwarrow Atoll National Park is the only major gazetted protected area at present. Previously recorded as having an area of $13,468 \mathrm{ha}$, a recent legal clarification has reduced this to only $160 \mathrm{ha}$, comprising the land area above mean high water mark. This represents $0.07 \%$ of the terrestrial Cook Islands and an even less significant proportion of the marine area, and whereas previously algal ridge, reef flat, patch reef and open lagoon were protected these are now excluded from the protected areas system.

One of the most recent proposals, originating in the Department of Internal Affairs and Conservation, envisaged a 1,000 ha kakerori reserve specifically for the conservation of 
Rarotongan flycatcher Pomarea dimidiata (Anon., 1985; SPREP, 1985a). Difficulties in establishing agreement between customary land owners and the government have led to this proposal being dropped in favour of two smaller sites in the same area (McCormack, 1988). Proposals to gazette Takutea Island, and Rarotonga water catchment and wildlife reserves have been identified as priority actions (SPREP, 1985a).

An Action Strategy for Protected Areas in the South Pacific (SPREP, 1985a), provides a work programme to implement conservation and protected areas objectives. The principal goals of the strategy cover conservation education, conservation policy development, establishment of protected areas, protected area management and regional and international cooperation. Priority recommendations for the Cook Islands are as follows: conduct baseline survey, prepare management plan and recruit and train personnel for Suwarrow Atoll National Park; establish Kakerori Reserve on Rarotonga Island, including completion of baseline survey, preparation of management plans, and conducting a public education and awareness campaign; develop and implement a public education and awareness campaign for the establishment of Rarotonga Water Catchment and Wildlife Reserve; develop a national conservation strategy; designate Takutea Island as a wildlife sanctuary through negotiation with customary land owners and a public awareness campaign followed by preparation of management plans (SPREP, 1985a).

Despite poor cooperation between private land owners and the government (G. McCormack, pers. comm., 1989), considerable progress was made in implementing these priorities during the period 1985-89. This included the establishment of the Conservation Service; development of Suwarrow National Park; control of rats threatening Rarotongan flycatcher (kakerori) and the preparation of a concept document detailing proposals for a kakerori reserve; preparation of proposals for Takutea and Te Manga nature reserves; and preparation and implementation of species management plans and public education and awareness programmes (SPREP, 1989).

Dahl (1986) recommends as priority the establishment of a major protected area in central Rarotonga. Further recommendations include protection of endemic species in natural areas in Mangaia, Mitiaro and possibly other islands, and the establishment of coastal and marine reserves, as contributions to enhanced environmental management (Dahl, 1986). These are based largely on early, more extensive and specific recommendations which include proposals to protect higher areas, swamps, marshes and other terrestrial vegetation, endemic bird habitats, elevated limestone (makatea) regions, barrier and fringing reefs, lagoons, motus (islets), banks of major streams and historical features (Dahl, 1980a).

Rarotonga, as the capital and most densely populated island, exhibits the most pronounced development and the severest environmental problems. The traditional subsistence economy has long since been replaced with a commercial plantation export economy. The deeply incised, mountainous interior, rising to $652 \mathrm{~m}$, restricts agriculture to a circumferential belt some $1 \mathrm{~km}$ wide (Johnston, 1959). Reefs, reef flats and lagoons play a leading role in protein supply in the Cook Islands (Hambuechen, 1973a). Islanders may depend on marine resources for $90 \%$ of their protein in the northern group and $60 \%$ in the southern group. In addition to fish, turtle meat, but not eggs, is consumed on Palmerston and in the Northem Cook Islands (G. McCormack, pers. comm., 1989).

Airport and hotel construction, port improvement, pollution and soil erosion have contributed to coastal degradation in Rarotonga. The reefs are considered to be in an advanced stage of degradation (Dahl, 1980b). Chemical run-off may be a significant problem (Hambuechen, 1973a and 1973b), and problems created by the increased use of pesticides are described by Hambuechen (1973b). Fish poisoning and dynamiting has been reported (Dahl, 1980b; 
Hambuechen, 1973a). Phosphate mining, a potentially serious environmental threat, may be investigated on Rakahanga and Manihiki (UNEP/IUCN, 1988).

A major crown-of-thorns starfish Acanthaster planci plague occurred on the north-west reefs of Rarotonga during 1972-73; there was a minor infestation on Aitutaki in 1973. There were no known previous infestations and there have been none since (G. McCormack, pers. comm., 1989). Other marine threats actually or potentially include offshore activities such as aggregate extraction, eutrophication and inappropriate recreational use. Fish poisoning and dynamiting has occurred and pearl oyster stocks have been depleted. Principal threats on land include agricultural encroachment into remaining forest, indiscriminate burning, deforestation and propagation oi exotic pests such as rhinoceros beetle, rats and feral animals. Coastal resource management is weak due to a division of administrative responsibilities and a lack of legislated authority (CSC, 1985a and 1985b; Dahl, 1980b; SPREP, 1985b; UNEP/IUCN, 1988). There is a risk of severe economic and social disruption in the event of increased sea level rises caused by global warming of the atmosphere (Pernetta, 1988). The agricultural belt of Rarotonga could be reduced in size and altered in profile by enhanced erosion (Nunn, 1988). More catastrophically, low-lying islands, such as Suwarrow or Takutea, could be inundated and completely destroyed (Pernetta, 1988)

Protected habitats are restricted to beach and wet atoll forest (Dahl, 1980a), in addition to important seabird breeding areas on Suwarrow (SPREP, 1985b). Omissions from the protected area system include lowland rain forest on Aitutaki and Mauke, limestone forest, the montane and ridge rain forest of central Rarotonga, freshwater marsh, tidal salt marsh, permanent lake, mountain stream, closed lagoon and fringing reef (Dahl, 1980a and 1986).

\section{Addresses}

The Director, Conservation Service, P O Box 371, Tupapa, Rarotonga

\section{References}

Anon. (1985). Endangered species management needs in the Cook Islands. In: Thomas, P.E.J. (Ed.), Report of the Third South Pacific National Parks and Reserves Conference. Volume II. Collected key issue and case study papers. South Pacific Commission, Noumea, New Caledonia. Pp. 271-275.

CSC (1985a). Environmental planning programme: coastal zone management of tropical islands. Proceedings of the workshop/planning meeting on coastal zone management of the South Pacific region, Tahiti. Commonwealth Science Council Technical Publications Series, London. No. 180.

CSC (1985b). Environmental planning programme: coastal zone management of tropical islands. SOPACOAST: the South Pacific coastal zone management programme. CSC Technical Publications Series, London. No. 204.

Crossland, C. (1928). Coral reefs of Tahiti, Moorea and Rarotonga. Journal of the Linnean Society 36: 577-620. (Unseen).

Dahl, A.L. (1980a). Regional ecosystem survey of the South Pacific Area. SPCIIUCN Technical Paper 179. South Pacific Commission, Noumea, New Caledonia. 99 pp.

Dahl, A.L. (1980b). Report on marine surveys of Rarotonga and Aitutaki (November 1976). South Pacific Commission, Noumea, New Caledonia.

Dahl, A.L. (1986). Review of the Protected Areas System in Oceania. IUCN, Gland, Switzerland and Cambridge, UK. 328 pp.

Dana, J.D. (1898). Corals and Coral Islands. Dodd, Mead and Co., New York. 
Davis, S.D., Droop, S.J.M., Gregerson, P., Henson, L., Leon, C.J., Lamlein Villa-Lobos, J., Synge, H. and Zantovska, J. (1986). Plants in Danger: What do we know? IUCN, Gland, Switzerland and Cambridge, UK. 488 pp.

Gauss, G.A. (1982). Sea bed studies in nearshore areas of the Cook Islands. South Pacific Marine Geology Notes, CCOP, ESCA 2: 131-154. (Unseen).

Hambuechen, W.H. (1973a). Cook Islands. Proceedings and Papers, Regional Symposium on Conservation of Nature - Reef and Lagoons, 1971. South Pacific Commission, Noumea, New Caledonia. (Unseen).

Hambuechen, W.H. (1973b). Pesticides in the Cook Islands. Proceedings and Papers, Regional Symposium on Conservation of Nature - Reef and Lagoons, 1971. South Pacific Commission, Noumea, New Caledonia. (Unseen).

IUCN (1988). From Strategy to Action: How to Implement the Report of the Commission on Environment and Development. IUCN, Gland, Switzerland. $116 \mathrm{pp}$.

Johnston, W.B. (1959). The Cook Islands: land use in an island group in the south-west Pacific. Journal of Tropical Geography 13: 38-57.

Lewis, K.B., Utanga, A.T., Hill, P.J. and Kingan, S.G. (1980). The origin of channel-filled sands and gravels on an algal-dominated reef terrace, Rarotonga, Cook Islands. South Pacific Geology Notes 2: 1-23

McCormack, G. (1988). Kakerori Nature Reserve. A concept document. Cook Islands Conservation Service. Unpublished. 4 pp.

McCormack, G. (1989). Cook Islands Conservation Service: two years under the 1986/87 Act. Fourth South Pacific Conference on Nature Conservation and Protected Areas, Port Vila, Vanuatu, 4-12 September. South Pacific Commission, Noumea, New Caledonia. 5 pp.

Merlin, M.D. (1985). Woody vegetation in the upland region of Rarotonga, Cook Islands. Pacific Science 39: 81-99. (Unseen).

Nunn, P. Potential impacts of projected sea level rise on Pacific Island States (Cook Islands, Fiji, Kiribati, Tonga, and Westem Samoa): a preliminary report. In: MEDU joint meeting of the task team on the implications of climatic change in the Mediterranean. Split, Yugoslavia, 3-7 October. Pp. 53-81.

Pernetta, J.C. (1988). Projected climate change and sea level rise: a relative impact rating for the countries of the Pacific Basin. In: MEDU joint meeting of the task team on the implications of climatic change in the Mediterranean. Split, Yugoslavia, 3-7 October. Pp. 1-11.

Philipson, W.R. (1971). Floristics of Rarotonga. Bulletin of the Royal Society of New Zealand 8: 49-54. (Unseen).

Sloth, B. (1988). Nature legislation and nature conservation as part of tourism development in the island Pacific. Pacific Regional Tourism Development Programme. Tourism Council of the South Pacific, Suva, Fiji. 82 pp.

SPREP (1985a). Action strategy for protected areas in the South Pacific Region. South Pacific Commission, Noumea, New Caledonia. 24 pp.

SPREP (1985b). Cook Islands. In: Thomas, P.E.J. (Ed.), Report of the Third South Pacific National Parks and Reserves Conference. Volume III. Country reviews. South Pacific Commission, Noumea, New Caledonia.

SPREP (1989). Cook Islands. Paper presented at the Fourth South Pacific Conference on Nature Conservation and Protected Areas, Port Vila, Vanuatu, 4-12 September. 5 pp.

Stoddart, D.R. (1972). Reef islands of Rarotonga, with list of vascular flora by F.R. Fosberg. Atoll Research Bulletin 160: 1-14.

Stoddart, D.R. (1975a). Scientific studies in the Southern Cook Islands: background and bibliography. In: Stoddart, D.R. and Gibbs, P.E. (Eds), Almost-atoll of Aitutaki: reef studies in the Cook Islands, South Pacific. Atoll Research Bulletin 190: 1-30. 
Stoddart, D.R. (1975b). Mainland vegetation of Aitutaki. In: Stoddart, D.R. and Gibbs, P.E. (Eds), Almost-atoll of Aitutaki: reef studies in the Cook Islands, South Pacific. Atoll Research Bulletin 190: 117-122.

Stoddart, D.R. (1975c). Vegetation and floristics of the Aitutaki motus. In: Stoddart, D.R. and Gibbs, P.E. (Eds), Almost-atoll of Aitutaki: reef studies in the Cook Islands, South Pacific. Atoll Research Bulletin 190: 87-116.

Sykes, W.R. (1983). Conservation on South Pacific islands. In: Given, D. R. (Ed.), Conservation of Plant Species and Habitats. Nature Conservation Council, Wellington, New Zealand. Pp 37-42. (Unseen).

UNEP/IUCN (1988). Coral Reefs of the World. Volume 3: Central and Western Pacific. UNEP Regional Seas Directories and Bibliographies. IUCN, Gland, Switzerland and Cambridge, UKUNEP, Nairobi, Kenya. 378 pp.

Utanga, A. (1989). Customary tenure and traditional resource management in the Cook Islands. In: SPREP, Report of the workshop on customary tenure, traditional resource management and nature conservation. South Pacific Commission, Noumea, New Caledonia. Pp 101-105. Venkatesh, S, Va'ai, S. and Pulea, M. (1983). An overview of environmental protection legislation in the South Pacific countries. SPREP Topic Review No. 13. South Pacific Commission, Noumea, New Caledonia. 63 pp.

Wilder, G.P. (1931). Flora of Rarotonga. Bulletin of the Bernice P. Bishop Museum 86. 113 pp. (Unseen).

\section{ANNEX \\ Definitions of protected area designations, as legislated, together with authorities responsible for their administration}

\section{Title (English): Conservation Act 1986-87}

\section{Date: 15 April 1987}

Brief description: An Act to establish a Conservation Service as a corporation and to make provision for the conservation and protection of the environment and national resources, and the establishment of national parks and reserves.

\section{Administrative authority: Conservation Service (Director)}

\section{Designations:}

National park Any land, lagoon, reef, or island, or any Cook Islands waters, or portion of the sea-bed of those waters may be proclaimed as a national park subject to the Act.

National parks, as defined in Section 30, are intended for the protection, conservation and management of wildlife and natural features, the encouragement and regulation of the appropriate use, appreciation and enjoyment of the park by the public and the protection of special features, e.g. archaeological sites, water catchments and soil resources.

Reserve Any land, lagoon, reef, or island, or any Cook Islands waters, or portion of the sea-bed of those waters may be proclaimed as a reserve subject to the Act. 


\section{Title (English): The Cook Islands Act}

Date: 1915

Brief description: Constitutes the earliest conservation legislation

Administrative authority: Island Councils

Designations:

Recreation reserve Established under Sections 356 and 357

Native reserve Established under Section 487 for protection of sites of historic or scenic interest and sources of water supply.

\section{Title (English): Trochus Act}

Date: 1975

Brief description: Provides for the establishment of fishing reserves.

Administrative authority: No information

Designations:

Fishing reserve Unlicensed diving and fishing for trochus shell is prohibited.

\section{SUMMARY OF PROTECTED AREAS}

\begin{tabular}{llccc}
\hline $\begin{array}{l}\text { Map } \\
\text { ref. }\end{array}$ & Name of area & $\begin{array}{c}\text { IUCN management } \\
\text { category }\end{array}$ & $\begin{array}{c}\text { Area } \\
\text { (ha) }\end{array}$ & $\begin{array}{c}\text { Year } \\
\text { notified }\end{array}$ \\
\hline & $\begin{array}{l}\text { National Parks } \\
\text { Suwarrow Atoll* }\end{array}$ & IV & 160 & 1978 \\
& $\begin{array}{l}\text { Proposed } \\
\text { Takutea Nature Reserve* }\end{array}$ & Proposed & $(150)$ & \\
3 & Te Manga Nature Reserve* & Proposed & $(100)$ & \\
4 & Kakerori Reserve* & Proposed & $(255)$ & \\
\hline
\end{tabular}

* Site is described in this directory.

${ }^{\dagger}$ Locations of most protected areas are shown in the accompanying map. 


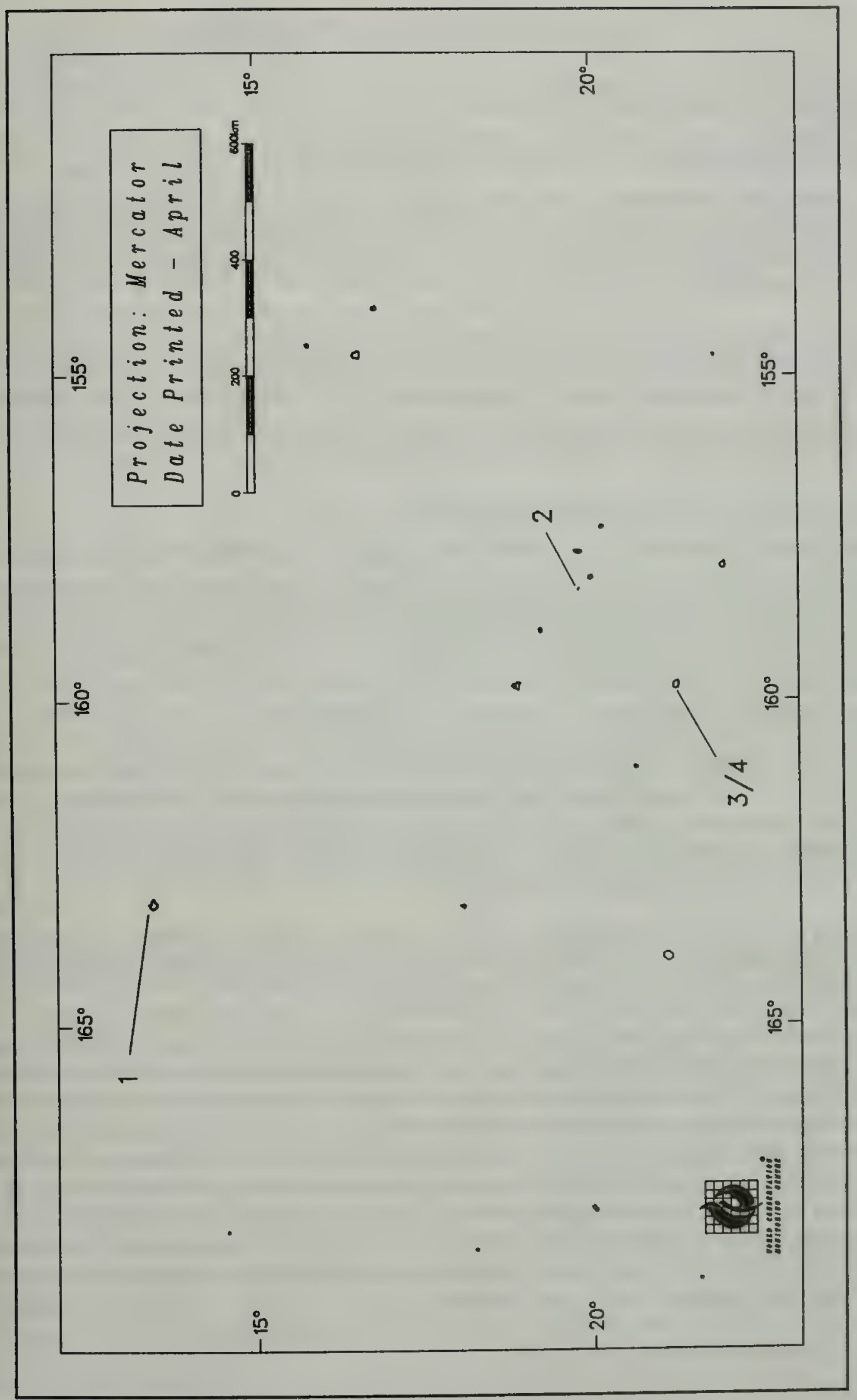

Protected Areas of the Cook Islands 


\section{KAKERORI RESERVE (PROPOSED)}

\section{IUCN Management Category (Proposed)}

\section{Biogeographical Province 5.04.13 (Southeastern Polynesian)}

Geographical Location Situated in central, south-east Rarotonga. The boundary is marked by a number of peaks: Te Kou in the west, Toroume in the east and Te Manga in the north. The coast, and a number of coastal villages lie some $1-2 \mathrm{~km}$ to the south and east. Approximately $21^{\circ} 11^{\prime} \mathrm{S}, 159^{\circ} 46^{\prime} \mathrm{W}$

Date and History of Establishment Proposals to designate protected areas in the central uplands of Rarotonga date from the 19th century. Current proposals to gazette the area under the 1975 Conservation Act are given in the Proceedings of the Third South Pacific National Parks and Reserves Conference (Anon., 1985) and as a priority action in the Action Strategy for Protected Areas in the South Pacific Region (SPREP, 1985).

Area 255ha (G. McCormack, pers. comm., 1990)

Land Tenure The reserve is proposed for an area currently under Native Customary and Native Freehold land (Anon., 1985). The more recent proposal covers large parts of three sections of land, namely Turagaare, Totokoitu-ki-uta and Arakuo harika-ki-uta. The first is owned by two families, whilst the latter two sections were both leased to the Cook Islands Government Property Corporation in 1970 by their respective owners.

Altitude Ranges from approximately $100 \mathrm{~m}$ to $427 \mathrm{~m}$

Physical Features The Turagaare section comprises the western side of the upper Avana Valley. The Totokoitu-ki-uta section to the west includes the upper part of the Totokoitu Valley, whilst the southerly Arakuo Karika-hi-uta section occupies the whole upper part of the Turoa Valley. The southerly-flowing Totokoitu and Turoa, and the Avana which drains to the east, are all perennial (G. McCormack, pers. comm., 1989).

Climate The mean daily temperature is $24^{\circ} \mathrm{C}$, similar to northern Rarotonga, although cloud cover can reduce the temperature range. The area is one of the wettest on the island, with some 4,000mm precipitation annually (Anon., 1985).

Vegetation Homalium montane tropical forest is the principal formation, dominated by mato Homalium acuminatum. Other species include Weinmannia samoensis, karaka Elaeocarpus tonganus, pua Fagraea berteriana, neinei Fitchia speciosa, rata Metrosideros collina, matira Canthium barbatum, kavakava Pittosporum arborescens, Coprosma laevigata, itoa Ixora bracteata, Meryta pauciflora and Xylosma gracile. Ground cover shrubs consist of anae Angiopteris longifolia, maire rakau Alyxia elliptica, kavakava atua Macropiper latifolia. A common sprawling vine on ridges is kiekie Freycinetia wilderi. The vegetation is mostly undisturbed, although areas have been grazed by cattle, and is very largely native. Introductions include 'au Hibiscus tiliaceus in the valleys, whilst guava Psidium guayava and $P$. cattleianum, and tataramoa Lantana camara are spreading into lower areas. Cyrtandra rarotongensis, Sclerotheca vividiflora and Euodia cf. bracteata are of conservation value due to extremely limited distributions (Anon., 1985).

Fauna The reserve has been proposed principally for conservation of Rarotongan flycatcher (kakerori) Pomarea dimidiata (E). It has probably been rare for most of this century and a survey 
in 1983 located only 21 birds and two nests, the first ever recorded; the bulk of the population occurs in the Totokoitu and Taipara valleys (Hay, 1986), although they may also occur in the upper valleys of the Turoa, some unnamed streams west of the Turoa and in some eastern valleys of the Avana (Anon., 1985). A 1987/88 survey found 35 birds in $2 \mathrm{sq} . \mathrm{km}$ in south-east Rarotonga, probably the wettest part of the island (Hay et al., 1989). Other land birds include Rarotonga starling Aplonis cinerascens (E), Rarotonga fruit dove Ptilinopus rarotongensis and Pacific imperial pigeon Ducula pacifica. Long-tailed koel Eudynamys taitensis, a nesting migrant from New Zealand, is also present during winter months. Seabirds in the proposed area are common noddy Anous stolidus and white tern Gygis alba, whilst white-tailed tropic bird Phaeton lepturus also nest on some of the cliffs on the Te Manga-Te Atukura divide. Native mammals are restricted to flying fox Pteropus sp. Feral cats are uncommon or absent (Anon., 1985).

Cultural Heritage No sites of cultural significance have been identified in the proposed area, although there is a marae (historic site) close by (Anon., 1985).

Local Human Population The reserve is uninhabited, with the nearest dwellings about $1 \mathrm{~km}$ from the southern perimeter (Anon., 1985).

Visitors and Visitor Facilities At present, visitors are limited to hikers. A road running up the Avana Valley to a water intake in the south-east of the reserve provides access (Anon., 1985).

Scientific Research and Facilities Surveys of Rarotongan flycatcher have been carried out in 1983 (Hay, 1986), 1987 (Collar and Andrew, 1988) and 1988/89 (Hay et al., 1989). A colour-banding programme has been in operation since 1987 and over half the population is now individually recognisable. Nesting success, which is extremely low, has been monitored, and the impact of feral cats has been investigated (Hay et al., 1989). Completion of baseline surveys of the reserve have been identified as priority activities in the 1985 Action Strategy for Protected Areas in the South Pacific Region (SPREP, 1985). Totokoitu Research Station has basic laboratory facilities and accommodation for two scientists (Anon., 1985).

Conservation Value The reserve has been proposed principally for conservation of Rarotongan flycatcher but secondary values include the conservation of herald petrel and the protection of watersheds.

Conservation Management The original proposal to gazette 1,000 ha has been replaced by more recent proposals to establish a smaller, single objective nature reserve, specifically for the protection of Rarotongan flycatcher. The higher altitude Te Manga Nature Reserve has also been proposed for the protection of flora and fauna included in the original Kakerori Reserve proposal (G. McCormack, pers. comm., 1989). Activities proposed in 1988 (McCormack, 1988) include: that a management committee be established consisting of a representative of the owners of each section of land, the leaser and the Director of Conservation; the management committee immediately approach the Minister to have the small area with kakerori set aside as Kakerori Nature Reserve; the management committee immediately begin the preparation of a management plan, as specified in the 1986-87 Conservation Act; while the management plan is being prepared, the management committee prohibit any activity in the reserve which would work against the survival of the kakerori and the committee encourages and monitors activities which favour the survival of the kakerori.

Principal management activities have included controlling rats and conducting research on the biology of the kakerori (Hay et al., 1989). The reserve will be under the control of the Conservation Service and Totokoitu Research Station. 
Management Constraints There are at least three flying fox colonies which may require periodic control. Rat and feral cats threaten Rarotongan flycatcher. Rat poisoning programmes do not appear to be effective (Hay et al., 1989). A number of introduced plant species are encroaching on the reserve (Anon., 1985).

Staff There are no full-time staff, although personnel from the Conservation Service and Research Station undertake day-to-day management (Anon., 1985).

Budget A project to conserve Rarotonga flycatcher has been funded by the New Zealand Department of Scientific and Industrial Research and SPREP.

Local Addresses Director, Conservation Service, PO Box 371, Rarotonga; The Manager, Totokoitu Research Station

\section{References}

Anon. (1985). Case Study: endangered species management in Cook Islands. In: Thomas, P.E.J. (Ed.), Report of the Third South Pacific National Parks and Reserves Conference. Volume II. Collected key issue and case study papers. South Pacific Commission, Noumea, New Caledonia. Pp. 271-275.

Collar, N.J. and Andrew, P. (1988). Birds to watch: the ICBP World Checklist of threatened birds. Technical Publication No. 8. International Council for Bird Preservation, Cambridge, UK. 303 pp.

Hay, R. (1986). Bird conservation in the Pacific Islands. Study Report No. 7. International Council for Bird Preservation, Cambridge, UK.

Hay, R., Robertson, H. and McCormack, G. (1989). Conservation of the Kakerori. Case Study 26. Fourth South Pacific Conference on Nature Conservation and Protected Areas, Port Vila, Vanuatu, 4-12 September. 5 pp.

McCormack, G. (1988). Kakerori Nature Reserve. A concept document. Cook Islands Conservation Service. Unpublished. 4 pp.

SPREP (1985). Action strategy for protected areas in the South Pacific region. South Pacific Commission, Noumea, New Caledonia. 24 pp.

Date September 1988, December 1990

\section{SUWARROW ATOLL NATIONAL PARK}

\section{IUCN Management Category IV (Managed Nature Reserve)}

Biogeographical Province 5.04.13 (Southeastern Polynesian)

Geographical Location Suwarrow Atoll, islets and superjacent waters lie approximately $950 \mathrm{~km}$ north-north-west of Rarotonga in the territorial sea of the Cook Islands and on the south-west rim of the Manihiki Plateau. The mean high water mark around the islets defines the boundary, the remainder of the reef flat and lagoon being excluded. Approximately $13^{\circ} 14^{\prime} \mathrm{S}, 163^{\circ} 06^{\prime} \mathrm{W}$

Date and History of Establishment Declared a national park, pursuant to Section 11(1) of the 1975 Conservation Act, on 29 June 1978, as 'Suwarrow Islands and its superjacent waters in the territorial sea of the Cook Islands'. Contrary to popular opinion, the Crown Solicitor's Office 
has advised that only land above the mean high water mark is included within the park, and thus the lagoon and reef flat is excluded (G. McCormack, pers. comm., 1990).

Area 160ha. Suwarrow lagoon has an area of $9,624 \mathrm{ha}$, while the total reef flat (including the reef-islands) is $2,912 \mathrm{ha}$. The reef-islands, comprising the legally designated national park, have a total area of $160 \mathrm{ha} \mathrm{(G.} \mathrm{McCormack,} \mathrm{pers.} \mathrm{comm.,} \mathrm{1990).}$

Land Tenure Crown (state) land.

Altitude Ranges from the mean high water mark to $2-4 \mathrm{~m}$ above mean sea level.

Physical Features Comprises a typical low coral atoll atop an extinct submarine volcano that rises from a depth of some $3,000 \mathrm{~m}$ (SPREP, 1985a). The atoll rim, $0.5-1 \mathrm{~km}$ wide, is continuous and encloses a $10 \mathrm{~km}$ wide lagoon which reaches $80 \mathrm{~m}$ in depth. Twenty-two islands occur on the rim, most featuring limestone exposures 0.5-1.5m above sea level, including Anchorage, Motu One, One Tree, Gull, Whale and the Seven Sisters. Limestone types include in situ raised reefs of faviids; boulder rocks of massive and branching corals that cap the in situ raised reefs; three prominent developments of encrusting, coralline algal ridges that occur in parallel sets on the atoll rim; and contemporary beachrock, predominantly on the oceanward sides of larger islands. Inconsistencies in the levels and ages of the raised in situ reefs imply recent tectonic disturbance of the atoll, a suggestion corroborated by the presence of large-scale fractures in the reef flat and tilted patch reefs in the lagoon (Scoffin et al., 1985). Anchorage Islet, located close to the lagoon entrance in the north-east, comprises unconsolidated broken coral, gravel, sand, and a lagoon beach of fine coral sand (Wood, 1967), in additiun to limestone exposures mentioned above.

The lagoon, which has a very irregular seabed due to the presence of patch reefs, has active water exchange with the sea via a wide, $10 \mathrm{~m}$ deep pass near Anchorage Islet. The range of spring tides is approximately $1 \mathrm{~m}$ (UNEP/IUCN, 1988). Several major hurricanes during the last 100 years may have reduced both the size and numbers of islands on the atoll rim. Most damage seems to have been caused by a 1942 hurricane, when more than half the land area was washed away (Wood, 1967), although this is not confirmed by maps dating from the 1920s (McCormack, pers. comm., 1989). Popular accounts are given in Helm and Percival (1973) and Neale (1966).

Climate Climatic data are not available for Suwarrow. However, data collected over 37 years at Aitutaki indicate a mean annual rainfall of $1984 \mathrm{~mm}$, with a dry season from June to September. Mean daily temperature is $25.6^{\circ} \mathrm{C}$ with a maximum of $37.2^{\circ} \mathrm{C}$ recorded in October and a minimum of $12.8^{\circ} \mathrm{C}$ in July (Johnson, 1967). Suwarrow is located in a cyclone zone (Dahl, 1980).

Vegetation Sand on the leeward side of the islets support a scrub of Pemphis sp., beach heliotrope, Lepturus sp. grass, native pigweed and sometimes Boerhavia sp. Some islets support more complex woodland, usually comprising a Cocos-Pandanus-Pisonia-Guettarda community, with small areas of Cordia sp. The only tree which remains in the understorey is Indian mulberry. Ground covers comprises fern Phymatosorus sp. and large patches of bird's nest fern Asplenium nidus. The central woodland is surrounded by lower, more tolerant plants, including Pemphis sp., beach heliotrope and Scaevola. Exposed rubble or sand may support Triumfetta sp. vine, native pigweed, Boerhavia sp., grass Lepturus sp. and occasional sedge Fimbristylus sp. Elsewhere, parasitic Cassytha sp. is common whilst grand moming glory is largely restricted to Anchorage. Numerous species have been introduced, including Polynesian arrowfoot, Colubrina sp., breadfruit Artocarpus sp., Hibiscus sp., banana and lemon and others (McCormack, 1986). 
Fauna Mammals are limited to a population of rat Rattus exulans restricted to Anchorage Islet, Entrance Island and Motu Tou (UNEP/IUCN, 1988). Five lizard species occur: two skinks and three gecko (McCormack, 1986). The atoll is a turtle nesting site, principally for green turtle Chelonia mydas (E) on Turtle Island (McCormack, 1986).

All the islets, especially Manu and Turtle, but with the exception of Anchorage, are major breeding areas for 11 seabirds. The most common bird on Suwarrow is sooty tern Sterna fuscata, with a conservative estimate of 200,000 nests in 1985 . The next most abundant species is brown noddy Anous stolidus with more than 3,000 nests. Birds having about 1,000 nests include red-footed booby Sula sula, lesser frigate bird Fregata ariel, greater frigate bird $F$. minor and white tern Gygis alba. Red-tailed tropic bird Phaethon rubricauda may have 500 nests. A small number, possibly one hundred, brown booby Sula leucogaster are present. The two rarest seabirds in 1985 were masked booby S. dactylatra and reef heron Egretta sacra. Black noddy A. minutus has been recorded on Suwarrow, although there was no evidence of nesting. Black-naped tern Sterna sumatrana and crested tern S. bergii may have nested on Suwarrow, but were not in evidence in 1985. Non-nesting migrant species included long-tailed cuckoo Eudynamis taitensis which migrates from New Zealand to the Southern Pacific islands during the austral winter. Other migrants, from the Arctic Circle, include golden plover Pluvialis dominica, wandering tattler Heteroscelus incanus, bristle-thighed curlew Numenius tahitiensis (R), turnstone Arenaria interpres and sanderling Calidris alba (McCormack, 1986). Additional bird records are given in Batham and Batham (1973). Coconut crab Birgus latro (R) is especially abundant on Turtle Island and Motu Tou and to a lesser extent on Anchorage, Entrance Island and Moto Oneone.

The islets also support abundant populations of about five terrestrial hermit-crabs. Tentative identifications include Carcinus rugosa, $C$. perlata and possibly $C$. brevimana. The most common diurnal crab on Suwarrow is the mauve cardisoma Cardisoma sp. particularly on moist ground in the wooded areas of the Northern Atolls. Three species of grapsid occur, namely weak-shelled rock crab, land rock cray and purple rock cray. Horned ghost crab Ocypode sp. and ghost crab both live in burrows in the sand which they excavate when the tide is out, especially at night. A single small colony of fiddler crab Uca sp. has been found on the southern end of Whale Island (McCormack, 1986).

Small giant clam Tridacna maxima $(\mathrm{K})$ beds are found in the lagoon and on the reef (UNEP/IUCN, 1988). Black-lipped pearl oyster Pinctada margaritifera (CT) was previously abundant but has declined due to heavy exploitation from the mid-19th century until 1967. Reef fish are described by Grange and Singleton (1985).

Cultural Heritage The atoll was named in 1813 when visited by the Russian ship Suvorov, although earlier occupation by Polynesians and later by Europeans may have occurred (McCormack, 1986). Some evidence remains of a coal bunking station operated by the British Navy in the 19th century. In 1902, part of Anchorage Islet was reserved as a Reserve for Imperial Naval and Military Defence. Pearl fishing was an important activity during the last 100 years (SPREP, 1985a).

\section{Local Human Population None}

Visitors and Visitor Facilities The atoll is a popular stopover for yachts, although these visits are illegal. Between 1952 and 1985 at least 50 yachts a year stopped over at the atoll. Nearly all yachts visit during the May to October hurricane-free season. It is not uncommon for several yachts to be moored illegally in the atoll at any one time (McCormack, 1986). Facilities are 
limited to a rain-fed freshwater tank, constructed during World War Two when Anchorage Islet was used as a coastal watch and weather-reporting station (SPREP, 1985a).

Scientific Research and Facilities The heavy metal content of Tridacna and Caulerpa in the lagoon has been studied by Khristoforova and Bogdanova (1981). A joint New Zealand DSIR/Royal Society of London Northern Cook Islands cruise visited the atoll in 1981. Black-lipped pearl oyster stocks have been surveyed and growth studies have been conducted by the Ministry of Marine Resources (UNEP/IUCN, 1988).

Conservation Value Primarily valued for the sea bird colonies.

Conservation Management The park is under the joint control of the Conservation Service assisted by Government departments (McCormack, 1986). The atoll was completely protected, with a number of limited exceptions. Exploitation of fish and other resources by visitors for immediate use is permitted, but commercial exploitation is prohibited. Section 55 of the Conservation Act 1986/87 permits any individual to fish in any waters and to take turtles. Consequently, green turtles are not protected (McCormack, 1986). Licences can be issued for: mother-of-pearl and trochus harvest and culture; other limited economic uses such as copra production; coconut crab culling; and rat control on Anchorage Islet. The area is zoned for pearl culture and commercial pelagic fishing (SPREP, 1985b). The recent clarification of the extent of the park has permitted the exploitation of the reef and lagoon. Completion of a baseline survey, preparation of a management plan and the recruitment and training of personnel for the park has been identified as a priority action under the Action Strategy for Protected Areas in the South Pacific Region (SPREP, 1985b). Trochus Trochus niloticus introductions were successfully carried out in 1985 and 1987; attempts to introduce goldlip pearl oyster Pinctada maxima have been unsuccessful (UNEP/IUCN, 1988). At present, a US-AID project is being implemented by the Cook Islands Department of Marine Resources to develop black-lip pearl oyster farms in the lagoon. The project includes construction of a conservation caretaker's house in the personnel complex, a limit to the number of buildings erected, and a provision for the Conservation Service to monitor the project to ensure that it does not interfere with the seabird colonies (G. McCormack, pers. comm., 1990).

Management Constraints The park is threatened by the introduction of exotic species by illegally visiting yachts and fishing vessels. Coconut termite has been present since 1915, and paper hornet and red ant have also been introduced (McCormack, 1990). Also of particular concern is the containment of rats to Anchorage Islet and the control of rhinoceros beetle, which, although currently absent from the park, has been introduced to the Cook Islands. The islands are potentially threatened by fires started by unsupervised visitors and poaching on the clam beds of Suwarrow Reef and lagoon (SPREP, 1985a). The establishment of pearl fishing is unlikely to affect the bird colonies adversely, but there is some concern that personnel will want to visit reef-islands for coconut crab, coconut, green turtle, crayfish, fish, sooty tern eggs and fledging birds of various types and that some form of control will be required (G. McCormack, pers. comm., 1990).

Staff There is one warden intermittently present for up to nine months annually (SPREP, 1989).

Budget No information

Local Addresses Conservation Service Director, PO Box 371, Rarotonga; Ministry of Marine Resources (Fisheries), Rarotonga 


\section{References}

Batham, J. and Batham, A. (1973). Field notes on birds observed on the "motus" of two atolls (Penrhyn and Suwarrow) in the northern Cook Islands. Notornis 20: 97-101.

Dahl, A.L. (1980). Regional ecosystems survey of the South Pacific Area. SPCIIUCN Technical Paper 179. South Pacific Commission, Noumea, New Caledonia.

Douglas, G. (1969). Draft check list of Pacific oceanic islands. Micronesica 5(2): 327-463.

Grange, K.R. and Singleton, R.J. (1985). A guide to the reef fishes of Palmerston and Suwarrow Atolls, Cook Islands. NZOI. Oceanographic Field Report 21. DSIR, New Zealand. 24 pp.

Helm, A.S. and Percival, W.H. (1973). Sisters in the Sun - the story of Suwarrow and Palmerston Atolls. Robert Hale \& Co., London/Whitcomb and Tombs Ltd., New Zealand. (Unseen)

Johnston, K.M. (1967). Village agriculture in Aitutaki, Cook Islands. Pacific Viewpoint Monographs 1: 1-122. (Unseen)

Khristoforova, N.K. and Bogdanova, N.N. (1981). Environmental conditions and heavy metal content of marine organisms from atolls of the Pacific Ocean. Proceedings of the Fourth International Coral Reef Symposium, Manila 1: 161-162.

McCormack, G. (1986). Suwarrow National Park. Report to the Secretary of Internal Affairs. Unpublished. $14 \mathrm{pp}$.

McCormack, G. (1989). Cook Islands Conservation Service: two years under the 1986/87 Act. Fourth South Pacific Conference on Nature Conservation and Protected Areas, Port Vila, Vanuatu, 4-12 September. 5 pp.

Neale, T. (1966). An Island to Oneself. Collins, London/Sydney. (Unseen)

Scoffin, T.P., Stoddart, D.R., Indhope, A.W. and Woodroffe, C.D. (1985). Exposed limestone of Suwarrow Atoll. Abstract. Proceedings of the Fifth International Coral Reef Congress, Tahiti 2: 348.

SPREP (1985a). Cook Islands. In: Thomas, P.E.J. (Ed.), Report of the Third South Pacific National Parks and Reserves Conference. Volume III. Country reviews. South Pacific Commission, Noumea, New Caledonia. Pp. 60-75.

SPREP (1985b). Action strategy for protected areas in the South Pacific region. South Pacific Commission, Noumea, New Caledonia. 24 pp.

SPREP (1989). Cook Islands. Paper presented at the Fourth South Pacific Conference on Nature Conservation and Protected Areas, Port Vila, Vanuatu, 4-12 September. 5 pp.

UNEP/IUCN (1988). Coral Reefs of the World. Volume 3: Central and Western Pacific. UNEP Regional Seas Directories and Bibliographies. IUCN, Gland, Switzerland and Cambridge, UK/UNEP, Nairobi, Kenya. 378 pp.

Wood, B.L. (1967). Geology of the Cook Islands. New Zealand Journal of Geology and Geophysics 10: 1429-1445.

Date September 1988, updated June 1989 and February 1990

\section{TAKUTEA NATURE RESERVE (PROPOSED)}

\section{IUCN Management Category Proposed}

Biogeographical Province 5.04.13 (Southeastern Polynesian) 
Geographical Location In the southern Cook Islands, approximately $215 \mathrm{~km}$ north-east of Rarotonga. Approximately $19^{\circ} 26 \mathrm{~S}, 158^{\circ} 10^{\prime} \mathrm{W}$

Date and History of Establishment Proposed by the Conservation Service in 1988.

Area Approximately 150 ha

Land Tenure Takutea was gifted to the King by Ngamaru Ariki on 31 March 1903, for the benefit of the people of the Cook Islands. In 1938 the island was freed of all trusts and reservations and its ownership opened for investigation. As a result, in 1950, the Aronga Mana of Atiu were appointed "as Trustees for all the native land owners of Atiu and their descendants". At present, the following representatives of the Aronga Mana are listed in the Land Court as Trustees of Takutea: Ada Ngamaru Ariki, Maka Kea Rongomatane Ariki, Mataio Kea Parua Ariki and Tangata Simiona Tinokura Mataiapo. The following titles are not at present represented: Makopi Mataiapo, Paerangi Mataiapo and Aumai Mataiapo (McCormack, 1988).

\section{Altitude No information}

Physical Features Comprises an oval sand cay on a coral foundation, with lithified beach rock on the northern beach (Wood, 1967). A reef flat entirely surrounds the island extending up to $800 \mathrm{~m}$ in width to the south-east (McCormack, 1988) and growing around narrow, elongated, curved submarine ridges between $6 \mathrm{~m}$ and $20 \mathrm{~m}$ deep, presumably also coral, which trend west to north-west (Wood, 1967).

Climate Data specific to Takutea are not available. The mean annual temperature at Aitutaki, approximately $200 \mathrm{~km}$ to the north-west, is $25.6^{\circ} \mathrm{C}$. Mean daily maxima exceed $30^{\circ} \mathrm{C}$ during January to April and mean daily minima fall below $22^{\circ} \mathrm{C}$ during June to October, absolute maxima and minima are $37.2^{\circ} \mathrm{C}$ and $12.8^{\circ} \mathrm{C}$, respectively. The 37 -year mean annual rainfall at Aitutaki is $1984 \mathrm{~mm}$ (Stoddart, 1975).

Vegetation A coastal scrub of Scaevola, beach Heliotrope and Suriana is found. Tree species include Pisonia, Messerchmidia, Pandanus and coconut (McCormack, 1988).

Fauna The island is the most important seabird breeding area in the Southern Group of the Cook Islands. Five of the eight breeding species do not breed elsewhere in the southern Cooks. A large colony of red-footed booby Sula sula nests in Pisonia trees in the south-west. A small colony of about 50 great frigate bird Fregata minor occurs within the red-footed booby colony. Some 20 brown booby Sula leucogaster nest under Messerchmidia trees on the beaches to the west and north-west. Approximately 50 pairs of white-capped noddy Anous minutus nest over the north-east of the island within about $150 \mathrm{~m}$ of the shore. One or two pairs of masked booby $S$. dactylatra probably nest on Takutea. Three species present on Takutea also breed elsewhere in the southern Cook Islands. Over 1,000 red-tailed tropic bird Phaeton rubricauda nest mainly under the coastal scrubs and brown noddy Anous stolidus is common, nesting in Pandanus and coconut. White tern Gygis alba is present in moderate numbers throughout the Cook Islands, including Takutea. Land birds are restricted to reef heron Egretta sacra which breeds on Takutea, and the migrant New Zealand long-tailed cuckoo Eudynamis taitensis which nests in New Zealand. A number of species migrate from Alaska for over-wintering, including bristle-thighed curlew Numenius tahitiensis, golden plover Pluvialis sp. and wandering tattler Heteroscelus incanus.

Cultural Heritage No information 


\section{Local Human Population Uninhabited}

Visitors and Visitor Facilities No information

Scientific Research and Facilities Preliminary surveys of the flora and fauna were carried out in April 1986 (McCormack, 1988), whilst a brief account of the geology is given by Wood (1967).

Conservation Value The island is particularly valued as a major part of the natural heritage of the Cook Islands.

Conservation Management A number of specific management proposals have been made pursuant to the 1986-87 Conservation Act, viz. that a management committee be established consisting of the trustees of Takutea, the Cao of Atiu, the Atiu Conservation Officer and the Director of Conservation; that the management committee immediately approaches the Minister to have Takutea set aside as Takutea Nature Reserve; that the management committee immediately begins the preparation of a management plan, as specified by the 1986-87 Conservation Act; that while the management plan is being prepared the committee prohibits any activity in the park which would interfere with the seabirds on the island and encourages and monitors activities which favour the survival of the seabirds on the island (McCormack, 1988).

Management Constraints Four of the five species restricted to within the southem Cook Islands occur in small or very small colonies and might desert the island if disturbed (McCormack, 1988).

Staff No information

Budget No information

Local Addresses Conservation Service, Box 371, Rarotonga

\section{References}

McCormack, G. (1988). Takutea Nature Reserve: a discussion document. Cook Islands Conservation Service, Rarotonga. 5 pp.

Stoddart, D.R. (1975a). Scientific studies in the Southern Cook Islands: background and bibliography. In: Stoddart, D.R. and Gibbs, P.E. (Eds), Almost-atoll of Aitutaki: reef studies in the Cook Islands, South Pacific. Atoll Research Bulletin 190: 1-30.

Wood, B.L. (1967). Geology of the Cook Islands. New Zealand Journal of Geology and Geophysics 10: 1429-1445.

Date July 1989

\section{TE MANGA NATURE RESERVE (PROPOSED)}

\section{IUCN Management Category Proposed}

Biogeographical Province 5.04.13 (Southeastern Polynesian) 
Geographical Location Central uplands of Rarotonga, the nearest coastline lying about $24 \mathrm{~km}$ to the south. The park boundary follows the $400 \mathrm{~m}$ contour circumvallating the three major peaks. Approximately $21^{\circ} 14^{\prime} \mathrm{S}, 159^{\circ} 47^{\prime} \mathrm{W}$

Date and History of Establishment Proposed by the Conservation Service in 1989.

Area Approximately $100 \mathrm{ha}$

Land Tenure Native customary and native freehold land

Altitude Ranges from $400-653 \mathrm{~m}$

Physical Features The whole of Rarotonga is the summit portion of an extinct Tertiary volcano that may have attained $1,000 \mathrm{~m}$ in height before dissection and erosion by streams. Te Kou is the eroded remnants of a small volcanic cone and flow sheets ejected from centres both within and outside the main crater (Wood, 1967). The proposed reserve includes Rarotonga's two highest peaks and comprises a north-south oriented ridge running between Te Manga (653m) and Te Atakura $(638 \mathrm{~m})$. Another ridge branches to the south-west, rising to Te Kou $(588 \mathrm{~m})$. The land drops away steeply on all sides, isolating the proposed reserve. The headwaters of a number of perennial streams are found in or immediately below the $400 \mathrm{~m}$ contour, namely the Papua, Taipara and Avana to the south, the Turangi and the Matavera to the east, and Tupapa and Takuvaine to the north (McCormack, 1989). Most hill slopes in Rarotonga have a moderate thickness of red soil resting on weathered volcanic rocks, but near the crests of the ridges, boulders and pebbles are common and the ridge crests are chiefly masses of broken rock held together by tree roots. Geology is further discussed by Wood (1967).

Climate The area is distinguished by having the highest rainfall, $3500 \mathrm{~mm}$ per year, the lowest level of sunshine, the strongest winds and most rapid changes of humidity in Rarotonga (McCormack, 1989).

Vegetation The proposed reserve supports a small, isolated mist community which includes numerous species not found elsewhere in the mountainous interior of Rarotonga. Nine Rarotongan native flowering plants are typically restricted to the mist zone. Rarotongan chloris Chloris cheesemanii, Rarotongan gamotia Garnotia cheesemanii, mist cyrtandra Cyrtandra lillianae and Rarotonga sclerotheca Sclerotheca viridiflora are all endemic to the island and rare. Mist orchid Liparis clypeolum is a very rare Polynesian endemic that has not been found since 1899. The very rare mist bulrush Scirpus nodosus, Pacific blueberry Vaccinium cereum, omalanthus Omalanthus nutans and ascarina Ascarina diffusa are widespread and typical of the mist zone. Thirteen native ferns, of which three are endemic to Rarotonga, are typically restricted to the proposed reserve. The three endemics, Rarotongan filmy-fern Hymenophyllum involucratum, mist-valley fem Pseudophegopteris sp. and mist phymatodes $P$ hymatodes sp., are all uncommon. The Cook Islands endemic pale-stem fern Acrophorus leucorhachis is very rare and typically restricted to the mist zone. A number of Polynesian endemic ferns occur, including sheet filmy-fern Trichomanes digitatum, glossy tongue-fern Elapho glossum, a very limited number of hairy tongue-fern $E$. savaiense and Polynesian dryopteris Dryopteris fatuhivensis. A number of more widespread ferns are also present, including mist tree fern Cyathea affinis, winged filmy-fern Trichomanes cf. maximum, the very rare Asplenium lunulatum, mist blechnum Blechnum procerum and mist grass-fern Grammitis hookeri. The mist zone is not generally invaded by weedy introductions, although tracks, clearings and slips can allow such plants to gain a foothold. In some areas the following weeds are common: T-grass Paspalum conjugatum, kopi-'enua Zingiber zerumbet and mile-a-minute weed Mikania micrantha. The South American 
tree Cecropia palmata, which is now present throughout most of the rugged inland, is uncommon and does poorly in the mist zone (McCormack, 1989).

Fauna The reserve includes one of the few known breeding grounds of herald petrel (koputu) Peterodroma arminjoniana which was recorded as extinct in 1899 . Nowadays it is not uncommon to see about 20 herald petrels soaring over the main Te Manga-Te Atukura breeding ground in the late afternoon. Smaller colonies exist on Maungatea, and possibly on Maungaroa. Mist landsnail Tekoulina sp. is uniquely viviparous, and endemic to the proposed reserve (McCormack, 1988).

\section{Cultural Heritage No information}

Local Human Population The area is uninhabited.

Visitors and Visitor Facilities No information

Scientific Research and Facilities The flora and fauna have been surveyed, but more specific information is not available.

Conservation Value The mist community found within the proposed area is the most restricted and scientifically interesting assemblage in inland Rarotonga. The presence of restricted species and general absence of human impact and introduced weeds adds to its conservation value.

Conservation Management A number of specific management proposals have been made, pursuant to the 1986-87 Conservation Act, viz. that a management committee be established consisting of a representative of the owners of each section of land, a representative of Te Koutu Nui, and the Director of Conservation; that the management committee immediately approaches the Minister of Conservation to have the Queen's Representative declare the area of Te Ko'u and the Te Manga-Te Atukura Ridge above $400 \mathrm{~m}$ as the Te Manga Nature Reserve; and that the management committee immediately begins the preparation of a management plan as specified by the Conservation Act (McCormack, 1989). The extent to which these proposals have been implemented is not known.

Management Constraints The proposed reserve was included in a 1985 proposal to gazette a 1,000ha kakerori reserve in the central Rarotongan uplands. However, since no progress was made, this much smaller single-objective reserve has been proposed (McCormack, 1989).

Staff No information

Budget None

Local Addresses Conservation Service, Box 371, Rarotonga

\section{References}

McCormack, G. (1989). Te Manga Nature Reserve: concept document. Cook Islands Conservation Service, Rarotonga. 6 pp.

Wood, B.L. (1967). Geology of the Cook Islands. New Zealand Journal of Geology and Geophysics 10: 1429-1445.

Date July 1989 


\section{FEDERATED STATES OF MICRONESIA}

Area 702 sq. km

Population 86,094 (1988)

Natural increase: No information

\section{GNP No information}

Policy and Legislation The Federated States of Micronesia consists of the states of Yap, Truk, Pohnpei and Kosrae and became a independent nation in free association with the USA on 3 November 1986, having previously been part of the United Nations Trust Territory of the Pacific Islands. Legally a sovereign nation, the Federation is loose, with each state having an elected governor and a unicameral assembly (Paxton, 1989), and in general the national government is relatively weak compared to the USA (C. Dahl, pers. comm., 1990).

Some United States Federal legislation and Trust Territory legislation applied while this country was a part of the Trust Territory. This included the Trust Territory Environment Act enacted by the former Congress of Micronesia in 1972. This provided for the establishment of a Trust Territory Environmental Protection Board. However, neither the Act, nor the work of the Board related specifically to protected areas. The Trust Territory Endangered Species Act (TTPI Public Law 6-55 of 1975) allowed for acquisition of land or water for the purpose of conserving threatened species. Other relevant Trust Territory Acts included the Fishing Law and the Land Use Planning Act, both 1972. US legislation relevant to the Trust Territories included various pollution laws and housing acts, as well as the Fish and Wildlife Coordination Act and the National Environmental Policy Act. With the termination of the Trust Territory, US Federal provisions only apply to the now very limited US actions within the Federation and do not apply to private individual or national government actions.

Neither the legislation, nor the policy on protected areas was clear while the country was a part of the Trust Territory, and no protected areas were actually established. This is largely because the United States, while administering the Territory, did not own property and hence had no direct jurisdiction to cover designation of protected areas. Virtually all land and reefs and coastal areas are in private or traditional ownership and this has continued to inhibit the establishment of protected areas (S.L. Anefal, pers. comm., 1990).

Legislation to support a coastal resource management programme in Kosrae has been drafted and submitted to the legislature. However, it will be some time before the bill is acted upon, and even if passed, there is likely to be a considerable delay before any protected areas are established. In Pohnpei, a watershed management act was passed in 1987 which gave the state government substantial authority to protect much of the island's interior and mangrove areas. However, implementation is slow and there is little awareness among the populace that the uplands are off-limits for traditional agricultural use (C. Dahl, pers. comm., 1990).

International Activities The Federated States of Micronesia is not yet party to any of the international conventions or programmes that directly promote the conservation of natural areas, namely the Convention concerning the Protection of the World Cultural and Natural Heritage (World Heritage Convention), Unesco Man and the Biosphere Programme and the Convention on Wetlands of International Importance especially as Waterfowl Habitat (Ramsar Convention). 
The Convention on the Conservation of Nature in the South Pacific (1976) has been neither signed nor ratified. Known as the Apia Convention, it entered into force during 1990. The Convention is coordinated by the South Pacific Commission and represents the first attempt within the region to cooperate on environmental matters. Among other measures, it encourages the creation of protected areas to preserve indigenous flora and fauna.

The Federated States of Micronesia is party to the South Pacific Regional Environment Programme (SPREP) and the 1986 Convention for the Protection of the Natural Resources and Environment of the South Pacific Region (SPREP Convention) has been signed (9 April 1987) and ratified (29 November 1988). The Convention entered into force during August 1990. Article 14 calls upon the parties to take all appropriate measures to protect rare or fragile ecosystems and threatened or endangered flora and fauna through the establishment of protected areas and the regulation of activities likely to have an adverse effect on the species, ecosystems and biological processes being protected. However, as this provision only applies to the convention areas, which by definition is open ocean, it is most likely to assist with the establishment of marine reserves and the conservation of marine species.

Administration and Management Pohnpei State has a Division of Parks and Recreation within its Department of Lands.

Systems Reviews The Federated States of Micronesia includes most of the Caroline Islands, running west-north-west from Kosrae to Yap, and consists of volcanic and metamorphic islands and atolls. "Almost atolls" are also present, making the group one of the more typical island chains. The development and origin of the Caroline Islands is described by Scott and Rotondo (1983); general information is given in SPREP (1980). The island's traditional economies have been undermined by a century of foreign influence, trade, control and warfare. The Japanese in particular disrupted land-use controls and ownership customs, permitted greater public access to resources and undermined traditional conservation (Maragos, 1986).

The islands support a rich flora and fauna with many endemic forms. Major ecosystems include lowland, montane, cloud, riverine, swamp, mangrove and atoll forest, savanna and grassland, seagrass beds, lagoons, and extensive coral reefs (Dahl, 1980). Much of the natural vegetation has been cleared for coconut plantations (e.g. on Yap and Puluwat) or disturbed by phosphate mining (e.g. on the raised coral island of Fais). Few areas of native vegetation remain on the Truk Islands, except on the high volcanic islands of Moen, Dublon, Uman, Fefan, Udot and Tol. Although the lowland forests on the Pohnpei Islands have been much disturbed, both Kusaie and the island of Pohnpei retain upland forests (IUCN, 1986). A description of forests and conservation problems is given by Fosberg (1973). An account of the reefs and reef resources is given in UNEP/IUCN (1988).

Environmental issues, reviewed by Maragos (1986), include poorly-planned coastal development leading to degraded or destroyed mangoves, reefs and sea grass beds and consequently reduced fisheries output, and the disposal of wastewater discharges and solid waste. Crowding and land shortages in Pohnpei has spurred immigration from the outer atolls and led to additional landfilling along the shorelines and mangrove areas in the Kolonia-Sokehs area for residences. This has not yet had serious environmental consequences but the rapidly expanding population may have escalating effects in the future. A major emerging problem is the increased fishing pressure from rising populations and over-fishing of preferred species. Truk is economically severely depressed and overcrowded conditions on some islands in the lagoons are affecting health and welfare. In particular, water supply and quality are unreliable. Truk has also experienced considerable reef degradation through dynamiting. 
Some degree of protection has been recommended for Gaferut (Dahl, 1980) although this has not been implemented, and turtle and bird populations are still traditionally exploited by the owners (S.L. Anefal, pers. comm., 1990). Turtle reserves have been recommended for Elato, Pikelot, West Fayu, all in Yap State, and Orulok. At present no turtle sanctuaries have been established in Yap State (S.L. Anefal, pers. comm., 1990). Dahl (1980 and 1986) stresses that there is an urgent need to inventory the biomes of the Federated States of Micronesia in view of the great richness of the area and the likelihood of increasing pressure in the near future.

Yap State's Marine Resources Management Division is working on a Marine Resources Coastal Management Plan, incorporating traditional customs and laws (S.L. Anefal, pers. comm., 1990). This is likely to include recommendations for the protection of specific areas. However, a strong system of reef ownership still exists in Yap so the establishment of protected areas in Yap is likely to be on a significantly different basis than elsewhere (C. Dahl, pers. comm., 1990).

The Pohnpei Coastal Resources Management Plan (1987) recommended numerous marine areas for protection, although these recommendations have not been acted upon. There has also been some interest at community level in the establishment of a mangrove reserve in Pohnpei, with the intention of generating revenues from tourists. Protected status has been conferred on inland areas of Pohnpei Island which contains a range of tropical high island forest, important both as wildlife habitat and watershed protection (Anon, 1989). Surveys of Oroluk Atoll are planned for 1991 , with the intention of recommending some form of protection. The traditional management of resources, and the pressures placed upon on it by economic and social pressures, is discussed by Yinug et al. (1989) with the conclusion that some form of legislated resource management is becoming necessary. A coastal resource management plan for Kosrae is being developed (Dahl, 1989) which includes proposals for the establishment of a contiguous marine reserve and terrestrial park and a resource reserve on the south coast of the island in which subsistence use would be allowed.

\section{Addresses}

Department of Human Resources, PO Box 490, Kolonia, Pohnpei, Eastern Caroline Islands 96941, FSM

Yap Institute of Natural Resources, PO Box 215, Yap, West Caroline Islands 96943, FSM

\section{References}

Anon. (1989). Progress with the action strategy for protected areas in the South Pacific. Information Paper 3. Fourth South Pacific Conference on Nature Conservation and Protected Areas. Port Vila, Vanuatu, 4-12 September. $19 \mathrm{pp}$.

Dahl, A.L. (1980). Regional ecosystems of the South Pacific area. SPC/IUCN Technical Paper 179. South Pacific Commission, Noumea, New Caledonia. 99 pp.

Dahl, A.L. (1986). Review of the Protected Areas system in Oceania. IUCN, Gland, Switzerland and Cambridge, UK/UNEP, Nairobi, Kenya. 328 pp.

Dahl, C. (1989). Developing a coastal resource management plan for Kosrae State, Federated States of Micronesia. Case Study No. 23. Fourth South Pacific Conference on Nature Conservation and Protected Areas, Port Vila, Vanuatu, 4-12 September. 7 pp.

Fosberg, F.R. (1973). On present condition and conservation of forests in Micronesia. In: Pacific Science Association, Planned Utilisation of the Lowland Tropical Forests. Proceedings of the Pacific Science Standing Committee Symposium, August 1971, Bogor, Indonesia. Pp. 165-171. 
Maragos, J.E. (1986). Coastal resource development and management in the US Pacific Islands: 1. Island-by-island analysis. Office of Technology Assessment, US Congress. Draft.

Paxton, J. (1989). The Statesman's Yearbook 1989-1990. The Macmillan Press Limited, London. $1691 \mathrm{pp}$.

Scott, G.A.J. and Rotondo, G.M. (1983). A model for the development of types of atoll and volcanic islands on the Pacific lithospheric plate. Atoll Research Bulletin $260.33 \mathrm{pp}$.

SPREP (1980). Trust Territory of the Pacific Islands. Country Report 14. South Pacific Commission, Noumea, New Caledonia.

UNEP/IUCN (1988). Coral reefs of the world. Volume 3. Central and Western Pacific. UNEP Regional Seas Directories and Bibliographies. IUCN, Gland, Switzerland and Cambridge, UK/UNEP, Nairobi, Kenya. 378 pp.

Yinug, M., Falanruw, M., Manmaw, C. (1989). Traditional and current resource management in Yap. In: SPREP, Report on the workshop on customary tenure, traditional resource management and nature conservation, Noumea, 28 March-1 April. South Pacific Commission, Noumea. Pp. 113-116.

Date December 1989, updated 1991

\section{ANNEX \\ Definitions of protected area designations, as legislated, together with authorities responsible for their administration}

\section{Title: Pohnpei Watershed Forest Reserve and Mangrove Protection Act}

Date: 1987

Brief description: Provides for the protection of soil, water and mangrove ecosystems in Pohnpei State

Administrative authority: No information

Designation:

Watershed forest reserve Designated in areas of soil instability, permitted uses include limited agriculture, research, dispersed recreation, gathering of wild plants, and some timber harvesting, provided environmental protection requirements are met. Forbidden uses include permanent occupancy, pesticide use, unauthorised tree-cutting, land clearing with fire, and grazing.

Important watershed areas Areas which have already been settled; restrictions include no additional building of roads or structures, no rebuilding or improvement of existing structures, and strict enforcement of other regulations.

Unauthorised cutting of trees in watershed forest reserves and in mangrove forests carry mandatory fines of one thousand dollars per tree cut. 


\section{FIJI}

Area 18,330 sq. km

Population 732,000 in 1988 (World Bank, 1990)

Natural increase: $2 \%$

GNP US\$1,520 per capita (1988) (World Bank, 1990)

Policy and Legislation Government policy on establishment of protected areas, as expressed in Development Plan DP8 and DP9, is to conserve and protect important and unique aspects of the country's natural heritage through the establishment of a comprehensive system of parks and reserves. It is intended that a National Parks and Reserves Act will be enacted which will "effectively provide for the preservation and protection of the natural environment including unspoilt landscape, reefs and waters, indigenous flora and fauna, habitats and ecological systems, features of scenic, historic or archaeological interest or other scientific interest". In addition, the bill would allow the use of the parks by the public for enjoyment, recreation and education purposes (Rabuka and Cabaniuk, 1989).

Legislative Council Paper No. 5 (1950) describes the Government of Fiji's forest policy, which includes the following aims: to protect and develop natural vegetation where its retention is necessary for climatic reasons and for the conservation of resources of soil and water for agriculture and to ensure adequate and continuous supplies of forest produce; to maintain and improve the fertility of the soil by preserving and, where necessary, extending the forest cover, to check soil erosion and to recover areas already eroded; and to provide and preserve amenities. The Ministry of Forestry has recognised the need to set aside forest from production and the currently proposed ten-year development plan for the Extension Division for Conservation, Environment and Parks Service outlines plans to set aside 15\% of the total natural forest for permanent protection, with a suggestion of 7,000 ha to be set aside annually for 20 years.

Eighty-three per cent of land is under constitutionally-inalienable native communal ownership, ten per cent is freehold and seven per cent is Crown (Government) land. Native land owned by indigenous people is reserved for use only by native Fijians, although areas may be leased through the Native Land Trust Board. Much of Fiji's native forest is "privately" owned in communal tribal tenure which severely constrains the Forestry Department's ability to manage forest resources. In view of this, the Native Land Trust Board prepared and approved a Forestry Policy in 1985. The main objectives include: ensuring that the forest is managed in accordance with sound forest management and land conservation practices; protecting the environment; and establishing a sound forest management policy to provide the basis for a national integrated land use policy. Both the Native Land Trust Board's Forestry Policy and Tourism Policy lend support to protected areas establishment, and the establishment of forest parks and reserves in particular (Rabuka and Cabaniuk, 1989).

Relevant legislation, described in Annex 1, comprises the 1923 Birds and Game Protection Act, the earliest nature conservation law, the Native Land Trust Act (1940), the Forest Act (1953) and the National Trust for Fiji Act (1970). The Native Land Trust Act provides for the establishment of the Native Land Trust Board, the principal agency through which Fijian land claims are administered. The Forest Act provides for the constitution of nature reserves, and the protection of any unalienated Crown land, or land leased to the Crown, as a reserved forest. Furthermore, nature reserves may be declared within reserved forests. Protected forests may also be established on native land, with the consent of the Native Land Trust Board (Sloth, 1988). 
The Forestry Act, however, has a number of serious weaknesses. For example, legal loopholes permit clearfelling of forests over which the Forestry Department has no control and all protected areas established under the provisions of the Forestry Act are subjected to dereservation at ministerial level; reserve forests have frequently been dereserved. This indicates an inadequate level of protection for sites of national or international importance (Watling, 1988a). The National Trust for Fiji Act provides for the preservation, protection and management of natural heritage in general.

In addition, the 1953 Land Conservation and Improvement Ordinance (Cap 120) provides for the establishment of a Land Conservation Board with powers to issue conservation orders prohibiting or controlling land clearance for any purpose, and also makes provision for the appointment of conservation officers. The 1946 Town Planning Ordinance (Cap 109) provides for the conservation of the "natural beauties of the area" in the preparation of town planning schemes.

International Activities Fiji is not yet party to either the Unesco Man and the Biosphere Programme or the Convention on Wetlands of International Importance especially as Waterfowl Habitat (Ramsar Convention), international conventions that directly promote the conservation of natural areas. However, a Cabinet decision to accede to the Convention concerning the Protection of the World Cultural and Natural Heritage (World Heritage Convention) has been taken.

At a regional level, Fiji signed the 1976 Convention on the Conservation of Nature in the South Pacific on 18 September 1989. Known as the Apia Convention, it entered into force during 1990. The Convention is coordinated by the South Pacific Commission and represents the first attempt within the region to cooperate on environmental matters. Among other measures, it encourages the creation of protected areas to preserve indigenous flora and fauna.

Fiji is party to the South Pacific Regional Environment Programme (SPREP) and has ratified (18 September 1989) the Convention for the Protection of the Natural Resources and Environment of the South Pacific Region, 1986 (SPREP Convention), which entered into force during August 1990. Article 14 calls upon the parties to take all appropriate measures to protect rare or fragile ecosystems and threatened or endangered flora and fauna through the establishment of protected areas and the regulation of activities likely to have an adverse effect on the species, ecosystems and biological processes being protected. However, as this provision only applies to the Convention area, which by definition is open ocean, it is most likely to assist with the establishment of marine reserves and the conservation of marine species.

Other international and regional conventions concerning environmental protection to which Fiji is party are reviewed by Venkatesh et al. (1983).

Administration and Management The National Trust for Fiji has broad legal responsibility for nature conservation and comprises a council of ten members, including a chairman and vice-chairman, appointed by the Minister for a period not exceeding two years. The National Trust is currently responsible for three reserves. The Forestry Department, under the Ministry of Forests, is primarily concerned with the management of indigenous forests and plantations for commercial production purposes, but is also responsible for administering nature reserves, as well as recreation and amenity areas (Dunlap and Singh, 1980; SPREP, 1985b). The Department currently administers seven nature reserves, established within forest reserves, under the 1953 Act (SPREP, 1985b), 18 forest reserves and a number of forest parks and amenity reserves. 
Although the Native Land Trust Board has no specific nature conservation policy, its stated role in protected areas establishment is to lend support to and facilitate the efforts of the National Trust and the Forestry Department in securing native lands for parks and reserves via the native lands leasing procedure (Rabuka and Cabaniuk, 1989). Protected area establishment on native reserves must proceed through established leasing procedures, to ensure that the landowners are fully aware from the outset as to the purpose of such areas and as to the benefits (socio-economic, environmental and otherwise) which will accrue to them through their lands being given park/reserve status; the landowners are fully aware of the implications of protected area status as it affects customary land use rights; landowner benefits are maximised, not only in terms of lease premiums, income, and visitor receipts, but also with regard to employment and, if appropriate, training opportunities; the lessee receives long-term security over the lands in question; and should any dispute arise between the landowners and lessee, both sides have recourse to arbitration through the Native Land Trust Board. It should be noted that Namenalala Island Nature Reserve (43ha, established in 1984 through lease agreement between the Native Land Trust Board, the landowners and Namenalala Island Resort Ltd) is the only protected area to have been established in Fiji to date through the Native Land Trust Leasing Procedure (Lenoa et al., 1989).

There are also lease agreements between the Forestry Department, the Fiji Pine Commission, and the Native Land Trust Board on the lease of land for 50 years for afforesting grasslands and re-afforesting logged areas with hardwoods.

\section{Addresses}

Conservator of Forests, Ministry of Forests, PO Box 2218, Government Buildings, Suva National Trust for Fiji, PO Box 2089, Government Buildings, Suva

Native Land Trust Board, PO Box 116, Suva

\section{References}

Ash, J. and Ash, W. (1984). Freshwater wetland vegetation of Viti Levu, Fiji. New Zealand Journal of Botany 22: 337-391.

CMC (1987). Conservation issues in Fiji. A briefing document prepared for Deutsche Gesellschaft für Technische Zusammenarbeit (GTZ) GmbH. IUCN Conservation Monitoring Centre, Cambridge, UK. Unpublished report. 33 pp.

Dahl, A.L. (1980). Regional ecosystem survey of the South Pacific Area. SPCIIUCN Technical Paper 179. South Pacific Commission, Noumea, New Caledonia. 99 pp.

Dahl, A.L. (1986). Review of the Protected Areas System in Oceania. IUCN, Gland, Switzerland and Cambridge, UK/UNEP, Nairobi, Kenya. 328 pp.

Davis, S.D., Droop, S.J.M., Gregerson, P., Henson, L., Leon, C.J., Lamlein Villa-Lobos, J., Synge, H. and Zantovska, J. (1986). Plants in Danger: What do we know? IUCN, Gland, Switzerland and Cambridge, UK. 488 pp.

Drysdale, P.J. (1988). Rainforest management and conservation in Fiji: a prescription for action. In: Proceedings of the Second National Conservation Congress 9-10 June. Volume 2. National Trust for Fiji, Suva, Fiji. Pp. 1-264.

Dunlap, R.C. and Singh, B.B. (1980). A national parks and reserves systems for Fiji. A report to the National Trust for Fiji. Three volumes. $117 \mathrm{pp}$.

Forestry Department (1989). Annual report for the year 1989. Paper No. 21 of 1990. Ministry of Forests, Suva. 22 pp. 
Juvik, J.O. and Singh, B. (1989). Conservation of the Fijian crested iguana: a progress report. Case Study 22. Fourth South Pacific Conference on Nature Conservation and Protected Areas, Port Vila, Vanuatu, 4-12 September. South Pacific Commission, Noumea, New Caledonia. 7 pp.

Lenoa, L., Waqaisavou, T. and Lees, A. (1989). A representative national parks and reserves system for Fiji. Case Study 7. Fourth South Pacific Conference on Nature Conservation and Protected Areas, Port Vila, Vanuatu, 4-12 September. South Pacific Commission, Noumea, New Caledonia. 15 pp.

Maruia Society (1989). A representative national parks and reserves system for Fiji's tropical forests. Maruia Society Policy Reports Series No. 9. 110 pp.

National Trust for Fiji (1988a). Fiji's rainforests: our heritage and future. Proceedings of the Second National Conservation Congress, Suva, Fiji, 9-10 June. Volume 1. National Trust for Fiji. 189 pp.

National Trust for Fiji (1988b). Fiji's rainforests: our heritage and future. Proceedings of the Second National Conservation Congress, Suva, Fiji, 9-10 June. Volume 2. National Trust for Fiji. 264 pp.

Parham, J.W. (1972). Plants of the Fiji Islands. Suva, Government Press. 490 pp. (Unseen).

Rabuka, M. and Cabaniuk, S. (1989). The role of the Native Land Trust Board in the establishment of parks and reserves in Fiji. In: Thomas, P.E.J. (Ed.), Report of the workshop on customary tenure, traditional resource management and nuture conservation. SPREP, Noumea, New Caledonia. Pp. 71-86.

Schmid, M. (1978). The Melanesian forest ecosystem (New Caledonia, New Hebrides, Fiji Islands and Solomon Islands. In: Unesco/UNEP/FAO, Tropical forest ecosystems. Unesco, Paris. Pp. 654-683.

Sloth, B. (1988). Nature legislation and nature conservation as part of tourism development in the island Pacific. Pacific Regional Tourism Development Programme. Tourism Council of the South Pacific, Suva, Fiji. 82 pp.

SPREP (1985a). Action strategy for protected areas in the South Pacific Region. South Pacific Commission, Noumea, New Caledonia. 24 pp.

SPREP (1985b). Fiji. In: Thomas, P.E.J. (Ed.), Report of the Third South Pacific National Parks and Reserves Conference. Conference. Volume III. Country reviews. South Pacific Commission, Noumea, New Caledonia.

SPREP (1989). Progress with the action strategy for protected areas in the South Pacific. Information Paper presented at the Fourth South Pacific Conference on Nature Conservation and Protected Areas. Port Vila, Vanuatu, 4-12 September. 19 pp.

UNEP/IUCN (1988). Coral Reefs of the World. Volume 3: Central and Western Pacific. UNEP Regional Seas Directories and Bibliographies. IUCN, Gland, Switzerland and Cambridge, UK and UNEP, Nairobi, Kenya. 378 pp.

Venkatesh, S, Va'ai, S. and Pulea, M. (1983). An overview of environmental protection legislation in the South Pacific countries. SPREP Topic Review No. 13. South Pacific Commission, Noumea, New Caledonia. 63 pp.

Watling, D. (1988a). The forestry sector development study. FUJ/86/004. Report of the environmental scientist. Unpublished Report. Suva, Fiji. 44 pp.

Watling, D. (1988b). The effects of logging on Fijian wildlife. In: Proceedings of the Second National Conservation Congress 9-10 June. Volume 2. National Trust for Fiji, Suva, Fiji. $25 \mathrm{pp}$.

World Bank (1990). World Tables 1989-1990 Edition. John Hopkins University Press, Baltimore. 646 pp. 


\section{ANNEX \\ Definitions of protected area designations, as legislated, together with authorities responsible for their administration}

Title (English): Birds and Game Protection Act

Date: 1923

Brief description: Proscribes hunting of specified bird species, establishes closed seasons and quotas for others, and enables the Minister to establish reserved areas. Original legislation is not available.

Administrative authority: No information

Designation:

Reserved areas Details not available

Title (English): Native Land Trust Act

Date: $1940 / 1943$

Administrative authority: Native Land Trust Board

Description: Establishes and requires the Native Land Trust Board to declare and administer native reserves for the use, maintenance and support of Fijian owners. Original legislation not available.

Designation: Native reserves may be declared on any native land.

Title (English): An Act Relating to Forest and Forest Produce (The Forest Act)

Date: 1 October 1953, last amended 1978

Administrative authority: Conservator of Forests, Ministry of Forests

Description: Provides for the protection of any unalienated Crown land, or land leased to the Crown, as a reserved forest, which may also be sub-classified into nature reserve, protected forest and silvicultural area.

Designation:

\section{RESERVED FOREST}

Nature reserve Part of a reserved forest not being a silvicultural area. Excludes people except between $6 \mathrm{am}$ and $9 \mathrm{pm}$. Prohibits logging and other damage and the Conservator may approve operations only if they protect flora and fauna. The Native Land Trust Board's right of de-reservation is not specified.

Protected forest Established with Native Land Trust Board consent on any native land not being part of a reserved forest or alienated and not being part of a silvicultural area. Once protected, the Native Land Trust Board may not alienate without consent of the Conservator. Licences may be issued but illegal logging and grazing are prohibited. 
Silvicultural area Part of a protected forest so declared. Excludes people except between $6 \mathrm{am}$ and $9 \mathrm{pm}$. Objectives are not clearly stated, but may suggest production forestry or conversion to plantation.

Section 12 defines offences against the Act. In addition to the restricted times of entry, the following general activities are forbidden: grazing; cutting or damaging any trees or forest produce; erecting buildings; setting fires; clearing land; constructing or obstructing roads; setting or possessing traps etc.; entering areas closed under forest regulations; damaging forest property; hunting and fishing.

NB: All areas protected under the Act are subject to de-reservation by the Minister of Forestry.

\section{Title (English): The National Trust for Fiji Act}

Date 1970

Brief description Makes provision for the establishment of the National Trust for Fiji, a statutory body under the Ministry of Housing and Urban Development.

Administrative authority National Trust for Fiji (Chairman)

\section{SUMMARY OF PROTECTED AREAS}

\begin{tabular}{|c|c|c|c|c|}
\hline $\begin{array}{l}\text { Map }^{\dagger} \\
\text { ref. }\end{array}$ & Name of area & $\begin{array}{l}\text { management } \\
\text { category }\end{array}$ & $\begin{array}{r}\text { Area } \\
\text { (ha) }\end{array}$ & $\begin{array}{c}\text { Year } \\
\text { notified }\end{array}$ \\
\hline & National Park and Reserve & & & \\
\hline \multirow[t]{2}{*}{1} & Sigatoka Sand Dunes* & Jnassigned & 240 & 1988 \\
\hline & Nature Reserves & & & \\
\hline 2 & Draunibota and Labiko Islands & I & 2 & 1959 \\
\hline 3 & Nadarivatu & $I$ & 93 & 1956 \\
\hline 4 & Namenalala Island & III & 43 & 1984 \\
\hline 5 & Naqarabuluti & $I$ & 279 & 1958 \\
\hline 6 & Ravilevu & I & 4,020 & 1959 \\
\hline 7 & Tomaniivi & I & 1,322 & 1958 \\
\hline 8 & Vunimoli & I & 19 & 1966 \\
\hline 9 & Vuo Island & I & 1 & 1960 \\
\hline \multirow[t]{2}{*}{10} & Yadua Taba Island Crested Iguana Reserve & * IV & 70 & 1981 \\
\hline & Forest Reserve & & & \\
\hline \multirow[t]{2}{*}{11} & J H Garrick Memorial* & IV & 428 & 1983 \\
\hline & Parks & & & \\
\hline 12 & Colo-i-Suva Forest* & Jnassigned & 91 & 1972 \\
\hline
\end{tabular}




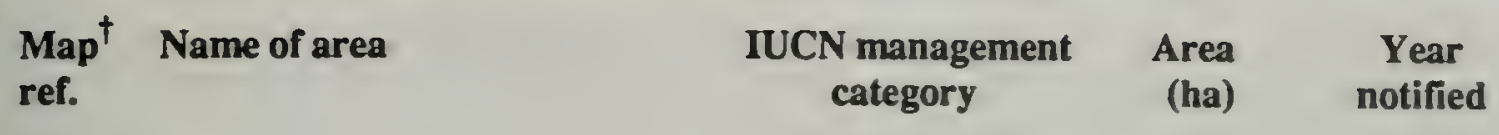

\begin{tabular}{|c|c|c|c|c|}
\hline & Amenity Reserves & & & \\
\hline 13 & Lololo & Unassigned & 1 & \\
\hline 14 & Lomolomo & Unassigned & 1 & \\
\hline 15 & Nukulau Island and Reef & Unassigned & 6 & 1970 \\
\hline 16 & Saweni Beach & Unassigned & 1 & \\
\hline 17 & Tavakubu & Unassigned & 1 & \\
\hline
\end{tabular}

\section{Proposed}

Bird Island, Beqa Lagoon Proposed

Bouma Forest Park and Reserve Proposed

Gau Proposed

Lower Vunivia Catchment Proposed

Moturiki Proposed

Mount Evans Forest Park Proposed

Mount Tomanivi Proposed

Mount Washington, Kadavu Proposed

Mubulau Island Proposed

Nadrau Plateau (Western Sector) Proposed

Namena Lala Island Proposed

Nanuku Islet - Proposed

Naulu-Lokia Swamps Proposed

Navua Swamp Proposed

Neoveitchia Storckii Palm Reserve Proposed

Nukubasaga and Bukubalati Proposed

Nukutolu Islets Proposed

Ogea Levu Proposed

Rokosalase Proposed

Selala Mangrove Reserve Proposed

Silktail Reserve Proposed

Sovi Basin Proposed

Sovu Islands Proposed

Taqua Rocks Proposed

Taveuni Proposed

Vatu-i-Lami Island Proposed

Vatu-i-Ra Island Proposed

Vatura Forest Amenity Reserve Proposed

Waikatakata Archaeological Park and Forest Park Proposed

Wainikavika National Park Proposed

Waisala Forest Park Proposed

Waisali Forest Amenity Reserve Proposed

White Rock Proposed

Yabu Island Proposed

* Site is described in this directory.

${ }^{\dagger}$ Locations of most protected areas are shown in the accompanying map. 
IUCN Directory of Protected Areas in Oceania

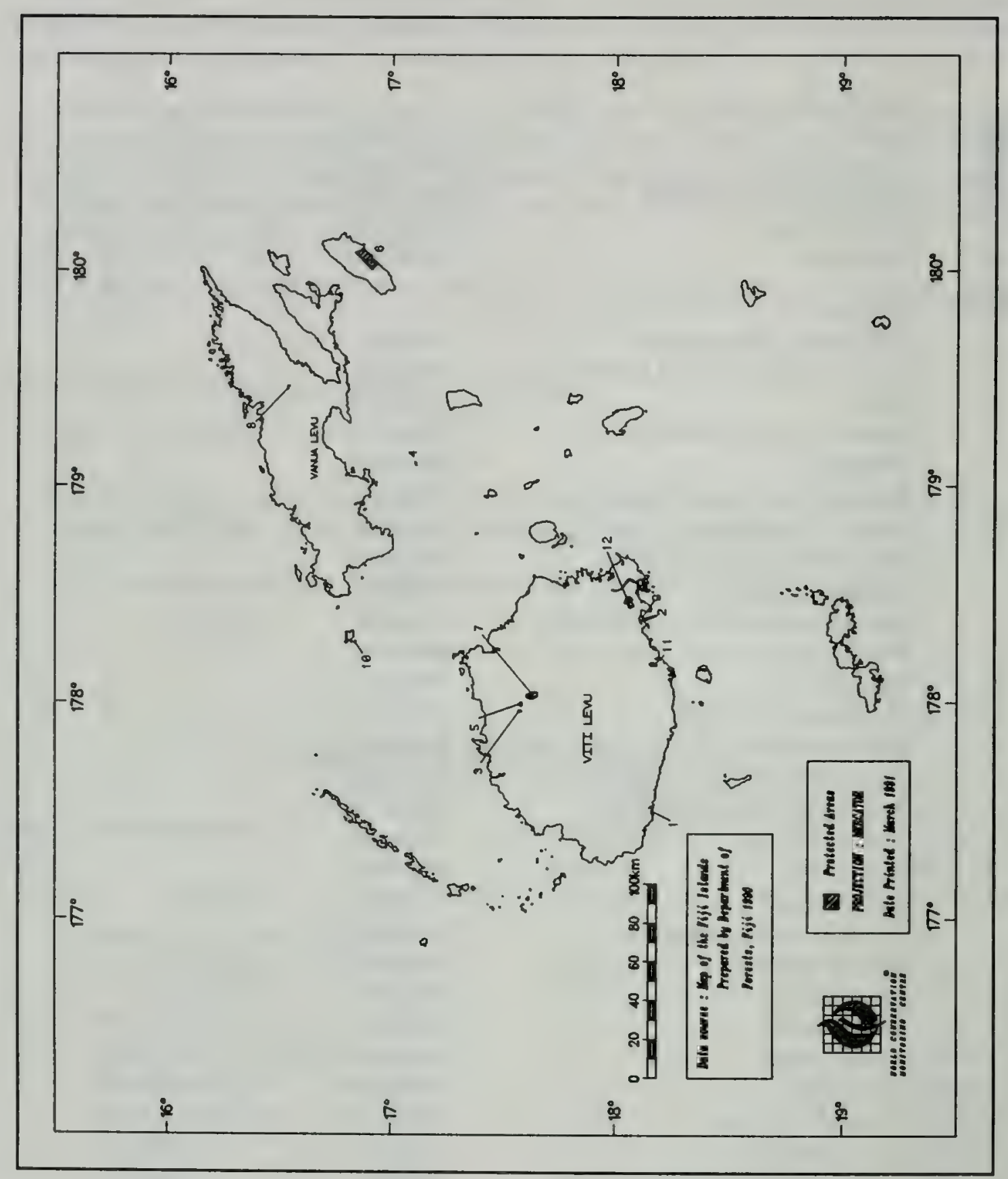

Protected Areas of Fiji 


\section{COLO-I-SUVA FOREST PARK}

IUCN Management Category Unassigned

Biogeographical Province 5.07.13 (East Melanesian)

Geographical Location The site is located $18 \mathrm{~km}$ from Suva in south-east Viti Levu. It is bounded to the south by the Kalabu road and to the west by the Colo-i-Suva Forest Station. Approximately $18^{\circ} 00^{\prime} \mathrm{S}, 178^{\circ} 30^{\prime} \mathrm{E}$

Date and History of Establishment No information

Area 91 ha

Land Tenure State

Altitude $120-200 \mathrm{~m}$

Physical Features The park comprises the entire upper drainage of the Waisila Creek, and includes a number of waterfalls, streams and canyons (Dunlap and Singh, 1980; Kay, 1986).

Climate Mean annual temperature is $24^{\circ} \mathrm{C}$, varying by only $2^{\circ} \mathrm{C}$ between February and July, the warmest and coolest months, respectively (Kay, 1986). No further details specific to the area are available.

Vegetation The area was originally lowland tropical forest. This has been selectively felled and, during the 1950s, replanted with mahogany Swietenia mahogoni.

Fauna No information

Cultural Heritage There is no known cultural value (G. Baines, pers. comm., 1989).

Local Human Population Uninhabited

Visitors and Visitor Facilities Facilities include a $0.5 \mathrm{~km}$ nature trail and over $3.6 \mathrm{~km}$ of other gravelled hiking trails. Natural pools have been developed for swimming. Other amenities include picnic and car parking areas. Camping facilities used to be available, and visitors are still allowed to pitch tents within the park. Transport to the site is by bus or car from Suva where the nearest accommodation is available (Dunlap and Singh, 1980; Kay, 1986). A total of 16,440 people visited the site in 1985, 5,099 more than in 1983 (Cabaniuk et al., 1986).

Scientific Research and Facilities The forestry station at Colo-i-Suva has undertaken some silvicultural studies (Dunlap and Singh, 1980). The Forestry Department Environmental Education Officer uses the park for school nature study.

Conservation Value Principally valued for recreation.

Conservation Management The site is protected under the Forest Act and is maintained by the Forestry Department as a recreational area and nature reserve.

Management Constraints According to a popular account extensive tree felling in the past has had a significant effect on the natural history of the area (Kay, 1986).

Staff Wardens are based at the Colo-i-Suva forestry station. 
Budget The National Trust has assisted the Department financially by contributing towards the development and management of the site. It also arranged for the development of a nature trail, financed by the WWF and IUCN (NTF, 1978). However, no specific details are available.

Local Addresses Ministry of Forests, PO Box 2218, Government Buildings, Suva

\section{References}

Cabaniuk, S, Tamani, A., Vulu, E. and Ratabua, A. (1986). A [draft advisory] plan for the conservation and development of the Sigatoka Sand Dunes for National Park and Reserve purposes. Prepared for the National Trust of Fiji by the Directorate of Town and Country Planning, Ministry of Housing and Urban Affairs. Suva, Fiji. 129 pp.

Dunlap, R.C. and Singh, B.B. (1980). A National Parks and Reserves System for Fiji. A report to the National Trust for Fiji. Three volumes. $117 \mathrm{pp}$.

Kay, R. (1986). Fiji, a travel survival kit. Lonely Planet, Australia.

National Trust for Fiji (1978). National parks and related reserves - Fiji island. Situation report of the National Trust for Fiji. 3 pp.

Date October 1988, revised July 1989

\section{J.H. GARRICK MEMORIAL RESERVE}

\section{IUCN Management Category IV (Managed Nature Reserve)}

Biogeographical Province 5.07 .13 (East Melanesian)

Geographical Location Located on the south side of high ground in central Viti Levu, $7 \mathrm{~km}$ north of Navua Town, the reserve lies within the Tikina of Veivatuloa, in the province of Namosi. The fully demarcated boundary follows the eastern bank of Wainikavika Creek in the west, and compass bearings elsewhere. Access is via the Navua/Namosi Road and Queen's Road. Approximately $18^{\circ} 19^{\prime} \mathrm{S}, 178^{\circ} 19^{\prime} \mathrm{E}$

Date and History of Establishment The reserve was donated to the National Trust for Fiji in 1984.

\section{Area $429 \mathrm{ha}$}

Land Tenure Owned freehold by the National Trust for Fiji

Altitude Approximately $15 \mathrm{~m}-800 \mathrm{~m}$

Physical Features The reserve has two contrasting features: the valley bottom with restricted views of forested ridges dominated by the peaks of Kadawa and Koromalewei; and the steep slopes of the reserve leading to the upper ridge. The geology includes rocks, exposed at Wainikavika and the surrounding area, which are volcanic, of two distinct ages and belonging to two lithostratigraphic groups: the Wainimala group and the Medrausucu group. Soils are classified as predominantly clay and bouldery clay humic latosols with stony, sandy clay red-yellow podzols. Within the reserve, which forms one-third of the Navua Irrigation Dam catchment, a small dam and an intake has been constructed on a tributary. The reserve is situated 
in a sensitive area, evidenced by the large number of natural landslides. Further details are given in Watling et al. (1989).

Climate The reserve is exposed to prevailing south-east trade winds, and rainfall is high and fairly consistent, with a drier period between June and August. Mean annual rainfall, recorded over 15 years, ranges from $3925 \mathrm{~mm}$ at Navua Reservoir ( $10 \mathrm{~m}$ above sea-level) to $5002 \mathrm{~mm}$ at Wainikavika ( $80 \mathrm{~m}$ above sea-level), indicating a considerable increase in rainfall with altitude (Watling et al., 1989).

Vegetation The reserve is mostly forested but has been disturbed by logging and road building; small areas in the north might be pristine. There are three distinct vegetation communities: tropical moist rain forest, riparian community and the vegetation of severely disturbed sites. The tropical moist rain forest is typical of south-east Viti Levu. The most common large trees are nutmeg (kauolamu) Myristica castaneifolia, laubu Garimia myrtifolia, sisisi Girroneira celtidifolia, yasiyasi Sysygium effusum, mavota Gonystylus punctatus, kuluva Dillenia biflor. and dulewa Xylopia pacifica. The most common species of the riparian community, on flood-prone river banks, are Acclypha ribularis, Bambusa vulgaris and several species of fig including Ficus vitiensis, $F$. smithii and $F$. storckii. Tree ferns $C y a t h e a$ hornei and $C$. alata are common with other ferns including Culcita straminea, Blechnum orientale and $B$. milnei on river banks. Finally, severely disturbed sites support a vigourous community of weed species, the majority of which are exotic. The most common are Clidemia hirta, Crassocephala crepidioides, Commersonia bartramia, Desmodium heterophylla, Dicramopteris linearis, Dipteris conjugita, Hyptis pectinata, Ludwigia octovalvis, Lycopodium cernum, Mimosa pudica, Mikania micrantha, Miscanthus floribundus, Piper aduncum, Culita straminea and Solanum torvum. The only large exotic tree is Spathodea campanulata, restricted to disturbed sites. Bamboo Bambusa vulgaris on the southern boundary provides evidence of earlier disturbance.

Areas subject to light selective logging in the 1960 s and 1970 s do not have a visibly different community structure and composition than unlogged areas. However, recent mechanised logging has more severely affected one-third of the reserve, although it is too early to predict how the forest will regenerate. The composition and viability of the regenerated community will depend on the extent of rehabilitation works especially fire prevention and control of exotic weeds, the rapidity with which they are undertaken and the degree of future disturbance.

There are no rare or endangered species within the reserve. The two palms Neoveitchia storckii and Gulubia microcarpa, found in south-east Viti Levu, are not found within the reserve. Degeneria vitiensis, one of only two species of the Fijian endemic family Degeneriaceae, is found in the reserve (Watling et al., 1989).

Fauna Both species of flying fox found on Viti Levu, insular flying fox Pteropus tonganus (I) and Samoan flying fox $P$. samoensis (E), have been observed. Feral pig Sus scrofa are commonly found but have been heavily hunted, making them wary and seldom observed. Feral cat Felis domesticus is also present. Introduced mongoose Herpestes auropunctatus is frequently seen in disturbed vegetation along the north road and river bank, probably occurring at low densities in forest throughout the reserve. Mongoose and feral cat have decimated the native ground herpetofauna, for example banded iguana Brachylophus fasciatus (V). Skinks Emoia concolor, $E$. parkeri and $E$. cyanura are quite common. Iguana and Pacific boa Candoia bibronii were not observed but may be present. Fijian burrowing snake $O$ gmodon vitianus (I) endemic to Viti Levu, was found in the Namosi area and therefore probably occurs in the reserve. Fiji tree frog Platymantis vitiensis is found in vegetation on creek banks and in canopy foliage. The introduced cane toad Bufo marinus is also present. 
The reserve has the expected complement of Fijian forest avifauna. However, black-faced shrike bill Clytorhynchus nigrogularis, collared lory Phigys solitarius and pink-billed parrotfinch Erythrura kleinschmidti (K) were not observed during the survey in 1989 but are believed to be present. Introduced red-vented bulbul Pycnonotus cafer and jungle mynah Acridotheres fuscus are restricted to Wainikavika Creek, but sometimes range over the whole reserve. Red-throated lorikeet Charmosyna amabilis may visit the reserve occasionally.

No detailed study of arthropods has been carried out. Nanai Baiateana knowlesi, a cicada with a mass hatching cycle of eight years, is thought to occur in the reserve and is expected to hatch next in 1993 (Watling et al., 1989).

Cultural Heritage The reserve was owned by the Garrick family, long-standing European settlers in Fiji, until donated to the National Trust for Fiji in 1984.

Local Human Population There are no settlements within the reserve, but it is used by local people for hunting feral pigs and for access to the upper reaches of Wainikavika Creek for prawning and fishing (Watling et al., 1989).

Visitors and Visitor Facilities There are no visitors or facilities. A number of proposals have been made by Watling et al. (1989), including the provision of camping and picnic facilities, forest trails, an interpretive centre and nature trail focusing on either the valley bottom or ridge. The proposed Wainikavika National Park would increase recreation facilities.

Scientific Research and Facilities Preliminary studies have been made of the flora and fauna and a summary of geological studies is available (Watling et al., 1989).

Conservation Value The reserve, despite its small area, is the most important protected area for the long-term protection of tropical moist rain forest in Fiji due to freehold ownership and consequent freedom from any management consideration other than conservation. Specifically, the reserve is important for the protection of a representative example of the tropical moist rain forest community of south-east Viti Levu; it forms a large part of the Navua irrigation dam catchment which needs to be conserved; it is ideally located close to Suva and Navua for the tourist development of Pacific Harbour, and it is a key component of the proposed Wainikavika National Park. However, damage caused by mechanised logging has diminished its conservation value (Watling et al., 1989).

Conservation Management Under the terms of the National Trust Act, the reserve provides for the permanent preservation of land for the benefit of the nation, to preserve its natural aspect and features, to protect animal and plant life and to provide for the recreation, access and enjoyment of the public. The South Pacific Regional Environment Programme (SPREP) was requested by the Fiji Government to compile a management plan in 1987/1988. This was not carried out until 1989 when a management plan was prepared (Watling et al., 1989). However, the National Trust for Fiji does not at present have the resources to manage the reserve. Possible alternatives to rectify this are either to strengthen the National Trust and initiate management of the reserve, or seek another organisation to assist or take over management. Immediate management requirements are the appointment of a warden to prevent further logging and the need to control access by repairing gates and physically closing the logging road. The objectives of the plan are the conservation of a tropical moist rain forest community and all its ecological values; second, to encourage scientific and educational enquiry and research into Fiji's tropical moist rain forest, and the promotion of an appreciation and enjoyment of Fiji's wildlife and forest through recreation; and third, the enlargement of the reserve to a more viable conservation unit, the incorporation of Melimeli freshwater swamp and the establishment of Wainikavika National 
Park incorporating areas of undisturbed forest to the north and west. The reserve lies within a declared "irrigation area" under the Irrigation Act (No. 32 of 1973), empowering the Commissioner for Irrigation to carry out functions under the Act.

Management Constraints Recent mechanised logging, affecting about one-third of the reserve in the north and east, has led to accelerated erosion, the spread of exotic weeds and a loss of conservation value. Approximately $400 \mathrm{~m}$ of the Wainikavika Creek above the reserve's southern boundary will be subject to flooding when Phase III of the Navua Irrigation Dam is constructed. The main threat is from logging which was revealed during the preparation of the management plan in January 1989 (Watling et al., 1989). This encroachment occurred due to incorrect boundary marking (B. Singh. pers. comm., 1990).

Staff Part time warden (B. Singh, pers. comm., 1990)

Budget No information

Local Addresses National Trust for Fiji, PO Box 2089, Government Buildings, Suva

\section{References}

Watling, R., Vodonivalu, S., Balawa, J., Singh, B. and Rodda, P. (1989). A management plan for the Garrick Memorial Reserve, Fiji. Environmental Consultants (Fiji) Ltd. Suva. 32pp.

Date October 1990

\section{SIGATOKA SAND DUNES NATIONAL PARK AND RESERVE}

\section{IUCN Management Category Unassigned}

Biogeographical Province 5.07.13 (East Melanesian)

Geographical Location Located on the south-west coast of Viti Levu, approximately $3 \mathrm{~km}$ south-west of Sigatoka. The park is bounded by the Suva-Nadi Highway to the north-west, and the Pacific Ocean to the south. The Sigatoka River mouth lies $1.5 \mathrm{~km}$ to the east. Approximately $177^{\circ} 30^{\prime} \mathrm{E}, 18^{\circ} 20^{\prime} \mathrm{S}$

\section{Date and History of Establishment May 1988}

Area Approximately 240ha

Land Tenure Crown Land without Title. The National Trust was negotiating in 1988 for 18.9 ha freehold land under private ownership to the east, and 38.9 ha of native land in the west to be included in the park and reserve (G. Fullman, pers. comm., 1989).

Altitude Sea-level to approximately $50 \mathrm{~m}$

Physical Features Comprises a series of parabolic sand dunes of various ages and activities, derived from magnetite deposits produced by fluvial erosion of the Sigatoka River catchment. Wave-driven longshore drift then transports this material onshore. The dunes have been reworked by wind and are aligned with prevailing south-easterly winds. Approximately half the area is 
unstable, especially in the east (Kirkpatrick and Hassall, 1981). The width of the complex system of dunes and interdunal hollows varies from approximately $200 \mathrm{~m}$ in the east to $800 \mathrm{~m}$ in the west. The south and eastern dunes have gentle slopes, while those in the west have gradients approaching the maximum possible for sand. The dunes, composed largely of eluvial sands, overlay deltaic and beach deposits. Stratified marly sandstones of the Cuvu series, visible only at the western end of the dune system, form the bedrock. A wide, steeply-shelved beach of clean, non-organic sands is present along the entire $5 \mathrm{~km}$ dune frontage with the ocean. Heavy, wind-driven rollers and surf are present owing to the absence of fringing coral reefs and the consequently exposed nature of the coastline (Cabaniuk et al., 1986). The mouth of the Sigatoka River coincides with the only major gap in the reefs which extend virtually unbroken for $63 \mathrm{~km}$ (Ryland, 1981). It has been suggested that Fiji's early settlers played a major role in the formation of the dunes through deforestation of the catchment of the Sigatoka River's (Cabaniuk et al., 1986)

Climate The local climate is strongly influenced by the mountainous nature of Viti Levu, which acts as a barrier to prevailing south-east trade winds, creating a "dry zone" along the south-west coast. Mean annual rainfall at Sigatoka is $1862 \mathrm{~mm}$, with well-marked November to April wet season and May to October dry season. The mean monthly rainfall during December to April, the wettest period, ranges between $200 \mathrm{~mm}$ and $300 \mathrm{~mm}$. The driest period occurs from June to August, when mean monthly rainfall varies from $75 \mathrm{~mm}$ to $70 \mathrm{~mm}$, respectively. Diurnal and seasonal temperature variations are small, due to the neighbouring ocean. The warmest period, December to March, has a mean maximum temperature of $31^{\circ} \mathrm{C}$ and a mean minimum of $23^{\circ} \mathrm{C}$. The coolest period, July and August, experiences a mean maximum temperature of $27^{\circ} \mathrm{C}$ and a mean minimum of $18^{\circ} \mathrm{C}$. Absolute maxima and minima may approach $40^{\circ} \mathrm{C}$ and less than $10^{\circ} \mathrm{C}$, respectively. The mean monthly relative humidity varies from $75 \%$ during February to March to $65 \%$ in August. Prevailing winds throughout the year are east or south-east trades, although winds from the north can occur during the wet season. Tropical cyclones occasionally arise between November and April (Cabaniuk et al., 1986).

Vegetation Comprises forest dominated by native trees and shrubs, coastal communities dominated variously by native and introduced species, and grassland dominated by introduced species. Seven major vegetation types occur: closed forest of Dysoxylum richii, Calophyllum inophyllum and Syzgium richii occurs in patches to the west and north. Degraded closed forest includes areas in which closed forest stratum has been reduced in density, either patchily by fire in the west or uniformly by grazing and cutting in the east. Open forest, dominated by Casuarina equisetifolia attaining $10-14 \mathrm{~m}$, usually has a sparse stratum of Leucaena leucocephala, which in turn is underlain by a $30-70 \%$ cover of Panicum maximum. Low open-woodland, dominated by $5-8 \mathrm{~m}$ tall Pandanus sp. with $P$. maximum grassland as ground cover, occurs in the west. Open grassland is dominated by Brachiaria reptans to the east and P. maximum to the west. Anthropogenic open-herbland has formed in areas where reclamation was carried out in the 1950s. Coastal vegetation is complex due to the nature of the dune system and the effect of prevailing winds, and comprises Ipomoea brasiliensis-Canavalia maritima open-herbland, Spinifex hirsutus-I. brasiliensis open-herbland, Scaevola taccada closed-heath, Vitex trifoliata-Hibiscus tiliaeceus open-heath, $H$. tiliaceus closed-scrub and Pandanus open-scrub, the approximate order being from coast to inland (Kirkpatrick and Hassall, 1981). Some 130 species have been recorded, of which 64 are exotic introductions. The majority of native species are common throughout the coastal regions of Fiji and no rare or endemic species were recorded (Kirkpatrick and Hassall, 1981; Cabiniuk et al., 1986). Further details, including a species list, are given in Kirkpatrick and Hassall (1981). 
Fauna Only very little is known about the diversity and abundance of wildlife in the park and reserve. A brief zoological survey was carried out in 1979. Bats, of unidentified species, represent the only native Fijian mammals. Rat and mongoose are present, and feral horses and both domestic cattle and horses use dunal vegetation for shade and grazing. Information on birds, reptiles, amphibians and invertebrates is very poor. Geckoes and skinks occur, and Pacific boa Candoia bibroni, banded iguana Brachylophus fasciatus (V) and frogs may be present (Cabaniuk et al., 1986).

Cultural Heritage Sigatoka Sand Dunes are the location of one of Fiji's earliest recorded prehistoric sites, and contain a wealth of Fijian material culture. Comprehensive excavations were carried out in 1965 and 1966 (Birks, 1968) indicating successive human occupation from $2,500 \mathrm{BP}$. The site was probably used as a camp for turtle catching, and the dunes may have been used for salt production (Cabaniuk et al., 1986). Another major archaeological excavation was carried out in 1986 (D. Watling, pers. comm., 1989). A burial ground dating from $1,800 \mathrm{BP}$ has been excavated and negotiations are being held with the landowner on the best way to protect the site (SPREP, 1989).

Local Human Population The north-eastern margin of the dunes is contiguous with intensively settled and farmed land, largely devoted to sugar cane (Kirkpatrick and Hassall, 1981). There has been a squatter settlement in the west since 1982, comprising 26 households in 1986. Most squatters formerly resided locally and are in casual or low-paid employment. The nearest settlement is Kulukulu to the north, which had a population of 1,137 in 1984.

Visitors and Visitor Facilities There is ready access to the dunes via the Suva-Nadi Highway, and the coastal tramline, which both cut through the western portion of the park and reserve, and via the Kulukulu Road from the north. Numerous paths and tracks ramify throughout the area. There is no accommodation available within the park, although much of the coast is developed for tourism. Approximately 6 ha of land in the west has been allocated to the Fiji Sports Council by the Lands Department for recreation. Preliminary management objectives include the provision of intensive recreational facilities in the west, with the remainder of the park zoned for extensive recreation and nature conservation. Other management recommendations also include the provision of facilities, including toilets, changing rooms and food service concessions, to be housed in a combined administration/services building in the west, and accommodation for educational purposes only (Cabaniuk et al., 1986).

Scientific Research and Facilities The geology of the dunes has been studied by Hirst and Kennedy (1962) and the vegetation by Parham (1972). Kirkpatrick and Hassall's (1981) study is the first quantitative vegetation analysis of any area in Fiji. A brief zoological survey of the dunes was undertaken by the Institute of Natural Resources of USP, as part of a baseline environmental study commissioned by Manganex Ltd (Layton and Associates Lid., 1979).

Conservation Value Sigatoka Sand Dunes has considerable development potential for nature conservation, historic site preservation, outdoor recreation and education. It also forms a unique part of Fiji's natural heritage and comprises a coastal landscape of great natural beauty. The dunes' mature beach forest is ecologically important and the sand hills are also the location of one of the country's earliest known and most important prehistoric sites.

Conservation Management No agricultural leases, grazing or cutting licences have been issued, thus making these activities illegal without recourse to the National Park and Reserves Bill, which has yet to be passed. The 1986 draft advisory plan (Cabaniuk et al., 1986), referring to a slightly larger area than that gazetted in 1988 , proposes a zonation system that broadly divides 
the dunes into an intensive recreation area in the west, managed nature reserve to the immediate east and a strict nature reserve area in the central dunes. Although the site has been gazetted, its legal status is not clear. The 1986 draft advisory plan includes a series of objectives and recommendations for the conservation and development of the dunes. Objectives include securing the permanent legal protection of the dunes for educational, scientific and recreational purposes and for ecological, geological and wildlife value.

Management Constraints Local farmers use the dunes for grazing cattle and horses and are responsible for numerous fires, the effects of which are now evident in vegetation patterns. A quarry, rubbish tip and scrap vehicle dump are located near the main road in the west, and the sand dunes, rich in iron, may be mined in the future (Hirst and Kennedy, 1962; Kirkpatrick and Hassall, 1981).

Staff It is proposed that two rangers be appointed (B. Singh, pers. comm., 1990).

Budget A small funding package has been made available by the South Pacific Culture Fund and further external assistance is being sought (B. Singh, pers. comm., 1990).

Local Addresses National Trust for Fiji, PO Box 2089, Government Buildings, Suva

\section{References}

Cabaniuk, S, Tamani, A., Vulu, E. and Ratabua, A. (1986). A [draft advisory] plan for the conservation and development of the Sigatoka Sand Dunes for National Park and Reserve purposes. Prepared for the National Trust of Fiji by the Directorate of Town and Country Planning, Ministry of Housing and Urban Affairs. Suva, Fiji. 129 pp.

Hirst, J.H. and Kennedy, E.M. (1962). Sigatoka iron sands. Economic investigation.No. 1. Geological Survey Department, Suva. (Unseen).

Kirkpatrick, J.B. and Hassall, D.C. (1981). Vegetation of the Sigatoka sand dunes, Fiji. New Zealand Journal of Botany 19: 285-297.

Layton and Associates Pty. Ltd. (1979). Baseline environmental study of SPL.1077Ba and SPL1009, Sigatoka, Fiji for Manganex Ltd. (Unseen).

Parham, J.W. (1972). Plants of the Fiji Islands. Suva. Govemment printer. (Unseen).

Ryland, J.S. (1981). Reefs of southwest Viti Levu and their tourism potential. In: Dogma, I.J. (Ed.), Proceedings of the Fourth International Coral Reef Symposium. Volume 1. Manila. Pp. 293-298.

SPREP (1989). Fiji. Paper presented at the Fourth South Pacific Conference on Nature Conservation and Protected Areas, Port Vila, Vanuatu, 4-12 September. 5 pp.

Date November 1988, revised July 1989, February 1990

\section{YADUA TABA CRESTED IGUANA SANCTUARY}

IUCN Management Category IV (Managed Nature Reserve)

Biogeographical Province 5.07 .13 (East Melanesian) 
Geographical Location Yadua Taba lies $200 \mathrm{~m}$ off the south-west coast of the much larger Yadua Island, and approximately $20 \mathrm{~km}$ west of Vanua Levu in Fiji. Approximately $16^{\circ} 50^{\text {'S }}$, $178^{\circ} 20^{\prime} \mathrm{E}$

Date and History of Establishment 7 August 1980. Gazettement was negotiated between The National Trust for Fiji, the Government and the indigenous landowners of Yadua.

Area $70 \mathrm{ha}$ (comprises the whole island)

Land Tenure Comprises property belonging to the indigenous Fijian people of Nakorolevu Village on neighbouring Yadua Island (NTF, 1981). The island has yet to be made the subjeci of a formal lease agreement between the National Trust for Fiji and the Native Land Trust Board (Lenoa, 1989).

Altitude Ranges from sea level to $100 \mathrm{~m}$.

Physical Features Yadua Taba is a small, rocky volcanic island within the Yadua fringing coral reef (IUCN/UNEP, 1988). It is low-lying in the west with coves and beaches, rising to cliffs, covering 5.5ha (Laurie et al., 1987), to the south and south-east. A crater in the south-east attains $100 \mathrm{~m}$ and is the highest part of the island. The soil is sandy, reaches a depth of $50 \mathrm{~cm}$ in places, and is interspersed with rocky outcrops (Gibbons, 1981).

Climate The island lies in the rain shadow of Vanua Levu. Consequently, precipitation, averaging $1800 \mathrm{~mm}$ per annum, is low for the region. The October-March hurricane season is the wettest period. Air temperatures range from a minimum of $16^{\circ} \mathrm{C}$ during July and August to a maximum of $31^{\circ} \mathrm{C}$ from January to February. Neither extreme is encountered under forest canopy (Gibbons, 1984a).

Vegetation The island vegetation is a complex mosaic of primary forest, secondary scrub and grassland which has been heavily modified since the introduction of goats in the 1950s (Singh, 1985). Five principal communities have been described: primary dry beach forest (24.8ha) characterised by cevue Vavaea amicorum; dry, exposed or disturbed areas (17.4ha) dominated by Casuarina equisetifolia; areas of scrub and small trees on exposed slopes and ridges with poor soil (10.2ha); grassland, mainly a result of burning (10.8ha); and small (1.3ha) coastal copra plantations (Gibbons, 1984a; Laurie et al., 1987). Forests are now regenerating.

Fauna The island supports a substantial population of Fijian endemic crested iguana Brachylophus vitiensis (V), estimated in 1983 at 2,000 to 5,000 individuals (Cogger and Sadlier, 1986). More recent estimates indicate that the population certainly exceeds 4,000 and is probably around 6,000 (Laurie et al., 1987). Crested iguana are distributed throughout the island, with the exception of coastal cliff and coconut fringes. Population densities are estimated at 140 per hectare in beach forest, 105 in Casuarina forest, 87 in coastal scrub and 23 in grassland. The species flourishes on Yadua Taba because its major predators, feral cat Felis domesticus, mongoose Herpestes auropunctatus, pig Sus scrofa and Pacific boa Candoia bibroni, have not been introduced (Gibbons, 1984a). Mammals include a colony of 1,500-3,000 Pacific flying fox Pteropus tonganus, abundant Polynesian rat Rattus exulans and a limited number of goat Capra sp. The composition of the avifauna is poor and very largely shared with Yadua. Both islands are relatively isolated, being $17 \mathrm{~km}$ from Vanua Levu, and there is an almost complete lack of forest on Yadua. A preliminary list of 24 bird species is given by Laurie $e t$ al. (1987). Swamp harrier Circus approximans, barn owl Tyto alba and reef heron Egretta sacra are all potential predators of the crested iguana and its hatchlings. The scincid fauna is exceptional since all species appear to be abundant, namely, Emoia trossula, green tree skink E. concolor, 
blue-tailed skink E. cyanura, snake-eyed skink Cryptoblepharus boutonii and Pacific gecko Gehyra oceanica. There is some evidence of turtle nesting (Laurie et al., 1987).

Cultural Heritage The crested iguana is the totem of local people, who consequently will neither kill nor eat specimens (Eaton, 1985).

Local Human Population Yadua Taba is uninhabited. Yadua Village is located on the far side of Yadua Island, itself separated from Yadua Taba by only $200 \mathrm{~m}$ of shallow water (Juvik and Singh, 1989). The villagers exploit the sanctuary for copra, but only under supervision (B. Singh. pers. comm., 1990).

\section{Visitors and Visitor Facilities None}

Scientific Research and Facilities Crested iguana was discovered and described as a new species in 1979 (Gibbons, 1981). A survey carried out in 1983 indicated that the population was increasing (Gibbons, 1987). Subsequent surveys have been undertaken (Laurie et al., 1987; Juvik, 1988; Juvik and Singh, 1989) indicating a stable crested iguana population.

Conservation Value The sanctuary was established to protect the endangered crested iguana and is also noted as Fiji's first wildlife reserve.

Conservation Management In 1980, WWF funded a project to pay Yadua villagers to remove their goats from Yadua Taba; to cease burning and felling on the island; and to prevent unauthorised access (NTF, 1981). The importance of Yadua Taba for crested iguana is not diminished by the discovery of the species in the Yasawa Group. These islands are relatively densely populated and have little forest. The Yadua Taba population is the only viable one with good prospects for survival. The pockets of beach forest remaining on Yadua Taba are good examples of what is undoubtedly Fiji's most critical habitat. These have been replaced by coconut plantations throughout the country and the small cover remaining on Yadua Taba is particularly valuable as it includes very little exotic vegetation (Laurie $e t$ al., 1987). Permanent transects have been established and, following the training of a local warden, routine population estimates can be made. The honorary warden has been equipped with a motor boat (B. Singh, pers. comm., 1990).

Management Constraints The island was once stocked with up to 300 goats; although most have been removed, attempts to shoot remaining individuals have failed for various reasons. Accidental fires have destroyed extensive forest tracts (Gibbons, 1987). The crested iguana population, by virtue of its density and small area occupied, is extremely vulnerable to chance introduction of predators or pathogens, or to the destruction of habitat (Cogger and Sadlier, 1986). As vegetation regenerates, there is a risk of "hot" burns which would seriously damage the beach forest, the most important crested iguana habitat. The National Trust for Fiji has been unable to sustain active management and there is an urgent need for a management plan. Villagers from Yadua continue to exploit the island for copra, building timber, fish and turtle eggs (Laurie et al., 1987).

Staff An honorary warden has been appointed.

Budget The National Trust for Fiji rents Yadua Taba for an annual fee of US $\$ 1,500$. The World Wildlife Fund provided US\$12,962 for the initial establishment of the sanctuary. The Honolulu Zoological Society agreement with the National Trust, if finalised, will provide US\$1,500 annually for five years, with not less than US $\$ 350$ to be directed annually to provide an official salary for a sanctuary warden (Juvik and Singh, 1989). 
Local Addresses The National Trust for Fiji, PO Box 2089, Government Buildings, Suva

\section{References}

Cogger, H.G. and Sadlier, R.A. (1986). Population size and structure of Fijian crested iguana. In: Rocek, Z. Studies in herpetology. Proceedings of the European Herpetological Meeting. (Third Ordinary Meeting of the Societas Europaea Herpetologica), Prague 1985. Charles University. Pp. 507-509.

Eaton, P. (1985). Land tenure and conservation: protected areas in the South Pacific. Report to the South Pacific Commission. 103 pp.

Gibbons, J.R.H. (1981). The biogeography of Brachylophus (Iguanidae) including the description of a new species $B$. vitiensis from Fiji. Journal of Herpetology 15: 255-273.

Gibbons, J.R.H. (1984a). Iguanas of the South Pacific. Oryx 18: 82-91.

Gibbons, J.R.H. (1984b). Discovery of a brand-new million-year old iguana. Animal Kingdom 87(1): 23-30.

Gibbons, J.R.H. (1985). On the trail of the crested iguana. Animal Kingdom 87(6): 40-45.

Juvik, J.O. (1988). A report to the National Trust for Fiji on issues relating to the protection of the crested iguana and management of the Yadua Taba Island Reserve. East-West Center, Environment and Policy Institute, Honolulu. 23 pp. (Unseen).

Juvik, J.O. and Singh, B. (1989). Conservation of the Fijian crested iguana: a progress report. Case Study 22. Fourth South Pacific Conference on Nature Conservation and Protected Areas, Port Vila, Vanuatu, 4-12 September. 7 pp.

Laurie, W.A., Uryu, H. and Watling, D. (1987). A faunal survey of Yaduataba Island Reserve with particular reference to the crested iguana (Brachylophus vitiensis Gibbons 1981). Domodomo (Fiji Museum Quarterly) 1-2: 16-28.

Lenoa, L., Waqaisavou, T. and Lees, A. (1989). A representative national parks and reserves system for Fiji. Case Study 17. Fourth South Pacific Conference on Nature Conservation and Protected Areas, Port Vila, Vanuatu, 4-12 September. 15 pp.

National Trust for Fiji (1981). Establishment of reserve for Fiji crested iguana. WWF Yearbook 1980-1981.. Pp. 153-155.

Singh, B. (1985). Owner involvement in the establishment of parks. In: Thomas, P.E.J. (Ed.), Third South Pacific National Parks and Reserves Conference. Conference Report. Volume II. Collected key issue papers and case study papers. Pp. 269-270.

SPREP (1989). Fiji. Paper presented at the Fourth South Pacific Conference on Nature Conservation and Protected Areas, Port Vila, Vanuatu, 4-12 September. 5 pp.

UNEP/IUCN (1988). Coral Reefs of the World. Volume 3. Central and Western Pacific. UNEP Regional Seas Directories and Bibliographies. IUCN, Gland, Switzerland and Cambridge, UK/UNEP, Nairobi, Kenya. 378 pp.

Date October 1988, revised July 1989, February 1990 



\section{FRANCE - FRENCH POLYNESIA}

Area $3,521 \mathrm{sq} . \mathrm{km}$ (spread over approximately $4,198,000 \mathrm{sq} . \mathrm{km}$ of ocean)

Population 188,814 (1988)

Natural increase: $1.9 \%$ (Dahl, 1986)

GNP Not available

Policy and Legislation The status of French Polynesia, a French overseas territory, under Law No. 77-772 of 12 July 1972 gives full power to the territory in environmental matters. The Governor of French Polynesia also has authority for Clipperton Island, some 5,000km north-west of Tahiti, although this is not part of French Polynesian territory.

There are no laws specifically providing for the creation and management of territorial parks and other protected areas. There is a general planning code, the Déliberation de l'Assemblée Territoriale No. 61-44 of 8 April 1961, which was modified in 1982 to take account of economic restraints. Book 1, Title 3 of this code makes provision for the creation of protected areas, by defining the procedure leading to classification of an area. A regulation specifically providing for the creation and management of protected areas is planned (Siu and Vernaudon, 1989). Law 56-836 of 26 July 1956 gives the Territorial Assembly the power to regulate nature protection. This is reinforced by the new statute in Law 84-260 of 6 September 1984 which made provision for the nomination of a Minister of Environment and a Délégation à l'Environnement. Legal power rests with the Territorial Assembly and executive power with the President of the Territorial Government and the Council of Ministers. Book 1, Chapter VIII, Title V, Articles D.151 1-14 of the 1984 Code provide for a list of sites and monuments for conservation. The Article states that a list of buildings and a list of natural sites and monuments of which the conservation or preservation is of historic, artistic, scientific, legendary or folkloric interest are established in the territory and published in the Journal Officiel. Inscription on these lists is announced by decree of the head of the territory in government council following proposal by the Commission on Natural Sites and Monuments (CNSM) under Article D.100-2 of this Code. The regional administrative authority will notify the owners of properties, sites and monuments of inscription. Inscription obliges the owner not to modify the aspect of any natural property, site or monument, nor to undertake any activity other than normal exploitation, running repairs and maintenance without advising the interested head of regional administration at least two months before the proposed date for the start of work.

The procedure for classifying natural protected areas is undertaken by the CNSM, which, since 1985, has been presided over by the Minister of the Environment. On the advice of the CNSM, and with the approval of the Council of Ministers, the classification of a protected area may be pronounced after consultation with the Territorial Assembly in the case of public property, or after informing land owners in the case of private property. In the latter case, a delay of three months is mandatory to allow representations to be made. An intermediary procedure involves inscribing proposed sites on a list, after which the site must be maintained whilst legal formalities are prepared. However, a delay of more than one year will render this null and void (Siu and Vernaudon, 1989).

The Forestry Regulations, resulting from nine legal instruments dating from 1942 to 1978, contain provisions for the protection of soil, vegetation and wildlife, and the establishment of strict nature reserves (réserves intégrales). However, there is no provision for supervision. Other regulations cover hunting and fishing, but with no provision for protected areas. 
Recommendations and outlines of possible protected area legislation has been put to the government as part of reports prepared and submitted by SPREP (Anon., 1989).

International Activities At the international level, France has entered into a number of obligations and cooperative agreements related to conservation. It is party to the Convention concerning the Protection of the World Cultural and Natural Heritage (World Heritage Convention) which it accepted on 27 June 1975. France became a contracting party to the Convention on Wetlands of International Importance especially as Waterfowl Habitat (Ramsar Convention) on 1 October 1986. At present there are no World Heritage or Ramsar sites within French Polynesia. France participates in the Unesco Man and Biosphere Programme and the Atoll de Taiaro in French Polynesia has been inscribed as biosphere reserve.

France signed the Convention on the Conservation of Nature in the South Pacific on 12 June 1976 with subsequent ratification on 20 January 1989. Known as the Apia Convention, it entered into force during 1990. The Convention is coordinated by the South Pacific Commission and represents the first attempt within the region to cooperate on environmental matters. Among other measures, it encourages the creation of protected areas to preserve indigenous flora and fauna.

The Convention for the Protection of the Natural Resources and Environment of the South Pacific Region (SPREP Convention) was signed on 25 November 1986 and ratified on 17 July 1990. The SPREP Convention entered into force during August 1990. Article 14 calls upon the parties to take all appropriate measures to protect rare or fragile ecosystems and threatened or endangered flora and fauna through the establishment of protected areas and the regulation of activities likely to have an adverse effect on the species, ecosystems and biological processes being protected. However, as this provision only applies to the Convention area, which by definition is open ocean, it is most likely to assist with the establishment of marine reserves and the conservation of marine species. However, the instrument of Approval is accompanied by the following reservation: "The Government of the French Republic, in signing the present Convention, declares that, insofar as it is concerned, the prescription of the aforesaid Convention will not cover wastes and other matter entailing a level of pollution caused by radioactivity to a degree less than that prescribed by the recommendations of the International Atomic Energy Agency".

Administration and Management The CNMS was established in 1962 to propose sites for classification or protection, and to provide advice on environmental issues. The Fisheries Department manages the marine environment, while the Forest Branch of the Agriculture Department is responsible for implementation of the Forestry Act. The Délégation a l'Environnement was created on 30 May 1985 (Déliberation 85-1040/AT), responsible to the Minister of the Environment, with a staff complement that has increased from two in 1985 to twelve in 1989. Objectives are to: monitor environmental protection and rehabilitation; monitor environmental risks arising from development; develop or coordinate studies and direct research into environmental issues; develop training programmes and information services to enhance environmental awareness; and to identify and classify natural and cultural sites. To achieve these objectives, the Délégation acts in concert with the relevant ministries and services and coordinates environmental policies (Siu and Vernaudon, 1989).

The Délegation has identified certain priorities in applying its statutory powers. It has established new regulations for environmental protection classification (Délibération 87-80/AT of 12 June 1987), modifying Book IV of the Code de l'aménagement du territoire. The aim is to increase the efficiency of pollution prevention with means better adapted to current economic constraints and local values, while at the same time allowing the development of economic activity in 
harmony with the environment. It has also established an environmental charter, of which two sections are at an advanced stage of preparation: environmental impact assessment and protection of natural areas (Anon., 1990).

Systems Reviews French Polynesia extends from $134^{\circ} 28^{\prime} \mathrm{W}$ (Temoe) to $145^{\circ} 40^{\prime}$ (Manuae or Scilly) and from $7^{\circ} 50^{\prime} \mathrm{S}$ (Motu One) to $27^{\circ} 36^{\prime}$ (Rapa). The emergent land area (3,521 sq. km) is augmented by about 7,000 sq. $\mathrm{km}$ of lagoon. The islands are situated on a general north-west to south-east orientation, their age decreasing from north-west to south-east, and they form five distinctive archipelagos: Society, Tuamotu, Gambier, Marquesas and Tubai or Austral Islands. There are around 130 islands, of which 84 are atolls; most of the remainder are high volcanic islands, many being very mountainous with inaccessible interiors.

Habitats range from atoll and lowland rain forest, through riverine and bamboo forest to cloud and montane formations. Most coastal forest has been destroyed, but that which remains is of low economic value and relatively unthreatened. Lying at the easternmost extremity on the Indo-Pacific Province, French Polynesia is at the limit of the axis of decreasing species richness and has a comparatively poor coral fauna. The main reef formations are found around the high islands and atolls, although there are several oceanic banks of variable forms (e.g. Ebrill Reef in the Gambiers and Moses Reef in the Australs). A detailed summary account of coral reefs in French Polynesia is given in UNEP/IUCN (1988).

The islands with the highest conservation interest have very few protected areas. On the basis of biological diversity, endemism and other factors, Nuku Hiva is rated as the most important island for conservation within the country and one of the most important volcanic islands in the Oceanian realm. Tahiti, Rapa and Moorea are all at risk from human activities and only Tahiti, with the recently established Vallée de Faaiti, includes a protected area. All have significant species endemism, and the establishment of appropriate protected areas should be a priority. Some habitat restoration may be needed on Moorea and other islands. In addition, protected area establishment should be considered at least on Raiatea and possibly Huahine and Tahaa. In the Austral Islands, Rimatara and Raivavai should be given priority for their endemism, as should Mangareva in the Gambier Islands. The Tuamotu atolls are simpler island ecosystems, with one reserve at Taiaro Atoll. Additional reserves are needed at least on Matureivavao, Niau, Napuka and the raised coral island of Makatea, which, despite former mining damage, retains some conservation value. The Marquesas are quite distinctive biologically and the four present island reserves are inadequate: protected areas should be established on each island. In addition to Nuku Hiva, priority should be given to protected areas on Hiva Oa and Ua Pou, and to the general control of the feral animals which are causing great destruction. A representative system of marine reserves across the great expanse of French Polynesia should also be developed (Dahl, 1986). Currently proposed protected areas comprise a territorial park at Atimaono, Pari Historic and Archaeological Site, Atoll de Scilly, Atoll de Tetiaroa, and Hemeni and Keokeo Ilets in the Marquesas for the protection of sea birds, particularly Sterna fuscata. The establishment of marine reserves and other terrestrial protected areas is being studied (Siu and Vernaudon, 1989).

The Délégation à l'Environnement has become actively involved inter alia in the organisation of environmental courses ranging from primary to university level, providing material for television broadcast, posters, information signs and the organisation of an annual environment day (SPREP, 1989).

Nooverall environmental policy has existed for many years, although protection has been applied ad hoc for a certain number of problems. Principal environmental problems include introduced mammals (particularly rats) and birds, and soil erosion and consequeit sedimentation of lagoons 
caused mainly by terracing undertaken during urbanisation. The recent expansion of Miconia calvescens (Melastomataceae), introduced in 1937 for its ornamental value, now threatens the indigenous flora of the islands of Tahita, Moorea and Raiatea. Arrêté territorial No. 290 of 14 March 1990 taken by the Council of Ministers forbids its propagation on the other Polynesian islands and a research programme by ORSTOM over the last two years continues to seek a method of counteracting the plant.

\section{Addresses}

Délégation à l'Environnement, Ministère de l'Environnement, BP 4562, Papeete, Tahiti

\section{References}

Anon. (1989). Progress with the action strategy for protected areas in the South Pacific. Information Paper 3. Fourth South Pacific Conference on Nature Conservation and Protected Areas. Port Vila, Vanuatu, 4-12 September. 19 pp.

Anon. (1990). Législation et administration du milieu naturel. Unpublished. 6 pp.

Dahl, A.L. (1986). Review of the Protected Areas System in Oceania. IUCN, Gland, Switzerland and Cambridge, UK/UNEP, Nairobi, Kenya. 328 pp.

Paxton, J. (1989). The Statesman's yearbook: 1989-90. MacMillan Press Ltd., London. 1691 pp.

SPREP (1980). French Polynesia. Country Report 5. South Pacific Commission, Noumea, New Caledonia. $11 \mathrm{pp}$.

SPREP (1989). Polynésie Française. Paper presented at the Fourth South Pacific Conference on Nature Conservation and Protected Areas, Port Vila, Vanuatu, 4-12 September 1989. 5 pp.

Siu, P and Vernaudon, Y. (1989). Programme de mise en place d'un système de périmètres protégés en Polynésie Française. Case study No. 18. Fourth South Pacific Conference on Nature Conservation and Protected Areas. Port Vila, Vanuatu, 4-12 September. 6 pp.

UNEP/IUCN (1988). Coral Reefs of the World. Volume 3. Central and Western Pacific. UNEP Regional Seas Directories and Bibliographies. IUCN, Gland, Switzerland and Cambridge, UK/UNEP, Nairobi, Kenya. 378 pp. 
SUMMARY OF PROTECTED AREAS

\begin{tabular}{|c|c|c|c|c|}
\hline $\begin{array}{l}\text { Map }^{\dagger} \\
\text { ref. }\end{array}$ & Name of area & $\begin{array}{l}\text { IUCN management } \\
\text { category }\end{array}$ & $\begin{array}{r}\text { Area } \\
\text { (ha) }\end{array}$ & $\begin{array}{c}\text { Year } \\
\text { notified }\end{array}$ \\
\hline & \multicolumn{4}{|c|}{ Internation designation: Biosphere Reserves } \\
\hline 1 & Atoll de Taiaro (W.A. Robinson)* & IX & 2,000 & 1977 \\
\hline \multirow[t]{2}{*}{1} & $\begin{array}{l}\text { Strict Nature Reserves } \\
\text { Atoll de Taiaro (W.A. Robinson)* }\end{array}$ & IV & 2,000 & 1977 \\
\hline & \multicolumn{4}{|l|}{ Nature Reserves } \\
\hline 2 & Eiao Island* & IV & 5,180 & 1971 \\
\hline 3 & Hatutu Island & IV & 1,813 & 1971 \\
\hline \multirow[t]{2}{*}{4} & $\begin{array}{l}\text { Parks } \\
\text { Vallee de Faaiti* }\end{array}$ & II & 750 & 1989 \\
\hline & \multicolumn{4}{|l|}{ Unclassified } \\
\hline 5 & Mohotani & IV & 1,554 & 1971 \\
\hline 6 & Sable Island (Motu One) & IV & & 1971 \\
\hline \multirow[t]{2}{*}{7} & Scilly Atoll (Manuae) & IV & 200 & 1971 \\
\hline & $\begin{array}{l}\text { Proposed } \\
\text { Hemeni Islet } \\
\text { Keokeo Islet }\end{array}$ & $\begin{array}{l}\text { Proposed } \\
\text { Proposed }\end{array}$ & & \\
\hline
\end{tabular}

*Site is described in this directory.

† Locations of most protected areas are shown in the accompanying map. 


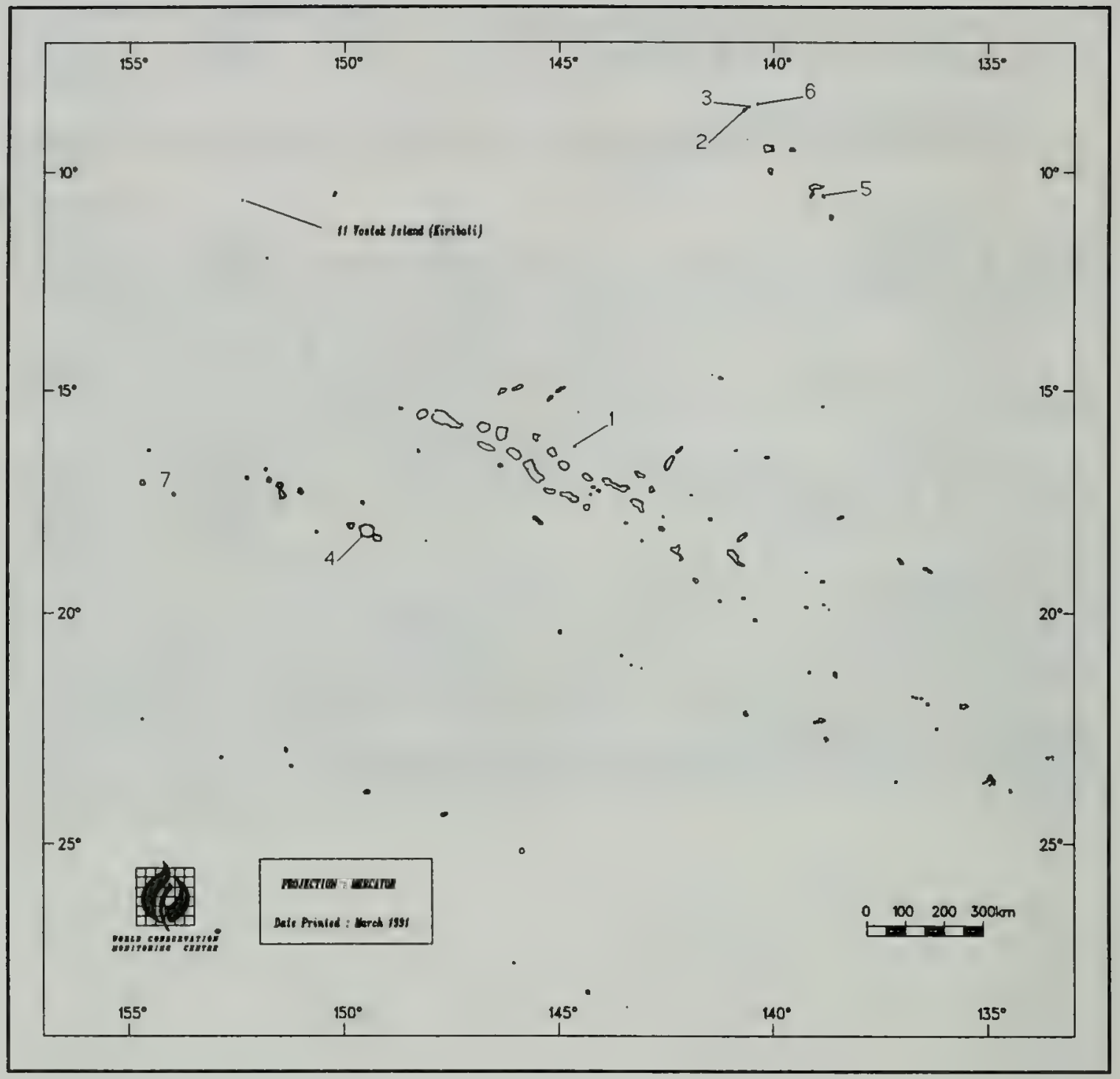

Protected Areas of French Polynesia 


\section{ATOLL DE TAIARO (RESERVE INTEGRALE W.A. ROBINSON)}

\section{IUCN Management Category IV (Managed Nature Reserve); IX (Biosphere Reserve)}

\section{Biogeographical Province 5.04.13 (Southeastern Polynesian)}

Geographical Location In the Tuamotu Archipelago in the west Pacific, 540km east-north-east of Tahiti and $230 \mathrm{~km}$ east of Raroia Atoll. Approximately $15^{\circ} 42^{\prime} \mathrm{S}, 144^{\circ} 34^{\prime} \mathrm{W}$

Date and History of Establishment The lagoon was proclaimed a strict reserve (Réserve Integrale W.A. Robinson) by its owner, with the agreement of the Governor of French Polynesia by Decree No. 2456/AA of 1 August 1972 (Journal Officiel de la Polynésie Française). The reserve was extended to cover the entire atoll and a surrounding $1 \mathrm{~km}$ protective offshore buffer zone on 14 February 1973. Accepted in January 1977 as a biosphere reserve.

\section{Area $2,000 \mathrm{ha}$}

\section{Land Tenure Private property}

Altitude From a recorded maximum depth of $29 \mathrm{~m}$ in the lagoon to $5 \mathrm{~m}$

Physical Features An almost circular atoll $5 \mathrm{~km}$ in diameter entirely enclosing a lagoon (previously connected by several channels) with water slightly saltier ( $43 \mathrm{ppt}$ ) than that of the ocean (36 ppt), due to excess rainwater evaporation. The lagoon is permanently isolated except possibly during severe storms. The emergent belt of the atoll measures $700 \mathrm{~m}$ from the sea to the lagoon at its widest part, and has a circumference of about $12 \mathrm{~km}$. The lagoon bottom, at between $22 \mathrm{~m}$ and $25 \mathrm{~m}$ depth, is apparently homogenous in its morphology.

\section{Climate No information}

Vegetation This atoll is unusual in that it is covered, not with coconut palms Cocos nucifera like most Tuamotu and Pacific atolls, but mainly with an open bush vegetation, including the following species: Lepidium spp., Morinda citrifolia, Pandanus spp., Suriana spp., Pemphis acidula, Erithalis polygama, Petesia carnosa, Guettarda speciosa, Scaveola sp., Tournefortia spp., Pentacarya anoniala, Myoporum spp., Boerhavia spp., Aichyrantes spp., Cassytha spp., Euphorbia ramosissima, Urtica spp., Digitaria spp., Psilotum spp., Polypodium spp., Asplenium spp. and Ramalina spp., as well as coconut.

Fauna There is an abundance of fauna in the lagoon, including the molluscs small giant clam Tridacna maxima (K), Pinctada maculata, Codakia divergens, and Gafrarium pectinatum (23 species in total), the echinoderm Holothuria atra and fish (50 species), but with a relative paucity of corals, with only Porites lobata present, down to a depth of $1.5 \mathrm{~m}$. Coconut crab Birgus latro (R) is present. Abundant coral fauna are found in the outer reefs, with a well-developed algal crest in the windward parts (south and south-east) of the island. On the sheltered western side, the reefs have a much richer and more diverse coral and mollusc fauna (Chevalier and Richard, 1976). Below $20 \mathrm{~m}$ little living fauna is found (Poli and Salvat, 1976).

Cultural Heritage The history of the island from the time of the first Polynesians is told in Robinson (1972). During the 1700s the island was the centre of a small but flourishing Polynesian kingdom, and is now of some archaeological interest (Siu and Vernaudon, 1989). 
Local Human Population The only permanent inhabitant was the guardian and his family, but according to Siu and Vernaudon (1989) the atoll has been uninhabited during the last few years.

\section{Visitors and Visitor Facilities No information}

Scientific Research and Facilities The earliest scientific work - botanical and malacological (mollusc) collections - dates from 1839 (US Exploring Expedition). In 1970 an experiment was begun to study competition between two mosquito species: Aedes polynesiensis, an abundant resident species and a vector of the human filariasis, and A. albopictus, which was introduced into the island. This research was conducted by the Pacific Research Section of the National Institute of Allergy and Infectious Diseases based at Honolulu, Hawaii. In 1972, a scientific mission was sent to the atoll by the Museum National d'Histoire Naturelle (Paris) and the Ecole Pratique des Hautes Etudes (Tahiti). Its purpose was to construct a floristic and faunistic inventory of the lagoon and the reefs and to study the distribution and ecology of species living in the marine environment, the geomorphology of the atoll, and the hydrology of the lagoon. The owner of the island provides housing for visiting scientists.

Conservation Value The atoll offers opportunities for research into the ecology and evolution of atoll lagoon coral ecosystems as well as the archaeology of the region.

Conservation Management There is close cooperation between the owner of the property, the Administrative Committee of the sanctuary and the Governor of French Polynesia for the protection of the atoll, lagoon and surrounding sea and a buffer zone around the atoll. Access to the reserve is restricted to scientific researchers who have been granted permission by the Committee (Y. Vernaudon, pers. comm., 1990). A permit is required to visit the reserve. It has been recommended that the atoll be re-surveyed to assess any changes that have taken place since it was last studied in 1972, and to re-affirm its importance as a protected area (UNEP/IUCN, 1988). The management objectives are currently being reviewed (Siu and Vernaudon, 1989).

Management Constraints In the past, several plant species (especially coconut) appear to have been introduced onto the atoll.

Staff A guardian and his family. Transient scientific missions.

Budget No information

Local Addresses Management Committee Secretariat, Conservateur, Délégué de la Commission des Monuments Naturels et Sites, BP 866, Papeete, Tahiti

\section{References}

Anon. (n.d.). Réserve intégrale W.A. Robinson. (Contains a description of the island, its history, and reports on research). $27 \mathrm{pp}$.

Chevalier, J.P. and Richard, G. (1976) Les récifs extérieur de l'atoll de Taiaro: bionomie et évaluations quantitatives. Cahiers du Pacifique 18(1): 143-158. (Unseen).

Chevalier, J.P. and Salvat, B. (1976). Etude géomorphologique de l'atoll fermé de Taiaro. Cahiers du Pacifique 19: 169-201.

Pickering, C. (1876). The geographical distribution of animals and plants, Part II. Plants in their wild state. Pp. 227-228.

Poli, G. and Salvat, B. (1976). Etude bionomique d'un lagon d'atoll totalement fermé: Taiaro. Cahiers du Pacifique 19: 227-251. (Unseen).

Robinson, W.A. (1972). Return to the sea. John de Graff Inc., Tuckhoe, New York. 
Siu, P. and Vernaudon, Y. (1989). Programme de mise en place d'un système de périmètres protégés en Polynésie Française. Case study No. 18. Fourth South Pacific Conference on Nature Conservation and Protected Areas. Port Vila, Vanuatu, 4-12 September. 6 pp.

UNEP/IUCN (1988). Coral Reefs of the World. Volume 3. Central and Western Pacific. UNEP Regional Seas Directories and Bibliographies. IUCN, Gland, Switzerland and Cambridge, UK/UNEP, Nairobi, Kenya. 378 pp.

Date September 1986; reviewed February 1990

\section{EIAO ISLAND NATURE RESERVE}

\section{IUCN Management Category Unassigned}

Biogeographical Province 5.04.13 (Southeastern Polynesian)

Geographical Location Located at the north-western end of the Marquesas Archipelago. The nearest island is Nuku Hiva, $104 \mathrm{~km}$ to the south-east. Approximately $08^{\circ} 02^{\prime} \mathrm{S}, 141^{\circ} 41^{\prime} \mathrm{W}$

Date and History of Establishment 29 July 1971. Established under Order No. 2559/DOM.

Area 5180ha

Land Tenure Owned by the Territoire de la Polynésie Française

Altitude Sea level to $557 \mathrm{~m}$

Physical Features Comprises a remote volcanic island, the centre of which is an extensive plateau, with three distinct summits, Mo'u'atiketike, the highest, Tohuanui and Tetiaenui. The coasts have high cliffs cut with valleys at Avaneo, Vaituha and Opituha which give access to the sea. There are only two permanent water bodies (Thibault, 1990).

Climate The Marquesas Archipelago is situated at the southern edge of an arid zone and receives irregular rainfall. There are no meteorological records from Eiao, but together with Hatuta'a and Mohotani, it constitutes one of the dry islands (Decker, 1973).

Vegetation The vegetation is xerophilic, with some 70 species present, including introductions. The tree layer is dominated by Pisonia grandis, the shrub layer by Cordia lutea and the herb layer by Eragrostris xerophila and Portulaca spp. The island is too low for the development of high altitude "cloud forest" found on other islands in the archipelago. The vegetation has been severely damaged, principally due to the introduction of sheep in 1880, and the distribution of most of the vascular plants has been reduced to a few inaccessible areas. Some species only survive on cliffs, with their numbers reduced to a few individuals, for example Bidens sp. and Oxalis gagneorum. The plateau of Mo'u'atiketike to Tetiaenui, as well as that of the eastern part of the island, has only bare soil, with the exception of groves of Thespia populnea and Hibiscus tiliaceus (introduced by the Polynesians) on Tetiaenui and Tohuanui. Pisonia grandis stands on the coast and plateau, and the forests in Opituha gorge all show symptoms of senescence and an absence of regeneration. The only exceptions are the trees on the cliffs between Opituha and Vaituha which are inaccessible. Groves of Pandanus tectorius, present in 1922, have been reduced to a few isolated individuals. Introduced Loecenia has become established on several 
islands in the archipelago and is widespread at Vaituha and is colonising the plateau. Coconut Cocos nucifera is at present restricted to scattered individuals between Tohuanui and Mo'u'atiktike and Vaituha (Thibault, 1990).

Fauna There are 11 species of breeding seabirds, some being pan-Pacific, while others, such as endemic white tern Gygis alba microrhynca, are localised to the Marquesas Archipelago. The only native passerine is the endemic long-billed warbler Acrocephalus caffer aquilonis; it is restricted to areas that are still wooded, and had a population in 1987 estimated at only 100-200 pairs. Red jungle fowl Gallus gallus and Marquesas ground dove Gallicolumba rubescens (R) have become extinct during the present century, and an endemic subspecies of iphis monarch Pomarea iphis fluxa $(\mathrm{R})$ has become locally extinct within the last few years. Chestnut-breasted mannikin Lonchura castaneothorax has recently been introduced into the archipelago and has colonised Eiao. Reptiles are very diverse with nine out of the ten species in Polynesia being present, viz., four skinks and five geckoes. However, all reptiles are threatened by habitat loss and are at present restricted to localised patches of woodland. The four mammal species that are present have all been introduced and include feral cats, Polynesian rat Rattus exulans, wild pig Sus scrofa, a Polynesian introduction, and sheep (Thibault, 1990).

Cultural Heritage Eiao supported a considerable pre-European Polynesian population, which established numerous stone pavements across the island. Stone working sites and debris give evidence that the island was an important location for tool-making (Candelot, 1980). Annexed by France in 1842, Eiao has served successively as a prison settlement (1850s), for pastoral farming (Hart concession in 1876) and as a plantation in the 1920s (Thibault, 1990).

\section{Local Human Population Uninhabited at present}

Visitors and Visitor Facilities Occasionally visited by passing yachts, and Marquesas people from Nuku Hiva (Thibault, 1990).

Scientific Research and Facilities The island has been visited by naturalists several times during the 20th century, allowing the condition of the island to be assessed over time. The most important avifauna study was made by Rollo H. Beck during the Whitney South Sea Expedition in 1922. Later work included visits from A.M. Adamson in 1929 (Adamson, 1936 and 1939). Botanical studies were undertaken by Decker (1973).

\section{Conservation Value No information}

Conservation Management Proposals to rid the island of introduced species have been made on a number of occasions. Thibault (1990) advocates the successive elimination of sheep, pigs and cats by hunting, trapping and the use of pathogens. This could lead to the recovery of plants that have become very localised and to the reintroduction of bird species that have been extirpated.

Management Constraints The continuing presence of introduced mammals has severely reduced the conservation value of the island. Sheep, present throughout the island and numbering not more than 1,000 in 1987, are the principal cause of vegetation loss and associated soil erosion. Pigs prevent birds nesting on the ground, while cats further restrict birds to the highest part of trees, particularly boobies Sula spp., great frigate bird Fregata minor, noddies Anous spp., and white tern Gygis alba, while sooty tern Sterna fuscata nests only on inaccessible ledges along the rocky coasts (Thibault, 1990). 
Budget No information

Local Addresses No information

\section{References}

Adamson, A.M. (1936). Marquesan insect environment. Bulletin of the Bernice P. Bishop Museum 139. (Unseen).

Adamson, A.M. (1939). Review of the fauna of the Marquesas Islands and discussion of its origin. Bulletin of the Bernice P. Bishop Museum 159. (Unseen).

Candelot, J.-L. (1980). Contribution à la prospection archéologique des îles Marquises: l'ìle d'Eiao. Journal Société Océanistes 37: 105-121.

Decker, B.G. (1973). Unique dry-island biota under official protection in north-westem Marquesas Islands (Iles Marquises). Biological Conservation 5: 66-67.

Thibault, J-C. (1990). Eiao (Eastern Polynesia): an island which urgently needs a conservation plan. Unpublished manuscript. $11 \mathrm{pp}$.

Date February 1990

\section{PARC NATUREL TERRITORIAL DE FAAITI}

\section{IUCN Management Category II (National Park)}

Biogeographical Province 5.04.13 (Southeastern Polynesian)

Geographical Location The Vallee de Faaiti is situated in the drainage basin of the River Papenoo in Tahiti. The boundary is defined to the west by the ridge running between mounts Pitohiti $(2,110 \mathrm{~m})$ and Pihaiateta $(1,742 \mathrm{~m})$; to the north by the ridge of Mount Pihaiateta and the confluence of the Vaipaea and Vaituoru rivers; and to the south by the Teivimarama ridge of Mount Pitihoto and the confluence of the Vaipaea and the Vaituoru rivers. Access is only possible on foot or in four-wheel drive vehicle by crossing eight fords in the River Papenoo. Approximately $17^{\circ} 40^{\prime} \mathrm{S}, 149^{\circ} 30^{\prime} \mathrm{W}$

Date and History of Establishment Established by Decree No. 678/CM on 5 June 1989.

Area $750 \mathrm{ha}$

\section{Land Tenure State}

Altitude Attains $2,110 \mathrm{~m}$

Physical Features The valley is oriented from the north-east to south-west and widens upstream to an impressive cirque marked by waterfalls. Its gradient is between $25^{\circ}$ and $50^{\circ}$ for $2 \mathrm{~km}$ upstream, with projections and abrupt falls, decreasing downstream to $3^{\circ}$ to $10^{\circ}$. The gradient is sufficient to produce rapid water flow and the effect of a mountain torrent hindered by large rounded rocks. The relief is no different to that of other valleys on Tahiti which reflect the geological characteristics of Tahiti Nui volcano, created in several phases over 950,000 years. Following an underwater volcanic episode, activity above ground 1.25 to 0.9 million years ago created an enormous volcanic cone reaching $3,000 \mathrm{~m}$ which was the site of vigorous erosion 
creating radiating valleys and causing the summit craters to collapse to produce a caldera of 7-8km in diameter 0.9-0.7 million years ago. Later "post-caldera" activity, between 0.7 and 0.3 million years ago, deposited various materials (basalt, lahars etc) in the valleys (Bonvallot, 1989).

Climate Within the country as a whole, annual rainfall affects the mean temperature through a warm rainy season from November to April and relatively cool and dry season from May to October. The eastern trade winds predominate from October to March. From April to June there are long calm periods broken by occasional cyclones, which generally arrive from the north-east and north-west. Average annual precipitation is $5300 \mathrm{~mm}$ (ORSTOM, 1989). Other information specific to the reserve is not available.

Vegetation Geographical isolation has ensured that original vegetation is still preserved (Siu and Vernaudon, 1989; Y. Vernaudon, pers. comm., 1990). Introduced Miconia calvescens is not much in evidence although the rest of the Papenoo valley is beginning to be invaded. Previous human occupation is evident in the lower valley (Y. Vernaudon, pers. comm., 1990).

Fauna Geographical isolation has ensured that endemic fauna are still present (Siu and Vernaudon, 1989; Y. Vernaudon, pers. comm., 1990).

Cultural Heritage Preliminary work in 1988 has revealed important cultural and archaeological structures such as alluvial terraces, dwellings, platforms, and erect stones (Siu and Vernaudon, 1989). Two small "marae" (religious structures) have recently been discovered near the park headquarters (Y. Vernaudon, pers. comm., 1990). The Charter calls for an extensive archaeological inventory to be undertaken by the Archaeological Department of the Polynesian Centre for Human Science (Anon., 1990).

Local Human Population The valley is uninhabited but hunting and collection occurs (Y. Vernaudon, pers. comm., 1990).

Visitors and Visitor Facilities The park is open to visitors. Facilities include a marked trail from the valley entrance to the foot of the waterfalls, and shelters. Construction of park headquarters is planned at the entrance to the Valley, to house the park warden and information and education facilities. Within two years it is hoped to construct a network of footpaths, shelters, a picnic area, and erect information boards, and to develop educational and training programmes (Y. Vernaudon, pers. comm., 1990).

Scientific Research and Facilities The park administration will direct research towards those activities it intends to carry out in different fields, such as archaeology, education, ecology etc. (Anon., 1990). Authorisation for research projects is accorded by the park consultative committee.

Conservation Value Geographical isolation has ensured that endemic fauna and original vegetation is still preserved.

Conservation Management A charter for the park was compiled in February 1990 by the Ministry of the Environment and put to the Council of Ministers for approval before 5 June. The Ministry is responsible for this project, in conjunction with the park's consultative committee and all interested individuals. Chapter I of the charter sets out the responsibilities of the Délégation à l'Environnement, consultative committee and personnel with regard to administration, relations with outside bodies, civil responsibilities etc. (Anon., 1990). Currently, the only legal reference is the Code de l'Aménagement du Territoire Title II which provides for a classification procedure for natural monuments and sites. In the absence of any more precise 
legislation conceming protected areas, Vallée Faaiti has been established voluntarily. The current classification defines park boundaries, general objectives and administrative organisation. With regard to general objectives, the charter details the location of different zones; equipment programme and financing, and the management of the park interior (Siu and Vernaudon, 1989). Management objectives include the protection and preservation of ecosystems and landscapes, the survey, protection and conservation of the park's archaeological and historical resources, development of educational, recreational and tourist activities and scientific research (C.E. Payri, pers. comm., 1989). The charter sets out measures to be taken to protect and conserve ecosystems, preserve the natural equilibrium by controlling the introduction of exotic plant and animal species to the park, authorise reintroduction and eradication programmes (Anon., 1990).

Agricultural, silvicultural, industrial, economic, mining activities and construction of dams are forbidden within the park. Fishing, hunting and collection, however, are authorised but can be forbidden temporarily by the park administration should overexploitation occur (Anon., 1990).

Management Constraints Feral pigs and goats have been reported (Siu and Vernaudon, 1989) but there are at present no noteworthy management problems (Anon., 1990).

Staff One person part-time within the Délégation à l'Environnement

Budget A total of FCP 20 million (approximately US\$ 165,000 ) was available in 1989. FCP 1.8 million (US\$ 14,850 ) is to be spent on the construction of a model of the park, a short film in French and Tahitian, and public education programmes. FCP 6.5 million (US\$ 53,625) is already assigned to archaeological studies which will be carried out by the Polynesian Academy of Human Sciences (Siu and Vernaudon, 1989).

Local Addresses Délégation à l'Environnement, BP 4562, Papeete

\section{References}

Anon. (1990). Charte du Parc naturel territorial de Faaiti. Délégation à l'Environnement, Papeete. Unpublished. $8 \mathrm{pp}$.

Bonvallot, J. (1989). Considérations géomorphologiques préliminaires sur la Vallée Faaiti-Tahiti. ORSTOM. Unpublished. 3 pp.

ORSTOM (1989). Caractéristiques hydrologiques de Vlle Faaiti. Organisation de Recherches scientifiques et techniques d'Outre Mer. Unpublished. 1 pp.

Siu, P and Vernaudon, Y. (1989). Programme de mise en place d'un système de périmètres protégés en Polynésie Française. Case study No. 18. Fourth South Pacific Conference on Nature Conservation and Protected Areas. Port Vila, Vanuatu, 4-12 September. 6 pp.

Date February 1990, reviewed January 1991 


\section{FRANCE - NEW CALEDONIA}

Area $19,000 \mathrm{sq} . \mathrm{km}$

Population 164,173 (April 1989) (Institut Territorial

Natural increase: No information

de la Statistique et des Etudes Economiques, Noumea)

GNP No information

Policy and Legislation New Caledonia was annexed by France in 1853 and became an Overseas Territory in 1958. Following constitutional changes in 1985 and 1988, the Territory is divided into three autonomous provinces, administered by a High Commissioner assisted by a four-member Consultative Committee. Law No. 88.1028 of 9 November 1988 gives the three provinces full powers in environmental matters.

Protection of natural heritage is one of the objectives of the "long-term economic and social plan for New Caledonia" adopted by the Territorial Assembly on 21 February 1979. Revised legislation pertaining to parks and reserves came before the Territorial Assembly in 1980 (Délibération No. 108 of 9 May 1980 enforced by Decree No. 1504 of 21 May 1980). Previously, existing laws covered establishment of complete reserves, botanical reserves, forest reserves and marine reserves. The revised legislation introduced the terms réserve naturelle intégrale (strict nature reserve), parc territorial (territorial park) and réserve spéciale (special reserve), and provided more complete definitions of these terms, which in principal relate to IUCN management categories I (strict nature reserve), II (national park) and IV (managed nature reserve), respectively (see Annex 1).

Protected areas can only be established on land belonging to the Territory, to the State, or on public land. The establishment of such protected areas on private property may be allowed on demand of private individuals. Reserves are not protected against mining activity unless located within mining reserves established under the mining laws (Decree No. 54-1110 of 13 November 1954).

Protection zones can also be established under the Water Resources and Pollution Law (Délibération No. 105 of 26 August 1968), whereby activities likely to endanger water quality can be prohibited or controlled. Decree 51-100 of 26 January 1951 lays down conditions for forest classification. Areas of archaeological, historic or tourist interest can also be declared as classified sites under Law No. 56-1106 of 3 November 1956 and Délibération No. 225 of 17 June 1965.

There are a few small zones where activities are restricted for the purpose of "good management of public land". These are afforestation zones and lands allocated to the Forestry Department for the production of timber in which certain measures for the protection of wildlife may also be applied (SPREP, 1985a).

International Activities At the international level, France has entered into a number of obligations and cooperative agreements related to conservation. It is party to the Convention concerning the Protection of the World Cultural and Natural Heritage (World Heritage Convention) which it accepted on 27 June 1975. France became a contracting party to the Convention on Wetlands of International Importance especially as Waterfowl Habitat (Ramsar Convention) on 1 October 1986. 
France signed the Convention on the Conservation of Nature in the South Pacific on 12 June 1976 , and subsequently ratified it on 20 January 1989 . Known as the Apia Convention, it entered into force during 1990. The Convention is coordinated by the South Pacific Commission and represents the first attempt within the region to cooperate on environmental matters. Among other measures, it encourages the creation of protected areas to preserve indigenous flora and fauna.

France also signed the Convention for the Protection of the Natural Resources and Environment of the South Pacific Region (SPREP Convention) on 25 November 1987, with ratification on 17 July 1990. The convention entered into force during August 1989. Article 14 calls upon the parties to take all appropriate measures to protect rare or fragile ecosystems and threatened or endangered flora and fauna through the establishment of protected areas and the regulation of activities likely to have an adverse effect on the species, ecosystems and biological processes being protected. However, as this provision only applies to the Convention area, which by definition is open ocean, it is most likely to assist with the establishment of marine reserves and the conservation of marine species. It should be noted that the instrument of Approval is accompanied by the following reservation: "The Government of the French Republic, in signing the present Convention declares that, insofar as it is concerned, the prescription of the aforesaid Convention will not cover wastes and other matter entailing a level of pollution caused by radioactivity to a degree less than that prescribed by the recommendations of the International Atomic Energy Agency".

Administration and Management The Service de l'Environnement et Gestion des Parcs et Réserves (Direction du Développement Rural) is responsible for the administration of parks and reserves which are controlled on a day-to-day basis by individual forestry districts, divided between three administrative centres. Déliberation No. 38-90/APS of 28 March 1990 makes provision for the creation of a Comité pour la Protection de l'Environnement dans la Province Sud. This body comprises a number of members from government departments, ORSTOM and, at present, the President of the Association pour la Sauvegarde de la Nature Néo-Caledonienne. The Committee's rôle is largely to act in an advisory capacity to the provincial authorities.

Systems Reviews The natural vegetation comprises tropical evergreen rain forest up to $1,000 \mathrm{~m}$ and tropical montane rain forest above $1,000 \mathrm{~m}$. A variant of evergreen rain forest, sometimes with Araucaria columnaris, is dominant near the coast on raised coral, especially in the Loyalty Islands and Ile des Pins. Dry sclerophyllous forest is characteristic of drier western slopes. Various types of scrub on acidic and ultrabasic rocks cover about $30 \%$ of the land area. Mangroves occur along western coasts. According to a $1974 / 75$ forest inventory, the major vegetation types are dense evergreen forest ( $22.8 \%$ of total land area), Niaouli savanna woodland (13.8\%), low scrub in mining areas $(25.1 \%)$, savanna grassland $(21.7 \%)$ and scrub (8.3\%) (SPREP, 1989). Hunter Island has some grassland with occasional trees; Walpole Island is covered by dense scrub; and Matthew Island has almost no vegetation (Davis et al., 1986). A more detailed vegetation account and vegetation maps are given by Schmid (1978).

A summary account of coral reefs is given in UNEP/IUCN (1988), with specific descriptions of Chesterfield Islands, D'Entrecasteaux Reefs, Great Reef Marine Reserve (Réserves Tournantes sur le Grand Recif), Maître and Amédée Islets Nature Reserves and Yves Merlet Marine Reserve. Grande Terre is surrounded by a barrier reef, more than $1,600 \mathrm{~km}$ in length, which borders a lagoon of clear and rather shallow water covering $16,000 \mathrm{sq} . \mathrm{km}$, second in size only to the Australian Great Barrier Reef (UNEP/IUCN, 1988). 
The protected areas system has relatively good coverage, although most sites were established to protect areas of botanical interest. However, enforcement is weak and it is not certain that the existing system is adequate to continue to protect such a rich and localised flora.

The two principal threats to the natural flora and fauna are mining and bushfires. Since mining is the basis of the country's economy, measures taken to conserve natural areas do not necessarily include the exclusion of mining activities. In these cases, no disturbance is permitted without prior review and approval. Moreover, before any mine can be developed an environmental impact assessment is carried out by the Commission de Prévention des Dégâts miniers. The environmental impact of mining in New Caledonia is discussed by Dupon (1986). Large areas are burnt annually, frequently deliberately, to attract rain, encourage fresh grass growth or to clear undergrowth. This has led to habitat destruction, denudation of soils and progressive shrinking of forests. There is now pressure for logging in many areas and, as there is still no complete forest classification, destruction can occur without the Department being empowered to take action. Forest exploitation has been uncontrolled and contributed to the destruction of forests, or depletion of the more valuable species. Today, the Direction du Développement Rural exercises control to prevent indiscriminate or excessive felling (SPREP, 1989).

An Action Strategy for Protected Areas in the South Pacific Region (SPREP, 1985b) has been prepared. The principal goals of the strategy cover conservation education, conservation policy development, establishment of protected areas, protected areas management and regional and international cooperation. Priority recommendations for New Caledonia are intensification of education and public information activities relating to nature conservation, with special attention being paid to school text-books for use at all levels; adoption of a Territorial "charter" on the protection of the natural and cultural heritage; establishment of new protected areas as follows: a bird reserve on Chesterfield Islands, rotating marine reserves in reef areas, extension of Rivière Bleue Territorial Park and preservation of the lake ecosystems of the Plaine des Lacs; legislative measures to ensure permanency of parks and reserves, redrafting of forestry legislation, taking into account customary ownership; protection of endemic endangered species; establishment of a central structure for the management and planning of protected areas; and support of SPREP's activities and promotion of co-operation among international scientists and experts with a view to furthering knowledge in the field of ecology. The extent to which these objectives have been achieved is not known. It has also been recommended that a protected area be established on Huon Island, to the north of the Territory for the protection of marine turtles (J-L. d'Auzon, pers, comm., 1991).

\section{Addresses}

Service de l'Environnement et Gestion des Parcs et Réserves, Direction du Développement Rural, BP 256, Noumea

\section{References}

Davis, S.D., Droop, S.J.M., Gregerson, P., Henson, L., Leon, C.J., Lamlein Villa-Lobos, J., Synge, H. and Zantovska, J. (1986). Plants in Danger: What do we know? IUCN, Gland, Switzerland and Cambridge, UK. 488 pp.

Dupon, J.F. (1986). The effects of mining on the environment of high islands: case study of nickel mining in New Caledonia. Environmental Case Study No. 1. SPREP, South Pacific Commission, Noumea, New Caledonia. 5 pp.

Paxton, J. 1989. The Statesman's Yearbook 1989-90. MacMillan Press Ltd., London. 1691 pp. 
Schmid, M. (1978). The Melanesian forest ecosystem (New Caledonia, New Hebrides, Fiji Islands and Solomon Islands). In: Unesco/UNEP/FAO, Tropical forest ecosystems. Unesco, Paris. Pp. 654-683.

SPREP (1980). New Caledonia. Country Report 8. South Pacific Commission, Noumea, New Caledonia.

SPREP (1985a). New Caledonia. In: Thomas, P.E.J. (Ed.), Report of the Third South Pacific National Parks and Reserves Conference. Volume III. Country reviews. South Pacific Commission, Noumea, New Caledonia. Pp. 125-133.

SPREP (1985b). Action strategy for protected areas in the South Pacific Region. South Pacific Commission, Noumea, New Caledonia. 24 pp.

SPREP (1989). New Caledonia. Paper presented at the Fourth South Pacific Conference on Nature Conservation and Protected Areas,. Port Vila, Vanuatu, 4-12 September 1989. 11 pp. UNEP/IUCN (1988). Coral Reefs of the World. Volume 3. Central and Western Pacific. UNEP Regional Seas Directories and Bibliographies. IUCN, Gland, Switzerland and Cambridge, UK/UNEP, Nairobi, Kenya. 378 pp.

\section{ANNEX \\ Definitions of protected area designations, as legislated, together with authorities responsible for their administration}

Title: Délibération No. 108

Date: 9 May 1980

Brief description: Introduced and defined the terms réserve naturelle intégrale (strict nature reserve), parc territorial (territorial park) and réserve spéciale (special reserve), and provided more complete definitions of these terms, which in principal relate to IUCN management categories I (strict nature reserve), II (national park) and IV (managed nature reserve), respectively. Enforced by Decree No. 1504 of 21 May 1980.

Administrative authority: Service de l'Environnement et Gestion des Parcs et Réserves (Direction du Développement Rural)

\section{Designation:}

Réserve naturelle intégrale (Strict nature reserve) Areas in which all hunting, fishing, forestry, agriculture or mining, all activities likely to modify the landscape or vegetation, disturbance to flora and fauna, all floral and faunal introductions, whether indigenous, wild, exotic or domestic, and collection of botanical and geological samples are strictly forbidden. It is also forbidden to enter, move about, camp, or carry out scientific research in such reserves without written permission of the Service de l'Environnement et Gestion des Parcs et Réserves, and flying over the reserves is regulated. Réserves naturelles intégrales may not be established except where all prospecting, mineral research or exploitation have been prohibited under Article 2210-1 of the present code.

Parc territorial (Territorial park) Set aside for the conservation of flora and fauna but also to cater for public education and recreation. Flora and fauna are fully protected and gathering of botanical or geological samples is forbidden without express permission of the Service 
de l'Environnement et Gestion des Parcs et Réserves and only for scientific purposes. There is provision for permission to be given by the service for facilities such as roads, paths, restaurants, hotels and associated infrastructure to be built for educational and recreational purposes. NB Subsequent to the recently introduced constitutional changes, parc territorial might be more properly termed parc provincial, although it is not known if this is the case.

Réserve spéciale (Special reserve) Areas where certain activities may be prohibited or regulated for specific environmental protection objectives. Réserves spéciales are divided into:

- Réserve spéciale botanique (Special botanical reserve) created for the restoration and conservation of habitats, and the conservation of rare, noteworthy or threatened plant species. It is expressly forbidden to modify the landscape or carry out any acts detrimental to the vegetation except with authorisation given by the Head of the Service de l'Environnement et Gestion des Parcs et Réserves.

- Réserve spéciale de faune (Special faunal reserve) in which particular measures for the protection of one or more animal species may be taken. Réserves spéciales de faune include a number of marine areas and islands that are totally or partially protected both for the purpose of species conservation and for stock management and scientific studies.

- Réserve spéciale marine (Special marine reserve) 


\section{SUMMARY OF PROTECTED AREAS}

\begin{tabular}{|c|c|c|c|c|}
\hline $\begin{array}{l}\operatorname{Map}^{\dagger} \\
\text { ref. }\end{array}$ & Name of area & $\begin{array}{c}\text { IUCN management } \\
\text { category }\end{array}$ & $\begin{array}{r}\text { Area } \\
\text { (ha) }\end{array}$ & $\begin{array}{c}\text { Year } \\
\text { notified }\end{array}$ \\
\hline
\end{tabular}

Strict Nature Reserves

1 Montagne des Sources*

1950

Special Botanical Reserves

2 Cap Ndua (Southern Botanical Reserve \#5) IV

3 Chutes de la Madeleine* IV

4 Fausse Yaté (Southem Botanical Reserve \#2) IV

5 Forêt Cachée (Southern Botanical Reserve \#7) IV

6 Forêt Nord (Southern Botanical Reserve \#4) IV

7 Forêt de Sailles IV

8 Mont Humboldt* IV

9 Mont Mou* IV

10 Mont Oungoué (Southern Botanical IV Reserve \#3)

11 Mont Panié IV

12 Pic Ningua IV

13 Pic du Pin (Southem Botanical Reserve \#6) IV

14 Yaté Barrage (Southern Botanical Reserve \#1) IV

Special Fauna and Flora Reserve

15 L'Ilot Maître

\section{Special Faunal Reserve}

\section{Special Marine Reserves}

\section{Territorial Parks}

26 Parc Territorial du Lagon Sud: Amédée Islet* V

27 Parc Territorial du Lagon Sud: Bailly Island V

28 Parc Territorial du Lagon Sud: Canard Island V

29 Parc Territorial du Lagon Sud:

$\begin{array}{rr}44 & 1989 \\ 154 & 1981 \\ 314 & 1989 \\ 50 & 1989 \\ & \\ 362 & 1989 \\ 181 & 1989\end{array}$


Map $^{\dagger}$ Name of area

ref.

31 Rivière Bleue*

32 Thy*

\section{Forest Reserves}

33 "South" of New Caledonia

34 Col d'Amieu

35 Kuebini

36 Mont Mou

37 Ouenarou

$38 \quad$ Povilla

39 Tangadiou

40 Tango

41 Tiponite

\section{Unclassified}

42 "Michel Corbasson"

43 Amoa/Tchamba

44 Boulouparis-Bourail

45 Branch Nord Dumbea et Couvelee

$46 \quad$ Haute Doutio

$47 \quad$ Koumac

48 Nord Côte Est

49 Ora Peninsula

50 Paita-Dumbea-Mt Dore

51 Ponerihouen

52 Pouembout
IUCN management category

Area

(ha)

Year notified

$\begin{array}{crr}\text { IV } & 9,054 & 1980 \\ \text { II } & 1,133 & 1980\end{array}$

$\begin{array}{lrr}\text { VIII } & 4,665 & 1980 \\ \text { VIII } & 12,368 & 1970 \\ \text { VIII } & 58 & 1980 \\ \text { IV } & 4,363 & \\ \text { VIII } & 1,171 & 1959 \\ \text { VIII } & 600 & 1971 \\ \text { VIII } & 1,016 & 1970 \\ \text { VIII } & 29,089 & 1979 \\ \text { VIII } & 1,085 & 1970\end{array}$

II

35

Unassigned

43,000

Unassigned

VI

Unassigned

245,000

1972

1981

Unassigned

7,000

1972

Unassigned

26,300

1975

Unassigned

89,000

848

Unassigned

71,000

1972

Unassigned

33,880

1975

Unassigned

* Site is described in this directory.

${ }^{\dagger}$ Locations of most protected areas are shown in the accompanying map. 


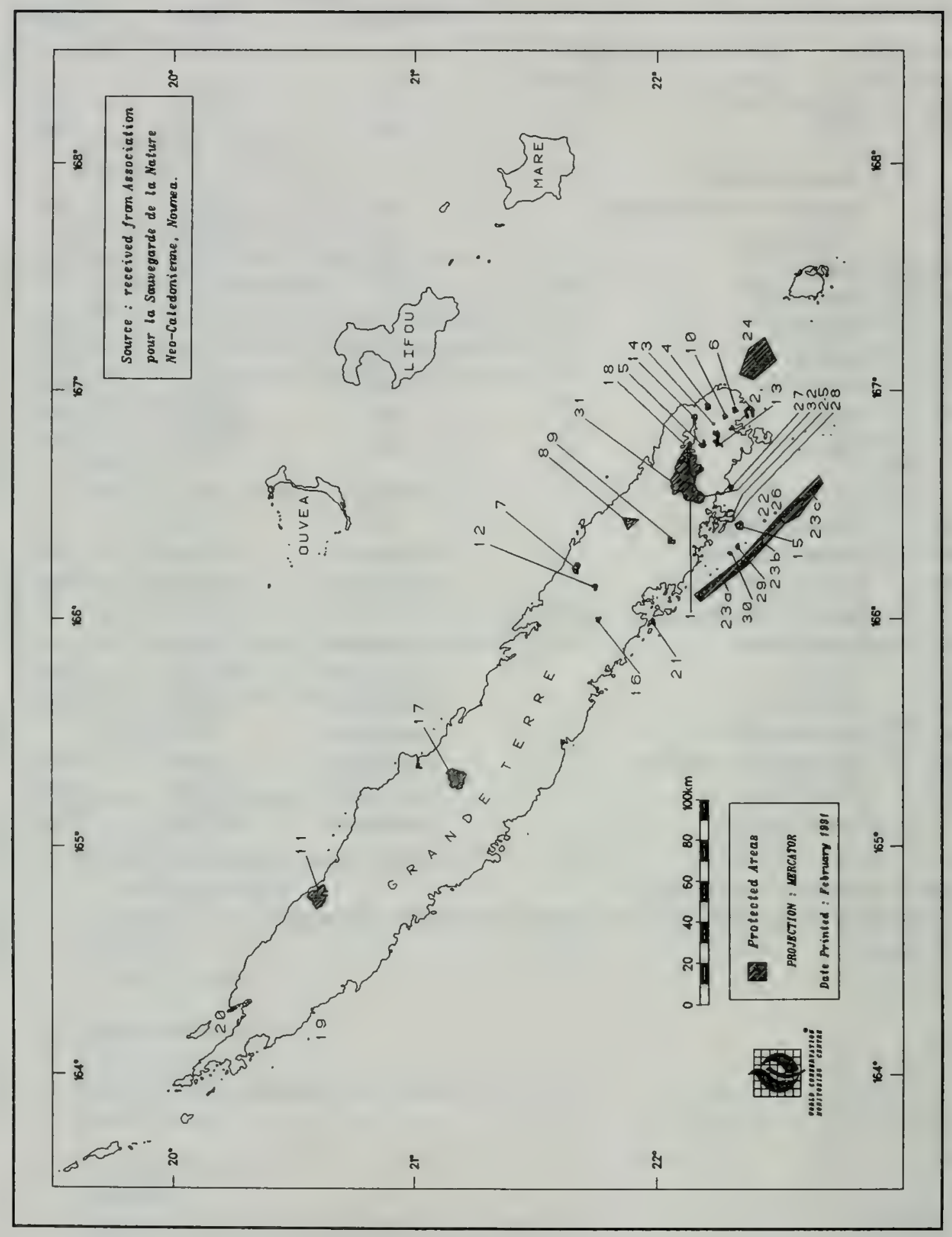

Protected Areas of New Caledonia 


\section{AOUPINIE SPECIAL FAUNA RESERVE (RESERVE SPECIALE DE FAUNE DE L'AOUPINIE)}

IUCN Management Category IV (Managed Nature Reserve)

Biogeographical Province 5.06.13 (New Caledonian)

Geographical Location On the eastern flank of Mount Aoupinie in central New Caledonia, above Ponerihouen. Approximately $21^{\circ} 10^{\prime} \mathrm{S}, 165^{\circ} 18^{\prime} \mathrm{E}$

Date and History of Establishment 14 November 1975 by Délibération 234; confirmed by Délibération 108 of 9 May 1980.

Area 5,400 ha

Land Tenure Public

Altitude $65 \mathrm{~m}-1,021 \mathrm{~m}$

Physical Features Comprises steep mountain slopes and upper watersheds. The underlying rock comprises sandstones.

Climate Mean annual precipitation is $2000 \mathrm{~mm}$.

Vegetation Rain forest which is more or less undisturbed

Fauna No information

Cultural Heritage No information

Local Human Population The nearest settlement is Goapin, to the south.

Visitors and Visitor Facilities None

Scientific Research and Facilities None

Conservation Value No specific information

Conservation Management Article A 1324-4 of the Code de la Protection de la Nature et de l'Environnement prohibits all unauthorised entry and Article A 1324-3 prohibits hunting. Bringing either arms or dogs into the reserve is also forbidden. Those holding titles permitting forest exploitation, mineral prospecting and officials are permitted entry and the site is not currently protected under the mining laws.

Management Constraints Mining and logging may be allowed under permit.

\section{Staff None}

Budget No special allocation

Local Addresses Service de l'Environnement et Gestion des Parcs et Réserves, Direction du Développement Rural, BP 256, Noumea (Province Nord) 


\section{References}

None listed

Date September 1983, updated February 1991

\section{SOUTHERN SPECIAL BOTANICAL RESERVE (RESERVE SPECIALE BOTANIQUE DU SUD)}

\section{IUCN Management Category IV (Managed Nature Reserve)}

Biogeographical Province 5.6.13 (New Caledonian)

Geographical Location The reserve comprises seven areas as follows: No 1: Yate Barrage

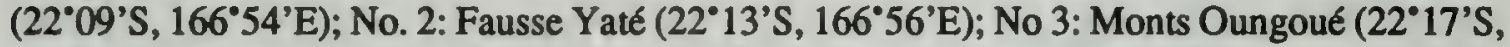
$\left.166^{\circ} 54^{\prime} \mathrm{E}\right)$; No 4 Forêt Nord $\left(22^{\circ} 19^{\prime} \mathrm{S}, 166^{\circ} 55^{\prime} \mathrm{E}\right)$; No 5: Cap Ndua $\left(22^{\circ} 22^{\prime} \mathrm{S}, 1^{\circ} 6^{\circ} 55^{\prime} \mathrm{E}\right)$;

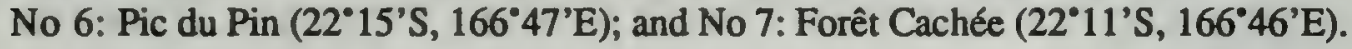

Date and History of Establishment 17 August 1972 by Arrêté $72-395 / C G$ as a mining reserve; 9 May 1980 by Délibération 108 as a special botanical reserve.

Area Total of 4,466ha comprising Yaté Barrage (546ha), Fausse Yaté (386ha), Monts Oungoué (307ha), Forêt Nord (280ha), Cap Ndua ( $830 \mathrm{ha}$ ), Pic du Pin (1,482ha), and Forêt Cacheé (635ha).

Land Tenure Public

Altitude Sea level to $669 \mathrm{~m}$

Physical Features Comprises six physically separate mountainous area and one coastal area on the southern plateau.

Climate Mean annual precipitation varies between 2500 to $3500 \mathrm{~mm}$.

Vegetation Yaté Barrage, Fausse Yaté and Monts Oungoué, all support lowland rain forest and serpentine scrub; Cap Ndua includes coastal rain forest and serpentine scrub; Pic du Pin, serpentine scrub with many endemic species; and Forêt Cacheé, forest and serpentine scrub.

Fauna No information

Cultural Heritage No information

Local Human Population There is a small settlement within the Yate Barrage area.

Visitors and Visitor Facilities None

Scientific Research and Facilities None

Conservation Value No specific information

Conservation Management All disturbance of the vegetation is prohibited and all mineral prospecting and mining is prohibited. 
Management Constraints The Yate Barrage area is transected by a road and includes the settlement of Yaté Barrage.

\section{Staff None}

Budget No special allocation

Local Addresses Service de l'Environnement et Gestion des Parcs et Réserves, Direction du Développement Rural, BP 256, Noumea

\section{References}

None listed

Date September 1983, reformatted January 1990

\section{RESER VE SPECIALE BOTANIQUE DE LA CHUTE DE LA MADELEINE (LA CHUTE DE LA MADELEINE SPECIAL BOTANICAL RESERVE)}

IUCN Management Category IV (Managed Nature Reserve)

Biogeographical Province 5.06 .13 (New Caledonian)

Geographical Location Located on the north-north-west border of the Plaine des Lacs, in the south of Grand Terre, and bordered in part by the Rivière de Lacs. Approximately $22^{\circ} 15^{\prime} \mathrm{S}$, $166^{\circ} 50^{\prime} \mathrm{E}$

Date and History of Establishment Established on 28 March 1990 by Délibération 39-90/APS.

Area Approximately $400 \mathrm{ha}$

\section{Land Tenure State}

Altitude Averages $240 \mathrm{~m}-260 \mathrm{~m}$, with the Pic du Pin at $600 \mathrm{~m}$

Physical Features The topographical complex known as the Plaine des Lacs is drained by the Rivière des Lacs from its source in the Lac en Huit across the northern edge of the plain. After the $10 \mathrm{~m}$ drop of $\mathrm{La}$ Chute de la Madeleine (Madeleine waterfall), the river enters the Yate dam reservoir beyond its confluence with Pernod Creek which drains the exterior of the north-west slopes of the Plaine des Lacs. The geological substrate comprises peridotites, and soils are ferrallitic and very poor in all chemical elements except magnesium, iron and chrome. Concentrations of nickel and manganese are also higher than normal.

Climate Annual rainfall on the plain varies between $2500 \mathrm{~mm}$ and $3000 \mathrm{~mm}$ and the mean annual temperature varies from $22^{\circ} \mathrm{C}$ to $23^{\circ} \mathrm{C}$.

Vegetation Comprises maquis minier formations of evergreen sclerophyllous-heliophyllous shrubs. Several characteristic types can be distinguished. First, the Gymnostoma deplancheanum group dominates the ferrallitic plain over the falls associated with more common species such 
as Tarenna leiloba, Gardenia aubryi, Agathis ovata and Exocarpus pseudocasuarina. The herbaceous layer is less important (coverage less than 10\%) and comprises principally Gahnia novocaledonensis, some common ferns such as Schizaea dichotoma, S. laevigata, Adiantum fournieri and a special monotypic Gleicheniaceae Stromatopteris moniliformis which is endemic to New Caledonia. The ground is covered in parts by lichens of the genus Cladonia and Cladina. The presence of some gum oaks Arillastrum gummiferum bears witness to the forested nature of climax vegetation and the recovery of degraded zones by plantation of large trees such as gum oak and kaori in exposed areas. Second, the Neocallitropsis pancheri group occupies the ferrallitic plateau. The vegetation cover averages between $2 \mathrm{~m}$ and $5 \mathrm{~m}$ in height and is discontinuous with bare patches. It comprises the principal species of the previous group but is distinguished by the presence of $N$. pancheri and of hygrophilous species such as Melaleuca gnidioides, Styphelia longistyles and Costularia fragilis. N. pancheri is a gymnosperm of the Cupressaceae family endemic to New Caledonia. The wood of this conifer is odiferous and it is the only species specifically protected in New Caledonia. Third, the Nageia minor and Dacrydium guillauminii community occupies an alluvial zone $1-5 \mathrm{~m}$ wide along the river banks which is flooded during high water. D. guillauminii is endemic to the banks of the Rivière des Lacs. The shrub layer, between 3-5m high, comprises these two gymnosperms which are amongst the most rare species in New Caledonia, the principal populations of which are located upstream of the falls. The low discontinuous shrub layer comprises Melaleuca brongnartii, Xanthostemon aurantiacum, Homalium kanaliense, Pancheria communis, Cloezia aquarum. The herbaceous layer, which is absent on gravelly soil but continuous on alluvial soil, comprises the Cyperaceae Costularia xyridioides, Schoenus brevifolius, Chorizandra cymbaria, Tricostularia guillauminii and the Xyridaceae Xyris pancheri and $X$. neocaledonica. Fourth, the aquatic vegetation is poor in species and not abundant, but is no less remarkable for the presence of a carnivorous species Utricularia of the Lentibulariaceae family and of a relatively rare aquatic fern Blechnum francii. There is also one species, Eriocaulon, endemic to the south of the Grande Terre. A detailed inventory of the flora has revealed 168 species of phanerogam and ferns belonging to 53 families, of which $95 \%$ are endemic to New Caledonia and about 20 locally endemic to the south of the Grande Terre. A full list is given in Jaffré (1988).

Fauna The area is notable for a population of fish of the genus Galaxias, an endemic and nocturnal living fossil from the Tertiary age, which is probably the same species as that in the Lac en Huit, $G$. neocaledonicus. Also of scientific interest are two shrimp, one sponge and one crustacean species.

\section{Cultural Heritage No information}

\section{Local Human Population No information}

\section{Visitors and Visitor Facilities No information}

Scientific Research and Facilities The vegetation and flora have been studied by the Laboratoire de Botanique (ORSTOM) (Jaffré, 1988).

Conservation Value The site is considered exceptional for the richness and diversity of the flora, the high concentration of gymnosperms and for the presence of many rare species such as the aquatic fern $B$. francii and the camivorous aquatic plant $U$ tricularia sp.

Conservation Management Establishing legislation prohibits the collection, removal, displacement or harvesting of any mineral or vegetation and the use of motor vehicles away from roads. The boundary will be marked by signs indicating these restrictions and any infringement is punishable. 
Management Constraints No information

Staff No information

Budget No information

Local Addresses Service de l'Environnement et Gestion des Parcs et Réserves, Direction du Développement Rural, BP 256, Noumea

\section{References}

Anon. (1990). Journal officiel de la Nouvelle-Calédonie. Pp. 1217-1218.

Jaffré, T. (1988). Vegetation et flore de la Chute de la Madeleine. Etude en vue d'une proposition de mise en réserve. Laboratoire de Botanique, ORSTOM. 11 pp.

Date February 1991

\section{HAUTE YATE SPECIAL FAUNA RESERVE (RESERVE SPECIALE DE FAUNE DE LA HAUTE-YATE)}

IUCN Management Category IV (Managed Nature Reserve)

Biogeographical Province 5.06.13 (New Caledonian)

Geographical Location South-central New Caledonia. The border is defined in Article A 1321-2 of the Code de la Protection de la Nature et de l'Environnement. Includes Parc Territorial de la Rivière Bleue. Approximately $22^{\circ} 08^{\prime} \mathrm{S}, 166^{\circ} 40^{\prime} \mathrm{E}$

Date and History of Establishment 3 February 1960 by Délibération 184, confirmed by Délibération 108 of 9 May 1980.

Area 15,900ha; Parc Territorial de la Rivière Bleue: 9,054ha

Land Tenure Public

Altitude Approximately $160 \mathrm{~m}$ to $785 \mathrm{~m}$

Physical Features Includes the watersheds of the western end of the artificial Lake Yaté, ranging from hill ridges to the lakeshore. The underlying rocks are ultrabasic.

Climate Mean annual rainfall is more than $3000 \mathrm{~mm}$.

Vegetation Mostly forest scrub including Podocarpus and Agathis spp. There is some freshwater marshland fringing the Rivière Blanche.

Fauna A number of endemic birds are present but specific details are not available.

Cultural Heritage None

Local Human Population None 
Visitors and Visitor Facilities None

\section{Scientific Research and Facilities None}

Conservation Value No specific information

Conservation Management Under Article A 1321-4 of the Code de la Protection de la Nature et de l'Environnement, entry into the reserve is regulated and only holders of titles for forestry or mining, and staff of La Société d'Energie Electrique are permitted to visit the area regularly. Hunting and fishing are prohibited. Permission may be given by the Head of the Service des Eaux et Forêts for scientific or tourist visits under Article 1321-5 of the Code.

Management Constraints Mineral prospecting and fires have degraded parts of the area. Lake Yaté flooded a rich forest in the valley bottom. There has been some forest exploitation in the past. The legal protection prohibits neither mineral prospecting or exploitation, nor forestry.

Staff One forest officer is assigned to the Parc territorial de la Rivière Bleue.

Budget No information

Local Addresses Service de l'Environnement et Gestion des Parcs et Réserves, Direction du Développement Rural, BP 256, Noumea; Service des Eaux et Forêts, Noumea

\section{References}

None listed

Date September 1983, updated February 1991

\section{PAM ISLAND SPECIAL FAUNA RESERVE (RESERVE SPECIALE DE FAUNE DE L'ILE DE PAM)}

IUCN Management Category IV (Managed Nature Reserve)

Biogeographical Province 5.06.13 (New Caledonian)

Geographical Location Located at the northern end of New Caledonia, in the mouth of the Diahot River. Approximately $20^{\circ} 15^{\prime} \mathrm{S}, 164^{\circ} 18^{\prime} \mathrm{E}$

Date and History of Establishment 29 December 1966, by Arrêté 66-603/CG; confirmed by Délibération 108 of 9 May 1980.

Area 460 ha

Land Tenure Public

Altitude Sea level to $166 \mathrm{~m}$

Physical Features Steep island bordered by mangrove and reef

Climate Mean annual precipitation is $1200 \mathrm{~mm}$ 
Vegetation Mangrove and secondary vegetation

Fauna No information

Cultural Heritage None

Local Human Population None on the island

Visitors and Visitor Facilities None

Scientific Research and Facilities None

Conservation Value No specific information

Conservation Management Entry and hunting are prohibited

Management Constraints No information

Staff None

Budget No special allocation

Local Addresses Service de l'Environnement et Gestion des Parcs et Réserves, Direction du Développement Rural, BP 256, Noumea (Province Nord)

\section{References}

None listed

Date September 1983, updated February 1991

\section{LEPREDOUR ISLET SPECIAL FAUNA RESERVE (RESERVE SPECIALE DE FAUNE DE L'ILOT LEPREDOUR)}

IUCN Management Category IV (Managed nature reserve)

Biogeographical Province 5.06 .13 (New Caledonian)

Geographical Location Mot Lepredour is just off the west coast of New Caledonia in the Baie de St Vincent, near Bouloupari. Approximately $21^{\circ} 58^{\prime} \mathrm{S}, 166^{\circ} 0^{\prime} \mathrm{E}$

Date and History of Establishment 12 September 1941 by Arrêté 985; confirmed by Délibération 108 of 9 May 1980

Area 760 ha

Land Tenure Public

Altitude Sea level to $225 \mathrm{~m}$

Physical Features Comprises a limestone and sandstone island with steep slopes fronted by mangroves. 
Climate Annual rainfall varies between $600 \mathrm{~mm}$ and $800 \mathrm{~mm}$

Vegetation Includes niaouli Melaleuca savannah and mangroves, but very disturbed.

Fauna Includes introduced deer.

Cultural Heritage None

Local Human Population There has been a settlement but the reserve is currently not populated (J-L. d'Auzon, pers. comm., 1991).

Visitors and Visitor Facilities None

Scientific Research and Facilities None

Conservation Management The area was created as the governor's hunting reserve. Article A 1322-2 of the Code de la Protection de la Nature et de l'Environnement prohibits disembarkation or approach on the seaward side within $100 \mathrm{~m}$. All game hunting is prohibited under Article A 1322-3 throughout the year, except with permission of the Service de l'Environnement et Gestion des Parcs et Réserves and the High Commissioner.

Management Constraints No information

Staff None

Budget No special allocation

Local Addresses Service de l'Environnement et Gestion des Parcs et Réserves, Direction du Développement Rural, BP 256, Noumea

\section{References}

None listed

Date September 1983, updated February 1991

\section{MONT HUMBOLDT SPECIAL BOTANICAL RESERVE (RESERVE SPECIALE BOTANIQUE DU MONT HUMBOLDT)}

IUCN Management Category IV (Managed Nature Reserve)

Biogeographical Province 5.06.13 (New Caledonia)

Geographical Location Mount Humboldt in south central New Caledonia. Approximately $21^{\circ} 53^{\prime} \mathrm{S}, 166^{\circ} 25^{\prime} \mathrm{E}$

Date and History of Establishment 7 July 1950 by Arêté 931; confirmed by Délibération 108 of 9 May 1980.

Area $3,200 \mathrm{ha}$ 
Land Tenure Public

Altitude $400 \mathrm{~m}-1,618 \mathrm{~m}$

Physical Features Comprises the summit and steep-sided ridges of Mount Humboldt in the centre of the Humboldt Massif. Ultrabasic rocks constitute the underlying geology.

Climate Rainfall exceeds $3000 \mathrm{~mm}$ annually.

Vegetation Includes Araucaria humboldtensis cloud forest, Araucaria rulei and other important species.

Fauna No information

Cultural Heritage None

\section{Local Human Population None}

Visitors and Visitor Facilities Two huts have been constructed by JEAN's, the young persons section of the Association pour la Sauvegarde de la Nature.

Scientific Research and Facilities None

Conservation Management All disturbance of the vegetation is prohibited. Not currently protected under the mining laws.

Management Constraints Mining prospecting is authorised under permit, but no disturbance is permitted without prior review and approval.

Staff None

Budget No special allocation

Local Addresses Service de l'Environnement et Gestion des Parcs et Réserves, Direction du Développement Rural, BP 256, Noumea

\section{References}

None listed

Date September 1983, reformatted January 1990

\section{MONT MOU SPECIAL BOTANICAL RESERVE (RESERVE SPECIALE BOTANIQUE DU MONT-MOU)}

IUCN Management Category IV (Managed Nature Reserve)

Biogeographical Province 5.06.13 (New Caledonian) 
Geographical Location Northern and western slopes of Mount Mou in southern New Caledonia near Paita. The reserve is entirely surrounded by Mont Mou Forest Reserve. Approximately $22^{\circ} 04^{\prime} \mathrm{S}, 166^{\circ} 20^{\prime} \mathrm{E}$

Date and History of Establishment 7 July 1950 by Arêté 931; confirmed by Délibération 108 of 9 May 1980.

Area 675ha; Mont Mou Forest Reserve: 5,038ha

Land Tenure Public

Altitude $320 \mathrm{~m}-1,211 \mathrm{~m}$

Physical Features Summit and upper slopes of Mount Mou, comprising ultrabasic rocks.

Climate No information specific to the reserve

Vegetation Botanically rich area including cloud forest with mosses.

Fauna No information

Cultural Heritage None

Local Human Population Paita village lies to the south-east whilst the Saint-Laurent tribe dwells on the western side (J-L. d'Auzon, pers. comm., 1991).

Visitors and Visitor Facilities A footpath exists.

Scientific Research and Facilities None

Conservation Management All disturbance of vegetation is prohibited. The area is not currently protected by mining laws.

Management Constraints Mining prospecting is authorised under permit, but no disturbance is permitted without prior review and approval.

Staff None

Budget No special allocation

Local Addresses Service de l'Environnement et Gestion des Parcs et Réserves, Direction du Développement Rural, BP 256, Noumea

\section{References}

None listed

Date September 1983, updated February 1991 


\section{MONT PANIE SPECIAL BOTANICAL RESERVE (RESERVE SPECIALE BOTANIQUE DU MONT PANIE)}

\section{IUCN Management Category IV (Managed Nature Reserve)}

Biogeographical Province 5.06.13 (New Caledonian)

Geographical Location Mount Panie on the north-east coast of New Caledonia, north of Hienghène. The boundary is defined by the course of the Coulna and Boualabio rivers and elsewhere by the $400 \mathrm{~m}$ contour. Approximately $20^{\circ} 36^{\prime} \mathrm{S}, 164^{\circ} 46^{\prime} \mathrm{E}$

Date and History of Establishment 7 July 1950 by Arrêté 931; confirmed by Délibération 108 of 9 May 1980.

\section{Area $5,000 \mathrm{ha}$}

Land Tenure Public

Altitude $400 \mathrm{~m}-1,628 \mathrm{~m}$

Physical Features Comprises the summit and flanks of Mount Panié, the highest mountain in New Caledonia. The underlying rock is micaschist.

Climate There is heavy annual rainfall of $4000 \mathrm{~mm}$.

Vegetation Rich forest with many endemics and unique palms

Fauna No information

Cultural Heritage None

\section{Local Human Population None}

Visitors and Visitor Facilities None

Scientific Research and Facilities Considerable botanical collecting

Conservation Management Mineral prospecting is authorised under permit, but no disturbance is permitted without prior review and approval. The Head of the Service de l'Environnement et Gestion des Parcs et Réserves may forbid mineral workings, although there is a right of appeal to the Comite Consultatif des Mines.

\section{Management Constraints No information}

\section{Staff None}

Budget No special allocation

Local Addresses Service de l'Environnement et Gestion des Parcs et Réserves, Direction du Développement Rural, BP 256, Noumea

\section{References}

None listed 
Date September 1983, updated February 1991

\section{MONTAGNE DES SOURCES STRICT NATURE RESERVE (RESERVE NATURELLE INTEGRALE DE LA MONTAGNE DES SOURCES)}

\section{IUCN Management Category I (Strict Nature Reserve)}

Biogeographical Province 5.06.13 (New Caledonia)

Geographical Location Upper Dumbea basin in south-central New Caledonia near Nouméa. The boundary is defined in the Code de la Protection de la Nature et de l'Environnement. Approximately $22^{\circ} 08^{\prime} \mathrm{S}, 166^{\circ} 34^{\prime} \mathrm{E}$

Date and History of Establishment 7 July 1950 by Arrêté 931, confirmed by Délibération 108 of 9 May 1980. Complete protection under mining law by Arrêté 58-101/CG of 26 March 1958.

\section{Area $5,870 \mathrm{ha}$}

\section{Land Tenure Public}

Altitude $117-1102 \mathrm{~m}$

Physical Features A complete upper watershed in the southern massif, comprising ultrabasic and basic rocks.

Climate The reserve has one of the highest rainfalls on the island, averaging $3000 \mathrm{~mm} /$ year.

Vegetation Includes montane rain forest and scrub with some cloud forest on the summits. The parasitic and endemic gymnosperm Parasitaxis ustus is reported within the reserve.

Fauna An important habitat for endemic birds, but no list is available.

\section{Cultural Heritage None}

\section{Local Human Population None}

Visitors and Visitor Facilities None

Scientific Research and Facilities None

Conservation Value No specific information

Conservation Management In addition to regulations covering strict nature reserves in the Code de la Protection de la Nature et de l'Environnement, it is forbidden to fly over the reserve at an altitude of less than $1,300 \mathrm{~m}$. Mineral prospecting and extraction is prohibited.

Management Constraints An access road and 200ha for a high alcitude station have been excluded from the reserve.

Staff None 
Budget No information

Local Addresses Service de l'Environnement et Gestion des Parcs et Réserves, Direction du Développement Rural, BP 256, Noumea

\section{References}

None listed

Date September 1983, updated February 1991

\section{MAITRE ISLET SPECIAL FAUNA AND FLORA RESERVE (RESERVE SPECIALE DE FAUNE ET DE FLORE DE L'ILOT MAITRE)}

\section{IUCN Management Category IV (Managed Nature Reserve)}

Biogeographical Province 5.6.13 (New Caledonian)

Geographical Location Ilot Maître lies in the lagoon off Noumea, the boundary approximately following the $10 \mathrm{~m}$ isobath. Approximately $22^{\circ} 20^{\prime} \mathrm{S}, 166^{\circ} 25^{\prime} \mathrm{E}$

Date and History of Establishment 2 July 1981 by Délibération 231. The original designation was for the Mâitre and Amédée Islets Special Fauna and Flora Reserve. However, Amédée Islet has since been redesignated under Délibération No. 73 of 26 January 1989 to form part of the Parc Provincial du Lagon Sud. Maître Islet has since been dereserved due to pressure from tourist developments, such that only the reefs remain protected.

Area 610ha

\section{Land Tenure Public}

Altitude $10 \mathrm{~m}$ depth to $2 \mathrm{~m}$

Physical Features Comprises low lagoon islets with sand beaches and fringing coral reefs.

Climate Mean annual rainfall is $1000 \mathrm{~mm}$.

Vegetation Vegetation on the island comprises tall trees, shorter trees, lianas, shrubs, a herb layer and beach strand vegetation, with some 31 recorded native species. Introduced Agave sp. and Opuntia sp. are invasive and a threat to the native flora.

Fauna Faure et al. (1981) and Thomassin and Coudray (1981) describe reef coral assemblages on the windward slope of Maître Reef. The inter-tidal reef flat has less than $20 \%$ coral coverage as a result of its sheltered position, and has abundant algae Sargassum and Turbinaria. Between $1 \mathrm{~m}$ and $2 \mathrm{~m}$ depth coral cover is still low and is predominantly short-branched species such as Acropora digitifera, Pocillopora damicornis and $P$. verrucosa, massive faviids and some branched and tabular Acropora (UNEP/IUCN, 1988). The intertidal reef flat around Maître islet has high coral coverage, due to its sheltered location. A survey in 1988 revealed the presence of 14 bird species (J-L. d'Auzon, pers. comm., 1991) 
Cultural Heritage The $56 \mathrm{~m}$ high Amédé lighthouse was constructed during the reign of Napoleon III in 1865.

Local Human Population Comprises the lighthouse keeper on llot Amédée who is permitted to maintain a garden for subsistence purposes, and hotel staff on llot Maître.

Visitors and Visitor Facilities A very popular area due to its proximity to Noumea, with some 40,000 visitors annually. A hotel was constructed on Dot Maitre in 1983, which has since been extended to cover the entire island, leading to the declassification of the island as a reserve (J-L. d'Auzon, pers. comm., 1991).

Scientific Research and Facilities Extensive research has been carried out in this area by ORSTOM scientists. Growth studies have been carried out on trochus on Amédée (Bour et al., 1982). The islet has been mapped using SPOT-LANDSAT satellite imagery (Bour et al., 1985). There are no special scientific facilities.

Conservation Value The reserve was created to protect both terrestrial and marine flora and fauna and to provide for public education and recreation.

Conservation Management Plants, animals and marine life are totally protected. Tourist development, recreation and management to further conservation aims are permitted.

Management Constraints Ilot Maître (and Ilot Amédée) are the most heavily exploited tourist destinations in New Caledonia, with large numbers of international visitors and local Noumeans. Corals on the reef are broken and collection of corals and shells and fishing take place (UNEP/IUCN, 1988); these activities are all illegal. A large coral head was recently sawn off and displaced to make a safer approach to the hotel on Ilot Maître.

\section{Staff None}

\section{Budget None}

Local Addresses Service de l'Environnement et Gestion des Parcs et Réserves, Direction du Développement Rural, BP 256, Noumea

\section{References}

Bour, W., Gohin, F. and Bouchet, P. (1982). Croissance et mortalité naturelle des Trocas (Trochus niloticus L.) de Nouvelle-Calédonie. Haliotis 12: 71-90. (Unseen).

Bour, W., Loubersac, L. and Rual, P. (1985). Reef thematic maps viewed through simulated data from the future SPOT satellite. Application to the biotope of topshell (Trochus niloticus) on the Tetembia reef (New Caledonia). Proceedings of the Fifth Coral Reef Congress, Tahiti 4: $225-230$.

Faure, G., Thomassin, B.A. and Vasseur, P. (1981). Reef coral assemblages on windward slopes in the Noumea Lagoon (New Caledonia). Proceedings of the Fourth Coral Reef Symposium, Manila 2: 292-301.

Thomassin, B. A. and Coudray, J. (1981) Presence of wide hardground areas on lagoonal bottoms of the coral reef complexes of Noumea (south-west New Caledonia). Proceedings of the Fourth Coral Reef Symposium, Manila 1: 512-522.

UNEP/IUCN (1988). Coral Reefs of the World. Volume 3. Central and Western Pacific. UNEP Regional Seas Directories and Bibliographies. IUCN, Gland, Switzerland and Cambridge, UK/UNEP, Nairobi, Kenya. 378 pp. 
Date September 1983, updated February 1991

\section{MARINE FAUNA ROTATING RESERVE (RESERVE SPECIALE TOURNANTE DE FAUNE MARINE)}

\section{IUCN Management Category VIII (Multiple Use Management Area)}

Biogeographical Province 5.6.13 (New Caledonian)

Geographical Location Comprises a barrier reef, lying parallel to the south-west of New Caledonia, near Noumea. Three narrow, rectangular sectors straddle the reef, as follows: Sector A includes Annibal Reef and Mbere Reef; $22^{\circ} 15^{\prime} S, 166^{\circ} 10^{\prime} \mathrm{E}$. Sector B includes Aboré Reef and Tabu Reef; $22^{\circ} 28^{\prime} S, 166^{\circ} 22^{\prime} \mathrm{E}$. Sector C includes To Reef, le Sournois Reef, Toombo Reef and Kué Reef; $22^{\circ} 35^{\prime} \mathrm{S}, 166^{\circ} 30^{\prime} \mathrm{E}$. A detailed description of the boundaries is given in Article A 1313-1 of the Code de la Protection de la Nature et de l'Environnement.

Date and History of Establishment 2 July 1981 by Délibération 230 and reconfirmed under Délibération 104.90 APS of 31 August 1990.

Area $35,570 \mathrm{ha}$, comprising Sector A $(12,190 \mathrm{ha})$, Sector B $(10,960 \mathrm{ha})$ and Sector C $(12,420 \mathrm{ha})$

Land Tenure Public

Altitude Up to sea level

Physical Features Comprises major sections of the Great Southem Reef, their outer slopes, adjacent lagoon bottom and surrounding waters. A general discussion of the New Caledonian reefs, including the Great Southern Reef, is given in UNEP/IUCN (1988).

Climate There are two principal seasons: a December to March hot season, and an April to November dry season. Mean daily temperatures range from $26.1^{\circ} \mathrm{C}$ in February to $19.9^{\circ} \mathrm{C}$ in July.

Vegetation No information

Fauna Typical species in the vicinity of the reserve include Acropora digitifera, A. humilis, Pocillopora spp., Porites lutea, Platygyra daedalea, Leptoria phrygia and faviids. Further details are given in UNEP/IUCN (1988).

\section{Cultural Heritage None}

Local Human Population The territorial capital, Noumea, is some $15 \mathrm{~km}$ to the north-east of Abore Reef.

Visitors and Visitor Facilities The area is very popular for recreational and fishing activities, on account of its accessibility from Noumea (UNEP/IUCN, 1988).

Scientific Research and Facilities Extensive research has been carried out in the area by ORSTOM, but there are few if any publications referring directly to this reserve (UNEP/IUCN, 1988). There are no special scientific facilities. 
Conservation Value Principally scientific research and recreation (UNEP/IUCN, 1988).

Conservation Management The capture or destruction of marine animals, including the collection of coral, is completely prohibited consecutively for three year periods in each of three sectors. In those areas where the closed season is not in force, collecting may take place according to normal fisheries regulations. Under the new (1990) legislation Section B is to be protected between August 1990 and August 1993; Section C from then until August 1996; and Section A subsequently until August 1999. Revision of the legislation will then be required. Although there has been no scientific monitoring of this reserve so far, divers from ORSTOM and the Noumea Aquarium, as well as many fishermen, reported a marked improvement in the condition of the reef since 1981 (Jourde, 1985).

Management Constraints The areas have been heavily fished in the past and a decline in species abundance and diversity was apparent in the late 1970s. The choice of a three-year closed period for each sector was made empirically on the assumption that good recruitment to fish populations would occur in this time span. However, there has been little quantitative research to support this. The great species diversity and the complexity of the interactions between the three reef sections has made the quantitative assessment of exploitable stocks virtually impossible (Jourde, 1985). Enforcement is difficult, particularly as boat traffic is still allowed to pass through the area.

Staff No information

Budget No special allocation

Local Addresses Service de la Marine Marchande et des Pêches Maritimes, Noumea; in cooperation with the Service des Eaux et Forêts, Noumea

\section{References}

Jourde, J-1. (1985). Marine reserves in New Caledonia. In: Thomas, P.E.J. (Ed.), Report of the Third Soush Pacific National Parks and Reserve Conference. Volume II. Collected key issue and case study papers. South Pacific Commission, Noumea, New Caledonia. Pp. 74-78.

UNEP/IUCN (1988). Coral Reefs of the World. Volume 3. Central and Western Pacific. UNEP Regional Seas Directories and Bibliographies. IUCN, Gland, Switzerland and Cambridge, UK/UNEP, Nairobi, Kenya. 378 pp.

Date September 1983, updated January 1990

\section{RIVIERE BLEUE TERRITORIAL/PROVINCIAL PARK (PARC TERRITORIAL/PROVINCIAL DE LA RIVIERE BLEUE)}

\section{IUCN Management Category II (National Park)}

Biogeographical Province 5.06.13 (New Caledonian)

Geographical Location Located in south-central New Caledonia, and entirely enclosed within the Réserve Spéciale de Faune de Haute Yaté. The boundary is defined in Article A 1210-2 of the Code de la Protection de la Nature et de l'Environnement. Approximately $22^{\circ} 06^{\prime}$ 'S, $166^{\circ} 38^{\prime} \mathrm{E}$ 
Date and History of Establishment 3 February 1960 by Délibération 184 as part of Haute Yaté Hunting Reserve; 17 August 1972 by Arrête 72-396/CG as a complete mining reserve; 9 May 1980 by Délibération 108 as a territorial park. Law No. 88.1028 of 9 November 1988 gives the three provinces full powers in environmental matters and thus this site may be properly titled a parc provincial, although this not clear.

Area 9,054ha; included within Haute Yaté Reserve (15,900ha)

Land Tenure Public

\section{Altitude $156 \mathrm{~m}-1,250 \mathrm{~m}$}

Physical Features Comprises upper watersheds on the eastern slopes of the Montagne des Sources and is bordered by mountains up to $1,000 \mathrm{~m}$ in height. Geologically, the area forms part of the ultrabasic rock of the southern massif, with significant alluvial deposits in the valley bottom of the Rivière Bleue.

Climate Average rainfall is estimated at $3000 \mathrm{~mm}$, reaching $5000 \mathrm{~mm}$ at higher elevations.

Vegetation The park protects the most important remnant of the once extensive southern forest and its associated fauna, and includes 6,000ha of thick rain forest (Anon., 1989). The area was logged in the 1930 s and includes secondary growth. Over 400 plant species are known, of which over $80 \%$ are endemic to New Caledonia. The following vegetation zones have been distinguished: rich forest of the alluvial plain, with a dense canopy at $25-30 \mathrm{~m}$, not counting emergents such as kaori Agathis lanceolata, one of which attains $40 \mathrm{~m}$ in height; forest of the lower mountain slopes; steep slope forest from $180-500 \mathrm{~m}$ with a canopy at $15-20 \mathrm{~m}$ height; open vegetation of the lower ridges $250-450 \mathrm{~m}$, with small trees of $5-10 \mathrm{~m}$ height; high ridge scrub (maquis) above $550 \mathrm{~m}$ with conifers such as Agathis ovata, Araucaria muelleri and Dacrydium araucarioides; and scrub on ultrabasic rocks (maquis minier) typical of the southern massif. Rare species such as Libocedrus yateensis and the parasitic gymnosperm Parasitaxis ustus occur in the park.

Fauna The park is the only reserve in the country containing all the endemic bird species of New Caledonia. It is a major breeding ground, and rehabilitation site, of the endemic flightless kagu Rhynochetos jubatus (E), the sole representative of the family Rhinochetidae. The 1989 population in the park was estimated at 200 individuals. A sample plot of 1,500ha has been monitored for kagu since 1980, and the number of recorded birds has increased from 21 in 1980 to 49 in 1989, reflecting the success of sustained predator control programmes and the contribution of captively bred birds to the wild population (Anon., 1989). The park also supports the largest remaining population (20-30 individuals) of crow honey-eater Gymnomyza aubryana.

Cultural Heritage There are the relicts of lumbering which took place during the $1900 \mathrm{~s}$ (J-L. d'Auzon, pers. comm., 1990).

Local Human Population The park is uninhabited and there are no villages in the immediate vicinity.

Visitors and Visitor Facilities The number of visitors varies between 10,000 and 12,000 annually (J-L. d'Auzon, pers. comm., 1990). There is a recently constructed refuge for visitors within the park on the north bank of the Rivière Bleue, and a network of trails, including $60 \mathrm{~km}$ suitable for motor vehicles, provides easy access. The Refuge de la Rivière Blanche is located to the south of the boundary. 
Scientific Research and Facilities Research on kagu began in 1980 with a population count. A census of kagu throughout the park, and in other selected parts of the country, was conducted between September 1989 and January 1990. The first three chapters of kagu study in the park have been published, covering feeding behaviour, diet and vocal activity and protection measures. Botanical studies have also been undertaken. There are no specific facilities.

Conservation Value Particularly valued for the presence of all endemic bird species including the kagu.

Conservation Management Total legal protection, including prohibition of prospecting and mining. The kagu is totally protected by Territorial Assembly Resolution No. 387 of 26 April 1972, brought into effect by Government Council Order No. 1017 of 4 May 1972. It is forbidden to hunt, capture and hold kagus, except by special authorisation which may be granted for purposes such as scientific research. Conservation of kagu has been actively pursued throughout the 1980s, with release of captively bred birds, radio tracking and predator control (Anon., 1989).

Management Constraints Much of the valley bottom was logged earlier this century, but this ceased in 1975 and the forest is regenerating. Lake Yaté, created by a hydroelectric scheme in 1959, penetrates a short distance into the park. Further hydroelectric development within the park has recently been avoided. The kagu is threatened nationwide by introduced dogs, cats, pigs and rats and by habitat destruction.

Staff One forest officer and some labourers. The Department of Forests has assigned a full-time member of staff to the conservation of kagu.

Budget No information

Local Addresses Service de l'Environnement et Gestion des Parcs et Réserves, Direction du Développement Rural, BP 256, Noumea

\section{References}

Anon. (n.d.). Parc Territorial de la Rivière Bleue. District Forestier de Noumea. Brochure.

Anon. (1989). New Caledonia: conservation of the kagu. Case Study 11. Fourth South Pacific Conference on Nature Conservation and Protected Areas, Port Vila, Vanuatu, 4-12 September. 5 pp.

Dahl, A.L. (1983). Etude préliminaire de l'impact du projet Ouinné-Pourina sur l'environnement et en particulier sur le Parc Territorial de la Rivière Bleue. Unpublished report to Service des Eaux et Forêts, Noumea, New Caledonia. 112 pp.

Date September 1983, updated February 1991

\section{THY TERRITORIAL/PROVINCIAL PARK (PARC TERRITORIAL/PROVINCIAL DE THY)}

IUCN Management Category II (National Park)

Biogeographical Province 5.06.13 (New Caledonian) 
Geographical Location South-west New Caledonia near Noumea. The boundary is defined in Article A 1220-2 of the Code de la Protection de la Nature et de l'Environnement. Approximately $22^{\circ} 11^{\prime} \mathrm{S}, 166^{\circ} 32^{\prime} \mathrm{E}$

Date and History of Establishment 28 February 1978 by Arrête 420 as a forest reserve; 9 May 1980 by Délibération 108 as a territorial park. Law No. 88.1028 of 9 November 1988 gives the three provinces full powers in environmental matters and thus this site may be properly titled a parc provincial, although this not clear.

Area 1,133ha; contiguous to Montagne des Sources Reserve (5,878ha)

Land Tenure Public

Altitude $110 \mathrm{~m}-1,079 \mathrm{~m}$

Physical Features Comprises a steep upper watershed with distinctive microclimate, ard soils derived from both acidic (granodiorite) and ultrabasic rocks.

Climate Mean annual rainfall is some $2000 \mathrm{~mm}$.

Vegetation The chief vegetation types are rain forest, scrub and Niaouli Melaleuca quinquenervia savanna. Some 425 native vascular plants and 50 ruderals have been reported. Pteridophyta and conifers are ecologically important. Families typical of New Caledonia, for example Myrtaceae, Cunoniaceae and Araliaceae dominate the vegetation. Three of five endemic families and a third of all endemic genera are represented. There are rarities especially among the 50 orchids found in the park.

Fauna Some endemic birds occur within the park, but more specific information is not available.

Cultural Heritage No information

Local Human Population The Saint-Louis tribe live some $5 \mathrm{~km}$ from the park (J-L. d'Auzon, pers. comm., 1991).

Visitors and Visitor Facilities There is a network of marked trails and facilities for public access.

Scientific Research and Facilities A detailed botanical inventory (Brinon, 1983) has been compiled for the park.

Conservation Management The site is totally protected under forestry laws, but not protected under mining laws and mining could theoretically take place.

Management Constraints Much of the park was previously logged. There are two enclaves, covering $46 \mathrm{ha}$, in the Vallée de Thy, approached by two access roads $10 \mathrm{~m}$ wide and belonging to the Commune du Mont-Dore.

Staff None

Budget No information

Local Addresses Service de l'Environnement et Gestion des Parcs et Réserves, Direction du Développement Rural, BP 256, Noumea 


\section{References}

Brinon, H. (1983). An inventory of plants in the Thy River valley, New Caledonia. 15th Pacific Science Congress, Abstracts. 26 pp.

Date September 1983, updated February 1991

\section{YVES MERLET MARINE RESERVE (RESERVE SPECIALE MARINE YVES MERLET)}

\section{IUCN Management Category I (Strict Nature Reserve)}

Biogeographical Province 5.06.13 (New Caledonian)

Geographical Location Located on the south-western barrier reef between the Canal de la Havannah and the Passe de la Sarcelle, in the waters between the main island and the lle des Pins. The boundary comprises a five-pointed polygon, the coordinates of which are given in the Code de la Protection de la Nature et de l'Environnement. Approximately $22^{\circ} 25^{\prime} \mathrm{S}, 167^{\circ} 08^{\prime} \mathrm{E}$

Date and History of Establishment 17 July 1970 by Délibération 244, confirmed by Délibération 108 of 9 May 1980

Area 16,700 ha

\section{Land Tenure Public}

Altitude $75 \mathrm{~m}$ depth to $2 \mathrm{~m}$ above sea-level

Physical Features Includes two islets, Amere and Kié, and a complex of reefs. The reserve protects the waters and bottom of a major section of barrier reef, with a rich variety of reef types and two coral islets.

Climate No information specific to the reserve

Vegetation The islets are covered by atoll/beach forest with Araucaria columnaris. The reef and lagoon bottom are rich in algae.

Fauna Representative colonies of some of the more common species of seabird and osprey Pandion haliaetus are found. There is a great diversity of corals, fishes and other marine life. The volute Cymbiola rossiniana is found only in the area between the Ile des Pins and the Passe de Boulari.

Cultural Heritage No information

Local Human Population No information

Visitors and Visitor Facilities No information

Scientific Research and Facilities Growth rates of trochus have been studied within the reserve (Bour et al., 1982). The legislation allows for the management of the reserve to be contracted to a private research organisation. 
Conservation Value The reserve constitutes a representative sample of New Caledonia's marine heritage and is a valuable area for biological and ecological studies on reef lagoon systems (Jourde, 1985).

Conservation Management Fishing, capture and collection of all animals is prohibited. The area is out of bounds to boats either for passage or for anchoring near the islands or emergent reefs, although these regulations may be waived for traditional canoes and customary fishing activities (Jourde, 1985). Local people may visit the reserve once a year to collect trochus (UNEP/IUCN, 1988). The area is relatively undisturbed because it is too far from Noumea for weekend boat excursions, and the complex reef topography within the reserve means that the few small boats which reach it generally keep to its perimeter (P. Bouchet, in litt., 1987).

Management Constraints A traditional right of passage through the reserve is permitted. Enforcement from the mainland is difficult and fishing by people from Touaorou and Goro continues illegally (UNEP/IUCN, 1988) although not destructively (P. Bouchet, in litt., 1987).

Staff None

Budget No information

Local Addresses Service de l'Environnement et Gestion des Parcs et Réserves, Direction du Développement Rural, BP 256, Noumea

\section{References}

Bour, W., Gohin, F. and Bouchet, P. (1982). Croissance at mortalité naturelles des Trocas (Trochus niloticus L.) de Nouvelle-Calédonie. Haliotis 12:71-90. (Unseen).

Jourde, J-L. (1985). Marine reserves in New Caledonia. Report of the Third South Pacific National Parks and Reserves Conference. Volume 2. Collected key issue and case study papers. SPREP, Noumea, New Caledonia. Pp. 74-78.

UNEP/IUCN (1988). Coral Reefs of the World. Volume 3. Central and Western Pacific. UNEP Regional Seas Directories and Bibliographies. IUCN, Gland, Switzerland and Cambridge, UK/UNEP, Nairobi, Kenya. 378 pp.

Date September 1983, updated January 1990 



\section{FRANCE - WALLIS AND FUTUNA}

Area $210 \mathrm{sq} \cdot \mathrm{km}$

Population 13,000 (1986) (SPREP, 1986)

Natural increase: $4.0 \%$ (Dahl, 1986)

\section{GNP No information}

Policy and Legislation Wallis and Futuna is an Overseas Territory of France but the legal status, as provided for by Law 61-814 of 29 July 1961, gives the Territory jurisdiction in environmental affairs. As all matters relating to land tenure lie exclusively within the jurisdiction of the traditional leaders, the administration's scope of action is extremely limited. Traditional law is applied to the day-to-day settlement of local affairs. There is no written protected area legislation. As a result of population increases and the Territory's exposure to outside influences, traditional laws no longer provide a sufficient means of control to preserve the existing land and sea resources. Supplementary legislation is desirable in respect of town planning and the protection of wooded areas, the water table, water catchments and coastal zones etc. (SPREP, 1982).

The Long-term Economic and Social Development Plan, passed by the Territorial Assembly on 24 July 1979, includes a chapter on the protection of the natural heritage of the islands (Chapter 9). Two of the priorities listed are protection of the coastal zone, and protection of natural sites (Alofi Forest). Restrictions and regulations are applied to specific areas and are decreed orally by the King and the Council of Ministers and relayed by word of mouth by the district or village chiefs to their subjects. To-day, radio broadcasts are also used to disseminate such instructions (SPREP, 1985).

International Activities At the international level, France has entered into a number of obligations and cooperative agreements related to conservation. It is party to the Convention concerning the Protection of the World Cultural and Natural Heritage (World Heritage Convention) which it accepted on 27 June 1975. France became a contracting party to the Convention on Wetlands of International Importance especially as Waterfowl Habitat (Ramsar Convention) on 1 October 1986.

France signed the Convention on the Conservation of Nature in the South Pacific on 12 June 1976, and subsequently ratified it on 20 January 1989. Known as the Apia Convention, it entered into force during 1990. The Convention is coordinated by the South Pacific Commission and represents the first attempt within the region to cooperate on environmental matters. Among other measures, it encourages the creation of protected areas to preserve indigenous flora and fauna.

France also signed the Convention for the Protection of the Natural Resources and Environment of the South Pacific Region (SPREP Convention) on 25 November 1987, with ratification on 17 July 1990. The Convention entered into force during August 1990 . Article 14 calls upon the parties to take all appropriate measures to protect rare or fragile ecosystems and threatened or endangered flora and fauna through the establishment of protected areas and the regulation of activities likely to have an adverse effect on the species, ecosystems and biological processes being protected. However, as this provision only applies to the Convention area, which by definition is open ocean, it is most likely to assist with the establishment of marine reserves and the conservation of marine species. It should be noted that the instrument of Approval is accompanied by the following reservation: "The Government of the French Republic, in signing 
the present Convention, declares that, insofar as it is concerned, the prescription of the aforesaid Convention will not cover wastes and other matter entailing a level of pollution caused by radioactivity to a degree less than that prescribed by the recommendations of the International Atomic Energy Agency".

Administration and Management No department has overall responsibility for coordination of activities relating to national environmental policy.

Systems Reviews Wallis and Futuna comprises three main islands: Uvea (lles Wallis), Futuna and the uninhabited Alofi (lles de Home).

Uvea (96 sq. $\mathrm{km}$ ) is a low volcanic island, with a maximum altitude of $145 \mathrm{~m}$, with volcanic lakes and seasonal springs. It is surrounded by a barrier reef, some 3-4km offshore, with about 22 reef islets. By contrast, Futuna (80 sq. $\mathrm{km}$ ) and Alofi ( $36 \mathrm{sq} . \mathrm{km}), 250 \mathrm{~km}$ to the south-west, are mountainous, with steep slopes interrupted by a series of uplifted coral tiers, reaching $524 \mathrm{~m}$ and $416 \mathrm{~m}$, respectively.

When the islands were first settled the natural vegetation appears to have consisted largely of forest, today in great jeopardy. Still used for supplying timber for building, it has also been cleared for agricultural land. The harmful effects of systematic and localised clearing of the vegetation have been further aggravated by bushfires occurring during the dry season. In the entire low-altitude zone that is permanently settled, the primary vegetation has been radically modified by pre- and post-European plant introductions and the large-scale extensions of coconut groves.

Evergreen closed forest covered about $15 \%$ of Uvea in 1983, the remainder including secondary forest and toafa (a poor, scrubby formation) with Pandanus, grasses and ferns (Morat $e$ t al., 1983). Much of the original vegetation has been cleared for coconut, breadfruit and bananas. The establishment of two airfields and a network of roads during World War Two increased the damage described by Burrows (1937). Now only patches of forest remain in the southern central and western region. Everywhere else, the forest has been replaced by gardens, fallow areas carrying a secondary bush, and, especially in the northern half of the island, by very poor lands on which only toafa grows.

In Futuna, which is believed to have been settled earlier than Uvea, the primary forest has receded to the upper parts of the hills and into almost inaccessible gorges. About $30 \%$ of Futuna still has dense forest cover, particularly in the montane regions above $400 \mathrm{~m}$ (Davis et al., 1986), but an extensive area of the central plateau bears only the very poor toafa vegetation. The steep outer slopes running down to the coast are cleared and given over to dryland crops grown under often quite difficult conditions (SPREP, 1986).

Alofi, which is uninhabited due to the lack of reliable water supplies, continues to support primary rain forest (Dahl, 1986) on as much of $70 \%$ of its surface (SPREP, 1986). Despite this predominance, toafa vegetation exists in a few places in central areas.

Analysis of aerial photographs suggests that the limits of toafa on Uvea and Futuna have not greatly changed during the last 20-40 years, possibly due to the unsuitability of soils for further agricultural expansion. However, aerial photography also confirms the diminishing primary cover on Uvea, being replaced by perennial plantations or secondary fallow cover. Although shortening of the fallow period to less than ten years is likely to lead to the appearance of toafa vegetation, reafforestation with pines accompanied by the development of a thick undergrowth, coconut plantations and trials with fodder crops have been successful in the toafa areas of both Uvea and Futuna (SPREP, 1986). 
An account of the coral reefs, which occur extensively around Uvea and Futuna and the north-west of Alofi, is given in UNEP/IUCN (1988). The local population obtains the greater part of its protein from marine products, particularly fish, and reefs and lagoons have been heavily fished. Fishing is carried out mainly by line, net, speargun or harpoon. Deep water bottom fishing is increasing. Trochus spp. from Uvea lagoon are exported in large numbers to New Caledonia (SPREP, 1982).

Although there are no designated protected areas, the "Vao Tapu" forests are protected by customary taboos. In the Uvea districts, utilisation of the primary forest is subject to control of the customary authority, but damage appears to have increased since the mid-1960s, particularly as a result of the extension of individual houses along roads, which in turn is directly related to the increase in motor vehicles and extension of water and electricity supplies.

Despite as much as half of the population living overseas, there is a serious question over the long-term availability of land. Consequently, there is an awareness that all land requires scme form of protection. Customary leaders attempt to dissuade the sale of land to foreigners, in order to better meet the future needs of the indigenous population (SPREP, 1985). A discussion of environmental issues is given in SPREP (1982). Major problems include damage caused by semi-feral pigs, soil erosion, loss of forest on Wallis and Futuna, and overfishing around Futuna. In general, the modest level of development and inhospitable terrain, for example on Alofi, has led to few severe environmental problems. However, with increasing pressure for land, resources and development, the current situation may change rapidly.

\section{Addresses}

Chef de la Mission des Affaires intérnationales et de la Coopération, Direction de l'Espace rural/Forêt, Ministère de l'Agriculture, 1 ter Ave. de Lowendal, 75700 Paris, France

\section{References}

Burrows, E.C. (1937). Ethnology of Uvea (Wallis Island). Bulletin of the Bernice P. Bishop Museum. No. 138. 239 pp.

Dahl, A.L. (1986). Review of the Protected Areas System in Oceania. IUCN, Gland, Switzerland and Cambridge, UK/UNEP, Nairobi, Kenya. 328 pp.

Davis, S.D., Droop, S.J.M., Gregerson, P., Henson, L., Leon, C.J., Lamlein Villa-Lobos, J., Synge, H. and Zantovska, J. (1986). Plants in Danger: What do we know? IUCN, Gland, Switzerland and Cambridge, UK. 488 pp.

Morat, P. Veillon, J.M. and Hoff, M. (1983). Introduction à la végétation et à la flore du territoire de Wallis et Futuna. ORSTOM, Nouméa, New Caledonia. 24 pp. (Unseen).

SPREP (1982). Wallis and Fortuna Islands. Country Report 19. South Pacific Commission, Noumea, New Caledonia. 14 pp.

SPREP (1985). Wallis and Futuna. In: Thomas, P.E.J. (Ed.), Report of the Third South Pacific National Parks and Reserves Conference. Volume III. Country reviews. South Pacific Commission, Noumea, New Caledonia. Pp. 229-231.

SPREP (1986). Wallis and Futuna: man against the forest. South Pacific Stucty No. 2. South Pacific Commission, Noumea, New Caledonia. 6 pp.

UNEP/IUCN (1988). Coral Reefs of the World. Volume 3. Central and Western Pacific. UNEP Regional Seas Directories and Bibliographies. IUCN, Gland, Switzerland and Cambridge, UK/UNEP, Nairobi, Kenya. 378 pp. 


\section{SUMMARY OF PROTECTED AREAS}

\begin{tabular}{|c|c|c|c|}
\hline Name of area & $\begin{array}{l}\text { IUCN management } \\
\text { category }\end{array}$ & $\begin{array}{r}\text { Area } \\
\text { (ha) }\end{array}$ & $\begin{array}{c}\text { Year } \\
\text { notified }\end{array}$ \\
\hline \multicolumn{4}{|l|}{ Forest Reserves } \\
\hline Wallis Toafa & Unassigned & 75 & \\
\hline \multicolumn{4}{|l|}{ Unclassified } \\
\hline Lalolalo Vao Tupu (Forbidden Forest) & I & 30 & \\
\hline
\end{tabular}

* Site is described in this directory.

NB: Due to the absence of any legally gazetted protected areas in Wallis and Futuna no map is provided. 


\section{REPUBLIC OF KIRIBATI}

Area The total land area is approximately $684 \mathrm{sq} . \mathrm{km}$, scattered over more than 5 million sq. $\mathrm{km}$ of ocean.

Population 66,250 (1987 estimate) (Paxton, 1990)

Natural increase: $2.1 \%$ (Dahl, 1986)

GNP US\$ 649 per capita (1988)

Policy and Legislation In 1980 the Government of Kiribati published a statement of its policy concerning nature conservation in the Line and Phoenix Islands. This recognised the need to integrate conservation and development with respect to the islands' natural resources. The role of conservation was defined in terms of providing for the present and future social and economic needs of the country (Garnett, 1983).

The legal basis for nature conservation is the Wildlife Conservation Ordinance (1975), amended in 1979. Under the new Ordinance, the 1938 Gilbert and Ellice Islands Colony Wild Birds Protection Ordinance was repealed and the status of bird sanctuaries was changed to wildlife sanctuaries. The 1975 Ordinance makes, inter alia, the following provisions. First, all 31 regularly occurring bird species, and their nests and eggs, are fully protected throughout Kiribati. All turtles are fully protected on land, although it is not clear from the legislation whether protection extends to marine areas. Secondly, under Section $8(1)$, wildlife sanctuaries may be declared and closed areas may be declared within such wildlife sanctuaries. Thirdly, Section 11 provides wildlife wardens with powers of search and arrest.

This current legislation is weak, because measures for the protection of vegetation, prohibiting the introduction of plants and animals, preventing fire, removal of soil, and dumping of refuse, and the control of vehicles are lacking. In particular, there is a lack of effective protection for wildlife sanctuaries, within which it is possible to clear vegetation without contravening the law. It would seem that under current legislation, the only areas adequately protected are those additionally designated as closed areas.

It should be noted that although Article 14(1) of the Constitution guarantets freedom of movement, restrictions required in the interests of environmental conservation are deemed not to be in contravention of the Article.

Prior to contact with Europeans, land owners in Kiribati held tenure of reefs and lagoons adjacent to their lands and had exclusive rights to fisheries and passage. Most land, particularly in the South Gilberts, was owned by groups of extended families (utu) who lived in small, scattered hamlets (kaainga), although in the northern atolls the ruling king had control of a large area of land, reefs and lagoons and dispensed fishing rights to the various clans in the domain. In the late 19 th century this system began to break down: under British colonial rule, sea tenure per se was not recognised, although there was an attempt to modify traditional fishing rights and the government did recognise tenure of fish weirs, reclaimed areas, fish ponds and other accretions (Zann, 1985). However, there are still a number of laws and customs regulating different aspects of fishing activities on many of the atolls. These are frequently formulated and applied by individual Island Councils.

International Activities Kiribati is not yet party to any of the international conventions or programmes that directly promote the conservation of natural areas, namely the Convention 
concerning the Protection of the World Cultural and Natural Heritage (World Heritage Convention), Unesco Man and Biosphere Programme and the Convention on Wetlands of International Importance especially as Waterfowl Habitat (Ramsar Convention).

At a regional level, Kiribati has not ratified the Convention on the Conservation of Nature in the South Pacific, 1976. Known as the Apia Convention, it entered into force during 1990. The Convention is coordinated by the South Pacific Commission and represents the first attempt within the region to cooperate on environmental matters. Among other measures, it encourages the creation of protected areas to preserve indigenous flora and fauna.

Kiribati is party to the South Pacific Regional Environment Programme (SPREP) but has not ratified the Convention for the Protection of the Natural Resources and Environment of the South Pacific Region, 1986 (SPREP Convention). The Convention entered into force during August 1990. Article 14 calls upon the parties to take all appropriate measures to protect rare or fragile ecosystems and threatened or endangered flora and fauna through the establishment of protected areas and the regulation of activities likely to have an adverse effect on the species, ecosystems and biological processes being protected. However, as this provision only applies to the Convention area, which by definition is open ocean, it is most likely to assist with the establishment of marine reserves and the conservation of marine species.

Other international and regional conventions concerning environmental protection to which Kiribati is party are reviewed by Venkatesh $\mathrm{et} \mathrm{al.} \mathrm{(1983).}$

Administration and Management The Wildlife Conservation Unit, established in 1977 under the Ministry of the Line and Phoenix Islands and based on Kiritimati, is the only Government division responsible for conservation management in the Line and Phoenix Islands (Garnett, 1983). In 1985 the Unit comprised one wildlife warden and two assistants. The bulk of the Unit's work is on Kiritimati; the other sanctuaries being protected by their remoteness (SPREP, 1985a). The Unit has as its principal responsibilities enforcement of the Wildlife Conservation Ordinance, education/public awareness, survey and research, advice to governments, control of introduced species, and tourism, though it is not the only agency concerned in each of these activities. There is no administrative body responsible for conservation in the Gilbert Islands.

Systems Reviews The Republic of Kiribati comprises all the Gilbert and Phoenix Islands, eight of the eleven Line Islands (the other three, Jarvis, Palmyra and Kingman Reef being dependencies of the USA) and Banaba (Ocean Island), lying approximately between longitudes $169^{\circ} \mathrm{E}$ and $147^{\circ} \mathrm{W}$ and latitudes $5^{\circ} \mathrm{N}$ and $12^{\circ} \mathrm{S}$. The islands extend nearly $5,000 \mathrm{~km}$ from east to west and straddle both the Equator and the International Date Line. All the islands are low-lying coral atolls (UNEP/IUCN, 1988), rising to no more than 3-4m above mean sea level, with the exception of Banaba which is a raised reef.

Most of the natural vegetation of the larger islands has been replaced by coconut plantations, breadfruit and Pandanus spp. (Davis et al., 1986). However, considerable ecological diversity remains on the different islands, largely because they fall within a zone of steep rainfall gradients. Thus, Kiritimati has tracts of open scrub and grassland, whilst Teraina, $380 \mathrm{~km}$ to the north-west, has a freshwater lake surrounded by peat bogs and woodland rich in epiphytes and fern undergrowth (Perry, 1980). There is relatively little information on the marine environment, although reefs at Tabuaeran, Teraina, Tarawa and Onotoa have been described (UNEP/IUCN, 1988).

The current protected areas network comprises wildlife sanctuaries covering the whole of three of the Phoenix Islands and four of the Line Islands. In addition, closed areas have been established 
within Kiritimati Wildlife Sanctuary, and covering all of Malden and Starbuck islands. There are no protected areas in the Gilbert Islands.

Most habitats found in Kiribati are represented in the protected areas system, although five are omitted: Guettarda forest; Pemphis acidula scrub; freshwater marsh; freshwater lake; and brackish lagoon. The existing network includes some of the most important sea bird colonies in the Pacific (Hay, 1986).

The most profound threat, both to protected areas and the country as a whole, lies in the putative rise in sea levels, caused by global climatic warming. This could lead to salinisation of freshwater aquifers, increased erosion and possibly inundation rendering the country uninhabitable (Pernetta, 1988). Alien species introduced by man affect all islands in the Line Group, with the exception of Vostok Island. Feral cats, which may number up to 2,000 on Kiritimati, have driven 10 or 11 bird species (out of 18 ) to nest only on isolated islets (Perry, 1980). Cats appear to be increasing in numbers, and bird populations are also threatened by poaching, especially red-tailed tropic bird Phaethon rubricauda, red-footed booby Sula sula and masked booby Sula dactylatra. Many new vehicles have been brought to the island, facilitating much greater human access to the bird colonies (E.A. Schreiber, pers. comm., 1989). Exotic plant species have been extensively introduced. Although the majority may have no effect on sea birds, a few may be deleterious. Other natural threats include periodic droughts (Dahl, 1986) and climatic perturbations such as the El Niño Southern Oscillation (ENSO). The latter is believed responsible for the precipitous decline in sea bird populations on Kiritimati in 1982-83 (Schreiber and Schreiber, 1984). The 1986-1987 ENSO set back the recovery of bird populations from the 1982-1983 ENSO (E.A. Schreiber, pers. comm., 1989)

An Action Strategy for Protected Areas in the South Pacific Region (SPREP, 1985b) has been developed. The principal goals of the strategy cover conservation education, conservation policy development, establishment of protected areas, protected area management and regional and international cooperation. Priority recommendations for Kiribati are as follows: formulate a national conservation strategy; and implement the Feral Animal Eradication Programme on Kiritimati. Proposals for a cat eradication programme were prepared by the Wildlife Conservation Unit in 1983 in conjunction with the New Zealand Wildlife Service (SPREP, 1985a). However, this has not yet been implemented (UNEP/IUCN, 1988).

Dahl (1980) recommends both the upgrading of the existing network and the establishment of new reserves, to include appropriate samples of atoll, forest, marine and lagoon environments. This would entail a communication link and surveillance centre on Kanton, retaining the extant reserves on Birnie, McKean and Rawaki (Phoenix) and creating new sites on Enderbury, Orona and possibly Manra. Most of the Line Islands, in particular Caroline and Malden, are considered candidates for reserve status, especially if existing predators can be controlled. Flint, Caroline, Kanton and Enderbury require protection as turtle breeding areas. The bogs, and possibly the lake on Tabuaeran, including adequate areas of Polynesian warbler habitat, should be protected, in addition to seabird breeding areas (Dahl, 1980).

Garnett (1983) makes a comprehensive set of recommendations, principally covering Kiritimati, which addresses aspects of legislation, development and land use planning, and conservation management. Specific recommendations include: amending Section 8 of the 1975 Wildlife Conservation Ordinance to give adequate protection to important ecosystems; gazetting Enderbury Island as a wildlife sanctuary and closed area; upgrading Birnie, McKean, Rawaki and Vostok islands to closed area status; and designating specific areas on Kiritimati as wildlife 
sanctuaries and closed areas, as opposed to the whole island as is currently the case (Gamett, 1983).

Dahl (1986) notes that there are no protected areas in the Gilbert Islands and suggests that small forested islands with seabird rookeries on Butaritari and Nonouti might be considered for reserves under local management. Marine reserves may be required for fisheries management. The principal omissions from the protected areas systems are bogs in the Line and Phoenix Islands and other natural habitats on Teraina (Dahl, 1986).

\section{Addresses}

The Director, Wildlife Conservation Unit, Kiritimati

\section{References}

Dahl, A.L. (1980). Regional ecosystems survey of the South Pacific area. SPC/IUCN Technical Paper 179. South Pacific Commission, Noumea, New Caledonia. 99 pp.

Dahl, A.L. (1986). Review of the Protected Areas System in Oceania. IUCN, Gland, Switzerland and Cambridge, UK/UNEP, Nairobi, Kenya. 328 pp.

Davis, S.D., Droop, S.J.M., Gregerson, P., Henson, L., Leon, C.J., Lamlein Villa-Lobos, J., Synge, H. and Zantovska, J. (1986). Plants in Danger: What do we know? IUCN, Gland, Switzerland and Cambridge, UK. 488 pp.

Douglas, G. (1969). Checklist of Pacific Oceanic Islands. Micronesica 5(2): 327-463.

Fosberg, F.R. (1953). Vegetation of central Pacific atolls. Atoll Research Bulletin 23: 1-26. (Unseen)

Garnett, M.C. (1983). A management plan for nature conservation in the Line and Phoenix Islands. Two volumes. Unpublished. $436 \mathrm{pp}$.

Hay, R. (1986). Bird conservation in the Pacific Islands. ICBP Study Report No. 7. International Council for Bird Preservation, Cambridge, UK. 102 pp.

Pernetta, J.C. (1988). Projected climate change and sea level rise: a relative impact rating for countries of the South Pacific Basin. In: MEDU joint meeting of the task team on the implications of climatic change in the Mediterranean. Split, Yugoslavia, 3-7 October. Pp. 1-11.

Paxton, J. (Ed.). (1990). The Statesman's Yearbook. 127th Edition. Macmillan Press, London. $1690 \mathrm{pp}$.

Perry, R. (1980). Wildlife Conservation in the Line Islands, Republic of Kiribati (formerly Gilbert Islands). Environmental Conservation 7: 311-318.

Schreiber, R.W. and Schreiber, E.A. (1984). Central Pacific seabirds and the El Niño Southern Oscillation: 1982-1983 perspectives. Science 225: 713-716.

SPREP (1985a). Kiribati. In: Thomas, P.E.J. (Ed.), Report of the Third South Pacific National Parks and Reserves Conference. Volume III. Country reviews. South Pacific Commission, Noumea, New Caledonia. Pp. 115-124.

SPREP (1985b). Action strategy for protected areas in the South Pacific Region. South Pacific Commission, Noumea, New Caledonia. 24 pp.

UNEP/IUCN (1988). Coral Reefs of the World. Volume 3. Central and Western Pacific. UNEP Regional Seas Directories and Bibliographies. IUCN, Gland, Switzerland and Cambridge, UK/UNEP, Nairobi, Kenya. 378 pp.

Venkatesh, S., Va'ai, S. and Pulea, M. (1983). An overview of environmental legislation in the South Pacific countries. SPREP Topic Review No. 13. South Pacific Commission, Noumea, New Caledonia. 63 pp 
Zann, L.P. (1985). Traditional management and conservation of fisheries in Kiribati and Tuvalu atolls. In: Ruddle, K. and Johannes, R.E. (Eds), The traditional knowledge and management of coastal systems in Asia and the Pacific. Unesco/ROSTEA, Jakarta. Pp. 53-77.

\section{ANNEX \\ Definitions of protected area designations, as legislated, together with authorities responsible for their administration}

\section{Title (English): Wildlife Conservation Ordinance}

Date: 1975, amended in 1979

Brief description: Under the Ordinance the 1938 Gilbert and Ellice Islands Colony Wild Birds Protection Ordinance was repealed and the status of bird sanctuaries was changed to wildlife sanctuaries.

Administrative authority: The Director, Wildlife Conservation Unit, Kiritimati

Designation:

Wildlife sanctuary Under Section 8(1), the Minister of the Line and Phoenix Islands, after consultation with the Council of Ministers, may declare any area to be a wildlife sanctuary. Under Section 8(2), it is stipulated that "no person shall in a wildlife sanctuary hunt, kill or capture any bird or other animal (other than a fish) or search for, take or wilfully destroy, break or damage the eggs or nest of any bird or other animal, except under and in accordance with the terms of a valid written licence granted to that person by the Minister under this section".

Closed area The Ordinance makes further provision by allowing closed areas to be declared within wildlife sanctuaries. With the exception of appropriate officials and licensed individuals, entry into a closed area is prohibited under Section 8(6). 
SUMMARY OF PROTECTED AREAS

\begin{tabular}{llrrr}
\hline $\begin{array}{l}\text { Map }^{\dagger} \\
\text { ref. }\end{array}$ & Name of area & $\begin{array}{c}\text { IUCN management } \\
\text { category }\end{array}$ & $\begin{array}{r}\text { Area } \\
\text { (ha) }\end{array}$ & $\begin{array}{c}\text { Year } \\
\text { notified }\end{array}$ \\
\hline & Closed Areas & & & \\
1 & Cook Islet Closed Area (Kiritimati WS) & I & 3 & 1975 \\
2 & Motu Tabu Islet Closed Area (Kirimati WS) & I & 1 & 1975 \\
3 & Motu Upua Closed Area (Kiritimati WS) & I & 4 & 1975 \\
4 & Ngaontetaake Islet Closed Area & I & 2 & 1979 \\
& $\quad$ (Kiritimati WS) & & & \\
& Wildlife Sanctuaries & & & \\
5 & Birnie Island* & IV & 20 & 1975 \\
6 & Kiritimati* & Unassigned & 32,100 & 1960 \\
7 & Malden Island (Closed Area)* & I & 3,930 & 1975 \\
8 & McKean Island* & IV & 57 & 1975 \\
9 & Phoenix Island (Rawaki)* & IV & 6,500 & 1975 \\
10 & Starbuck (Closed Area)* & I & 16,200 & 1975 \\
11 & Vostok Island* & IV & 24 & 1979 \\
\hline
\end{tabular}

* Site is described in this directory.

t Locations of most protected areas are shown in the accompanying map. 


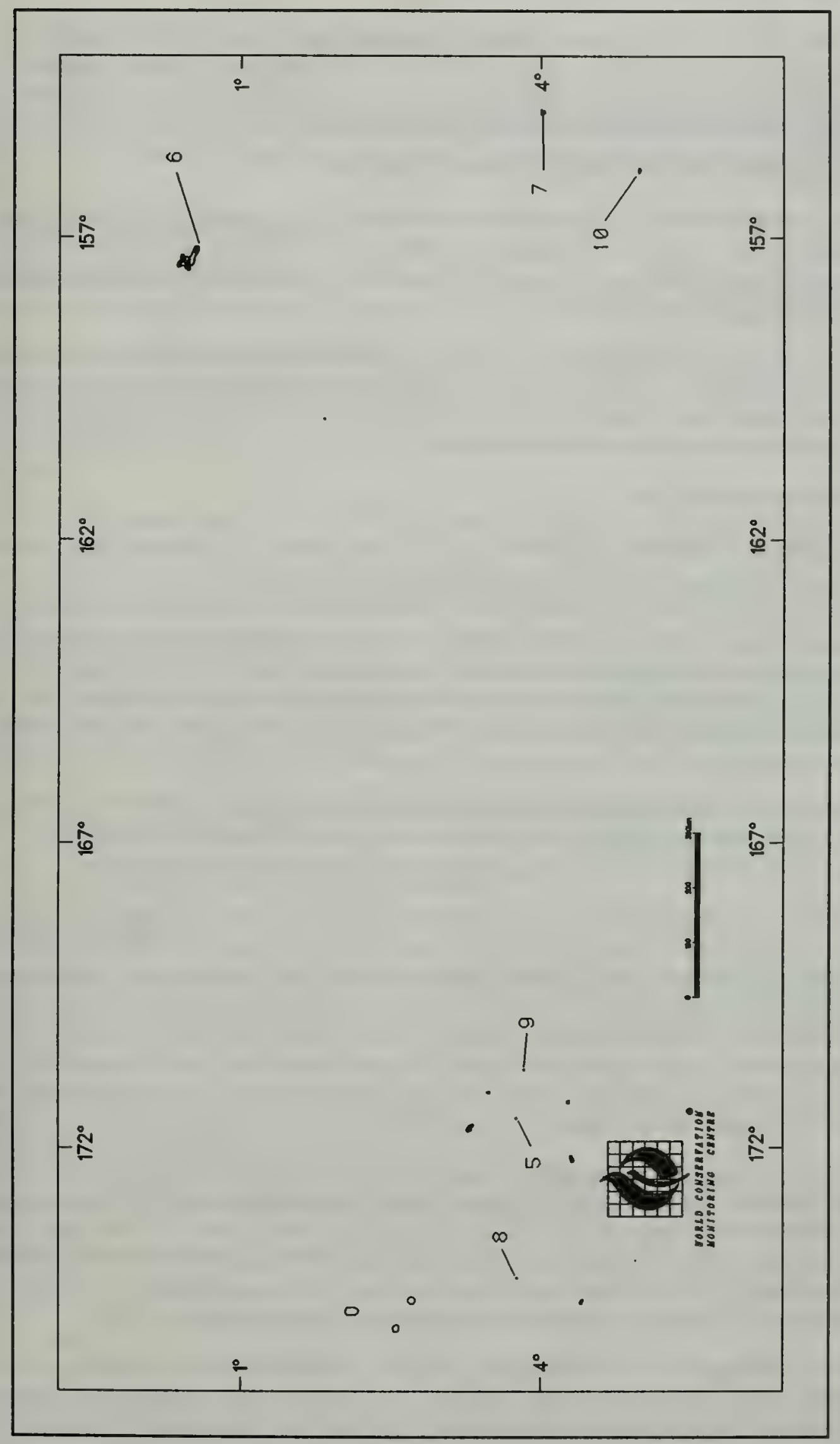

Protected Areas of the Republic of Kiribati 


\section{BIRNIE ISLAND}

\section{IUCN Management Category IV (Managed Nature Reserve)}

\section{Biogeographical Province 5.05.13 (Central Polynesian)}

Geographical Location Located in the Phoenix Islands, in the central Pacific, and encircled by five other islands. These are Kanton Island $80 \mathrm{~km}$ south-south-east, Enderbury Island $67 \mathrm{~km}$ south-west, Rawaki $90 \mathrm{~km}$ west, Maura $100 \mathrm{~km}$ north-north-west and Oronoa $120 \mathrm{~km}$ north-east. Approximately $3^{\circ} 35^{\prime} \mathrm{S}, 171^{\circ} 33^{\prime} \mathrm{W}$

Date and History of Establishment 21 June 1938. The island was declared a bird sanctuary under the Gilbert and Ellice Islands Colony Wild Birds Protection Ordinance. This protected status was reconfirmed under the 1975 Wildlife Conservation Ordinance when the area was re-designated as a wildlife sanctuary in 1975.

Area Approximately $20 \mathrm{ha}$

\section{Land Tenure Government of Kiribati}

Altitude Ranges from sea level to $4 \mathrm{~m}$ on the eastern beach crest.

Physical Features This is the smallest of the Phoenix Islands, measuring only $1.2 \mathrm{~km}$ by $0.5 \mathrm{~km}$. A small, shallow, land-locked saline lagoon which, despite being stream-fed often completely dries out, occupies a depression in the south-east. The northern half of the island is flat, fairly smooth and covered in uniform vegetation. The east coast is rocky and consists of a steep beach of coral sandstone and coral fragments whilst the west coast is low and sandy (Garnett, 1983a).

Climate No data specific to the island are available. Birnie is one of the drier Phoenix Islands, with an inferred mean annual rainfall of between $600 \mathrm{~mm}$ and $800 \mathrm{~mm}$ or less, owing to the high ground-surface albedo. The prevailing winds are easterly trades (Garnett, 1983a).

Vegetation The vegetation cover is considered to be of international significance (Garnett, 1983b). It is extremely simple and much of the island is covered uniformly by low herbs, dominated by Portulaca lutea and some Boerhavia albiflora. These occur as pure stands, or in varying codominant mosaics. The beach, beach crest and lagoon flats have either sparse or no vegetation cover, whilst the lagoon shoreline has an interrupted strip of uniform Sesuvium portulacastrum. This also occurs in a number of shallow depressions. Scattered dwarf scrub Sida fallax and bunch grass, probably Lepturus sp., have been recorded but have since become locally extinct. There are no trees or shrubs (Garnett, 1983a).

Fauna Polynesian rat Rattus exulans is the only mammal. Six species of seabird breed, but none in large numbers. Populations of 100 brown booby Sula leucogaster and 100 blue-grey noddy Procelsterna cerulea are considered to be nationally important, whilst $350-800$ masked booby Sula dactylatra may be internationally important. Other breeding and non-breeding species are listed in Garnett (1983a). Green turtle Chelonia mydas (E) nests on the island. Invertebrates are poorly studied, but include a mite and two parasitic fly species (Garnett, 1983a).

Cultural Heritage No archaeological remains or artefacts have been found, and the only evidence to suggest prehistoric visits by Polynesian or Micronesian voyagers is the presence of Polynesian rat, introduced at an unknown date. The island was discovered by Europeans in 1823 and named after an Australian merchant. Birnie was bonded under the 1856 American Guano 
Act on 8 February 1860, and was formally placed under British protection on $10 \mathrm{July} 1889$. The rights to exploit the island passed through a number of commercial concerns in the 19th and early 20 th century, although no activities were undertaken. Colonisation by Gilbert and Ellice Islanders was considered in 1937, but not implemented. Since an unsuccessful attempt to establish coconut palms in 1939, the island has remained uninhabited, unused and only seldom visited (Garnett, 1983a).

\section{Local Human Population Uninhabited}

Visitors and Visitor Facilities Few people have ever visited the island. There is no anchorage, but landings can be made on the sandy west coast in normal easterly weather (Garnett, 1983a).

Scientific Research and Facilities Only limited research has been undertaken and there are no facilities. A bibliography is given in Garnett (1983a).

Conservation Value The island is valued for its vegetation, supersaline lagoon, bird and turt'e populations.

Conservation Management The Wildlife Conservation Unit, based on Kiritimati, has administrative responsibility for the sanctuary. Current legislation makes no provision for the protection of habitat although the island particularly requires protection due to extreme ecological simplicity which confers a natural fragility (Garnett, 1983b). Details about management activities are not available, although the remoteness and inhospitable nature of the island are its major source of protection. Garnett (1983b) recommends the erection of multilingual noticeboards advising visitors, for example long-distance yachtsmen and fishermen from Japanese, Taiwanese and Korean fleets which are active in the region, of the importance of the island for science and nature conservation, and of the wildlife laws.

Management Constraints Active law enforcement programmes are impractical, due to the island's remoteness (Garnett, 1983b).

Staff No staff are assigned specifically to the sanctuary.

Budget No information

Local Addresses Wildlife Conservation Unit, Ministry of the Line and Phoenix Islands, Kiritimati

\section{References}

Gamett, M.C. (1983a). A management plan for nature conservation in the Line and Phoenix Islands. Part 1 Description. Unpublished. Pp. 129-138.

Gamett, M.C. (1983b). A management plan for nature conservation in the Line and Phoenix Islands. Parts 2 and 3. Policy and Recommendation. Unpublished. 131 pp.

Date June 1985, revised December 1988 


\section{KIRITIMATI (CHRISTMAS ISLAND) WILDLIFE SANCTUARY}

IUCN Management Category No category assigned to the wildlife sanctuary as a whole. Cook Island, Motu Tabu, Ngaon te Taake, North-west Point and Motu Upua closed areas are Category I (Strict Nature Reserve).

\section{Biogeographical Province 5.04.13 (Southeastern Polynesian)}

Geographical Location Kiritimati is located about $285 \mathrm{~km}$ south-west of Tabuaeran, $670 \mathrm{~km}$ north-north-west of Malden Island, 2,500km south of Honolulu and 2,700km north of Tahiti. Approximately $2^{\circ} 00^{\prime} \mathrm{N}, 157^{\circ} 20^{\prime} \mathrm{W}$

Date and History of Establishment 20 December 1960. Christmas Island was gazetted as a bird sanctuary under the 1938 Gilbert and Ellice Islands Colony Wild Birds Protection Ordinance. The three principal lagoon islets of Cook Island, Motu Tabu and Motu Upua were declared reserves with restricted access. Under the 1975 Wildlife Conservation Ordinance the entire island was re-gazetted as a wildlife sanctuary on 29 May 1975, with five areas designated as closed areas.

Area 32,100ha (Cook Island 19ha, Motu Tabu 3.5ha, Ngaontetaake 27ha, Motu Ubua 19-20ha)

\section{Land Tenure State}

\section{Altitude From below sea level to $13 \mathrm{~m}$}

Physical Features Kiritimati has the largest land area of any coral atoll in the world, with an approximately equal area of saltwater and supersaline lagoons. In common with the other northern Line Islands, it was formed between the Cretaceous and Eocene divisions of the late Mesozoic and early Caenozoic periods as part of a line of submarine volcanoes, and consists of coral and other biogenic formations overlying volcanic rocks. The coral overlay varies from $30 \mathrm{~m}$ to $120 \mathrm{~m}$ in depth. The single, large, flat island is D-shaped, with a stem oriented south-east, and has a large tidal lagoon, covering $160 \mathrm{sq} . \mathrm{km}$, opening to the north-west. The eastern end of this lagoon consists of several hundred smaller land-locked lagoons, occupying $168 \mathrm{sq} . \mathrm{km}$, delimited by causeways and larger tracts of land. The lagoon system is extensive, with considerable variation in water area, and unique to the Line and Phoenix Group. These tidal and land-locked lagoons contain hundreds of islets which are critical to the seabird breeding colonies, the three principal ones being Cook, Motu Tabu and Motu Upua. Extensive intertidal mudflats also occur. There are substantial areas of fossil reef and rubble scree, as well as beach-rock. The island reaches $7-13 \mathrm{~m}$ in height along the north coast of the South-east Peninsula, where there are dunes. Gamett (1983a) classifies, and briefly describes, 13 different physical units, namely: seaward reef; seaward beach; beach crest, coastal dunes and boulder rampart; coastal plain; central ridge and inland dunes; lagoon scarp and lagoon dunes; lagoon flats and beach; and lagoon reef. Freshwater lenses occur, with salinity varying between 0 and $3,500+\mathrm{ppm} \mathrm{Cl}$, and with a water table generally between 0 and $2 \mathrm{~m}$ depth.

Soil development is poor due to the limited supply of organic matter. Variously described as entisols, lithosols or regosols, they are composed of more or less chemically unaltered tests of foraminifera and shell fragments of molluscs, coral and other marine animals. Garnett (1983a) distinguishes several soil types, principally by fragment size. These include oceanic deposits comprising coral sands, gravel, rubble and coral rubble in varying textures and locations, and lagoon deposits, composed of lagoon mud with, and without, hardpan. A reef platform extends 
$30 \mathrm{~m}$ to $120 \mathrm{~m}$ from the shoreline around the whole island, being widest along northerly coasts. The seaward margin is characterised by a spur and groove formation which is most strongly developed on the lee side of the island. Along the windward coast, and especially in the Bay of Wrecks, there are ridges, covered with red-purple algae, which are emergent at low tide. On the sheltered eastern side of the main lagoon, the lagoon reef is moderately well developed. Elsewhere, the high turbidity and rate of sedimentation inhibits coral growth. Patch reefs and coral heads are found in the western part of the main lagoon where conditions are favourable (Garnett, 1983a).

Climate Kiritimati lies within the equatorial dry zone. Mean annual rainfall is $873 \mathrm{~mm}$, varying widely between a minimum and maximum of $177 \mathrm{~mm}$ and $2621 \mathrm{~mm}$, respectively. Rainfall is usually heaviest in March and April, and lightest in October and November. The temperature is constant, ranging diurnally between $24^{\circ} \mathrm{C}$ and $30^{\circ} \mathrm{C}$, with little seasonal variation. The relative humidity is unfluctuating at about $70 \%$, maintained by constant easterly trade winds which blow perennially at a mean speed of $14 \mathrm{kph}$ (Garnett, 1983a).

Vegetation The vegetation is generally not vigorous and, due to the island's extremely remote position and harsh environment, is low in diversity. Garnett (1983a) lists some 69 species, whilst Dahl (1986) gives figures of 18-41 native species and 50 introductions. Perry (1980) discusses the introduction of alien species, most of which arrived in the 20th century. Native vegetation generally follows a regular pattern from ocean coast to the lagoon, and is closely correlated with soil type, depth and salinity, factors which are themselves closely correlated. Communities may be broadly defined as forest, scrub, dwarf scrub, grassland and herb communities. Indigenous forest is restricted to three small $P$ isonia grandis groves, attaining $10 \mathrm{~m}$, at South-east Point, Motu Tabu and near North-west Point.

The dominant scrub found over most of the island, on all landform types, is Scaevola taccada, in either pure stands or with Messerschmidia argentea and Suriana maritima. Lower lagoon flats are dominated by Suriana, growing to a maximum height of $2 \mathrm{~m}$. Messerschmidia is found on all landform types, but most commonly on the beach ridge, coastal plain and lagoon shores. Sida fallax, reaching $2 \mathrm{~m}$, is abundant on the coastal plain to the south, and on sandy soils elsewhere. Heliotropum anomalum forms a dwarf scrub on beach ridges and boulder ramparts, mixed with sparse Portulaca lute $a$ and $P$. oleracea, and elsewhere. Extensive Sida dwarf scrub, mixed with Heliotropium, Boerhavia repens, Portulaca, Cassytha filiformis and Lepturus repens, is found in the South-east Peninsula and southern coastal plains. Lepturus-dominated grasslands cover large areas of the coastal plains, excluding the South-east Peninsula. A number of other species, viz. Boerhavia, Portulaca, Cassytha, Tribulus, Heliotropium, scattered clumps and individual bushes of Messerschmidia and Scaevola also occur, giving the appearance of a savannah. The principal herbaceous community is dense Sesuvium pertulacastrum mat which frequently covers the low-lying, waterlogged lagoon shore soils.

Approximately $52 \mathrm{sq} . \mathrm{km}$ in the west have been planted with coconut palm Cocos nucifera (Dahl, 1986). A variety of introduced plants occurs around villages, old nuclear bomb test installations and other disturbed areas (Garnett, 1983a). A total of 18 species is believed to be indigenous, and a species list is given in Garnett (1983a). Most formations and some half dozen species are considered to be of international, or national importance (Garnett, 1983b). Cuscuta campestris is endemic (Dahl, 1986). Distribution maps are included in Garnett (1983a).

Fauna Polynesian rat Rattus exulans is widespread and abundant, occurring on the mainland and many of the small islets. Black rat $R$. rattus has been recorded in the past, but apparently no longer persists. Small numbers of feral pig occur, although numbers have declined recently due 
to eradication programmes (Garnett, 1983b). Feral cats are widespread, with a distribution closely correlated with that of nesting seabirds (Garnett, 1983a).

Thirty-seven bird species, listed in Garnett (1983a), occur, with nineteen breeding. Kiritimati has the widest variety and some of the largest populations of tropical seabirds anywhere in the world. However, 11 out of the 18 resident seabird species are restricted to nesting on islets due to predation by cats. The most noteworthy species, according to Dahl (1986), include sooty tem Sterna fuscara, which nests in a number of discrete colonies on Cook Island, North-west Point, Paris Peninsula and at various localities on the South-east Peninsula. The total population was estimated at 15 million birds in the 1960s. This has since declined to 4-6 million, but remains the largest known population in the world. An estimated 100,000 pairs of sooty tern nested on Cook Islet every six months in the past, but since 1982 fewer than 3,000-8,000 adults have been present each nesting season. Predation by cats and frigate birds has subsequently limited the reproductive success of this species (Schreiber and Schreiber, 1987). Phoenix petrel Pterodroma alba breeds only on islets in the main and land-locked lagoons, but the population of 20,000 to 25,000 birds is still the largest known. Approximately one million wedge-tailed shearwater Puffinus pacificus, the largest population in the Pacific and possibly the world, breed in scattered colonies in the remoter parts of the mainland and on islets. Black shearwater Puffinus nativitatus nests only on lagoon islets and numbers 6,000 to 15,000 individuals. Christmas Island warbler Acrocephalus aequinoctialis has a restricted distribution, being most abundant at the western end of the island, with a population of approximately 1,000 individuals (Garnett, 1983a). This species only occurs elsewhere on Tabuaeran (Collar and Andrew, 1988). Internationally significant populations of a number of other species occur, including white-throated storm petrel Nesofregetta albigularis, red-tailed tropicbird Phaethon rubricauda, masked booby Sula dactylatra, great frigate bird Fregata minor, lesser frigate bird $F$. ariel, grey-backed tern Sterna lunata and blue-grey noddy Procelsterna cerulea (Gamett, 1983a), although to a greater or lesser extent all bird populations have remained relatively low since the 1982-83 ENSO (Schreiber and Schreiber, 1987) and the populations of most species remain below 1981 levels (E.A. Schreiber, pers. comm., 1989). Seabird population estimates for 1982-83 and 1984 are given in Schreiber and Schreiber (1986b). Threatened scarlet-breasted lorikeet Vini kuhlii has been introduced but remains scarce, and is globally threatened (Collar and Andrew, 1988). Frequently-observed migrants include golden plover Pluvialis dominica, turnstone Arenaria interpres, bristle-thighed curlew Numenius tahitiensis $(\mathrm{R})$ and wandering tattler Heteroscelus incanus.

A small population of green turtle Chelonia mydas $(\mathrm{E})$ is present, sporadically nesting on beaches in the Bay of Wrecks and between Poland and Paris villages. Mourning gecko Lepidodactylus lugubris and snake-eyed skink Ablepharus boutonii are abundant and widespread. The only other recorded reptile species is stump-toed gecko Gehyra mutilata.

Noteworthy invertebrates include land crab Cardisoma carnifex and land hermit crab Coenobita perlata, both of which are abundant and widespread. Land crab Geograpsus grayii is also widely found. Coconut crab Birgus latro $(R)$ is present, occurring infrequently in coconut plantations near Poland village. Ghost crabs Ocypode spp. are abundant on sandy beaches. Spiny lobster Panulirus sp. is present on the reef. No detailed studies have been made of the insect fauna, which is probably impoverished owing to the dry climate and paucity of vegetation (Garnett, 1983a). Plant and animals species lists are given in Garnett (1983a).

Cultural Heritage Archaeological research (Emory, 1934) indicates that Kiritimati was visited by Polynesians during prehistory, but not settled for any prolonged period. Remains include two sites which may have been villages, and a number of stone structures. The island was discovered by Captain James Cook on 24 December 1777, and named Christmas Island following his 
landing the next day. Kiritimati was bonded under the 1856 American Guano Act on 20 June 1858 , after which it was sporadically exploited for phosphate. A British claim was made on 17 April 1882, since when the island has been occupied more or less continuously. By 1886, some 18,000-20,000 coconut palms had been planted, and 200 tons of pear shell exported. Formal British possession was established on 17 March 1888. A number of commercial concerns were licensed to exploit the island, with some 70,000 coconut palm planted at the turn of the century, although only $25 \%$ survived due to severe drought. From 1905 to 1912 the island was uninhabited, but following that, 560,000 coconut were planted by Central Pacific Coconut Plantation Ltd, with 400,000 surviving. Greater government control was achieved by bringing the islands into the Gilbert and Ellice Islands Colony in 1919. During World War Two Kiritimati was used by Allied forces, with up to 2,621 personnel on the island. During this perioo, engineering works, such as construction of a $2,100 \mathrm{~m}$ runway, vere undertaken. Following the war, Gilbert and Ellice Islanders were settled on the island which was being managed as a coconut plantation. From 1956 to 1958, atmospheric nuclear bomb tests were conducted by the UK 30 miles south of the island, and up to 4,000 servicemen were present. During 1962 US bomb tests were conducted, and again, several thousand servicemen occupied the island. Military interest ceased in 1969 (Garnett, 1983a).

Local Human Population The 1983 population numbered some 1,500 people, the great majority of whom lived in London, Banana and Poland villages in the west. Most residents are Kiribati government workers and their families. The principal economic activity has been copra production, although during the 1960 s this became less viable due to very low productivity and high labour and shipping costs. Since 1980 the industry has been under the control of the Ministry of the Line and Phoenix Islands, and licences are issued to individuals for copra production. This has been more successful financially. Other recent developments include small-scale vegetable production and the export of live crayfish, chilled reef and ocean fish. A pilot project to determine the potential for salt production has been undertaken (Garnett, 1983a, 1983b).

Visitors and Visitor Facilities A 48-bed hotel and improved air connections with Honolulu have enabled the development of small-scale tourism for sport fishing and naturalists. There is another surfaced airstrip at Aeon Field in the South-east Peninsula. The harbour has a $1.5 \mathrm{~m}$ maximum draft access channel into the lagoon and a deep water jetty is proposed. There is an extensive road system. Specialist wildlife tours consist of six-day guided visits to reserves, reefs and the South-east Peninsula (Garnett, 1983a, 1983b).

Scientific Research and Facilities Kiritimati has been the subject of numerous studies and surveys. A 1971 University of Hawaii expedition investigated production of brime shrimp Artemisia salina; a commercial implementation of the project was abandoned in 1978. A preliminary assessment of natural resources and development potential was undertaken in 1978 (Floyd, 1978). The University of Hawaii has several projects in the Line Islands, which use Kiritimati as a shipment and marshalling point; a meteorological observatory and projects on sea level and water temperature are based on the island. The New Zealand Meteorological Office maintains a weather station in London (Groves, 1983). A bibliography of studies on the flora, fauna and past and present human use is given in Garnett (1983a).

Conservation Value Kiritimati is valued principally for the diversity, and rarity, of natural habitats, native plants and breeding birds, and for the abundance of certain other breeding birds.

Conservation Management A Wildlife Conservation Unit was established on Kiritimati in 1977. The Unit is represented on the Kiritimati Development Committee and the Local Land 
Planning Board. In addition to blanket wildlife protection under the 1975 Wildlife Conservation Ordinance, entry into the discrete closed areas is prohibited. These were designated for the protection of sooty tems. However, as the birds have not used these areas fully an alternative policy has been implemented. Areas used seasonally by sooty terns have and will continue to be declared "closed areas" - usually a total of five or six areas each season (K.Teeb'aki, pers. comm., 1989). Management activities include feral animal eradication (Anon., 1985), flora and fauna surveys, law enforcement, education programmes and provision of advice to the Government (Garnett, 1983b). Although the entire island is gazetted as a wildlife sanctuary, several areas are. in effect, zoned for human activities. Garnett (1983b) recommends that the island as a whole loses its wildlife sanctuary status, and that a number of specific areas be gazetted, namely: all islets; central lagoons, North-west Point, Paris Peninsula and South-east Peninsula. Within these proposed wildlife sanctuaries it is recommended that the following areas be declared closed areas: Cook Island, Motu Tabu, Motu Ubua, Ngaontetaake, Frigatebird Island; and all sooty tem colonies. Garnett also proposed a five-year management plan (1983-1987) involving law enforcement, education and public awareness, surveys and research, advice to government, control of introduced species and appropriate development of tourism. A grant has been made available by New Zealand to fund feral cat and pig eradication programmes, which have met with success, although anti-poaching patrols have been less effective (E.A. Schreiber, pers. comm., 1989).

Management Constraints Unusual weather conditions were experienced during the abnormal 1982-1983 El Niño Southem Oscillation (ENSO), with a high sea level and very high rainfall (Groves, 1983). This led directly to $90 \%$ mortality and no reproductive success in a number of seabird species (Schreiber and Schreiber, 1984). Previous ENSOs in 1940-41, 1957-58 and 1963-65 had little apparent effect on bird populations (Schreiber and Schreiber, 1987). Both numbers and reproductive activity increased in 1983, but recovery was set back by the 1986-1987 ENSO (E.A. Schreiber, pers. comm., 1989). Evidence suggests that food supplies were poor (Schreiber and Schreiber, 1986a), although the relationship between primary productivity and food availability to birds is not yet understood (Schreiber and Schreiber, 1987). Feral cats and pigs have had a deleterious effect on terrestrial flora and fauna and cat populations are currently increasing. An increase in fishing activity has led to many additional vehicles being brought to the island, with consequent ease of access to the seabird colonies. This has contributed to increased levels of bird poaching particularly in red-tailed tropic bird, red-footed booby and masked booby colonies. There is little prospect of these populations recovering to pre-1981 levels whilst both feral cats and poaching are prevalent, and there may be a possibility of their extirpation (E.A. Schreiber, pers. comm., 1989). Only limited patrolling has been undertaken in recent years. It is not known if the island was adversely affected by atmospheric nuclear bomb test programmes during 1956-58 and 1962 (Garnett, 1983a).

Staff The Wildlife Unit was established with three full-time and one part-time staff members. Although the Unit's activities concentrate on Kiritimati, it is also responsible for other wildlife sanctuaries in the Republic (Gamett, 1983b).

Budget No information

Local Addresses Wildlife Conservation Unit, Ministry of the Line and Phoenix Islands, Kiritimati 


\section{References}

Anon. (1985). Feral animal eradication programme Kiritimati, Kiribati. Third South Pacific National Parks and Reserves Conference. Volume 2. Collected key issue and case study papers. South Pacific Commission, Noumea, New Caledonia. Pp. $276-277$.

Collar, N.J. and Andrew, P. (1988). Birds to watch: the ICBP world check-list of threatened birds. Technical publication No. 8. Intemational Council for Bird Preservation, Cambridge, UK. 304 pp.

Dahl, A.L. (1986). Review of the Protected Areas System in Oceania. IUCN, Gland, Switzerland and Cambridge, UKUNEP, Nairobi, Kenya. 328 pp.

Emory, K.P. (1934). Archaeology of Pacific Islands. Bernice P. Bishop Museum Bulletin 123. (Unseen)

Floyd, C.H. (1975). Christmas Island (Gilbert Islands): Physical Planning Report. UNDAT Report. (Unseen).

Garnett, M.C. (1983a). A management plan for nature conservation in the Line and Phoenix Islands. Part 1: Description. Unpublished. Pp. 2-92.

Garneth, M.C. (1983b). A management plan for nature conservation in the Line and Phoenix Islands. Parts 2 and 3. Policy and Recommendation. Unpublished. $131 \mathrm{pp.}$

Groves, G.W. (1983). Opportunities for scientific research at Kiritimati Island. Atoll Research Unit. Technical Report. Tarawa. (Unseen).

Perry, R. (1980). Wildlife Conservation in the Line Islands, Republic of Kiribati (formerly Gilbert Islands). Environmental Conservation 7: 311-318.

Schreiber, R.W. and Schreiber, E.A. (1984). Central Pacific seabirds and the El Niño Southern Oscillation: 1982 to 1983 perspectives. Science 225: 713-716.

Schreiber, R.W. and Schreiber, E.A. (1986a). Unusual seabird breeding parameters on Christmas Island. Climate Diagnostics Bulletin. NOAAVNational Weather Service. No 64/4. 1 pp.

Schreiber, R.W. and Schreiber, E.A. (1986b). Christmas Island (Pacific Ocean) seabirds and El Niño oscillation (ENSO): 1984 perspectives. NATO ASI Series, Volume G12. Pp. 397-408.

Schreiber, R.W. and Schreiber, E.A. (1987). Tropical seabirds and the El Niño: 1983 and 1986 perspectives. In: Proceedings of the Jean Delacour/International Foundation for the Conservation of Birds Symposium on Breeding Birds in Captivity, 12-15 February, North Hollywood, California, USA. Pp. 352-359.

\section{General notes on Kiritimati closed areas}

Cook Islet Narrow $1 \mathrm{~km}$ long islet at the entrance of the main lagoon harbour. The $19 \mathrm{ha}$ of the islet support a colony of 200,000 sooty tern Sterna fuscata, the only colony of crested tern Thalasseus bergii in the Line Islands and the largest breeding numbers of white-capped noddy Anous minutus and white tern Gygis alba on Kiritimati, and smaller populations of brown and blue-grey noddies Anous stolidus and Procelsterna cerulea.

Motu Tabu This 3.5ha triangular-shaped islet lies within the lagoon and has a small central wooded area with planted $P$ isonia grandis. There are large colonies of wedge-tailed shearwater Puffinus pacificus and Phoenix petrel Pterodroma alba in the open areas. Other breeders include Christmas Island shearwater Puffinus nativitatis, white-throated storm petrel Nesofregetta albigularis and white tern Gygis alba.

Ngaontetaake This 27 ha islet is situated in the eastern part of the central lagoon and was gazetted in 1979. It has 300 pairs of red-tailed tropicbird $P$ haethon rubricauda and some great frigatebirds Fregatta minor and red-footed boobies Sula sula. 
Motu Upua This is a 19-20ha islet covered with mixed Messerschmidia, Heliotropium, Suriana and Scaevola scrub and scattered coconut palms. It supports the largest colonies of Phoenix petrel Pterodroma alba and Christmas Island shearwater Puffinus nativitatis.

North-west Point This area, declared in 1975 but since degazetted (K. Teeb'aki, pers. comm. 1989 ), lies between the main road and the sea, $5-9 \mathrm{~km}$ north of the village of London. It supports up to 250,000 sooty tern Sterna fuscata. Cat eradication and egg collection control is being undertaken.

Date June 1985, updated December 1988, July 1989, February 1990

\section{MALDEN ISLAND WILDLIFE SANCTUARY}

IUCN Management Category I (Strict Nature Reserve)

Biogeographical Province 5.04.13 (Southeastern Polynesian)

Geographical Location Lies in the central Pacific Ocean, 200km north-north-east of Starbuck Island and $670 \mathrm{~km}$ south-south-east of Kiritimati in the Line Islands. Approximately $4^{\circ} 03^{\prime} S$, $155^{\circ} 01^{\prime} \mathrm{W}$

Date and History of Establishment 29 May 1975. Gazetted as a wildlife sanctuary and closed area under the 1975 Wildlife Conservation Ordinance.

Area $3,930 \mathrm{ha}$

\section{Land Tenure State}

Altitude Maximum elevation of $8 \mathrm{~m}$ is attained on the beach crest.

Physical Features Comprises a low, roughly triangular-shaped island, measuring about $8 \mathrm{~km}$ from east to west and $6 \mathrm{~km}$ from north to south. A prominent feature is a series of sand and coral boulder ridges which forms a circumferential beach crest. The island contains an enclosed and very saline lagoon covering approximately $13 \mathrm{sq} . \mathrm{km}$, connected to the sea by underground channels, and with numerous small coral islets. There may be a freshwater lens. The soil is composed of course coral gravel and sand, and lagoon mud. Soils are finer inland and interspersed with exposed outcrops of coral rock where phosphate was removed. The fringing reef is about $100 \mathrm{~m}$ wide and extends $300 \mathrm{~m}-400 \mathrm{~m}$ at its north-western and south-eastern points (Garnett, 1983a).

Climate Meteorological records were kept from 1890 to October 1919. The mean temperature was $29.3^{\circ} \mathrm{C}$, with a minimum and maximum of $23.8^{\circ} \mathrm{C}$ and $37.2^{\circ} \mathrm{C}$, respectively. Prevailing winds were easterly trades and severe storms were extremely rare. The mean annual rainfall was $726 \mathrm{~mm}$, but varied between $101 \mathrm{~mm}$ in 1890 and $2394 \mathrm{~mm}$ during January to October 1919, after which records ceased. The wettest period was usually between January and May and periods of drought also occurred (Garnett, 1983a).

Vegetation Dominant vegetation cover is stunted Sida fallax scrub, with low herbs and grasses. Three or four clumps of Pisonia grandis, historically extensive but reduced through 
indiscriminate felling and introduction of goats in the 19th century, remain in the north-east, although these may be dying. Parts of the lagoon flat are devoid of vegetation. A total of 16 species has been recorded, of which seven are introductions (Garnett, 1983a).

Fauna The only mammals are feral cats and house mouse Mus musculus, since previously recorded feral pigs and goats and Polynesian rat Rattus exulans have become locally extinct. The island has large seabird colonies with 11 species recently recorded as breeding. One species may breed but two or three species, which formerly bred, are now extinct. A population of 300-3,000 masked booby Sula dactylatra is considered of international importance (Gamett, 1983b). A number of other populations may be nationally or intemationally important, although size estimates vary greatly. These include $0-2,000$ brown booby $S$. leucogaster, 500-5,000 red-footed booby $S$. sula, 4,500-7,000 lesser frigatebird Fregata ariel, 10,000-300,000 sooty tern Sterna fuscata, 200-2,500 grey-backed tern S. lunata and 120-200 blue-grey noddy Procesterna cerulea (Garnett, 1983a).

Two species of lizard, mourning gecko Lepidodactylus lugubris and snake-eyed skink Ablepharus boutonii, have been recorded. Green turtle Chelonia mydas (E) breeds in small numbers. Hermit crab Ceonobita spp. and a brown libellulid dragonfly have been recorded (Bloxham, 1925), but there are no records of other invertebrates (Garnett, 1983a).

Cultural Heritage Twenty-one archaeological sites, with a total of over 70 ruined buildings and other stoneworks, indicate that the island was populated by Polynesians for several generations. A series of impressive marae (Polynesian temples) is found in the north-west, whilst other ruins are scattered circumferentially around the entire coast (Emory, 1934, cited in Garnett, 1983a). However, when the islands were discovered by Europeans in 1825, they were deserted. The island was bonded in 1860 under the 1856 American Guano Act, and heavily exploited for phosphate from 1860 until 1927. Malden was occupied during 1956-1959 by British servicemen, in order to monitor the Christmas Island atmospheric nuclear bomb test programme, and was itself used as a target for some of the larger detonations (Garbett, 1983).

Local Human Population The island has been unpopulated since the departure of British servicemen in 1962 (Garnett, 1983a).

Visitors and Visitor Facilities An airstrip was constructed for the atomic weapons testing base in 1958 and was in regular use until July 1979. There is no anchorage, and landing is difficult and dangerous (Garnett, 1983a).

Scientific Research and Facilities The island was visited by personnel from the Smithsonian Institution's Pacific Ocean Biological Survey Program on several occasions in the 1960s, by the Line Islands Expedition in September 1974 and by staff of the Wildlife Conservation Unit on a roughly annual basis. The US mineral exploration company GEOMAREX surveyed in the island in 1980 and found substantial gypsum deposits which might be worth exploiting commercially in the future (Garnett, 1983a).

Conservation Value The island has large seabird colonies with 11 species recently recorded as breeding.

Conservation Management The Wildlife Conservation Unit, located on Kiritimati, has administrative responsibility for the island. The island is gazetted under the 1975 Wildlife Conservation Ordinance, which has no provision for the protection of habitat. Nevertheless, the inhospitable nature and remoteness of the island ensure there is little disturbance. A herd of five 
feral pigs was extirpated by the Pacific Ocean Biological Survey Party in 1964 (Gamett, 1983a). A bibliography is given by Garnett (1983a).

Management Constraints Potholes and trenches, dating back to phosphate mining days, mar the interior of the island. The original vegetation cover has been severely damaged by phosphate workings, indiscriminate felling and feral animals. There is little, if any, standing freshwater (Garnett, 1983).

Staff There are no staff permanently assigned to the island.

Budget No information

Local Addresses Wildlife Conservation Unit, Ministry of Line and Phoenix Islands, Kiritimati

\section{References}

Bloxham, A. (1925). Diary of Andrew Bloxham, naturalist of the "Blonde" on her trip from the Hawaiian Islands from England, 1824-1825. Bernice P. Bishop Museum Special Publication 10.

Emory, K.P. (1934). Archaeology of Pacific Islands. Bernice P. Bishop Museum Bulletin 123. (Unseen).

Garnett, M.C. (1983a). A management plan for nature conservation in the Line and Phoenix Islands. Part 1: Description. Unpublished. Pp. 129-138.

Garnett, M.C. (1983b). A management plan for nature conservation in the Line and Phoenix Islands. Parts 2 and 3. Policy and Recommendation. Unpublished. $131 \mathrm{pp.}$

Date June 1985, updated December 1988, July 1989

\section{McKEAN ISLAND WILDLIFE SANCTUARY}

\section{IUCN Management Category IV (Managed Nature Reserve)}

Biogeographical Province 5.05.13 (Central Polynesian)

Geographical Location This is the most westerly of the Phoenix Group, lying $280 \mathrm{~km}$ west-south-west of Kanton Island and $125 \mathrm{~km}$ north-north-west of Nikumaroro in the central Pacific Ocean. Approximately $3^{\circ} 35^{\prime} \mathrm{S}, 174^{\circ} 02^{\prime} \mathrm{W}$

Date and History of Establishment 21 June 1938. The island was declared a bird sanctuary under the Gilbert and Ellice Island Colony Wild Birds Protection Ordinance of 1938. The area was designated a wildlife sanctuary in 1975 under the 1975 Wildlife Conservation Ordinance.

Area 57ha

\section{Land Tenure State}

Altitude Ranges from sea level to $5 \mathrm{~m}$ on the northem beach crest.

Physical Features Comprises a flat, sand and coral island, approximately circular in shape, with a diameter of some $800 \mathrm{~m}$. The beach is largely composed of reef rock and coral rubble, and rises 
sharply to a circumferential crest, within which the land is concave. The interior basin has been further depressed by extensive 19th century phosphate workings. There is no information about soils, but these probably consist of coral sand and rubble, with little humus. There is no standing surface freshwater, nor any evidence of a freshwater lens. A small, shallow, landlocked and highly saline lagoon occupies the centre of the island. The depth of the lagoon, which fills the area of the former phosphate workings, fluctuates with the tide, reaching a maximum depth of $60 \mathrm{~cm}$ at high water. McKean is surrounded by a fringing reef of between $100 \mathrm{~m}$ and $200 \mathrm{~m}$ width; the landward 30m dries at low water (Garnett, 1983a).

Climate No data specific to the island are available. The inferred mean annual rainfall is $800 \mathrm{~mm}$. The prevailing winds are easterly trades (Garnett, 1983b).

Vegetation Comprises stunted Sida fallax scrub, with low herbs and grasses, and is considered to be of international conservation importance. Seven species have been recorded in five vegetation types, although distinctions between them are not always clear. The western part of the island is covered by an extensive mat of Tribulus cistoides, while inland saline flats support Sesuvium portulacastrum. Most of the remainder of the island supports a mixture of Portulaca lutea and Boerhavia albiflora. The highest ground is covered by Digitaria pacifica grass with scattered mats of Boerhavia and Tribulus on a coarse coral rubble substrate. Stunted Sida fallax between the two complexes of ruins supports a frigatebird colony. Lepturus pilgerianus is located mostly on the west coast of the island, mixed with Tribulus cistoides (Garnett, 1983a).

Fauna Polynesian rat Rattus exulans is the only mammal. The island supports 17 breeding seabird species, with six occurring in internationally important colonies. These comprise 5,000 Audubon's shearwater Puffinus l'herminieri, 1,000 white-throated storm petrel Nesofregatta albigularis, 40,000 lesser frigatebird Fregata ariel, one of the largest populations in the world, 23,400 grey-backed tern Sterna lunata, 20,000 brown noddy Anous stolidus and 15,000 blue-grey noddy Procelsterna cerulea, one of the largest colonies in the central Pacific. Breeding, migrant and visiting bird species are listed by Gamett (1983a). Reptiles are restricted to mourning geckoes Lepidodactylus lugubris. Detailed information on invertebrates is not available, although species recorded include hermit crab Coenobita perlata, land crabs, including Geograpsus grayii and at least 15 insects (Garnett, 1983a).

Cultural Heritage No archaeological evidence has been found to suggest that McKean was ever settled in prehistoric times. The presence of Polynesian rat may indicate that the island was visited, or that canoes were wrecked there. The island was discovered by Europeans on 28 May 1794, and bonded under the 1856 American Guano Act on 14 March 1859. Phosphate was exploited between 1839 and 1870 , by which time all reserves were exhausted. A year after annexation to the United Kingdom in 1936, the island was investigated for colonisation by Gilbert and Ellice Islanders. However, it was considered too small and dry and was consequently designated as a bird sanctuary. A scheme to introduce coconut was prevented by the outbreak of World War Two (Garnett, 1983a).

\section{Local Human Population Uninhabited}

Visitors and Visitor Facilities The island has seldom been visited, and there is no infrastructure. There is a reasonably good anchorage off the west coast, and landing is comparatively easy (Garnett, 1983a).

Scientific Research and Facilities McKean has been visited by the Smithsonian Institution's Pacific Ocean Biological Survey Program. Bird populations have been surveyed by irter alia 
Sibley and Clapp (1967), King (1973), Crossin (1974) and Nelson (1978). There are no scientific facilities. A bibliography is given in Garnett (1983a).

Conservation Value The sanctuary is valued for its various habitats, the diversity, rarity and abundance of various breeding birds, its naturalness and ecological fragility (Gamett, 1983a).

Conservation Management The Wildlife Conservation Unit, based on Kiritimati, has administrative and managerial responsibility for the sanctuary. Current legislation protects species, but has no provisions for habitat. Information on curnent management activities is not available, although the remoteness and inhospitable nature of the island is its main source of protection. Garnett (1983b) makes a number of general management recommendations for the Phoenix Islands, including erection of multilingual notice boards advising visitors, for example long-distance yachtsmen and fishermen from Japanese, Taiwanese and Korean fleets which are active in the region, of the importance of the island for science and nature conservation, and of the wildlife laws.

Management Constraints The islands are too remote for any law enforcement or other conservation activities (Garnett, 1983b).

Staff No staff are assigned specifically to the sanctuary.

Budget No information

Local Addresses Wildlife Conservation Unit, Ministry of the Line and Phoenix Islands, Kiritimati

\section{References}

Crossin, R.S. (1974). The storm petrels (Hydrobatidae). Smithsonian Contributions to Zoology 158: $154-205$.

Garnett, M.C. (1983a). A management plan for nature conservation in the Line and Phoenix Islands. Part 1 Description. Unpublished. Pp. 129-138.

Garneth, M.C. (1983b). A management plan for nature conservation in the Line and Phoenix Islands Parts 2 and 3. Policy and Recommendation. Unpublished. $131 \mathrm{pp}$.

King, W.B. (1973). Conservation status of birds of central Pacific islands. Wilson Bulletin 85: 89-103.

King, W.B. (1974). Wedge-tailed shearwater (Puffinus pacificus). Smithsonian Contributions to Zoology 188: 53-95.

Nelson, J.B. (1978). The Sulidae. Oxford University Press for the University of Aberdeen. $1012 \mathrm{pp}$.

Sibley, F.C. and Clapp, R.B. (1967). The distribution and dispersal of central Pacific lesser frigate birds Fregata ariel. Ibis 109: 328-337.

Date June 1985

\section{PHOENIX ISLAND (RAWAKI) WILDLIFE SANCTUARY}

IUCN Management Category IV (Managed Nature Reserve) 


\section{Biogeographical Province 5.05.13 (Central Polynesian)}

Geographical Location The island is the most easterly of the Phoenix Islands, lying in the central Pacific, $74 \mathrm{~km}$ south-east of Enderbury Island, $90 \mathrm{~km}$ east of Birnie Island and about $180 \mathrm{~km}$ south-east of Kanton. The sanctuary includes the entire island. Approximately $3^{\circ} 42^{\prime} \mathrm{S}$, $170^{\circ} 43^{\prime} \mathrm{W}$

Date and History of Establishment 21 June 1938. Declared a bird sanctuary under the Gilbert and Ellice Islands Colony Wild Birds Protection Ordinance (1938). The island was designated a wildlife sanctuary in 1975 under the 1975 Wildlife Conservation Ordinance.

Area $6,500 \mathrm{ha}$

\section{Land Tenure State}

Altitude Ranges from sea level to $6 \mathrm{~m}$ on the beach crest.

Physical Features Comprises a small island, measuring about $1.2 \mathrm{~km}$ along its north-west to south-east axis, by $0.8 \mathrm{~km}$, with a circumferential beach crest. Inland areas slope gently downwards to a $20 \mathrm{ha}$, landlocked, shallow supersaline lagoon which occupies much of the centre. There is no surface freshwater and probably no freshwater lens. The steep beach is fringed by a narrow platform reef, $30 \mathrm{~m}$ to $100 \mathrm{~m}$ wide, and on the east coast there are storm ridges of broken coral (Gamett, 1983a).

Climate No data specific to the islands are available. Phoenix is one of the drier islands in the Phoenix Group, with an inferred mean annual rainfall of $800 \mathrm{~mm}$. Prevailing winds are easterly trades (Garnett, 1983a).

Vegetation Vegetation patterns are simple, comprising low herbs, grasses and stunted Sida fallax. These mainly form single species stands, although mixtures of Lepturus pilgerianus and Sesuvium portulacastrum, and of Boerhavia sp. and Portulaca lutea, also occur. The windward east coast outer ridge is covered with Lepturus, and the inner ridge with sparse Portulaca and Boerhavia mixture. The trough between the ridges supports a Boerhavia mat. Inland, pure Portulaca stands and Portulaca-Boerhavia mixture occur. A broad belt of Sesuvium is found along the lagoon shore. The leeward west coast ridge is lower and further inland, with Lepturus forming broad belts from the shore almost to the lagoon, with localised patches of Boerhavia and Portulaca. A narrow belt of mixed Sesuvium-Lepturus occurs along the lagoon shore. Two large patches of Sida scrub are located near the north end of the lagoon, with another at the northern end of the island. Portulaca-Boerhavia mixture is found in the south near the lagoon. Vegetation patterns vary with climatic conditions, and after droughts Sida and Lepturus die back, leaving Sesuvium, Portulaca and Boerhavia at a competitive advantage. Triumfetta procumbens has become locally extinct during this century (Garnett, 1983a).

Fauna European rabbit Oryctolagus cuniculus was introduced in the 1860 s and currently numbers between 100 and 1,000 individuals. Altogether, 18 seabird species breed, with some of the largest populations in the central Pacific. Noteworthy populations include 10,000 wedge-tailed shearwater $P$ uffinus pacificus, 3,000 Christmas shearwater $P$. nativitatis, 12,000 Audubon's shearwater $P$. $l$ ' herminieri, 400 white-throated storm petrel Nesofregatta albigularis, 850 masked booby Sula dactylatra, 16,000-45,000 lesser frigatebird Fregata ariel, 250,000 sooty tern Sterna fuscata and 500 Bulwer's petrel Bulweria bulwerii, the largest Line and Phoenix Island population of this species. Other breeding, non-breeding migrants and visitors are listed in Garnett (1983a). Green turtle Chelonia mydas (E) nests in small numbers. Insects are abundant, 
but exhibit low species diversity, and principally comprise Cicadellidae, Mallophaga, Coleoptera and Diptera (Garnett, 1983a). Plant and animal species lists are given in Garnett (1983a).

Cultural Heritage No prehistoric remains or artefacts have been reported, and there is no evidence to suggest that the island was ever visited in prehistoric times. European discovery of the island has been dated to either 1794 or 1815 , and it was probably known to whalers who frequented the region in the early years of the 19th century. Phoenix was bonded under the 1856 American Guano Act in 1859 and 1860. Phosphate extraction commenced in 1862 and continued until August 1871, by which time reserves had been exhausted. Some 20,000 to 40,000 tonnes were exported during this period. On 29 June 1889, Phoenix was annexed to Great Britain and until 1938 various commercial concerns were licensed to develop the island, although no activities were undertaken. In $1937 \mathrm{it} \mathrm{was} \mathrm{surveyed} \mathrm{for} \mathrm{possible} \mathrm{colonisation} \mathrm{by} \mathrm{Gilbert} \mathrm{and} \mathrm{Ellice}$ Islanders, although it was considered unsuitable. In 1939, an unsuccessful attempt to establish coconut was made, regardless of the bind sanctuary status. However, the outbreak of World War Two prevented any planting (Garnett, 1983a).

\section{Local Human Population Uninhabited}

Visitors and Visitor Facilities The island is seldom visited and there are no buildings or infrastructure. There is no anchorage, but landing is comparatively easy in moderate weather through a small break in the reef on the south-west side, or on the east coast (Garnett, 1983a).

Scientific Research and Facilities The Smithsonian Institution's Pacific Ocean Biological Survey Program survey teams visited several times in the 1960s. The Line Islands Expedition visited Phoenix on 13 October 1974. The joint Royal Society/Smithsonian Institution expeditions visited in 1973 and 1975. Studies of birds include Crossin (1974), King $(1973,1974)$ and Nelson (1978). There are no scientific facilities.

Conservation Value The sanctuary is valued for its various habitats; the diversity, rarity and abundance of various breeding birds; its naturalness; and ecological fragility (Garnett, 1983a).

Conservation Management The Wildlife Conservation Unit, based on Kiritimati, has administrative and managerial responsibility for the sanctuary. Current legislation protects species, but makes no provisions for habitat. Information on current management activities is not available, although the remoteness and inhospitable nature of the island is its main source of protection. Garnett (1983b) makes a number of general management recommendations for the Phoenix Islands, including erection of multilingual notice boards advising visitors, for example long-distance yachtsmen and fishermen from Japanese, Taiwanese and Korean fleets which are active in the region, of the importance of the island for science and nature conservation, and of the wildlife laws.

Management Constraints The islands are too remote for any law enforcement or other conservation activities (Garnett, 1983b).

Staff No staff are assigned specifically to the sanctuary.

Budget No information

Local Addresses Wildlife Conservation Unit, Ministry of the Line and Phoenix Islands, Kiritimati 


\section{References}

Crossin, R.S. (1974). The storm petrels (Hydrobatidae). Smithsonian Contributions to Zoology 158: 154-205.

Garnett, M.C. (1983a). A management plan for nature conservation in the Line and Phoenix Islands. Part 1 Description. Unpublished. Pp. 129-138.

Garnett, M.C. (1983b). A management plan for nature conservation in the Line and Phoenix Islands. Parts 2 and 3. Policy and Recommendation. Unpublished. 131 pp.

King, W.B. (1973). Conservation status of birds of central Pacific islands. Wilson Bulletin 85: 89-103.

King, W.B. (1974). Wedge-tailed shearwater (Puffinus pacificus). Smithsonian Contro. Zool. 188: 53-95.

Nelson, J.B. (1978). The Sulidae. The Oxford University Press for the University of Aberdeen. $1012 \mathrm{pp}$.

Date June 1985

\section{STARBUCK ISLAND WILDLIFE SANCTUARY}

\section{IUCN Management Category I (Strict Nature Reserve)}

Biogeographical Province 5.04.13 (Southeastern Polynesian)

Geographical Location Remotely located in the central Pacific, $830 \mathrm{~km}$ south-south-east of Kiritimati in the Line Islands. The wildlife sanctuary and closed area covers the entire island. Approximately $5^{\circ} 37^{\prime} \mathrm{S}, 155^{\circ} 56^{\prime} \mathrm{W}$

Date and History of Establishment 29 May 1975. Established as a wildlife sanctuary and closed area under the 1975 Wildlife Conservation Ordinance.

Area $16,200 \mathrm{ha}$

\section{Land Tenure State}

Altitude Sea level to $6-8 \mathrm{~m}$ on a steep bank behind the reef

Physical Features Comprises a low, dry, flat coral island, extending $8.9 \mathrm{~km}$ from east to west, and up to $3.5 \mathrm{~km}$ from north to south. Fringing reefs are about $100 \mathrm{~m}$ wide, with offshore reefs located $400-600 \mathrm{~m}$ south of the southernmost point and $1.4 \mathrm{~km}$ east of the most easterly point of the island. The beach is steep and backed by a 6-8m high bank, composed of large, sharp coral fragments. This rampart drops $2.5 \mathrm{~m}$ to the flat interior, which is largely composed of broken, black coral pieces. Several small, shallow and highly saline lagoons are found in the east. There is no free-standing freshwater, although a lens may form. Soils appear to be mainly coral sand interspersed among larger areas of coral rag and broken reef rock (Garnett, 1983a).

Climate Starbuck is one of the drier Line Islands with an inferred mean annual rainfall of about $800 \mathrm{~mm}$. The prevailing winds are easterly trades (Garnett, 1983a). 
Vegetation With the exception of a limited number of Cordia subcordata bushes, the vegetation consists entirely of stunted Sida fallax scrub with low herbs and grasses. Five other species have been tentatively identified: a bunch-grass, probably Lepturus repens; Bidens pilosa; Portulaca lutea; Tribulus cistoides; and Ipomoea sp. Bidens, Ipomea and Tribulus are all likely to have been introduced, whilst the other species are probably indigenous (Garbett, 1983a).

Fauna Polynesian rat Rattus exulans and three feral cats were sighted in 1974 and are the only known mammals (Garbett, 1983a). The island is noted for its avifauna, principally sooty tem Sterna fuscata, estimated at 1.5 million pairs in 1974 (Garnett, 1983a). A number of other species, including petrel, booby, frigate bird and noddy also occur, and are listed by Garnett (1983a). Green turtle Chelonia mydas $(E)$ has been recorded but there is no information on its status. There is no information about the invertebrate fauna (Garnett, 1983a).

Cultural Heritage The presence of Polynesian rat suggests the island may have been visited during pre-historic time. However, no archaeological remains or artefacts have been recorded and it is unlikely that it was inhabited by Polynesians. Starbuck was discovered by Europeans in February 1819 and was named after Captain V Starbuck of the whaler "L'Aigle", who visited in 1823. The island was bonded under the 1856 American Guano Act and mined for phosphate from 1870 to 1893 by British interests. The rights to exploit the island passed through a number of companies until 1920, since when no action has been taken to develop or use the island in any way. The remains of numerous wooden sailing ships are found on the northern shore, thrown bodily over the beach rampart by violent storms (Garnett, 1983a).

\section{Local Human Population None}

Visitors and Visitor Facilities The island has seldom been visited in recent years. There is no safe anchorage. A landing has been blasted through the reef on the north coast, but it is difficult and at times dangerous to negotiate (Garnett, 1983).

Scientific Research and Facilities The Line Islands Expedition visited Starbuck in 1974 (Garnett, 1983a).

Conservation Value The island is valued for its sooty tern colony which is thought to be of international significance.

Conservation Management The island is the administrative responsibility of the Wildlife Conservation Unit, Kiritimati. There are at present no management activities on the island. The elimination of feral cats would considerably enhance the nature conservation value of the island (Garnett, 1983b).

Management Constraints No information

Staff There are no staff assigned to the island.

Budget No information

Local Addresses Wildlife Conservation Unit, Ministry of the Line and Phoenix Islands, Kiritimati

\section{References}

Garnett, M.C. (1983a). A management plan for nature conservation in the Line and Phoenix Islands. Part 1: Description. Unpublished. Pp. 129-138. 
Garnett, M.C. (1983b). A management plan for nature conservation in the Line and Phoenix Islands. Parts 2 and 3. Policy and Recommendation. Unpublished. 131 pp.

Date June 1985

\section{VOSTOK ISLAND WILDLIFE SANCTUARY}

\section{IUCN Management Category IV (Managed Nature Reserve)}

Biogeographical Province 5.M4.13 (Southeastern Polynesian)

Geographical Location The island is situated in the southern Line Islands, $158 \mathrm{~km}$ north north-west of Flint Island, $230 \mathrm{~km}$ west of Caroline Island, $709 \mathrm{~km}$ south south-east of Malden Island and $1,490 \mathrm{~km}$ north-west of Rarotonga in the Cook Islands. The sanctuary comprises the entire island. Approximately $10^{\circ} 06^{\prime} \mathrm{S}, 152^{\circ} 23^{\prime} \mathrm{W}$

Date and History of Establishment 19 June 1979. Gazetted as a wildlife sanctuary under the 1975 Wildlife Conservation Ordinance.

Area 24 ha

Land Tenure State; leased to a private individual in Moorea, French Polynesia (Garnett, 1983)

Altitude Sea level to $5 \mathrm{~m}$

Physical Features Comprises a small, triangular, low, sand and coral island with no standing freshwater and no lagoon. There is no evidence of a freshwater lens, although peat in the forest is moist at $30 \mathrm{~cm}$ depth. The beaches are widest $(45 \mathrm{~m})$ to the south and the west and rise abruptly at the edge of the forested interior. Sunken reefs are found at the northern, south-western and south-eastern corners and extend $500 \mathrm{~m}$ offshore. Outside the forest soils are a mixture of coral sands and rubble. Inside the $P$ isonia forest, layers of peat, up to $1 \mathrm{~m}$ in depth, cover a phosphatic hardpan (Garnett, 1983; Clapp and Sibley, 1971).

Climate No data specific to the island are available.

Vegetation The vegetation is extremely simple. The central portion of the island is occupied by a pure stand of Pisonia grandis forest. This has been sheared by prevailing easterly winds and reaches its maximum density, and a height of $30 \mathrm{~m}$, at the edge of the western beach. A small cover of Boerhavia repens grows on the sandy edges of clearings in the forest, but the most vigorous growth is in a stand $3 \mathrm{~m}$ to $10 \mathrm{~m}$ wide extending from the north to the south-east point of the island. The low-growing succulent herb Sesuvium portulacastrum may be present (Clapp and Sibley, 1971).

Fauna Polynesian rat Rattus exulans is abundant and apparently feeds largely on leaves and stems. Eight seabird species breed in small numbers, although population estimates vary considerably. The approximately 400 masked booby Sula dactylatra, 3,000 red-footed booby Sula sula and 4,500 great frigatebird Fregata minor are considered to be of national importance (Garnett, 1983). Other breeding species include brown booby S. leucogaster, lesser frigate bird F. ariel, brown noddy Anous stolidus, black noddy A. minutus and white tern Gygis alba. 
Non-resident golden plover Pluvialis dominica, bristle-thighed curlew Numenius tahitiensis (R), wandering tattler Heteroscelus incanus and sooty tern Sterna fuscata have been recorded. The only terrestrial reptile recorded is azure-tailed skink Emoia cyanura. Green turtle Chelonia mydas (E) has been seen offshore, but there is no record of nesting. Terrestrial invertebrates are represented solely by a nationally important population of coconut crab Birgus latro (R).

Cultural Heritage There are no known archaeological sites, although the presence of rats suggests that Polynesians may have visited the island in pre-historic times. The island was first sighted by Europeans on 3 August 1820, and bonded under the 1856 American Guano Act in 1860. A British claim was made in 1873, although it is unlikely that phosphate deposits were ever worked. A cursory, and unsuccessful, attempt was made in 1922 to establish a coconut plantation. No use has been made of the island since (Garnett, 1983).

Local Human Population Uninhabited (Perry, 1980)

Visitors and Visitor Facilities With the exception of scientists, there are no visitors. There is no anchorage but landings can be made in calm weather through a break in the reef at its southwestern point (Gamett, 1983).

Scientific Research and Facilities Plant specimens were collected on 22 March 1935 for the Berenice P. Bishop Museum, Honolulu. More recently, Vostok has been visited by the Smithsonian Institution's Pacific Ocean Biological Survey Program on 15-16 June 1965, the Line Islands Expedition on 7 September 1974 and by Wildlife Conservation Unit staff on 11 November 1977. There are no facilities (Garnett, 1983).

Conservation Value Vostok is valued as the least disturbed of the Line Islands, and for its natural vegetation.

Conservation Management The Wildlife Conservation Unit, Kiritimati, has administrative responsibility for the island. There are no management activities, but the island is protected by its remoteness and inhospitable nature (Garnett, 1983).

Management Constraints No information

Staff No staff are specifically assigned to Vostok.

Budget No information

Local Addresses Wildlife Conservation Unit, Ministry of the Line and Phoenix Islands, Kiritimati

\section{References}

Clapp, R.B. and Sibley, F.S. (1971). The vascular flora and terrestrial vertebrates of Vostok Island, South-central Pacific. Atoll Research Bulletin 144: 1-9.

Garneth, M.C. (1983). A management plan for nature conservation in the Line and Phoenix Islands. Part 1. Description. Unpublished. Pp. 164-172.

Perry, R. (1980). Wildlife conservation in the Line Islands, Republic of Kiribati (formerly Gilbert Islands). Environmental Conservation 7: 311-318.

Date June 1985 


\section{REPUBLIC OF THE MARSHALL ISLANDS}

Area 181 sq. km

Population 40,609 (July 1988)

Natural increase: No information

GNP No information

Policy and Legislation Since October 1986 the Marshall Islands have been a sovereign state in free association with the United States which remains responsible for defence and provides financial support. A number of Trust Territory regulations remain in force, but will be revised in due course and cover topics such as water supply, pesticides and sewage disposal. The Trust Territory Endangered Species Act (TTPI Public Law 6.55 of 1975), which allowed for acquisition of land or water for the purpose of conserving threatened species, is no longer applicable.

US regulations still apply at the Kwajalein Missile Range and other areas, and Kwajalein is likely to experience considerable development pressure due to activities relating to the Strategic Defence Initiative. Other US legislation relevant to the Trust Territories includes the National Environmental Protection Act, enacted by the Nitijela (Parliament) on 19 December 1984. This Act includes many Trust Territory regulations which are under review such that the act will address the needs of the Marshall Islands in a more specific manner (SPREP, 1989). The National Environmental Protection Act, along with the Coastal Conservation Act (1988), charges the Marshall Islands Environmental Protection Authority with responsibility to, inter alia, "preserve and improve the quality of the environment". Amongst other measures the Act makes provision for the preservation of important historical, cultural and natural aspects of the nation's heritage.

There is currently no protected areas legislation, although most other environmental issues are quite well covered by existing legislation. Protected areas established prior to independence are no longer recognised. Thus, two reserves, Bokaak (Taongi) and Bikar, set up by Order of the District Administrator during the 1950s, are not recognised by the government nor by the Irooj Laplap (paramount chief of the Ratak Chain). At present (1990) it is not clear whether protected areas legislation will take the form of additional regulations within the National Environmental Protection Act, or be part of an entirely new Conservation Act. Thomas et al. (1989) present a suggested outline of legislation which would enable the establishment of a legal and administrative framework for the coordinated development and implementation of policies and programmes for nature conservation and protected areas in the Marshall Islands. Virtually all land is held in traditional ownership and any legislation must make provision for strong landowner involvement in protected area management.

International Activities The Marshall Islands are not party to the three major international conventions concerned with the protection of nature, namely the Convention concerning the Protection of the World Cultural and Natural Heritage (World Heritage Convention), Unesco Man and Biosphere Programme and the Convention on Wetlands of International Importance Especially as Waterfowl Habitat (Ramsar Convention).

The Convention on the Conservation of Nature in the South Pacific (1976) has been neither signed nor ratified. Known as the Apia Convention, it entered into force during 1990. The Convention is coordinated by the South Pacific Commission and represents the first attempt 
within the region to cooperate on environmental matters. Among other measures, it encourages the creation of protected areas to preserve indigenous flora and fauna.

The Convention for the Protection of the Natural Resources and Environment of the South Pacific Region (SPREP Convention) has been signed and was ratified on 4 May 1987. The Convention entered into force during August 1990. Article 14 calls upon the parties to take all appropriate measures to protect rare or fragile ecosystems and threatened or endangered flora and fauna through the establishment of protected areas and the regulation of activities likely to have an adverse effect on the species, ecosystems and biological processes being protected. However, as this provision only applies to the Convention area, which by definition is open ocean, it is most likely to assist with the establishment of marine reserves and the conservation of marine species.

Administration and Management Until independence, this role would have been the responsibility of the Chief Conservationist for the Trust Territory. The Director of Coast Conservation, who may be the General Manager of the Environmental Protection Authority, is responsible for submitting a comprehensive Coastal Zone Management Plan, and permits for development activities consistent with that plan. The Environmental Protection Authority is an autonomous body established under the provisions of the 1984 National Environmental Protection Act, with a broad remit in environmental protection and management, including, potentially, the protection of natural sites. The General Manager heads a staff of ten, including a full-time Public Education Officer, two Environmental Specialists, a Consultant to the General Manager and two US Department of the Interior assisted positions (Director of Water Quality Monitoring and Legal Counsel) (SPREP, 1989). Thomas et al. (1989) propose a three-fold administrative structure comprising an ad hoc National Conservation Service, local Atoll Conservation Authorities and a Conservation Service within the Ministry of Resources and Development or the Environmental Protection Authority.

Systems Reviews The Marshall Islands are the easternmost island group of Micronesia, comprising two island chains, Ralik ( 18 atolls) and Ratak ( 15 atolls), between $8^{\circ}-12^{\circ} \mathrm{N}$ and $162^{\circ}-172^{\circ} \mathrm{E}$. Small remnants of atoll/beach forest (mostly comprising pan-Pacific species) occur on some of the northern atolls, for example Wotho, Ujae, and some of the islets of Kwajalein. Small areas of mangrove forest are found on Jaluit, Ailinglaplap and Mejit (Dahl, 1980). Vegetation on almost all the Marshall Islands has been extensively modified; most atolls have coconut and breadfruit plantations. Fosberg (1973) provides an account of the condition and status of the forests and brief summaries for each of the islands are given by Dahl (1986) and Douglas (1969). There have been few descriptions of the coral reefs, but in general windward ocean reef slopes have submarine terraces and often descend gradually, in contrast to leeward ocean reef slopes which descend nearly vertically. Detailed accounts for Bikini, Kawajalein, Enewetak, Majuro and Arno are given in UNEP/IUCN (1988).

The Marshall Islands have abundant marine resources and the potential for commercial fisheries and mariculture is high. Copra production could be developed further. There may be some important mineral resources, including deep sea cobalt-rich manganese crust deposits and possibly some phosphate rock deposits in the lagoon. However, the potential for developing mineral resources is either unknown or not economically feasible at present. Consequently, the major options for economic development appear to lie in increased use of living marine resources, coastal tourism, mariculture and enhanced low-input agriculture. Most of the atolls and individual islands are inhabited, and potable water is available on the southern islands but scarce in the northern islands. Only six atolls and one island are currently unoccupied, namely: Ailinginae, Bikar, Bikini, Erikub, Rongerik, Taka and Taongi Atolls, and Jemo Island (L.S. Hamilton, pers. comm., 1989). 
Bikini and Enewetak were used as atomic weapon test sites by the USA from 1946 to the 1960s. The full extent of the disruption to the atoll ecosystems has not been fully documented or evaluated. The 1954 Bravo test, the first and largest thermonuclear explosion by the US, spread fallout to several of the northern Marshall atolls and caused inestimable damage and social disruption to many reef and island communities (UNEP/IUCN, 1988). The potentially most threatening environmental hazard is that posed by increasing sea-levels due to global warming. Threats to freshwater supplies, land loss and episodic destruction through hurricanes may make the country uninhabitable if worst case scenarios are realised (Pernetta, 1988).

The Marshall Islands were included in a review of the protected areas systems of Oceania (Dahl, 1986), which indicated a need to reinstate the protected status of Taongi and Bikar as well as gazetting protected areas for the conservation of birds, remaining natural vegetation and at least one major coral reef. A more recent and more detailed review of the biological diversity of the northern atolls and their potential as protected areas (Thomas et al., 1989) also confirms the significance of Taongi and Bikar and identifies sites of special conservation significance, especially for seabird protection. The survey, a cooperative venture, indicates a willingness on the behalf of the government to contemplate the establishment of protected areas.

Following independence there has been a strong desire to establish the economic foundation for the future prosperity of the nation, indicating a need for careful natural resource management. Neither the legislation, nor the policy, on protected areas was clear while the country was a part of the Trust Territory, and this is one reason why so few protected areas were actually established. This is largely because the United States, while administering the Territory did not own property, and hence had no direct jurisdiction over designation of protected areas. However, there is a strong possibility that a protected areas system will be implemented in the near future (L.S. Hamilton, pers. comm., 1989).

\section{Addresses}

Ministry of Resources and Development, Majuro, Republic of the Marshall Islands, RMI 96960 Environmental Protection Authority, PO Box 1322, Majuro, RMI 96960

\section{References}

Douglas, G. (1969). Check list of Pacific Oceanic islands. Micronesica 5: 327-463.

Dahl, A.L. (1980). Regional ecosystems survey of the South Pacific area. SPC/UCN Technical Paper No 179. South Pacific Commission, Noumea, New Caledonia. 99 pp.

Dahl, A.L. (1986). Review of the Protected Areas System in Oceania. IUCN, Gland, Switzerland and Cambridge, UK/UNEP, Nairobi, Kenya. 328 pp.

Fosberg, F.R. (1973) On present condition and conservation of forests in Micronesia. In: Pacific Science Association, Planned Utilisation of Lowland Tropical Forests. Proceedings of the Pacific Science Standing Committee Symposium, Bogor, Indonesia, August 1971. Pp. 165-171.

Pernetta, J.C. (1988). Projected climate change and sea level rise: a relative impact rating for countries of the South Pacific Basin. In: MEDU joint meeting of the task team on the implications of climatic change in the Mediterranean. Split, Yugoslavia, 3-7 October. Pp. 1-11.

SPREP (1989). Republic of the Marshall Islands. Paper presented at the Fourth South Pacific Conference on Nature Conservation and Protected Areas, Port Vila, Vanuatu, 4-12 September. $7 \mathrm{pp}$. 
Thomas, P.E.J., Fosberg, F.R., Hamilton, L.S., Herbst, D.R., Juvik, J.O., Maragos, J.E., Naughton, J.J. and Streck, C.J. (1989). Report on the Northern Marshall Islands natural diversity and protected areas survey: 7-24 September 1988. South Pacific Regional Environment Programme, Noumea, New Caledonia and East-West Center, Honolulu, Hawaii. 133 pp.

UNEP/IUCN (1988). Coral Reefs of the World. Volume 3. Central and Western Pacific. UNEP Regional Seas Directories and Bibliographies. IUCN, Gland, Switzerland and Cambridge, UK/UNEP, Nairobi, Kenya. 378 pp.

\section{SUMMARY OF PROTECTED AREAS}

\begin{tabular}{lllrr}
\hline $\begin{array}{l}\text { Map } \\
\text { ref. }\end{array}$ & Name of area & $\begin{array}{c}\text { IUCN management } \\
\text { category }\end{array}$ & $\begin{array}{r}\text { Area } \\
\text { (ha) }\end{array}$ & $\begin{array}{c}\text { Year } \\
\text { notified }\end{array}$ \\
\hline & Unclassified & & \\
1 & Bikar Atoll* & Unprotected & 5,631 \\
2 & Bokaak (Taongi) Atoll* & Unprotected & 10,697 \\
\hline
\end{tabular}

* Site is described in this directory.

${ }^{\dagger}$ Locations are shown in the accompanying map. 


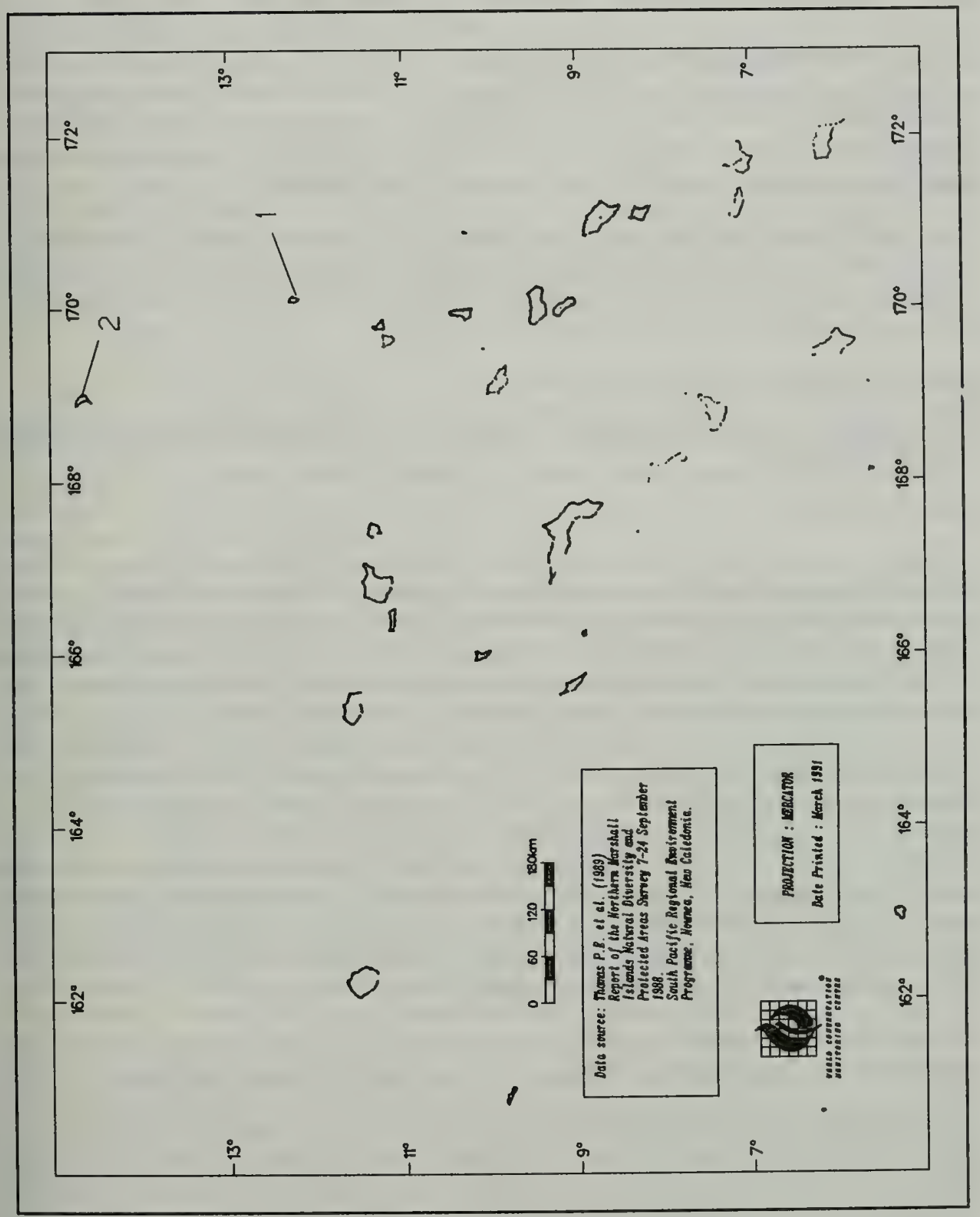

Protected Areas of the Republic of the Marshall Islands 


\section{BIKAR ATOLL}

\section{IUCN Management Category Unprotected}

Biogeographical Province 5.02.13 (Micronesian)

Geographical Location Bikar is the second most northern atoll of the Marshall Islands, lying some $320 \mathrm{~km}$ south of Taongi. $12^{\circ} 10^{\prime}-12^{\circ} 19^{\prime} \mathrm{N}, 170^{\circ} 04^{\prime}-170^{\circ} 08^{\prime} \mathrm{E}$

Date and History of Establishment Established in 1958, by order of the District Administrator of the Trust Territory of the Pacific Islands administration, but no longer recognised since independence in October 1986. It is expected that the atoll will be restored to its protected status in the near future (L.S. Hamilton, pers. comm., 1989).

Area Lagoon area: 5,631ha; dry land: 53ha

Land Tenure Traditionally under the control of the Irooj Laplap (paramount chief of the northern Ratak chain)

Altitude 0-6m

Physical Features The atoll is oval, or diamond, in shape, $11-13 \mathrm{~km}$ long, $6.5-8 \mathrm{~km}$ wide, with its long axis oriented north/south and with a reef morphology very similar to that of Taongi. The reef is almost fully circumferential and is broken only by one narrow forked passage on the western side. There are five distinct islets, although with the inclusion of exposed reef areas at low tide, seven or eight can be identified. The largest islet, Bikar, is oval-shaped with a large expanse of sand and beach on the northern end and extensive reef flats to the south and south-west. The centre of the islet is relatively high at $4.5-6 \mathrm{~m}$. Jabwelo and Almani, the second and third largest islets, respectively, are separated only by a narrow channel at low tide and have more exposed aspects with extensive reef flats on their eastern shores. Jaboero, the smallest islet, is a simple sand/gravel cay of only 2-3m elevation. A feature of the soils on the islets is the presence of a thick layer of raw-humus over phosphate hard pan, characteristic of the Jemo soil series which builds up under Pisonia forest. The narrow channel makes access very difficult and at times hazardous, especially at ebb tide, when the outflowing current becomes very strong and lagoon water level is $0.5 \mathrm{~m}$ higher than the ocean. The lagoon is relatively shallow with fine bottom sediments and the occasional coral head (Thomas et al., 1989).

Climate Although moderately dry, Bikar receives more rainfall than Taongi, which has a mean annual rainfall of approximately $1100 \mathrm{~mm}$. More specific details are not available.

Vegetation Biogeographically, the atoll is linked to the islands of the Radak chain to the south rather than the dryer Taongi to the north. Previously only nine species of plants were recorded from the atoll (Fosberg, 1988), namely Pandanus tectorius, Lepturus repens, Cocos nucifera, Boerhavia repens, Pisonia grandis, Portulaca lutea, Triumfetta procumbens, Tournefortia argentea and Scaevola sericea. All except Pandanus tectorius were observed during the 1988 survey, with Triumfetta being very rare. Bikar is recorded as having dense, healthy Pisonia forests covering much of its interior. However, the survey revealed that the forests were devastated by a cyclone some time since 1978 when they appeared still intact in aerial photos. The Pisonia forest included trees $18 \mathrm{~m}$ tall surrounded by a narrow zone of Tournefortia. Few of the downed Pisonia trees or their limbs have rooted, and most are dead or partially decayed. Tournefortia is invading the devastated areas and young trees $2 \mathrm{~m}$ tall are scattered throughout. Several of the 
mixed-age Cocos trees planted on the north side of the islet were also uprooted. Little ground cover persists on Bikar and even Portulaca, Lepturus and Boerhavia are uncommon (Thomas et al., 1989). On Jabwelo, an estimated $80-90 \%$ of the Pisonia forest was devastated with many fallen trees littering the centre of the islet. Completely open, it had a dense growth of Boerhavia covering or growing around the rotting fallen logs. Some Pisonia remained on the north-eastern (ocean) side where it was protected by a narrow fringe of Tournefortia. A few isolated Pisonia trees remained, nearly all along the margin of the forest. A dense pure stand of Portulaca, ringed by a dense growth of Lepturus, covered the large sand apron to the south of the islet (Thomas et al., 1989). An estimated 60\%-70\% of the Pisonia forest on Almani Islet was destroyed. Some large trees $(12 \mathrm{~m}-17 \mathrm{~m}$ tall) remained, but little regeneration of the forest is taking place. Tournefortia shrubs were growing in the open devastated areas (Thomas et al., 1989). Jaboero Islet, the smallest, supports only Portulaca lutea. There is no vegetation on the small sand cay to the north-west.

Although the vegetation of Bikar lacks the number of distinct semi-arid associations found on Taongi and has lost substantial ecosystem biomass with the recent loss of mature Pisonia grandis forest, it is still, by Pacific atoll standards, relatively undisturbed by invasive exotics. The destruction of the Pisonia forest (doubtless a natural periodic event), and its subsequent regeneration or replacement by other species, is of considerable scientific interest and should be the subject of further study (Thomas et al., 1989).

Fauna Mammals are restricted to Polynesian rat Rattus exulans, which is common on Bikar and Jabwelo. Twenty-three species of birds are listed by Amerson (1969), of which 19 were observed during a survey in September 1988. Previous observers had sighted large numbers of great frigate bird Fregata minor and red-footed booby Sula sp. on all three main islets and these birds are the main large nesting species on the atoll. Although abundant, the numbers present appear to be less than those recorded previously, perhaps due to the destruction of the Pisonia forests. Red-tailed tropic bird Phaeton rubricauda was seen in flocks of 20+ on Bikar and Jabwelo and in smaller numbers on Almani. However, white-tailed tropic bird Phaethon lepturus, recorded as being present in large numbers in April and May of 1964 and $1967(1,000+)$, was not common, with only three birds being observed. Masked booby Sula dactylatra was present on all islets, but not common. Brown booby Sula leucogaster was common but in considerably fewer numbers than recorded in 1964 or 1967. Of the smaller resident breeding birds, white tern Gygis alba was the most common, numbering in the thousands for the atoll. Brown noddy Anous stolidus was also abundant on the three main islands, with perhaps 1,000 for the atoll. The numbers of these species were in keeping with those observed in 1967 (Amerson, 1969). In past surveys, very large numbers of sooty tern Sterna fuscata were observed in rookeries on Jabwelo $(35,000$ in 1967) and Almani (17,000 in 1967), but these numbers have declined greatly and only one small rookery (500-800 birds) was observed in 1988 on the sand apron at the south-west end of the island, with none sighted on Almani. Migrants common to these islands include ruddy turnstone Arenaria interpres, wandering tattler Hetreroscelus incanus, bristle-thighed curlew Numenius tahitiensis (R), lesser golden plover Pluvialis dominica and Pacific reef heron Egretta sacra, but these are present only in small numbers. The most significant feature of Bikar's fauna is the relative abundance of green sea turtle Chelonia mydas (E). Over 264 sets of nesting tracks were observed in 1988 around the perimeters of Bikar (176), Jabwelo (74), Almani (14), together with numerous new and old nest sites. The coral fauna is generally depauperate and shows signs of frequent storm damage. Although the corals are not considered unusual for this habitat, it is interesting to note that Bikar contains several genera not reported for Taongi, providing further evidence of the biogeographical isolation between these atolls. Three marine sites are considered to have exceptional features worthy of protection. The diversity of fish is much greater than 
Taongi. Lutjanus bohar, L. gibbus, leopard groupers, humphead parrot fish Bolmetapan muricatus are present at Bikar but all are absent at Taongi. These species indicate a faunal break, at least in fish fauna, between Taongi and the rest of the Marshall Islands. Although gastropod molluscs are uncommon, small bivalves, including black-lipped pearl oyster Pinctada margaritifera $(\mathrm{CT})$, are fairly common. No giant clams were found but smaller clam species were very abundant, particularly Hippopus (I) and Tridacna maxima (K), and top shell Trochus is found. No marine mammals are evident in the vicinity of the lagoon (Thomas et al., 1989).

Cultural Heritage No archaeological remains have been identified (Thomas et al., 1989). The wreck of the Noho Maru No. 11 Japanese fishing boat lies in the north fork of the reef passage.

Local Human Population Although occasionally visited by the Marshallese, there is no resident human population and little possibility of intensive use of Bikar because of the lack of water and the susceptibility of the atoll to cyclone and storm disturbance (Thomas et al., 1989).

Visitors and Visitor Facilities None (L.S. Hamilton, pers. comm., 1989)

Scientific Research and Facilities The biogeographical importance of Bikar is revealed in its marine environment, which was studied for the first time in September 1988 (Thomas et al., 1989).

Conservation Value Turtle nesting activity at Bikar Atoll is apparently much greater than on any atoll in the Marshall Islands surveyed, clearly justifying its protection solely on these grounds. Bikar is also a bird rookery of considerable importance, ranking second only to Taongi in terms of species diversity and abundance and thus complements Taongi as an undisturbed breeding refuge for sea birds (Thomas et al., 1989).

Conservation Management As with Taongi, the natural diversity of Bikar Atoll, in terms of species numbers, is relatively low in comparison with other atolls of the Marshall Islands. Bikar has the rare distinction of a virtually undisturbed, pristine natural environment, due mainly to its isolation and hazardous access. These factors, together with its inhospitable climate and the frequency of tropical storms and cyclones, render it unsuitable for human occupation or development and has tended to ensure the protection of its natural diversity over the years. The protection of Bikar as a national preserve would complement the diversity of species and habitat proposed for protection at Taongi, and would ensure that a significant proportion of the range of habitats and natural diversity represented in the northern Marshall Islands was under the same category of protection.

It has been recommended that: Bikar Atoll and its surrounding ocean waters be designated a national preservation area; all visitation be prohibited; the introduction of exotic flora and fauna be prevented; fishing boats, yachts and other unauthorised vessels be expressly excluded; dredging or enlarging of the existing channel be prohibited; special consideration be given to the conservation of green turtle; the recovery of the Pisonia grandis forests on Bikar, Jabwelo and Almani islets be monitored; and that, in the longer term and following establishment of the preservation area, consideration be given to its nomination, together with Taongi, as a World Heritage Site under the Unesco World Heritage Convention (Thomas et al., 1989).

Management Constraints No information

Staff None

Budget None 
Local Addresses No information

\section{References}

Amerson, A.B. (1969). Omithology of the Marshall and Gilbert Islands. Atoll Research Bulletin 127. $348 \mathrm{pp}$.

Fosberg, F.R. (1988). A review of the natural history of the Marshall Islands. Report prepared for the East West Center/MacArthur Foundation/SPREP Northern Marshall Islands natural diversity and protected area survey. East-West Center, Honolulu, Hawaii. Unpublished. (Unseen).

Thomas, P.E.J., Fosberg, F.R., Hamilton, L.S., Herbst, D.R., Juvik, J.O., Maragos, J.E., Naughton, J.J. and Streck, C.F. (1989). Report on the Northern Marshall Islands natural diversity and protected areas survey: 7-24 September 1988. South Pacific Regional Environment Programme, Noumea, New Caledonia and East-West Center, Honolulu, Hawaii. 133 pp.

Date November 1989, updated February 1990

\section{BOKAAK (TAONGI) ATOLL}

\section{IUCN Management Category Unprotected}

Biogeographical Province 5.02.13 (Micronesian)

Geographical Location The most northerly of the Marshall Islands, approximately $240 \mathrm{~km}$ north-north-west of Bikar Atoll, its nearest neighbour in the Radak chain, in the western Pacific Ocean. $168^{\circ} 53^{\prime}-169^{\circ} 01^{\prime} \mathrm{E}, 14^{\circ} 32^{\prime}-14^{\circ} 43^{\prime} \mathrm{N}$

Date and History of Establishment Originally established in the 1960s under the Trust Territory of the Pacific administration. This designation has not been recognised since the creation of the Republic in 1986 and the atoll is not currently a legally constituted protected area, although its reinstatement has been recommended (L.S. Hamilton, pers. comm., 1989).

Area $10,697 \mathrm{ha}$; total dry land area $376 \mathrm{ha}$

Land Tenure No information

Altitude Sea level to $6 \mathrm{~m}$

Physical Features The atoll is roughly crescent-shaped, measuring about $18 \mathrm{~km}$ by $9 \mathrm{~km}$, and oriented in a north-south direction. The convex side to the east extends for approximately $34 \mathrm{~km}$, while the concave side to the west is about $22 \mathrm{~km}$ long. The atoll reef is unbroken except for a $20 \mathrm{~m}$-wide channel in the west. Ten islets lie on the southern part of the eastern reef. At low tide several of the smaller islets join with the larger adjacent islets. Sibylla is the largest, measuring approximately $7.2 \mathrm{~km}$ in length and up to $305 \mathrm{~m}$ in width. Kamwome Islet to the north-east of Sibylla is the second largest, while Taongi (Pokak), after which the atoll is named, lies to the south of Sibylla. High boulder ridges and sand ridges indicate a history of severe storms and are a feature of the islets. The northern two-thirds of Sibylla is backed by a very large boulder ridge up to $6 \mathrm{~m}$ high. Large boulders are also scattered inland, carried by storm waves. The seaward 
sides of most of the islets have two, or more, concentrically parallel boulder and cobble ridges. Inland on the wider islets are sand and rubble flats, while back from the lagoon sides are low sand and gravel ridges. On both eastward and lagoon sides are stretches of exposed rock platform comprising coral conglomerate. Soils are mostly very immature, generally belonging to the Shioya Series, and characterised by a mixture of coarser coral sand and gravel of various textures with very little humus accumulation. Large areas of fine sand show little development beyond the stage of unaltered coral sand. The lagoon is shallow, probably not exceeding $30 \mathrm{~m}$ depth, and has many coral heads and patch reefs, some reaching the surface. The lagoon water level is up to $1 \mathrm{~m}$ higher than the surrounding ocean due to an influx of wind-driven waters over the wind ward ocean reef and the presence of only one narrow reef passage on the leeward side. Water cascades over the coral-covered rim and flats of the sloping leeward reef. A massive algal ridge lines the outer edge of the windward reef, while the south and west reefs are coral-covered narrow flats where landings can be made in quiet weather. A very small algal rim, $10-15 \mathrm{~cm}$ high, on lagoon shores of the westernmost islets, on east-facing lagoon reef-fronts and on the windward edges of coral patches in the lagoon, may be a feature unique to Taongi. This rim is maintained by the constant flow of water over the reef flat at virtually all stages of the tide (Thomas et al., 1989).

Climate Taongi is the driest of the Marshall Islands atolls, having a semi-arid character (Thomas et al., 1989). Mean annual temperature is approximately $28^{\circ} \mathrm{C}$, mean annual rainfall approximately $1100 \mathrm{~mm}$ and prevailing winds are north to north-easterlies (Fosberg, 1955a, 1955b).

Vegetation Taongi supports just nine plant species, all native to the Marshall Islands and is entirely undisturbed by exotics. Six vegetation types occur, each dominated by a different species and in a variety of combinations. The most characteristic formation is a low, sparse scrub forest of Tournefortia argentea, $2-6 \mathrm{~m}$ tall, with occasional taller trees. The understorey typically comprises Scaevola sericea, or sparse Lepturus gasparricensis, L. repens, Portulaca lutea, Sida fallax or Boerhavia repens, the latter being more abundant on broken coral rubble substrate. A small stand of Pisonia grandis is found on Kamwome Islet and another very small stand on Sibylla. In 1988 the larger stand was found to contain many dead individuals and a dense stand of $L$. repens was forming the ground cover. Pure stands of very dense Scaevola sericea shrubland, sometimes with Tournefortia trees, are predominant and cover 50-75\% of southern, and nearly $100 \%$ of north-eastern Sibylla. The other woody type is a lower stature, more open Sida fallax shrubland, $0.5-1.0 \mathrm{~m}$ high. This may occur in practically pure stands but more often includes scattered Tournefortia trees. Other associated species include Lepturus, Portulaca or Boerhavia in any combinations. Extensive tracts are found on sandy beaches, usually on the lagoon side of the broader islets, and is the dominant formation on Sibylla. Sida often grades into a bunch-grass savanna with one or more species of Lepturus. The Tournefortia, Scaevola, Sida dominated shrublands and the sandy bunchgrass savanna (Lepturus spp.) represent the finest examples of such vegetation in the Marshalls and probably the entire Pacific region. The final vegetation type is a pioneer community of Portulaca lutea, existing in pure stands on the lagoon side, on rubble and even on pure broken coral, and elsewhere may form a sparse ground cover under Sida shrub and Tournefortia forest. The vegetation of the shallow edges of the lagoon is sparse nodular lithothamnion, encrusting fragments of coral, shell etc., and patches of Caulerpa. In the passages, also, Caulerpa, Lithothamnion and Turbinaria occur (Thomas et al., 1989).

Fauna The atoll supports an abundant seabird and shorebird fauna, with up to 26 species present (Amerson, 1969). Species confirmed as breeding during 1988 included brown booby Sula leucogaster, red footed booby S. sula, great frigate bird Fregata minor, red-tailed tropic 
bird Phaethon rubricauda, sooty tern Sterna fuscata, white tern Gygis alba, brown noddy Anous stolidus, and possibly reef heron Egretta sacra. Migratory birds present during 1988 included bristle-thighed curlew Numenius tahitiensis (R), turnstone Arenaria interpres, Heteroscelus incanus, Asiatic golden plover Pluvialis dominica and Crocethia alba. In total, 20 species were recorded and birds were present in the greatest densities on the three islets to the north of Sibylla: North (Kita), Kamwome and an unnamed islet. Taongi is the only known breeding ground of Christmas Island shearwater Puffinus nativitatus and possibly Bulwer's petrel Bulweria bulwerii. Other terrestrial fauna includes Polynesian rat Rattus exulans on Sibylla but the more aggressive $R$. rattus appears to be absent. A small lizard Cryptoblepharus boutonii poecilopleurus and large hermit crabs Coenobita perlata are common. The 1988 survey confirmed the absence of marine turtles noted in the 1950s, both on land and in surrounding waters. Smaller clam species are very abundant, particularly Tridacna maxima (K), T. squamosa (I), Hippopus (I), but giant clam $T$. gigas (V) was entirely absent. Gastropod molluscs (cowries, cones, lambis etc) were generally lacking although smaller bivalves were present. The very abundant reef fish population is dominated by Lethrinids, Scarids and Lutjanus fulvus and is relatively low in diversity. Other noteworthy species included moray eel Gymnothorax javanicus and grey reef shark Carcarhinus amblyrhyachos. The coral fauna is healthy, but generally depauperate and of low diversity, possibly due to the atoll's extreme isolation. Approximately 100 coral species in the families Acroporidae, Astrocoeniidae, Pocilloporidae, Poritidae, Siderastreidae, Agariciidae, Fungiidae, Mussidae, Merulinidae, Faviidae, Helioporidae, Milleporidae, Tubiproidae, Dendrophyllidae and Stylasteridae, and two soft coral species, are present; a species list is given in Thomas et al. (1989).

Cultural Heritage The atoll is traditionally used for hunting and gathering, particularly sea birds, controlled by the Irooj Laplap (paramount chief of the northern Ratak chain). There appear to be no traditional Marshallese artefacts present. Historic remains include an abandoned camp/homestead, several wrecked ships and the remnant of a former World War Two Japanese communication outpost (Thomas et al., 1989).

Local Human Population The atoll has never been inhabited and the harsh, desiccating climate, lack of significant sources of potable water and the poverty of the soils indicate that the atoll will probably remain uninhabited (Thomas et al., 1989).

Visitors and Visitor Facilities None. The potential for tourist development is severely limited by the dangerous boat passage and lack of anchorage (Thomas et al. , 1989)

Scientific Research and Facilities The atoll has been surveyed a number of times in the past (Amerson, 1969; Fosberg, 1955a, 1955b, 1957, 1965) and more recently (Thomas et al., 1989). An historical account of omithological work is given in Amerson (1969).

Conservation Value The principal values of the atoll are the entirely natural vegetation, abundance of birds, unique reef, shoreline and water circulation characteristics, its biogeographical significance and its importance as a resource sanctuary or gene pool (Thomas et al., 1989).

Conservation Management There is currently no management, although the atoll is protected by its remoteness from human populations. Despite this, it has been recommended that the Republic reinstates its protected area status, possibly as a national preservation area, and considers nomination of the atoll for inscription on the Unesco World Heritage List (L.S. Hamilton, pers. comm., 1989). Further specific management recommendations included in Thomas et al. (1989) cover prohibition of most visitation, control of introduced species, 
opposition to inappropriate development and the disposal of unexploded munitions abandoned after World War Two.

Management Constraints There was a proposal to dump 25 million tons of unspecified waste from the mainland US into the lagoon and to build a town, resort and golf course on the resulting landfill (Fosberg, 1989; Thomas et al., 1989). However, this project has subsequently been cancelled (J. Thorsell, pers. comm., 1991).

Staff None

\section{Budget None}

Local Addresses No information

\section{References}

Amerson, A.B. (1969). Ornithology of the Marshall and Gilbert Islands. Atoll Research Bulletin $127.348 \mathrm{pp}$.

Fosberg. F.R. (1955a). Northern Marshall Islands Expedition, 1951-1952. Atoll Research Bulletin $38.37 \mathrm{pp}$

Fosberg. F.R. (1955b). Northern Marshall Islands Expedition, 1951-1952. Atoll Research Bulletin $39.22 \mathrm{pp}$

Fosberg, F.R. (1957). Description and occurrence of atoll phosphate rock. American Journal of Science 255: 584-592.

Fosberg, F.R (1965). Northern Marshall Islands land biota: birds. Atoll Research Bulletin 114. $35 \mathrm{pp}$

Fosberg, F.R. (1989). Garbage dump in the Marshall Islands? Environmental Conservation 16: 79-79.

Thomas, P.E.J., Fosberg, F.R., Hamilton, L.S., Herbst, D.R., Juvik, J.O., Maragos, J.E., Naughton, J.J. and Streck, C.F. (1989). Report on the Northern Marshall Islands natural diversity and protected areas survey: 7-24 September 1988. South Pacific Regional Environment Programme, Noumea, New Caledonia and East-West Center, Honolulu, Hawaii. 133 pp.

Date November 1989, updated February 1990 


\section{REPUBLIC OF NAURU}

Area $20.7 \mathrm{sq} . \mathrm{km}$

Population 8,100 (1983) (Paxton, 1989)

Natural increase: No information

\section{GNP US\$ 9,091 per capita}

Policy and Legislation Information on policies is not available. There is no protected areas legislation.

International Activities Nauru is not yet party to any of the international conventions or programmes that directly promote the conservation of natural areas, namely the Convention concerning the Protection of the World Cultural and Natural Heritage (World Heritage Convention), Unesco Man and the Biosphere Programme and the Convention on Wetlands of International Importance especially as Waterfowl Habitat (Ramsar Convention).

The Convention on the Conservation of Nature in the South Pacific (1976) has been neither signed nor ratified. Known as the Apia Convention, it entered into force during 1990. The Convention is coordinated by the South Pacific Commission and represents the first attempt within the region to cooperate on environmental matters. Among other measures, it encourages the creation of protected areas to preserve indigenous flora and fauna.

Nauru is party to the South Pacific Regional Enviroenment Programme (SPREP), and the 1986 Convention for the Protection of the Natural Resources and Environment of the South Pacific Region (SPREP Convention) has been signed (15 April 1987) but not yet ratified. The Convention entered into force during August 1990. Article 14 calls upon the parties to take all appropriate measures to protect rare or fragile ecosystems and threatened or endangered flora and fauna through the establishment of protected areas and the regulation of activities likely to have an adverse effect on the species, ecosystems and biological processes being protected. However, as this provision only applies to the Convention area, which by definition is open ocean, it is most likely to assist with the establishment of marine reserves and the conservation of marine species.

\section{Administration and Management Not applicable}

Systems Reviews Nauru is a single raised coral island in the west-central Pacific Ocean located at $0^{\circ} 32^{\prime} \mathrm{S}, 166^{\circ} 56^{\prime} \mathrm{E}$. The highest point is $71 \mathrm{~m}$, surrounded by a terrace and fringing reef. The plateau is largely composed of phosphate rock and is encircled by cliffs which give way to a flat, fertile coastal belt, $90-270 \mathrm{~m}$ wide. The soil is an a mixture of sand and fine corals, which with an irregular rainfall, restricts cultivation of the coastal belt (UNEP/IUCN, 1988).

Vegetation comprises mixed plateau forest, dominated by Calophyllum, a few remaining areas of atoll forest, with Pandanus and Cocos (Douglas, 1969) and just two hectares of mangroves (Dahl, 1986). The vegetation in the interior has been greatly modified by phosphate mining although the extent to which vegetation has re-established on the worked-out phosphate pits has been examined by Manner et al. (1984). Land with little or no top soil has been denuded to allow mining but there has generally been no run-off as the bedrock is very porous (Manner et al., 1984). Continuing denudation may cause long-term environmental micro-climate changes but there has been no monitoring of the impact of phosphate mining on the island (UNEP/IUCN, 1988). 
There is no true reef and no lagoon; the island is surrounded by an almost consistent $150-200 \mathrm{~m}$ wide intertidal platform, cut into the original limestone of the island and typified by the presence of numerous emergent coral pinnacles. The platform is dominated by large yellow-brown algae and little or no coral growth occurs on the reef flat. However, a rich fauna is evident in deeper water, although species diversity has not been documented. The benthic fauna is quite well represented with many common Indo-Pacific species. Reef crabs and other crustaceans are found as well as molluscs, urchins, sea cucumbers and other invertebrates. There around 80 commonly caught fish species (Petit-Skinner, 1981; UNEP/IUCN, 1989).

Most of the population, which enjoys one of the highest per capita incomes in the world, lives near the main coastal road and/or shoreline. There is no evidence of over-exploitation of marine resources. Coastal waters are relatively unpolluted although there may have been one or two instances of silt accumulating on some parts of the reef flat. To date there has been no recorded damage to reef flora and fauna (UNEP/TUCN, 1988). Phosphate is the only significant resource on Nauru, and therefore commercial development of phosphate mining takes priority over the conservation of the natural environment. It was stated at the Second South Pacific Conference on National Parks and Reserves that it was not possible to consider conservation of the remaining phosphate-bearing areas on the island. About $60 \%$ of the island is phosphate bearing, and of this about two-thirds has already been mined.

Restoration of mined land is a key environmental problem. A Commission of Inquiry into the Rehabilitation of the Worked-Out Phosphate Lands in Nauru has been established to look at the issue of rehabilitation of the island and its cost and feasibility (Anon., 1987). It was charged with examining all forms of alternative land usage, including agriculture, and the impact of phosphate mining on fisheries and marine resources. Financial compensation is being sought from Australia, United Kingdom and New Zealand, the main consumers of phosphate. An account of the British Phosphate Commissioners, responsible for phophate extraction prior to independence, with reference to the extensive mining on Nauru and other Pacific islands, is given by Williams and Macdonald (1985). A study should be started immediately to provide baseline data for future environmental impact monitoring. Efforts should be made to establish protected areas, including reefs and important cultural sites (Dahl, 1980) and any forested areas should be protected from any further mining (Dahl, 1986).

\section{Addresses}

No information

\section{References}

Anon. (1987). Commission of Inquiry into the Rehabilitation of Worked-out Phosphate Lands in Nauru. Republic of Nauru.

Anon. (1989). Proceedings of the Second South Pacific Conference on National Parks and Reserves, 24-27 April 1979. Situation Report Nauru. National Parks and Wildlife Service, Sydney, New South Wales, Australia.

Dahl, A.L. (1980). Regional ecosystem surveys of the South Pacific Area. SPC/IUCN Technical Paper 179. South Pacific Commission, Noumea, New Caledonia. 99 pp.

Dahl, A.L. (1986). Review of the Protected Areas System in Oceania. IUCN, Gland, Switzerland and Cambridge UK/UNEP, Nairobi, Kenya. 328 pp.

Davis, S.D., Droop, S.J.M., Gregerson, P., Henson, L., Leon, C.J., Lamlein Villa-Lobos, J., Synge, H. and Zantovska, J. (1986). Plants in Danger: What do we know? IUCN, Gland, Switzerland and Cambridge, UK. 488 pp. 
Manner, H.I, Thaman, R.R and Hassall, D.C. (1984). Phosphate mining induced changes on Nauru Island. Ecology 65(5): 1454-1465.

Petit-Skinner, S. (1981). The Nauruans. MacDuff Press, San Francisco. (Unseen).

Williams, M and Macdonald, B. (1985). The Phosphateers. Melbourne University Press. Carlton, Australia. 586 pp. (Unseen).

Date December 1989 



\section{GNP No information}

Policy and Legislation Niue is a self-governing nation in free association with New Zealand. The 1980-1985 Niue National Development Plan (NNDP) had a number of objectives relating to the environment "as government is aware of the dangers from unwise practices" (Sloth, 1988). The 1985-1990 NNDP emphasises socio-economic development and social services and does not specify protection of the biological environment, although it is recognised in one chapter.

The role of traditional law in the management of island affairs is very strong. Traditional conservation measures are in effect for different times of the year and for different species (UNEP/IUCN, 1988). Customary restrictions, or "fono", are applied from time to time in certain temporary "reserves" which allow the recovery of exploited resources (Yaldwyn, 1973). There is no protected areas legislation and no formally protected areas, although there is a "tapu" forest area. Despite a lack of government legislation under which reserves may be created, the existing tapu forest is probably secure. Niueans and the Government own all the land; no alienation is permitted, although the government may lease areas for up to 60 years (Hay, 1986; UNEP/IUCN, 1988; SPREP, 1980).

International Activities Niue is not yet party to any of the three major international conventions concerned with with the conservation of nature, namely the Unesco Man and Biosphere Programme, the Convention on Wetlands of International Importance especially as Waterfowl Habitat (Ramsar Convention) and the Convention concerning the Protection of the World Cultural and Natural Heritage (World Heritage Convention).

At a regional level, Niue has neither signed nor ratified the Convention on the Conservation of Nature in the South Pacific, 1976. Known as the Apia Convention, it entered into force during 1990. The Convention is coordinated by the South Pacific Commission and represents the first attempt within the region to cooperate on environmental matters. Among other measures, it encourages the creation of protected areas to preserve indigenous flora and fauna.

Niue is party to the South Pacific Regional Environment Programme (SPREP) but has neither signed nor ratified the Convention for the Protection of the Natural Resources and Environment of the South Pacific Region, 1986 (SPREP Convention). The Convention entered into force during August 1990. Article 14 calls upon the parties to take all appropriate measures to protect rare or fragile ecosystems and threatened or endangered flora and fauna through the establishment of protected areas and the regulation of activities likely to have an adverse effect on the species, ecosystems and biological processes being protected. However, as this provision only applies to the Convention area, which by definition is open ocean, it is most likely to assist with the establishment of marine reserves and the conservation of marine species.

Systems Reviews Niue is a single, isolated island located at $169^{\circ} 53^{\prime} \mathrm{W}, 19^{\circ} 03^{\prime} \mathrm{S}, 480 \mathrm{~km}$ north-east of Tonga and $560 \mathrm{~km}$ south-east of Western Samoa. The island is roughly circular and comprises a raised atoll of coralline limestone about $62 \mathrm{~m}$ high with coastal terraces, the most prominent being $20-28 \mathrm{~m}$ above sea level. A number of submerged terraces also occur. The island 
has a slightly depressed upper surface representing the "lagoon" of the original atoll (Yaldwyn, 1973).

The original tropical high rain forest which once covered the island has now been reduced to fragments, generally in the east, and totalling $3,200 \mathrm{ha}$ ( $12.3 \%$ of total land area) in 1981 . There is also a narrow $(200 \mathrm{~m}-800 \mathrm{~m}$ width) strip of coastal forest encircling the island's lower terrace. This forest is still largely intact and covered some $2,500 \mathrm{ha}(9.6 \%)$ in 1981 . Second-growth or regenerating forest is more widespread, totalling 12,000ha (46.2\%) in 1981.

Unproductive "fernland", principally comprising Nephrolepsis hirsutula, covering approximately $3,200 \mathrm{ha}(12.4 \%)$, is found largely in the south in the old lagoon basin. This is generally thought to have arisen as a result of prolonged burning, overcropping and subsequent soil impoverishment (Wodzicki, 1971; Yaldwyn, 1973), and early attempts at mechanised cultivation using bulldozers and discing equipment (G.S.T. Talagi, pers. comm., 1990).

There is no true reef or lagoon. The island is partly surrounded by a platform reef, varying from a few metres to several hundred metres in width and cut in the limestone of the island. Large parts of this are subtidal, the remainder being intertidal. Much of the south and east sides of the islands are entirely devoid of reef flats; some parts have $1 \mathrm{~m}-8 \mathrm{~m}$ wide pools about $1.5 \mathrm{~m}-2.5 \mathrm{~m}$ above sea level. The flat has a thin discontinuous veneer of living corals on its upper (intertidal) surface and rich coral growth over the edge in sub-tidal waters. At least 43 coral genera occur and there is a rich, though largely undocumented, invertebrate fauna (UNEP/IUCN, 1988; Yaldwyn, 1973).

Principal environmental issues include forest destruction by clearing and milling; soil loss due to inappropriate cultivation; and decline in bird and flying fox populations through habitat loss and over-hunting. Reef blasting has been strictly limited in extent (van Westendorp, 1961; Yaldwyn, 1973).

The existing protected areas network is restricted to Huvalu Tapu Forest, and temporary "fono" marine reserves. Dahl (1986) identifies five ecosystems, viz. limestone rain forest, coastal forest on terraces, secondary formations, scrub and fern, and fringing reefs. Only the first of these ecosystems is protected within Huvalu Tapu Forest. Nevertheless, Huvalu probably provides adequate protection for Niue's original terrestrial habitat (Hay, 1986). Dahl (1980) recommends a number of specific sites for designation as protected areas. These include: caves, reefs, historic sites, coastal features, chasms and freshwater springs. Huvalu is one of the few remaining traditional taboo protected areas in Oceania. Dahl (1986) recommends that it should be maintained, and reinforced with legislation if necessary. Other sites may also need protection if they are being degraded. Forest reserves additional to Huvalu would help conserve the Polynesian triller sub-species (Hay, 1986).

Other Relevant Information Huvalu Tapu Forest - comprises approximately $150 \mathrm{ha}$ ( $0.6 \%$ of total land area) of Huvalu Forest, which covers $800-1,200 \mathrm{ha}$ (3.1\%-4.6\%), in eastern-central Niue (Wodzicki, 1973). The forest was set aside as a tapu area in pre-European times, and is believed to house the remains of pre-Christian gods. The tapu still exists, and the area represents a fragment of primeval Niuean forest which has survived since before the arrival of the Polynesians (Wodzicki, 1971). The site is maintained by the Village Council of Hakupu which lies some $3 \mathrm{~km}$ to the south. Human entry and any use of the forest is forbidden, except very occasionally in the case of privileged individuals who have been permitted to enter. The forest is pristine and contains very large trees and an abundant fauna including pigeon and flying fox as well as diurnal, as opposed to the more usual nocturnal, land crabs (Yaldwyn, 1973). 


\section{Addresses}

The Department of Agriculture, Forestry and Fisheries, P O Box 74, Alofi

Secretary to Government, Administrative Department, Alofi

\section{References}

Dahl, A.L. (1980). Regional ecosystem surveys of the South Pacific Area. SPC/IUCNTechnical Paper 179. South Pacific Commission, Noumea, New Caledonia. 99 pp.

Dahl, A.L. (1986). Review of the Protected Areas System in Oceania. IUCN, Gland, Switzerland and Cambridge, UK/UNEP, Nairobi, Kenya. 328 pp.

Hay, R. (1986). Bird conservation in the Pacific Islands. Study Report No. 7. International Council for Bird Preservation, Cambridge, UK. 102 pp.

Schofield, J.C. (1959). The geology and hydrology of Niue Island, South Pacific. New Zealand Geological Survey Bulletin 62.

Sloth, B. (1988). Nature legislation and nature conservation as part of tourism development in the island Pacific. Tourism Council of the South Pacific, Suva, Fiji. 82 pp.

SPREP (1980). Niue. Country Report No. 4. South Pacific Commission, Noumea, New Caledonia. $7 \mathrm{pp}$.

UNEP/IUCN (1988). Coral Reefs of the World. Volume 3. Central and Western Pacific. UNEP Regional Seas Directories and Bibliographies. IUCN, Gland, Switzerland and Cambridge, UK/UNEP, Nairobi, Kenya. 378 pp.

van Westendorp, F.J. (1961). Agricultural development on Niue. South Pacific Bulletin 11: 67-69. (Unseen).

Yaldwyn, J.C. (1973). The environment, natural history and special conservation problems of Niue Island. In: SPC, Regional symposium on conservation of nature: reefs and lagoons. Part 2. South Pacific Commission, Noumea, New Caledonia. 49-55.

Wodzicki, K. (1971). The birds of Niue Island, South Pacific: an annotated checklist. Notornis 18(4): 291-304. 


\section{COMMONWEALTH OF THE NORTHERN MARIANA ISLANDS}

\section{Area 477 sq. km}

Population 20,350 (1985 estimate)

Natural increase: No information

GNP No information

Policy and Legislation The Commonwealth of the Northern Mariana Islands (CNMI) was officially granted the status of a Commonwealth of the USA in October 1986, having previously been part of the Trust Territory of the Pacific Islands; it had, however, been functioning as a Commonwealth since 9 January 1978 (UNEP/IUCN, 1988).

Prior to October 1986, the islands were formally under United States federal legislation and 'irust Territory legislation. This included the Trust Territory Environment Enabling Act, enacted by the former Congress of Micronesia in 1972, which provided for the establishment of a Trust Territory Environmental Protection Board. However, neither the Act, nor the work of the Board related specifically to protected areas. The Trust Territory Endangered Species Act (TTPI Public Law 6-55 of 1975) allowed for acquisition of land or water for the purpose of conserving threatened species. Other relevant Trust Territory Acts included the Fishing Law and the Land Use Planning Act, both 1972. US legislation relevant to the Trust Territories included various pollution laws and housing acts, as well as the Fish and Wildlife Coordination Act and the National Environmental Policy Act. Neither the legislation, nor the policy, on protected areas was clear while the country was a part of the Trust Territory, and this is why so few protected areas were actually established over the whole area. Furthermore, the United States, while administering the Territory, did not own property, and hence had no direct jurisdiction over designation of protected areas. New national legislation is under development.

Under the original constitution, passed on 5 December 1976, the islands of Managaha, Sariguan (sic) and Maug were protected, with the provision that Sariguan might be substituted by another island by the legislature in due course. This substitution did not occur until the constitutional amendment of 3 November 1985 which removed Sariguan's protected status. The island was considered a poor candidate for protection due to the depredations of past human habitation, large populations of rats and goats and the destruction of many native species and habitats. In place of Sariguan, which was opened for possible development, Uracas (Farallon de Parajos), Asuncion and Guguan, as well as Maug, were given strict protection under the Constitution (Anon., 1985).

Thus, Section 2 of Article XIV of the Commonwealth Code, as amended in 1985, states that "the island of Managaha shall be maintained as an uninhabited place and used only for cultural and recreational purposes. The islands of Maug, Uracas, Asuncion, Guguan and other islands specified by law shall be maintained as uninhabited places and used only for the preservation and protection of natural resources, including but not limited to bird, wildlife and plant species".

Public Law 1-8, Chapter 13, Sections (a), (b), (c), (e) and (f) empowers the Department of Natural Resources to protect and enhance natural resources. Public Law 2-51 establishes the Division of Fish and Wildlife within the Department of Natural Resources and mandates this Division to provide for the conservation of fish and wildlife and to acquire areas for the protection of fish and wildlife resources (SPREP, 1985). 
International Activities The Commonwealth of the Northern Mariana Islands is not yet directly party to any of the international conventions concerned with protected areas, namely, the Unesco Man and Biosphere Programme, the Convention on Wetlands of International Importance especially as Waterfowl Habitat (Ramsar Convention) or the Convention concerning the Protection of the World Cultural and Natural Heritage (World Heritage Convention).

The compact between the USA and CNMI leaves international pacts and conventions in the control of the former which itself is a party to all three conventions. However, it is not clear whether the conventions are applicable to CNMI (J.D. Reichel, pers. comm., 1989). At a regional level, CNMI has neither signed nor ratified the Convention on the Conservation of Nature in the South Pacific, 1976. Known as the Apia Convention, it entered into force during 1990. The Convention is coordinated by the South Pacific Commission and represents the first attempt within the region to cooperate on environmental matters. Among other measures, it encourages the creation of protected areas to preserve indigenous flora and fauna.

CNMI is party to the South Pacific Regional Environment Programme (SPREP) but has neither signed nor ratified the Convention for the Protection of the Natural Resources and Environment of the South Pacific Region, 1986 (SPREP Convention). The Convention entered into force during August 1990. Article 14 calls upon the parties to take all appropriate measures to protect rare or fragile ecosystems and threatened or endangered flora and fauna through the establishment of protected areas and the regulation of activities likely to have an adverse effect on the species, ecosystems and biological processes being protected. However, as this provision only applies to the Convention area, which by definition is open ocean, it is most likely to assist with the establishment of marine reserves and the conservation of marine species.

Administration and Management Administration of official parks and reserves lies in the CNMI Department of Natural Resources, which includes Divisions of Fish and Wildlife, Parks and Recreation and Plant Industry (Forestry). All lands not held with deeds by other agencies are controlled by the Marianas Public Land Corporation (J.D. Reichel, pers. comm., 1989).

Systems Reviews Vegetation comprises pioneer stands of Casuarina sp., broad-leaved evergreen thickets, mixed scrub forest, with some Miscanthus sp. and Nephrolepsis sp. herbaceous communities on the northern islands. Broad-leaved evergreen forest on old lava flows and Miscanthus sp. and tree ferns on ash slopes of those northern islands with dormant volcanoes are found (Douglas, 1969). Tinian has mostly secondary forest while Rota has some closed evergreen and limestone forests (Fosberg, 1973). Small areas of cloud forest occur on the volcanic islands of Saipan, Agrihan, Alamagan and Anatahan (Dahl, 1980). The lower slopes of many islands have been cleared for cultivation (Davis et al., 1986) and Saipan, Rata, Tinian and Aguijuan are much disturbed. Remaining areas of natural vegetation, mostly on cliffs, contain rare native and endemic species of plants and birds. The islands to the north, from Farallon de Medinilla to Uracas, are less disturbed and are of prime interest for the study of biotic colonisation under natural conditions (Dahl, 1980). Coral reefs around Rota, Tinian, Saipan and elsewhere are described in UNEP/IUCN (1988).

There are permanent human populations on only the three largest islands to the south, namely Saipan, Tinian and Rota, but two other islands (Almagan and Agrihan) are regularly inhabited. Pagan was continuously inhabited by the largest of the northern island's populations until an eruption in May 1985 forced evacuation of the island. Over $87 \%$ of the population lives on Saipan, where tourism is the main source of income; 163,000 tourists visited Saipan in 1986, the majority being Japanese (IUCN/UNEP, 1988). There has subsequently been a considerable 
increase, with 233,291 tourists visiting during 1988 and an estimated 300,000 during 1989 (L. Eldredge, pers. comm, 1989).

Moves to protect some of the northerly islands commenced in the $1960 \mathrm{~s}$, when Farallon de Medinilla, Guguan, Maug and Uracas were designated as "islands for science" through the efforts of the International Biological Programme and IUCN. Subsequently, Farallon de Medinilla lost its conservation importance due to military training exercises.

\section{Addresses}

Division of Parks and Recreation, Department of Natural Resources, Saipan, MP 96950, USA

\section{References}

Anon. (1985). CNMI northern islands win preservation. Coastal Views 8(3): 1, 8-9.

Dahl, A.L. (1980). Regional ecosystems survey of the South Pacific Area. SPC/IUCN Technical Paper 179. South Pacific Commission. Noumea, New Caledonia. 99 pp.

Davis, S.D., Droop, S.J.M., Gregerson, P., Henson, L., Leon, C.J., Lamlein Villa-Lobos, J., Synge, H. and Zantovska, J. (1986). Plants in Danger: What do we know? IUCN, Gland, Switzerland and Cambridge, UK. 488 pp.

Douglas, G. (1969). Draft checklist of Pacific Islands. Micronesica 5: 327-463.

Fosberg. F.R. (1973). On present condition and conservation of forests in Micronesia. In: Pacific Science Association Standing Committee on Pacific Botany Symposium: planned utilization of the lowland tropical forests, August 1971. Bogor, Indonesia.

Owen, R.P. (1973). A conservation program for the Trust Territory. Country Report. Regional Symposium on Conservation of Nature - Reefs and Lagoons. South Pacific Commission, Noumea, New Caledonia.

SPREP (1980). Trust Territory of the Pacific Islands. Country Report 14. South Pacific Commission, Noumea, New Caledonia.

SPREP (1985). Northem Mariana Islands. In: Thomas, P.E.J. (Ed.), Report of the Third South Pacific National Parks and Reserves Conference. Volume III. Country reviews. South Pacific Commission, Noumea, New Caledonia. Pp. 159-161.

UNEP/IUCN (1988). Coral Reefs of the World. Volume 3. Central and Western Pacific. UNEP Regional Seas Directories and Bibliographies. IUCN, Gland, Switzerland and Cambridge, UK/UNEP, Nairobi, Kenya. 378 pp.

\section{ANNEX \\ Definitions of protected area designations, as legislated, together with authorities responsible for their administration}

\section{Title (English): Commonwealth Code}

Date: 5 December 1976; Amendment No. 37 passed 3 November 1985

Brief description: Section 2 of Article XIV states that "the island of Managaha shall be maintained as an uninhabited place and used only for cultural and recreational purposes. The islands of Maug, Uracas, Asuncion, Guguan and other islands specified by law shall be 
maintained as uninhabited places and used only for the preservation and protection of natural resources, including but not limited to bird, wildlife and plant species".

Administrative authority: Not specified

Designation: Not specifically stated

\section{SUMMARY OF PROTECTED AREAS}

\begin{tabular}{llccc}
\hline $\begin{array}{l}\text { Map } \\
\text { ref. }\end{array}$ & Name of area & $\begin{array}{c}\text { IUCN management } \\
\text { category }\end{array}$ & $\begin{array}{c}\text { Area } \\
\text { (ha) }\end{array}$ & $\begin{array}{c}\text { Year } \\
\text { notified }\end{array}$ \\
\hline & Preserves & & & \\
1 & Asuncion Island* & I & 722 & 1985 \\
2 & Guguan Island* & I & 412 & 1985 \\
3 & Maug Island* & I & 205 & 1976 \\
4 & Uracas Island (Farallon de Pajaros)* & I & 202 & 1985 \\
& Proposed & & & \\
Bird Island Wildlife Reserve & Proposed & $(90)$ & \\
Kagman Peninsula and Forbidden Island & Proposed & $(105)$ & \\
Kastiyu Wildlife Area & Proposed & $(200)$ & \\
Marpi Wildlife Area & Proposed & $(150)$ \\
Mt Tapotchau Wildlife Area & Proposed & $(317)$ & \\
Naftan Point Wildlife Area & Proposed & $(195)$ \\
Saguagaha Wildlife Area & Proposed & $(150)$ & \\
Marpi Commonwealth Forest & Proposed & $(463)$ \\
Rota Commonwealth Forest & Proposed & $(500)$ \\
\hline
\end{tabular}

* Site is described in this directory.

${ }^{\dagger}$ Locations of most protected areas are shown in the accompanying map. 


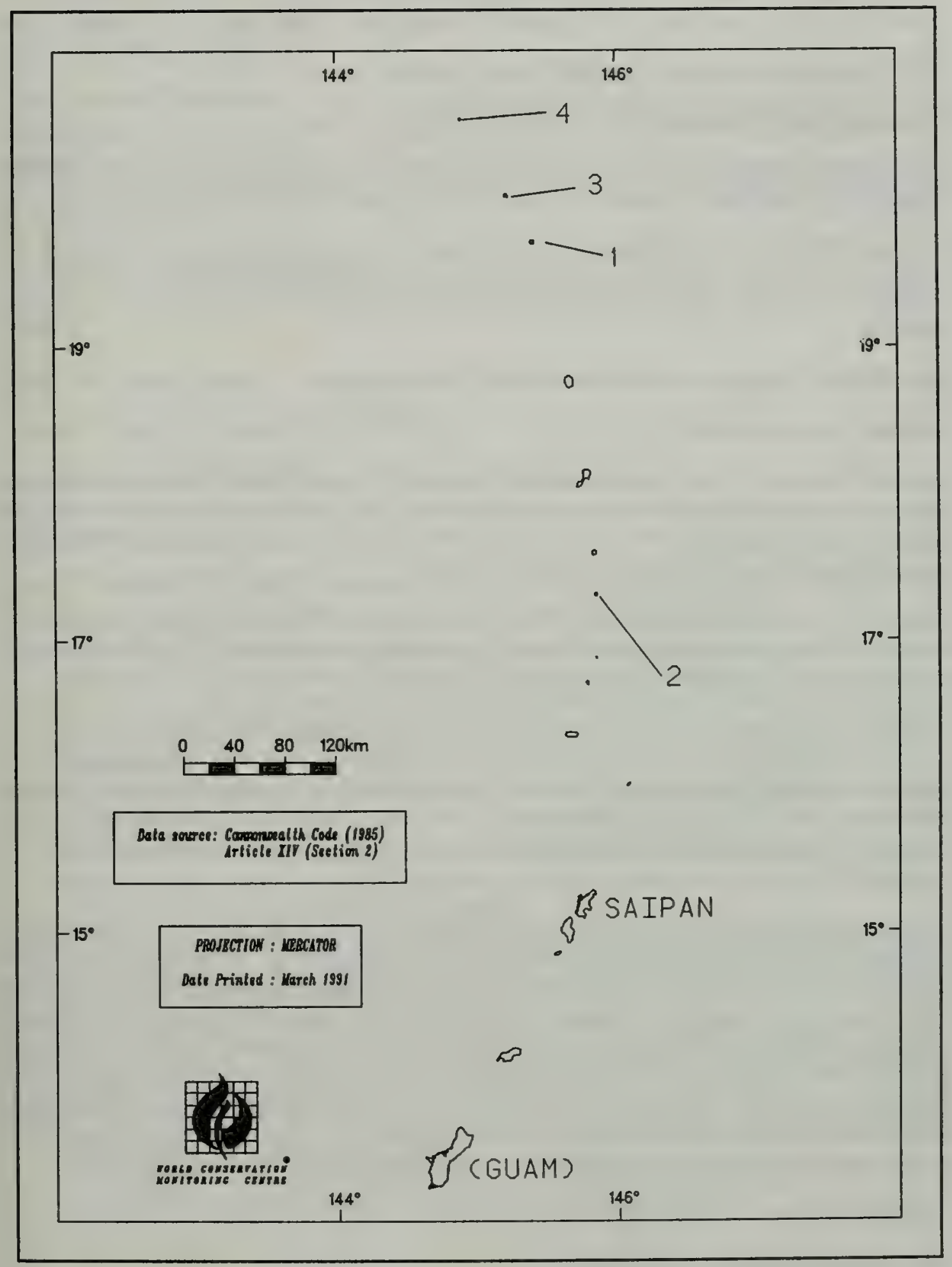

Protected Areas of the Commonwealth of the Northern Mariana Islands 


\section{ASUNCION ISLAND}

\section{IUCN Management Category I (Strict Nature Reserve)}

\section{Biogeographical Province 5.02.13 (Micronesian)}

Geographical Location An island in the northerly part of the Marianas island chain, flanked by Maug to the north and Agrihan to the south. Approximately $19^{\circ} 40^{\prime} \mathrm{N}, 145^{\circ} 24^{\prime} \mathrm{E}$

Date and History of Establishment Established as a preserve under Article 14 of the Commonwealth Code, following its amendment on 3 November 1985.

Area $722 \mathrm{ha}$

Land Tenure Commonwealth of the Northem Mariana Islands

Altitude Sea level to $891 \mathrm{~m}$

Physical Features A nearly conical, currently quiescent volcanic island. The extreme southem tip and a large portion of the east coast comprise rock cliffs and loose scree slopes which are largely devoid of vegetation (Pratt and Lemke, 1984). A hot water spring periodically floods at least one inter-tidal pool, killing all transient animals

Climate Data specific to the island are not available but the following figures are generally applicable. The mean air temperature is $26.4^{\circ} \mathrm{C}$, mean water temperature is $26.9^{\circ} \mathrm{C}$ and mean annual rainfall is $1567 \mathrm{~mm}$ (Eldredge et al., 1977).

Vegetation The island is forested on the lower slopes to the west with large coconut groves. The native forest is dense with a low canopy of less than $10 \mathrm{~m}$. Dominant tree species include Hibiscus, Pandanus, Neisosperma, Erythrina, Terminalia and Phyllanthus. Ferns are a common understorey plant. The ridge line and ravine mixed forest eventually reaches a broad band of swordgrass near the top of the island (Pratt and Lemke, 1984). Further information is given by Fosberg (1960).

Fauna There is an estimated population of 400 Mariana flying fox Pteropus mariannus (E) on the island (Wiles et al., 1989). Twenty-five bird species are known to use the island, although a number do not breed there. Common bird species include migratory wedge-tailed shearwater Puffinus pacificus, Matsudaira's storm-petrel Oceanodroma matsudairae and ruddy turnstone Arenaria interpres. Resident and breeding species include white-tailed tropic bird Phaethon lepturus, brown booby Sula leucogaster, sooty tem Sterna fuscata, brown noddy Anous stolidus, white tern Gygis alba, collared kingfisher Halcyon chloris, Micronesian starling Aplonis opaca and Micronesian honeyeater Myzomela rubrata (Reichel and Glass, in press). A checklist of pelagic, deep water bottom and reef fishes has been compiled by Bryan and Falig (1987).

\section{Cultural Heritage No information}

Local Human Population Uninhabited

Visitors and Visitor Facilities No information. There are no developments on the island.

Scientific Research and Facilities The island has been the subject of a number of surveys, although there is little published material. There are no facilities. 
Conservation Value Asuncion is little disturbed and not easily accessible, being north of the most northerly inhabited island. Vegetation is abundant and includes a number of endemic species (Eldredge, 1977).

Conservation Management Access is restricted but there are no other management activities (J.D. Reichel, pers. comm., 1989). Section 2, Article 14 of the Commonwealth Code states that "Asuncion (and other islands) ... shall be maintained as uninhabited places and used only for the preservation and protection of natural resources, including but not limited to bird, wildlife and plant species".

Management Constraints Polynesian rat Rattus exulans is present in very small numbers and may cause the loss of seabirds. Poaching may occur sporadically (J.D. Reichel, pers. comm, 1989).

Staff None on the island

Budget There are no specific allocations for any of the protected islands

Local Addresses CNMI Division of Fish and Wildlife, Saipan

\section{References}

Bryan, P. and Falig, C. (1987). Checklist of pelagic, deep water bottom and reef fishes. CNMI Division of Fish and Wildlife. Five year report: FY 83-87. Unpublished.

Eldredge, L.G. (1977). Comments on preserving uninhabited islands of the Commonwealth of the Northern Mariana Islands. University of Guam Marine Laboratory. Unseen.

Eldredge, L.G., Tsuda, R.T., Moore, P., Chernin, M. and Neudecker, S. (1977). A natural history of Maug, Northern Mariana Islands. University of Guam Marine Laboratory Technical Report $43.87 \mathrm{pp}$.

Fosberg, F.R. (1960). The vegetation of Micronesia. Bulletin of the American Museum of Natural History 119: 1-75.

Pratt, T.K. and Lemke, T.O. (1984). Wildlife field trip report from the Townsend Cromwell Raioma cruise, 18 February-5 March, 1984. Division of Fish and Wildlife; Department of Natural Resources. Unpublished report. 49 pp.

Reichel, J.D. (in press). The status and conservation of seabirds in the Mariana Islands. In: Status and conservation of the world's seabirds, part 2. ICBP Technical Bulletin. International Council for Bird Preservation, Cambridge, UK.

Reichel, J.D. and Glass, P.O. (in press). Checklist of the birds of the Mariana Islands. 'Elepaio.

Reichel, J.D., Taisacan, S. Villagomez, S.C. Glass, P.O. and Aldan, D.T. (1987). Field trip report: Northern Islands. Unpublished manuscript. $15 \mathrm{pp}$.

Reichel, J.D., Taisacan, S. and Glass, P.O. (1988). Wildlife Unit field Trip Report: Northem Islands. Unpublished manuscript. $13 \mathrm{pp}$

Wiles, G.J., Lemke, T.O., Payne, N.H. (1989). Population estimates of fruit bats (Pteropus mariannus) in the Mariana Islands. Conservation Biology 3: 66-76.

Date February 1990 


\section{GUGUAN ISLAND}

\section{IUCN Management Category I (Strict Nature Reserve)}

\section{Biogeographical Province 5.02.13 (Micronesian)}

Geographical Location An island in the central part of the Marianas chain in the western Pacific Ocean. Flanked by Alamagan to the north and Sarigan to the south. Approximately $17^{\circ} 19^{\prime} \mathrm{N}$, $145^{\circ} 51^{\prime} \mathrm{E}$

Date and History of Establishment Established as a preserve under Article 14 of the Commonwealth Code, following its amendment on 3 November 1985.

Area $412 \mathrm{ha}$

Land Tenure Commonwealth of the Northern Mariana Islands

Altitude Sea level to $301 \mathrm{~m}$

Physical Features A volcanic island that may have been active as recently as the early 1900 s. It comprises two humps with an old vent on the south side and a more recent vent on the north. A recent lava flow covers much of the north-east side which is barren. There are unstable rock cliffs to the south and east (J.D. Reichel, pers. comm., 1989).

Climate Data specific to the island are not available but the following figures are generally applicable. The mean air temperature is $26.4^{\circ} \mathrm{C}$, mean water temperature is $26.9^{\circ} \mathrm{C}$ and mean annual rainfall is $1567 \mathrm{~mm}$ (Eldredge et al., 1977).

Vegetation The south is well forested with Pandanus, Erythrina, Terminalia, Ficus, Neisosperma and Morinda among other species. Relatively small patches of swordgrass are interspersed throughout the south. Forest fills a number of narrow ravines leading to the south-west and south-east coasts. A low canopy of trees covers the flat plateau in the south-central and south-east of the island (Pratt and Lemke, 1984). Further information is given in Fosberg (1960).

Fauna There is an estimated population of 400 Mariana flying fox Pteropus mariannus (E) distributed around the centre and southern part of the island (Wiles et al., 1989). Guguan is amongst the important bird colonies in the Mariana Islands (Reichel, 1988). Some 25 species are known to use the island, although a number do not breed there. The most common bird species include migratory great frigatebird Fregata minor, lesser golden plover Pluvialis dominica and ruddy turnstone Arenaria interpres. Resident and breeding species include white-tailed tropicbird Phaethon lepturus, red-tailed tropic bird P. rubricauda, brown booby Sula leucogaster, red-footed booby S. sula, Micronesian megapode Megapodius laperouse (R), grey-backed tern Sterna lunata, sooty tern $S$. fuscata, brown noddy Anous stolidus, black (white-capped) noddy A.minutus, white tern Gygis alba, white-throated ground dove Gallicolumba xanthonura, Micronesian starling Aplonis opaca and Micronesian honeyeater Myzomela rubrata (Reichel and Glass, in press). A more detailed account of the abundance and distribution of bird species is given by Villagomez et al. (1986). A checklist of pelagic, deep water bottom and reef fishes has been compiled by Bryan and Falig (1987).

Cultural Heritage No information 


\section{Local Human Population Uninhabited}

Visitors and Visitor Facilities No information. There are no developments on the island.

Scientific Research and Facilities The island has been the subject of a number of surveys, although there is little published material. There are no facilities.

Conservation Value No specific information

Conservation Management Access is restricted but there are no other management activities (J.D. Reichel, pers. comm., 1989). Section 2, Article 14 of the Commonwealth Code states that "Guguan (and other islands) ... shall be maintained as uninhabited places and used only for the preservation and protection of natural resources, including but not limited to bird, wildlife and plant species".

Management Constraints Polynesian rat Rattus exulans is present in very small numbers and may cause the loss of seabirds. Poaching may occur sporadically (J.D. Reichel, pers. comm, 1989).

Staff None on the island

Budget There are no specific allocations for any of the protected islands

Local Addresses CNMI Division of Fish and Wildlife, Saipan

\section{References}

Bryan, P. and Falig, C. (1987). Checklist of pelagic, deep water bottom and reef fishes. CNMI Division of Fish and Wildlife. Five year report. FY 83-87. Unpublished.

Eldredge, L.G., Tsuda, R.T., Moore, P., Chernin, M. and Neudecker, S. (1977). A natural history of Maug, Northern Mariana Islands. University of Guam Marine Laboratory Technical Report 43.87 pp.

Fosberg, F.R. (1960). The vegetation of Micronesia. Bulletin of the American Museum of Natural History 119: 1-75.

Pratt, T.K. and Lemke, T.O. (1984). Wildlife field trip report from the Townsend Cromwell Raioma cruise, 18 February-5 March, 1984. Division of Fish and Wildlife, Department of Natural Resources. Unpublished report. $49 \mathrm{pp}$.

Reichel, J.D. (in press). The status and conservation of seabirds in the Mariana Islands. In: Status and conservation of the world's seabirds, part 2. ICBP Technical Bulletin. International Council for Bird Preservation, Cambridge, UK.

Reichel, J.D. and Glass, P.O. (in press). Checklist of the birds of the Mariana Islands. 'Elepaio.

Reichel, J.D., Taisacan, S. Villagomez, S.C. Glass, P.O. and Aldan, D.T. (1987). Field trip report: Northern Islands. Unpublished manuscript. $15 \mathrm{pp}$.

Reichel, J.D., Taisacan, S. and Glass, P.O. (1988). Wildlife Unit field Trip Report: Northem Islands. Unpublished manuscript. $13 \mathrm{pp}$

Wiles, G.J., Lemke, T.O., Payne, N.H. (1989). Population estimates of fruit bats (Pteropus mariannus) in the Mariana Islands. Conservation Biology 3: 66-76.

Villagomez, S., Glass, P. and Palacios, T. (1986). Field trip report: Guguan Island. CNMI Division of Fish and Wildlife and Division of Plant Industry. Unpublished report. 8 pp.

Date February 1990 


\section{MAUG ISLAND}

\section{IUCN Management Category I (Strict Nature Reserve)}

\section{Biogeographical Province 5.02.13 (Micronesian)}

Geographical Location One of the 15 islands in the Mariana chain in the western Pacific Ocean. Maug lies at the northern end of the chain, flanked to the north by Farallon de Pajaros and to the south by Asuncion Island. Approximately $20^{\circ} 01^{\prime} \mathrm{N}, 145^{\circ} 13^{\prime} \mathrm{E}$

Date and History of Establishment Maug Island was designated "an island for science" in November 1968 at the "Technical Meeting on Conservation of Pacific Islands" held at Koror, Palau and Guam. This has no legal standing, but the island is also protected under the national constitution. Maug Island is listed in the 1976 Constitution (Article XIV, Natural Resources) as an area "to be maintained as an uninhabited place and used only for the preservation of bird, fish, wildlife and plant species".

Area 205ha

\section{Land Tenure Commonwealth of the Northern Mariana Islands}

\section{Altitude Sea level to $227 \mathrm{~m}$}

Physical Features Maug island comprises three steep-sided islets, North Island (227m), East Island $(215 \mathrm{~m})$ and West Island $(178 \mathrm{~m})$, encircling a central lagoon. They represent the remains of a volcano which probably collapsed following a massive and explosive eruption. Much of the shoreline comprises large rounded boulders or low, consolidated headlands. The islets rise steeply from the sea, often as near vertical or undercut cliffs. There are a few small "beaches" along the coastline of East Island and a man-made bulk-head has been constructed near the northern end of the island. Since the geology is of volcanic origin the vertical basalt dykes with intermittent stratified unconsolidated material are a particularly interesting feature of the landscapes of North and West Island. There is a narrow, smooth terrace of limestone extending some $10 \mathrm{~m}$ ( $25 \mathrm{~m}$ depth) from the eastern shore of West Island (Eldredge, 1983). No true coral reef exists within the crater lagoon; sediments and basaltic boulders, products of terrestrial erosion, inhibit its development (Eldredge et al., 1977).

Climate Data specific to the island are not available but the following figures are generally applicable. The mean air temperature is $26.4^{\circ} \mathrm{C}$, mean water temperature is $26.9^{\circ} \mathrm{C}$ and mean annual rainfall is $1567 \mathrm{~mm}$. Approximately four typhoons occur each year within 300 miles of the island (Eldredge et al., 1977).

Vegetation East and West Islands have a similar vegetation pattern. The steep valleys on the lagoon side are matted by a variety of low growing grasses, sedges, herbs and climbers. Three notable species of fern grow in rocky crevices and the bases of valleys, namely Asplenium nidus, Polypodium scolopendria and Pteris quadriaurita. Interspersed among this low growth are stands of Terminalia catappa, Morinda citrifolia, Pipturus argenteus, Hibiscus tiliaceus, Pisonia grandis, Vitex negundo and Crinum asiaticum. There is a large plantation of Cocos nucifera in the central part of East Island, with thick stands of Pandanus tectorius and Crinum asiatica on the lower slopes. Species found on West Island, but not on East, include Canavalia sp., Hedyotis sp., Capsicum sp., Scaevola taccada, Gossypium hirsutum and Achyrantes canescens. The summit of North Island is covered predominantly with communities of Ipomoea pes-caprae, 
Cyperus javanica, Fimbristylis cymosa (endemic to Northern Marianas) and Capparis cordifolia. Large stands of Crinum asiatica grow on the lower slopes, with Terminalia catappa and Pisonia grandis at higher elevations. Four grasses are known from Maug, Digitaria mariannensis (endemic to the Marianas) sword grass Miscanthus floridulus, Stenotaphrum micranthum and temple grass Zoysia matrella. Other species common to all three islets include sedge Cyperus javanica, the four climbers, Wedelia biflora, wood rose Operculina ventricosa, Colubrina asiatica and Ipomoea pes-caprae, the shrub Capparis cordifolia (considered threatened in the southern Marianas), the herbs Vernonia cinerea, Phyllanthus marianus (endemic to the Marianas), $P$. amarus, Hyptis pectinata and three species of Portulaca. Fifty-nine species of terrestrial plants have been identified from Maug, none of which is endemic to Maug Island alone. Eldredge et al. (1977) includes a checklist of terrestrial vascular plants found on the island. During their stay on the island, the Japanese inhabitants introduced Cocos nucifera, Hernandia sonora, Melochia compacta, Neiosperma oppositifolia, Trema orientalis and Cordia subcordata. The marine benthic algal flora is also described in Eldredge et al. (1977). Some $75-95 \%$ of the basalt boulder and pavement in the lagoon is covered by a mat of red algae Gelidiopsis intricata, Tolypiocladia glomerulata, Jania capillacea and Polysiphonia sp. and brown alga Lobophora variegata. Of the 60 species identified from Maug, the following are of particular interest: red algae Laurencia succisa, considered rare on Maug; brown algae Homoeostrichus flabellatus, otherwise known in Micronesia only from Guam; and Stypopodium hawaiiensis, a new record for the Marianas.

Fauna The only indigenous mammal known from Maug Island is Mariana flying fox Pteropus mariannus (E), a species endemic to the Mariana Islands. Surveys undertaken during 1984 failed to locate any bats during three days searching, and the population was estimated at less than 25 individuals (Wiles et al., 1989). Sheath-tailed bat Emballonura semicaudata has been recorded on East Island (Lemke, 1986), a considerable northerly extension to this species' range.

Some 25 bird species have been identified (with population estimates and status from Reichel (1988) and Reichel and Glass, in press): wedge-tailed shearwater P uffinus pacificus (uncommon, migrant), Matsudaira's storm petrel Oceanodroma matsudairae (common, migrant), red-tailed tropic bird Phaethon rubricauda (200 pairs, possibly breeding), white-tailed tropic bird $P$. lepturus (15 pairs, possibly breeding), masked booby Sula dactylatra (250 pairs, migrant), red-footed booby $S$. sula (1,000 pairs, possibly breeding), brown booby S. leucogaster (130 pairs, breeding), great frigatebird Fregata minor (uncommon, migrant), sooty tern Sterna fuscata (common, possibly breeding), brown noddy Anous stolidus (6,000 pairs, possibly breeding), black (white-capped) noddy A. minutus (150 pairs, migrant), white tem Gygis alba (100 pairs, possibly breeding), lesser golden plover Pluvialis dominica (uncommon, migrant), wandering tattler Heteroscelus incanus (uncommon, migrant), grey-tailed tattler $H$. brevipes (uncommon, migrant), ruddy turnstone Arenaria interpres (common, migrant), reef heron Egretta sacra (uncommon, breeding), Micronesian starling Aplonis opaca (common, breeding), white-collared kingfisher Halcyon chloris (common, resident), Micronesian honeyeater Myzomela rubrata (common, breeding), white-throated ground dove Gallicolumba xanthonura (rare, breeding) and Micronesian megapode Megapodius laperouse (R) (rare, possibly breeding) which is listed under the US Federal Endangered Species Act of 1973.

Hawksbill turtle Eretmochelys imbricata (E) has been reported from the island. The marine fish fauna has been extensively surveyed. The herbivorous kyphosids and acanthurids are predominant in all habitats. Dominant species include Kyphosus cinarascens, Acanthurus lineatus, A. leucopareius, Ctenochaetus striatus and Naso lituratus. Two species, Chromis caerulea and Pomacentrus melanopterus, are found on the seaward side of West Island but not 
in the lagoon. The checklist in Eldredge et al. (1977), derived from five expedition surveys, comprises 232 species of fish. The marine invertebrate fauna is typical of other Indo-West Pacific coastal areas. So far, 130 species have been identified, including 24 species of opisthobranchs, collected in only four hours in 1972, indicating a particularly rich opisthobranch fauna worthy of further investigation. Within the lagoon only a few localised coral communities have been identified; there is no true coral reef development. Predominant species include Millepora platyphylla, Acropora spp., Porites lutea, Goniastrea retiformis, Pocillopora spp., and Favia spp. A narrow but well developed fringing reef extends along the southern seaward shore of West Island, characterised by massive growths of many of the species found within lagoon, complemented by Lobophyllia spp., Diplastrea heliopora and Heliopora coerulea.

Cultural Heritage Discovered by Europeans on 17 August 1669, when Diego de Sanvitores named the island San Lorenzo (Eldredge et al., 1977).

Local Human Population Uninhabited; the native population was removed from the island by the Spanish in 1695. A weather station and fish processing plant were established by the Japanese in 1939, but these have since been abandoned.

\section{Visitors and Visitor Facilities None}

Scientific Research and Facilities Maug Island was first described in 1907 by Governor G. Fritz, the administrator of the Marianas. A magnetic survey team from Japan further described the general and submarine topography in 1922. The next major survey was not until 1971, when a team from the University of Guam and Guam's Fish and Wildlife Division made collections of the fish and coral fauna. Another group visited Maug aboard the 'Wanderer' and collected terrestrial plants, algae and invertebrates (Fosberg et al., 1975). The University of Guam Marine Laboratory undertook a broad-based marine survey of the Mariana island chain in 1975. This was followed in the same year by some detailed studies of marine algae (Tsuda and Tobias, 1977a and 1977b) and terrestrial flora (Fosberg et al., 1977). Sir Peter Scott and R. and V. Taylor visited Maug twice in August 1976 aboard the "Lindblad Explorer". Based on their brief observations of the fish and avifauna, they recommended to the Resident Commissioner that the island be protected. An on-site environmental survey was carried out in November 1977 (Eldredge et al., 1977). Virtually no studies have been made of the terrestrial vertebrates, gastropods or insects.

Conservation Value Maug is amongst the important bird colony locations in the Mariana Islands (Reichel, 1988).

\section{Conservation Management No information}

Management Constraints Several exotic plant species were introduced by the Japanese and a few Polynesian rats have been reported; none is believed to pose a particularly serious threat to the native flora and fauna (Eldredge et al., 1977). The presence of goats has been reported (Reichel et al., 1987), although this was not confirmed on subsequent visits (Reichel et al., 1988).

Staff No information

Budget No information

Local Addresses No information 


\section{References}

Anon. (1978). Maug, a wildlife preserve in the Northern Marianas Commonwealth. Pacific Science Association Information Bulletin 30(2): 17-18.

Eldredge, L.G. (1983). Summary of environmental and fishing information on Guam and the Commonwealth of the Northern Mariana Islands: Historical background, description of the islands and review of the climate, oceanography and submarine topography. National Oceanic and Atmospheric Administration Technical Memorandum, National Marine Fisheries Service. University of Guam Marine Laboratory.

Eldredge, L.G., Tsuda, R.T., Moore, P., Chernin, M. and Neudecker, S. (1977). A natural history of Maug, Northern Mariana Islands. University of Guam Marine Laboratory Technical Report $43.87 \mathrm{pp}$.

Fosberg, F.R., Falanruw, M.V.C. and Sachet, M.H. (1975). Vascular flora of the Northern Mariana Islands. Smithsonian Contributions to Botany 22:1-44.

Fosberg, F.R. Falanruw, M.V.C. and Sachet, M.H. (1977). Additional records of vascular plants from the Northern Mariana Islands. Micronesica 13(1): 27-31.

Lemke, T.O. (1986). Distribution and status of the sheath-tailed bat (Emballonura semicaudata) in the Mariana Islands. Journal of Mammalogy 67: 743-746.

Owen, R.P. (1977). A checklist of birds of Micronesia. Micronesica 13(1): 65-81.

Reichel, J.D. (1988). The status and conservation of seabirds in the Mariana Islands. Division of Fish and Wildlife, Saipan. Unpublished manuscript. 5 pp.

Reichel, J.D. and Glass, P.O. (in press). Checklist of the birds of the Mariana Islands. 'Elepaio.

Reichel, J.D., Taisacan, S. Villagomez, S.C. Glass, P.O. and Aldan, D.T. (1987). Field trip report: Northern Islands. Unpublished manuscript. $15 \mathrm{pp}$.

Reichel, J.D., Taisacan, S. and Glass, P.O. (1988). Wildlife Unit field trip report: Northern Islands. Unpublished manuscript. $13 \mathrm{pp}$

Tsuda, R.J. and Tobias, W.J. (1977a). Marine benthic algae from the Northern Mariana Islands, Chlorophyta and Phaeophyta. Bulletin of the Japanese Society of Phycology 25(2): 67-72.

Tsuda, R.J. and Tobias, W.J. (1977b). Marine benthic algae from the Northern Mariana Islands, Cyanophyta and Rhodophyta. Bulletin of the Japanese Society of Phycology 25(3): 155-158.

Wiles, J., Lemke, T.O and Payne, N.H. (1989). Population estimates of fruit bats (Pteropus marianus) in the Mariana Islands. Conservation Biology 3: 66-76.

Date 1977, reviewed February 1990

\section{SARIGAN ISLAND (DEGAZETTED)}

\section{IUCN Management Category Degazetted}

\section{Biogeographical Province 5.2.13 (Micronesian)}

Geographical Location An island in the Northern Marianas chain in the western Pacific Ocean, flanked to the north by Guguan Island and to the south by Anatahan Island. Approximately $16^{\circ} 42^{\prime} \mathrm{N}, 145^{\circ} 47^{\prime} \mathrm{E}$

Date and History of Establishment The island is no longer officially designated a protected area, but was formerly protected under the national consitution, in which it was listed under Article XIV (Natural Resources) as an area "to be maintained as an uninhabited place and used 
only for the preservation of bird, fish, wildlife and plant species". On 3 November 1985 the Constitution was amended such that Sarigan (Sariguan) was opened for development.

Area 500ha

\section{Land Tenure Government}

Altitude Sea level to $549 \mathrm{~m}$

Physical Features Sarigan Island is an extinct volcano with no historical record of volcanic activity. The irregular shoreline is primarily of high cliffs and steep slopes, with a small stretch of low-lying old lava flow along the south-west coast. The island rises to the extinct cone in the south. Much of the upland area is at various stages of erosion.

Climate No information

Vegetation Fosberg et al. (1975) list 128 species of terrestrial vascular plants for the island.

Fauna In 1978 some 10-15 adult Micronesian megapode Megapodius laperouse (R) were reported.

Cultural Heritage Extensive archaeological remains have been found on the island, including latte stones and pottery.

\section{Local Human Population Uninhabited}

\section{Visitors and Visitor Facilities None}

Scientific Research and Facilities There have been a few brief visits paid to the island in the past. Fosberg et al. (1975) describes the flora. Bats, birds and reef fish communities are being studied by staff from the Division of Fish and Wildlife (L. Eldredge, pers. comm., 1989).

Conservation Value Conservation value has been lost to such an extent that the island is no longer protected.

Conservation Management An active goat control programme was being implemented during 1989 (L. Eldredge, pers. comm., 1989).

Management Constraints Numerous goats were seen grazing on the island slopes during a brief visit to Sarigan in 1975. More recent reports indicate that goats and rats have proliferated, at the expense of endemic flora and fauna, leading to erosion (Anon., 1985). Sarigan was a poor candidate for conservation status since many native species and habitats have either been disturbed or destroyed.

Staff No information

Budget No information

Local Addresses No information

\section{References}

Anon. (1985). N. Islands slated for preservation. Commonwealth of the Northern Mariana Islands Coastal Resources Management Programme. Coastal Views 7(2). 12 pp 
Eldredge, L.G. (1983). Summary of environmental and fishing information on Guam and the Commonwealth of the Northern Mariana Islands: Historical background, description of the islands and review of the climate, oceanography and submarine topography. National Oceanic and Atmospheric Administration Technical Memorandum, National Marine Fisheries Service. University of Guam Marine Laboratory.

Fosberg, F.R., Falanruw, M.V.C. and Sachet, M.-H. (1975). Vascular flora of the Northern Mariana Islands. Smithsonian Contributions to Botany 22: 1-44.

Date 1983, updated October 1989, February 1990

\section{URACAS ISLAND}

IUCN Management Category I (Strict Nature Reserve)

Biogeographical Province 5.02.13 (Micronesian)

Geographical Location The northernmost of the Marianas island chain, in the western Pacific Ocean, also known as Farallon de Pajaros. Maug lies to the south. Approximately $20^{\circ} 32^{\prime} \mathrm{N}$, $144^{\circ} 54^{\prime} \mathrm{E}$

Date and History of Establishment Established as a preserve under Article 14 of the Commonwealth Code, following its amendment on 3 November 1985.

Area $202 \mathrm{ha}$

Land Tenure Commonwealth of the Northern Mariana Islands

Altitude Sea level to $319 \mathrm{~m}$

Physical Features Comprises a nearly conical, currently active, volcanic island. Over $90 \%$ of the island is lava, cinder and ash associated with the formation of the present volcanic cone (Pratt and Lemke, 1984).

Climate Data specific to the island are not available but the following figures are generally applicable. The mean air temperature is $26.4^{\circ} \mathrm{C}$, mean water temperature is $26.9^{\circ} \mathrm{C}$ and mean annual rainfall is $1567 \mathrm{~mm}$ (Eldredge et al., 1977).

Vegetation Two small, hard rock outcroppings along the south coast (perhaps the remnant of a volcanic plug and flows from an earlier cone) are covered with some vegetation (Pratt and Lemke, 1984). Species include Pipturus argenteus, Morinda citrifolia, Scaevola taccada, Colubrina asiatica, Rhynchospora corymbosa, Brasiliensis sp., Wedelia biflora, Phymatodes scolopendria, Asplenium nidus, Miscanthus floridulus (Reichel et al., 1987).

Fauna Some 20 bird species have been identified. Common migrants include great frigatebird Fregata minor and ruddy turnstone Arenaria interpres. Common resident and breeding species include red-tailed tropic bird $P$ haethon rubricauda, white-tailed tropic bird $P$. lepturus, masked booby Sula dactylatra, red-footed booby S. sula, brown booby S. leucogaster, brown noddy Anous stolidus, white tern Gygis alba, Micronesian starling Aplonis opaca, white-collared kingfisher Halcyon chloris, Micronesian honeyeater Myzomela rubrata and Micronesian 
megapode Megapodius laperouse (R) (common, breeding) which is listed under the US Federal Endangered Species Act of 1973 (Reichel and Glass, in press).

A checklist of pelagic, deep water bottom and reef fishes has been compiled by Bryan and Falig (1987). Surveys undertaken in 1983 and 1984 located no fruit bats Pteropus sp. (Wiles et al., 1989).

\section{Cultural Heritage No information}

\section{Local Human Population Uninhabited}

Visitors and Visitor Facilities No information. There are no developments on the island.

Scientific Research and Facilities The island has been the subject of a number of surveys, although there is little published material.

Conservation Value Uracas is amongst the important bird colonies in the Mariana Islands (Reichel, 1988).

Conservation Management Access is restricted but there are no other management activities (J.D. Reichel, pers. comm., 1989). Section 2, Article 14 of the Commonwealth Code states that "Uracas (and other islands) ... shall be maintained as uninhabited places and used only for the preservation and protection of natural resources, including but not limited to bird, wildlife and plant species".

Management Constraints Norway rat Rattus norvegicus is present in very small numbers and may cause the loss of seabirds (J.D. Reichel, pers. comm., 1989).

Staff None on the island

Budget There are no specific allocations for any of the protected islands.

Local Addresses CNMI Division of Fish and Wildlife, Saipan

\section{References}

Bryan, P. and Falig, C. (1987). Checklist of pelagic, deep water bottom and reef fishes. CNMI Division of Fish and Wildlife. Five year report. FY 83-87. Unpublished.

Eldredge, L.G., Tsuda, R.T., Moore, P., Chernin, M. and Neudecker, S. (1977). A natural history of Maug, Northern Mariana Islands. University of Guam Marine Laboratory Technical Report $43.87 \mathrm{pp}$.

Pratt, T.K. and Lemke, T.O. (1984). Wildlife field trip report from the Townsend Cromwell Raioma cruise, 18 February-5 March, 1984. Division of Fish and Wildlife; Department of Natural Resources. Unpublished report. 49 pp.

Reichel, J.D. (1988). The status and conservation of seabirds in the Mariana Islands. Division of Fish and Wildlife, Saipan, CNMI. Unpublished manuscript. 5 pp.

Reichel, J.D. (in press). The status and conservation of seabirds in the Mariana Islands. In: Status and conservation of the world's seabirds, part 2. ICBP Technical Bulletin. International Council for Bird Preservation, Cambridge, UK.

Reichel, J.D. and Glass, P.O. (in press). Checklist of the birds of the Mariana Islands. 'Elepaio.

Reichel, J.D., Taisacan, S. Villagomez, S.C. Glass, P.O. and Aldan, D.T. (1987). Field trip report: Northern Islands. Unpublished manuscript. $15 \mathrm{pp}$. 
Reichel, J.D., Taisacan, S. and Glass, P.O. (1988). Wildlife Unit field Trip Report: Northern Islands. Unpublished manuscript. $13 \mathrm{pp}$

Wiles, G.J., Lemke, T.O., Payne, N.H. (1989). Population estimates of fruit bats (Pteropus mariannus) in the Mariana Islands. Conservation Biology 3: 66-76.

Date February 1990 


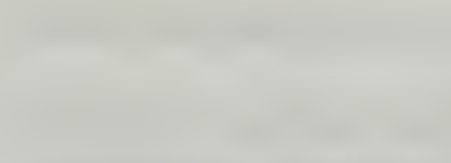




\section{REPUBLIC OF PALAU}

Area 492 sq. $\mathrm{km}$

Population 13,873 (1986); 14,106 (1988 estimate)

Natural increase: $-0.3 \%$

GNP No information

Policy and Legislation Prior to 1981, some United States federal legislation and Trust Territory legislation was applicable, including the Trust Territory Environment Enabling Act enacted by the former Congress of Micronesia in 1972. This provided for the establishment of a Trust Territory Environmental Protection Board. However, neither the Act, nor the work of the board related specifically to protected areas. The Trust Territory Endangered Species Act (TTPI Public Law 6-55 of 1975) allowed for acquisition of land or water for the purpose of conserving threatened species. Other relevant Trust Territory Acts included the Fishing Law and the Land Use Planning Act, both 1972. US legislation relevant to the Trust Territory included various pollution laws and housing acts, as well as the Fish and Wildlife Coordination Act and the National Environmental Policy Act. Prior to 1981, neither the legislation, nor the policy on protected areas was clear, with the result that few areas were actually established. This is largely because the United States, while administering the Trust Territory, did not own property, and hence had no direct jurisdiction over designations of protected areas.

The Republic of Palau was established as a constitutional democratic government on 1 January 1981. Article VI of the Constitution places responsibility upon the national government to take postive action to conserve a "beautiful, healthful and resourceful natural environment". There are 16 states within the Republic, each with an individual constitution; 14 states are within the Palauan archipelago and two are in the South-east Islands group (BRD, 1989). On 21 February 1986 Palau and US Government representatives formally signed a Compact of Free Association. To date, six plebiscites have been held on the Compact, but the constitutionally mandated $75 \%$ approval vote has not been achieved. A subsequent simple majority vote has been overturned in the courts as unconstitutional. Consequently, Palau has continued to be a remnant of the former Trust Territory of the Pacific.

National protected areas legislation includes Palau National Code, Title 24, Division 3 (Reserves and Protected Areas), Chapter 30 (Ngerukewid Islands Wildlife Preserve), Sections 3001 to 3004 , which provides for the creation, prohibitions, penalties and regulations relating to Ngerukewid Islands Wildlife Preserve. As of 1988, Ngerukewid Islands Wildlife Preserve was the only legally established perennially protected natural area in the Republic of Palau (Thomas et al., 1989). Palau National Code, Sections 3101 to 3103 provide for the seasonal protection of the Ngerumekaol grouper spawning area. There are also a number of State Ordinances, including Ordinance of Koror No. 150-69 (48-69) which provides for the establishment of Trochus sanctuaries in Koror. Legal instruments which provide for the protection of cultural and sunken resources include, for example, the Palau Lagoon Monuments Law (Palau National Code, Section 301). A fuller listing of environmental legislation is given in BRD (1989).

International Activities Palau is not yet party to the Unesco Man and Biosphere Programme, the Convention on Wetlands of International Importance especially as Waterfowl Habitat (Ramsar Convention) or the Convention concerning the Protection of the World Cultural and Natural Heritage (World Heritage Convention). It has been recommended that Palau become a 
State Party to the World Heritage Convention in order that Ngerukewid Islands Wildlife Preserve can be inscribed on the World Heritage List (Thomas et al., 1989).

The Convention on the Conservation of Nature in the South Pacific (1976) has been neither signed nor ratified. Known as the Apia Convention, it entered into force during 1990. The Convention is coordinated by the South Pacific Commission and represents the first attempt within the region to cooperate on environmental matters. Among other measures, it encourages the creation of protected areas to preserve indigenous flora and fauna.

Palau signed the Convention for the Protection of the Natural Resources and Environment of the South Pacific (SPREP Convention) on 25 November 1986, although this has not been ratified. Article 14 calls upon the parties to take all appropriate measures to protect rare or fragile ecosystems and threatened or endangered flora and fauna through the establishment of protected areas and the regulation of activities likely to have an adverse effect on the species, ecosystems and biological processes being protected. However, as this provision only applies to the Convention area, which by definition is open ocean, it is most likely to assist with the establishment of marine reserves and the conservation of marine species.

Administration and Management Prior to independence a Conservation Officer for Palau, and the rest of the Trust Territory, was hired to work under the Chief of Agriculture for the Trust Territory. Management of parks, recreation areas and historical sites fell under the Bureau of Community Services in the Ministry of Social Services, while responsibility for conservation areas was placed upon the Bureau of Resources and Development in the Ministry of Natural Resources. Enforcement of the laws pertaining to these areas was the responsibility of the Bureau of Public Safety in the Ministry of Justice (SPREP, 1985).

Since 1981, Ngerukewid Islands and Ngerumekaol have been administered by the Division of Marine Resources, Bureau of Resources and Development, Ministry of National Resources. Parks and recreation areas are administered by the Chief of the Division of Parks and Recreation in the Bureau of Community Services, Ministry of Social Services. The Division of Conservation and Entomology, also within the Bureau of Resources and Development, was created under Executive Order No. 70, with a broad remit to prepare conservation programmes and pest control and entomological activities (Otobed, 1989). Trochus breeding sanctuaries are under the protection of the governors of each State (BRD, 1989). In general, surveillance and patrolling activities have been hindered by a lack of staff and resources (D. Otobed, pers. comm., 1989).

Systems Reviews Palau comprises an archipelago of 8 large and 18 small high volcanic islands, a number of low limestone islands and about 350 islets surrounded by a complex of fringing and patch reefs. Babeldaob is the largest island, covering $397 \mathrm{sq} . \mathrm{km}$. The climate is maritime, tropical and wet, with only small seasonal and diumal temperature fluctuations. Rainfall is high throughout the year but especially intense during the June to October monsoon (Smith, 1977).

Undisturbed forest is predominant, varying little between the high volcanic islands and low platform islands. Principal formations are species-rich broadleaf lowland rain forest on weathered basalt, limestone forest on coralline limestone with very little soil, dense riverine forest along rivers on all high islands and mixed broadleaf atoll and beach forest on the central portion of atolls and islets and on level areas behind the sand beaches of high islands (Dahl, 1980). Some $75 \%$ of Babeldaob is covered by mature forest in upland, mangrove and swampy areas (Merlin and Keene, n.d.), and mangroves occur along as much as $80 \%$ of the coast of Babeldaob although they are not prevalent around the shorelines of the limestone islands (Smith, 1977). Palau is considered to have the richest coral reefs in the Pacific with the highest diversity (Faulkner, 1974; 
Smith, 1977); 300 species have been recorded. A summary account is given in UNEP/IUCN (1988), including detailed accounts of the Chelbacheb and Helen Island reefs.

In general, Palau's natural environment remains in good condition, partly due to a low population density. Abundant and diverse terrestrial and marine ecosystems occur, particularly the very widespread reefs and lagoons. This natural beauty, and the numerous islands and beaches, give the country considerable tourism potential. There have been a number of major capital projects and there is now a risk that unplanned development could have serious environmental consequences. The improvement of living standards on Koror, the capital island where some $40 \%$ of the population dwells, is a major priority. The provision of sewage and waste disposal facilities, and the disposal of hazardous waste and unexploded munitions, such as on Peleliu, constitute major environmental issues (Maragos, 1986). The compact of Free Association between Palau and the United States entitles, inter alia, the latter to use large areas of the archipelago for military purposes (Caufield, 1986) which may lead to environmental degradation. Smith (1977) provides an overview of the major natural resources and some of the threats to them.

Palau has been included in a recent review of the protected areas systems in Oceania (Dahl, 1986), and the establichment of terrestrial reserves on Babeldaob and in the Chelbacheb Islands, including marine lakes, is recommended. The richness of the marine environment warrants protection in some significant marine reserves at sites such as Ngemlis. Helen should probably also be protected because of the problem with poaching.

\section{Addresses}

Division of Conservation and Entomology, PO Box 100, Biology Laboratory, Koror 96940, USA

\section{References}

Bureau of Resources and Development (1989). Palau. Country Review No. 10. Fourth South Pacific Conference on Nature Conservation and Protected Areas. Port Vila, Vanuatu, 4-12 September. South Pacific Commission, Noumea. 12 pp.

Caufield, C. (1986). Peace makes waves in the Pacific. New Scientist 3 April.

Dahl, A.L. (1980). Regional ecosystem survey of the South Pacific Area. SPC/IUCN Technical Paper 179. South Pacific Commission, Noumea, New Caledonia. 99 pp.

Dahl, A.L. (1986). Review of the Protected Areas System in Oceania. IUCN, Gland, Switzerland and Cambridge, UK/UNEP, Nairobi, Kenya. 328 pp.

Faulkner, D. (1974). This living reef. Quadrangle/New York Books, New York. 179 pp.

Merlin, M. and Keene, T. (n.d.). Dellomel er a Belau: plants of the Belauan Islands. East-West Centre, Honolulu, Hawaii and Office of the Chief Conservationist and Bureau of Education, Oreor, Belau. 48 pp.

Smith, S.V. (1977). Palau environmental study: a planning document. Contribution to the IUCN Marine Project 3.7.70. 102 pp.

SPREP (1980). Trust Territory of the Pacific Islands. Country Report 14. South Pacific Commission, Noumea, New Caledonia.

SPREP (1985). Republic of Palau. In: Thomas, P.E.J. (Ed.), Report of the Third South Pacific National Parks and Reserves Conference. Volume III. Country reviews. South Pacific Commission, Noumea, New Caledonia. Pp. 162-174.

Thomas, P.E.J., Holthus, P.F. and Idechong, N. (1989). Ngerukewid Islands Wildlife Preserve: proposed management plan. IUCN/World Wide Fund for Nature/South Pacific Regional Environment Programme. South Pacific Commission, Noumea, New Caledonia. 43 pp. 
UNEP/IUCN (1988). Coral Reefs of the World. Volume 3. Central and Western Pacific. UNEP Regional Seas Directories and Bibliographies. IUCN, Gland, Switzerland and Cambridge, UK/UNEP, Nairobi, Kenya. 378 pp.

Otobed, D. (1989). Conservation in Palau - rebuilding the Conservation Service. Case study No. 34. Fourth South Pacific Conference on Nature Conservation and Protected Areas. Port Vila, Vanuatu, 4-12 September. South Pacific Commission, Noumea, New Caledonia. 3 pp.

\section{ANNEX \\ Definitions of protected area designations, as legislated, together with authorities responsible for their administration}

\section{Title (English): Palau National Code}

Date: Not known

Brief description: Division 3, Title 24, Chapter 30 provides for the creation (S.3001) and protection (S.3002-3004) of Ngerukewid Islands Wildlife Preserve

Administrative authority: Division of Marine Resources, Ministry of National Resources

Designations: The Ngerukewid Islands Preserve is hereby established to include all land, water, reef and underwater areas of the island group known as Ngerukewid (Orukuisu) Islands, bounded by the grid coordinates 91 and 94 and 18 and 22 on sheets 1043-I SW and 1043 II NW on Army Map Series W 856. The preserve is henceforth to be retained in its present primitive condition where the natural plant and animal life shall be permitted to develop undisturbed.

\section{SUMMARY OF PROTECTED AREAS}

\begin{tabular}{llccc}
\hline $\begin{array}{l}\text { Map }^{\dagger} \\
\text { ref. }\end{array}$ & Name of area & $\begin{array}{c}\text { IUCN management } \\
\text { category }\end{array}$ & $\begin{array}{c}\text { Area } \\
\text { (ha) }\end{array}$ & $\begin{array}{c}\text { Year } \\
\text { notified }\end{array}$ \\
\hline 1 & $\begin{array}{l}\text { Wildlife Reserves } \\
\text { Ngerukewid Islands* }\end{array}$ & III & 1,200 & 1956 \\
2 & $\begin{array}{l}\text { Sanctuaries } \\
\text { Trochus Sanctuaries (n=21) }\end{array}$ & Unassigned & & \\
3 & $\begin{array}{l}\text { Spawning Areas } \\
\text { Ngerumekaol Grouper Spawning Area }\end{array}$ & Unassigned & 259 \\
\hline
\end{tabular}

* Site is described in this directory.

${ }^{\dagger}$ Locations of most protected areas are shown in the accompanying map. 

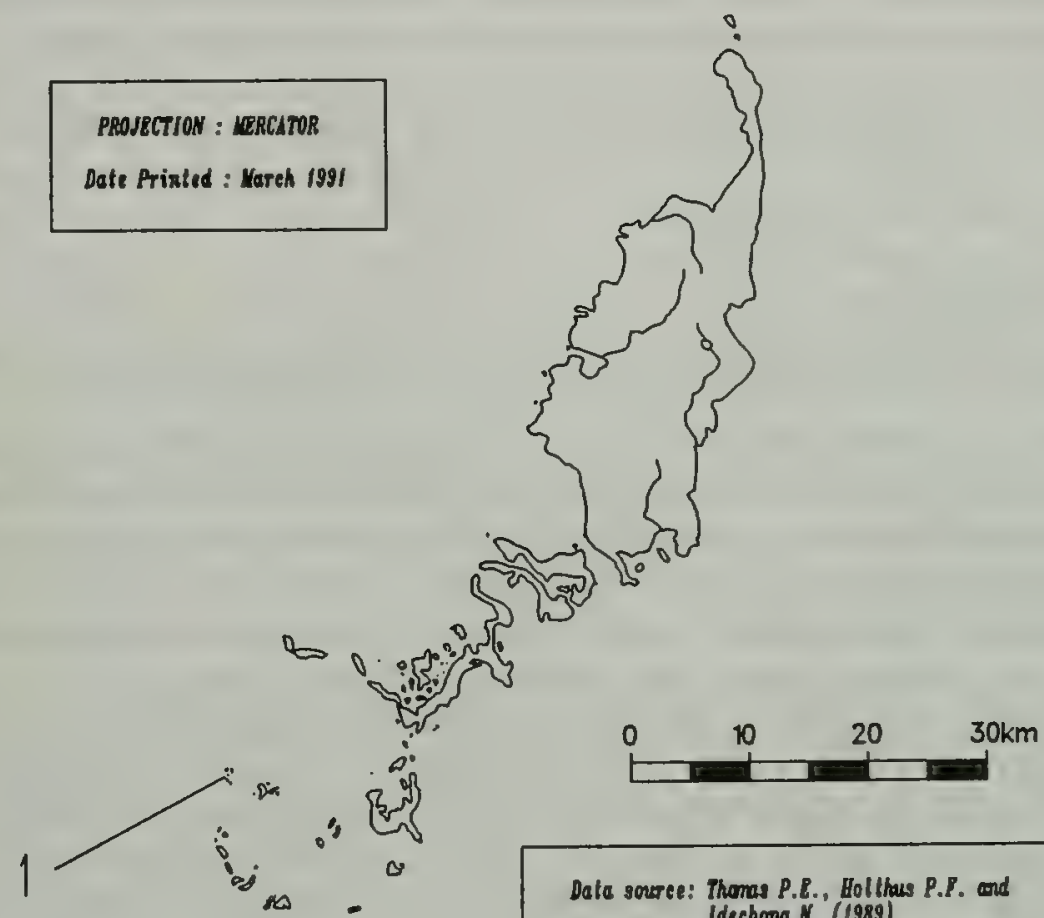

Date soures: Thermas P.E., Holthas P.I. and Idechong N. (1989) Ngerukewid Islonds Tildlife Freserve Ioragenent Plor.

South Pucific Regional Prwiromext Programe, Normea, Now Caledonia.

The Kinistry of Ketural Reserves, Toror.

Protected Areas of the Republic of Palau 


\section{NGERUKEWID ISLANDS WILDLIFE PRESERVE}

\section{IUCN Management Category III (Natural Monument)}

\section{Biogeographical Province 5.02.13 (Micronesian)}

Geographical Location Situated within the Palau barrier reef, approximately $15 \mathrm{~km}$ south-west of Koror, $7 \mathrm{~km}$ west of Mecherechar and $13 \mathrm{~km}$ north of Peleliu. The current boundary is described in the enabling legislation as Grid Coordinates 91, 94, 18 and 22 on Sheets 1043-I SW and 1043-II NW on US Army Map Service Series W856. These coordinates describe a rectangle measuring $4 \mathrm{~km}$ by $3 \mathrm{~km}$ and includes the main Ngerukewid Islands, several patch reefs and fringing reefs of varying sizes and a large body of open water. Approximately $7^{\circ} 10^{\prime} \mathrm{N}, 134^{\circ} 15^{\prime} \mathrm{E}$

Date and History of Establishment 1956. Established by the Palau District Legislature and formally established in law in Palau District Code 201. Following the establishment of a Constitutional Government in 1981 and a subsequent review of all former legislation, the Palau National Code (PNC) was promulgated. Modern legislation relating to the preserve is promulgated under Palau National Code, Title 24, Chapter 30, paragraphs 3001-3004.

Area $1,200 \mathrm{ha}$, of which $90 \mathrm{ha}$ is terrestrial

\section{Land Tenure Koror State}

Altitude Ranges from approximately $22 \mathrm{~m}$ below sea level to $80 \mathrm{~m}$ (Thomas et al., 1989).

Physical Features Comprises a cluster of small, high limestone islands characterised by steep slopes and undercut notches at sea level. The largest island is deeply embayed with sheltered coves. The limestone consists of clastic carbonate material from calcareous algae, corals, foramnifera and other organisms (US Army, 1956) cemented by secondary deposition. Rift and shear faulting associated with tectonic and volcanic activity has elevated the islands. Sea level fluctuations have successively exposed and submerged limestone areas, alternately subjecting them to subaerial erosion and marine reef building. Differential erosion and freshwater solution have modified exposed limestone and created a jagged pit and pinnacle topography, solution fissures, sink holes and caves. Marine solution and biological activity have combined to undercut the limestone at sea level, giving the islands a characteristic "mushroom" shape. Beaches composed of reef rubble and sand often form in coves and other locations where reef material is deposited by waves and currents. Back beaches contain well-drained Ngedebus soils, which are derived from wind and wave deposited coralline sands. These are classified as isohyperthermic Typic Tropopsamments (Smith, 1983). About six small pocket beaches are found at the shoreward portion of reef flats along the convoluted shoreline of the main Negerukewid Islands. Some beaches appeared to be undergoing moderate erosion in January 1988.

The main islands share a common reef platform and ridges of scattered coral growth connect many of the islands. Between these ridges are shallow basins, $5-10 \mathrm{~m}$ deep, which are slowly filling with coralline sand. The shallow sand and rubble dominated reef flat extends to the reef edge, which dips lagoonward with increased coral cover. At lower depths along the slope, sand and rubble become predominant and the sand lagoon floor is encountered at $8-10 \mathrm{~m}$ depth (Birkeland and Holthus, 1989). The preserve contains numerous patch reefs of various sizes and shapes, similar in construction to the fringing reef platform. The shallow $(0.5-1.0 \mathrm{~m})$ reef interior consists of coral sand and rubble deposits and low coral cover. Some patch reefs, or portions of 
reefs, are more submerged and support much greater coral coverage. Sand and rubble deposits become increasingly dominant on the lower slope (Birkeland and Holthus, 1989).

The soils which accumulate under the upraised limestone forest have been classified by Smith (1983) as part of the Rock Outcrop-Peleliu series. These consist of clayey-skeletal, oxidic, isohyperthermic Lithic Eutropepts which form in residuum derived from coral limestone. Soils are not found to any large extent on the steep slopes and cliffs. Precipitation percolates rapidly into the porous limestone and there is very little, if any, surface run-off (Thomas et al., 1989). There is little published information on the water quality or circulation patterns of Palau's large southern lagoon. There is little lagoon current activity generated by the transport of ocean waters across the wide $(2 \mathrm{~km})$ barrier reef to the immediate west of the preserve. In general, circulation is tidal, with a northerly flow on flooding tides and southerly on ebbing tides. The currents are weak and do not effectively flush the area of naturally occurring suspended materials such as planktonic, particulate and miscellaneous organic matter resulting in reduced water clarity. The tidal regime is semi-diurnal, with periodic extreme low tides that can expose coral reefs and may cause coral bleaching and die-back if coincident with heavy rain (Thomas et al., 1989).

Climate Data specific to the preserve are not available. In general, Palau has a maritime tropical wet climate, with little seasonal temperature variation. The mean daily temperature throughout the year is approximately $27^{\circ} \mathrm{C}$, with a mean diurnal range of about $7^{\circ} \mathrm{C}$. The coolest and warmest months are January and April, respectively (US Army, 1956). Mean annual rainfall is about $3700 \mathrm{~mm}$, ranging from $3150 \mathrm{~mm}$ to $4400 \mathrm{~mm}$. Rainfall is heavy during December and January with some $300 \mathrm{~mm}$ monthly, but decreasing markedly when the intertropical convergence zone moves to the south of the islands. February, March and April are driest, with monthly mean rainfalls of between $190 \mathrm{~mm}$ and $230 \mathrm{~mm}$ (Smith, 1983). Relative humidity is about $90 \%$ at night and $75 \%$ to $80 \%$ during the day (US Army, 1956). A north-east wind prevails during December to March, veering to the east during April and the south-east and north-east during May. The mean wind speed is $13 \mathrm{~km}$ per hour. Palau is on the southern margin of the north-west Pacific tropical cyclone zone and is rarely hit by the full forces of typhoons (Smith, 1953).

Vegetation Four terrestrial habitat types have been identified, viz. exposed beach strand, protected beach strand, cliff and upraised limestone forests (Manner and Raulerson, 1989). All of these are dominated by indigenous or endemic species and can be considered representative of the terrestrial habitats and vegetation of Palau's Rock Islands. Surveys conducted during January 1988 (Manner and Raulerson, 1989) identified 113 species in 49 genera of which all but four were indigenous or endemic to Palau. Introduced species include coconut palm Cocos nucifera, and endemics include the threatened Palau palm Gulubia palauensis.

The beach strand habitat comprises narrow sand beaches and back beaches with support salt-tolerant species, many of which are pan-Pacific. The protected strand habitat occurs in sheltered islets and coves within the main island cluster. Reduced wave and current action allow organic and mineral detritus deposits to accumulate and support a limited area of Rhizophora mucronata mangroves. Cliff habitat areas support a relatively high diversity of low or shrubby plants given their near vertical topography, lack of soils and xeric and halophytic conditions. On less steeply inclined areas a limestone forest occurs. Salt tolerant species predominate at the lower levels, whilst at mid-elevations up to $30 \mathrm{~m}$ altitude a mixed forest of trees and shrubs occurs. On exposed ridges and outcrops a few species form almost pure stands of small, closely spaced individuals, including Eugenia reinwardtiana, Intsia bijuga and Gulubia palauensis. At higher elevation a moist, less dense forest is found, with trees up to $20-30 \mathrm{~m}$ in height. The ground is covered with root systems and deep leaf litter which supports a wide diversity of ferns and other herbaceous ground cover. 
The reefs support 22 algae species on interior and outer reefs and 27 species on the fringing reef perimeter. Overall substrate cover ranges from $7-17 \%$. Only one small sea grass area, predominantly Syringodium, occurs (Wilkens, 1989).

Fauna Terrestrial mammals appear to be restricted to two bat species, namely an abundance of Belau fruit bat but relatively scarce insectivorous sheath-tailed bat Emballonura sp. The former species is not thought to roost in the islands. A survey in 1989 (Wiles and Conry, 1989) indicated that the preserve may be free of rodents which is possibly unique for Palau and an important factor for the sustained conservation of the islands. Dugong Dugong dugon $(V)$ has been reported occasionally. The same 1989 survey revealed the presence of 28 bird species, 23 of which breed within the preserve, this being some $50 \%$ of the total number of species breeding within Palau. Threatened species found within the preserve include Palau fruit dove Ptilinopus pelewensis, Micronesian imperial pigeon Ducula oceanica, Nicobar pigeon Caloenas nicobarica (R) Micronesian scrub fowl Megapodius laperouse (R) and the Palau fantail Rhipidura lepida. Species endemic to Palau include shrike-thrush Colluricincla tenebrosa, Palau monarch Myiagra erythrops, dusky white-eye Zosterops finschii (Wiles and Conry, 1989) and Palau scops owl Otus podarginus (Dahl, 1986). Terrestrial vertebrates are also represented by the endemic Palau frog, found only on the largest island in the preserve, four species of skink, two geckoes, Pacific island boa Candoia carinata and Palau tree snake Dendrolaphis lineolatus in the upper slopes of the highest and largest island. Terrestrial invertebrates are poorly known, but include coconut crab Birgus latro (R) (Wiles and Conry, 1989), two land crabs, Cardisoma hirtepes and Gecarcoidea lalandii (D. Otobed, pers. comm., 1990) and members of at least 11 arachnid families (Kerr, 1989).

Little quantitative information is available on the coral communities which may be categorised into reefs within the island cluster, fringing reefs around the outside edge of the island cluster and patch reefs. Interior reefs support limited coral communities on submerged reef ridges, with a patchy coral cover of 5-25\% cover. Thickets of Acropora and large Porites mounds and micratolls are common, with 17 species or species groups being dominant out of a total of 39 recorded for interior reefs. Fringing reefs support 53 species or species groups, with 23 being dominant and diversity being greatest at $10-15 \mathrm{~m}$ depth. Patch reefs support up to 60 species or species groups, with 20 dominant and with the greatest diversity and coverage (40-90\%) occurring below 2-5m (Birkeland and Holthus, 1989). All seven of the known giant clam species Tridacnidae are found, representing a valuable gene pool. Approximately 200 fish species occur, representing only $20 \%$ of the number expected for Palau and reflecting the limited number of marine habitats within the preserve (Amesbury, 1989). Hawksbill turtle Eretmochelys imbricata (E) and green turtle Chelonia mydas (E) are present and probably all ten beaches in the preserve and associated islands are used for nesting by hawksbills. Nesting occurs throughout the year with a peak of activity during July and August (Pritchard, 1981). Estuarine crocodile Crocodylus pororus (E) has been sighted occasionally although there is apparently no resident population. Banded sea snake Laticauda colubrina has been recorded (Wiles and Conry, 1989).

Cultural Heritage There has been no systematic survey for archaeological sites and artefacts, although many sites have been identified in the Rock Islands (Snyder, 1985). Pottery shards of an unknown age have been found (Manner and Raulerson, 1989). The islands may have been inhabited for lengthy periods of time but it is unknown whether there are particular histories, legends or natural features of cultural significance associated with the Ngerukewid Islands (Thomas et al., 1989). 
Local Human Population There is no resident population and there is no indication of permanent habitation in the past (Thomas et al., 1989). The present law prohibits habitation (D. Otobed, pers. comm., 1990).

Visitors and Visitor Facilities There is regular and increasing visitor use on most days of the week, but mostly on weekends, with boat traffic passing through the preserve. However, most visitors do not use the preserve for recreation, probably because there are few beaches or good landing sites and the preserve is relatively isolated. There are no visitor facilities (Thomas et al., 1989).

Scientific Research and Facilities Scientists and consultants visit the preserve, usually escorted by personnel from the Marine Resources Division of the Bureau of Resources and Development, or the Micronesian Mariculture Demonstration Centre (MMDC), who also informally undertake surveys during these visits (Thomas et al., 1989). There are no scientific facilities.

Conservation Value The preserve has considerable scientific and conservation importance because pristine and virtually unmodified examples of Palau's distinctive limestone island habitats, and many indigenous, endemic and threatened species persist.

Conservation Management The preserve is recognised by both the Koror State and the Palau National Government as being Koror State Land. The State recognises that, as the preserve is created under national legislation, its management is the responsibility of a national agency. The enabling legislation states that the preserve is to be retained "in its present primitive condition where the natural plant and animal life shall be permitted to develop undisturbed". Although the title of the preserve suggests its principal function is the preservation of wildlife, a broader conservation role covering all biota and ecological processes is clearly intended in the legislation. Other relevant legislation includes Palau National Code Title 31 Land Planning, Division 3, Koror Zoning, Chapters 30 and 31; and Title 24 Environmental Protection, Division 2, Wildlife Protection, Chapter 10 (Endangered Species Act), Chapter 12 (Protected Sea Life), Chapter 13 (Illegal Methods of Capture) and Chapter 14 (Protected Land Life). Furthermore, according to Koror Zoning Law, all the Koror Rock Islands are designated as Conservation Areas (D. Otobed, pers. comm., 1990).

A management plan has been compiled (Thomas et al., 1989), based on a comprehensive resource inventory (Birkeland and Manner, 1989). Four broad goals are identified in the plan, namely: to protect and preserve in perpetuity, as a representative example of Palau's Rock Islands, the indigenous flora and fauna, physical features and natural ecological processes of the Ngerukewid Islands; to expand scientific understanding of the ecosystems and ecological processes of the preserve in order to aid future management and add to the body of scientific knowledge of tropical Pacific ecosystems; to expand public awareness and understanding of the preserve and its values and to foster interest in, and respect for, Palau's natural heritage; and to develop an effective institutional framework for the management of the preserve and the overall expansion of nature conservation activities and capabilities in Palau. The provisions of Palau National code, Title 24, Chapter 30, under which the preserve is established, need to be amended in order to give legal status to the plan and to provide for its implementation. The plan is to cover a five-year period and makes allowance for review and amendment (Idechong, 1989). One specific recommendation suggests nomination of the preserve for inscription on the Unesco World Heritage List, following the Republic of Palau joining the World Heritage Convention as a State Party. 
Management Constraints Prior to 1981 surveillance and enforcement activities were undertaken by the Koror-based Conservation Office of the Trust Territories of the Pacific Islands, but these activities lapsed when the Office was incorporated into the Ministry of National Resources. The preserve has thus not been actively managed for many years although some surveillance is undertaken by the Bureau of Resources and Development, Ministry of National Resources. There is evidence that many people visit the preserve to poach turtles, take turtle and megapode eggs, hunt coconut crab, fruit bats and pigeons and take clams and fish, sometimes using illegal methods such as dynamite or poison fishing (Thomas et al., 1989).

Staff Personnel from the Marine Resources Division of the Bureau of Resources and Development, or the Micronesian Mariculture Demonstration Centre visit the site (Thomas et al., 1989).

\section{Budget No information}

Local Addresses Division of Conservation and Entomology, Bureau of Resources and Development, Ministry of National Resources, PO Box 100, Biology Laboratories, Koror, 96940

\section{References}

Amesbury, S.S. (1989). Fishes of the Ngerukewid Islands Wildlife Preserve. In: Resource Survey of the Ngerukewid Islands Wildlife Preserve, Republic of Palau. SPREP Topic Review. South Pacific Commission, Noumea, New Caledonia. (Unseen).

Birkeland, C. and Holthus, P. (1989). Coral communities of the Ngerukewid Islands Wildlife Preserve. In: Resource Survey of the Ngerukewid Islands Wildlife Preserve, Republic of Palau. SPREP Topic Review. South Pacific Commission, Noumea, New Caledonia. (Unseen).

Dahl, A.L. (1986). Review of the Protected Areas System in Oceania. IUCN, Gland, Switzerland and Cambridge, UK/UNEP, Nairobi, Kenya. 328 pp.

Idechong, N. (1989). The development of Ngerukewid management plan. Fourth South Pacific Conference on Nature Conservation and Protected Areas, Port Vila, Vanuatu, 4-12 September. South Pacific Commission, Noumea, New Caledonia. 3 pp.

Kerr, A. (1989). Arachnids of the Ngerukewid Islands Wildlife Preserve. In: Resource Survey of the Ngerukewid Islands Wildlife Preserve, Republic of Palau. SPREP Topic Review. South Pacific Commission, Noumea, New Caledonia. (Unseen).

Manner, H.I and Raulerson, L. (1989). Flora and vegetation of the Ngerukewid Islands Wildlife Preserve. In: Resource Survey of the Ngerukewid Islands Wildlife Preserve, Republic of Palau. SPREP Topic Review. South Pacific Commission, Noumea, New Caledonia. (Unseen).

Smith, C.W. (1983). Soil survey of islands of Palau, Republic of Palau. USDA, Soil Conservation Service. (Unseen).

Thomas, P.E.J., Holthus, P.F. and Idechong, N. (1989). Ngerukewid Islands Wildlife Preserve: management plan. South Pacific Regional Environment Programme. South Pacific Commission, Noumea, New Caledonia. 43 pp.

US Army (1956). Military geology of Palau Islands, Caroline Islands. Prepared by US Army, Office of the Engineer and US Geological Survey. (Unseen).

Wiles, G. J. and Conry, P.J. (1989). Terrestrial vertebrates of the Ngerukewid Islands Wildlife Preserve. In: Resource Survey of the Ngerukewid Islands Wildlife Preserve, Republic of Palau. SPREP Topic Review. South Pacific Commission, Noumea, New Caledonia. (Unseen).

Date December 1989, updated March 1990 


\section{PAPUA NEW GUINEA}

Area 462,842 sq. km

Population 3,900,000

Natural increase: $2.7 \%$

(Population Reference Bureau, Washington DC, 1989)

GNP US\$ 790 per capita (1988)

Policy and Legislation An Environment and Conservation Policy was adopted by the National Parliament in 1977, in recognition that development must be ecologically, socially and culturally suitable for Papua New Guinea. The Policy was drawn up in response to the Fourth Goal of the National Constitution:

"4. Natural Resources and Environment. We declare our fourth goal to be for Papua New Guinea's natural resources and environment to be conserved and used for the collective benefit of us all, and be replenished for the benefit of future generations."

The Fourth Goal provides for: (1) wise use of natural resources, (2) conservation and replenishment of the environment and (3) protection of flora and fauna for the benefit of present and future generations (SPREP, 1985b).

In order to implement the constitutionally-based policies, various laws have been introduced. Of particular relevance to the establishment of protected areas are the National Parks Act, Conservation Areas Act and the Fauna (Protection and Control) Act (Venkatesh et al., 1983). (See Annex 1).

The National Parks Act, 1982 replaced the amended 1971 Act, which in turn superseded the original National Parks and Gardens Act, 1966. It provides for:

"the preservation of the environment and of the national cultural inheritance by -

(1) the conservation of sites and areas having particular biological, topographical, geological, historical, scientific or social importance ."

and thereby upholds the Fourth National Goal and Directive Principle of the Constitution.

The Act contains provisions for reserving government land and for leasing and accepting gifts of land. Powers to make regulations to control hunting, fishing, sports, vehicles and domestic animals, and law enforcement provisions are contained in the Act. Although comprehensive in its coverage of different types of protected area, the Act does not define or even list the various categories nor is there any statutory requirement for the provision of park management plans (Eaton, 1985; SPREP, 1985b). The procedure for establishment of protected areas under this Act involves three stages: proposal, approval and declaration (Kwapena, 1984).

The Conservation Areas Act, 1978 has similar objectives to the National Parks Act but is more comprehensive and, to some extent, remedies deficiencies in the other legislation. For example, provisions include the establishment of a National Conservation Council to advise on the identification and management of protected areas, and the formation of management committees for each area to be responsible for inter alia the production of management plans. Conservation areas may be established on land under public, private or customary ownership. The Act awaits implementation due to financial constraints (Eaton, 1985; SPREP, 1985b). 
Although concerned primarily with the protection of endangered species, the Fauna (Protection and Control) Act, 1966 provides for the establishment of wildlife management areas (WMAs) on land held under customary ownership, of which there are three categories, defined in Annex 1. The Act provides for the setting up of wildlife management committees to administer them, thereby involving customary land-owners in the control of wildlife resource exploitation. The committees advise on the provision of specific rules for each area for "the protection, propagation, encouragement, management, control, harvesting and destruction of fauna" (Eaton, 1985; SPREP, 1985b). The procedure for the establishment of WMAs is fully described by Kisokau and Lindgren (1984) and Asigau (1989), and also outlined by Eaton (1986). The WMA concept recognises customary land ownership, and places landowners in direct control. Further, the establishment of WMAs is invariably initiated by the local landowners. The major failings in the WMA system are the generally inadequate size of each area, lack of local resource management expertise, delays in responding to requests for WMA establishment, leading to apathy and weak enforcement of regulations (Asigau, 1989).

The following are the principal classifications and general criteria for protected areas (SPREP, 1985b):

National parks are extensive areas of outstanding scenic and scientific interest which are of national significance. They should be of at least $1,000 \mathrm{ha}$ and preferably in excess of $2,000 \mathrm{ha}$. Ideally, the whole range of land-forms and environments found in Papua New Guinea should be represented. National parks have two main functions; first for public use and education and second, for the conservation of nature through protection of undisturbed habitat.

Provincial parks are less extensive natural areas than national parks; frequently less than $2,000 \mathrm{ha}$ and often less than $1,000 \mathrm{ha}$. Not necessarily of national significance, they are of scenic and recreational importance at provincial level. Their main role is to provide for cutdoor recreation in a natural setting close to urban centres.

Historical sites are areas of historic significance, covering prehistory and recent history. They may be of any size and, in many cases, adjacent areas will be developed for recreational purposes. They should provide for the preservation of areas of historic and prehistoric significance and their interpretation to the public.

Nature reserves can be areas of any size in which samples of ecosystems and habitats are preserved, either for their intrinsic value or for the protection of wildlife. Scientific research is permitted, but access by members of the public is very limited.

National walking tracks are physically challenging and scenic primitive routes through natural landscape that provide for walking in natural surroundings over long distances. Wherever possible, there should be a minimum easement of $10 \mathrm{~m}$ of natural vegetation on either side of tracks. Advantage may be taken of existing national parks or other large areas of reserved natural landscape.

Sanctuaries are areas set aside primarily for breeding and research on indigenous wildlife and its display to the public for education and recreation purposes. They can be of any size but should contain some natural habitat in addition to the display area.

Wildlife management areas are areas reserved at the request of the land-owners for the conservation and controlled utilisation of the wildlife and its habitat. Declaration of a wildlife management area does not in any way affect ownership of the land, only the way in which resources are used. Thus, wildlife management areas represent an attempt to develop 
conservation on a customary basis, using traditional methods of resource management (Eaton, 1986).

The customary land tenure system and associated subsistence economy traditionally contains many forms of resource management and conservation. The shifting cultivation system, for example, with its long periods (10-35 years) of fallow helps to maintain soil fertility. Customary rules may prevent the felling of trees along river banks. There are also prohibitions against cutting down trees near villages, while other trees of special economic value or of particular importance for certain types of wildlife may be protected from indiscriminate felling. In addition to controls consciously imposed by village societies, there are a great many associated traditional beliefs and practices that have often proved extremely effective in protecting certain habitats and species. In many Papua New Guinean societies there are prohibitions or tambu against entering certain areas or hunting or felling trees within them. These may be sites of old settlements, burial grounds or physical features, such as mountain tops, caves, ponds and forests. Some areas may be protected permanently, in others the restriction may be for a limited period as may happen after a death in the group (Eaton, 1985).

While traditional beliefs and customs have helped to protect the environment in the past and are often still operative, the integrity of the environment is under increasing threat from pressures associated with population growth, increased mobility and growth of the cash economy. The establishment of a protected areas system has proved to be extremely difficult on account of the traditional land tenure system. New legislation and novel approaches to environmental management have proved necessary.

Other environmental legislation is reviewed by Eaton (1985). Some of this legislation is relevant to protected areas. The Forestry Act (Amalgamated), 1973 is the main legislation responsible for the conservation and management of forest resources. Under this Act the government purchases timber rights from customary landowners for a certain period and then grants a licence to commercial companies to extract the timber. Royalties are paid to the government and a proportion of these is passed on to the provincial government and landowners. Environmental safeguards are provided for in the agreements between the government and logging companies. For example, logging is not allowed within $20 \mathrm{~m}$ of permanent watercourses, or $50 \mathrm{~m}$ in the case of major rivers, nor on gradients above $25^{\circ}-30^{\circ}$. The interests of customary land-owners are also protected. They retain rights of access for gardening, hunting and collection of wood for fuel and construction purposes. Reforestation is not provided for in the forestry legislation but depends on arrangements between the landowners and permit-holders. The Forestry Act is seen to be inadequate to cope with the modern system of provincial government, and is readily circumvented by recourse to the provisions of the Forestry (Private Dealings) Act which enables landowners to enter into private agreements with logging companies with few if any statutory controls over the scale and manner of the operations (TFAP, 1989). The Act is also discussed further by Sargent (1989). An important statute is the Environmental Planning Act, 1978 which calls for an assessment of the impact of a development project on the environment. Both the Environmental Planning Act and permits issued under the Forestry Act may also require logging companies to leave certain areas undisturbed as reserves for wildlife (Venkatesh $e t$ al., 1983). There is evidence, however, that much of this legislation is not effectively enforced, with some $70 \%$ of logging companies continuing to operate despite the mandatory provision of environmental impact assessments (Anon., 1990).

International Activities Papua New Guinea is not yet party to any of the international conventions or programmes that directly promote the conservation of natural areas, namely the Convention concerning the Protection of the World Cultural and Natural Heritage (World 
Heritage Convention), Unesco Man and the Biosphere Programme and the Convention on Wetlands of International Importance especially as Waterfowl Habitat (Ramsar Convention).

At a regional level, Papua New Guinea signed the 1976 Convention on the Conservation of Nature in the South Pacific on 12 June 1976. Known as the Apia Convention, it entered into force during 1990. The Convention is coordinated by the South Pacific Commission and represents the first attempt within the region to cooperate on environmental matters. Among other measures, it encourages the creation of protected areas to preserve indigenous flora and fauna.

Papua New Guinea is also party to the South Pacific Regional Environment Programme (SPREP) and has signed (3 November 1987) and ratified (15 September 1989) the 1986 Convention for the Protection of the Natural Resources and Environment of the South Pacific Region (SPREP Convention). The Convention entered into force during August 1990. Article 14 calls upon the parties to take all appropriate measures to protect rare or fragile ecosystems and threatened or endangered flora and fauna through the establishment of protected areas and the regulation of activities likely to have an adverse effect on the species, ecosystems and biological processes being protected. However, as this provision only applies to the Convention area, which by definition is open ocean, it is most likely to assist with the establishment of marine reserves and the conservation of marine species.

Other international and regional conventions conceming environmental protection to which Papua New Guinea is party are reviewed by Venkatesh et al. (1983).

Administration and Management The Department of Environment and Conservation, headed by a Secretary and with its own Ministry, was originally established in 1974 as the Office of Environment and Conservation, Department of Lands, Surveys and Mines. It successively passed through the departments of Natural Resources, Lands, National Mapping \& Environment, Lands, Surveys \& Environment, and Physical Planning \& Environment before being upgraded to departmental status in 1985. The constitutional basis for the existence and operations of the Department of Environment and Conservation is the Fourth Goal of the National Constitution. The Department is divided into four main divisions: Environment, Nature Conservation, Water Resources and Management Services (DEC, 1988).

Administration of acts directly concerned with protected areas, i.e. Fauna (Protection and Control), Conservation Areas, National Parks, is the responsibility of the Nature Conservation Division, which comprises three branches: Conservation Surveys, National Parks, and Wildlife Conservation (DEC, 1988). Under the National Parks Act, 1982 the First Assistant Secretary of the National Parks Service is responsible for the administration and management of national parks, marine national parks, provincial parks, historical sites, nature reserves, national walking tracks and other protected areas. This differs from the previous Act whereby powers were assigned to a National Parks Board (Eaton, 1985; SPREP, 1985b). The National Parks Service internal revenue, collected from park entrance fees, totals some $\mathrm{K} 30,000$ (approximately US\$ 35,300 ). Wildlife management areas, which are declared by the Minister for Environment and Conservation under the Fauna (Protection and Control) Act, are managed by the landowners themselves, who are also responsible for making the rules (SPREP, 1985b; Eaton, 1986).

Systems Reviews Papua New Guinea lies between the Equator and latitude $12^{\circ} \mathrm{S}$ and between longitudes $141^{\circ} \mathrm{E}$ and $164^{\circ} \mathrm{E}$. It comprises the eastern half of New Guinea and includes the Bismarck Archipelago (principally New Britain, New Ireland, New Hanover and Manus), d'Entrecasteaux Islands, the Louisiade Archipelago and the North Solomon islands of 
Bougainville and Buka. The western half of New Guinea forms the Indonesian province of Irian Jaya.

Forest of some sort, including successional forest, covers $71 \%(328,617 \mathrm{sq} . \mathrm{km})$ of mainland Papua New Guinea. Undisturbed rain forest constitutes $65 \%(300,847 \mathrm{sq} . \mathrm{km})$ of the total area and man-disturbed lands (grassland, gardens, degraded forest, plantation) some $20 \%$ $(92,568 \mathrm{sq} . \mathrm{km})$ (Beehler, 1985). Summary estimates for 1990 indicate natural forest cover of $78 \%$ ( 361,250 sq. km), including 420 sq. km of forest plantation (FAO, 1987). Discrepancies between the two sets of data can probably be ascribed to different definitions of forests, and different survey and analytical techniques. Approximately $20 \%$ of the total land area of Papua New Guinea is currently used for agriculture and $10 \%$, or $46,000 \mathrm{sq} . \mathrm{km}$, is under intensive cultivation (Freyne and McAlpine, 1985). An account of the forests, the threats to them and maps depicting current distribution is given in Collins et al. (1991).

The following description of the vegetation, based on Johns (1982) and an unpublished account by M.D.F. Udvardy reflects marked altitudinal zonation. A fringe of mangrove occurs along much of the coastline. Inland, swamps are extensive and covered by high forest with screw "palm" Pandanus and sago palm Metroxylon sagu forming a lower canopy. On drier land, mixed lowland rain forest is widespread and comprises complex communities, with epiphytes, orchids, tree and ground ferns. In contrast to rain forests elsewhere in Malesia, dipterocarp species are poorly represented. Throughout the lowlands, rain forests have been extensively destroyed or modified by shifting agriculture. Few areas of rain forest have escaped some form of cataclysmic destruction over the past 200-300 years (Johns, 1982). Areas having a markedly seasonal climate support monsoon forest which is characterised by the presence of a number of species that remain leafless for prolonged periods. Savanna vegetation, a degraded form of monsoon forest, occurs in areas receiving an annual rainfall of less than $1000-1300 \mathrm{~mm}$. Dominated by Eucalyptus spp., it is quite distinct from lowland alluvial plains vegetation elsewhere in Papua New Guinea and resembles that of northern Australia.

Above $700 \mathrm{~m}$ coniferous trees appear in the rain forest. Various altitudinally overlapping forest types can be distinguished within the montane zone, which usually extends from $700 \mathrm{~m}$ to $2,700-3,000 \mathrm{~m}$. The upper montane forest, which may extend to $3,300 \mathrm{~m}$, is a cloud forest, with 10-25m tall moss-covered trees and a dense understorey. In the subalpine zone, the "high mountain forest" has a closed canopy at about $10 \mathrm{~m}$, with moss carpeting the forest floor. Ericaceous (heather family) shrubs supplant the forest near its upper limit at $3,800-4,100 \mathrm{~m}$, and are in turn replaced by grasslands, tams and bogs (Smith, 1982). These are supplanted by tundra, which extends from about $4,400 \mathrm{~m}$ to $4,700 \mathrm{~m}$. With the possible exception of the montane grasslands around Henganofi, all grasslands below $3,000 \mathrm{~m}$ probably originate from a combination of agriculture and firing. The vegetation of the various island groups is mainly lowland rain forest, and at higher elevation, montane rain forest. The enclaves of grasslands and savannas are likely to be anthropogenous.

The various types of wetlands are described by Paijmans (1976) and Scott (1989), the latter providing detailed accounts of 33 wetland sites. Among the most extensive are mangrove swamps which occupy large parts of the coastal areas of Papua New Guinea, predominantly along protected bays and near the mouths of rivers. The largest expanses are in the south, notably in the Gulf of Papua with 162,000-200,000ha of mangroves. The north coast is not as rich in mangroves as the south coast.

The coral reefs of Papua New Guinea are virtually pristine compared to those of many countries, although they are coming under increasing threat from higher siltation and effluent loads in 
coastal areas and from commercial exploitation (UNEP/IUCN, 1988). The total area of reefs and associated shallow water to depths of $30 \mathrm{~m}$ or less is estimated to be $40,000 \mathrm{sq} . \mathrm{km}$ (Wright and Richards, 1985; Wright and Kurtama, 1987), with the greatest concentration (12,870 sq. km) lying off Milne Bay Province (Dalzell and Wright, 1986).

The present protected areas system is very inadequate, particularly for a country of such biological importance as Papua New Guinea. Together with the rest of New Guinea, it ranks third in importance to Lord Howe and New Caledonia among 226 Oceanic islands of particular conservation interest (Dahl, 1986). The other islands within Papua New Guinea that fall within the top 12 most important Oceanic islands for conservation are New Britain, Goodenough, and Bougainville in descending order.

Although Dahl (1986) assesses the conservation importance of the different islands within Papua New Guinea and the extent of protected areas coverage, gaps in the protected areas system are not highlighted at national level. Previously (Dahl, 1980), an attempt was made to identify whether the various habitat types within Papua New Guinea are conserved within protected areas, but this review no longer reflects the present situation because many protected areas (notably wildlife management areas) have since been established.

It is instructive to compare the existing network of protected areas with that proposed by Diamond (1976). This proposed system, although more extensive, is largely analogous to a scheme earlier outlined by Specht et al. (1974) in which areas of habitat that might be expected to incorporate an almost complete range of biogeographical and ecological patterns are defined. The majority of existing protected areas lie outside the 22 areas of conservation importance identified by Diamond (1976); moreover, most of these conservation areas are not even represented in the protected areas network.

The protected areas network proposed by Diamond (1976) is based largely on bird distributions because these have been studied in most detail. (Available information suggests that fairly similar patterns hold for other animals and for plants.) Less ambitious and focused principally on conserving birds of paradise and their rain forest habitat throughout New Guinea is a 4,882 sq. km system of eight reserves proposed by Beehler (1985). Similarly, Parsons (1983) has proposed the establishment of a network of 20 reserves to meet the conservation requirements of birdwing butterflies. Many of these proposed sites coincide or overlap with those recommended under the schemes already discussed.

An action strategy for protected areas in the South Pacific Region has already been launched (SPREP, 1985a). Principal goals of the strategy cover conservation education, conservation policies, establishment of protected areas, effective protected areas management, and regional and international cooperation. Priority recommendations for Papua New Guinea are as follows: review conservation legislation; develop public awareness programmes in environmental education; review administrative structures to effect efficient implementation of environmental and conservation policies; review "protected areas register"; draw up a list of endangered species of plants and animals; review the effectiveness of the current system of protected areas; undertake a comprehensive survey of terrestrial and marine ecosystems and design a representative system of protected areas; secure assistance and support for the preparation of management plans for Mt Wilhelm National Park, McAdam National Park and Mt Gahavisuka Provincial Park; and develop a national conservation strategy. The outline of an environmental management programme for sustainable developed has been compiled (Kula, 1989), including a timetable for its implementation by 1992 . However, the degree of progress with this programme is not known. 
Of paramount importance is the need to develop a national conservation plan and identify priorities for the establishment of a comprehensive protected areas network. Not only are more protected areas required to conserve the great diversity of life on the mainland, but attention should also be directed towards developing the network on other large islands such as New Britain, New Ireland, Manus, Goodenough, Fergusson and Bougainville. Smaller islands with significant levels of endemism, such as Ninigo Islands and Luf (Hermit) Islands, may require priority action, however, because they may be under greater relative human threat (Dahl, 1986). Similarly, marine sites need to be identified and incorporated within the protected areas network (Genolagani, 1984; Dahl, 1986). Preliminary recommendations from the 1989 Tropical Forestry Action Plan donor coordination mission suggest that improvements in the existing protected areas network should receive a higher priority than the establishment of new areas. Twenty protected areas are identified as suitable for rehabilitation under any TFAP operations (Srivastava and Bützler, 1989).

The most significant natural resource problems facing Papua New Guinea are forest depletion, soil loss and soil fertility in the mid-montane valley systems, degradation from large-scale mining and agricultural activities, and exploitation of reef fisheries which are among the richest in the world (Viner, 1984; ADB, 1987; UNEP, 1987). Forests are being destroyed at an estimated rate of 80,000 ha per year, commercial logging accounting for some 60,000 ha yearly, and shifting cultivation 10,000-20,000ha yearly (ADB, 1987; WEI, 1988). This rate is increasing: in 1981-1985, it is estimated to have been 22,000 ha per year (Repetto, 1988). These estimates contrast with the more conservative FAO figure of some 12,000ha deforestation annually, with a further 60,000 ha disturbed in some way by logging (FAO, 1987). About 1,000,000ha of former have now been converted to grassland as a result of over-intensive shifting agriculture (Collins et al., 1991). Papua New Guinea is relatively free from industrial pollution, except in coastal areas where much of the industry is sited. Considerable environmental damage has also been caused by mining activities, notably those of New Guinea Goldfields near Wau, Bougainville Copper in the Jaba catchment area and Ok Tedi in the Fly River region (Viner, 1984; ADB, 1987; WEI, 1988; Hughes, 1989).

\section{Addresses}

Department of Environment and Conservation, PO Box 5749, Boroko

\section{References}

ADB (1987). Papua New Guinea. Environmental natural resources briefing profile. Asian Development Bank, Manila. $6 \mathrm{pp}$.

Anon. (1990). PNG bans logging permits. Christian Science Monitor: 19.

Asigau, W. (1989). The wildlife management area system in Papua New Guinea. Case Study 15. Fourth South Pacific Conference on Nature Conservation and Protected Areas, Port Vila, Vanuatu, 4-12 September. $17 \mathrm{pp}$.

Beehler, B.M. (1985). Conservation of New Guinea forest birds. ICBP Technical Publication No. 4. International Council for Bird Preservation, Cambridge, UK. Pp. 223-246.

Collins, N.M., Sayer, J.A. and Whitmore, T.C. (Eds) (1991). The Conservation Atlas of Tropical Forests: Asia and the Pacific. Prepared by the International Union for Conservation of Nature, Switzerland and the World Conservation Monitoring Centre, Cambridge, UK. Macmillan Press Limited, London. 256 pp. 
Cragg, S.M. (1987). Papua New Guinea. In: Umali, R.M. et al. (Eds), Mangroves of Asia and the Pacific: status and management. Natural Resources Management Center and National Mangrove Committee, Ministry of Natural Resources, Manila. Pp. 299-309.

Dahl, A.L. (1980). Regional ecosystems survey of the South Pacific. South Pacific Commission Technical Paper No. 179.99 pp.

Dahl, A.L. (1986). Review of the Protected Areas System in Oceania. IUCN, Gland, Switzerland and Cambridge, UK/UNEP, Nairobi, Kenya. 328 pp.

Dalzell, P. and Wright, A. (1986). An assessment of the exploitation of coral reef fishery resources in Papua New Guinea. In: Maclean, J.L., Dizon, L.B. and Hosillos, L.V. (Eds), The first Asian fisheries forum. Asian Fisheries Society, Manila, Philippines.

DEC (1988). Department of Environment and Conservation Handbook. Department of Environment and Conservation, Boroko. $64 \mathrm{pp}$.

Diamond, J.M. (1976). A proposed natural reserve system for Papua New Guinea. Unpublished report. $16 \mathrm{pp}$.

Eaton, P. (1985). Land tenure and conservation: protected areas in the South Pacific. SPREP

Topic Review No. 17. South Pacific Commission, Noumea, New Caledonia. 103 pp.

Eaton, P. (1986). Grass roots conservation. Wildlife management areas in Papua New Guinea. Land Studies Centre Report 86/1. University of Papua New Guinea. 101 pp.

FAO (1987). Assessment of forest resources in six countries. Special study on forest management, afforestation and utilization of forest resources in the developing regions. Field Document 17. GCP/RAS/106/JPN. FAO, Bangkok. 104 pp.

Freyne, D.F. and McAlpine, J.R. (1985). Land clearing and development in Papua New Guinea. In: Tropical land clearing for sustainable agriculture. IBSRAM, Jakarta.

Genolagani, J.M.G. (1984). An assessment of the development of marine parks and reserves in Papua New Guinea. In: McNeely, J.A. and Miller, K.R. (Eds), National parks, conservation, and development. The role of protected areas in sustaining society. Smithsonian Institution Press, Washington, DC. Pp. 322-329.

Hughes, P.J. (1989). The effects of mining on the environment of high islands: a case study of gold mining on Misima Island, Papua New Guinea. Environmental Case Studies 5. South Pacific Regional Environment Programme, SPC, Noumea, New Caledonia. 6 pp.

Johns, R.J. (1982). Plant zonation. In: Gressitt, J.L. (Ed.), Biogeography and ecology of New Guinea. Monographiae Biologicae 42: 309-330.

Kisokau, K. and Lindgren, E. (1984). Ndrolowa Wildlife Management Area. A report on proposals to establish a wildlife management area for a variety of wildlife resources in Manus Province. Office of Environment and Conservation, Department of Physical Planning and Environment. $12 \mathrm{pp}$.

Kwapena, N. (1984). Wildlife management by the people. In: McNeely, J.A. and Miller, K.R. (Eds) (1984), National parks, conservation, and development. The role of protected areas in sustaining society. Smithsonian Institution Press, Washington, DC. Pp. 315-321.

Kula, G.R. (1989). Environmental management for sustainable development programme. Case Study No. 20. Fourth South Pacific Conference on Nature Conservation and Protected Areas, Port Vila, Vanuatu, 4-12 September. 8 pp.

Paijmans, K. (1975). Vegetation map of Papua New Guinea $(1: 1,000,000)$ and explanatory notes to the vegetation map of Papua New Guinea. CSIRO Land Research Series 35: 1-25.

Parsons, M.J. (1983). A conservation study of the birdwing butterflies Ornithoptera and Troides (Lepidoptera: Papilionidae) in Papua New Guinea. Final Report to Department of Primary Industry, Papua New Guinea. 111 pp.

Repetto, R. (1988). The forest for the trees? Government policies and the misuse of forest resources. World Resources Institute, Washington, DC. 105 pp. 
Sargent, C. (1989). Papua New Guinea Tropical Forest Action Plan: land use issues. Draft. International Institute for Environment and Development/United Nations Development Programme. Unpublished. 78 pp.

Scott, D.A. (Ed.). (1989). A Directory of Asian Wetlands. IUCN, Gland, Switzerland and Cambridge, UK. Pp. 1111-1155.

Seddon, G. (1984). Logging in the Gogol Valley, Papua New Guinea. Ambio 13: 345-350.

Sloth, B. (1988). Nature legislation and nature conservation as a part of tourism development in the island Pacific. Tourism Council of the South Pacific, Suva, Fiji. 82 pp.

Smith, J.M.B. (1982). Origin of the tropicoalpine flora. In: Gressitt, J.L. (Ed.), Biogeography and ecology of New Guinea. Monographiae Biologicae 42: 287-308.

Specht, R.L., Roe, E.M. and Boughton, V.H. (1974). Conservation of major plant communities in Australia and Papua New Guinea. Australian Journal of Botany Supplementary Series 7: 591-605.

SPREP (1985a). Action strategy for protected areas in the South Pacific region. South Pacific Commission, Noumea, New Caledonia. 21 pp.

SPREP (1985b). Papua New Guinea. In: Thomas, P.E.J. (Ed.), Report of the Third South Parific National Parks and Reserves Conference. Volume III. Country reviews. South Pacific Commission, Noumea, New Caledonia. Pp. 175-194.

SPREP (1989). Papua New Guinea. Paper presented at the Fourth South Pacific Conference on Nature Conservation and Protected Areas, Port Vila, Vanuatu, 4-12 September. 13 pp.

Srivastava, P. and Bützler, W. (1989). Protective development and conservation of the forest environment in Papua New Guinea: priority needs and measures proposed under the Tropical Forest Action Plan. Draft. Unpublished. 40 pp.

TFAP (1989). Tropical Forestry Action Plan. Papua New Guinea: forestry sector review. Draft. Unpublished. 165 pp.

UNEP (1987). Environmental management in Papua New Guinea. Volume 2. Review of background information. A programme document submitted by the Government of Papua New Guinea to the United Nations Environment Programme for funding through the UNEP clearing house programme. $108 \mathrm{pp}$.

UNEP/IUCN (1988). Coral Reefs of the World. Volume 3: Central and Western Pacific. UNEP Regional Seas Directories and Bibliographies. IUCN, Gland, Switzerland and Cambridge, UK/UNEP, Nairobi, Kenya. 378 pp.

Venkatesh, S., Va'ai, S. and Pulea, M. (1983). An overview of environmental protection legislation in the South Pacific countries. SPREP Topic Review 13. South Pacific Commission, Noumea, New Caledonia. 63 pp.

Viner, A.B. (1984). Environmental protection in Papua New Guinea. Ambio 13: 342-344.

WEI (1988). Protecting the environment. A call for support. Wau Ecology Institute, Wau, Papua New Guinea. 19 pp.

Wright, A. and Richards, A.H. (1985). A multispecies fishery associated with coral reefs in the Tigak Islands, Papua New Guinea. Asian Marine Biology 2: 69-84.

Wright, A. and Kurtama, Y.Y. (1987). Man in Papua New Guinea's coastal zone. Resource Management and Optimization 4: 261-296. 


\section{ANNEX \\ Definitions of protected area designations, as legislated, together with authorities responsible for their administration}

\section{Title: The National Parks Act}

Date: 1982

Brief description: Replaced the amended 1971 Act, which in turn superceded the original National Parks and Gardens Act, 1966.

Administrative authority: Nature Conservation Division, Department of Environment and Conservation

Designation: Not defined

\section{Title: The Conservation Areas Act}

Date: 12 September 1978

Brief description: Provides (a) for the preservation of the environment and of the national cultural inheritance by (i) the conservation of sites and areas having particular biological, topographical, geological, historic, scientific or social importance; and (ii) the management of those sites and areas, in accordance with the fourth goals of the National Goals and Directive Principles; and (b) to give effect to those goals and Principles under Section 25 of the Constitution, and (c) to establish a National Conservation Council and (d) for other purposes. NB: The Act awaits implementation due to financial constraints.

Administrative authority: No information

Designation: No information

\section{Title: Fauna (Protection and Control) Act}

Date: 1966

Brief description: Although concerned primarily with the protection of endangered species, the Act provides for the establishment of wildlife management areas (WMAs) on land held under customary ownership, of which there are three categories.

Administrative authority: The Act provides for the setting up of wildlife management committees, thereby involving customary land-owners in the control of wildlife resource exploitation. The committees advise on the provision of specific rules for each area for "the protection, propagation, encouragement, management, control, harvesting and destruction of fauna".

\section{Designation:}

\section{Wildlife management area}

- Category I WMAs are either terrestrial or marine areas reserved at the landowner's request for the conservation and controlled utilisation of all wildlife and habitat. 
- Category II WMAs (sometimes referred to as "protected areas") are areas where only specific named species are protected.

- Category III WMAs (or "sanctuaries") are areas where most resources, excluding specific named animal species, are fully protected.

\section{SUMMARY OF PROTECTED AREAS}

\begin{tabular}{|c|c|c|c|c|}
\hline $\begin{array}{l}\text { Map }^{\dagger} \\
\text { ref. }\end{array}$ & Name of area & $\begin{array}{l}\text { N management } \\
\text { category }\end{array}$ & $\begin{array}{r}\text { Area } \\
\text { (ha) }\end{array}$ & $\begin{array}{c}\text { Year } \\
\text { notified }\end{array}$ \\
\hline & National Parks & & & \\
\hline 1 & Jimi Valley & II & 4,180 & 1986 \\
\hline 2 & Kokoda Trail & Unassigned & & \\
\hline 3 & McAdam* & II & 2,080 & 1970 \\
\hline 4 & Mt Wilhelm* & Unassigned & 4,856 & \\
\hline 5 & Varirata* & II & 1,063 & 1969 \\
\hline \multirow[t]{2}{*}{6} & $\begin{array}{l}\text { Wildlife Sanctuaries } \\
\text { Moitaka }\end{array}$ & Unassigned & & \\
\hline & Nature Reserves & & & \\
\hline \multirow[t]{2}{*}{7} & Talele Islands (Bismarck Archipelago)* & IV & 40 & 1973 \\
\hline & Reserves & & & \\
\hline 8 & Namanatabu Historic Reserve* & Unassigned & 27 & 1979 \\
\hline 9 & $\begin{array}{l}\text { Sanctuaries } \\
\text { Baiyer River S }\end{array}$ & Unassigned & 120 & 1968 \\
\hline 10 & $\begin{array}{l}\text { Scenic Reserves } \\
\text { Paga Hill ScR }\end{array}$ & Unassigned & 10 & 1986 \\
\hline \multirow[t]{2}{*}{11} & $\begin{array}{l}\text { Marine Parks } \\
\text { Horseshoe Reef MP }\end{array}$ & Unassigned & 396 & \\
\hline & Parks & & & \\
\hline \multirow[t]{2}{*}{12} & Cape Wom International Memorial Park* & Unassigned & 105 & 1973 \\
\hline & Wildlife Management Areas (Categories & I to III) & & \\
\hline 13 & Bagiai (I)* & VIII & 13,760 & 1977 \\
\hline 14 & Balek (III) & IV & 470 & 1977 \\
\hline 15 & Baniara Island (II) & VIII & 15 & 1975 \\
\hline 16 & Crown Island (III) & IV & 5,969 & 1977 \\
\hline 17 & Garu $(I)^{*}$ & VIII & 8,700 & 1976 \\
\hline 18 & Iomare (I) & VIII & 3,837 & 1987 \\
\hline 19 & Lake Lavu (I) & VIII & 2,640 & 1981 \\
\hline
\end{tabular}


Hansa Bay Marine Park*

Djaul Islands

Duke of York

Hermit Islands

Hoskins Bay

Island between New Hanover and Kavieng

Kerema

Kikori

Killerton Islands

Kulu, Manus, Passu

Kuvenimas Lake Marine Park*

Lea Lea Salt Flats

Lihir Group

Los Negrosls

Manam Island

Mangrove Island

Milne Bay Islands

Misima Islands

Murik Lakes

Ninigo Group

Normanby Islands

Papuan Barrier Reef

Pinipel-Nassau Group

Pocklington Reef

Rambutyo Islands

Sabben Islands

Salamaua Peninsula Marine Park*

Shouten Islands

St Mathias Group

Tabar Islands

Tami Islands

Tanga Islands

Trobriand Islands

Tumelo Ali, Seleo and Angel Islands

Umboi Islands

Unei Island

Vuvulu Islands

Ware Islands

Western Islands

Woodlark Islands

Yela Islands

Yimas Lake

Balabob

Lou Island*

Matupit
Proposed

Proposed

Proposed

Proposed

Proposed

Proposed

Proposed

Proposed

Proposed

Proposed

Proposed

Proposed

Proposed

Proposed

Proposed

Proposed

Proposed

Proposed

Proposed

Proposed

Proposed

Proposed

Proposed

Proposed

Proposed

Proposed

Proposed

Proposed

Proposed

Proposed

Proposed

Proposed

Proposed

Proposed

Proposed

Proposed

Proposed

Proposed

Proposed

Proposed

Proposed

Proposed

Proposed

Proposed

Proposed 
IUCN Directory of Protected Areas in Oceania

Map $^{\dagger}$ Name of area

ref.

IUCN management category

Area

(ha) Year notified
Motupore Island

Towifro

Afore Lakes

Huon Peninsula

Idlers Bay

Kinikini

Labu

Mt Kemenagi

Waigani Swamp Provincial Park*

Taurama Beach

White Beach
Proposed

Proposed

Proposed

Proposed

Proposed

Proposed

Proposed

Proposed

Proposed

Proposed

Proposed

* Site is described in this directory.

${ }^{\dagger}$ Locations of some protected areas are shown in the accompanying map. 


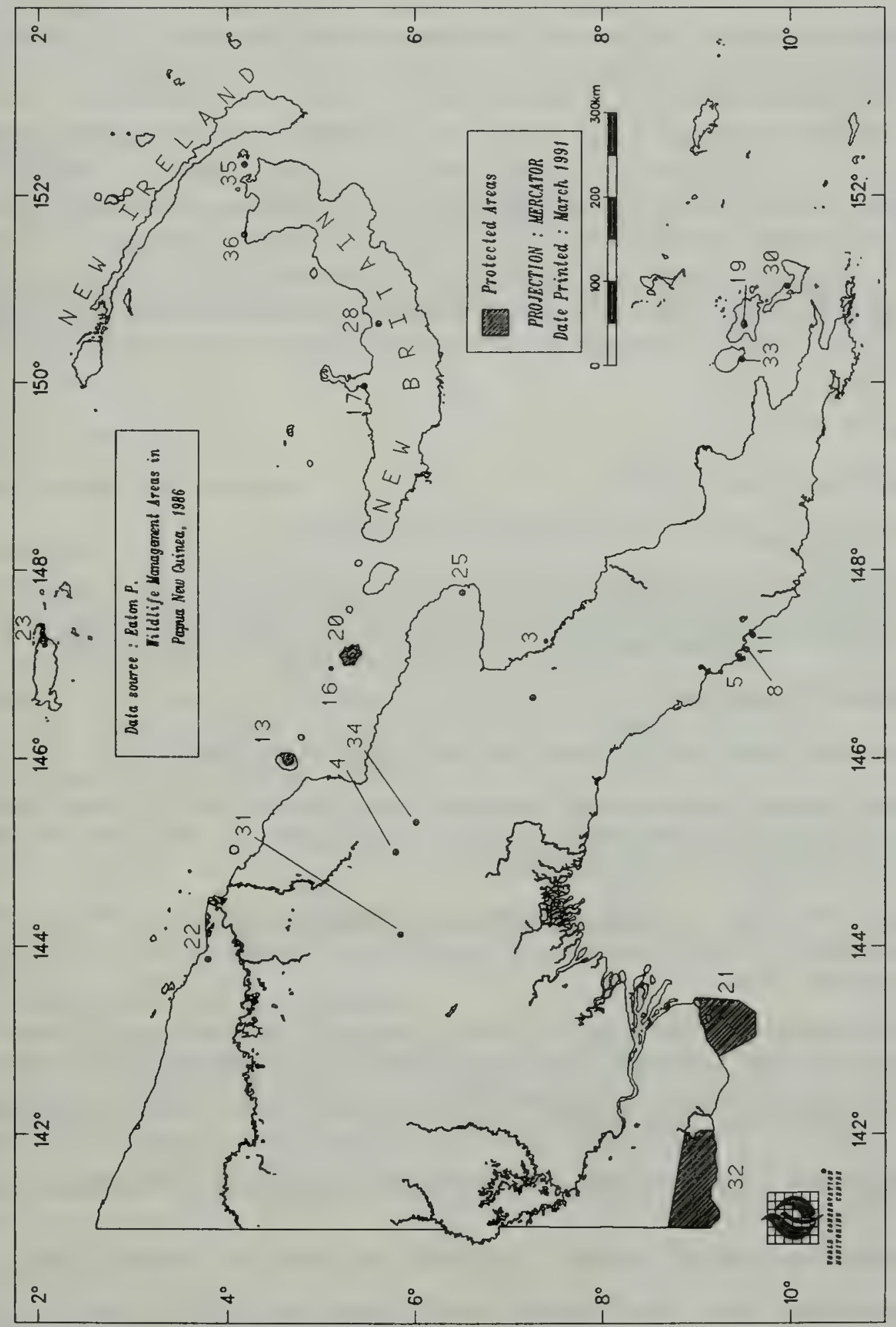

Protected Areas of Papua New Guinea 


\section{BAGIAI WILDLIFE MANAGEMENT AREA}

\section{IUCN Management Category VIII (Multiple Use Management Area)}

Biogeographical Province 5.01.13 (Papuan)

Geographical Location Situated on Karkar Island in the Bismarck Sea, Madang Province, some $50 \mathrm{~km}$ north of Madang town. The site occupies the central and eastern sections of Karkar and includes two small islands (Tuale and Mangamenek) to the north-east, coastal areas and reefs up to $2 \mathrm{~km}$ from the shore. Approximately $4^{\circ} 40^{\prime} \mathrm{S}, 146^{\circ} \mathrm{E}$

Date and History of Establishment Bagiai was declared a wildlife management area on 15 January 1977 and gazetted in March 1977. Initiative for its establishment came from the local people who expressed concern over use of guns for hunting the islands increasingly scarce wildlife.

Area 13,760 ha

Land Tenure Customary land

Altitude Ranges from sea level to $1,840 \mathrm{~m}$ (Mount Kunugui)

Physical Features The interior is mountainous. In the centre is a large volcanic crater over $3 \mathrm{~km}$ in width, within which are two cones, Bagiai and Uluman. The volcano is still active and last erupted in 1979. The black volcanic soil of the island is very fertile (Eaton, 1986).

Climate No information

Vegetation Includes two large plantations, the Bulu and Wadau (Anon., 1978).

Fauna Mammals include wild pig Sus scrofa, dugong Dugong dugon(V), cuscus Phalanger spp. and flying foxes Pteropodidae. Avifauna includes black kite Milvus migrans, pigeons Columbidae and sea birds (Eaton, 1986).

Cultural Heritage The volcano is traditionally a sacred place. According to local belief, if customary rules relating to protection of the wildlife and habitat are broken, the volcano may erupt (Eaton, 1986).

Local Human Population Bagiai lies in the least populated part of the island and contains seven villages. The total population of the island is approximately 22,000 (Eaton, 1986). The major food crops, taro, yams, sweet potatoes and corn, are grown in fenced gardens. Major cash crops are coconuts Cocos nucifera and cocoa (Eaton, 1986).

Visitors and Visitor Facilities Information is not available. The local people are keen to encourage tourism (Eaton, 1986).

Scientific Research and Facilities Volcanologists have visited the site (Eaton, 1986).

Conservation Value The management area was established to protect wildlife. Tuale and Mangamenek are important nesting sites for sea birds and also for fish, turtles and dugong.

Conservation Management A wildlife management committee comprising 46 representatives from the different villages has been appointed. Traditional methods of resource management continue to operate within the management area, with traditional methods of hunting restricted 
to persons having customary rights to land. Hunting and fishing are only completely unrestricted from the beginning of December to the end of February. At other times there may be moratoria as, for example, when a member of the community dies (Eaton, 1986). The use of fire arms is prohibited except to kill wild pigs on home territories, black kites attacking poultry and flying foxes destroying cocoa pods. Use of commercially manufactured nets for fishing has been banned as has the use of kerosene or hurricane lamps to attract fish at night. Restrictions on the use of derris root poison and the size of mesh of nets for fishing have been examined by the committee (Eaton, 1986).

Management Constraints Few offenders are prosecuted, making enforcement of rules difficult. It seems that magistrates, court of ficials and public servants are not always familiar with the rules of the area and with relevant legislation under the Fauna (Protection and Control) Act, 1966. Other problems include hunting, over-fishing, and soil erosion where bush has been cleared (Eaton, 1986).

Staff No information

Budget No information

Local Addresses No information

\section{References}

Anon. (1978). Wildlife in Papua New Guinea: conservation in wildlife management areas, sanctuaries and national parks in Papua New Guinea. Department of Lands and Environment, Konedobu, Papua New Guinea. Pp. 25-26.

Eaton, P. (1986). Grassroots conservation. Wildlife Management in Papua New Guinea. Land Studies Centre Report 86/1. University of Papua New Guinea. Pp. 27-32.

Date February 1989, updated July 1989

\section{BAIYER RIVER SANCTUARY}

IUCN Management Category Unassigned

Biogeographical Province 5.01.13 (Papuan)

Geographical Location Occupies part of Baiyer River Valley, in the north-west of the Bismarck Range, West Highland Province. Approximately 5'09'S, $144^{\circ} 09^{\prime} \mathrm{E}$

Date and History of Establishment Gazetted as a sanctuary on 13 January 1968 under the Lands Act 1962-1967.

Area 120ha

Land Tenure Government expropriated land

Altitude $800-1,200 \mathrm{~m}$

Physical Features The Baiyer River basin is dissected by numerous creeks and streams. 
Climate The pattern of rainfall is seasonal. Of the $2590 \mathrm{~mm}$ mean annual rainfall, least $(100 \mathrm{~mm})$ falls in July, the driest month, and most $(367 \mathrm{~mm})$ in March, the wettest month. Regular temperature inversions in Baiyer Valley are responsible for the daily alternating katabatic and anabatic winds, which give rise to a pattern of clear valley bottoms and clouded slopes in the morning and clouded bottoms and clear slopes in the evening. Diurnal temperature range is likely to be greater than the annual range (CSIRO, 1970).

Vegetation Lowland hill forest is contiguous with the forests of the lower Baiyer River which joins those of the Lai, Jimi, Yuat, and Sepik rivers. Forest within the sanctuary consists principally of oak Quercus spp., with a canopy at $30 \mathrm{~m}$ and frequent emergents rising to about $35 \mathrm{~m}$. A distinct lower canopy is present, with shrubby undergrowth and a rather sparse ground cover (Croxall, 1977). Other species of trees include Evodia elleryane, Elmerillia, Gnetum, Casuarina, Pandanus, Eucalyptus deglupta and Mucuna novoguineensis (MacKay 1980). Forest clearance has given rise to secondary grasslands dominated by Themeda australis (CSIRO, 1970).

Fauna Eight species of mammal were recorded by Anderson et al. (1985). Species include rats Melomys rufescens and Parahydromys asper, New Guinea spiny bandicoot Echymipera kalabu, long-tailed bandicoot Peroryctes raffrayanus and dasyurid marsupial Murexia longicaudata. Kangaroos and possum are also present (Gorio, S., pers. comm., 1980). Some 185 species of birds have been recorded (MacKay, 1980). Significant populations of lesser bird of paradise Paradisaea minor and magnificent bird of paradise Cicinnurus magnificus are present (B.M. Beehler, pers. comm., 1989).

Cultural Heritage No information

\section{Local Human Population No information}

Visitors and Visitor Facilities The sanctuary was popular among tourists but has not been frequented by tours for two years due to security problems (R. Hicks, pers. comm., 1989). There is a self-catering hostel.

Scientific Research and Facilities Research includes surveys of the birds (Mackay, 1980) and mammals (Anderson et al, 1985). Various species are bred in captivity including cassowaries Casuarius sp., and Raggiana bird of paradise Paradise raggiana. Other work includes a study of phalanger breeding and cassowary diet by faecal analysis (S. Gorio, pers. comm., 1980). Facilities include aviaries for research, enclosures for cassowaries and a laboratory (SPREP, 1985).

\section{Conservation Value No specific information}

Conservation Management Administered by a small trust. A simple system of zonation has been established consisting of zoo areas, a recreational area and natural environment areas (SPC, 1985).

Management Constraints Threats include hunting by local villagers and disturbance by domestic pigs (SPREP, 1985). Lack of funds is threatening the survival of the sanctuary (R. Hicks, pers. comm., 1989).

Staff One superintendent, one ranger, one business manager (SPC, 1985)

Budget K 36,000 NK (1980)

Local Addresses Superintendent, Baiyer River Sanctuary, P O Box 490, Mt Hagen 


\section{References}

Anderson, T., Amos, N., Berry, A. and Cook, J. (1985). A study of the parasitology and behaviour of forest mammals using spool-and-line tracking. In: de Winser, N. and de Winser, S. (Eds), Expedition Yearbook 1985. Expedition Advisory Centre, London. Pp. 215-216.

SPREP (1985). Papua New Guinea. In: Thomas, P.E.J. (Ed.), Report on the Third South Pacific National Parks and Reserves Conference. Volume III. Country reviews. South Pacific Commission, Noumea, New Caledonia. 269 pp.

Croxall, J. (1977). Insectivorous rainforest passerines. Ibis 119: 115.

CSIRO (1970). Lands of Goroka - Mount Hagen Area, Papua New Guinea. CSIRO Land Research Series 27: 16-117.

Gorio, S. (1978). Papua New Guinea involves its people in national park development. Parks 3: 12-14.

MacKay, R., (1980). A list of birds of the Baiyer River Sanctuary and adjacent areas. Papua New Guinea Bird Society Newsletter 167-168: 24-38.

Date June 1980, reviewed January 1989, updated July 1989

\section{CAPE WOM INTERNATIONAL MEMORIAL PARK}

\section{IUCN Management Category Unassigned}

Biogeographical Province 5.01.13 (Papuan)

Geographical Location Situated on the north coast of East Sepik Province, $13 \mathrm{~km}$ from the town of Wewak. Approximately $3^{\circ} 45^{\prime} \mathrm{S}, 143^{\circ} 40^{\prime} \mathrm{E}$

Date and History of Establishment Gazetted as an international memorial park on 8 October 1973, having been originally approved on 24 April 1969.

Area 105 ha

\section{Land Tenure State}

Altitude Sea level

Physical Features A sandy beach lies within the park.

Climate Information is limited to meteorological data from Wewak. Here, mean annual rainfall is $2093 \mathrm{~mm}$, with $95 \mathrm{~mm}$ falling in the driest month (January) and $246 \mathrm{~mm}$ in the wettest (May). Temperatures are uniformly high throughout the year (CSIRO, 1968).

Vegetation Comprises coastal vegetation with species such as Cocos nucifera, Chrysalidocarpus lutescens and Casuarina sp. (S. Gorio, pers. comm., 1980).

Fauna Noteworthy fauna includes starlings Aplonis spp., parrots Psittacidae and red imperial pigeon Ducula bicolor (S. Gorio, pers. comm., 1980).

Cultural Heritage The park is recognised as the site of the surrender of the last major Japanese land force to the Australians in 1945. A shrine and war relics are present (SPREP, 1985). 
Local Human Population There are residential areas within the park.

Visitors and Visitor Facilities Facilities include picnic areas.

Scientific Research and Facilities No information

Conservation Value No information

Conservation Management No information

Management Constraints Gravel is excavated from the park (S. Gorio, pers. comm., 1980).

Staff One provincial ranger and one park ranger

Budget K 2,000 NGK (1980)

Local Addresses Ranger-In-Charge, Cape Wom International Memorial Park, P O Box 516, Wewak, East Sepik Province

\section{References}

CSIRO (1968). Lands of the Wewak - Lower Sepik Area, Territory of Papua New Guinea. CSIRO Land Research Series 22: 16-24.

Gorio, S. (1978). Papua New Guinea involves its people in national park development. Parks 3: 12-14.

SPREP (1985). Papua New Guinea. In: Thomas, P.E.J. (Ed.), Report on the Third South Pacific National Park and Reserves Conference. Volume III. Country reviews. South Pacific Commission, Noumea, New Caledonia. 269 pp.

Date June 1980, reviewed January 1989, updated July 1989

\section{GARU WILDLIFE MANAGEMENT AREA}

\section{IUCN Management Category VIII (Multiple Use Management Area)}

Biogeographical Province 5.01.13 (Papuan)

Geographical Location Situated on the western side of Willaumez Peninsula, West New Britain. The site lies within the South Bagum Timber area. It is bounded by Reibek Bay to the west and a volcanic cone complex to the east running between Mounts Welcker and Krummel. Kulu River forms the south-western boundary and Garu village is included to the north. $5^{\circ} 00^{\prime}-5^{\circ} 30^{\prime} \mathrm{S}, 149^{\circ} 30^{\prime}-151^{\circ} 15^{\prime} \mathrm{E}$

Date and History of Establishment Gazetted as a wildlife management area in 1976. The site was established to protect the Bukenga, Pao, Mandagarili and Maga megapode egg-grounds.

Area 8,700 ha

Land Tenure Much of the land is government-owned, having been purchased in 1966 . The rest is customary land belonging to the people of Garu, although most of this is covered by timber rights purchase agreement (Eaton, 1986). 
Physical Features Consists of a coastal plateau which rises to mountainous terrain in the east. The area is drained by the Vulevulu, Gaivo and Pelnaru rivers (Spring, 1977). The eastern boundary is dissected by deep gullies originating from the north-south aligned volcanic cone complex of Mt Welcker $(1,200 \mathrm{~m})$ and Mt Krummel $(980 \mathrm{~m})$ (Miniotas and Lindgren, 1972). Associated thermal areas are found on the slopes of the mountains, including extensive solfataric fields, while subsidiary vents and hot springs occur sporadically throughout the lowland area (Spring, 1977). A large tidal swamp is located at the mouth of the Kulu River in the extreme south-west section of the area (Miniotas and Lindgren, 1972). Geologically the area ranges from basaltic lava deposits interbedded with ash to the alluvial and coralline deposits of the coastai plain and swamp. Soils are fertile, consisting of multiple horizons of permeable pumice and ash typical of volcanically active regions (Miniotas and Lindgren, 1972).

Climate Mean annual rainfall is $4450 \mathrm{~mm}$, most of which falls between December and April. Mean daytime temperature is approximately $31^{\circ} \mathrm{C}$ and mean minimum night-time temperature is $23^{\circ} \mathrm{C}$.

Vegetation Most of the area is covered by lowland rain forest consisting of CanariumSyzygium-Meliaceae associations (Liem, 1976). Other species present include taun Pometia tomentosa, New Guinea walnut Dracontomelon spp., Myristica spp. and Litsea spp. (Kwapena, 1974). Freshwater swamp forest occurs in the south-west around the lower reaches of the Kule River. It is characterised by large spreading trees, Buchanania mollis, Campnosperma sp., sago palm Metroxylon sagu, nipa palm Nypa fruticans and a ferm Acrostichum avreum (Liem, 1976). Mangrove occurs at the mouth of the Kulu and Gaivo rivers and is characterised by Rhizophora mucronata, Bruguiera parviflora, Sonneratia alba and fleshy-leaf shrubs Acanthus ilicifolius, with patches of Nypa fruticans (Liem, 1976). Areas previously logged support an Artocarpus-Horsfieldia-Evodia-Ficus association. Artocarpus incisa, Myristica sp., Evodia crassiramis and Micromelum pubescens are present in the upper storey. Subdominant trees include Leea indica, Polyscias sp. and Gretum gnemon. Ground cover is dominated by gingers Alpinia oceanica and Hornstedtia lycostoma. Various ferns occur under dense canopy, and non-woody lianes abound (Liem, 1976). To the south of Garu are areas of garden regrowth. Short-lived shrubs and trees of the families Euphorbiaceae and Urticaceae predominate. Some grassland also occurs where forest vegetation has been disturbed (Liem, 1976).

Fauna Mammals include wallaby Thylogale, cuscus Phalanger, glider Petaurus and bandicoot Echympiera. Bats are the most common placentals on the island. There are nine species of fruit bat including Melonycteris melanops, Rousettus amplexicaudatus, Dobsonia praedatrix, Macroglossus sp. and Pteropus macrotis (I), and six insectivorous bats including Emballonura sp. and Hipposideros galeritus. Three unidentified species of rat have been recorded, along with Uromys neobritannicus. Wild pig Sus scrofa and dugong Dugong dugon (V) are present (Miniotas and Lindgren, 1972).

A total of 116 bird species has been recorded (Bishop, n.d.), including dwarf cassowary Casuarius bennetti and common scrubfowl Megapodius eremita.

Reptiles include crocodiles Crocodylidae and four species of marine turtle, hawksbill turtle Eretmochelys imbricata (E), green turtle Chelonia mydas (E), leatherback Dermochelys coriacea (E) and flatback turtle Chelonia depressa (Spring, 1977). Snakes include brown tree snake Boiga irregularis and tree boa Candoia carinatus, and a third venomous species reported by villagers. Five lizard species have been collected: Emoia cyanura, E. callistica, Gecko vittatus, Dasia 
smaragdina and Sephemomorphus elegantulum (Miniotas and Lindgren, 1972). Amongst the amphibians present are several species of frog: Platymantis papuensis, Rana novaebritannae, Discodeles sp., Oreophryne brachypus and Bufo marinus (Miniotas and Lindgren, 1972).

Cultural Heritage The solfataric regions and a site besides Pao creek, where there are rock carvings, are very sacred to the Garu people (Kwapena, 1974).

Local Human Population The only settlement within the management area is Garu, with a human population of approximately 200 . The people of the village exercise traditional rights to hunt, gather wood, collect fruit, megapodes, turtles, eggs and fish (Eaton, 1986).

Visitors and Visitor Facilities Development of the tourist industry in New Britain is planned and will be centred on sites of special interest such as Garu (Miniotas and Lindgren, 1972).

Scientific Research and Facilities Research includes a survey of birds of the Whiteman Mountains (Gilliard and Le Croy, 1967), turtle ecology (Kisokau, 1973), megapode breeding behaviour (Downes, 1970) and vegetation and habitat (Kwapena, 1974), and habitats and ecosystems in Garu Wildlife Management Area (Liem, 1976). Bishop (n.d.) has conducted floral and faunal surveys.

Conservation Value Garu Wildlife Management Area was established to protect major breeding grounds of the common scrubfowl, one of seven species of incubator birds with a total world distribution centred upon Papua New Guinea (Miniotas and Lindgren, 1972).

Conservation Management Rules have been drawn up forbidding hunting of megapodes and restricting collection of eggs to those with customary rights. Collection is restricted to Tuesdays and Thursdays, and a maximum of 80 eggs per day, with a minimum disturbance to nest burrows. Use of shotguns is limited to general hunting for those with traditional rights (Eaton, 1986).

Management Constraints The main threat is from logging. The Peninsular Logging Company has timber rights to an adjacent area and has constructed a road that runs through the management area. Villagers have complained that trees within the wildlife management area have been felled (Eaton, 1986). Fears are that logging will lead to erosion, loss of habitat for megapodes and changes in the microclimate of megapode nesting grounds.

Staff No information

Budget No information

Local Addresses No information

\section{References}

Anon. (1978). Wildlife in Papua New Guinea: conserving wildlife in wildlife management areas, sanctuaries and national parks in Papua New Guinea. Division of Wildlife 78/4. Department of Lands and Environment, Konedobu. Pp. 21-24.

Bishop, D. (n.d.). Birds of Garu Wildlife Management Area, West New Britain Province, Papua New Guinea. Unpublished. 2 pp.

Bishop, D. (n.d.) General flora Garu scrubfowl breeding grounds. Unpublished. 2 pp.

Downes, M.C. (1970). A preliminary plan for the management of Nakanai (New Britain) wildfowl egg-grounds. Division of Wildlife 70/7. Department of Lands and Environment, Konedobu. (Unseen). 
Eaton, P. (1986). Grassroots conservation. Wildlife Management Areas in Papua New Guinea. Land Studies Centre Report 86/1. University of Papua New Guinea. Pp. 37-40.

Gilliard, E.T. and Le Croy, M. (1967). Results of the 1958-59 Gilliard New Britain Expedition 4. A notated list of birds of the Whiteman Mountains, New Britain. Bulletin of the American Museum of Natural History 135: 173-217.

Kisokau, K. (1973). Turtle surveys of Garu village, West New Britain. Unpublished Field Report. (Unseen)

Kwapena, N. (1974). Ecological analysis of plant communities and vegetation mapping of the actual wildfowl egg-grounds of Garu, Talasea, West New Britain. Wildlife Publication 77/13. Department of Natural Resources, Wildlife Branch, Konedobu. 20 pp.

Liem, D. (1976). Report on the habitat survey and habitat assessment of Garu Wildlife Management Area, West New Britain. Wildlife Publication 77/6. Department of Natural Resources, Wildlife Branch, Konedobu. 10 pp.

Miniotas, R. and Lindgren, E. (1972). Joint field report on the Garu egg-grounds and environs, West New Britain. National Parks Board, Port Moresby. 13 pp.

NPB (1972). Land use on West New Britain. Conservation areas 3: joint field report on the Kapiuar-Mt Bango area, West New Britain. Department of Agriculture, Stocks and Fisheries, Port Moresby. Unpublished. 12 pp.

Spring, S. and Turi, M.P. (1977). Wildlife management areas in Papua New Guinea: Garu. Wildlife Publication 77/4. Department of Lands and Environment, Konedobu. 5 pp.

Date May 1985, reviewed February 1989, updated July 1989

\section{HANSA BAY MARINE PARK}

\section{IUCN Management Category Proposed}

Biogeographical Province 5.01.13 (Papuan)

Geographical Location Situated in Hansa Bay, off the north coast of Papua New Guinea, between the mouth of the Sepik River and Bogia in Madang and East Sepik proyinces. Three islands lie within the proposed area, Manam, Laing and Boisa. Approximately $4^{\circ} 11^{\prime} \mathrm{S}, 144^{\circ} 55^{\prime} \mathrm{E}$; Manam approximately $4^{\circ} 08^{\prime} \mathrm{S}, 145^{\circ} 00^{\prime} \mathrm{E}$ and Laing $4^{\circ} 10^{\prime} \mathrm{S}, 144^{\circ} 55^{\prime} \mathrm{E}$

Date and History of Establishment The site was recommended as a marine park but no further action has been taken (UNEP/IUCN, 1988).

Area No information

Land Tenure Laing Island is privately owned.

Altitude $0-1 \mathrm{~m}$

Physical Features The reef string, aligned on a north-south axis in Hansa Bay, may represent an old coastline which developed during the Holocene transgression. Laing Island is surrounded by a well-developed fringing reef including a small lagoon $(400 \times 200 \mathrm{~m})$ on the western shore. The reef flat is emergent at most spring tides. Coral growth is luxuriant and a wide variety of reef biotopes occur around the island, from exposed reef crest to deep $(60 \mathrm{~m})$ bank reefs (Clareboudt, cited in UNEP/IUCN, 1988). Manam Island, an active volcano lying approximately 
$16 \mathrm{~km}$ from Laing Island, is partially surrounded by fringing reef up to $300 \mathrm{~m}$ wide. Reef slopes are usually steep. Fringing reef surrounds Boisa, a small volcanic island, and a shallow bank reef lies off its north-west coast. Mean depth of Hansa Bay is $25 \mathrm{~m}$. Tides have a maximum range of $1.2 \mathrm{~m}$. Water quality fluctuates seasonally. During the rainy season (November to April), the Sepik and Ramu rivers release muddy water, rich in drift material, into the bay. In the dry season (June to October) currents from the south-east bring clear water, short swells and strong waves. Mean vertical transparency in the bay is $9 \mathrm{~m}$ during the wet season and $19 \mathrm{~m}$ during the dry season, with an overall range of 2-35m (Kojis et al., 1985). Large amounts of freshwater may be released by local rivers after heavy rainstorms (Claereboudt, cited in UNEP/IUCN, 1988).

\section{Climate No information}

Vegetation Laing Island is densely forested and more than 100 vascular plant species have been recorded. Mangroves occur on the periphery of the island and are extensive at river mouths on the mainland (UNEP/IUCN, 1988). Marine vegetation includes alga Caulerpa (Coppejans and Meinesz, n.d.).

Fauna A dugong Dugong dugon (V) was recorded in Laing Island Lagoon in February 1987 and there are occasional unconfirmed reports of the species in nearby rivers. Green turtle Chelonia mydas (E) nest on Laing Island in small numbers, four in 1984.

Common among the avifauna are noddies and terns Laridae, megapodes Megapodius spp., sandpipers Scolopacidae, white-bellied sea eagle Haliaeetus leucogaster, eastern reef egret Egretta sacra and frigate birds Fregata spp. Sharks occur in the bay (Claereboudt, cited in UNEP/IUCN, 1988). Two hundred and fifty species of hermatypic coral, belonging to 73 genera, have been recorded. Acropora palifera is abundant on partially exposed reefs between 2 and $5 \mathrm{~m}$ (Kojis et al., 1984 and 1985). Some portions of reef are densely covered by soft corals (Tursch and Tursch, 1982). In general, coral cover is very high (more than 60\%) in exposed areas, high on partially exposed areas and moderate in sheltered sites (30-60\%).

Cultural Heritage World War Two wrecks lie on the sea bed (UNEP/IUCN, 1988).

Local Human Population Manam and Boisa islands are inhabited by approximately 5,000 and 700 people, respectively (UNEP/IUCN, 1988).

Visitors and Visitor Facilities Divers visit the war wrecks. The lagoon along the western shore of Laing Island provides a safe anchorage for vessels up to $21 \mathrm{~m}$ long (UNEP/IUCN, 1988).

Scientific Research and Facilities A small laboratory (King Leopold III Biological Station) has been operated by the Université Libre de Bruxelles on Laing Island since 1974. Over 150 scientific papers have been published on research carried out since then, including a large number on reef systematics. Other topics include: coral-inhabiting gastropods; marine molluscs; polychaete systematics and ecology; hydrozoan biology, ecology and systematics; echinoderm studies; plant ecology and systematics; spider systematics; biology, behaviour and systematics of social insects; herpetology (Anon., n.d.). Until recently, however, little work had been carried out on reef ecology, distribution or conservation. No scientific work has been carried out on the reefs around Boisa and Manam.

\section{Conservation Value No specific information}

Conservation Management Catching of adult turtles and consumption of turtle eggs appears to be traditionally forbidden in the villages around Hansa Bay. 
Management Constraints The possible impact of the active Manam volcano on the reefs around Laing Island, through acid rain, ashes and lava flows, has not been studied. The only major human disturbance to the reefs at present is fishing with explosives; this activity is illegal but is very popular with fishermen, largely owing to the ready availability of explosives from road construction, mining activities or World War Two ammunition dumps. Some divers are reported to collect artifacts from the war wrecks in the bay, despite these being legally protected. The reefs of Madang Province are potentially threatened by possible oil exploitation in the Ramu-Sepik Basin (M.R. Claereboudt, cited in UNEP/IUCN, 1988).

Staff No information

Budget No information

Local Addresses No information

\section{References}

Information for this sheet is based on UNEP/IUCN (1988).

Anon. (n.d.). Publications effectuées à partir de matériel récolté à Laing. Unpublished report. $13 \mathrm{pp}$.

Coppejans, E. and Meinesz, A. (n.d.). A. The Caulerpales of Hansa Bay area (Province Mandang - Papua New Guinea). The genus Caulerpa. Publication of the King Leopold III Biological Station, Free University of Brussels.

Kojis, B.L., Quinn, N.J. and Claereboudt, M.R. (1985). Living coral reefs of north-east New Guinea. Proceedings of the V International Coral Reef Congress, Tahiti 6: 323-328.

Kojis, B.L., Quinn, N.J., Claereboudt, M.R. and Tseng, W.Y. (1984). Coral reefs of the Huon Gulf and Hansa Bay, Papua New Guinea. Paper presented at the joint meeting of The Atlantic Reef Committee and the International Society for Reef Studies. Advances in Reef Science, Miami, Florida, October 1984.

UNEP/IUCN (1988). Coral Reefs of the World. Volume 3. Central and Western Pacific. UNEP Regional Seas Directories and Bibliographies. IUCN, Gland, Switzerland and Cambridge, UK/UNEP, Nairobi, Kenya. 378 pp.

Tursch, A. and Tursch (1982). Soft corals in Hansa Bay. The King Leopold III Biological Station, Free University of Brussels.

Date January 1989, updated July 1989

\section{HORSESHOE REEF MARINE PARK}

\section{IUCN Management Category Unassigned}

Biogeographical Province 5.01.13 (Papuan)

Geographical Location Situated in Central Province (south-east Papua New Guinea) approximately $9 \mathrm{~km}$ east of Port Moresby. Horseshoe Reef constitutes part of the barrier reef portion of the "Papuan Barrier Reef" and lies off Bootless Inlet and next to Nateavu Reef. Approximately $9^{\circ} 35^{\prime}-9^{\circ} 36 \mathrm{~S}, 147^{\circ} 19^{\prime} \mathrm{E}$ 
Date and History of Establishment The site, first proposed in 1978, was approved as a marine park by the Department of Lands in July 1981 subsequent to the completion of boundary descriptions in 1980 (Genolagani, 1984). Establishment procedures have been suspended, however, due to problems of traditional ownership and the interests of a local diving company (UNEP/IUCN, 1988). Also referred to by its local name as Tahiro (Aioro) Marine Park.

Area 396ha. The park is entirely marine.

Land Tenure Customary ownership

\section{Altitude Sea level}

Physical Features The portion of barrier reef lying within the park is horseshoe-shaped. The southern part is exposed during low-water spring tides, but the northern part remains submerged (Genolagani, 1984). The south-eastern end of the reef abuts adjacent reefs, while the north-western section borders the Padana Nahua Channel, one of four major channels of the western sector of the "Papuan Barrier Reef" (Genolagani, 1984). Water temperatures fluctuate seasonally between $26^{\circ} \mathrm{C}$ and $30^{\circ} \mathrm{C}$, July and December being the coolest and warmest months, respectively. Surface salinity varies seasonally from approximately $35 \%$ to $35.9 \%$ during dry seasons, while during the wet season water becomes increasingly saline with depth. In general, seas are calm but areas facing east or west are subject to wave action from trade winds (Genolagani, 1984).

Climate Information is based on meterological data from Port Moresby. Mean annual rainfall is $1182 \mathrm{~mm}$. July is the driest month with a mean monthly rainfall of $22 \mathrm{~mm}$ and December the wettest with a mean of $209 \mathrm{~mm}$ (CSIRO, 1973). Wirds blow from the south-east during the dry season and the north-east during the wet season. Light, changeable winds, and doldrums, occur in November and May. Early mornings are generally calm with winds increasing from 10 a.m. onwards (Coleman, 1982). Diurnal temperature range on the coast is approximately $3^{\circ} \mathrm{C}$. The slight seasonality in temperature that does exist tends to be greater for day than night temperatures (CSIRO, 1973).

\section{Vegetation No information}

Fauna Over 500 species have been recorded, 70 of which are corals: 37 hard coral species, 43 species of alcyonarians and seven species of hydroids. The hard corals include species of Acropora, Seriatopora, Stylophora, Pocillopora, Montipora, Fungia, Herpolitha, Parahalomitra, Goniopora, Porites, Echinopora, Favia, Hydnophora, Leptiora, Tubastrea and Turbinaria genera (Genolagani, 1984). The alcyonarians include Echinogorgia spp, Sinularia sp. and Dendronephthya spp. (Coleman, 1982).

Among fishes are wobbegongs Orectolobus dasypogon, catsharks Hemiscyllium ocellatum and sharks Sphyrna lewini, Carcharchinus spallanzoni, C. archarchinus sp. and Triaenodon obesus. Other species include Adioryx spp., Myripristis spp., Sphyraena barracuda, Katsuwonus pelamis, Caranx spp., Cheilodipterus spp., Epinephelus spp., Lutjanus spp., Caesio spp., Scolopsis spp., Plectorhynchus spp., Parupeneus spp., Chaetodon spp., Euxiphipops spp., Siganus spp., Acanthurus spp. and Scorpaenopsis spp. (Coleman, 1982). A wreck houses a big grouper Epinephelus sp., a moray eel Gymnothorax flavimarginatus and a sea snake Laticauda colubrina (Genolagani, 1984). Numerous invertebrate species are present (Genolagani, 1984).

Cultural Heritage No information 
Local Human Population Fishermen from the coastal villages of Pari, Tubusereia and Barakau are occasionally seen on the reef, which is also visited by the more recent settlers from Tahira and Mirigeda areas of Bootless Inlet (UNEP/TUCN, 1988).

Visitors and Visitor Facilities Port Moresby Sub-aqua Club and Tropical Diving Adventures Company specialise in water-based recreational activities, particularly SCUBA diving and underwater photography (Genolagani, 1984). There is considerable potential for expansion of the tourist industry because the area is easily accessible from Port Moresby (UNEP/IUCN, 1988).

Scientific Research and Facilities Research includes surveys of the fauna (Coleman, 1980) and fishes (E. Lindgren, cited in UNEP/IUCN, 1988), and some studies carried out by the University of Papua New Guinea. A number of boats have been scuttled to provide the National Park Service with sites for artificial reef studies.

Conservation Value No specific information

Conservation Management The reef harbours a great variety of habitats and species. The park lies within a traditional fishing zone. The aims of the park are to provide a model for the conservation of marine resources for recreational and educational purposes. No management plan has yet been prepared (Genolagani, 1984).

Management Constraints Legal protection of the park is lacking (UNEP/IUCN, 1988). There is some exploitation by local fishermen on the reef, and by people spearfishing at night. Fishermen use either spear guns or monofilament gill nets. Other marine resources such as shells may be collected. The development of Port Moresby increases threats of pollution (Genolagani, 1984).

Staff No information

Budget No information

Local Addresses Provincial Ranger (Central Province), National Parks Service Office, P O Box 6601 , Boroko

\section{References}

Coleman, N. (1982). Tahira Marine Park: Preliminary underwater fauna survey. Underwater 2: 8-13. Sea Australia Productions, Caringbah, New South Wales, Australia.

CSIRO (1973). Landform types and vegetation of Eastern Papua. CSIRO Land Research Series 32: 7-124.

Genolagani, J.M.G. (1984). An assessment on the development of marine parks and reserves in Papua New Guinea. In: McNeely, J.A. and Miller, K.R. (Eds), National Parks, conservation and development. The role of protected areas in sustaining society. Smithsonian Institution Press, Washington DC. Pp. 322-329.

UNEP/IUCN (1988). Coral Reefs of the World: Volume 3. Central and Western Pacific. UNEP Regional Seas Directories and Bibliographies. IUCN, Gland, Switzerland and Cambridge, UK/UNEP, Nairobi, Kenya. 378 pp.

Date June 1985, reviewed January 1989, updated July 1989 
IUCN Directory of Protected Areas in Oceania

\title{
LAKE DAKATAUA NATIONAL PARK
}

\section{IUCN Management Category Proposed}

\author{
Biogeographical Province 5.01.13 (Papuan)
}

Geographical Location Situated on the Willaumez Peninsula in West New Britain Province, $55 \mathrm{~km}$ north of Kimbe. Approximately $5^{\circ} 02^{\prime} \mathrm{S}, 150^{\circ} 05^{\prime} \mathrm{E}$

Date and History of Establishment No information

Area 4,920ha

\section{Land Tenure Customary land}

\section{Altitude $76 \mathrm{~m}$}

Physical Features Lake Dakataua is a large freshwater lake which fills the caldera at the tip of the Willaumez Peninsula. A peninsular produced by post-collapse volcanic activity divides the lake into two basins connected by a narrow channel. The surface area of the lake is $4,800 \mathrm{ha}$ and the maximum depth $c .120 \mathrm{~m}$. A bathometric map of the lake has been constructed from fathometer transects. In October-November 1974, the lake was alkaline throughout, with surface $\mathrm{pH} 7.6-8.2$; acidity increased with depth to $\mathrm{pH} 7.1-7.5$. Surface temperatures were $30.8-31.9^{\circ} \mathrm{C}$. There were thermoclines at $22 \mathrm{~m}$ and at $40-45 \mathrm{~m}$. Minimum temperature recorded was $26.8^{\circ} \mathrm{C}$ at $80 \mathrm{~m}$. Oxygen saturation curves were similar to the temperature curves, with sharp gradients at $22 \mathrm{~m}$ and $40-45 \mathrm{~m}$ and no measurable $\mathrm{O}_{2}$ from $80 \mathrm{~m}$ downward. Living organisms were common in dredge hauls to $20 \mathrm{~m}$ but were not found in those from greater depths. Average Secchi disc transparency was $11.1 \mathrm{~m}$ (Ball and Glucksman, 1980).

Climate Conditions are humid tropical with an annual rainfall of approximately $4270 \mathrm{~mm}$, most of which falls during the north-west monsoon from December to March or April. There follows a transition period prior to the south-east trade season, which reaches its peak in July-August and dies out by about September. The period after the north-west monsoon is usually one of light, variable winds. Monthly mean maximum and minimum temperatures range from $29.5^{\circ} \mathrm{C}$ to $30.8^{\circ} \mathrm{C}$ and from $22.7^{\circ} \mathrm{C}$ to $23.5^{\circ} \mathrm{C}$, respectively (Scott, 1989).

Vegetation Shallow water areas of the lake support a rich growth of Najas tenuifolia, Chara fibrosa, C. corallina and $C$. globularis. These plants extend to depths of at least $8 \mathrm{~m}$, but appear to grow best between $2 \mathrm{~m}$ and $4 \mathrm{~m}$. Lemna perpusila occurs in sheltered areas of the lake. Other plants include Ludwigia octavalvis and fern Nephrolepis biserrata (Scott, 1989).

Fauna The lake supports populations of both estuarine crocodile Crocodylus porosus (E) and New Guinea freshwater crocodile $C$. novaeguineae (V). Water birds recorded during a brief survey in 1979 by D. Bishop included 57 nesting little grebe Tachybaptus ruficollis, 68 little pied cormorant Phalacrocorax melanoleucos, 120 wandering whistling duck Dendrocygna arcuata (reported to be nesting on the island), 35 nesting white-headed stilt Himantopus leucocephalus and 5,000 red-necked phalarope Phalaropus lobatus. Other waterfowl known to occur at the lake include Pacific black duck Anas superciliosa, lesser golden plover Pluvialis dominica, Mongolian plover Charadrius mongolus, large sand plover $C$. leschenaultii, common sandpiper Tringa hypoleucos, grey-tailed tattler Heteroscelis brevipes, sharp-tailed sandpiper Calidris acuminata and crested tern Sterna bergii. No fish are present (Scott, 1989). Amphibians include two species of frogs. Invertebrates include two species of sponge, a rotifer, an ostracod, six 
species of molluscs, seven species of Cladocera, a copepod, eight species of Hemiptera, two species of Trichoptera, ten species of Odonata, two species of Coleoptera, and seven species of Chironomidae (Ball and Glucksman, 1980).

Cultural Heritage No information

Local Human Population No information

Visitors and Visitor Facilities No information

Scientific Research and Facilities The avifauna was surveyed in 1975 (Bishop, 1983) and the benthic has been studied (Ball and Glucksman, 1980).

Conservation Value No information

Conservation Management No information

Management Constraints Some subsistence fishing occurs.

Staff No information

Budget No information

Local Addresses Assistant Secretary, National Parks Service, Department of Environment and Conservation, P O Box 5749, Boroko

\section{References}

Ball, E. and Glucksman, J. (1980). A limnological survey of Lake Dakataua, a large caldera lake on West New Britain, Papua New Guinea, with comparisons to Lake Wisdom, a younger nearby lake. Freshwater Biology 10(1): 73-84.

Bishop, K.D. (1983). Some notes on non-passerine birds in West New Britain. Emu 83: 235-236. Scott, D.A. (Ed.) (1989). A Directory of Asian Wetlands. IUCN, Gland, Switzerland and Cambridge, UK. 1,197 pp.

Date January 1989, updated July 1989

\section{LAKE HARGY NATIONAL PARK}

\section{IUCN Management Category Proposed}

Biogeographical Province 5.01.13 (Papuan)

Geographical Location Situated in the Nakanai mountains of New Britain, and lies $16 \mathrm{~km}$ east of Bialla Plantation, in the district of West New Britain. Approximately $7^{\circ} 06^{\prime} \mathrm{S}, 150^{\circ} 24^{\prime} \mathrm{E}$

Date and History of Establishment The National Parks Board recommended in 1972 that the area be set aside for conservation.

Area The National Parks Board proposes that the entire catchment area of Lake Hargy be included in the designation. 


\section{Land Tenure Customary land}

Altitude The lake lies at $330 \mathrm{~m}$.

Physical Features Lake Hargy, a crater lake with a surface area of 930 ha, is situated within a caldera approximately $11 \mathrm{~km}$ in diameter. Mount Galloseulo, a strato volcano, lies on the western rim where it is contiguous with the external face of the caldera. The inner north-west wall is steep and scarred by small surface slides. To the south and east, the rim abuts rugged mountains that rise to $1,100 \mathrm{~m}$. The lake drains through a break in the caldera wall north of Mount Galloseulo, via the Lobu River. Most rock throughout the area is vesicular basalt, weathered to various degrees. Soils, which consist of volcanic ash with bands of pumice, are extremely permeable and unsuitable for agriculture (NPB, 1972).

Climate Mean annual rainfall is $4445 \mathrm{~mm}$, most of which falls during the north-west monsoon from December to April. The south-east trade wind season in July and August is the driest time of year (Scott, 1989). Mean daytime and night-time temperatures are $31^{\circ} \mathrm{C}$ and $23^{\circ} \mathrm{C}$, respectively.

Vegetation Comprises lowland rain forest, with Taun as the predominant species (NPB, 1972).

Fauna The avifauna is rich. Fish occur in the lake (NPB, 1972).

Cultural Heritage Access to the area is via a "walking track", part of an ancient network of routes that once covered Papua New Guinea (NPB, 1972).

Local Human Population There are no settlements within the catchment area. The total population for the region is small and sparsely scattered (NPB, 1972).

Visitors and Visitor Facilities Lake Hargy is easily accessible compared with other crater lakes. There is no visitor accommodation, but arrangements can be made with Complex Timber for overnight stays (NPB, 1972).

Scientific Research and Facilities A preliminary appraisal of the hydroelectric potential of Lake Hargy was made on behalf of Elcom (Commonwealth Department of Works, 1969).

Conservation Value In addition to the site's scenic and geological value, it supports a diverse flora and fauna (NPB, 1972).

Conservation Management The crater lake, Mount Galloseulo, which emits steam in several places, and the caldera wall present a spectacular sight.

Management Constraints The western portion of the catchment area, comprising the lower slopes of Mount Galloseulo to the lakeside, is under licence to the Complex Timber for logging. Timber extraction will have dire effects on the ecology of the lake due to soil erosion. Siltation of the Lobu River will adversely affect its hydroelectric potential. Some hunting and fishing is carried out by local people (NPB, 1972).

Staff None

\section{Budget None}

Local Addresses First Assistant Director (National Parks), Office of Environment and Conservation, PO Box 5749, Boroko 


\section{References}

Commonwealth Department of Works (1969). Preliminary appraisal of the hydroelectric potential at Lake Hargy. Elcom, Port Moresby. (Unseen).

Scott, D.A. (Ed.) (1989). A Directory of Asian Wetlands. IUCN, Gland, Switzerland and Cambridge, UK. 1,197 pp.

NPB (1972). Land use on West New Britain conservation areas: joint field report on Lake Hargy, West New Britain. National Parks Board, Department of Agriculture, Stocks and Fisheries, Port Moresby. Unpublished report. 8 pp.

Date December 1988, updated July 1989

\section{LAKE LAVU WILDLIFE MANAGEMENT AREA}

IUCN Management Category VIII (Multiple Use Management Area)

Biogeographical Province 5.01.14 (Papuan)

Geographical Location Situated on Fergusson Island, $45 \mathrm{~km}$ off the eastern tip of the Papuan mainland, in Milne Bay Province. Approximately 9 $31^{\prime}$ 'S, 150 $37^{\prime} \mathrm{E}$

Date and History of Establishment Gazetted and declared a wildlife management area in 1981, following a resolution in favour of its establishment passed by the West Fergusson Island local government council in November 1975 (Eaton, 1986).

Area $2,640 \mathrm{ha}$

Land Tenure Customary land

Altitude $0-40 \mathrm{~m}$

Physical Features The freshwater lake occupies a swamp depression in a region of rugged relief, generally unsuited to agriculture. The waters of the lake are neutral-alkaline. Depih fluctuates seasonally (Scott, 1989).

Climate Conditions are tropical and monsoonal.

Vegetation Consists of lowland forest and grassland (Scott, 1989).

Fauna The lake supports a rich fauna, with estuarine crocodile Crocodylus porosus (E) and New Guinea crocodile $C$. novaeguineae (V), fishes, eels and waterfowl (Eaton, 1986). Mammals include wild pig Sus scrofa and cuscus Phalanger. The avifauna includes megapodes Megapodius spp. and Blyth's hornbill Rhyticeros plicatus (Eaton, 1986).

Cultural Heritage No information

Local Human Population The villages of Lapapai, Niubowo, Masimasi, Ebadidi, Sobakadi and Yamalele lie in the vicinity of the lake.

Visitors and Visitor Facilities No information 
Scientific Research and Facilities No information

Conservation Value No information

Conservation Management A wildlife management committee of seven representing the surrounding villages has been established. Hunting rights are limited to customary land-owners using traditional methods. Use of shotguns is prohibited, as are spears for hunting crocodile. Collection of crocodile eggs is forbidden. The wildlife management committee has considered imposing limits on the numbers of crocodiles taken by individual hunters and proposes that a small royalty should be paid to the committee, based on size of skins (Eaton, 1986).

Management Constraints In the past hunting of crocodiles by locals and expatriates has not been controlled. Current information is lacking.

Staff No information

Budget No information

Local Addresses No information

\section{References}

Eaton, P. (1986). Grassroots conservation. Wildlife Management in Papua New Guinea. Land Studies Centre Report 86/1. University of Papua New Guinea. Pp. 49-50.

Scott, D.A. (Ed.) (1989). A Directory of Asian Wetlands. IUCN, Gland, Switzerland and Cambridge, UK. 1,197 pp.

Date February 1989, updated July 1989

\section{LEA LEA SALT FLATS MARINE PARK}

IUCN Management Category Proposed

Biogeographical Province 5.01.13 (Papuan)

Geographical Location Situated in Central Province, about $30 \mathrm{~km}$ north-west of Port Moresby. Approximately $9^{\circ} 18^{\prime} \mathrm{S}, 146^{\circ} 59^{\prime} \mathrm{E}$

Date and History of Establishment No information

Area No information

Land Tenure Customary land

Altitude $0-10 \mathrm{~m}$

Physical Features The proposed area includes intertidal sand and mud flats with a complex of mangrove swamps, salt flats and sandy beach ridges. Parts of the wetland are subject to seasonal flooding by brackish water (Scott, 1989). 
Climate Tropical monsoonal conditions prevail, with a prolonged dry season from May to December. Mean monthly maximum and minimum temperatures range from $27^{\circ} \mathrm{C}$ to $32^{\circ} \mathrm{C}$, and from $22^{\circ} \mathrm{C}$ to $24^{\circ} \mathrm{C}$, respectively (Scott, 1989).

Vegetation Comprises evergreen thicket and low to mid-height mangrove, with Avicennia, Sonneratia, Rhizophora and Bruguiera represented. Ground cover is absent. Mixed herbaceous cover occurs on tidal flats. A total of 48 species has been recorded including Imperata cylindrica, Acacia auriculiformis, Pluchea indica, Acrostichum aureum, Chloris barbata, Avicennia marina, Sonneratia alba, Nypa fruticans, Sesuvium portulacastrum, Ceriops tagal, Sporobolus virginicus, Eriochloe procera, Tecticornia cincrea, Themeda novoguineensis and T. australis (Scott, 1989).

Fauna The wetland supports a wide variety of aquatic birds and is particularly important for migratory shorebirds (Scott, 1989).

Cultural Heritage No information

Local Human Population No information

Visitors and Visitor Facilities No information

Scientific Research and Facilities The site is close to Port Moresby, where research facilities are readily available.

Conservation Value No information

Conservation Management No information

Management Constraints A salt factory has been proposed.

Staff No information

Budget No information

Local Addresses No information

References

Scott, D.A. (Ed.) (1989). A Directory of Asian Wetlands. IUCN, Gland, Switzerland and Cambridge, UK. 1,197 pp.

Date January 1989, updated July 1989

\section{LOU ISLAND WILDLIFE MANAGEMENT AREA}

\section{IUCN Management Category Proposed}

Biogeographical Province 5.01.13 (Papuan)

Geographical Location Situated about $20 \mathrm{~km}$ south of Manus Island, Manus Province. Approximately $2^{\circ} 25^{\prime} \mathrm{S}, 147^{\circ} 22^{\prime} \mathrm{E}$ 
IUCN Directory of Protected Areas in Oceania

Date and History of Establishment Proposed

Area No information

Land Tenure Customary land

Altitude No information

Physical Features There are sand flats and extensive beds of seagrass. The reef extends up to $200 \mathrm{~m}$ from the shoreline.

Climate No information

Vegetation Includes seagrasses.

Fauna Dugong Dugong dugon (V) and turtles are present, along with a variety of fishes and invertebrates, including molluscs and corals.

Cultural Heritage No information

Local Human Population No information

Visitors and Visitor Facilities No information

Scientific Research and Facilities No information

Conservation Value No information

Conservation Management No information

Management Constraints Traditional customs have been eroded and traditional methods of hunting have been replaced by modern techniques. Natural resources have been over-exploited. Although Lou islanders traditionally do not eat dugong or turtle meat, persons without traditional rights to hunt these animals do so.

Staff No information

Budget No information

Local Addresses No information

References

Anon. (1985). Report on the Third South Pacific National Parks and Reserves Conference. Volume II. Collected key issue and case study papers. South Pacific Commission, Noumea, New Caledonia. P. 260.

Date February 1989

MAZA WILDLIFE MANAGEMENT AREA

IUCN Management Category VIII (Multiple Use Management Area) 
Biogeographical Province 5.01.13 (Papuan)

Geographical Location Lies off the coast of Westem Province, in the Torres Strait, to the west of the mouth of the Fly River. The boundary runs parallel to the mainland coast in the north and extends as far south as Wapa Reef. Daru and Bristow islands lie within the management area. Approximately $9^{\circ} 14^{\prime} \mathrm{S}, 143^{\circ} 14^{\prime} \mathrm{E}$

Date and History of Establishment Declared a wildlife management area in 1979. Its establishment followed negotiations between the local people and Government concerning the hunting of dugongs. In 1976 the Government included dugong on the list of species protected under the Fauna (Protection and Control) Act in order to curb hunting, but local people requested exemption from the Act. The Government agreed on the condition that the local population made some attempt to manage and control dugong hunting. This was accepted and lead to the establishment of Maza (Eaton, 1986).

Area $184,230 \mathrm{ha}$

Land Tenure Customary land

Altitude No information

Physical Features The site is exclusively marine and reefs are extensive.

Climate No information

Vegetation Includes large seagrass flats within the WMA and mangroves along Daru and Bristow Island and the coastline (Asigau, 1989).

Fauna Large vertebrates include deer on the islands, dugong Dugong dugon (V) and turtles. Crayfish Decapoda sp., prawns and barramundi perch Perca sp. are present.

Cultural Heritage No information

Local Human Population No information

Visitors and Visitor Facilities No information

Scientific Research and Facilities No information

Conservation Value The area was established to protect dugong.

Conservation Management Administered by a wildlife management committee which has 14 members, representing six villages (Asigau, 1989). Dugong can only be caught using traditional methods (hand-harpoon from cano) and must be over $2.4 \mathrm{~m}$ in length. Females and young are totally protected. Dugong are sold, only one at any one time, at Daru Market where they are examined by a Wildlife Officer or member of the committee. A royalty of $\mathrm{K} 5.00$ must be paid for each dugong sold. Likewise, turtles can only be sold at Daru Market and a royalty of K1.00 is charged for each animal sold. Use of nets has been forbidden, except for catching barramundi perch. Mesh size is limited to $5 \mathrm{~cm}$ for the reefs around Daru and Bristow islands, and $15 \mathrm{~cm}$ elsewhere in the management area.

Management Constraints Measures to protect dugong and turtle have had limited success, as is evident from recent declines in the populations of these species (Eaton, 1986). In 1981, the chairman of the management committee expressed concern over the activities of commercial 
fishermen who were using crowbars to break open coral reefs for crayfish. Also, Torres Straits islanders used rifles to hunt dugong. In 1985, traditional right-owners complained that outsiders were catching crayfish and prawns from within the wildlife management area (Eaton, 1986).

Staff No information

Budget No information

Local Addresses No information

\section{References}

Asigau, W. (1989). The wildlife management area system in Papua New Guinea. Case Study 15. Fourth South Pacific Conference on Nature Conservation and Protected Areas, Port Vila, Vanuatu, 4-12 September. 17 pp.

Eaton, P. (1986). Grassroots conservation, wildlife management areas in Papua New Guinea. Land Studies Centre Report 86/1. University of Papua New Guinea. Pp. 45-47.

Date February 1989, updated February 1990

\section{MCADAM NATIONAL PARK}

\section{IUCN Management Category II (National Park)}

Biogeographical Province 5.01.13 (Papuan)

Geographical Location Lies between the towns of Wau and Bulolo at the south end of the Bismark Range, Wau sub-district, Morobe Province. Boundaries to the north-west and south-east follow ridges. Approximately $7^{\circ} 15^{\prime} \mathrm{S}, 146^{\circ} 39^{\prime} \mathrm{E}$

Date and History of Establishment Gazetted as a national park on 1 July 1970. Initially notified in 1962, it was originally declared a national park in 1956 by the Forestry Division of Papua New Guinea.

Area 2,080ha

Land Tenure Government expropriated land

\section{Altitude $670-1,980 \mathrm{~m}$}

Physical Features The terrain is mountainous with steep slopes, narrow valleys and steep gorges and some wide, flat-bottomed valleys. The Bulolo River and its gorge border the park (Gagne and Gressitt, 1982).

Climate No specific information. The nearest meteorological stations are at Wau and Bulolo for which climatic tables are available (McAlpine et al., 1975).

Vegetation Consists of submontane mixed mesophyll-notophyll vine rain forest between $600-1500 \mathrm{~m}$, with Castanopsis acuminatissima alliances between $600-1,800 \mathrm{~m}$ (Specht $e t$ al., 1974). Hoop pine Araucaria cunninghamii and klinkii pine $A$. hunsteinii are predominant (Hoyle, 
1975). There is some invasion of bamboo. Other species include Pometia tomentosa, Elmerrillia tsiampacca, Flindersia pimenteliana and Terminalia spp.

Fauna Mammals include marsupials. Noteworthy birds include dwarf cassowary Casuarius bennetti, New Guinea harpy eagle Harpyopsis novaeguineae (V) and birds of paradise.

Cultural Heritage No information

Local Human Population Surrounded by settlements and cultivations of the suburbs of Wau and Bulolo.

Visitors and Visitor Facilities The park is not easily accessible, the gorge is not bridged and facilities are limited (Gagné and Gressitt, 1982). It tends to attract only keen bushwalkers (Gorio, 1978). It can be reached from the Wau-Bulolo road at the northern end of the park, near Pinetops Bridge. The western slopes are accessible from logging roads (No. 22).

Scientific Research and Facilities A floral survey was conducted by Womersley and Schcdde (Sprecht et al., 1974). The nearby Wau Ecology Institute provides a base for field studies (Lamb and Gressitt, 1976). Staff at the Papua New Guinea Forestry College (Bulolo) have conducted studies in the park and have taken students there for field work.

Conservation Value The park was created to preserve one of the last major stands of Klinkii and hoop "pine" (Hoyle, 1975).

Conservation Management Information is not available regarding present management.

Management Constraints Problems include uncontrolled development of roads encouraging settlement by squatters, establishment of garden plots, and hunting ( R. Hicks and L. Lamothe, pers. comm., 1989). In addition, some mining occurs (Viner, 1984). There has also been some difficulty with logging occurring within (or immediately outside, depending on the outcome of a boundary dispute) the park on the western slopes. Logging on terrain visible from the park also reduces its scenic value (L. Lamothe, pers. comm., 1989).

Staff One park ranger, one assistant park ranger (1980)

Budget K 1,000 NGK (1980)

Local Addresses Ranger-In-Charge, McAdam National Park, PO Box 127, Bulolo, Morobe Province

\section{References}

Gagné, W.C. and Gressitt, J.L. (1982). Conservation in New Guinea. In: Gressitt, J.L. (Ed.), Biogeography and ecology of New Guinea. Monographiae Biologicae 42: 945-955.

Gorio, S. (1978). Papua New Guinea involves its people in national park development. Parks 3(2): $12-14$.

Hoyle, M.A. (1975). Wildlife conservation in Papua New Guinea. First impressions. University of Papua New Guinea. Unpublished report. 7 pp.

Lamb, K.P. and Gressitt, J.L. (Eds) (1976). Ecology and Conservation in Papua New Guinea. Wau Ecology Institute Pamphlet No. 2. IUCN/WWF, Morges. 151 pp.

McAlpine, J.R., Keig, G. and Short, K. (1975). Climatic tables of Papua New Guinea. CSIRO, Division of Land Use Research, Technical Paper No. 37. 
Specht, R.L., Row, E.M. and Boughton, V.H. (eds) (1974). Conservation of Major Plant Communities in Australia and Papua New Guinea. CSIRO, Melbourne, Australia. Pp. 591-605.

Viner, A.B. (1984). Environmental protection in Papua New Guinea. Ambio 13(5-6): 342.

Date April 1984, reviewed December 1988, updated July 1989, September 1989

\section{MOJIRAU WILDLIFE MANAGEMENT AREA}

IUCN Management Category VIII (Multiple Use Management Area)

Biogeographical Province 5.01.13 (Papuan)

Geographical Location Located to the east of the recently constructed Wewak-Angoram road in East Sepik Province. Approximately $3^{\circ} 47^{\prime} \mathrm{S}, 143^{\circ} 52^{\prime} \mathrm{E}$

Date and History of Establishment Gazetted a wildlife management area in 1978. It was established by local people concerned about their decreasing wildlife (Eaton, 1986).

Area 5,079ha

Land Tenure Customary land

Altitude No information

Physical Features The landscape is undulating.

Climate No information

Vegetation Consists of tropical rain forest with occasional patches of Kunai grass (Eaton, 1986).

Fauna Eleven mammals, 61 birds, and seven reptile species have been recorded. The avifauna includes cassowary Casuarius sp., goura pigeons Goura spp., and birds of paradise (Eaton, 1986).

\section{Cultural Heritage No information}

Local Human Population The villages of Samap, Wau, Wandomi and Yibab lie in the vicinity of the management area.

Visitors and Visitor Facilities Outsiders wishing to visit the area must obtain permission from the Wildlife Management Committee and pay an entry fee of K2. Camping is not allowed. Villagers hope to set up a small zoo containing local wildlife species and to charge visitors an admission fee.

Scientific Research and Facilities A faunal survey was carried out in 1981 by Unkau.

Conservation Value The wildlife management area provides a refuge and breeding site for wildlife. 
Conservation Management $A$ wildlife management committee representing villagers has been established. No hunting or egg collecting is allowed within the management area. A buffer zone, some $2 \mathrm{~km}$ wide, has been created around the wildlife management area, but has not been surveyed. Within this buffer zone landowners may hunt using traditional methods. Not all rules are gazetted, but they seem to be strictly enforced and widely observed. Prosecutions are handled by the village courts. A cassowary farm has been established (Eaton, 1986).

Management Constraints Rights to cut timber in the vicinity of the management area and buffer zone have been obtained. However, logging has been excluded from the management area and the forest surrounding it (Eaton, 1986).

Staff No information

Budget Some financial assistance has been received from the Government for the establishment of the cassowary farm (Eaton, 1986).

Local Addresses No information

\section{References}

Eaton, P. (1986). Grassroots conservation, wildlife management areas in Papua New Guinea. Land Studies Centre Report 86/1. University of Papua New Guinea. Pp. 33-35.

Unkau, C. (1981). Report on fauna and utilization survey of the Mojirau Wildlife Management Area, East Sepik Province, Papua New Guinea. Wildlife Division, Port Moresby. Unpublished. (Unseen)

Date February 1989

\section{MOTUPORE ISLAND WILDLIFE MANAGEMENT AREA}

\section{IUCN Management Category Proposed}

\section{Biogeographical Province 5.01.13 (Papuan)}

Geographical Location Situated at the mouth of Bootless Inlet, $15 \mathrm{~km}$ south-east of Port Moresby and $1 \mathrm{~km}$ from the mainland in Central Province. Approximately 9 $32^{\prime} \mathrm{S}, 147^{\circ} 17^{\prime} \mathrm{E}$

Date and History of Establishment The island has been classified as National Cultural Property. This designation does not extend to the reefs (Anon., n.d.).

Area No information

Land Tenure Leased by the Government to the University of Papua New Guinea.

Altitude Ranges from sea-level to $60 \mathrm{~m}$.

Physical Features The island lies within the lagoon of the Papuan Barrier Reef, and is one of a cluster of islands which span the entrance to a reef-fringed bay. It is oriented north-south and consists of a small, hilly, cigar-shaped emergent ridge of steeply-dipping mudstone, $800 \mathrm{~m}$ long and $200 \mathrm{~m}$ wide (Munro, n.d.). Soils are somewhat shallow, varying from calcareous and 
non-calcareous gravelly clay loams to gravelly clays and gravel (Anon., 1984). A fringing reef lies on the shore platform surrounding the island. Reef crests are exposed at most spring tides (Munro, n.d.). Between Motupore and the outer barrier are a variety of reefs, with associated seagrass, algal beds and extensive carbonate sand and mud areas (Anon., n.d.). Surface water temperatures range from $28^{\circ} \mathrm{C}$ to $30^{\circ} \mathrm{C}$ and salinity is $30 \mathrm{ppt}$. Maximum tidal range is $2.9 \mathrm{~m}$ (Munro, n.d.). Currents are strong offshore in a few lagoon areas.

Climate During the dry season (May-October), south-east winds are predominant. Waters are typically clearer throughout this period than in the calmer, wet season (late December-March) when north-west winds prevail. Doldrums occur from the end of October to mid-December and from late March to early May (Anon., n.d.).

Vegetation Most of the island is covered by Eucalyptus savannah. Monsoonal scrub and palms also occur (Munro, n.d.).

Fauna Marine fauna is extremely diverse. The fringing reef surrounding Motupore Island is well developed and representatives of most coral genera are present (Munro, n.d.).

Cultural Heritage The island is an important archaeological site. A midden extends along the edge of the hill slope on the north-west side of the island. A stabilised sand-spit at the north-westem tip of the island, occupied almost constantly between 800 and 200 years ago, is rich in artefacts (UPNG, 1984).

Local Human Population Local people from nearby villages on the mainland fish and collect shells in the area, often employing traditional methods (Scott, in press).

Visitors and Visitor Facilities The University restricts access to the island to research and training groups, so there is little tourism (UNEP/IUCN, 1988).

Scientific Research and Facilities The island's archaeological sites have been intensively studied. In 1983 a long-term project to map the marine habitats around the island was initiated. Other recent research includes studies of isopod crustacea (Bruce, 1982), maricultural potential of tridacnid clams (Munro and Gwythen, 1983), productivity of the tropical seagrass Enhalus acoroides (Aioi, 1983), and algal productivity and fish herbivory (Polunin, 1988). Facilities on the island are based at a centre and include three dormitory bedrooms, lecture hall, dry and wet laboratories and workshop. A cottage is available for use by University of Papua New Guinea staff and post-graduate students. Boats and a limited amount of diving equipment is available.

Conservation Value The island is an important archaeological site and supports a relatively undisturbed flora and fauna, particularly in the case of corals.

Conservation Management Papua New Guinea appears to lie near to a centre of genetic diversity for the Indo-Pacific hermatypic scleratinian corals. A nature trail has been laid out and signposted (UPNG, 1984).

\section{Management Constraints No information}

Staff One senior technician, one caretaker/watchman

Budget Recurrent expenditure K9,000 and equipment K5,780. Income from visitor fees for 1983 was K4,574, all but K300 of which had been spent by the end of December (Polunin, 1983). 
Local Addresses Motupore Island Research Department, PO Box 320, University of Papua New Guinea, Port Moresby

\section{References}

Aioi, K. (1983). Growth and production of a tropical seagrass, Enhalus acorides. (L.F.) Royle. Proceedings of the International Symposium on Aquatic Macrophytes, Nijmegen. Pp. 21-24. (Unseen)

Anon. (n.d.). General information on the Motupore Island Research Station. University of Papua New Guinea, Port Moresby. 11 pp.

Bruce, N.L. (1982). Records of isopod crustacea (Corallanidae, Cirolanidae) from Papua New Guinea, with the description of a new species. Journal of Crustacean Biology 2: 612-618. (Unseen)

Munro, J.L. (n.d.). Motupore Island Research Center on the Papuan Barrier Reef. Geography of Papua New Guinea. Pp. 1-2.

Munro, J.L. and Gwythen, J. (1983). Growth rates and maricultural potential of tridacnid ciams. Proceedings of the 4th International Coral Reef Symposium 1: 633-636.

Polunin, N.V.C. (1983). Annual report. Motupore Island Research Department.

Polunin, N.V.C. (1988). Efficient uptake of algal production by a single resident herbivore fish on the reef. Journal of Experimental Marine Biology and Ecology 123: 61-76.

UNEP/IUCN (1988). Coral Reefs of the World. Volume 3. Central and Western Pacific. UNEP Regional Seas Directories and Bibliographies. IUCN, Gland, Switzerland and Cambridge, UK/UNEP, Nairobi, Kenya. Pp. 262-263.

UPNG (1984). Welcome to Motupore Island. University of Papua New Guinea. Brochure.

Date February 1989, updated July 1989

\section{MOUNT GAHAVISUKA PROVINCIAL PARK, INCLUDING LIPIZAUGA BOTANICAL SANCTUARY}

\section{IUCN Management Category Unassigned}

Biogeographical Province 5.01.13 (Papuan)

Geographical Location Situated on the foothills of Mount Otto in the Bismarck Range, Eastern Highland Province, $8 \mathrm{~km}$ north of Goroka ( $11 \mathrm{~km}$ by road). Approximately $6^{\circ} 00^{\prime} \mathrm{S}, 145^{\circ} 20^{\prime} \mathrm{E}$

Date and History of Establishment First proposed as a provincial park in 1982 and officially declared on 27 March 1983, the park was gazetted in 1989. Lipizauga Botanical Sanctuary was established as a separate unit following gazettal of the park.

Area Total area of the park is 77ha. Lipizauga Botanical Sanctuary, which is fenced off, occupies less than Sha and lies within the park.

Land Tenure The land has been leased to the Eastern Highlands Provincial Government for 49 years from 27 March 1983.

Altitude $2,000 \mathrm{~m}-2,600 \mathrm{~m}$ 
Physical Features The park lies on the steep west-facing slopes of a spur of Mount Otto, called Mount Gahavisuka. It covers two ridges with two streams and a low-lying bowl where a small lake is being created. The mountains are geologically recent and deeply tropically weathered. The subsoil is very deep except at the summit where there are small cliffs of emergent rock. Saprolyte clays overlay hard basaltic rocks throughout most of the area and there is often a deep peaty humus layer on tope (J. Gore and N.E.G. Cruttwell, pers. comm., 1985, 1989).

Climate Conditions are cool, and annual rainfall in 1988 was $2500 \mathrm{~mm}$ at $2,250 \mathrm{~m}$ altitude (N.E.G. Cruttwell, pers. comm., 1989). Minimum recorded temperature is $10^{\circ} \mathrm{C}(1989)$. Relative humidity is approximately $74 \%$ throughout the year (Petr, 1983).

Vegetation About $70 \%$ of the area comprises mid-mountain rain forest. Castanopsis acuminatissima is dominant, with local patches of Lithocarpus rufovillosus. Pandanus spp. also abound in the damper places. Epiphytes, including orchids and rhododendrons, are abundant. The lower part of the park comprises anthropogenic grasslands, dominated by Saurauia spp. and a dense cover of Miscanthus sp. and Gleichenia sp., where terrestrial thododendrons are common. Lipizauga Botanical Sanctuary extends into both these habitats and contains highland plants from throughout the country including many undescribed species especially in the genera rhododendron, schefflera and orchids. There are no exotic species. It is being developed into a "gene bank" for conservation of threatened and rare species of plants, and is registered with the IUCN Botanic Gardens Conservation Secretariat (N.E.G. Cruttwell, pers. comm., 1989).

Fauna Mammals recorded include tree kangaroo Dendrolagus spp., forest wallaby Dorcopsulus sp., common striped possum Dactylopsila trivirgata, cuscus Phalanger spp., New Guinea marsupial cat Dasyurus albopuncatus, striped possum, ring-tailed possum and bandicoot Peroryctes spp. (N.E.G. Cruttwell, pers. comm., 1989). Pig Sus scrofa is also present, both wild and domestic, which cause much damage. Avifauna includes six species of bird of paradise, notably Princess Stephanie Astrapia stephaniae, brown sicklebill Epimachus meyeri, Loria's bird of paradise Loria loriae, King of Saxony bird of paradise Pteridophora alberti, Lawes' parotia Parotia lawesii (B.M. Beehler, pers. comm., 1989), as well as cassowary Casuarius sp. (J. Gore and N.E.G. Cruttwell, pers. comm., 1985). The rare chimaera birdwing Ornithoptera chimaera (I) and Morphopsis meeki are present (N.E.G. Cruttwell, pers. comm., 1989).

Cultural Heritage Inhabitants of Nagazima Village belong to the Gahuku tribe. Nokondi's Cave, believed to be the home of the local masalai or spirits, lies just outside the park (N.E.G. Cruttwell, pers. comm., 1989).

Local Human Population There are no settlements within the park now but there have been in the past, long since abandoned. Nagamiza Village is nearby and park workers are recruited there. The inhabitants take a great interest in the park and are preparing to set up a guest lodge for visitors just outside the park (Crutwell, 1989).

Visitors and Visitor Facilities The park is relatively inaccessible. Visitor facilities include tracks, look-outs, shelters, barbecue sites, picnic areas and toilets. Accommodation is not available. A guest house is planned.

Scientific Research and Facilities A register of plant specimens is currently being compiled by the curator. Research has been carried out by botanists, zoologists, ornithologists and entomologists. There are no special scientific facilities. 
Conservation Value The park is noted for its fine scenery, with magnificent views of the valley and mounts Michael, Kerigomna and Wilhelm. Lipizauga Botanical Sanctuary provides an area for the display and conservation of Papua New Guinea's highland flora.

Conservation Management Managed by the Eastern Highlands Provincial Government with assistance from the National Parks Service. Management activities include patrolling and maintenance of tracks and buildings. In certain areas selective weeding, cutting and planting is undertaken. Boundary fencing and irrigation, partially financed by a grant from the Stanley Smith Horticultural Trust, have been constructed, along with an orchid house, propagation house and tool shed. A second orchid house is under construction. Proposed development includes construction of an information centre, camping site, propagation frames, a nursery with plants for sale, display cases for animals and birds, a small lake and extension of the park (J. Gore and N.E.G. Cruttwell, pers. comm., 1985).

Management Constraints Domestic pigs straying from local villages dig up soil and vegetation, and cause damage at construction sites (SPREP, 1985). Access to the park is limited to ar $8 \mathrm{~km}$ track that becomes impassable during the wet season due to landslides and washout (J. Gore and N.E.G. Cruttwell, pers. comm., 1985).

Staff One expatriate curator, one assistant curator, one ranger, one assistant ranger

Budget Park maintenance $-\mathrm{K} 20,000$, road maintenance $-\mathrm{K} 8,000$, curator's salary - K6,000 and collection of specimens $-\mathrm{K} 1,500$ (1985)

Local Addresses Eastern Highlands Provincial Government, PO Box 348, Goroka, EHP; Provincial Ranger (Eastem Highlands Province), National Parks Office, PO Box 657, Boroko

\section{References}

CSIRO (1970). Lands of Goroka - Mount Hagen Area, Papua New Guinea. CSIRO Land Research Series 27: 16-117.

Petr, T. (Ed.). (1983). The Purari-tropical environment of a high rainfall river basin. W. Junk, The Hague, The Netherlands. Pp. 9-46.

SPREP (1985). Papua New Guinea. In: Thomas, P.E.J. (Ed.), Report of the Third South Pacific National Parks and Reserves Conference. Volume III. Country reviews. South Pacific Commission, Noumea, New Caledonia. 269 pp.

Date 1984, reviewed January 1989; updated July 1989, September 1989

\section{MT WILHELM NATIONAL PARK}

IUCN Management Category Unassigned

Biogeographical Province 5.01.13 (Papuan)

Geographical Location Situated in Simbu Province, in the Bismarck Range, $100 \mathrm{~km}$ south-west of Madang. Approximately 5 $47^{\circ} \mathrm{S}, 145^{\circ} 01^{\prime} \mathrm{E}$ 
Date and History of Establishment Approved as a national park by the Government in 1974 and established in 1976, the site has not yet been gazetted (SPREP, 1985).

Area 4,856ha

\section{Land Tenure Government expropriated land}

Altitude Ranges from $2,500 \mathrm{~m}$ to $4,509 \mathrm{~m}$ at the top of Mt Wilhelm.

Physical Features Mount Wilhelm is the highest peak in Papua New Guinea. Late Pleistocene glacial landforms are evident. These include cirques, "U"-shaped valleys, glacial lakes and tarns. The mountain massif is drained mainly by tributaries of the Kaugal River (Petr, 1983).

Climate Mean annual rainfall at Keglsugl $(2,400 \mathrm{~m})$, on the eastern slopes of the mountain, is $2314 \mathrm{~mm}$, while at $3,480 \mathrm{~m}$ it is $3000 \mathrm{~mm}$ (Croxall, 1977). Mean annual rainfall on the mountain ridge is $4380 \mathrm{~mm}$ (Hnatiuk et al., 1976). May to August are the driest months (Croxall, 1977). Frosts are frequent at higher altitudes and snow falls regularly above $4,000 \mathrm{~m}$, although it usually melts during the day (Petr, 1983).

Vegetation Forest cover is minimal (Hoyle, 1977). Undisturbed lower montane forest occurs between $2,630 \mathrm{~m}$ and $3,000 \mathrm{~m}$. The closed canopy is at approximately $30 \mathrm{~m}$, with some emergents, mainly gymnosperms of the Papuacedrus, Libacedrus and Dacrycarpus genera. The subcanopy consists of woody undergrowth. Trees are rich in epiphytes and there is an abundant ground flora including mosses and liverworts (Croxall, 1977). Above 3,050m upper montane forest occurs consisting of a single dense crowned tree layer, $10-20 \mathrm{~m}$ high, and a rich undergrowth (Croxall, 1977). At approximately $3,660 \mathrm{~m}$, near the tree line, montane forest merges into subalpine scrub. The dense growth of shrubs and dwarfed trees rise to a canopy of about $6 \mathrm{~m}$. Species of Ericaceae, Epacridaceae and Rubiaceae are predominant. Rhododendron spp., Vaccinium spp., tree ferns and orchids are also present. The genera Eurya, Olearia, Pittosporum, Schefflera, and Tasmannia are well represented (Petr, 1983). Primary forest destroyed by fire at higher altitudes has been replaced by alpine grassland (CSIRO, 1970). Tussock grass and herb associations extend to greater heights on the warmer and drier east and north-east facing slopes (Petr, 1983).

Fauna Mammals include marsupials. Notable among the avifauna are New Guinea harpy eagle Harpyopsis novaeguineae (V), long-bearded honeyeater Melidectes princeps (R), Princess Stephanie's astrapia Astrapia stephaniae and crested bird of paradise Cnemophilus macgregorii (B.M. Beehler, pers. comm., 1989).

\section{Cultural Heritage No information}

\section{Local Human Population No information}

Visitors and Visitor Facilities There is a mountain hut.

Scientific Research and Facilities Research undertaken include studies of the vegetation (Hope, 1976), phytoplankton (Thomasson, 1967) and blue-green algae (Watanabe et al., 1979) of several lakes on Mt Wilhelm. There is an Australian National University field station situated on the shore of Lake Anude, established in 1966.

Conservation Value No specific information

Conservation Management A fire ban has been in operation on Mount Wilhelm for the last 25 years (Petr, 1983). 
Management Constraints There is considerable faunal depletion from hunting (B.M. Beehler, pers. comm., 1989).

Staff One caretaker

Budget No information

Local Addresses Provincial Ranger, PO Box 657, Goroka, Eastern Highland Province

\title{
References
}

Brass, L.J. (1964). Results of the Archbold expedition, No. 86: Summary of the sixth Archbold expedition to New Guinea. American Museum of Natural History Bulletin 127:145-215. (Unseen)

CSIRO (1970). Lands of Goroka-Mount Hagen area, Papua New Guinea. CSIRO Land Research series $27: 16-117$.

Croxall, J.P. (1977). Insectivorous Rainforest Passerines. Ibis 119: 116.

Hnatiuk, R.J., Smith, J.M.B. and McVean, D.N. (1976). Mount Wilhelm studies 2: the climate of Mount Wilhelm. Res. School of Pacific studies. Department of Biogeography and Geomorphology. Publication BG/4. Australian National University, Canberra. (Unseen)

Hope, G.S. (1976). The vegetational history of Mt Wilhelm, Papua New Guinea. Journal of Ecology 64: 627-664.

Hoyle, M.A. (1977). Forestry and conservation in Papua New Guinea. Tigerpaper 4: 10-12.

Illies, J. (1969). Trichoptera from the high mountain lakes Pinde and Aunde, New Guinea. Pacific Insects V: 487-493. (Unseen)

Löffler, H. (1973). Tropical high mountain lakes of New Guinea and their zoogeographical relationships compared with other tropical high mountain lakes. Artic and Alpine Res. 5(2): 193-A198. (Unseen)

Petr, T. (Ed.). (1983). The Purari, tropical environment of a high rainfall river basin. Monographiae Biologicae 51: 624.

SPREP (1985). Papua New Guinea. In: Thomas, P.E.J. (Ed.), Report on the Third South Pacific National Parks and Reserves Conference. Volume III. Country reviews. South Pacific Commission, Noumea, New Caledonia. 269 pp.

Thomasson, K. (1967). Phytoplankton from some lakes on Mount Wilhelm, east New Guinea. Blumea 15: 285-296. (Unseen)

Watanabe, M., Prescott, G.W. and Yamagishi, T. (1979). Freshwater algae of Papua New Guinea (3). Blue-green algae from Mt Wilhelm. In: S. Kurokawa (ed.) Studies on cryptogams of Papua New Guinea. Academia Scientific Book Inc., Tokyo. Pp. 67-85.

Date December 1988, updated July 1989

\section{NAMANATUBU HISTORIC RESERVE}

\author{
IUCN Management Category Unassigned
}

Biogeographical Province 5.01.13 (Papuan) 
Geographical Location Situated in Central Province, $15 \mathrm{~km}$ north-east of Port Moresby. Approximately $9^{\circ} 30^{\prime} \mathrm{S}, 147^{\circ} 07^{\prime} \mathrm{E}$

Date and History of Establishment Gazetted as an historic reserve on 15 May 1979.

Area $27 \mathrm{ha}$

Land Tenure Government expropriated land

Altitude $160-1,000 \mathrm{~m}$

Physical Features A lake lies within the reserve.

Climate Information is based on meteorological data from Port Moresby. Mean annual rainfall is $1182 \mathrm{~mm}$. There is a marked dry period from March to November. Mean monthly rainfall for the driest month, July, is $22 \mathrm{~mm}$ and that for February, the wettest, is $209 \mathrm{~mm}$. Winds blow from the south-east during the dry season and the north-east during the wet season. Light, changeable doldrums occur in November and May (CSIRO, 1973).

Vegetation Savanna grassland covers much of the reserve. Sago palms Metroxylon sagu surround the lake (SPREP, 1985).

Fauna No information

Cultural Heritage The reserve is the site of General Blamey's hide-out and contains relics of World War Two.

Local Human Population No information

Visitors and Visitor Facilities No information

Scientific Research and Facilities No information

Conservation Value No information

Conservation Management No information

Management Constraints No information

Staff No information

Budget No information

Local Addresses Central Provincial Ranger, National Parks Service, Department of Environment and Conservation, PO Box 5749, Boroko

\section{References}

CSIRO (1973). Landform types and vegetation of eastern Papua. CSIRO Land Research Series 32: 50-57.

SPREP (1985). Papua New Guinea. In: Thomas, P.E.J. (Ed.), Report on the Third South Pacific National Parks and Reserves Conference. Volume III. Country reviews. South Pacific Commission, Noumea, New Caledonia. 269 pp.

Date January 1989 


\section{NANUK ISLAND PROVINCIAL PARK}

IUCN Management Category IV (Managed Nature Reserve)

Biogeographical Province 5.01.13 (Papuan)

Geographical Location Situated between New Britain and New Ireland, in the St Georges Channel of East New Britain Province. Approximately 4'10'S, $152^{\circ} 20^{\prime} \mathrm{E}$

Date and History of Establishment Gazetted as a provincial park on 26 November 1973.

Area $12 \mathrm{ha}$

Land Tenure Government expropriated land

Altitude $0-4 \mathrm{~m}$

Physical Features The park consists of a low coralline island covering 4ha, associated reefs and marine area.

Climate No information

Vegetation Much of the island is covered with coconut palm Cocos nucifera. Natural vegetation consists of creeping plants at ground level, surrounded by an open-canopied association of tall trees dominated by Casuarina spp. Some mangrove is present (SPREP, 1985).

Fauna Island inhabitants include crows Corvus spp., sunbirds Nectarinia spp. and beach stone curlew Esacus magnirostris (S. Gorio, pers. comm., 1980).

Cultural Heritage The island is a staging point, still used today, along an ancient canoe route between Kopo in East New Britain and the Duke of York Islands (SPREP, 1975).

Local Human Population No information

Visitors and Visitor Facilities No information

Scientific Research and Facilities No information

Conservation Value No information

Conservation Management No information

Management Constraints Threats include the establishment of coconut plantations and fishing within park boundaries (S. Gorio, pers. comm., 1980).

Staff One caretaker

Budget K 750 NGK (1980)

Local Addresses No information

\section{References}

SPREP (1975). Proceedings of the South Pacific Conference on National Parks and Reserves. Department of Lands and Survey, Wellington, New Zealand. P. 214. 
SPREP (1985). Papua New Guinea. In: Thomas, P.E.J. (Ed.), Report on the Third South Pacific National Parks and Reserves Conference. Volume III. Country reviews. South Pacific Commission, Noumea, New Caledonia. 269 pp.

UNEP/IUCN (1988). Coral Reefs of the World. Volume 3. Central and Western Pacific. UNEP Regional Seas Directories and Bibliographies. IUCN, Gland, Switzerland Cambridge, UK/UNEP, Nairobi, Kenya. 378 pp.

Date June 1980, reviewed December 1988

\section{NDROLOWA WILDLIFE MANAGEMENT AREA}

\section{IUCN Management Category VIII (Multiple Use Management Area)}

Biogeographical Province 5.01.13 (Papuan)

Geographical Location Situated on the island of Manus, Manus Province, in the eastern uplands, $1 \mathrm{~km}$ south of Lorengau. Approximately $2^{\circ} 03^{\prime} \mathrm{S}, 147^{\circ} 16^{\prime} \mathrm{E}$

Date and History of Establishment Declared a wildlife management area in March 1985, following proposals in 1983 by representatives of Rossun who were concerned about the depletion of terrestrial and marine wildlife resources (Eaton, 1986).

Area $5,850 \mathrm{ha}$

Land Tenure Customary land

Altitude No information

Physical Features Ndrolowa Wildlife Management Area consists of terrestrial and marine components. Inland are hills, deeply dissected by rough valleys with steep slopes. The uplands are formed mainly of Tertiary tuffaceous clastic sediments, 2-15 million years old. Igneous rock also occurs. Weathering produces rich red plastic clays. To the east along the coast are alluvial sediments which have been eroded and deposited within the last two million years. These alluvia are low-lying and frequently submerged by flood waters or high tides. Penetrating both the upland and alluvial areas are a number of volcanic intrusions or plugs, often conspicuous, standing well above the surrounding terrain. The marine component consists of the almost land-locked Lomucher Inlet, with shallow still waters, Paratau Bay, several islands, open water and reef areas. The reef platform drops steeply to a sandy bottom at about $20 \mathrm{~m}$ depth (Kisokau and Lindgren, 1984).

\section{Climate No information}

Vegetation Well-developed, secondary forest, with a sparse ground and shrub layer occurs in upland areas. Taller trees rise to about $25 \mathrm{~m}$. Small remnant patches of undisturbed hill rain forest are found on the steeper areas and volcanic plugs. Dense mangrove occurs on the alluvial sediments. There is little or no ground cover, apart from the exposed root systems. Swamp forest occurs in areas prone to prolonged flooding. Tree species present include sago palm Metroxylon sagu. Areas of regeneration and garden plots are found throughout the more accessible parts of 
the management area. Long-abandoned areas support gingers and fast-growing secondary tree species (Kisokau and Lindgren, 1984).

Fauna Mammals present include fruit bat, either Pteropus admiraltatum or Dobsonia sp., cuscus Phalanger maculatus and an unidentified dolphin, possibly Stenella sp. (Kisokau and Lindgren, 1984). Avifauna includes five species endemic to Manus Island: Manus friarbird Philemon albitorques, Manus pied monarch Monarcha infleix, Manus rufous fantail Rhipidura semirubra, superb pitta Pitta superba (I) and Meek's pygmy parrot Micropsitta meeki. Grey imperial pigeon Ducula pickeringii (R) is also present (Kisokau and Lindgren, 1984).

Four reptiles have been recorded, namely ground boa Candoia aspera, file snake Acrochordus sp., blue-tailed skink Emoia cyanogaster and green turtle Chelonia mydas (E) (Kisokau and Lindgren, 1984). Among the insects on record are five species of butterflies: Danaus hamata, Papilio aegeus, $P$. ulysses, Ornithoptera priamus and Parthenos sylvia (Kisokau and Lindgren, 1984). Fourteen freshwater and 181 marine fish have been recorded (Lindgren and Pasca, cited in Kisokau and Lindgen, 1984). Other marine species include octopus, cuttlefish Sepia apana, crayfish Panulirus sp., mudcrabs and corals (Kisokau and Lindgren, 1984).

Cultural Heritage People of the Ndrawo, Rossun, Loniu and Warembu clan groups are the traditional landowning groups in the area.

Local Human Population No information

Visitors and Visitor Facilities No information

Scientific Research and Facilities A faunal survey was undertaken in 1983 by Lindgren and Pasca (cited in Kisokau and Lindgren, 1984).

Conservation Value The area has a rich and interesting fauna, including five of the six bird species endemic to Manus.

Conservation Management The area is administered by a wildlife management committee comprising 21 representatives of Rossun, Ndrawo and Loniu villages (Eaton, 1986). The rules proposed prohibit use of firearms, explosives, poisons, chemicals and the use of torches or lamps for hunting or spear-fishing at night. In addition, commercially manufactured fishing nets and spear guns are forbidden. Traditional hunting by landowners is allowed, but outsiders have to purchase a licence to hunt or collect fauna. A system of fines has been established. These are paid into the consolidated revenue fund (Eaton, 1986).

Management Constraints Terrestrial and marine resources have been depleted through the use of root poisons, shotguns, explosives, motor canoes and nets, and spear-fishing with torches or pressure lamps (Eaton, 1986).

Staff No information

Budget No information

Local Addresses No information 


\section{References}

Eaton, P. (1986). Grassroots conservation in Papua New Guinea. Land Studies Centre Report, 89/1. University of Papua New Guinea, Port Moresby. Pp. 51-52.

Kisokau, K. and Lindgren, E. (1984). Wildlife Management Area. A report on the proposals to establish a wildlife management area for a variety of wildlife resources in Manus Province. Office of Environment and Conservation, Department of Physical Planning and Environment. Unpublished report. $15 \mathrm{pp}$.

Date February 1989, updated July 1989

\section{NUSERANG WILDLIFE MANAGEMENT AREA}

IUCN Management Category VIII (Multiple Use Management Area)

Biogeographical Province 5.01.13 (Papuan)

Geographical Location Situated in the Finschhafen area of Morobe Province. Approximately $6^{\circ} 30^{\prime} \mathrm{S}, 147^{\circ} 46^{\prime} \mathrm{E}$

Date and History of Establishment Established as a wildlife management area on 16 September 1986.

Area $22 \mathrm{ha}$

Land Tenure Customary land

Altitude $1,000 \mathrm{~m}$

Physical Features The region is hilly. Mount Nuserang lies within the area. Caves are present.

Climate Climate is similar to that of northern coastal regions. The management area receives an annual rainfall of up to $2000 \mathrm{~mm}$ (P. Eaton, pers. comm., 1988).

Vegetation Consists mainly of lowland hill forest with patches of regrowth resulting from subsistence farming activities (P. Eaton, pers. comm., 1988).

Fauna The avifauna includes Macgregor's bowerbird Amblyornis macgregoriae and emperor bird of paradise Paradisaea guilielmi (P. Eaton, pers. comm., 1988).

Cultural Heritage No information

Local Human Population There are no residents in the area. The Masangko and Maruruo clan groups have traditional rights of access to the area (P. Eaton, pers. comm., 1988).

Visitors and Visitor Facilities No information

Scientific Research and Facilities No information

Conservation Value No specific information 
Conservation Management The area is administered by a wildlife management committee consisting of ten representatives of Maruruo and Masangko villages. Killing or collection of all fauna is prohibited within the management area. Collection and destruction of birds eggs is also prohibited. Use of bows and arrows, shotguns and catapults is banned. Dogs are not allowed into the management area or within $500 \mathrm{~m}$ of the its perimeter. Gardening is prohibited. Collection of edible plants by customary owners is controlled: villagers wishing to collect must obtain permission from the wildlife management committee before entering the area. Fires are prohibited in and around the area. If found guilty, offenders are fined $\mathrm{K} 100$ by the village courts (P. Eaton, pers. comm., 1988).

Management Constraints In the past overhunting has led to depletion of wildlife (P. Eaton, pers. comm., 1988).

Staff No information

Budget No information

Local Addresses No information

References

None listed

Date February 1989, updated July 1989

\section{POKILI WILDLIFE MANAGEMENT AREA}

\section{IUCN Management Category VIII (Multiple Use Management Area)}

Biogeographical Province 5.01.13 (Papuan)

Geographical Location Lies on the north coast of West New Britain, just inland from Cape Hoskins. The Kapiura River forms the south-western boundary. Mount Pago lies at the westernmost tip. Approximately $5^{\circ} 36^{\prime} \mathrm{S}, 150^{\circ} 38^{\prime} \mathrm{E}$

Date and History of Establishment Declared and gazetted as a wildlife management area in 1975. Rules and a committee were established by the local people in 1974.

Area 9,840ha

Land Tenure Customary land

Altitude Mount Pago attains $800 \mathrm{~m}$

Physical Features A thermally-active area with spectacular hot springs, geysers, fumaroles and boiling pools of mud (Bishop, 1980). Mount Pago is an active volcano, and has associated geothermal areas with small geysers, hot springs and bubbling mud craters. The 9ha known as Pokili grounds lie around one such area (King, 1990). 
Climate The dry season begins in early April and the wet season in late December (Bishop, 1980).

Vegetation Tropical lowland rain forest covers much of the area. Mid-mountain forest with Calophyllum occurs on the higher slopes, and palm forest and Pandanus forest on the lower floodplains.

Fauna Includes common scrub hen Megapodius freycinet which incubates its eggs by burying them in the geothermally warm soil. The breeding grounds radiate out from the thermal area for up to $2 \mathrm{~km}$, and the number of nests is reported to be in the tens of thousands.

Cultural Heritage Village people have collected megapode eggs, to eat and to trade, for centuries, and have customary egg collection rights (Anon., 1978). In the past wars were fought and men and women died defending their traditional right to the collect eggs (Bishop, 1980).

Local Human Population Nine villages claim rights to the area, namely Vavua, Galilo, Komimumu, Makasili, Raparu, Ubai, Gule, Rikau and Lavege, and as many as 200 people may attend the egg collecting grounds daily. All villages, with the exception of Lavege, are located outside the management area and have their own customary land for taro gardens and growing cash crops such as coconuts, cocoa and oil palm. Fishing is important in coastal villages (Eaton, 1986).

\section{Visitors and Visitor Facilities No information}

Scientific Research and Facilities Aspects of the megapode's biology relevant to its conservation have been studied (Bishop, 1980) and a review of information relating to the occurrence of Megapodius freycinet in the islands of Papua New Guinea has been compiled (Bishop, 1978). Questionnaire surveys were conducted by students from the University of Papua New Guinea during September 1989 to determine whether there was a widespread understanding of both the reasons for establishing the wildlife management area and the rules concerning its management (King, 1990).

Conservation Value Principally valued for the sustainable collection of megapode eggs.

Conservation Management The government was made aware of local concern for the area in August 1970 when a complaint was made about logging in the egg-grounds. The Pokili committee comprises representatives from each of the nine land-owning villages. Each village has a designated egg collecting zone in Pokili Grounds, although the boundaries of the zones have not been registered. Rules prohibit the hunting of megapodes and only landowners can take eggs or hunt in the area. Harvesting of eggs is prohibited in August to allow the megapode population to sustain itself. No trees can be cut within $1,000 \mathrm{~m}$ of a megapode nesting hole, and dogs are not allowed within $500 \mathrm{~m}$ of a hole. There are, however, no rules relating to the wider habitat of the megapodes outside the egg laying area. A recent addition to the rules, although not gazetted by the Wildlife Officer at Kimbe, is a restriction on egg collecting on Tuesdays and Thursdays. Rules are enforced by the committee, or village elders, and offenders may be fined up to K20 (Eaton, 1986; King, 1990).

Management Constraints For several years, the people of Lavege have been pressing for part of the boundary to be shifted westward to free their land for development. Realignment of the boundary would not endanger the megapode nesting grounds. In 1977 the Stettin Bay Lumber Company felled 26 trees just inside the management area and subsequently paid the committee $\mathrm{K} 267.58$ in compensation. There have been complaints about settlers from the oil palm schemes 
hunting with shotguns and one village has cleared a patch of forest within the management area to plant coconuts. In the case of infringements of the rules, wamings have been issued (Eaton, 1986) and a limited number of fines imposed (King, 1990). Results from questionnaire surveys in 1989 indicate that enforcement of the rules may be weak, that megapode egg collection may exceed sustainable limits and that outsiders are stealing eggs. There is also evidence that megapode eggs are becoming increasingly scarce, and that there is some misunderstanding of the need to conserve an area of undisturbed forest in addition to the egg laying area to support the megapodes (King, 1990).

Staff No information

Budget No information

Local Addresses No information

\section{References}

Anon. (1978). Wildlife in Papua New Guinea, conserving wildlife in wildlife management areas, sanctuaries and national parks in Papua New Guinea. Division of Wildlife, Department of Lands and Environment, Konedobu. Pp. 17-20.

Bishop, K.D. (1980). Birds of the volcanoes - the scrubfowl of West New Britain. The World Pheasant Association Journal 5: 80-90.

Bishop, K.D. (1978). A review of the information relating to the occurrence of Megapodius freycinet in the islands of Papua New Guinea. The World Pheasant Association Journal 3: 22-30.

Eaton, P. (1986). Grassroots conservation. Wildlife management areas in Papua New Guinea. Land Studies Centre Report 86/1. University of Papua New Guinea. Pp. 41-43.

King, B. (1990). Does wildlife management work: a case study, Pokili Wildlife Management Area, West New Britain Province, Papua New Guinea. Tiger Paper. Pp. 1-6.

Date February 1989, updated July 1989, February 1991

\section{RANBA WILDLIFE MANAGEMENT AREA (INCLUDING LONG ISLAND AND CROWN ISLAND WILDLIFE MANAGEMENT AREAS)}

IUCN Management Category:

$\begin{array}{lll}\text { Ranba WMA } & \text { VII } & \text { (Multiple Use Management Area) } \\ \text { Long Island WMA } & \text { IV } & \text { (Managed Nature Reserve) } \\ \text { Crown Island WMA } & \text { IV } & \text { (Managed Nature Reserve) }\end{array}$

Biogeographical Province 5.01.13 (Papuan)

Geographical Location Long Island, which constitutes the whole of Ranba Wildlife Management Area, lies in the Bismarck Sea off the north coast of Papua New Guinea, about $150 \mathrm{~km}$ east of Madang. Long Island Sanctuary covers Lake Wisdom in the centre of Long Island. 
Crown Island Sanctuary, which occupies the whole island, lies $15 \mathrm{~km}$ to the north-west of Long Island. Long Island is at approximately $5^{\circ} 20^{\prime} \mathrm{S}, 147^{\circ} 06^{\prime} \mathrm{E}$ and Crown Island at $5^{\circ} 08^{\prime} \mathrm{S}, 146^{\circ} 57^{\prime} \mathrm{E}$.

Date and History of Establishment The whole of Long Island was declared and gazetted as Ranba Wildlife Management Area in 1977. Long Island and Crown Island sanctuaries were declared in 1977.

Area Ranba Wildlife Management Area: 41,922ha; Long Island Sanctuary: 15,724ha; Crown Island Sanctuary: 5,969ha

\section{Land Tenure Customary land}

\section{Altitude $0-1,280 \mathrm{~m}$}

Physical Features Long Island, a Quaternary volcanic island, consists of two strato volcanoes at either end of a caldera complex. Two peaks, Mount Reamur $(1,280 \mathrm{~m})$ and Mount Cerisy $(1,112 \mathrm{~m})$, are located at the northern and southern ends of the island, respectively (Eaton, 1986). Lake Wisdom, a large freshwater caldera lake $(9,500 \mathrm{ha})$ formed by an immense volcanic explosion, occupies the centre of Long Island. The outer flanks of the island are covered by a thick pyroclastic mantle judged to have been deposited during the first half of the period 1700-1827. Subsequent volcanic activity in the southern part of Lake Wisdom resulted in the formation of Motmot Island, whose eruptions have been recorded in 1953-1955, 1968 and 1973-1974 (Ball and Johnson, 1976).

\section{Climate No information}

Vegetation Consists of savanna and woodland. Coconut Cocos nucifera is the main cash crop.

Fauna Mammals include wild pig Sus scrofa, a distinctive subspecies of brown cuscus Phalanger sp. found on the mainland, fruit bats Pteropdidae, feral dogs Canis familiaris and cats. Sixty-nine species of birds have been recorded (Ball, 1974), including 11 species of pigeon and megapode Megapodius sp.

Green turtle Chelonia mydas (E), hawksbill turtle Eretmochelys imbricata $(\mathrm{E})$ and leatherback Dermochelys coriacea $(\mathrm{E})$ breed on the northern and north-western beaches of Long Island. There are said to be no fish in Lake Wisdom, although there are freshwater shrimps and reports of crocodiles Crocodylus sp. (Eaton, 1986).

\section{Cultural Heritage No information}

Local Human Population Approximately 1,000 people live on the island. There are five main villages, Matfun, Bok, Kaut, Malala, Point Kiau, and a number of smaller isolated settlements around the coast. There are no permanent settlements in Long Island Sanctuary. Crown Island is uninhabited. Food crops are grown in small scattered gardens. Wildlife provides an important source of protein. Cuscus or wild pig are eaten at least once a week by most families; some also eat fruit bats, feral cats and dogs. Turtle and megapode eggs are collected.

Visitors and Visitor Facilities Long Island receives only the occasional visitor.

Scientific Research and Facilities Includes studies of the colonisation of Motmot Island and other islands of Lake Wisdom (Ball and Glucksman, 1978; Bassot and Ball, 1969, 1972), and of the limnology of Lake Wisdom (Ball and Glucksman, 1978).

Conservation Value No specific information 
Conservation Management Long Island is rich in wildlife. A wildlife management committee of six has been appointed to represent the main villages. All wildlife is protected within Long Island Sanctuary and elsewhere within Ranba Wildlife Management Area hunting is confined to those with customary rights. There is a complete ban on the ownership and use of shotguns, which has proven particularly effective, as traditionally bows and arrows are not used. Turtles can only be taken or killed by hunters with customary rights in that part of the island where they occur. In addition, a hunting ban is imposed during the breeding season (May to July) and the sale of turtles is regulated (Eaton, 1986). Fishing is of only limited importance. Traditionally, hook and line or spears are used rather than nets. Sea shells are collected from Crown Island Sanctuary by people with traditional rights (Eaton, 1986).

Management Constraints The rules conceming protection of turtles have not always been observed. Killing has occurred within sanctuary areas and during the breeding season. There have been no prosecutions partly because villagers and administrators are unsure of the exact procedures and rules. An additional problem has been pressure to allow some commercial logging on Long Island.

Staff No information

Budget No information

Local Addresses No information

\section{References}

Ball, E. (1975). List of the island fauna of Long and Crown Islands, Madang District, Papua New Guinea. In: Lindgren, E. (Ed.), Long Island Wildlife Report. Department of Agriculture, Stocks and Fisheries, Port Moresby. (Unseen)

Eaton, P. (1986). Grassroots conservation, wildlife management areas in Papua New Guinea. Land Studies Centre Report 86/1: 22-25.

Date February 1989, updated July 1989

\section{SALAMAUA PENINSULA MARINE PARK}

\section{IUCN Management Category Proposed}

Biogeographical Province 5.01.13 (Papuan)

Geographical Location Lies south of Huon Gulf on the east coast, $37 \mathrm{~km}$ south of Lae, in Morobe Province. Approximately $7^{\circ} 00^{\prime} S, 147^{\circ} 01^{\prime} \mathrm{E}$

Date and History of Establishment No information

Area No information

Land Tenure The peninsula is customary land. Information on reef tenureship is not available.

Altitude Ranges from below sea level to $274 \mathrm{~m}$ 
Physical Features The steep 5.5km-long, steep-sided peninsula is connected to the mainland by a sandy isthmus about $1 \mathrm{~m}$ about sea level. The peninsula is fringed by reefs which extend half way down the isthmus on the north side. Those on the south side are protected from the south-east swells which occur from June to September. Water currents are generally slight, with only one notable tidal cycle per day. Maximum spring tidal range at Lae is $1.1 \mathrm{~m}$ (Kojis and Quinn, 1984). Visibility is good. Water temperature ranges between $27.5^{\circ} \mathrm{C}$ and $32^{\circ} \mathrm{C}$, being warmest from December to March and coolest from July to August. Salinity is usually $32 \mathrm{ppt}$ on the south side of the peninsula.

\section{Climate No information}

\section{Vegetation No information}

Fauna Coral cover is high (43-58\%) at depths less than $20 \mathrm{~m}$; moderate (23-28\%) at $20-35 \mathrm{~m}$ and low (less than 10\%) at depths greater than $35 \mathrm{~m}$. At $45 \mathrm{~m}$ there is about $5 \%$ coral cover. Calcareous sand largely replaces the coral substrate below $40 \mathrm{~m}$. There is a shallow reef flat dominated by massive Porites colonies and Acropora palifera which is most abundant in shallow water is not reported below $15 \mathrm{~m}$. Ninety-five species from 48 genera of coral have been recorded in the Huon Gulf (Kojis et al., 1984), including black coral Anthipathidae (CT).

\section{Cultural Heritage No information}

\section{Local Human Population No information}

Visitors and Visitor Facilities The reefs are popular with snorkelers and SCUBA divers. A resort, Naus Kibung, has been built and is operated by the Morobe Provincial Govemment. It provides a conference venue, accommodation and cooking facilities for tourists, and caters for about 30 people.

Scientific Research and Facilities Fecundity of Acropora palifera at Salamaua has been compared with that of a reef at Busama, $28 \mathrm{~km}$ south of Lae where sedimentation rates are higher (Kojis and Quinn, 1984); sexual reproduction of $A$. palifera at both these reefs has been compared with that at Lizard Island and Heron Island reefs on the Great Barrier Reef, Australia (Kojis, 1986). The area is used for biology field trips by the University of Technology in Lae and by high schools.

\section{Conservation Value No information}

\section{Conservation Management No information}

Management Constraints There is concern that dredging for the proposed port development at Lae could cause damage to the reefs. An environmental impact statement was in preparation in 1981. Slash and burn agriculture on the peninsula could result in siltation of the reefs because the region is mountainous with high rainfall, as appears to be the case along the coastline to the north (Kojis and Quinn, 1984).

Staff No information

Budget No information

Local Addresses No information 


\section{References}

Information for this sheet is based on UNEP/IUCN (1988).

Kojis, B.L. and Quinn, N.J. (1984). Seasonal and depth variation in fecundity of Acropora palifera at two reefs in Papua New Guinea. Coral Reefs 3: 165-172.

Kojis, B.L. and Quinn, N.J., Claereboudt, M.R. and Tseng, W.Y. (1984). Coral reef of the Huon Gulf and Hansa Bay, Papua New Guinea. Paper presented at the joint meeting of the Atlantic Reef Committee and the International Society for Reef Studies. Advances in Reef Science, Miami, Florida, October 1984.

Kojis, B.L. (1986). Sexual reproduction in Acropora (Isopora) (Coelentera: Scleractinia). 2. Latitudinal variation in A. palifera from the Great Barrier Reef and Papua New Guinea. Marine Biology 91: 311-318.

UNEP/IUCN. (1988). Coral Reefs of the World. Volume 3. Central and Western Pacific. UNEP Regional Seas Directories and Bibliographies. IUCN, Gland, Switzerland and Cambridge, UK/UNEP, Nairobi, Kenya. 378 pp.

Date January 1989

\section{SAWATAETAE WILDLIFE MANAGEMENT AREA}

IUCN Management Category VIII (Multiple Use Management Area)

Biogeographical Province 5.01.13 (Papuan)

Geographical Location Lies off the eastern tip of Papua New Guinea, in north-central Normanby Island, adjacent to Etabu Bay, in Milne Bay Province. Approximately $9^{\circ} 57^{\prime} S$, $151^{\circ} 02^{\prime} \mathrm{E}$

Date and History of Establishment Declared a wildlife management area in 1977. Management rules were gazetted in 1978. Established on a plantation owned by an expatriate holding agricultural and pastoral leases (Eaton, 1986).

Area 700 ha

Land Tenure Customary land

Altitude $0-120 \mathrm{~m}$

Physical Features The area is flat and low-lying, becoming hilly further inland (Eaton, 1986). Wetlands include seasonal, slow-flowing streams, swampy areas and seasonally flooded grasslands (Scott, 1989).

Climate Conditions are tropical and monsoonal.

Vegetation Plantation covers part of the management area. Natural vegetation consists of lowland rain forest, secondary regrowth and grassland. In the sheltered waters of the bays mangroves are extensive (Eaton, 1986). 
Fauna Large mammals include wild pig Sus scrofa, cuscus Phalanger spp. and fruit bats Pteropodidae (Eaton, 1986). The area has a diverse avifauna including waterfowl such as banded stilt Himantopus leucocephalus, Stiltia isabella, beach stone-curlew Esacus magnirostris, American golden plover Pluvialis dominica, little ringed plover Charadrius dubius, Mongolian plover $C$.mongolus and greater sand plover $C$. leschenaultii. Birds of paradise namely curl-breasted manucode Manucodia comrii, cockatoos, parrots, egrets and megapodes, are also present (Scott, 1989). The wetlands support a small population of estuarine crocodile Crocodylus porosus (E) (Scott, 1989).

\section{Cultural Heritage No information}

Local Human Population There are about 300 residents distributed among the villages of Sawataetae, Paewese, Eneyai and Gomalimali (Eaton, 1986).

Visitors and Visitor Facilities No information

Scientific Research and Facilities No information

Conservation Value No specific information

Conservation Management The site is administered by a wildlife management committee. The major objective of the wildlife management area is to protect wildlife from hunters without traditional rights. Local taboo forbids eating of crows, eagles and cockatoos. Under the management rules, traditional land-owners are allowed use of shotguns to kill wild pigs and birds damaging crops. Restrictions on burning vegetation are imposed. Fires can be lit by customary owners to clear garden areas only and they must be carefully controlled. In addition to gazetted rules, the cutting of mangrove has been prohibited. Dynamite fishing has been forbidden but pressure lamps and root poisons may still be used. Outsiders wishing to fish or gather trochus shells must obtain permission. It is forbidden to kill megapodes, but no controls are in force relating to egg collection. Further protection has been extended to all fauna, and only cuscus can be taken using traditional methods. It also appears that a larger area than gazetted is effectively included in the wildlife management area. This additionally managed land extends further inland and includes the coastal waters of Etabu and Sawataetae bays (Eaton, 1986).

Management Constraints Initial impetus has declined since Milne Bay Province lost its wildlife officers due to lack of government support (Eaton, 1986).

Staff No information

Budget No information

Local Addresses No information

\section{References}

Eaton, P. (1986). Grassroots conservation. Wildlife Management in Papua New Guinea. Land Studies Centre Report 86/1. University of Papua New Guinea. Pp. 53-55.

Scott, D.A. (Ed.) (1989). A Directory of Asian Wetlands. IUCN, Gland, Switzerland and Cambridge, UK. 1,197 pp.

Date February 1989, updated July 1989 


\section{SIWI-UTAME WILDLIFE MANAGEMENT AREA}

\section{IUCN Management Category VIII (Multiple Use Management Area)}

\section{Biogeographical Province 5.01.13 (Papuan)}

Geographical Location Situated in Ialibu District, South Highlands Province, to the south of Mount Giluwe. The main road between the provincial capital of Mendi and Mount Hagen runs through the northern part of the area. Boundaries comprise the Anggura River to the north and west, Mambu River to the south and the Yorio and Iaro to the east. Approximately $5^{\circ} 50^{\prime} \mathrm{S}$, $144^{\circ} 08^{\prime} \mathrm{E}$

Date and History of Establishment Declared a wildlife management area in January 1977, following negotiations between local people and the Government that commenced in 1974.

Area 12,540 ha

Land Tenure Customary land. Kume Wildlife Centre (4ha) is sited on Government land.

\section{Altitude $1,800-2,317 \mathrm{~m}$}

Physical Features The area features a series of parallel limestone hogback ridges running in a north-westerly direction and separated by corridors of less resistant rocks such as siltstone, mudstone and greywacke, partly covered by volcanic products and lahars from Mount Giluwe. Soils comprise humic brown latosols on well-drained sites, gleyed pelosols on fine-textured impervious sediments, meadow podzolic and laterite soils on old valley fills, bog soils in depressions and alluvial soils on level plains (Kwapena, 1982).

Climate Being a highland region, rainfall is typically high with an annual mean of $3000 \mathrm{~mm}$. Mean temperature is $16^{\circ} \mathrm{C}$ (Eaton, 1986). Relative humidity at Mendi fluctuates between $70 \%$ and $83 \%$ throughout the year and mean monthly evaporation ranges between $82 \mathrm{~mm}$ and $103 \mathrm{~mm}$. Evaporation rates are highest from October to January due to drier conditions (Kwapena, 1982).

Vegetation Consists of anthropogenic grassland, forest margins, secondary growth in logged areas and mixed broadleaf and Nothofagus forest (Kwapena, 1982).

Fauna Twenty-one mammal species are present, including domesticated pig Sus sp., scrub wallaby Thylogale stigmatica, mountain wallaby Dorcopsis hageni, jumping mouse Lorentzimys nouhuysi, bandicoot Peroryctes sp., flying phalangers Petaurus australis and P. breviceps, ring-tailed phalangers $P$ seudocheirus albertisi, $P$. mayeri and Pseudocheirus sp., and rats Rattus leucopus, $R$. rattus, $R$. verecundus, Mallomys argentata, $M$. hercules, $M$. rothschildi, Melomys fellowsi, M. hageni, M. levipes and giant rat Hyomys goliath (Kwapena, 1982).

Some 44 bird species have been recorded, including Macgregor's bowerbird Amblyornis macgregoriae, dwarf cassowary Casuarius bennetti, Princess Stephanie's astrapia Astrapia stephaniae, eclectus parrot Eclectus roratus, black sicklebill Epimachus fastuosus (R), brown sicklebill E. meyeri, black-capped lory Lorius lory, Belford's honeyeater Melidetes belfordi, canary flycatcher Microeca papuana, hooded pitta Pitta sordida, frogmouth Podargus sp. and large scrubwren Sericornis nouhuysi (Kwapena, 1982). 
Among the reptiles are fence lizard Cryptoblepharus sp., gecko Crytodactylus sp., angle-headed dragon Gonocephalus sp., scrub python Liasis sp. and an unidentified brown snake. Amphibians include six species of frogs and cane toad Bufo marinus (Kwapena, 1982).

\section{Cultural Heritage No information}

Local Human Population The area has a total population of about 6,000 , distributed among 19 villages. All residents speak the Kawabi language. The main occupation is subsistence farming, sweet potatoes and taro being the main crops. More temperate vegetables such as potatoes and cabbage are also grown. There are few sources of cash income, but vegetables, woven hats, bags, baskets and trays are sold at roadside markets (Eaton, 1986).

Visitors and Visitor Facilities A wildlife centre has been established at Kume adjacent to the highway. This attracts a small number of visitors, scientists and educational parties. An entry fee is charged (Eaton, 1986). Facilities available include an information centre, picnic area and a small hut where visitors can spend the night. An orchid farm is also being developed (Eaton, 1986).

Scientific Research and Facilities Vegetation and faunal surveys have been carried out (Kwapena, 1982).

\section{Conservation Value No specific information}

Conservation Management The bower bird is traditionally protected. It is believed to have magic powers, especially in its ability to find wives for young men (Eaton, 1986). The area is managed by a wildlife management committee, consisting of 14 members representing different villages. Hunting is restricted to those with customary rights and the use of bows and arrows, shotguns, slings and metal traps is forbidden. No dogs are allowed in the area and eggs are not to be taken or disturbed. In addition, trees can only be felled with the landowner's permission and special protection is extended to fruit trees, trees harbouring wildlife and bird of paradise display trees. About 35 people have been charged and prosecuted for breaking the rules. Some offenders have been fined between $\mathrm{K} 5$ and $\mathrm{K} 1,000$ by the committee or village courts; others have been brought before local courts and serious cases heard by district courts (Eaton, 1986). Cassowaries are reared at Kume wildlife centre. Most are brought when young from other parts of the Southern Highlands. They are in considerable demand for ceremonies and bride prices.

Management Constraints Population pressure has resulted in forest clearance around the village of Kirune for subsistence cultivation. The main Mendi-Mount Hagen road makes the area accessible to outsiders. Birds have been shot from vehicles, but offenders are difficult to apprehend. There has been some loss of momentum since the end of 1981, when budgetary cuts reduced the effectiveness of the Ministry of the Environment and Conservation, and wildlife officers were transferred to the Department of Primary Industry (Eaton, 1986).

\section{Staff No information}

Budget Provision of money necessary for the construction of facilities at Kume Wildlife Centre was partly supported by provincial rural development funds.

\section{Local Addresses No information}




\section{References}

Anon. (1978). Wildlife in Papua New Guinea; conserving wildlife in wildlife management areas, sanctuaries and national parks in Papua New Guinea. Division of Wildlife, Department of Lands and Environment, Konedobu. Pp. 29-31.

Eaton, P. (1986). Grassroots conservation. Wildlife Management areas in Papua New Guinea. Land Studies Centre Report 86/1. University of Papua New Guinea. Pp. 17-20.

Kwapena, N. (1982). Ecology and conservation of six species of bird of paradise in Papua New Guinea. Unpublished. Pp. 27-164.

Date 1984, reviewed February 1989, updated July 1989

\section{TALELE ISLANDS PROVINCIAL PARK}

\section{IUCN Management Category IV (Managed Nature Reserve)}

Biogeographical Province 5.01 .13 (Papuan)

Geographical Location Situated in the Bismarck Archipelago, East New Britain District, 60km west-north-west off the northern coast of New Britain. Approximately $4^{\circ} 10^{\prime} \mathrm{S}, 151^{\circ} 35^{\prime} \mathrm{E}$

Date and History of Establishment Gazetted as a provincial park on 1 October 1973.

Area 40ha

Land Tenure Government expropriated land

Altitude Sea level

Physical Features Comprises a group of eight low coralline islands lying on a loosely-connected steep-sided reef. The islands are noted for their sandy beaches.

Climate No information

Vegetation The islands support mangrove species and beach forest species including Scaevola, Hibiscus and Eremophylla spp. (S. Gorio, pers. comm., 1980).

Fauna Includes a variety of unidentified seabirds, lizards and turtles along with fringing and lagoon reefs (UNEP/IUCN, 1988).

Cultural Heritage No information

Local Human Population No information

Visitors and Visitor Facilities No information

Scientific Research and Facilities Some research has been carried out by the Wildlife Division.

Conservation Value No information

Conservation Management No information 
Management Constraints Some gardening occurs.

Staff No information

Budget K 750 (1980)

Local Addresses National Parks Service Headquarters, PO Box 6601, Boroko

\section{References}

SPREP (1985). Papua New Guinea. In: Thomas, P.E.J. (Ed.), Report on the Third South Pacific National Parks and Reserves Conference. Volume III. Country reviews. South Pacific Commission, Noumea, New Caledonia. 269 pp.

UNEP/IUCN (1988). Coral Reefs of the World. Volume 3. Central and Western Pacific. UNEP Regional Seas Directories and Bibliographies. IUCN, Gland, Switzerland and Cambridge UK/UNEP, Nairobi, Kenya. 378 pp.

Date June 1980, reviewed January 1989, updated July 1989

\section{TONDA WILDLIFE MANAGEMENT AREA}

\section{IUCN Management Category VIII (Multiple Use Management Area)}

Biogeographical Province 5.01.13 (Papuan)

Geographical Location Lies in the extreme south-west of Papua New Guinea, bordered by Irian Jaya to the west and the Mai Kussa River to the east. The site extends inland from the Torres Straits for about $50 \mathrm{~km} .8^{\circ} 15^{\prime}-9^{*} 15^{\prime} \mathrm{S}, 141^{\circ} 01^{\prime}-141^{\circ} 45^{\prime} \mathrm{E}$

Date and History of Establishment Declared a wildlife management area on 6 February 1975, the rules being gazetted in 1976. Various proposals have been made since 1968 regarding its designation. In 1971 the Land Development Board approved the establishment of a wildlife reserve covering approximately $5,000 \mathrm{sq} . \mathrm{km}$, but existing legislation was found to be inadequate and amendments to the Faunal Protection and Control Act (1966) were necessary (Herington, 1978).

Area $590,000 \mathrm{ha}$

Land Tenure Customary land

Altitude $0-45 \mathrm{~m}$

Physical Features The entire management area lies on the southern margin of the Oriomo Plain, a relict alluvial floodplain rising to $45 \mathrm{~m}$ at Morehead Ridge on the reserve's northern boundary. The southern boundary is formed by the northern shores of the Torres Straits, the coast being a narrow band of mudflats backed by low beach ridges. Landward of the beach are seasonal swamps on recent estuarine and marine deposits, since the coast is one of accretion. Three major river systems traverse the area from the north: Bensbach River in the west, Morehead River in the centre and the Wassi Kussa and Mai Kussa estuarine complex in the east. The rivers flow slowly, meander a great deal and are flanked by conspicuous levees. Impeded drainage causes 
widespread seasonal flooding, although permanent swamps are not extensive. During the dry season the rivers are tidal in their lower reaches and brackish water may extend inland for over $100 \mathrm{~km}$ in especially dry years (N. Stronach, pers. comm., 1988). Soils are described by Bleeker (1971). Those of the higher ground are freely-draining red and yellow latosols, acid with loamy topsoils overlying clayey subsoils. Local areas subject to seasonal inundation have gleyed soils. Soils of poorly drained river floodplains and swamps are organic peats overlying clays (N. Stronach, pers. comm., 1988).

Climate Conditions are distinctly seasonal, with a wet season lasting from November to March and a dry season from June to December. Total annual rainfall ranges between $1500 \mathrm{~mm}$ and $2000 \mathrm{~mm}$. Conditions vary from year to year: in 1980 there was a severe drought (Eaton, 1986).

Vegetation The vegetation is similar in physiognomy and species composition to that of northern Australia, in contrast to that of most of lowland New Guinea. This reflects the strongly seasonal climate and the history of former land connections with the Australian continent. The main vegetation comprises various types of forest, savanna and grassland, influenced to a great extent by anthropogenic fire, the degree of inundation experienced in the wet season, and, to a lesser extent, the history of human occupation. Henty (1973) recognised four vegetation types based on physiognomy, following Paijmans (1971). These are subdivided into a total of 14 , based on a combination of physiognomy and species composition (N. Stronach, pers. comm., 1988).

1. Forests and woodlands support many species in common but can be distinguished into several types: (a) Mangrove forest and woodland forming a belt of up to $1 \mathrm{~km}$ wide along the coast. Associates include Rhizophora, Avicennia and Ceriops. (b) Littoral forest and woodland, with mixed species composition trees up to $30 \mathrm{~m}$ high, and Melaleuca cajaputi and Acacia auriculiformis are common. (c) Monsoon forest, on sites not subject to flooding, with a canopy of $25 \mathrm{~m}$ and emergents reaching $40 \mathrm{~m}$, is relatively rich in tree species with Acacia spp., Tristania, Syzygium, Parinari, Mangifera and others. The soils of this vegetation type are sought after for cultivation and much has been converted to Imperata grassland and maintained as such by fires. (d) Gallery forest and woodland in narrow belts along banks of streams and on levees of major rivers. Trees include Terminalia, Calophyllum, Acacia, Melaleuca and Tristania, while Mangifera inocarpoides may be predominant locally. (e) Mixed swamp forest and woodland on floodplains of major rivers, with a canopy of up to $30 \mathrm{~m}$ and sometimes with an abundant grass layer. Associates include Vitex, Sarcocephalus coadunata, Mangifera inocarpoides and Dillenia alata. (f) Melaleuca swamp forest, consisting almost entirely of Melaleuca spp. on soils subjected to prolonged flooding of $2 \mathrm{~m}$ depth or more, especially along the lower Bensbach and Morehead rivers, although not necessarily close to the rivers themselves.

2. Savanna covers most of the area and is affected by frequent fires. There are several types: (a) Tall mixed savanna is fairly open, with Acacia spp., Tristania, Xanthostemon, Melaleuca spp., Alstonia and other trees up to $25 \mathrm{~m}$ tall and a dense ground layer dominated by grasses. (b) Low mixed savanna with trees usually less than $20 \mathrm{~m}$ high, widely spaced on land waterlogged or flooded in the wet season, intergrading with tall mixed savanna on more nutrient-rich soils, and consisting of Melaleuca spp., Xanthostemon, Tristania spp., Grevillea glauca, Banksia dentata, Dillenia alata and Eucalyptus spp. The ground layer is dominated by grasses including Imperata, Aristada and Eriachne. (c) Melaleuca savanna canopy, usually below $15 \mathrm{~m}$, on land subject to flooding, dominated by thin-stemmed Melaleuca spp., with Dillenia alata and Tristania suaveolens, and a species-rich ground layer including many sedges and grasses (though lacking Imperata) and forbs. (d) Monsoon scrub on soils of very low nutrient status and with impeded drainage, with trees lower than $7 \mathrm{~m}$, include Melaleuca viridiflora, Banksia marginata and Grevillea glauca. Low shrub Synoga lysicephala may form dense thickets and the ground 
layer is dominated by sedges, especially Schoenus and Tricostularia. The insectivorous forbs Nepenthes and Drosera are conspicuous.

3. Grassland is subject to frequent burning. The largest area forms the Bulla Plains $(60,000 \mathrm{ha})$ between the Bensbach and Morehead rivers. (a) Imperata grassland occurs south of the Bensbach River and at Tonda, which are not subjected to flooding. Imperata cylindrica is predominant but in various stages of replacement by other grass species through the combined agencies of fire and grazing by rusa deer. Associates include scattered trees of Sarcocephalus coadunata, Melaleuca spp. and Corypha. Possibly this vegetation type developed under previous cultivation and is now being invaded by Melaleuca savanna and forest communities. (b) Swamp grassland occupies large areas on either side of the Bensbach and Morehead rivers on black soils continuously flooded for several months each wet season. It is now largely dominated by grass Pseudoraphis spinescens, with relict patches of Phragmites karka and robust sedges in decline due to the activities of introduced rusa deer and feral pigs. This grassland type also interdigitates with other grassland and woodland/forest types along shallow creeks. (c) Sedge grassland occupies a large area between the Bensbach and Morehead rivers on clay soils of markedly impeded drainage. It is dominated by sedges and grasses and characterised by scattered $P$ andanus and thickets of low Melaleuca viridiflora.

4. Riparian and aquatic vegetation has been greatly modified by the grazing activities of rusa deer but relict patches survive at inaccessible sites along rivers and in swamps. It consists of Phragmites karka, Panicum spp., Hymenachne pseudointerrupta, Oryza spp., Cyperus platystylis and other species often forming floating mats. The tree Barringtonia tetraptera is often conspicuous, as are Pseudoraphis spinescens, Utricularia aurea, Nelumbo and Nymphaea in seasonal lagoons (N. Stronach, pers.comm., 1988).

Fauna Knowledge about mammals is based on a few surveys only, and is largely held by the local people, except in the case of the introduced rusa deer which has been the subject of several scientific studies. The numbers of all wallaby species are probably depressed by human hunting close to villages. The monotreme short-beaked echidna Tachyglossus aculeatus is present. Marsupials are represented by a diversity of small to medium-sized carnivorous and omnivorous species. Agile wallaby Macropus agilis, typical of savanna and grassland, is abundant on the Bulla Plains; forest wallabies Thylogale stigmatica and Dorcopsis veterum are common in monsoon forest. Both rodents and bats are well represented. Rusa deer Cervus timorensis rusa, which is widespread and commonest around river floodplains, has had fundamental effects on the ecology of the area. The Bulla Plains has a population of up to 20,000 deer. The deer support a small harvest for trophies and meat and probably contribute to the very high density of scavenging birds of prey. Other introduced mammals include domestic pig (in prehistoric times), which has modified large areas of swamp grassland by its digging, domestic dog (introduced prehistorically), domestic cat, which has established itself widely in the savanna at least, and domestic cattle, of which there is a small population in the vicinity of the Bensbach and Tarl rivers (N. Stronach, pers. comm., 1988).

Birds are the only group which is at all well-known, with an expanding check-list of over 250 species for the reserve (N. Stronach, pers. comm., 1988). Of these, the majority of savanna birds are typically Australian species, for example wedge-tailed eagle Aquila audax, brolga Grus rubicunda, Australian bustard Ardeotis australis and blue-winged kookaburra Dacelo leachii. A number of Australian migrants visit the area, most notable being the abundant waterfowl during the wet season. The most conspicuous Palaearctic migrants are shorebirds, with hundreds of thousands occupying the tidal mudflats during the northern winter. The Bulla Plains are most important for much of the world population of little curlew Numenius minutus during the late 
dry season. New Guinea endemics are more typical of forest and include New Guinea harpy eagle Harpyopsis novaeguineae (V), New Guinea flightless rail Megacrex inepta, and a variety of pigeons, parrots and passerines, including Raggiana's bird of paradise Paradiseae raggiana. Southern cassowary Casuarius casuarius is common but numbers, unlike those of other bird species, may be depressed by human hunting pressure. Transfly endemics known to occur in the area are spangled kookaburra Dacelo tyro, little paradise kingfisher Tanysiptera hydrocharis (both species are also found in Aru Islands), Fly River grassbird Megalurus albolimbatus (R) and white-spotted mannikin Lonchura nevermanni (N. Stronach, pers. comm., 1988). Scott (1989) provides details of waterfowl recorded during a survey in 1988.

Amphibians and reptiles are conspicuous. Many species are shared with Australia including frilled lizard Chlamydosaurus kingi. Large turtles Emydura sp. are common in rivers and snakes are abundant, including taipan Oxyuranus scutellatus, Papuan black snake $P$ seudechis papuans and death adder Acanthrophis antarcticus. Monitor Varanus spp. are abundant; three species are known from the reserve, while a further three have been recorded from just outside the boundary. They support a negligible indigenous harvest of skins for kundu drums. Estuarine crocodile Crocodylus porosus $(\mathrm{E})$ and New Guinea crocodile $C$. novaeguineae $(\mathrm{V})$ are hunted intensively for their skins and juveniles are captured to stock village farms. Large male estuarine crocodiles are undoubtedly removed from the vicinity of villages as they pose a threat to human life and others have been drowned in nylon fishing nets. The habitat of both species has been degraded by rusa deer. Cane toad Bufo marinus is known to have been introduced from time to time in cargoes, but populations are not known to have become established; if they do, they could pose a serious threat to many species (N. Stronach, pers. comm., 1988).

Fish are abundant. The seasonal floodplains are highly productive and are the feeding grounds of catadromous barramundi Lates calcifer, which supports a modest sport fishery along the Bensbach River. A commercial fishery, based on Daru, extends along the coast to the east. Significant natural mortality of fish occurs when water levels fall at the beginning of the dry season and with the first flow of water at the beginning of the rains (N. Stronach, pers. comm., 1988). Invertebrates are diverse and little known. Termites, both terrestrial mound-forming and arboreal, and ants are conspicuous. Freshwater crayfish are abundant, providing a major food supply for many waterfowl, monitor lizards and fish; they aestivate in the mud when swamps and floodplains dry out (N. Stronach, pers. comm., 1988).

\section{Cultural Heritage No information}

Local Human Population Population density is very low as much of the area remains wild and untouched. There are about 1,200 inhabitants distributed among 16 villages. Ten of these villages have lands lying completely within the management area and six have lands within the boundaries and beyond (Herington, 1978). The population is mobile and abandoned villages are evident. Hunting, fishing and egg-collecting play an important part in subsistence and cash economies. Shifting cultivation occurs in forest areas, operating with a fallow period of 15-30 years. The main crops are yams, taro and sweet potatoes. Sago is collected in some areas. Gardening is carried out on rich soils by river banks (Eaton, 1986).

Visitors and Visitor Facilities Visitors, consisting mainly of hunters and those wishing to observe wildlife, are obliged to travel with a paid guide. Tourism is centred on Bensbach Wildlife Lodge, which handles sport hunting and fishing (Eaton, 1986). 
Scientific Research and Facilities Research includes geomorphological and flora surveys (CSIRO, 1971) and faunal surveys, notably of waterfowl (Scott, 1989). Downes (1969) studied the rusa deer population.

Conservation Value The importance of the management area for conservation lies in the presence of a relict Australian flora and fauna, mixed with those characteristic of, or endemic to New Guinea.

Conservation Management The rules of the area state that only customary landowners may hunt freely. Tourists are charged a nominal entry fee of K1 (US\$1.1), and may only hunt deer, duck and two species of barramundi; hunters must have a licence for each. A limit of five duck or deer can be taken. Anyone wishing to use guns must obtain a firearm permit from the police department. Royalties must be paid for animals caught. Royalties for deer are on a sliding scale, ranging from $\mathrm{K} 15$ for the first deer to $\mathrm{K} 60$ for the fifth. K1 must be paid for each duck and 30 toea per $\mathrm{kg}$ of fish (Eaton, 1986). According to the rules, hunting is prohibited in the region between the Bensbach and Morehead rivers and is not allowed from vehicles or boats. These conditions are inappropriate, and not applied by the local people (N. Stronach, pers. comm., 1989). The landowners hunt wallaby, wild pig and cassowary using traditional methods, and are encouraged to hunt deer but prefer indigenous species. Crocodiles killed for their skins provide a source of cash income. Trade in skins is controlled by the Government through the Crocodile Trade Protection Act. The only traditional restrictions, varying from village to village, appear to be bans on food eaten by pregnant women (Eaton, 1986).

Management Constraints The activities of exotic ungulates (deer and pigs) have caused considerable changes to the habitat and may be affecting the integrity of the area through the gradual colonisation of the Bulla Plains by trees. Introduced fauna also threaten wildlife. For example, feral dogs kill wallabies and bandicoots. Feral cats are potentially a much bigger problem (N. Stronach, pers. comm., 1989). Poachers from Irian Jaya have been found setting nets across the mouth of the Bensbach River. This could have serious effects on the migratory barramundi. Poachers have also killed deer and caught crocodiles. Some smuggling of outsize crocodile skins occurs across the border. Cuts in public expenditure and restructuring of Government departments have meant that the landowners receive little supervision or guidance in the management of their natural resources; projects initiated with the aid and encouragement of the Government, such as crocodile, cassowary and butterfly farming, have been allowed to run down (Eaton, 1986). In addition, rules relating to "traditional" use of natural resources have been open to interpretation by the local people (N. Stronach, pers. comm., 1988).

\section{Staff One wildlife officer}

Budget Licence fees and half the royalties collected are deposited in a bank trust account (K19,514 in 1983). It is intended that monies raised will be used for the development and welfare of the management area. The other half is paid to individual owners of the land where hunting or fishing occurs (Eaton, 1986).

Local Addresses No information

\section{References}

Bleeker, P. (1971). Soils of the Morehead-Kiunger area. CSIRO Land Research Series 29: 69-87. Downes, M.C. (1969). Deer in New Guinea. Part II. A preliminary note on the distribution of deer in the territory of Papua New Guinea. Papua New Guinea Agricultural Journal 20: 95-99. (Unseen). 
Eaton, P. (1986). Grassroots conservation, wildlife management areas in Papua New Guinea. Land Studies Centre Report 86/1. University of Papua New Guinea. Pp. 9-15.

Herington, J.G. (1978). Wildlife in Papua New Guinea: Wildlife Management Areas in Papua New Guinea: 2 Tonda. Division of Wildlife, Department of Lands and Environment, Konedobu. 127 pp.

Kwapena, N. (n.d.). The habitat of deer (Rusa Timorensis) in Tonda Wildlife Management Area, Western District, Papua New Guinea. Wildlife Branch, Department of Agriculture, Stocks and Fisheries, Papua New Guinea. Pp. 52-64.

Paijmans, K. (1971). Land research of the Morehead-Kiunga Area, Papua New Guinea. CSIRO Land Research Series 29: 89-90.

Scott, D.A. (Ed.) (1989). A Directory of Asian Wetlands. IUCN, Gland, Switzerland and Cambridge, UK. 1,197 pp.

Date 1984, reviewed February 1989, updated July 1989

\section{VARIRATA NATIONAL PARK}

\section{IUCN Management Category II (National Park)}

\section{Biogeographical Province 5.01.13 (Papuan)}

Geographical Location Situated on the Sogeri Plateau, in Central Province, $48 \mathrm{~km}$ east of Port Moresby. $9^{\circ} 26^{\prime}-9^{\circ} 30^{\prime} \mathrm{S}, 147^{\circ} 20^{\prime}-147^{\circ} 23^{\prime} \mathrm{E}$

Date and History of Establishment Gazetted as a national park on 18 December 1969 and officially opened on 18 October 1973. Land on which the park lies was acquired on 23 October 1986 under Part 2 of the Crown Land Ordinance. The park was originally reserved on 17 February 1963 under the trusteeship of the District Commission, Director of Forest and Ruth Isobel Sefton.

Area 1,063 ha

Land Tenure Government expropriated land

Altitude $120-1,065 \mathrm{~m}$

Physical Features Lying atop Sogeri Plateau at the edge of the escarpment, the terrain is rugged and deeply-weathered and characterised by steep precipitous slopes, narrow accordant ridges and cliffs. Geological features include andesitic tuff, lava and dyke rock, and basaltic and andesitic agglomerates, such as Astrolabe Agglomerate (Blake et al., 1973).

Climate No meteorological data are available for the park. Nearby, Sogeri receives $2400 \mathrm{~mm}$ of rain annually (B.M. Beehler, pers. comm., 1989).

Vegetation Comprises rain forest, savanna grassland, gallery forest and secondary regrowth. Savanna grassland occurs on hilltops, up to $1,000 \mathrm{~m}$. Eucalyptus spp., including E. tereticornis, are present along with Melaleuca spp. (Specht et al., 1974). Themeda australis, Imperata cylindrica and Sehima nervosum are the dominant grasses. Climbers and epiphytes, such as Usnea and Dischidia spp., are present (Paijmans, 1973). Rain forest is confined to the valleys. Three structural formations can be distinguished. Complex mesophyll vine forest, 
semi-deciduous mesophyll vine forest and mixed mesophyll vine forest with an estimated cover of $10 \%, 30 \%$, and $40 \%$, respectively. Common genera are Terminalia, Celtis, Myristica, Castanopsis, Bombax, Erythrina, Ficus and Vitex (Specht et al., 1974).

Fauna Among terrestrial vertebrates are significant populations of lesser forest wallaby Dorcopsulus vanheurni, Papuan python Liasis papuensis and dwarf cassowary Casuarius bennetti (B.M. Beehler, pers. comm., 1989). Other mammals present include bandicoots Peroryctes spp., wild boar Sus scrofa and deer. Nearly 150 species of birds have been recorded by the Papua New Guinea Bird Society, including five species of bird of paradise, viz. glossy mantled monucode Monocodia atra, crinkled-collared monucode $M$. chalybata, magnificent riflebird Ptiloris magnificus, magnificent bird of paradise Cicinnurus magnificus and Raggiana bird of paradise Paradisaea raggiana, two species of bowerbird, namely white-eared catbird Ailuroedus buccoides and fawn-breasted bowerbird Chlamydera cerviniventris, and 60 other species endemic to New Guinea. Several species reach their altitudinal limits within the park (M. Hopkins, pers. comm., 1989). For example, rufous whistler Pachycephala rufiventris, leaden flycatcher Myiagra rubecula and black-backed butcherbird Cracticus mentalis, associates of eucalypt savannas attain their highest altitude in the park, while rain forest associates, such as dwarf whistler Pachycare flavogrisea, grey-green scrub-wren Sericornis arfakianus and bi-coloured mouse-warbler Craterocelis nigrorufa, occur at lower altitudes than elsewhere in the Owen Stanley Range (R. Hicks and M. Hopkins, pers. comm., 1989).

Cultural Heritage The park lies in the traditional hunting grounds of the Koiari people. A "walking track", part of an ancient network covering Papua New Guinea, runs through the park, traditionally a refuge for women and children during inter-tribal fights, but this no longer exists. The Koiari Tree House remains, however, and is one of the park's major attractions. This was used by the Koiari during inter-tribal conflicts to both shelter women and children and to provide a handy spear-lobbing platform.

\section{Local Human Population No information}

Visitors and Visitor Facilities Easily accessible along a sealed road, about one hour's drive from Port Moresby. The site is well developed, with five walking tracks, six picnic sites, and camp sites and lodges accommodating ten and six people, respectively. Visitor numbers have increased steadily from 13,045 in 1974 to 20,629 in 1987 (Nyama, 1989).

Scientific Research and Facilities Preliminary surveys have been made of the vegetation (Schodde and Mackay, cited in Specht et al., 1974) and birds (Dyson, n.d.; Weston, n.d.). Various studies are undertaken by the Biology Department, University of Papua New Guinea.

Conservation Value The park has three main functions, viz: to preserve natural communities of plants and animals, and the Koiari culture; to protect an outstanding landscape; and to provide the opportunity for recreation, research and public education on the concept of national parks (Nyama, 1989).

Conservation Management Varirata is popular for viewing wildlife and has an important educational function (Gagné and Gressitt, 1982). Basic policies on land acquisition, planning and management have been established (Gorio, 1978) and the park is effectively managed (Diamond, 1982). A simple system of zonation has been established, with recreational, minimum access and totally restricted areas. Park buildings are of local design and materials (SPREP, 1985), and the Department of Works maintains major vehicular roads and the administration buildings (Nyama, 1989). 
Management Constraints There is potential conflict between conservation and mining, as prospecting rights are planned, although there are no settlements or other current land use activities around the park which conflict with management objectives. Clearing of fire breaks and culling are used to control the two major problems, namely annual man-made bush fires and damage to trees by deer (Nyama, 1989).

Staff One Ranger-in-Charge, one artisan and five general workers (Nyama, 1989)

Budget The annual operating budget is K 41,600 (US\$ 48,940 ), of which two-thirds is paid in salaries. Varirata generates more than $50 \%$ of the National Parks Service total internal revenue of $\mathrm{K} 30,000$. Charges are made for entry and accommodation, and may be set at the discretion of the Director of National Parks.

Local Addresses Ranger-in-Charge, Varirata National Park, National Parks Service, PO Box 5749, Boroko

\section{References}

Beehler, B.M., Pratt, T.K. and Zimmerman, D.A. (1986). Birds of New Guinea. Princeton University Press, Princeton, New Jersey. 293 pp.

Blake, D.H., Paijmans, K. and McAlpine, J.R. (1973). Land form types and vegetation of Eastern Papua. CSIRO Land Research Series 32: 9-124.

Diamond, J.M. (1982). Biological principals relevant to protected area design in the New Guinea region. In: McNeely, J.A. and Miller, K.R. (Eds), National Parks, conservation and development. The role of protected areas in sustaining society. Smithsonian Institution Press, Washington, DC. Pp. 330-332.

Dyson, W. (n.d.). Varirata National Park wildlife survey: a bird list for Varirata National Park. (Unseen).

Gagné, W.C. and Gressitt, J.L. (1982). Conservation in New Guinea. In: Gressitt, J.L. (Ed.), Biogeography and ecology of New Guinea. Monographiae Biologicae 42: 945-955.

Gorio, S. (1978). Papua New Guinea involves its people in national park development. Parks $3(2): 12-14$.

Nyama, V. (1989). Varirata National Park: visitor use and income generation. Case Study 22. Fourth South Pacific Conference on Nature Conservation and Protected Areas, Port Vila, Vanuatu, 4-12 September. 8 pp.

Specht, R.L., Roe, E.M. and Boughton, V.H. (Eds). (1974). Conservation of major plant communities in Australia and Papua New Guinea. CSIRO, Melbourne, Australia. Pp. 591-605.

SPREP (1985). Papua New Guinea. In: Thomas, P.E.J. (Ed.), Report on the Third South Pacific National Parks and Reserves Conference. Volume III. Country reviews. South Pacific Commission, Noumea, New Caledonia. 269 pp.

Weston, I.L. (n.d.). Papua New Guinea Bird Society, Boroko. Unpublished list of 113 species of birds. $2 \mathrm{pp}$.

Date June 1980, reviewed December 1988, updated July 1989, February 1990 


\section{WAIGANI SWAMP PROVINCIAL PARK}

\section{IUCN Management Category Proposed}

\section{Biogeographical Province 5.01.13 (Papuan)}

Geographical Location Situated 15km north of Port Moresby in National Capital District. Approximately $9^{\circ} 22^{\prime} \mathrm{S}, 147^{\circ} 10^{\prime} \mathrm{E}$

Date and History of Establishment The area has been approved as a provincial park but not yet gazetted.

\section{Area 120ha (Waigani Lake)}

\section{Land Tenure Customary land}

\section{Altitude $5 \mathrm{~m}$}

Physical Features Waigani is the largest among a complex of shallow, eutrophic, freshwater lakes and surrounding swamps associated with Laloki River. The swamps are permanent but subject to marked fluctuations in water level, with high levels from January to April. The wetland is fed by local rainfall (December-April). Depth is $1-2 \mathrm{~m}$; the water is neutral-alkaline. Low Secchi disc readings $(0.07-0.76 \mathrm{~m})$ are due to the large populations of phytoplankton occurring with high loadings of nitrate and total phosphorus. The maximum surface temperature of the open water ranges from $24.6^{\circ} \mathrm{C}$ to $33^{\circ} \mathrm{C}$ (Scott, 1989 ).

Climate Conditions are tropical monsoonal, with mean annual rainfall of $1000 \mathrm{~mm}$ and a prolonged dry season from May to December.

Vegetation The swamp vegetation is dominated by reeds Phragmites karka and Typha orientalis, with some Ludwigia adscendens, Ipomoea aquatica and Hanguana malayana. Nymphoides indica, Ceratophyllum demersum and Nymphaea pubescens occur in undisturbed lakes. Salvinia molesta has declined under early pilot experiments on biological control. Other aquatic plants include Marsilea crenata, Ceratopteris thalictroides, Acrostichum aureum, Ampelopteris prolifera, Cyclosorus interruptus, Sagittaria platyphylla, Alternanthera sessilis, Pistia stratoites, Cyperus platystylis, Eleocharis dulcis, Scirpus grossus, Hymenachne acutigluma, Ischaemum polystachyum, Leersia hexandra, Hydrocharis dubia, Spirodela polyrhiza, Najas indica, Nymphaea dictyophlebia, Ludwigia hyssopifolia, L.octovalvis, Polygonum barbatum and Monochoria hastata (Scott, 1989). Over the past forty years, dominant emergent vegetation at Waigani Lake has been replaced by floating-leaved aquatics, which have subsequently been lost to an open water system (Osborne and Leach, 1983). These changes can be partly attributed to nutrient enrichment over the period. In early 1984, the lake was covered for about two months by a dense growth of fern Salvinia molesta which subsequently declined rapidly to small peripheral patches.

Fauna Crocodile Crocodylus spp. occurs in small numbers. The wetland supports a wide variety of aquatic birds. Australian grebe Tachybaptus novaehollandiae, pied heron Egretta picata, wandering whistling duck Dendrocygna arcuata, Pacific black duck Anas superciliosa, dusky moorhen Gallinula tenebrosa, purple swamphen Porphyrio porphyrio, comb-crested jacana Irediparra gallinacea, white-headed stilt Himantopus leucocephalus, masked lapwing Vanellus miles and whiskered tern Chlidonias hybridus are particularly common. Tilapia Oreochromis mossambicus and common carp Cyprinus carpio have been introduced into the lake (Scott, 1989). 
Moitaka settling ponds, immediately to the south, drain into Waigani Swamp. They have been regularly watched by members of the Papua New Guinea Bird Society over the last 25 years, during which several species, such as redshank Tringa totanus, black tern Chlidonias niger and starling Sturnus vulgaris, have been recorded in Papua New Guinea for the first time. A total of 119 species, including 18 species of Palaearctic waders and two New Guinea endemics, orange-fronted fruit-dove Ptilinopus aurantiifrons and white-shouldered fairy wren Malurus alboscapulatus, has been recorded from these ponds (R. Hicks, pers. comm., 1989).

Cultural Heritage No information

Local Human Population No information

Visitors and Visitor Facilities No information

Scientific Research and Facilities Much research has been carried out on the ecology of the wetland, including studies on the effects of eutrophication (Saulei, 1978), changes in the macrophytic flora and vegetation in response to nutrient enrichment from sewage effluent (Osborne and Leach, 1983; Osborne and Polunin, 1986), and sediment geochemistry (Polunin et al., 1988). Research facilities are available at the University of Papua New Guinea in Port Moresby.

\section{Conservation Value No information}

\section{Conservation Management No information}

Management Constraints The lake receives large quantities of untreated sewage effluent from the capital, Port Moresby. Resultant nutrient enrichment has caused major changes in the aquatic flora of the lake (Osborne and Leach, 1983; Osborne and Polunin, 1986). A fish-kill that occurred in 1984 was due to low oxygen conditions resulting from dense growths of Salvinia molesta, inefficient sewage treatment, and possibly heavy metal contamination (Polunin et al., 1988). While sewage disposal has reduced the value of the swamp in terms of its aquatic flora, it has increased it for its avifauna.

Staff No information

Budget No information

Local Addresses Assistant Secretary, National Parks Service, Department of Environment and Conservation, PO Box 5749, Boroko

\section{References}

Osborne, P.L. and Leach, G. (1983). Changes in the distribution of aquatic plants in a tropical swamp. Environmental Conservation 10: 323-329. (Unseen).

Osborne, P.L. and Polunin, N. (1986). From swamp to lake: recent changes in a lowland tropical swamp. Journal of Ecology 74: 197-210. (Unseen).

Polunin, N.V.C. (1988). Efficient uptake of algal production by a single resident herbivore fish on the reef. Journal of Experimental Marine Biology and Ecology 123: 61-76.

Saulei, S. (1978). The effect of eutrophication on a tropical lentic ecosystem: the Waigani Swamp Lake. Honours Thesis, University of Papua New Guinea. (Unseen). 
Scott, D.A. (Ed.) (1989). A Directory of Asian Wetlands. IUCN, Gland, Switzerland and Cambridge, UK. 1,197 pp.

Date January 1989, updated July 1989 


\section{SOLOMON ISLANDS}

Area 28,450 sq. $\mathrm{km}$ of land distributed over $1,340,000 \mathrm{sq} . \mathrm{km}$ of sea

Population 304,000 (1988) (World Bank, 1990)

Natural increase: $3.6 \%$

\section{GNP US\$ 630 per capita (1988)}

Policy and Legislation The Solomon Islands Constitution protects the right of land owners to utilise their land and forests as they wish. Consequently, any restriction resulting from designation of a reserve or forest park would impose upon this basic right. Given that some $87 \%$ of all land is held in customary or tribal tenure (C. Turnbull, pers. comm., 1990), it is the attitudes and activities of local people, not Government, that determine the extent and nature of land reservation for nature conservation.

Formal protected areas legislation principally comprises two acts, both dating from the colonial era. The Wild Birds Protection Act (1914) enabled the Minister, under Section 14, to declare any island or islands, or any part or parts of any island or any district, as a bird sanctuary. The National Parks Act (1954) makes provision for the establishment of strictly protected natural areas as national parks. This legislation is considered to be inconsistent with current concepts of resource use, by making inadequate allowance for genuine customary needs and by placing no obligation upon the administering agency to manage a national park in accordance with stated park objectives (SPREP, 1985a). Some provincial governments have passed Ordinances with provisions for the establishment of protected areas, including Temotu and Isabel provinces (Leary, 1990). However, provisional legislation is equally subject to the restrictions of the constitution and traditional practices.

The forest policy of the Solomon Islands was reviewed in 1983, and a National Forest and Timber Policy was approved by Government in 1984. The policy called for the maximum desirable log processing, minimum wastage and increased investment in forests, aims that were restated in the 1985-89 National Development Plan. Failure to achieve these and more detailed aims is attributed to shortcomings in the forest legislation, institutional weakness and a lack of public participation and awareness. Consequently, a revised forest policy has been promulgated. This identifies six imperatives, viz. protection, sustainable use, basic needs, development, participation and distribution. Six objectives are established including "(VI) set aside areas for environmental, ecological, scientific and heritage reserves taking into account landowner needs and customary values; protect sensitive areas".

The Forestry and Timber Act, 1969 (amended 1977) has a narrow perspective, but makes some provision for controlled forest areas for forest water catchment protection. The Forest Resources and Timber Utilisation (Amendment) Act 1987 was approved in March 1987, with a retrospective commencement date of 16 June 1978. There was a new Forestry Bill 1989 that was due to go before Parliament in November 1989, which included provisions for the establishment of conservation areas. The Town and Country Planning Act (1979) provides for tree preservation orders for "any tree, groups of trees or woodlands ... in the interests of amenity". The Lands and Titles Act (1968, amended 1970) makes provision for preservation orders to be applied to land of "historic or religious" value, and permits the establishment of nature reserves.

Regulations prescribing measures for the protection and preservation of the marine environment can be promulgated under the Delimitation of Marine Waters Act (1978). A new forestry bill 
was due to be presented to parliament in November 1989. This includes provisions for environmental protection and the establishment and management of conservation areas (Isa, 1989).

International Activities The Solomon Islands is not yet party to any of the international conventions or programmes that directly promote the conservation of natural areas, namely the Convention concerning the Protection of the World Cultural and Natural Heritage (World Heritage Convention), Unesco Man and the Biosphere Programme and the Convention on Wetlands of International Importance especially as Waterfowl Habitat (Ramsar Convention).

The Convention on the Conservation of Nature in the South Pacific (1976) has been neither signed nor ratified. Known as the Apia Convention, it entered into force during 1990. The Convention is coordinated by the South Pacific Commission and represents the first attempt within the region to cooperate on environmental matters. Among other measures, it encourages the creation of protected areas to preserve indigenous flora and fauna.

The Solomon Islands is party to the South Pacific Regional Environment Programme (SPREP) and has ratified (10 August 1989) the 1986 Convention for the Protection of the Natural Resources and Environment of the South Pacific Region (SPREP Convention). The Convention entered into force during August 1990. Article 14 calls upon the parties to take all appropriate measures to protect rare or fragile ecosystems and threatened or endangered flora and fauna through the establishment of protected areas and the regulation of activities likely to have an adverse effect on the species, ecosystems and biological processes being protected. However, as this provision only applies to the Convention area, which by definition is open ocean, it is most likely to assist with the establishment of marine reserves and the conservation of marine species.

Other international and regional conventions concerning environmental protection to which the Solomon Islands is party are reviewed by Venkatesh $e t$ al. (1983).

Administration and Management General responsibility for environmental matters is part of the portfolio of the Minister of Lands, Energy and Natural Resources. The Environment and Conservation Division of the Ministry of Natural Resources has responsibility for environmental protection and the conservation of natural resources and in 1989 had five members of staff, with the expectation that this would increase to nine during 1990 (Isa, 1989).

The Solomon Islands Development Trust is a rural development organisation which places its operations, with a particular focus on community education, in an environmental context and is a significant influence in the rain forest logging debate (Baines, 1990). Community-based associations have been formed to counter the growing threat of over-exploitation, including the Fauro Peoples Association and The Vella 2000. Their principal objectives are to: promote community unity; promote resource management and utilisation; derive economic returns for their members; promote resource-management awareness amongst their membership; and promote respect for traditional values of their communities. In addition, these groups have approached Government for advice on the establishment and management of protected areas, with three sites covering 6,000ha already earmarked (Isa, 1988).

Nominal protected areas are few in number and currently cover some $0.2 \%$ of the terrestrial territory of the Solomons, and an even less significant percentage of the total national area. This can be largely attributed to the failure to consider traditional attitudes toward land and natural resources and the unwillingness amongst local people to be permanently alienated from their lands (Isa, 1988). For example, Arnavon Wildlife Sanctuary was gazetted without consultation with parties claiming rights under customary law, leading to serious management implementation 
problems and a failure to protect the site. A number of other reserves exist on paper but none is functional. Customary land-owners are frequently willing to grant temporary access rights for timber felling, but reluctant to be alienated permanently from land following the establishment of a protected area (Isa, 1989). The best conservation practice at present is that carried out by some of the customary land-owning groups, although these efforts have thus far escaped recognition and lack the support of formal legislation (G.B.K. Baines, pers. comm., 1989). However, this is likely to be rectified with formal government recognition of these community based protected areas (Isa, 1988).

As an additional hindrance to the establishment of formal protected areas, state-owned land covers only $257 \mathrm{sq} . \mathrm{km}$ (9\% of total land area), of which $240 \mathrm{sq} . \mathrm{km}$ is committed to forestry plantations or operations (C. Turnbull, pers. comm., 1990). Therefore, at present, there is little opportunity to develop conservation areas on uncommitted government land (Leary, 1989). The existing protected areas system is thus very weak, none of the formally gazetted protected areas is managed or has field staff, and they have very little conservation significance or official recognition. Indeed, as there are no legally gazetted forest reserves, the Solomon Islands effectively has no formal protected areas system.

Systems Reviews The Solomon Islands occupies a central position in the Melanesian Arc that extends from Papua New Guinea in the west to Fiji in the east. They consist of two roughly parallel island chains, forming the western continental margin of the Pacific Basin. The central archipelago lies between $5^{\circ} \mathrm{S}-12^{\circ} \mathrm{S}$ and $152^{\circ} \mathrm{E}-163^{\circ} \mathrm{E}$. A brief summary of the physical features and coral reefs is given in UNEP/IUCN, 1988.

Prior to recent, extensive logging, the Solomons supported a rain forest mantle, unbroken except for areas of, probably anthropogenic, grassland and heath. Grasslands are probably a fire-climax, with invasion by tree species checked. Lowland formations are largely uniform throughout the archipelago. There is, however, considerable local variation in the floristics and structure, due largely to tropical cyclones. There are about a dozen very common tree species which constitute the lowland forest canopy at $30-45 \mathrm{~m}$ height. Alluvial valleys sometimes support high forest, to which a number of large tree species are restricted. In many places, however, valley floors carry a dense low scrub, presumably the result of former cultivation, or destructive floods. Forests have also been shaped by natural events. Natural catastrophes, such as earthquakes, landslips, lightning and cyclone-force winds, are not infrequent; high forest may take decades to recover from such events (Whitmore, 1969). The mangrove forest has never been heavily exploited and the canopy is typically $24 \mathrm{~m}$ tall (Whitmore, 1969). Mangroves around Marovo Lagoon have been felled due to the mistaken belief that they inhibit coconut plantation production (Baines, 1985 ) and there is some exploitation for firewood and construction timber in rural areas (Collins et al., 1991).

Some 24,200 sq. $\mathrm{km}, 80 \%$ of the total land area, were forested in 1976 , of which 20,000 sq.km were accounted for by various communities at low and medium altitudes, on basalts or andesites. Revised data from December 1988 indicate 25,500 sq. km of forest cover (C. Turnbull, pers, comm., 1990), of which $23,000 \mathrm{sq} . \mathrm{km}$ is unproductive for physical reasons. This discrepancy does not reflect a substantive increase in forest cover but is most probably the result of different definitions of forests, and different survey and analytical techniques. By way of illustration, some 95\% of logging takes place on land in customary tenure, whilst reforestation on the same class of land is restricted to just 98ha on Malaita (Wenzel, 1989), indicating a serious imbalance between reforestation and logging operations. 
Prior to the 1970 s, forest cover was largely pristine, but has since been heavily exploited by foreign interests. During the last 20 years, a timber industry has developed. Widespread logging has resulted in the loss of primary forest on several islands, especially Ghizo and Kolombangara, with consequent loss of wildlife habitat (Dahl, 1986), soil compaction and erosion, leading to reef sedimentation (Anon., 1986). Historically, forestry practice has not given due consideration to the ecological effects of logging, and small-scale operations are underway or planned in several small areas, rather than utilising larger blocks on larger islands (Hoyle, 1978). However, since 1986 logging companies have been required to fell only trees with a diameter in excess of $60 \mathrm{~cm}$, thus preventing the removal of supersmalls (trees with diameters as little as $35 \mathrm{~cm}$ ) (MNR, 1988). This regulation is likely to reduce damage substantially to forests during logging and enhance natural regeneration.

Plantations are being established at the rate of approximately 1,500ha annually (Collins $e t$ al., 1991), with 24,000ha established by December 1989 (C. Turnbull, pers. comm., 1990). It is hoped that plantations of fast-growing and commercially-valuable introduced species, such as teak, mahogany and gmelina, will replace the volume felled from natural forests, as a source of export revenue (Anon., 1988). Extensive plantations are also planned for Kolombangara, in a joint venture between the Government and the Commonwealth Development Corporation (G.B.K. Baines, pers. comm., 1989).

Very little scientific work has been carried out on coral reefs. The 1965 Royal Society Expedition, which produced the only substantial account, found that in general the Solomon Islands lacked the luxuriant reefs of many parts of the Pacific, due to unfavourable environmental conditions such as steep and exposed shores with little suitable substrate for coral growth. Coral reefs are further discussed in UNEP/IUCN (1988), which also gives a detailed account of Marovo Lagoon.

Of the 31 terrestrial and marine habitats identified by Dahl (1980), only three are included within even nominal protected areas, namely some lowland rain forest types, mixed species montane rain forest and grassland. The much wider range of habitats which at present receive no protection broadly include: various lowland rain forest formations; Neonauclea/Sloanea montane rain forest; cloud, riverine, swamp, mangrove and atoll/beach forests; Casuarina woodland and scrub; serpentine vegetation and dwarf-shrub heath; various freshwater habitats; sea turtle nesting areas; algal and seagrass beds with associated fauna; various reef formations, rocky coast, lagoons, estuaries and offshore environments (Dahl, 1980). In terms of conservation importance, Rennell Island is ranked ninth in the entire Oceanian Realm, and is the second most important raised coral island, after Guam (Dahl, 1986). According to Collins et al. (1991) critically important sites, none of which is protected at present, include Rennell, the Amavon islands and the kauri Agathis macrophylla stands in Santa Cruz. Coastal, mangrove, lowland, freshwater swamp and montane forests are all critically unprotected.

On the basis of the distribution of birds, Diamond (1976) proposed a system of three large high-priority, three smaller high-priority and eight medium-priority protected areas. Mammal, insect and plant species would also benefit as their distribution patterns are probably similar (Diamond, 1976). Dahl (1980) reiterated these recommendations, but also identifies a number of and adds reef, lagoon, mangrove and small botanical reserves. Less specific recommendations in Dahl (1986) include the establishment of protected areas on Rennell, San Cristobal, Guadalcanal, Malaita and Vanikolo, with smaller areas to protect interesting sites and species on other islands. Reforestation with native species might be considered alongside Kolombangara Reserve, to reinforce it and to buffer it from encroachment (Dahl, 1986). 
An Action Strategy for Protected Areas in the South Pacific Region (SPREP, 1985b) has been prepared. The principal goals of the strategy cover conservation education, conservation policy development, establishment of protected areas, protected area management and regional and international cooperation. Priority recommendations for the Solomon Islands are as follows: develop a national conservation strategy, and review all environmental aspects of development; develop, expand and implement a national environmental awareness programme, including radio broadcasts, publications and the establishment of a mobile unit; review and update all existing legislation relating to protected areas and conservation, and, where necessary, draw up new legislation; undertake staff training in the fields of biology, botany, ecology and park management; develop the following as protected areas: Oema Atoll and the island of Oema as a wildlife sanctuary; Mount Austin, Mount Gallego; Island of Arnavon; Lake Te Nggano and its flora and fauna.

A number of recommendations, constituting a putative conservation strategy, aimed at removing obstacles to conservation-based development, are made in SPREP (1985a). These broadly comprise environmental education, environmental surveys, conservation-based rural development, a zoned forest reserve system and an effective environmental law and policing system.

A comprehensive survey of conservation area needs and priorities is required prior to implementing any protected areas network (G.B.K. Baines, pers. comm., 1989). In response to this need, a SPREP-funded project, in cooperation with the Overseas Service Bureau, Australian Volunteer Abroad Programme and the National Environment and Conservation Division, has examined wildlife management issues, with emphasis on species trade, changes in traditional practice and habitat destruction. The project aims to provide guidelines for the sustainable use and management of Solomon Islands fauna, possibly stimulating the formulation of a National Policy on the Environment and Conservation (Leary, 1989) and draws the following broad conclusions. In the long-term it is a priority that a comprehensive Conservation Act is developed for the Solomon Islands. Such an act should encompass the establishment of conservation areas, the protection of flora and fauna, regulation of wildlife trade, and the conservation of traditional resources management knowledge. A system of natural protected areas for the Solomon Islands urgently needs to be developed. In addition to large scale reserves, consideration needs to be given to the protection, in terms of good management, of small areas. One such means is the concept of wildlife management areas which has proven successful in Papua New Guinea. It is recommended that wildlife management areas legislation be enacted at the provincial or national level as soon as possible (Leary, 1990).

Rennell has been the subject of logging proposals, which once again were being actively considered in 1989 (Collins et al., 1991). At one time bauxite mining posed a considerable threat, particularly to Rennell. However, these proposals have now been dropped. Conversely, there is a current nationwide threat from gold prospecting and there has been localised environmental damage from prospecting activities, a notable example being Fauro Island (G.B.K. Baines, pers. comm., 1989).

\section{Addresses}

Ministry of Natural Resources, P O Box G24, Honiara

\section{References}

Anon. (1986). Deforestation problems in the Solomon Islands. Forest 15: 11. 
Anon. (1987). SPREP makes considerable progress with implementation of action strategy for protected areas. Environment Newsletter No. 10, South Pacific Regional Environment Programme, South Pacific Commission, Noumea, New Caledonia.

Anon. (1988). Projects in the Pacific. British Overseas Development: Forestry Supplement. Overseas Development Administration, London.

Baines, G.B.K. (1981). Environmental management for sustainable development in the Solomons: a report on environment and resources. Prepared for the Government of the Solomon Islands. Unpublished. $57 \mathrm{pp}$.

Baines, G.B.K. (1985). Study Area One: Marovo Lagoon, Solomon Islands. Working paper on pilot project for Commonwealth Science Council. $15 \mathrm{pp}$.

Baines, G.B.K. (1990). South Pacific Conservation Programme. World Wide Fund for Nature, Gland, Switzerland and Australia. $50 \mathrm{pp}$.

Collins, N.M., Sayer, J.A. and Whitmore, T.C. (Eds) (1991). The Conservation Atlas of Tropical Forests: Asia and the Pacific. Prepared by the International Union for Conservation of Nature, Switzerland and the World Conservation Monitoring Centre, Cambridge, UK. Macmillan Press Limited, London. 256 pp.

Dahl, A.L. (1980). Regional ecosystem survey of the South Pacific Area. SPC/IUCN Technical Paper 179. South Pacific Commission, Noumea, New Caledonia. 99 pp.

Dahl, A.L. (1986). Review of the Protected Areas System in Oceania. IUCN, Gland, Switzerland and Cambridge, UK/UNEP, Nairobi, Kenya. 328 pp.

Diamond, J.M. (1976). A proposed forest reserve system and conservation strategy for the Solomon Islands. Summary. Unpublished report. $19 \mathrm{pp}$.

Glaser, T. (1987). Solomon Islands: paradise lost and found. The Courier 102: 44-51.

Hoyle, M.A. (1978). Forestry and conservation in the Solomon Islands and the New Hebrides. Tigerpaper 5(2): 21-24.

Isa, H. (1988). The current trend in protected area development in Solomon Islands. In: Thomas, P.E.J. (Ed.) Report on the workshop on customary tenure, traditional resource management and nature conservation. South Pacific Regional Environment Programme, Noumea, New Caledonia. Pp. 97-99.

Isa, H. (1989). Solomon Islands. Country Review 6. Fourth South Pacific Conference on Nature Conservation and Protected Areas, Port Vila, Vanuatu, 4-12 September. South Pacific Commission, Noumea, New Caledonia. 9 pp.

Leary, T. (1989). Wildlife management in the Solomon Islands. Case Study 10. Fourth South Pacific Conference on Nature Conservation and Protected Areas, Port Vila, Vanuatu, 4-12 September. $6 \mathrm{pp}$.

Leary, T. (1990). Survey of Wildlife Management in Solomon Islands. SPREP project PA 17. Final Report. A joint project of Solomon Islands Government, South Pacific Regional Environment Programme and Traffic (Oceania). SPREP, Noumea, New Caledonia. 74 pp.

Ministry of Natural Resources (1989). Forest policy statement August 1989. Forestry Division. $23 \mathrm{pp}$.

Sloth, B. (1988). Nature legislation and nature conservation as part of tourism development in the island Pacific. Pacific Regional Tourism Development Programme. Tourism Council of the South Pacific, Suva, Fiji. 82 pp.

SPREP (1985a). Solomon Islands. In: Thomas, P.E.J. (Ed.), Report of the Third South Pacific National Parks and Reserves Conference. Volume III. Country reviews. South Pacific Commission, Noumea, New Caledonia. Pp. 115-124.

SPREP (1985b). Action strategy for protected areas in the South Pacific region. South Pacific Commission, Noumea, New Caledonia. 24 pp. 
UNEP/IUCN (1988). Coral Reefs of the World. Volume 3. Central and Eastern Pacific. UNEP Regional Seas Directories and Bibliographies. IUCN, Gland, Switzerland and Cambridge, UK/UNEP, Nairobi, Kenya. 378 pp.

Venkatesh, S, Va'ai, S. and Pulea, M. (1983). An overview of environmental protection legislation in the South Pacific countries. SPREP Topic Review No. 13. South Pacific Commission, Noumea, New Caledonia. $63 \mathrm{pp}$.

Wenzel, L. (1989). Environment and change in the Pacific: a survey of resource use and policy in Fiji, Tonga, W. Samoa, Vanuatu and Solomon Islands. INR Environmental Studies Report No. 43. Institute of Natural Resources, University of the South Pacific, Suva, Fiji. 95 pp.

Whitmore, T.C. (1969). The vegetation of the Solomon Islands. Philosophical Transactions of the Royal Society of London B 255: 259-270.

World Bank (1990). World Tables 1989-1990 Edition. John Hopkins University Press, Baltimore. 646 pp.

\section{ANNEX \\ Definitions of protected area designations, as legislated, together with authorities responsible for their administration}

Title (English): The National Parks Act

Date: 1954

Brief description: Makes provision for the establishment of strictly protected natural areas as national parks.

Administrative authority: Conservation Officer, The Environment and Conservation Division, Ministry of Lands, Energy and Natural Resources

Designations: National Park

Title (English): The Wild Birds Protection Act

Date: 1914

Brief description: Enabled the Minister, under Section 14, to declare any island or islands, or any part or parts of any island or any district, as a bird sanctuary. The Act provides protection for bird species only, and makes no provision for the conservation of habitat.

Administrative authority: Unknown

\section{Designations:}

Bird sanctuary Only interference with birds is an offence within sanctuaries. 
Title: An Ordinance to Consolidate and Amend the Law on Forests and to Control and Regulate the Timber Industry and for Matters Incidental Thereto and Connected (Forests and Timber Ordinance, 1969)

Date: 1969 (amended 1977)

Administrative authority: The Conservator of Forests

Description:

State forest Established under the provisions of S.9, on any land that is public land, land in which the government holds a freehold interest in land or a leasehold interest in land by or on behalf of the Government. The Commissioner shall not grant any interest in a state forest without the Conservator's consent (S.10). Prohibited activities (S.11) include felling, cutting etc trees; damaging vegetation; clearing land; residing or erecting buildings; grazing livestock; possessing any equipment for cutting or working forest produce; constructing roads, saw pits or workplaces.

Controlled forest Established, in either forests or other vegetation types, for water catchment protection. Rights which may be exercised in a controlled forest are specified in the notification of establishment. Activities specifically prohibited under S.16 comprise felling, cutting etc. forest produce except for personal or domestic use; clearing or breaking land for cultivation or any other purposes; residing, or erecting any building etc.; grazing livestock.

NB: Repealed Forests Ordinance (Cap. 71)

\section{Title: The Town and Country Planning Act}

Date: 1979

Brief description: Provides for tree preservation orders for "any tree, groups of trees or woodlands ... in the interests of amenity"

Administrative authority: Unknown

Designation: Unknown

\section{Title: The Lands and Titles Act}

Date: 1968 (amended 1970)

Brief description: Makes provision for preservation orders to be applied to land of "historic or religious" value, and permits the establishment of nature reserves.

Administrative authority: Unknown

Designation: Unknown 
SUMMARY OF PROTECTED AREAS

Name of area

IUCN management

category

National Parks

Queen Elizabeth*

Wildlife Sanctuaries

Amavon*

Bird Sanctuaries

Tulagi

Forest Reserves

Kolombangara

Unclassified

Dalakalau

Dalakalonga

Mandoleana

Oema Island
Unassigned $\quad 1,090$

1954

Unassigned

1,000

1980

Unassigned

1930

Unassigned

500

Unassigned

1954

Unassigned

1954

Unassigned

1937

Unassigned

*Site is described in this directory.

NB: In the absence of any effective protected areas in the Solomon Islands no map is provided. 


\section{ARNAVON WILDLIFE SANCTUARY}

\section{IUCN Management Category Unassigned}

\section{Biogeographical Province 5.01.13 (Papuan)}

Geographical Location Lies in the Manning Straits, about $25 \mathrm{~km}$ equidistant between northem Santa Isabel and south-east Choiseul. The boundary is defined by the three islands and includes encompassed reefs and waters. $7^{\circ} 25^{\prime}-7^{\circ} 35^{\prime} \mathrm{S}, 157^{\circ} 56^{\prime}-158^{\circ} 03^{\prime} \mathrm{E}^{\circ}$

Date and History of Establishment Established as a wildlife sanctuary on 17 April 1980 under the Local Government Ordinance (CAP 14): The Santa Ysabel Province (Wildlife Sanctuary) Bye-Law 1980. In 1975 the Ministry of Natural Resources designated the islands as "off-limits" under a trespass law. The islands were included within a provincial Protected Lands Bye-law during May 1979. Although designated under the 1980 Bye-law, problems relating to customary land rights have prevented full gazettement (Sloth, 1988).

Area $1,000 \mathrm{ha}$

Land Tenure Customary jurisdiction

Altitude Ranges from the seabed between the islands to $1 \mathrm{~m}$ above sea level.

Physical Features Comprises three slightly-raised coral reefs, viz. Sikopo, Kerehikapa and Amavon. The atoll substrate is mostly coral rock and sand. The elevated vegetated areas have accumulated organic matter, but sand remains a major component and the soil is very salty. A strong, south-easterly current is funnelled through the strait which frequently causes rough seas in the passages between the islands. There are several other submerged reefs in the area. The fringing reefs of all the island are highly attenuated and have extremely steep fore-reef slopes. There is evidence that the islands are occasionally completely flooded. There is also evidence that the islands have sunk slightly in recent years as the internal tidal lagoons have expanded, killing a large number of trees around lagoon peripheries on two of the islands (Vaughan, 1981).

Climate Data specific to the islands are not available. A preliminary account of climate in the Solomons is given by Brookfield (1969). Mean annual rainfall in the Manning Straits area is approximately $3000 \mathrm{~mm}$. The wettest period is January to April with $1270-1500 \mathrm{~mm}$ rainfall. Coastal temperatures throughout the country vary between mean maxima and minima of approximately $29^{\circ} \mathrm{C}$ and $24^{\circ} \mathrm{C}$, respectively. Prevailing winds are south-easterly trades (Brookfield, 1969).

Vegetation Comprises mainly trees and bushes of the genera Pisonia, Casuarina, Pandanus, Callophyllum, Cordia and coconut palm Cocos nucifera. There are also several species of herbaceous plants, including at least three kinds of grasses and sedges (McKeown, 1977).

Fauna The sanctuary supports a high diversity of bird species, including endemic Solomon's sea eagle Haliaeetus sanfordi, Brahminy kite Haliastur indus, osprey Pandion halietus, megapode Megapodius freycinet, terns Sterna spp. and several pigeons (Columbidae). Many migratory shorebirds use the islands and tidal flats as feeding and resting areas during November to January, for example whimbrel Numenius phaeopus, long-billed curlew $N$. americanus and common sandpiper Actitis hypoleucos (Vaughan, 1981). 
Nesting by hawksbill turtle Eretmochelys imbricata (E) and green turtle Chelonia mydas (E) occurs throughout the year. In the 19-month period from May 1979 to December 1980 (excluding December 1979), 656 hawksbill turtle nests and 53 green turtle nests were recorded in the sanctuary. Subsequently, an annual estimate of 560 hawksbill and 45 green nests has been made. In spite of the predominance of hawksbill on the nesting beach, green turtle is seen much more frequently in surrounding waters (Vaughan, 1981). The biology of hawksbill turtle on Amavon is discussed in some details by McKeown (1977).

Estuarine crocodile Crocodylus porosus (V) no longer inhabits the islands, due to intensive hunting for skins in the 1960s and early 1970s (Vaughan, 1981).

Cultural Heritage The islands traditionally belonged to the Galicana tribe. Migrations, inter-marriage and religious changes have dispersed the members of this group who now live on Santa Isabel, Choiseul and New Georgia. Sea turtles, a noteworthy feature of the sanctuary, have held a traditional place in local customs and culture (Vaughan, 1981). The island group was an important stopover point for 19 th century headhunting operations, when canoes were en route between the western Solomons and Ysabel (G.B.K. Baines, pers. comm., 1989).

Local Human Population Uninhabited since the Galicana tribe departed in the 1930s (Vaughan, 1981).

Visitors and Visitor Facilities Restricted to those who take turtles, clams and megapode eggs (G.B.K. Baines, pers. comm., 1989).

Scientific Research and Facilities The Solomon Islands Turtle Project was initiated in 1975, with much of the work being carried out in the Arnavon Islands. Research activities have included nest monitoring, tagging, head starting and surveys of various factors in the surrounding islands. Facilities include two leaf houses with water catchment tanks and various out-buildings on Kerehikapa (Vaughan, 1981).

Conservation Value The islands were originally protected in 1975 in response to growing evidence that Solomon Island hawksbill turtle populations were declining, and that the Manning Straits may be a significant breeding area. With the exception of Campbell and Long Islands in Australia, Arnavon may be the most heavily used hawksbill nesting site in the Oceanic Pacific (Vaughan, 1981).

Conservation Management Since the 1981 incident described below, there has been no management (G.B.K. Baines, pers. comm., 1989). The administrative responsibility for the sanctuary is held by the Ministry of Natural Resources and Santa Ysabel Province. The bye-law establishing the sanctuary prohibits entry other than for. wardens and their immediate families; persons entering for official or educational reasons; and people in transit whose route passes through the sanctuary. It was also prohibited to take, disturb or kill any mature, immature or embryonic forms of flora and fauna, with the exception of all shark species, ghost crab, hermit crab and rats, which could be killed in control efforts to increase the sanctuary's potential for other life forms. Wardens could utilise local resources for personal consumption within the sanctuary, with the exception of turtles, seabirds and megapodes, and their respective eggs.

Management activities, carried out by Turtle Project staff, included law enforcement to curb poaching of megapode eggs, shells, fish, turtles and ebony, turtle nest predator control, and making educational presentations amongst the local populace. The training of four local wardens was given a high priority. Management recommendations included placing the sanctuary under the control of a Solomon Islander, establishing a constant presence on the islands to prevent 
poaching; maintaining complete turtle nesting records for Kerehikapa only; continued rat trapping on Sikopo; head starting of turtles at the discretion of the head warden; tagging of immature green turtle for growth studies; intensive tagging of nesting hawksbill during June and July, with less intensive tagging at other times on Kerehikapa (Vaughan, 1981). It has subsequently been recommended that the sanctuary be reinstated, for the conservation of hawksbill turtle, but only if this would be in accordance with the wishes of those claiming traditional ownership (Leary, 1990).

Management Constraints Marine crocodiles have been eliminated by excessive hunting (Vaughan, 1981). Natural threats include cyclones, earthquakes (Dahl, 1986) and rising sea levels. The research facilities were destroyed in 1981 by a section of a Choiseul island group which claimed a customary right of ownership of the islands which had not been allowed for in the negotiations by Government officers which led to the establishment of the sanctuary (G.B.K. Baines, pers. comm., 1989). No attempt has been made to re-establish these facilities (S. Diake, pers. comm. 1987). Although the islands have been returned to customary jurisdiction, there remains some dispute as to which groups are entitled to exert customary rights (G.B.K. Baines, pers. comm., 1989).

Staff There have been no staff since 1981.

Budget No information. The Turtle Project was supported by WWF under Project No. 1452, with grants totalling US\$8,078 during 1980 and 1981 .

Local Addresses Ministry of Natural Resources, P O Box G24, Honiara

\section{References}

Brookfield, H.C. (1969). Some notes on the climate of the British Solomon Islands. Philosophical Transactions of the Royal Society of London B 255: 207-210.

Dahl, A.L. (1986). Review of the Protected Areas System in Oceania. IUCN, Gland, Switzerland and Cambridge, UKJUNEP, Nairobi, Kenya. 328 pp.

Leary, T. (1990). Survey of Wildlife Management in Solomon Islands. SPREP project PA 17. Final Report. A joint project of Solomon Islands Govemment, South Pacific Regional Environment Programme and Traffic (Oceania). SPREP, Noumea, New Caledonia. 74 pp.

McKeown, A. (1977). Marine turtles of the Solomon Islands. Ministry of Natural Resources, Honiara. Unpublished. 47 pp.

Sloth, B. (1988). Nature legislation and nature conservation as a part of tourism development in the Island Pacific. Tourism Council of the South Pacific, Fiji. 82 pp.

Vaughan, P.W. (1981). Marine turtles: a review of their status and management in the Solomon Islands. Ministry of Natural Resources, Honiara. 70 pp.

Date January 1989, updated July 1989, November 1990

\section{QUEEN ELIZABETH NATIONAL PARK}

\section{IUCN Management Category Unassigned}

Biogeographical Province 5.01.13 (Papuan) 
Geographical Location Situated on Mount Austin in western-central Guadalcanal, immediately south of Honiara. Approximately $9^{\circ} 22^{\prime} \mathrm{S}, 160^{\circ} 00^{\prime} \mathrm{E}$

Date and History of Establishment 9 June 1954. Established by Proclamation No. 5 of 1954 under the 1954 National Parks Act No. 5 (CAP 34), as Queen Elizabeth Park. The boundary was amended by Legal Notice No. 29 on 5 April 1973.

Area $1,090 \mathrm{ha}$ (reduced from 6,080 ha by 1973 boundary amendment)

Land Tenure Public ownership

Altitude $50-200 \mathrm{~m}$

Physical Features Comprises a hilly area with numerous ridges and valleys (SPREP, 1985)

Climate Data specific to the park are not available.

Vegetation Originally comprised Pometia pinnata and Vitex coffasus (Collins et al., 1991). The park supports roughly equal areas of grassland and severely degraded secondary forest, dominated by the introduced paper mulberry Brousonettia papyrifera in many places (SPREP, 1985).

Fauna No details are available, but numerous bird species are present, in contrast to a paucity of mammals (SPREP, 1985).

Cultural Heritage No information

Local Human Population Four enclaves, each containing a village of some half-dozen families, were included within the original boundary. The subsequent boundary change may have excised these enclaves. Squatters, within Honiara town boundary, have cultivated substantial areas of the remaining woodland (SPREP, 1985).

Visitors and Visitor Facilities There are no visitors (G.B.K. Baines, pers. comm., 1989). Access from Honiara is by way of sealed road, built across Mount Austin to the Lunga Valley to serve the proposed hydroelectric dam site. Off the road, access is by track and footpath. There are no visitor facilities (SPREP, 1985).

Scientific Research and Facilities Some forestry planting trials have been conducted on a small block. There are no facilities (SPREP, 1985a).

Conservation Value The site has been so severely degraded that there is little if any conservation value remaining.

Conservation Management There is no management structure and no management activities are carried out.

Management Constraints Although legally gazetted the site is not recognised as such (G.B.K. Baines, pers. comm., 1989) and is a good example of the futility of establishing protected areas that largely ignore local practice and requirements. The area has been taken over by squatters for gardens, or is being stripped for firewood, and has ceased to exist as a protected area (I. Reti, pers. comm., 1989).

Staff Forestry staff monitor plantation tree species trials (G.B.K. Baines, pers. comm., 1989). 
IUCN Directory of Protected Areas in Oceania

Budget No information

Local Addresses No information

\section{References}

Collins, N.M., Sayer, J.A. and Whitmore, T.C. (Eds) (1991). The Conservation Atlas of Tropical Forests: Asia and the Pacific. Prepared by the International Union for Conservation of Nature, Switzerland and the World Conservation Monitoring Centre, Cambridge, UK. Macmillan Press Limited, London. 256 pp.

SPREP (1985). Solomon Islands. In: Thomas, P.E.J. (Ed.), Report of the Third South Pacific National Parks and Reserves Conference. Volume III. Country reviews. South Pacific Commission, Noumea, New Caledonia. Pp. 195-209.

Date January 1989, updated July 1989 


\section{TOKELAU (NEW ZEALAND OVERSEAS TERRITORY)}

Area 12.25 sq. km

Population 3,000 (1982); 1,700 (1988)

Natural increase: No information

GNP No information

Policy and Legislation Tokelau is a non-self-governing territory of New Zealand. There is no protected areas legislation, and apparently no government conservation policy relating to native species and habitats. Instead, there is a long-standing system of resource management based on traditional custom, although this is now starting to lose its effectiveness (Toloa and Gillett, 1989).

Traditional marine conservation measures can be considered in two categories: those that are specifically designed for conservation and those aspects of the traditional system which indirectly result in a reduced amount of fishing effort on particular species. The most important explicit conservation measure is the "lafu" system, whereby all types of fishing are banned in specific areas of the main reef. The decision to establish a "lafu" is made by the Council of Elders. Another specific conservation measure is the rejection of undersized fish and the prohibition of fish poisoning. In addition to these specific measures, there is a wide variety of traditional practices which effectively reduce fishing effort. For example, only certain individuals may capture sea turtes, and the elevated community status of pelagic fishing relieves pressure from inshore fisheries (Toloa and Gillett, 1989).

International Activities Tokelau is not yet party to the Unesco Man and Biosphere Programme the Convention on Wetlands of International Importance especially as Waterfowl Habitat (Ramsar Convention) or the Convention concerning the Protection of the World Cultural and Natural Heritage (World Heritage Convention). It is not known if New Zealand's active participation in the latter two conventions has any siginifcance for Tokelau.

At a regional level, Tokelau has neither signed nor ratified the Convention on the Conservation of Nature in the South Pacific, 1976. Known as the Apia Convention, it entered into force during 1990. The Convention is coordinated by the South Pacific Commission and represents the first attempt within the region to cooperate on environmental matters. Among other measures, it encourages the creation of protected areas to preserve indigenous flora and fauna. Tokelau has not signed the Convention for the Protection of the Natural Resources and Environment of the South Pacific Region, 1986 (SPREP Convention). However, the convention has been signed ( 25 November 1986) and ratified (3 May 1990) by New Zealand, although again it is not clear if this places any obligation upon Tokelau itself. The Convention entered into force during August 1990. Article 14 calls upon the parties to take all appropriate measures to protect rare or fragile ecosystems and threatened or endangered flora and fauna through the establishment of protected areas and the regulation of activities likely to have an adverse effect on the species, ecosystems and biological processes being protected. However, as this provision only applies to the Convention areas, which by definition is open ocean, it is most likely to assist with the establishment of marine reserves and the conservation of marine species.

Administration and Management Responsibility for conservation of natural resources rests with the Council of Elders, a body comprising most males over 60 years of age and totalling some 25 individuals from each island. All land is under customary ownership. The Department 
of Agriculture and Fisheries has facilitated resource surveys and provided scientific information to support conservation and resource management (Anon, 1989).

Systems Reviews Tokelau consists of three small islands set on a north-west to south-east axis from $8^{\circ} \mathrm{S}$ to $10^{\circ} \mathrm{S}$ and $171^{\circ} \mathrm{W}$ to $173^{\circ} \mathrm{W}$. Nukunonu is the biggest atoll at $4.7 \mathrm{sq} . \mathrm{km}$, Fakaofo is $4.0 \mathrm{sq} . \mathrm{km}$ and Afafu is $3.5 \mathrm{sq} . \mathrm{km}$. Each atoll consists of a number of reef bound islets encircling lagoons. These islets vary in length from $90 \mathrm{~m}$ to $6 \mathrm{~km}$ and up to $200 \mathrm{~m}$ in width. At no point do they rise more $5 \mathrm{~m}$ above sea level. The atolls comprise coral rubble and sand mixed with a thin layer of humus and are of generally low fertility.

In general the vegetation has not been greatly modified. Nukunonu includes areas of Cordia, Pisonia and Guertarda woodland which is dense and may reach heights of $10 \mathrm{~m}$ to $20 \mathrm{~m}$. Fakaofo supports a beach scrub of Scaevola and Tournefortia (Davis et al., 1986). An account of the extent and composition of the vegetation is given in Parham (1971).

There have been few studies of the coral reefs (UNEP/IUCN, 1988). Hinds (1969/1971) carried out a brief survey and reported that coral growth was limited to the upper portions of old coral growth massifs rising from the floor, the main portions of which were barren. Laboute (in press) briefly surveyed reefs on all three atolls in 1987 to assess damage caused by Hurricane Tusi. The degree of destruction was variable, reaching $90 \%$ in some places. A significant area of Nukunonu lagoon reef was damaged by a pesticide spill in 1969: all corals in a $2 \mathrm{~km}$ section of the lagoon along Motu Te Kakai died with the exception of Porites. There was little recovery by 1976 (Marshall, 1976). Rhinoceros beetle Oryctes rhinoceros was accidentally introduced from Western Samoa to Nukunonu where it spread to all islets, creating a serious risk to coconuts (Wodzicki, 1971). Control measures have been taken (SPREP, 1980). Turtles are now rare and there has been serious depletion of giant clam Tridacna spp. (Wodzicki, 1973) but there is no evidence of depletion of other marine resources (Hooper, 1985). The potentially most threatening environmental hazard is that posed by increasing sea-levels due to global warming. Threats to freshwater supplies, land loss and episodic destruction through hurricanes may make the country uninhabitable, if the worst case scenarios are realised (Pernetta, 1988).

Because of the small size of the island, and the number of people it supports, most conservation measures reflect the need to protect the "human" environment. For example, tree planting is one of the principal aims of an annual conservation week. It has recently been reported that some 47 ha of land on Nukunonu has been designated a protected area by the local Council of Elders, with adjoining reef areas to be added at a later date (B. Lear, pers. comm., 1990). More detailed information is not available. However, this development is in line with previous recommendations (Dahl, 1986) that remaining forest on Nukunonu should be protected. Dahl (1986) also suggests that the establishment marine reserves might become necessary if traditional conservation measures cease to be effectively applied.

\section{Addresses}

Director of Agriculture and Fisheries, Office of Tokelau Affairs, Apia, Western Samoa

\section{References}

Dahl, A.L. (1986). Review of the Protected Areas System in Oceania. IUCN, Gland, Switzerland and Cambridge, UK/UNEP, Nairobi, Kenya. 328 pp. 
Davis, S.D., Droop, S.J.M., Gregerson, P., Henson, L., Leon, C.J., Lamlein Villa-Lobos, J., Synge, H. and Zantovska, J. (1986). Plants in Danger: What do we know? IUCN, Gland, Switzerland and Cambridge, UK. 488 pp.

Hinds, V.J. (1969/71). A rapid fisheries reconnaissance in the Tokelau Islands, August 18-25, 1971. South Pacific Commission, Noumea, New Caledonia. (Unseen).

Hooper, A. (1985). Tokelau fishing in tradtional and modern contexts. In: Ruddle, K. and Johannes, R.E. (Eds), The traditional knowledge and mangement of coastal systems in Asia and the Pacific. Unesco/ROSTEA, Jakarta, Indonesia. Pp. 7-38.

Laboute, P. (in press). Mission to the Tokelau Islands to evaluate cyclone damage to coral reefs. SPREP Topic Review 31. South Pacific Commission, Noumea, New Caledonia.

Marshall, K.J. (1976). Critical marine habitats and insect control in the South Pacific. Proceedings of the SPC and IUCN Second Regional Symposium on Conservation of Nature, Apia, Western Samoa, June. (Unseen).

Parham, B.E.V. (1971). The vegetation of the Tokelau Islands with special reference to plants of Nukunonu Atoll. New Zealand Journal of Botany 9: 576-609.

Pernetta, J.C. (1988). Projected climate change and sea level rise: a relative impact rating for countries of the South Pacific Basin. In: MEDU joint meeting of the task team on the implications of climatic change in the Mediterranean. Split, Yuogslavia, 3-7 October. Pp. 1-11.

SPREP (1980). Tokelau. Country Report 12. South Pacific Commission, Noumea, New Caledonia. 4 pp.

SPREP (1989) Tokelau. Paper presented at the Fourth South Pacific Conference on Nature Conservation and Protected Areas. Port Vila, Vanuatu, 4-12 September. 2 pp.

Toloa, F. and Gillett, R. (1989). Aspects of traditional marine conservation on Tokelau. Case Study 31. Fourth South Pacific Conference on Nature Conservation and Protected Areas, Port Vila, Vanuatu, 4-12 September. 5 pp.

UNEP/IUCN (1988). Coral Reefs of the World. Volume 3. Central and Western Pacific. UNEP Regional Seas Directories and Bibliographies. IUCN, Gland, Switzerland and Cambridge, UKUUNEP, Nairobi, Kenya. 378 pp.

Wodzicki, K. (1973) The Tokelau Islands-environment, natural history and special conservation problems. Paper 10, Section 3. Proceedings and Papers, Regional Symposium on Conservation of Nature - Reefs and Lagoons. South Pacific Commission, Noumea, New Caledonia. Pp. 63-68.

Date May 1985, reviewed February 1990 


\section{KINGDOM OF TONGA}

Area Total land area of 747 sq. km, spread over $347,282 \mathrm{sq.} \mathrm{km}$ of sea (IDEC, 1990)

Population Approximately 101,000 1990 (IDEC, 1990)

Natural increase: $0.84 \%$

\section{GNP US\$ 800 per capita}

Policy and Legislation The role of parks, reserves and protected areas, according to IDEC (1990), is to prevent depletion or extinction of valuable wildlife communities and to enrich and improve production of land and marine resources; and to protect areas or items of importance for Tongan cultural heritage and provide the people of Tonga and visitors with places of recreational, educational and scientific importance.

The legal and land tenure system in Tonga gives the Government considerable powers to acquire and reserve land for public purposes. All land is ultimately owned by the Crown, but is divided into four categories: the King's hereditary estates, Royal family hereditary estates, hereditary estates for the nobles and matapule, and Government. The latter two are subdivided by law to provide town and tax (garden) allotments which can only be held by Tongans. The 19th century land reforms have meant that there is no customary tenure of the type found in many other countries of the South Pacific and thus the establishment of protected areas is generally easier than in many Pacific nations because much of the land is owned by the state. The foreshore is the property of the Crown and is defined in the Land Act as "land adjacent to the sea, alternately covered and left dry by the ordinary ebb and flow of the tides and all land adjoining thereunto lying within fifty feet of the high water mark." All territorial seas and internal waters are the property of the Crown and may be subject to Government restrictions and regulations. Every Tongan has the right to fish in these waters. There are no traditional fishing rights giving villages or individuals exclusive rights to fish or gather shells in certain areas and such rights may have never existed in the past (Eaton, 1985).

The 1976 Parks and Reserves Act provides for "the establishment of a Parks and Reserves Authority and for the establishment, preservation and administration of parks and reserves". It states that every park "shall be administered for the benefit and enjoyment of the people of Tonga and there shall be freedom of entry and recreation therein by all persons. Every reserve, subject to any conditions and restrictions which the Authority may impose, shall be administered for the protection, preservation and maintenance of any valuable feature of such reserve and activities therein and entry thereto shall be strictly in accordance with any such conditions and restrictions" (SPREP, 1985a).

The 1961 Forest Act provides for the establishment of forest reserves, the conservation of important "culture trees" used in traditional crafts, and the protection of water catchments (Eaton, 1985).

The 1915/1974 Birds and Fish Preservation Act limits or prohibits the catching or injuring of certain species of fish, birds and turtles and establishes the legal authority to fine and imprison offenders, and confiscate equipment used to catch protected animals. Under the provisions of the Act, the two major lagoons of Tongatapu, Fanga'uta and Fanga Kakau, are protected as areas of environmental importance. The trapping of fish without permit, damaging mangroves, drilling, dredging, or discharging any effluent is prohibited (SPREP, 1985a), although some of these 
activities continue (P. Thomas, pers. comm., 1989). The Birds and Fish Preservation Act is weak and it is acknowledged that it requires updating (SPREP, 1980).

The Preservation of Objects of Archaeological Interest Act (1969) provides for the protection of a number of historical, cultural and archaeological sites, many of which are also protected by traditional law.

Other legislation with provision for environmental protection is reviewed by Venkatesh et al. (1983). An Environmental Protection Act and a Fisheries Act were under consideration in 1987 (U.F. Samani, pers. comm., 1987).

International Activities Tonga is not yet party to any of the international conventions or programmes that directly promote the conservation of natural areas, namely the Convention concerning the Protection of the World Cultural and Natural Heritage (World Heritage Convention), Unesco Man and the Biosphere Programme and the Convention on Wetlands of International Importance especially as Waterfowl Habitat (Ramsar Convention).

The Convention on the Conservation of Nature in the South Pacific (1976) has been neither signed nor ratified. Known as the Apia Convention, it entered into force during 1990. The Convention is coordinated by the South Pacific Commission and represents the first attempt within the region to cooperate on environmental matters. Among other measures, it encourages the creation of protected areas to preserve indigenous flora and fauna.

Although Tonga is party to the South Pacific Regional Environment Programme (SPREP), the 1986 Convention for the Protection of the Natural Resources and Environment of the South Pacific Region (SPREP Convention) has not yet been signed or ratified. The convention entered into force during August 1990. Article 14 calls upon the parties to take all appropriate measures to protect rare or fragile ecosystems and threatened or endangered flora and fauna through the establishment of protected areas and the regulation of activities likely to have an adverse effect on the species, ecosystems and biological processes being protected. However, as this provision only applies to the convention area, which by definition is open ocean, it is most likely to assist with the establishment of marine reserves and the conservation of marine species.

Other international and regional conventions concerning environmental protection to which Tonga is party are reviewed by Venkatesh et al. (1983).

Administration and Management Under the provisions of the 1976 Parks and Reserves Acts, a Parks and Reserves Authority was established in 1989 within the Ministry of Lands, Survey and Natural Resources to protect, manage and develop natural areas in the Kingdom. The authority is headed by an ecologist and environmentalist who is directly responsible to the Secretary of Lands, Survey and Natural Resources. There are two park rangers directly responsible to the head of the Authority. In addition to the general administration of parks and reserves, the authority is also responsible for environmental impact assessment of all physical developments, physical planning and environmental education.

Park management is hampered by shortages of funds and personnel, and there has been only limited development of protected areas. Signposts advertising rules prohibiting the destruction or removal of marine life have been erected. However, there are no means of enforcing these rules and people are not always aware of them; shellfish are still collected from the reef in Ha'atafu Reserve. No biological surveys or inventories of reserves have been carried out (U.F. Samani, pers. comm., 1987). R.H. Chesher (pers. comm., 1987) reported virtually complete neglect of park boundaries. The marine parks on the small islands adjacent to Tongatapu 
are regularly and destructively fished. The advent of new fishing technology and increasing depletion of fisheries resources indicate that these parks are likely to come under greater threat in the future (IDEC, 1990). There is an urgent need for improved management of existing protected areas.

No baseline information or inventory has been conducted at any of the marine park sites other than a brief overview in 1984 (Chesher, 1985), which revealed extensive damage due to destructive fishing methods in the Pangaimotu reef area, long-term coral damage in the Monuafe area and extensive coral damage of unknown cause in the Malinoa Island area. A recent review (Pernetta, 1988) suggests that the potential impact of climate change and sea-level rise could have severe impacts with economic and social disruption, with inter-island movement of populations, and emigration. Clearly marine and coastal protected are also under considerable threat.

Systems Reviews Tonga, the last remaining Kingdom in the South Pacific, lies between $15^{\circ} 30^{\prime}-22^{\circ} 20^{\prime} \mathrm{S}$ and $173^{\circ} 00^{\prime}-176^{\circ} 15^{\prime} \mathrm{W}$. There are 17 main islands forming three major groups, namely the Vava'u Group (143 sq. $\mathrm{km}$ ) to the north, the central Ha'apai Group (119 sq. km) and the southerly Tongatapu Group ( $256 \mathrm{sq} . \mathrm{km}$ ). The islands are mainly flat, elevated coral reefs which cap the peaks of two parallel submarine ridges, although some are high and volcanic in origin.

Brief summaries of the vegetation and coral reefs of most islands are given in Douglas (1969) and UNEP/IUCN (1988), respectively. The original vegetation on limestone islands comprised lowland rain forest. However, on the larger islands this has been entirely cleared (A.L. Dahl, pers. comm., 1989) for settlements and cultivation. According to a 1989 report (Wenzel, 1989), Tonga's exploitable indigenous forest was expected to be exhausted within 3-5 years, although whether this has occurred is not known. The best examples of volcanic island lowland rain forest are found on 'Eua in the Tongatapu Group (Dahl, 1980). In 1982 some 3,779ha of forest reserve existed on 'Eau (Larsen and Upcott, 1982) along the eastern ridge of the island. Subdivision of the area into tax 'apis (leases for agriculture), and deforestation by government and private logging have reduced the indigenous forest of these reserves (IDEC, 1990).

Moss forest occurs on the summit of Kao, and on Tafahi, to the north of the Vava'u Group. Coastal scrub is found on most islands, and recent lava flows support Casuarina. The islands of Tongatapu, 'Eua and Uta Vava'u in the Vava'u Group all have extensive areas of secondary vegetation, including scrub and grasslands. Mangroves and Cyperus reed swamp are present, the latter especially around the crater lake on Ninafo'ou, an isolated volcanic island to the north-west of the Vava'u Group. The crater zones of most volcanic islands have distinct, but sparse herbaceous flora (Dahl, 1980; IUCN, 1986).

The existing protected areas network covers $4.5 \%$ of the terrestrial area of Tonga, but nearly $90 \%$ of the network is accounted for by just one site, namely Fanga'uta and Fanga Kakau Lagoons Marine Reserve. Thus, protected habitats are largely marine or littoral and, according to Dahl (1980), include mangrove forest, possibly non-tidal salt marshes in Fanga'uta Lagoon, sea turtle nesting areas, sea grass beds, animals in sediments, algal, barrier, fringing and lagoon reef formations, beach, and open lagoon.

Habitats that are omitted from the protected area system are largely terrestrial and include lowland rain forest, savanna, grasslands, freshwater marsh, rock desert, reed swamp, permanent lake, seabird rookeries, as well as marine lake, offshore environments and submarine trenches (Dahl, 1980). Efforts to incorporate remaining fragments of lowland tropical rain forest in the protected 
areas system included an attempt to establish Vaomapa Park on Tongatapu, although the lease securing the site has lapsed and the site is no longer protected (SPREP, 1989). A long-standing proposal to gazette a 1,400 ha protected area on 'Eua has not yet been implemented, although funding for preliminary surveys and facilities has been sought from the New Zealand Government. The proposed park area includes fringing reefs, coastal regions, eastern ridge and terrace, and ridge summit, with rain forest and important bird habitats (Dahl, 1980). The park would also contain some of the last stands of sandalwood remaining in the Pacific, a number of plant species with restricted distributions and Matalanga-'a'Maui natural limestone bridge (SPREP, 1985a).

An Action Strategy for Protected Areas in the South Pacific Region (SPREP, 1985b) has been prepared. The principal goals of the strategy cover conservation education, conservation policy development, establishment of protected areas, effective protected area management and regional and international cooperation. Priority recommendations for Tonga are as follows: develop and implement intensive public education and training programmes, including radio broadcasts on environmental conservation, and grants for overseas study on environment-related disciplines; survey all potential protected areas, followed by preparation of management plans and provision of funds for management; develop a national environmental strategy; prepare resource inventories to help identify areas of critical importance for resource conservation; and exchange between countries in the region of environmental expert staff for short periods, to cooperate in addressing specific problems and in exchanging ideas (SPREP, 1985b).

A number of these recommendations have been acted upon. A Government department of public information has been set up in the Prime Minister's Office to coordinate public education and the spread of environmental information from government ministries. Radio broadcasting, however, is seen as less effective than video, itself a very popular medium, for disseminating environmental information. An aerial photography survey has been completed which may provide the basis for a nationwide review of potential protected areas (R.H. Chesher, pers. comm., 1990).

As one response to the Action Strategy, a comprehensive Environmental Management Plan (IDEC, 1990) was published in 1990, in a cooperative effort between the United Nations Economic and Social Commission (UN/ESCAP) and the Government of Tonga. The plan was formally introduced during a three-day symposium in August 1990 in Nuku'alofa. Responsibility for the compilation of the plan was undertaken by the Interdepartmental Environment Committee (IDEC), comprising Lands, Survey and Natural Resources (Chairman); Health; Foreign Affairs; Agriculture, Fisheries and Forestry; Works; Labour, Commerce and Industries, Central Planning; and Tonga Visitors Bureau. The objectives of the environmental management plan are to: examine the existing state of the environment in Tonga and summarise the relevant existing information in a single document; determine the environmental participants in the Kingdom and their resources needs; discover environmental resource needs that are not being met and identify these as problems; and recommend a plan of action to deal with existing and projected environmental problems. The plan includes coverage on demography and economics, geomorphology, mineral resources and coastal processes, fisheries, tourism, wildlife conservation and management, the institutional and legal framework, and a strategy for implementing the recommendations in the plan.

A number of recommendations concerning the development of protected areas are made in the plan. Community participation in the site selection, research, monitoring and protection of parks and reserves will assist in long-term park management, including establishment of local park or reserve committees to maintain or assist in the management of local resources. Within the 
framework of community parks, new marine and land parks should be gazetted, including Vava'u Coral Gardens, Neiafu Harbour Wreck and Swallows cave, all on Vava'u. The plan identifies a number of opportunities for further protected areas, namely microparks, resource parks, mangrove parks, botanical gardens, steep-slope forest, turtle and wildlife resources islands, coastal littoral forest and water reserves parks. At present there are no officially designated forest sanctuaries, although some forests on steep coastal slopes and on some volcanic islands with difficult or dangerous access are unofficially protected. The remaining indigenous forests should be divided into parks, reserves and sanctuaries depending on their present condition and status. The proposed national park on 'Eua, designed to protect forest on the steep slopes of south-east 'Eua and to prevent erosion, should be set up in accordance with the recommendations of the Ministry of Lands, Survey and Natural Resources. The proposed 'Ohonua water supply reserve on 'Eua should be implemented by insisting on the maintenance of a $50 \mathrm{~m}$ border of forest adjacent to all streams and tributaries in the area. Compliance by landowners should be enforced and seedling trees made available to re-plant areas which have already been cleared. Mount Talau National Park in Vava'u should be established. The plan also makes a series of recommendations aimed at increasing public involvement, monitoring and research. A series of policy recommendations covers institutional, legal and regulatory issues, monitoring and assessment, and research.

Dahl (1980) recommends gazetting the following reserve types: forest reserves on Tafahi or Niuatoputapu, for endemic birds, and perhaps other volcanic islands, viz. Tofua, Kao, Lalo, 'Ata or Toku; other areas of 'Eua of botanical interest; samples of other terrestrial biomes not yet protected; marsh, lake and lagoon habitats, namely Niuafo'ou, Kao and 'Uta Vava'u; and further marine areas to include a full range of marine biomes, especially outside Tongatapu. Much of this is reiterated by Dahl (1986) with the recommendation to gazette 'Eua National Park, a protected area on 'Ata and some protected areas on Niuafo'ou and Kao. Other small reserves should be considered for particular features, and there should be an extended role for coral reef reserves in managing coastal fisheries with the support of the local population. It is intended that the Parks and Reserves Authority will review proposals for terrestrial and marine parks, with a view to implementation.

\section{Addresses}

Parks and Reserves Authority, Ministry of Lands, Survey and Natural Resources, PO Box 5, Nuku'alofa

\section{References}

Chesher, R. H. (1985). Practical problems in coral reef utilization and management: A Tongan study. In: Proceedings of the Fifih Coral Reef Congress, Tahiti. Pp. 213-217.

Dahl, A.L. (1980). Regional ecosystem surveys of the South Pacific Area. SPCIIUCNTechnical Paper 179. South Pacific Commission, Noumea, New Caledonia. 99 pp.

Dahl, A.L. (1986). Review of the Protected Areas System in Oceania. IUCN, Gland, Switzerland and Cambridge UK/UNEP, Nairobi, Kenya. 328 pp.

Davis, S.D., Droop, S.J.M., Gregerson, P., Henson, L., Leon, C.J., Lamlein Villa-Lobos, J., Synge, H. and Zantovska, J. (1986). Plants in Danger: What do we know? IUCN, Gland, Switzerland and Cambridge, UK. 488 pp.

Douglas, G. (1969). Draft checklist of Pacific Oceanic Islands. Micronesica 5(2): 327-463.

Eaton, P. (1985). Land tenure and conservation in the South Pacific. SPREP Topic Review 17. South Pacific Commission, Noumea, New Caledonia. 103 pp. 
Interdepartmental Environment Committee. (1990). Environmental Management Plan for the Kingdom of Tonga. Economic and Social Committee for Asia and Pacific. Bangkok, Thailand. 197 pp.

Larsen, A. ard Upcott, A. (1982). A study of the forest resources of 'Eua Island and their potential for furure management. Chandler, Fraser And Larsen, Rotorua, New Zealand. 125 pp. (Unseen).

Pernetta, J.C. (1988). Projected climate change and sea level rise: a relative impact rating for countries of the South Pacific Basin. In: MEDU joint meeting of the task team on the implications of climatic change in the Mediterranean. Split, Yugoslavia, 3-7 October. Pp. 1-11.

SPREP (1980). Tonga. Country Report 13. South Pacific Commission, Noumea, New Caledonia. $60 \mathrm{pp}$.

SPREP (1985a). Tonga. In: Thomas, P.E.J. (Ed.), Report of the Third South Pacific National Parks and Reserves Conference. Volume III. Country reviews. South Pacific Commission, Noumea, New Caledonia. Pp. 211-216.

SPREP (1985b). Action strategy for protected areas in the South Pacific Region. South Pacific Commission, Noumea, New Caledonia. 24 pp.

SPREP (1989). Tonga. Paper presented at Fourth South Pacific Conference on Nature Conservation and Protected Areas, Port Vila, Vanuatu, 4-12 September. 3 pp.

UNEP/IUCN (1988). Coral Reefs of the World. Volume 3. Central and Eastern Pacific. UNEP Regional Seas Directories and Bibliographies. IUCN, Gland, Switzerland and Cambridge, UK/UNEP, Nairobi, Kenya. 378 pp.

Venkatesh, S., Va'ai, S. and Pulea, M. (1983). An overview of environmental protection legislation in the South Pacific Countries. SPREP Topic Review 13. South Pacific Commission, Noumea, New Caledonia. 63 pp.

Wenzel, L. (1989). Environment and change in the Pacific: a survey of resource use in Fiji, Solomon Islands, Tonga, Vanuatu and Western Samoa. INR Environmental Studies Report No. 43. Institute of Natural Resources, The University of the South Pacific, Suva, Fiji. 95 pp.

\section{ANNEX \\ Definitions of protected area designations, as legislated, together with authorities responsible for their administration}

\section{Title: Parks and Reserves Act}

Date: 21 September 1976 (Royal Assent: 22 January 1977)

Brief description: Provides for the establishment of a Parks and Reserves Authority and for the establishment, preservation and administration of parks and reserves. The Authority may, with consent of the Privy Council, declare any area of land or sea to be a park or reserve and in the same manner declare any park or reserve to cease to be such.

Administrative authority: Parks and Reserves Authority, established in 1989 within the Ministry of Lands, Survey and Natural Resources. 


\section{Designation:}

Park Subject to any conditions and restrictions which the Authority may impose, shall be administered for the benefit and enjoyment of the people of Tonga and there shall be freedom of entry and recreation therein by all persons (s.7).

Reserve Subject to any conditions and restrictions which the Authority may impose, shall be administered for the protection, preservation and maintenance of any valuable feature of such reserve, and activities therein and entry thereto shall be strictly in accordance with any such conditions and restrictions (s.8).

Marine reserve Administered for the protection, preservation and control of any aquatic form of life and any organic or inorganic matter therein (s.10). (Defined as an area of sea).

All parks and reserves shall be registered and recorded in accordance with the provisions of the Land Act (s.4.3). Prohibited activities include: alteration, disturbance, destruction or removal etc. of any feature whether organic or inorganic in any park or reserve; damage etc. to any notice, fence or building; depositing rubbish in any park or reserve; obstructing, disobeying etc. any instruction issued by the Authority (s.11).

\section{Title (English): The Birds and Fish Preservation Act}

Date: 1915 (amended in 1916, 1934 and 17 September 1974, gaining Royal Assent on 26 June 1975)

Administrative authority: Enforcement officers include police, fisheries and agricultural officers

Description: Makes provision for the preservation of wild birds and fish

Designation: Not applicable

NB: See The Birds and Fish Preservation (Amendment) Act, 1974

\section{Title: The Birds and Fish Preservation (Amendment) Act, 1974)}

Date: 17 September 1974 (Royal Assent 26 June 1975)

Administrative authority: Enforcement officers include police, fisheries and agricultural officers

Description: Amends the Birds and Fish Preservation Act. The Act is to be read and construed as one with The Birds and Fish Preservation Act ("the Principle Act").

Section 2 of the Principle Act is amended by defining "protected area".

\section{Designation:}

Protected area Any area comprising land, or water, as specified in the Third Schedule of the Act. Section 7 prohibits discharge of effluent etc.; erecting buildings etc.; cutting, damaging, removing or destroying any mangrove; erecting fish fences or fish traps, fish trawling or commercial fishing; or carrying out any boring, drilling or dredging operations within a protected area. 
The two major lagoons of Tongatapu, Fanga'uta and Fanga Kakau, are declared protected in the Third Schedule.

\section{Title: Forests Act}

Date: 2 November 1961

Administrative authority: Ministry of Agriculture, Fisheries and Forestry

Description: Provides for the setting aside of areas as forest areas or reserved areas and for the control and regulation of such areas and of forest produce and related matters (the King in Council may declare any unalienated land to be a forest reserve or reserved area (s.3) or may revoke such declarations (s.5)).

\section{Designation:}

Forest reserve Any demarcated forest or proclaimed forest reserve but shall not include a village forest reserve.

Reserved area Any demarcated area of land or proclaimed area of land which may be under grass or scrub which may be needed for afforestation in the future.

Village forests Governed by such regulations concerning the protection, control and management of forest produce as the Minister may prescribe.

Section 4 defines activities prohibited within forest reserves and reserved areas, including damage to forest produce, grazing, clearing land, killing, taking or injuring animals, setting fires etc.

\section{Title: Land (Timber Cutting) Act}

Date: No information

\section{Administrative authority: No information}

Brief description: Regulates cutting and taking of trees. Land (Timber Cutting) Regulations (G33/43) state that, where permission is granted to cut timber on Crown land, no timber can be cut within 50 feet $(\mathrm{c} .15 \mathrm{~m})$ of the high-water mark.

Designation: No information

\section{Title: The Preservation of Objects of Archaeological Interest Act}

Date: 1969

Administrative authority: Committee on Tongan Traditions

Brief description: Provides for the preservation of objects of archaeological interest.

Designation: Conditions can be specified to protect an object of archaeological interest from injury or removal. 
Miscellany: An Environmental Protection Act and a Fisheries Act were under consideration in 1987.

SUMMARY OF PROTECTED AREAS

\begin{tabular}{|c|c|c|c|c|}
\hline $\begin{array}{l}\text { Map }^{\dagger} \\
\text { ref. }\end{array}$ & Name of area & $\begin{array}{l}\text { IUCN management } \\
\text { category }\end{array}$ & $\begin{array}{r}\text { Area } \\
\text { (ha) }\end{array}$ & $\begin{array}{c}\text { Year } \\
\text { notified }\end{array}$ \\
\hline 1 & $\begin{array}{l}\text { Marine Reserves } \\
\text { Fanga'uta and Fanga Kakau Lagoons* }\end{array}$ & VIII & 2.835 & 1974 \\
\hline & Reserves & & & \\
\hline 2 & Ha'atafu Beach* & IV & 8 & 1979 \\
\hline 3 & Hakaumama'o Reef* & IV & 260 & 1979 \\
\hline 4 & Malinoa Island* & IV & 73 & 1979 \\
\hline 5 & Monuafe Island* & IV & 33 & 1979 \\
\hline 6 & Mui Hopo Hoponga & V & & 1972 \\
\hline 7 & Pangaimotu Reef* & IV & 49 & 1979 \\
\hline 8 & $\begin{array}{l}\text { Sanctuaries } \\
\text { Mounu Reef (Giant Clam) }\end{array}$ & - Unassigned & & \\
\hline & Parks & & & \\
\hline 9 & Ha'amonga Trilithon & Unassigned & 19 & 1972 \\
\hline
\end{tabular}

* Site is described in this directory.

${ }^{\dagger}$ Locations of most protected areas are shown in the accompanying map. 


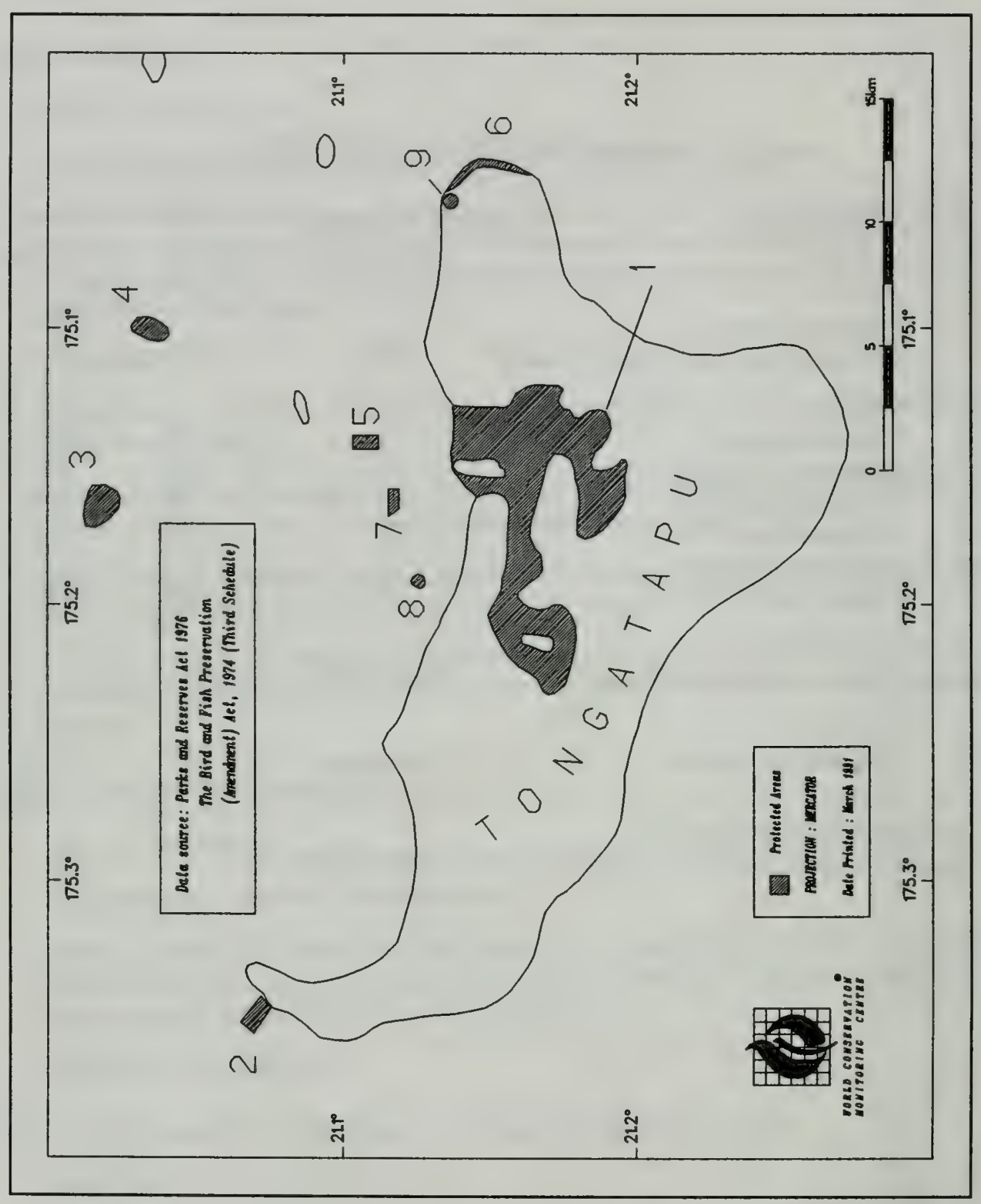

Protected Areas of the Kingdom of Tonga 


\section{FANGA’UTA AND FANGAKAKAU LAGOON}

\section{IUCN Management Category VIII (Multiple Use Management Area)}

\section{Biogeographical Province 5.05.13 (Central Polynesian)}

Geographical Location Comprises the main lagoons situated in the centre of Tongatapu. The Birds and Fish Preservation Act (Amendment), 1974, defines the boundaries of the site as the entire lagoon in Tongatapu, known as Fanga'uta and Fanga Kakau, being the area lying to the south of a straight line drawn from Niutao to the northernmost point of Nukunuku Motu and including the straits known as Holvea and all mangroves and foreshore. Approximately $175^{\circ} 10^{\prime} \mathrm{W}, 21^{\circ} 10^{\prime} \mathrm{S}$

Date and History of Establishment Established under the provisions of the Bird and Fish Preservation (Amendment) Act, 1974, passed in the Legislative Assembly on 17 September 1974 and receiving Royal assent on 26 June 1975.

Area 2,835ha (Wilkinson, 1977); 3,423ha (Zann et al., 1984)

\section{Land Tenure State}

Altitude Ranges from sea level to a maximum depth of some $6 \mathrm{~m}$ in the Mu'a Branch.

Physical Features The lagoon comprises a shallow, almost enclosed estuarine embayment on the northem Tongatapu coastline. There are two main branches separated from each other and from the ocean by a complex system of reefs and channels. The westernmost part, directly to the south of Nuku'alofa, is made up of a sinuous channel, the Folaha Sector, approximately $0.5 \mathrm{~km}$ wide, and a broad, shallow basin, the Pe'a Sector, surrounding Kanate Island, roughly $2 \mathrm{~km}$ in diameter. The Mu'a Branch, which connects directly to the sea, can be subdivided into the southerly Vaini Sector, a shallow basin, and the deeper Mu'a Sector. Water is generally shallow, reaching only $1-2 \mathrm{~m}$ depth in the Pe'a and Vaini sectors, $3 \mathrm{~m}$ in the Folaha Sector and $6 \mathrm{~m}$ in the Mu'a Sector. Tidal circulation in the lagoon is constrained by the geometry of the reef flats and channels, with a range of $0.13 \mathrm{~m}$ compared to an open sea range of $1.06 \mathrm{~m}$. Lagoon tides lag some 3-4 hours behind ocean tides and currents of up to $1.5 \mathrm{~m} / \mathrm{second}$ occur in the main channel. A mean residence time of 23 days has been calculated, whilst tidal mixing is about $12 \%$ efficient. Freshwater input to the lagoon occurs entirely from the ground water lens, except during heavy rains. Average input is approximately 26,000 cu.m per day, of which $83 \%$ enters through diffuse subsurface springs and $15 \%$ from solution channels onshore. The ground water is rich in nutrients and provides essentially the entire nutrient supply to the lagoon. The long residence time of water in the lagoon allows most nutrients to be incorporated into living organisms and ultimately remain in basement sediments. This would normally cause the lagoon to infill at the rate of a few millimetres each century. However, it is highly likely that much more rapid infilling occurs through erosion and run-off during infrequent heavy storms. The putative $20-40 \mathrm{~cm}$ uplift in the lagoon entrance area, some 40-200 years ago, created a damming effect, allowing sediments to accumulate more rapidly than before the uplift. A number of islands are included within the lagoon, the principal ones being Nukunuku Motu, Kanatea, Talakite, Mata'aho and Mo'ungatapu (Zann et al., 1984).

Climate Data specific to the site are not available. The following is a general account for the Tongatapu region. The prevailing winds are south-east trades: $60 \%$ of wind observations are from the east and south-east, and about $10 \%$ each from the north-east and south. Mean wind 
speeds are 7-10 knots. Hurricanes occur infrequently during the southern summer, approaching Tongatapu from the north and north-west. Mean annual rainfall at Nuku'alofa is $1784 \mathrm{~mm}$, being highest during January to March and lowest in June; annual totals are rather variable. Mean daily maximum temperatures vary from $25^{\circ} \mathrm{C}$ in July to September, to $29^{\circ} \mathrm{C}$ during January to March. The mean of the highest temperatures recorded in each month reaches $31^{\circ} \mathrm{C}$ in February to March, and the mean of the lowest in each month falls to $13^{\circ} \mathrm{C}$ in July to August. The tidal range at Nuku'alofa is $1.22 \mathrm{~m}$ at springs and $0.98 \mathrm{~m}$ at neaps (Stoddart, 1975).

Vegetation Biological processes within the lagoon are controlled by nutrient input, tidal exchange, water depth and wind. Where the wind influence is strong and water is shallow, as in the Pe'a Sector, the water is turbid and the bottom has only slight sea-grass cover. The Vaini Sector is also shallow, but is more protected from wind; a dense mat of sea-grass has developed, further stabilising the sediments. Thus, while the Pe'a Sector is plankton-dominated, the Vaini Sector is dominated by benthic processes. The Folaha and Mu'a sectors are both deeper, so sea-grass cover is restricted to the margins. Plankton growth is more rapid in the Pe'a Sector than in the Mu'a Sector, probably because of the high concentration of particulate matter, and, therefore, higher availability of recycled nutrients (Zann et al., 1984). The principal sea-grass species are Halophilia ovalis and Halodule pinifoliosa. Algae include Caulerpa serratula, C. racemosa, C.ashmeadii, Cladophora sp., Chorodesmis spp., Halimeda discoidea and Gracilaria sp. (Brock, 1981). The relative abundance and productivity of these species in the major lagoon sectors is discussed in Zann et al. (1984). Of the total $58 \mathrm{~km}$ of Fanga'uta Lagoon shoreline, $44.5 \mathrm{~km}$ are covered by a mangrove tidal forest. The coverage is greatest in the Nuku'alofa branch, being about $30-35 \mathrm{~km}$, as compared to the $14 \mathrm{~km}$ covered of the Mu'a branch's $24 \mathrm{~km}$ circumference. The southern coast of the Mu'a branch comprises raised limestone and is hence less suitable for mangrove growth; where present, the mangrove zone is very narrow.

In the Pe'a Sector Brugiera gymnorhyza is dominant along the water's edge, with Excoecaria agallocha present as a secondary canopy. A rich community of creepers and epiphytes is present. Lumnitzera lottorea and Xylocarpus granatum lie shoreward, with Hibiscus tiliaceus, Pandanus sp., Acrostichum and Ficus obliqua scrubs further inland.

At 'Alaki, Rhizophora samoensis and $R$. stylosa dominate the shoreline community; towards the landward edge the fern Acrostichum aureum and tallerXylocarpus range into the coastal or littoral forest behind.

The raised limestone shore from Longoteme to "Kauvai" is distinct. Irregular $R$. samoensis is found in shallower shoreline areas, but elsewhere Hibiscus tiliaceus, Pandanus and Acrostichum dominate the coastline. Shoreward lie remnants of the littoral forest, largely cleared and planted in copra. A species list is given in Zann et al. (1984).

Fauna Invertebrate species with a lagoon-wide distribution include alpheid shrimp Alpheus mackayi, mantis shrimp Squilla sp. and Lysiosquilla sp. commercially important prawns Metapenaeus ensis and Penaeus sensculcatus and crabs Scylla serrata, Thalamita prymna, Calappa hepatica and several species of the Xanthidae family. The holothurian Holothuria atra is common in parts of the lagoon; H. edulis, $H$. leucospilota, $H$. impatiens, Stichopus variegatus and $S$. chloronotus are all found on the patch reefs near the lagoon entrance. Starfishes and Astropecten sp. are common on the intertidal flats and deeper soft-bottom areas of the Vaini, Mu'a and entrance channel regions. Blue starfish Linckia laevigata and sea urchins Diadema setosum, Tripnuestes gratilla and Toxopnuestes pileolus are frequently seen on the entrance channel patch and fringing reefs. A small number of Capitellidae polychaete species are found in sediments. Sand-trapping chaetopterids are common on the patch and fringing reefs at the 
entrance. Several sponges are present on shallow fringing reefs, most commonly near the lagoon entrance. A number of bivalves are found throughout the lagoon. Small tellinids and Gafrarium tunidum are common in the sediments of all sectors; towards the lagoon entrance cockle Anadara maculata, strawberry cockle Fragum unedo, tellin Tellina sp., cockle Periglypta sp., Lucina sp. and scallop Pecten sp. are found, along with pinna Atrina sp. and pearl oyster Pinctado marginatifera. Larger gastropods found near the entrance include ringed money cowry Cypraea annulus, money cowry $C$. moneta, milk spotted cowry $C$. vitellus and tiger cowry C. tigris, spider shell Lambis lambis, humpback strom Strombus gibberulus and cone Conus pulicarius. Jellyfish Cassiopea sp. is harvested for consumption and is very common in the Nuku'alofa branch of the lagoon, with local densities reaching 4 per sq.m. The diversity of coral declines from 10-15 genera at the lagoon entrance, to only one, Porites, in the Mu'a Sector. Living coral coverage declines from $70 \%$ outside the lagoon entrance, to $15-30 \%$ at the entrance, to much less than $0.1 \%$ in the lagoon. This reflects the intolerance of coral species to hyposaline and turbid conditions. The proportion of dead coral increases further into the lagoon. A species list, including Scleractinia, Alcyonaria and Hydroidea taxa, is given in Zann et al. (1984).

A total of 96 fish species is present in the lagoon, with the greatest diversity occurring to seaward. A species list is given in Zann et al. (1984).

Fauna associated with fringing vegetation include mudskippers Periophthalmus sp., fiddler crab Uca lactea, nerites Nerita plicata and $N$. undata, whelks Cypeomorus and other invertebrates.

Bird species associated with the lagoon include golden plover Pluvialis dominica, Australian grey duck Anas superciliosa, frigate bird Fregata ariel, abundant crested tern Sterna bergii, fairy tern S. nareis, reef heron Egretta sacra, in both white and grey morphs, bar-tailed godwit Limosa lapponica, Pacific swallow Hirunda tahitica and white-tailed swiftlet Apus pacificus. Reptiles include banded sea-snake Laticauda colubrina, seen off the outer lagoon patch reef (Zann et al., 1984).

\section{Cultural Heritage No information}

Local Human Population A number of settlements are contiguous to the lagoon including Haveluloto, a suburb of Nuku'alofa, Nukuhetulu, Mu'a, Pe'a, Talafo'ou and Sifsia, located on Nukunukumotu Island. The local populace has historically exploited the lagoon resources; Mu'a was the capital of Tonga for many centuries. The introduction of synthetic monofilament gill nets, arrowhead fish fences, commercial trawling, and the effects of pollution led to a rapid decline in reported catches during the late 1960s. A commercial trawling operation for penaeid prawns began in 1974 but because large numbers of juvenile fish were caught (Braley, 1974) and the fishery for mullet, milkfish and bonefish continued to decline, the lagoon was gazetted for protection. Mangroves around the lagoon have been used for fuel and construction purposes and littoral vegetation has been cleared for agriculture (Zann et al., 1984).

Visitors and Visitor Facilities The site was gazetted to protect marine resources and was not intended as a tourist attraction. Information on facilities and access is not available.

Scientific Research and Facilities The ecology of the lagoon has been investigated by Zann et al. (1984), including aspects of circulation and hydrology, water chemistry, plankton abundance and primary production; corals; fish and benthic communities; fringing vegetation; and fisheries.

Conservation Value The lagoon is valued as a nursery ground for many reef and other food fishes which are the mainstay of the local subsistence fishery. The lagoon also supports juvenile 
populations of grey mullet Mugil cephalus and several species of penaed prawn, the most important commercially being Penaeus semisulcatus (De-haan) and Metapenaeus ensis (De-haan). Important breeding grounds for snappers Lethrinus sp. and Lutjanus sp. are also found (Wilkinson, 1977).

Conservation Management The 1974 Birds and Fish Preservation (Amendment) Act places principal responsibility for the lagoon on the Fisheries Division and provides the following legal protection for the site. No person may, within a protected area, and without the prior consent in writing of the Prime Minister. discharge or cause to be discharged into the protected area any effluent or noxious or toxic liquid or substance; erect any harbour, wharf, pier, jetty or other building works, temporary or permanent; cut, damage, remove or destroy any mangrove; erect any fish fence, or set any fish trap; or trawl for fish (including shellfish) or engage in any fishing for commercial purposes; and carry out any boring, drilling or dredging operations. The enabling legislation does not prohibit subsistence fishing, and many families supplement their diet with fish and shellfish collected from the lagoon (Zann et al., 1984). A number of recommendations are given in Zann et al. (1384), including the continued prohibition of commercial fisheries and dredging, and the development of aquaculture of prawns, shellfish, mullet, milkfish and baitfish.

Management Constraints The lagoon has been overfished, with a consequent gradual decline in mullet yields. The removal of mangroves, land reclamation and rubbish dumping has caused localised disturbances. The location of numerous arrow-head fish fences around the entrance channel, and the subsistence fishery within the lagoon, have prevented fish stocks from recovering (Zann et al., 1984). A bridge and causeway across the lagoon entrance is planned (R. Chesher, in litt., 1987). Mangroves have been damaged for fuelwood collection, clearing for gardens and collection of bark for tapa dye. Effluents are discharged directly into the lagoon from several sources (P. Thomas, pers. comm., 1989).

Staff No information

Budget No information

Local Addresses Fisheries Division, Ministry of Lands, Survey and Natural Resources, PO Box 5, Nuku'alofa

\section{References}

Braley, R. (1974). The present marine turtle situation in Tonga. Fisheries Section, Tongan Agricultural Department. Unpublished report. (Unseen).

Stoddart, D.R. (1975). The sand cays of Tongatapu. Atoll Research Bulletin 181.8 pp.

Wilkinson, W.A. (1977). Marine conservation in Tonga. Parks 2(2): 11-12.

Zann, L.P., Kimmerer, W.J. and Brock R.E. (1984). The Ecology of Fanga' uta Lagoon, Tongatapu, Tonga. Sea Grant Cooperative Report UNIHI-SEAGRANT CR-84-04. Institute of Marine Resources, University of the South Pacific, Suva, Fiji and International Sea Grant Program, University of Hawaii, Honolulu, Hawaii. 100 pp.

Date January 1989 


\section{HA'ATAFU BEACH RESERVE}

\section{IUCN Management Category IV (Managed Nature Reserve)}

\section{Biogeographical Province 5.05.13 (Central Polynesian)}

Geographical Location Situated on the western tip of Tongatapu, off Niuaunofo Point. The reserve, which includes both beach and reef, is bounded by the following points: (1) $21^{\circ} 04^{\prime} 11.6^{\prime \prime S}, 1^{\circ} 20^{\prime} 00.3^{\prime \prime W}$; (2) $21^{\circ} 04^{\prime} 05.9^{\prime \prime} \mathrm{S}, 175^{\circ} 20^{\prime} 09.6^{\prime \prime} \mathrm{W}$; (3) $21^{\circ} 04^{\prime} 00.1^{\prime \prime} \mathrm{S}$, $175^{\circ} 20^{\prime} 04.3^{\prime \prime} \mathrm{W}$; (4) $21^{\circ} 04^{\prime} 05.2^{\prime \prime} \mathrm{S}, 175^{\circ} 09^{\prime} 56.1^{\prime \prime} \mathrm{W}$

Date and History of Establishment 1 June 1979. Gazetted under the 1976 Parks and Reserves Act.

Area 8ha

\section{Land Tenure State}

Altitude Ranges from the beach to approximately $5 \mathrm{~m}$ depth.

Physical Features Comprises an attractive beach with lagoon and fringing reef (Tongilava, 1979; Eaton, 1985).

Climate Data specific to the site are not available. The following is a general account for the Tongatapu region. The prevailing winds are south-east trades: $60 \%$ of wind observations are from the east and south-east, and about $10 \%$ each from the north-east and south. Mean wind speeds are 7-10 knots. Hurricanes occur infrequently during the southern summer, approaching Tongatapu from the north and north-west. Mean annual rainfall at Nuku'alofa is $1784 \mathrm{~mm}$, being highest during January to March and lowest in June; annual totals are rather variable. Mean daily maximum temperatures vary from $25^{\circ} \mathrm{C}$ in July to September, to $29^{\circ} \mathrm{C}$ during January to March. The mean of the highest temperatures recorded in each month reaches $31^{\circ} \mathrm{C}$ in February to March, and the mean of the lowest in each month falls to $13^{\circ} \mathrm{C}$ in July to August. The tidal range at Nuku'alofa is $1.22 \mathrm{~m}$ at springs and $0.98 \mathrm{~m}$ at neaps (Stoddart, 1975).

\section{Vegetation No information}

Fauna Fish are abundant and include butterfly fish Chaetodon sp., wrasses Holocentorus sp., clown fish Amphrion sp. and damsel fish (Tongilava, 1979). Giant clam Tridacna maxima (K) and scaly clam $T$. squamosa (I) occur (McKoy, 1980). Information on reef structure and corals is not available.

\section{Cultural Heritage No information}

Local Human Population The nearest settlement is Ha'atafu on the eastern side of Niuaunofo Point.

Visitors and Visitor Facilities The beach is a popular recreation area (Eaton, 1985). A low impact, small-scale tourist resort is located on land immediately adjacent to the reserve and used both by local people and international visitors for swimming, picnics, surfing and other activities (P. Thomas, pers. comm., 1989).

Scientific Research and Facilities Giant clams have been surveyed (McKoy, 1980). 
Conservation Value No information

Conservation Management There are no management activities at present. Notice boards indicating the regulations prohibiting the destruction or removal of marine life have been erected (Eaton, 1985).

Management Constraints There is reported to have been some damage to corals by crown-of-thorns starfish Acanthaster planci (Tongilava, 1979). Shellfish are collected from the reef (Eaton, 1985).

Staff No information

Budget No information

Local Addresses Ministry of Lands, Survey and Natural Resources, P O Box 5, Nuku'alofa

\section{References}

Dahl, A.L. (1978). Environmental and ecological report on Tonga. Part 1 Tongatapu. South Pacific Commission, Noumea, New Caledonia. 48 pp.

Chesher, R.H. (1984). Resource assessment report. Black coral of Tonga. SPREP, South Pacific Commission, Noumea, New Caledonia. 30 pp.

Eaton, P. (1985). Land tenure and conservation in the South Pacific. South Pacific Regional Environment Programme. Topic Review 17. South Pacific Commission. Noumea, New Caledonia. 103 pp.

McKoy, J.L. (1980). Biology, exploitation and management of giant clams (Tridacnidae) in the Kingdom of Tonga. Fisheries Bulletin 1. Fisheries Division, Tonga. 61 pp.

Stoddart, D.R. (1975). The sand cays of Tongatapu. Atoll Research Bulletin 181. 8 pp.

Tongilava, S.L. (1979). Development and management of marine parks and reserves in the Kingdom of Tonga. In: Proceedings of the Second South Pacific Conference on National Parks and Reserves, Sydney 1: 148-152.

Date January 1989

\section{HAKAUMAMA'O REEF RESERVE}

IUCN Management Category IV (Managed Nature Reserve)

Biogeographical Province 5.05.13 (Central Polynesian)

Geographical Location The reserve is $19 \mathrm{~km}$ north of Nuku'alofa and is bounded by the following points: (1) $20^{\circ} 59^{\prime} 30.6^{\prime \prime} \mathrm{S}, 175^{\circ} 12^{\prime} 57.3^{\prime \prime} \mathrm{W}$; (2) $20^{\circ} 59^{\prime} 30.0^{\prime \prime} \mathrm{S}, 175^{\circ} 12^{\prime} 04.4^{\prime \prime} \mathrm{W}$; (3) $21^{\circ} 00^{\prime} 13.2^{\prime \prime} \mathrm{S}, 175^{\circ} 12^{\prime} 03.8^{\prime \prime} \mathrm{W}$; (4) $21^{\circ} 00^{\prime} 13.7^{\prime \prime} \mathrm{S}, 175^{\circ} 12^{\prime} 56.8^{\prime \prime} \mathrm{W}$

Date and History of Establishment 1 June 1979. Gazetted under the 1976 Parks and Reserves Act.

Area $260 \mathrm{ha}$

Land Tenure State 
Altitude Ranges between sea-level and a depth of approximately $5 \mathrm{~m}$.

Physical Features An isolated, exposed barrier and algal reef, often exposed to strong current and hurricanes, and which is not associated with an island (Wilkinson, 1977; Dahl, 1978 and 1980).

Climate Data specific to the site are not available. The following is a general account for the Tongatapu region. The prevailing winds are south-east trades: $60 \%$ of wind observations are from the east and south-east, and about $10 \%$ each from the north-east and south. Mean wind speeds are 7-10 knots. Hurricanes occur infrequently during the southern summer, approaching Tongatapu from the north and north-west. Mean annual rainfall at Nuku'alofa is $1784 \mathrm{~mm}$, being highest during January to March and lowest in June; annual totals are rather variable. Mean daily maximum temperatures vary from $25^{\circ} \mathrm{C}$ in July to September, to $29^{\circ} \mathrm{C}$ during January to March. The mean of the highest temperatures recorded in each month reaches $31^{\circ} \mathrm{C}$ in February to March, and the mean of the lowest in each month falls to $13^{\circ} \mathrm{C}$ in July to August. The tidal range at Nuku'alofa is $1.22 \mathrm{~m}$ at springs and $0.98 \mathrm{~m}$ at neaps (Stoddart, 1975).

Vegetation No information

Fauna Giant clam Tridacna maxima $(\mathrm{K})$ and scaly clam $T$. squamosa $(\mathrm{I})$ are present (McKoy, 1980).

Cultural Heritage No information

Local Human Population None

Visitors and Visitor Facilities No information

Scientific Research and Facilities Giant clams have been surveyed (McKoy, 1980).

Conservation Value No information

Conservation Management No information

Management Constraints The site is virtually undisturbed by man due to its remote location (Tongilava, 1979).

Staff No information

Budget No information

Local Addresses Ministry of Lands, Survey and Natural Resources, P O Box 5, Nuku'alofa

\section{References}

Dahl, A.L. (1978). Environmental and ecological report on Tonga. Part 1 Tongatapu. South Pacific Commission, Noumea, New Caledonia. 48 pp.

Dahl, A.L. (1980a). Regional ecosystem survey of the South Pacific Area. SPCIIUCNTechnical Paper 179. South Pacific Commission, Noumea, New Caledonia.

Dahl, A.L. (1980b). Report on marine surveys of Rarotonga and Aitutaki (November 1976). South Pacific Commision, Noumea, New Caledonia.

Eaton, P. (1985). Land tenure and conservation in the South Pacific. South Pacific Regional Environment Programme. Topic Review 17. South Pacific Commission, Noumea, New Caledonia. 103 pp. 
McKoy, J.L. (1980). Biology, exploitation and management of giant clams (Tridacnidae) in the

Kingdom of Tonga. Fisheries Bulletin 1. Fisheries Division, Tonga. 61 pp.

Stoddart, D.R. (1975). The sand cays of Tongatapu. Atoll Research Bulletin 181. 8 pp.

Tongilava, S.L. (1979). Development and management of marine parks and reserves in the Kingdom of Tonga. In: Proceedings of the Second South Pacific Conference on National Parks and Reserves, Sydney 1: 148-152.

UNEP/IUCN (1988). Coral Reefs of the World. Volume 3. Central and Eastern Pacific. UNEP Regional Seas Directories and Bibliographies. IUCN, Gland, Switzerland and Cambridge, UK/UNEP, Nairobi, Kenya. 378 pp.

Wilkinson, W.A. (1977). Marine conservation in Tonga. Parks 2(2): 11-12.

Date January 1989

\section{MALINOA ISLAND PARK AND REEF RESERVE}

\section{IUCN Management Category V (Protected Landscape)}

Biogeographical Province 5.05.13 (Central Polynesian)

Geographical Location Located $12 \mathrm{~km}$ north-north-east of Nuku'alofa. The boundary is defined by the following points: (1) $21^{\circ} 02^{\prime} 24.0^{\prime \prime} \mathrm{S}, 175^{\circ} 07^{\prime} 59.1^{\prime \prime} \mathrm{W}$; (2) $21^{\circ} 01^{\prime} 48.7^{\prime \prime} \mathrm{S}, 175^{\circ} 07^{\prime} 59.6^{\prime \prime} \mathrm{W}$; (3) $21^{\circ} 01^{\prime} 48.2^{\prime \prime} \mathrm{S} ; 175^{\circ} 07^{\prime} 21.3^{\prime \prime} \mathrm{W}$; (4) $21^{\circ} 02^{\prime} 23.6^{\prime \prime} \mathrm{W}, 175^{\circ} 07^{\prime} 20.8^{\prime \prime} \mathrm{W}$

Date and History of Establishment 1 June 1979. Gazetted under the 1976 Parks and Reserves Act. The island component is gazetted as a national park, and surrounding reef as a reserve (U. Samani in litt., 1987).

Area $73 \mathrm{ha}$, of which the island covers $0.5 \mathrm{ha}$

\section{Land Tenure State}

Altitude Ranges from the surface of the island to approximately $5 \mathrm{~m}$ depth.

Physical Features Comprises a small island with fringing reef. Tides create strong currents (Tongilava, 1979).

Climate Data specific to the site are not available. The following is a general account for the Tongatapu region. The prevailing winds are south-east trades: $60 \%$ of wind observations are from the east and south-east, and about $10 \%$ each from the north-east and south. Mean wind speeds are 7-10 knots. Hurricanes occur infrequently during the southern summer, approaching Tongatapu from the north and north-west. Mean annual rainfall at Nuku'alofa is $1784 \mathrm{~mm}$, being highest during January to March and lowest in June; annual totals are rather variable. Mean daily maximum temperatures vary from $25^{\circ} \mathrm{C}$ in July to September, to $29^{\circ} \mathrm{C}$ during January to March. The mean of the highest temperatures recorded in each month reaches $31^{\circ} \mathrm{C}$ in February to March, and the mean of the lowest in each month falls to $13^{\circ} \mathrm{C}$ in July to August. The tidal range at Nuku'alofa is $1.22 \mathrm{~m}$ at springs and $0.98 \mathrm{~m}$ at neaps (Stoddart, 1975).

Vegetation No information 
Fauna The area is said to be rich in fish, octopus, clams and other shellfish (Eaton, 1985). Giant clam Tridacna maxima $(\mathrm{K})$ is present (McKoy, 1980). It is the only known turtle nesting site in the Tongatapu Group, although the species concerned are not known (Groombridge and Luxmoore, in press; Wilkinson, 1979).

Cultural Heritage The graves of six men executed for attempting to assassinate Tonga's second Prime Minister, Shirley Baker, in 1886, are on the island (Tongilava, 1979).

\section{Local Human Population None}

Visitors and Visitor Facilities The six graves remain clearly marked and are still attended to. Malinoa is within easy reach of visitors from Nuku'alofa on day trips. Strong tides preclude all but the strongest swimmers on the reef (Tongilava, 1979).

Scientific Research and Facilities The reefs have been briefly surveyed (Chesher, 1984) as have giant clams (McKoy, 1980).

\section{Conservation Value No information}

Conservation Management Designation of the island as a park requires it to be available for recreational use. However, the reserve designation of the reef invokes more rigorous protection. Signboards indicating the regulations prohibiting the destruction or removal of marine life have been erected (Eaton, 1985). An $8 \mathrm{~m}$ boat has been used for protected area surveillance (U. Samani, pers. comm., 1987), although details are not available.

Management Constraints Coral mortality is high, but the cause is unknown (Chesher, 1984).

Staff No information

Budget No information

Local Addresses Ministry of Lands, Survey and Natural Resources, P O Box 5, Nuku'alofa

\section{References}

Chesher, R.H. (1984). Resource assessment report. Black coral of Tonga. SPREP, South Pacific Commission, Noumea, New Caledonia. $30 \mathrm{pp}$.

Eaton, P. (1985). Land tenure and conservation in the South Pacific. South Pacific Regional Environment Programme. Topic Review 17. South Pacific Commission, Noumea, New Caledonia. 103 pp.

Groombridge, B. and Luxmoore, R. (in press). The green turtle and hawksbill (Reptilia: Cheloniidae): world status, exploitation and trade. A report to the CITES Secretariat. World Conservation Monitoring Centre, Cambridge, UK.

McKoy, J.L. (1980). Biology, exploitation and management of giant clams (Tridacnidae) in the Kingdom of Tonga. Fisheries Bulletin 1. Fisheries Division, Tonga. 61 pp.

Stoddart, D.R. (1975). The sand cays of Tongatapu. Atoll Research Bulletin $181.8 \mathrm{pp}$.

Tongilava, S.L. (1979). Development and management of marine parks and reserves in the Kingdom of Tonga. In: Proceedings of the Second South Pacific Conference on National

Parks and Reserves, Sydney 1: 148-152.

Wilkinson, W.A. (1977). Marine conservation in Tonga. Parks 2(2): 11-12.

Date January 1989 


\section{MONUAFE ISLAND PARK AND REEF RESERVE}

\section{IUCN Management Category IV (Managed Nature Reserve)}

\section{Biogeographical Province 5.05.13 (Central Polynesian)}

Geographical Location Located approximately $6 \mathrm{~km}$ north-east of Nuku'alofa and bounded by the following points: (1) $21^{\circ} 06^{\prime} 44.7^{\prime \prime} \mathrm{S}, 175^{\circ} 08^{\prime} 37.0^{\prime \prime} \mathrm{W}$; (2) $21^{\circ} 06^{\prime} 12.7^{\prime \prime} \mathrm{S}, 175^{\circ} 08^{\prime} 37.4^{\prime \prime} \mathrm{W}$; (3) $21^{\circ} 06^{\prime} 12.5^{\prime \prime} \mathrm{S}, 175^{\circ} 08^{\prime} 20.0^{\prime \prime} \mathrm{W}$; (4) $21^{\circ} 06^{\prime} 44.5^{\prime \prime} \mathrm{S}, 175^{\circ} 08^{\prime} 19.6^{\prime \prime} \mathrm{W}$

Date and History of Establishment 1 June 1979. Gazetted under the 1976 Parks and Reserves Act. The island component is gazetted as a park and the surrounding reef as a reserve (U. Samani, pers. comm., 1987).

Area 33 ha; the island covers $2 \mathrm{ha}$

\section{Land Tenure State}

Altitude Ranges from the surface of the island to a depth of approximately $5 \mathrm{~m}$.

Physical Features Comprises a small, sand island, surrounded by a sheltered lagoon reef. It is situated at the confluence of two main water currents which provide good conditions for reef growth.

Climate Data specific to the site are not available. The following is a general account for the Tongatapu region. The prevailing winds are south-east trades: $60 \%$ of wind observations are from the east and south-east, and about 10\% each from the north-east and south. Mean wind speeds are 7-10 knots. Hurricanes occur infrequently during the austral summer, approaching Tongatapu from the north and north-west. Mean annual rainfall at Nuku'alofa is $1784 \mathrm{~mm}$, being highest during January to March and lowest in June; annual totals are rather variable. Mean daily maximum temperatures vary from $25^{\circ} \mathrm{C}$ in July to September, to $29^{\circ} \mathrm{C}$ during January to March. The mean of the highest temperatures recorded in each month reaches $31^{\circ} \mathrm{C}$ in February to March, and the mean of the lowest in each month falls to $13^{\circ} \mathrm{C}$ in July to August. The tidal range at Nuku'alofa is $1.22 \mathrm{~m}$ at springs and $0.98 \mathrm{~m}$ at neaps (Stoddart, 1975).

Vegetation The island supports a scrub formation, probably dominated by Hibiscus tiliaceus, in common with other sand cays in the vicinity (Stoddart, 1975).

Fauna The adjacent sand flats are rich in molluscs (Wilkinson, 1977). The giant clam Tridacna maxima $(\mathrm{K})$ is present $(\mathrm{McKoy}, 1980)$ The reef is a small section of a large, very diverse and vigorous reef. Acropora sp. is dominant, but all coral species known from Tonga are found here (Tongilava, 1979). The reef to the south and west of Monuafe Island is considered to be one of the richest in the vicinity of Tongatapu and is a good example of sheltered reef development (Dahl, 1978).

\section{Cultural Heritage No information}

\section{Local Human Population None}

\section{Visitors and Visitor Facilities No information}

Scientific Research and Facilities The reefs have been briefly surveyed (Chesher, 1984) as have giant clams (McKoy, 1980) 


\section{Conservation Value No information}

Conservation Management No specific details are available. However, an $8 \mathrm{~m}$ boat has been acquired for patrolling protected areas (U. Samani, pers. comm., 1987).

Management Constraints The reefs have suffered from the local fishing method 'tu'afeo' which involves the breaking of coral to scare fish into nets (Wilkinson, 1977). Chesher (1984) reports that there have been no recent changes in reef condition.

Staff No information

Budget No information

Local Addresses Ministry of Lands, Survey and Natural Resources, P.O. Box 5, Nuku'alofa

\section{References}

Chesher, R.H. (1984). Resource assessment report. Black coral of Tonga. SPREP, South Pacific Commission, Noumea, New Caledonia. $30 \mathrm{pp}$.

Dahl, A.L. (1978). Environmental and ecological report on Tonga. Part 1 Tongatapu. South Pacific Commission, Noumea, New Caledonia. 48 pp.

McKoy, J.L. (1980). Biology, exploitation and management of giant clams (Tridacnidae) in the Kingdom of Tonga. Fisheries Bulletin 1. Fisheries Division, Tonga. 61 pp.

Stoddart, D.R. (1975). The sand cays of Tongatapu. Atoll Research Bulletin $181.8 \mathrm{pp}$.

Tongilava, S.L. (1979). Development and management of marine parks and reserves in the Kingdom of Tonga. In: Proceedings of the Second South Pacific Conference on National Parks and Reserves, Sydney 1: 148-152.

Wilkinson, W.A. (1977). Marine conservation in Tonga. Parks 2(2): 11-12.

Date January 1989

\section{PANGAIMOTU REEF RESERVE}

IUCN Management Category IV (Managed Nature Reserve)

Biogeographical Province 5.05.13 (Central Polynesian)

Geographical Location Lies some $3 \mathrm{~km}$ north-east of Nuku'alofa and immediately north of Pangaimotu Island. Navigation beacons at the following points mark the boundary: (1) $21^{\circ} 07^{\prime} 09.8^{\prime \prime} \mathrm{S}, 175^{\circ} 09^{\prime} 54.1^{\prime \prime} \mathrm{W}$; (2) $21^{\circ} 06^{\prime} 56.7^{\prime \prime} \mathrm{S}, 175^{\circ} 09^{\prime} 64.2^{\prime \prime} \mathrm{W}$; (3) $21^{\circ} 06^{\prime} 56.4^{\prime \prime} \mathrm{S}$, $175^{\circ} 09^{\prime} 29.1^{\prime \prime W}$; (4) $21^{\circ} 07^{\prime} 09.5^{\prime \prime} \mathrm{S}, 175^{\circ} 0929.0^{\prime \prime} \mathrm{W}$

Date and History of Establishment 1 June 1979. Gazetted under the 1976 Parks and Reserves Act.

Area $49 \mathrm{ha}$

Land Tenure State

Altitude Sea level to a depth of approximately $5 \mathrm{~m}$. 
Physical Features Comprises a shallow reef, bounded on the northern, seaward side by the deep Piha Passage; the reef is best developed here (Tongilava, 1979). An outer reef extends into Piha Passage and sand flats occur (Dahl, 1978; Eaton, 1985).

Climate Data specific to the site are not available. The following is a general account for the Tongatapu region. The prevailing winds are south-east trades: $60 \%$ of wind observations are from the east and south-east, and about $10 \%$ each from the north-east and south. Mean wind speeds are 7-10 knots. Hurricanes occur infrequently during the southern summer, approaching Tongatapu from the north and north-west. Mean annual rainfall at Nuku'alofa is $1784 \mathrm{~mm}$, being highest during January to March and lowest in June; annual totals are rather variable. Mean daily maximum temperatures vary from $25^{\circ} \mathrm{C}$ in July to September, to $29^{\circ} \mathrm{C}$ during January to March. The mean of the highest temperatures recorded in each month reaches $31^{\circ} \mathrm{C}$ in February to March, and the mean of the lowest in each month falls to $13^{\circ} \mathrm{C}$ in July to August. The tidal range at Nuku'alofa is $1.22 \mathrm{~m}$ at springs and $0.98 \mathrm{~m}$ at neaps (Stoddart, 1975).

Vegetation Eel grass beds and mangroves are present (Eaton, 1985). The contiguous northern shore of Pangaimotu Island supports a coastal woodland, mainly of Hibiscus tiliaceus, but also with Thespesia, Cordia, Guettarda and clumps of Rhizophora in shallow water offshore (Stoddart, 1975).

Fauna Fish are abundant, especially Chromis caerulens, Holocentrus, Chaetodon and Amphrion spp. (Tongilava, 1979). Giant clam Tridacna maxima (K) and scaly clam $T$. squamosa (I) are present (McKoy, 1980). Coral is reportedly predominantly Acropora (Tongilava, 1979). The reef edge has at least 12 genera of coral (Zann et al., 1984). There is good coral cover in shallow water (Chesher, 1984).

\section{Cultural Heritage No information}

Local Human Population The nearest settlement is located on the southern point of Pangaimotu Island (Stoddart, 1975).

Visitors and Visitor Facilities In June 1989 an underwater coral trail was established for tourist use (SPREP, 1989).

Scientific Research and Facilities Some of the reefs were briefly surveyed by Zann et al. (1981) and Chesher (1984). Giant clams have been surveyed (McKoy, 1980).

Conservation Value To protect wildlife, provide undisturbed breeding grounds and provide an area for research and recreation (Tongilava, 1989).

Conservation Management Signs indicating regulations prohibiting the destruction or removal of marine life have been erected (Eaton, 1985). An underwater trail has been developed (Tongilava, 1989), although it appears that this may have been destroyed by disgruntled fishermen following attempts to enforce regulations prohibiting fishing (Chesher, 1990).

Management Constraints The reef has suffered from overfishing and collecting by tourists (Dahl, 1978; Tongilava, 1979) and coral breakage and infection with blue-green algae is common (Chesher, 1984). There are no means of enforcing the regulations and people are not always aware of them (Eaton, 1985).

Staff None

Budget No information 
Local Addresses Ministry of Lands, Survey and Natural Resources, P O Box 5, Nuku'alofa

\section{References}

Chesher, R.H. (1984). Resource assessment report. Black coral of Tonga. SPREP, South Pacific Commission, Noumea, New Caledonia. 30 pp.

Chesher, R.H. (1990). The giant clams of Tonga: a video proposal. Unpublished. 22 pp.

Dahl, A.L. (1978). Environmental and ecological report on Tonga. Part 1 Tongatapu. South Pacific Commission, Noumea, New Caledonia. 48 pp.

Eaton, P. (1985). Land tenure and conservation in the South Pacific. South Pacific Regional Environment Programme. Topic Review 17. South Pacific Commission, Noumea, New Caledonia. $103 \mathrm{pp}$.

McKoy, J.L. (1980). Biology, exploitation and management of giant clams (Tridacnidae) in the Kingdom of Tonga. Fisheries Bulletin 1. Fisheries Division, Tonga. 61 pp.

SPREP (1989). Tonga. Paper presented at Fourth South Pacific Conference on Nature Conservation and Protected Areas, Port Vila, Vanuatu, 4-12 September. 3 pp.

Stoddart, D.R. (1975). The sand cays of Tongatapu. Atoll Research Bulletin 181.8 pp.

Tongilava, S.L. (1979). Development and management of marine parks and reserves in the Kingdom of Tonga. In: Proceedings of the Second South Pacific Conference on National Parks and Reserves, Sydney 1: 148-152.

Tongilava, S.L. (1989). The role of protected areas in sustaining society. Case study 21. Fourth South Pacific Conference on Nature Conservation and Protected Areas. Port Vila, Vanuatu, 4-12 September. $7 \mathrm{pp}$.

UNEP/IUCN (1988). Coral Reefs of the World. Volume 3. Central and Eastern Pacific. UNEP Regional Seas Directories and Bibliographies. IUCN, Gland, Switzerland and Cambridge, UK/UNEP, Nairobi, Kenya. 378 pp.

Wilkinson, W.A. (1977). Marine conservation in Tonga. Parks 2(2): 11-12.

Zann, L.P. , Kimmerer, W.J. and Brock R.E. (1984). The Ecology of Fanga'uta Lagoon, Tongatapu, Tonga. Sea Grant Cooperative Report UNIHI-SEAGRANT-CR-84-04. Institute of Marine Resources, University of the South Pacific, Suva, Fiji and International Sea Grant Program, University of Hawaii, Honolulu, Hawaii. 100 pp.

Date January 1989 
- 


\section{TUVALU}

Area $26 \mathrm{sq} . \mathrm{km}$ land area in approximately 1.3 million sq. $\mathrm{km}$ of territorial waters

Population 8,229 (1985)

Natural increase: No information

GNP No information

Policy and Legislation Prior to independence on 1 October 1978, Tuvalu was part of the Gilbert and Ellice Islands, and therefore subject to the 1938 Gilbert and Ellice Islands Colony Wild Birds Protection Ordinance and the 1975 Wildlife Protection Ordinance; the latter was not enforced.

The Fourth Development Plan 1987-1991 contains a chapter entitled Land Management, Environment and Conservation. This states that the government's general aim is to bring about improved "environmental control through better utilisation of the country's very meagre lind and environmental resources".

The Prohibited Areas Ordinance and Wildlife Ordinance (1975) provides for the establishment of wildlife reserves, although none has yet been gazetted, and the protection of seabirds (UNEP/IUCN, 1988).

The Ordinance to Provide for the Conservation of Wildlife (1975, revised 1978) lists 32 fully protected bird species and a number with partial protection. Provision is also made for the declaration of wildlife sanctuaries (Sloth, 1988). There is, however, no legislation for the protection of vegetation (Hay, 1986).

The enactment of legislation to better integrate existing laws and to provide for Environmental Impact Assessments has been recommended (ESCAP, 1988).

International Activities Tuvalu is not yet party to any of the international conventions or programmes that directly promote the conservation of natural areas, namely the Convention concerning the Protection of the World Cultural and Natural Heritage (World Heritage Convention), Unesco Man and the Biosphere Programme and the Convention on Wetlands of International Importance especially as Waterfowl Habitat (Ramsar Convention).

The Convention on the Conservation of Nature in the South Pacific (1976) has been neither signed nor ratified. Known as the Apia Convention, it entered into force during 1990. The Convention is coordinated by the South Pacific Commission and represents the first attempt within the region to cooperate on environmental matters. Among other measures, it encourages the creation of protected areas to preserve indigenous flora and fauna.

Although Tonga is party to the South Pacific Regional Environment Programme (SPREP), the 1986 Convention for the Protection of the Natural Resources and Environment of the South Pacific Region (SPREP Convention) has not yet been signed or ratified. The convention entered into force during August 1990. Article 14 calls upon the parties to take all appropriate measures to protect rare or fragile ecosystems and threatened or endangered flora and fauna through the establishment of protected areas and the regulation of activities likely to have an adverse effect on the species, ecosystems and biological processes being protected. However, as this provision only applies to the Convention area, which by definition is open ocean, it is most likely to assist with the establishment of marine reserves and the conservation of marine species. 
Other international and regional conventions concerning environmental protection to which Tuvalu is party are reviewed by Venkatesh et al. (1983).

\section{Administration and Management No information}

Systems Reviews Tuvalu comprises nine islands of fossil coral and other calcareous marine materials, rarely exceeding $4 \mathrm{~m}$ in elevation, with a total land area of 2,511 ha. The islands form a $570 \mathrm{~km}$ chain which describes an arc between $176^{\circ} \mathrm{E}$ and $180^{\circ} \mathrm{E}$. Funafuti, Nanumea, Nui, Nukufetau and Nukulaelae are atolls, generally with narrow strips of land on the east and reefs with scattered islets on the west. Nanumanga, Niulakita and Niutao are reef islands consisting of single islets with brackish internal lakes. Vaitupu is intermediate in type, with a large, but virtually land-locked central lagoon (Douglas, 1969; UNEP/IUCN, 1988; Zann, 1980). Most of the natural vegetation has been cleared for cultivation, especially for copra production. Rhizophora mucronata mangrove is found in the central swamp on Funafuti. Niutao is densely covered by coconut, and Nukunono supports small areas of atoll/beach forest (Douglas, 1969; Davis et al., 1986; Buckley, 1985).

Tuvalu's extreme remoteness, small land area and lack of industrial and natural resources pose special problems for development (Zann, 1980). In common with other Pacific states, budget deficits recur. The country is thus dependent upon foreign aid and remittances from expatriates (SPREP, 1981; Paxton, 1985). The major export is postage stamps, earning four times as much as copra, which is the only natural resource exported at present.

Major environmental problems are both anthropogenic and natural. The only urban area is on Funafuti and at present this is the only area where human activity is having a noticeable impact (UNEP/IUCN, 1988). Water may be contaminated by both saltwater and sewage, and in short supply during dry spells. Soils are extremely poor and difficult to manage and improve (SPREP, 1981). The impact of new fishing technology, for example outboard motors, is not yet noticeable, but new management controls and fisheries extension work may be needed (UNEP/IUCN, 1988). There is great concern about the erosion of land areas, but these changes may be natural events and beyond the control of any reasonable coastal engineering projects. Efforts are being made to control coastal erosion with gabion sea wall construction on almost all islands, but there is little understanding of the currents and coastal processes involved (Baines, 1982).

Some of these concerns are reflected in a recent SPREP/ESCAP review of environmental legislation and issues in Tuvalu (ESCAP, 1988). The major environmental issues were identified as coastal erosion; detrimental impacts of land reclamation activities; degradation of fisheries resources; inefficient land use practices; pollution, mainly caused by the absence of a sewerage system and lack of proper garbage disposal sites; and uncontrolled exploitation of flora and fauna, particularly of turtles and coconut crabs. Increased mean sea level, due to global climatic warming, may pose the most serious threat. In the event of severe sea level rises, the loss of freshwater resources, erosion and increased episodic destruction through hurricanes may force the evacuation of the country (Pernetta, 1988).

Dahl (1980) recommends the establishment of reserves for small areas of native vegetation, appropriate series of reef and lagoon environments, perhaps including Kosciusko Bank, and seabird and turtle breeding areas, if any. Dahl (1986) recommends marine protected areas to help control overfishing around Funafuti and Vaitupu. A joint Tourism Council of the South Pacific/Pacific Regional Tourism Development Programme attempted to identify sites of potential tourist interest; suggest development strategies for nature management/conservation 
programmes; advise on information for visits to nature sites; and carry out background studies for the establishment of training programmes under nature conservation legislation (Sloth, 1988).

The recent ESCAP (1988) review recommends the establishment of coordinating mechanisms between those government departments principally charged with responsibility for environmental issues to ensure more effective resource management. The extent to which these recommendations have been implemented is not known.

\section{Addresses}

Ministry of Commerce and Natural Resources, Vaiku, Funafuti

\section{References}

Baines, G.B.K. (1982). Pacific islands: development of coastal marine resources of selected islands. In: Soysa, C., Chia, L.S. and Coulter, W. L. (Eds), Man, land and sea: coastal resource use and management in Asia and the Pacific. The Agricultural Development Council, Bangkok, Thailand. Pp 189-198.

Buckley, R. (1985). Environmental survey of Funafuti Atoll. Proceedings of the Fifth International Coral Reef Congress, Tahiti 6: 305-310

Dahl, A.L. (1980). Regional ecosystem survey of the South Pacific Area. SPC/IUCN Technical Paper 179. South Pacific Commission, Noumea, New Caledonia. 99 pp.

Dahl, A.L. (1986). Review of the Protected Areas System in Oceania. IUCN, Gland, Switzerland and Cambridge, UK/UNEP, Nairobi, Kenya. 328 pp.

Davis, S.D., Droop, S.J.M., Gregerson, P., Henson, L., Leon, C.J., Lamlein Villa-Lobos, J., Synge, H. and Zantovska, J. (1986). Plants in Danger: What do we know? IUCN, Gland, Switzerland and Cambridge, UK. 488 pp.

Douglas, G. (1969). Draft checklist of Pacific Oceanic Islands. Micronesica 5(2): 327-463.

ESCAP (1988). ESCAP environment mission to Tuvalu, 1988. (Unseen)

Hay, R. (1986). Bird conservation in the Pacific. ICBP Study Report No. 7. International Council for Bird Preservation, Cambridge, UK. 102 pp.

Paxton, J. (Ed.). (1989). The Statesman's Yearbook 1989-90. Macmillan Press, London. $1691 \mathrm{pp}$.

Pernetta, J.C. (1988). Projected climate change and sea level rise: a relative impact rating for countries of the South Pacific Basin. In: MEDU joint meeting of the task team on the implications of climatic change in the Mediterranean. Split, Yugoslavia, 3-7 October. Pp. 1-11.

Sloth, B. (1988). Nature legislation and nature conservation as part of tourism development in the Island Pacific. Pacific Regional Tourism Development Programme. Tourism Council of the South Pacific, Suva, Fiji. 82 pp.

SPREP (1981). Tuvalu. Country Report No. 18. South Pacific Commission, Noumea, New Caledonia. 13 pp.

UNEP/IUCN (1988). Coral Reefs of the World. Volume 3: Central and Western Pacific. UNEP Regional Seas Directories and Bibliographies. IUCN, Gland, Switzerland and Cambridge, UK/UNEP, Nairobi, Kenya. 378 pp.

Venkatesh, S., Va'ai, S. and Pulea, M. (1983). An overview of environmental protection legislation in the South Pacific countries. SPREP Topic Review 13. South Pacific Commission, Noumea, New Caledonia. 63 pp. 
Zann, L.P. (1980). Tuvalu's subsistence fisheries. Effects of energy crisis on small craft and fisheries in the South Pacific. Report 4. Institute of Marine Resources, University of the South Pacific, Suva, Fiji.

\begin{abstract}
ANNEX
Definitions of protected area designations, as legislated, together with authorities responsible for their administration
\end{abstract}

\title{
Title: The Prohibited Areas Ordinance and Wildlife Ordinance
}

Date: 1975

Brief description: Provides for the establishment of wildlife reserves, although none has yet been gazetted, and the protection of seabirds.

Administrative authority: No information

Designation: No information

Title: Ordinance to Provide for the Conservation of Wildlife

Date: 1975, revised 1978

Brief description: Lists 32 fully protected bird species and a number with partial protection. Provision is also made for the declaration of wildlife sanctuaries

Administrative authority: No information

Designation: No information 


\section{USA - AMERICAN SAMOA}

Area 202 sq. $\mathrm{km}$

Population 36,000 (NPS and ASG, 1988)

Natural increase: No information

GNP No information

Policy and Legislation American Samoa is a semi-autonomous, unincorporated Territory of the United States in which most, but not all, of the Articles of the US Constitution apply. A constitution was adopted in 1960 under which the legislature, executive and judicial branches of government are created. The traditional form of government, the matai system, primarily comprises the high chiefs. In matters concerning the use of land the traditional system plays a pivotal role and decisions regarding land are still controlled by the matai (NPS and ASG, 1988).

Communal tenure exists in American Samoa, with rights to use resources being held in common. The land tenure system is derived from the structure of the family organisation, usually referred to as the matai system. The most important social unit is the "aiga", a large extended family headed by a matai, or chief, who holds the traditional title of that family. Each village has matai titles and land rights belong to the aiga in perpetuity. Land may be passed from one member of the aiga to another, or to another family when a new matai is created. Under American Samoa law, a matai is prohibited from selling, giving, exchanging or in any way disposing of communal lands to a non-Samoan without the written permission of the Governor. While the American Samoan constitution protects Samoans against alienation of their land, communal land may be conveyed or transferred for public purposes to the US government or the government of American Samoa, although this has never been done on a sufficient scale to establish a protected area.

The various protected areas in the country have been established under a diversity of legal acts. Some United States Federal legislation applies, including the 1972 Marine Protection, Research and Sanctuaries Act (P.L. 92-532; 16 USC 1431-1434), which authorises the Secretary of Commerce, with Presidential approval, to designate ocean water as marine sanctuaries for the purpose of preserving or restoring conservation, recreational, ecological or aesthetic values. Such marine sanctuaries are built around existing, distinctive resources where protection and beneficial use require comprehensive planning and management. A site can be nominated by a private party, a state or a state agency. Once a site has been nominated a public hearing must be held in the area most directly affected (Weiting et al., 1975). Fagatele Bay National Marine Sanctuary was established under the provisions of this Act.

Rose Atoll is established under provisions of the National Wildlife Refuge System Administration Act 1966. The basic statutory protection for wildlife refuges prohibits entry, disturbance or exploitation of the site, although there are provisions for exceptions to be made.

A number of national natural landmarks have been designated. The objective of the National Natural Landmark Program, administratively created and not defined in any legislation, is to assist in the preservation of sites illustrating the geological and ecological character of the United States, to enhance the educational and scientific value of sites thus preserved, to strengthen cultural appreciation of natural history, and to foster a wider interest and concern in the nation's natural heritage (NPS, 1977). 
American Samoa National Park has been authorised as a national park by the US Congress, under the provisions of federal legislation.

There is an American Samoa Parks and Recreation Act (1980), with provision for the establishment of natural preserves, conservation preserves and territorial parks, although none has been established.

International Activities American Samoa is not yet directly party to any of the international conventions or programmes that promote the conservation of natural areas, namely the Convention concerning the Protection of the World Cultural and Natural Heritage (World Heritage Convention), Unesco Man and the Biosphere Programme and the Convention on Wetlands of International Importance especially as Waterfowl Habitat (Ramsar Convention). The United States is an active participant in all three conventions although it is not known if this involves American Samoa in any way.

The Convention on the Conservation of Nature in the South Pacific (1976) has been neither signed nor ratified by either the United States or American Samoa. Known as the Apia Convention, it entered into force during 1990. The Convention is coordinated by the South Pacific Commission and represents the first attempt within the region to cooperate on environmental matters. Among other measures, it encourages the creation of protected areas to preserve indigenous flora and fauna.

The United States is party to the South Pacific Regional Environment Programme (SPREP), and the 1986 Convention for the Protection of the Natural Resources and Environment of the South Pacific Region (SPREP Convention) has been signed (25 November 1986) but not ratified. The Convention entered into force during August 1990. Article 14 calls upon the parties to take all appropriate measures to protect rare or fragile ecosystems and threatened or endangered flora and fauna through the establishment of protected areas and the regulation of activities likely to have an adverse effect on the species, ecosystems and biological processes being protected. However, as this provision only applies to the Convention area, which by definition is open ocean, it is most likely to assist with the establishment of marine reserves and the conservation of marine species.

Administration and Management Administration of protected areas falls into two categories: those that are the responsibility of the territorial government and those that are mandated under federal legislation. The American Samoa Department of Parks and Recreation is principally concerned with development of recreation, and to date most of the areas designated under the Parks and Recreation Act are for recreational purposes. Fagatele Bay is administered and funded by the National Oceanic and Atmospheric Administration (NOAA); it is locally administered by the Economic and Developrnent Planning Office. Rose Atoll is administered by the US Fish and Wildlife Service and the American Samoa Department of Marine Resources. American Samoa National Park is the responsibility of the National Park Service. The national natural landmarks are part of a programme within the National Park Service, although the precise status of each site is not known.

In 1975 an American Samoa Recreation Area Development Plan was issued which provided for recreation facilities and also identified national historic landmarks and national natural landmarks.

Le Vaomatua ("tropical rain forest" in the Samoan language) is an active non-governmental organisation established in 1985 by local residents concerned with protecting forests, reefs and marshes. Recent successful activities have included advocacy for the establishment of American 
Samoa National Park and cancellation of the dredging and construction of a harbour in Leone Bay.

Systems Reviews American Samoa comprises five volcanic islands and two coral atolls, and is the only United States territory south of the Equator. Principal vegetation types include lowland tropical evergreen rain forest up to $300 \mathrm{~m}$ altitude and montane forest at $300-700 \mathrm{~m}$. Cloud forest is found only on Tau and Olosega at $500-930 \mathrm{~m}$ and small areas of montane scrub occur on Tutuila. Mangroves, and coastal swamps, largely consisting of sedges and ferns, are found near the coast, but have been drastically reduced in coverage, being felled for housing and other uses. About two-thirds of the native vegetation has been disturbed or cleared for settlements or agriculture and, for example, littoral forest has been almost entirely eliminated from sandy coastal areas. Most of the interior of Tutuila, the main island, is covered by a patchwork of secondary forest mixed with primary or primary-like forest on the steeper, more inaccessible slopes. Most of the remaining primary forest on Tutuila is on the central portion of the north coast (Amerson et al., 1982).

Although much of the forested interior remains inaccessible due to the steep terrain, an increasing proportion of marginal areas is being cleared. Furthermore, an estimated $1 \%$ of rain forest cover is lost annually to plantation cover. One of the consequences of this vegetation clearance has been the increase in erosion, flooding and silting of coastal areas.

Coral reefs, which occur extensively throughout the country, are described in UNEP/IUCN (1988). Tutuila and Manu'a both have fringing reefs rarely more than $50-100 \mathrm{~m}$ in width which are particularly vulnerable to sedimentation and the effect of run-off carrying agricultural fertiliser, herbicides and pesticides, and animal wastes particularly from piggeries.

An Action Strategy for Protected Areas in the South Pacific Region (SPREP, 1985b) has been prepared. The principal goals of the strategy cover conservation education, conservation policy development, establishment of protected areas, effective protected area management and regional and international cooperation. Priority recommendations for American Samoa are as follows: implement recommendations regarding new areas for reservation and taking fish; possible reservation of reef area of Ofa; possible reservation of forest on Mount Lata; and implementation of a management programme at the Fagatele Bay National Marine Sanctuary. In response to both the general and specific recommendations of the Action Plan, fruit bat surveys have been undertaken by the US-Fish and Wildlife Service. A recent feasibility study (NPS and ASG, 1988) identified remaining areas critical for protection, leading to the establishment of American Samoa National Park. Management activities have been initiated in Fagatele Bay National Marine Sanctuary.

Dahl (1980) identifies a number of habitat types that were excluded from the protected areas system prior to the establishment of American Samoa National Park, and provides a list of potential reserves to remedy these omissions. In a 1986 review, Dahl (1986) states that there is an urgent need for protected areas on Tau, Tutuila and Ofu. However, the new national park has included coral reefs, beaches, coastal, lowland, montane and cloud forest and so probably includes most ecosystems in the country.

The Territorial Comprehensive Outdoor Recreation Plan 1980-85, and the American Samoa Coastal Management Plan (ASCMP) set out a comprehensive system of parks, forest and nature reserves (SPREP, 1980). The ASCMP, which is funded under the National and Oceanic and Atmospheric Administration and operates out of the Economic Development Planning Office, has undertaken some conservation activities. The programme has jurisdiction over all land areas 
and to the limit of territorial seas. The ASCMP has also initiated a land use permitting system, known as the Project Notification and Review System (PNRS). The PNRS provides for land-use reviews for any planned construction, which include environmental considerations. The ASCMP annually sponsors a three-week coastal awareness programme, highlighting coastal and marine conservation issues.

\section{Addresses}

Department of Parks and Recreation, US Department of the Interior, PO Box 3809, Pago Pago 96799

National Oceanic and Atmospheric Adminstration, 3300 Whitehaven NW, Washington DC 20235

National Park Service, Pacific Area Office, 300 Ala Moana Blvd., Box 50165, Room 6305, Honolulu, HI 96850

\section{References}

Amerson, A.B., Whistler, W.A. and Schwaner, T.D. (1982). Wildlife and wildlife habitat of American Samoa: Environment and ecology. US Fish and Wildlife Service, Washington, DC. 119 pp.

Dahl, A.L. (1980). Regional ecosystem surveys of the South Pacific Area. SPCIIUCNTechnical Paper 179. South Pacific Commission, Noumea, New Caledonia. 99 pp.

Dahl, A.L. (1986). Review of the Protected Areas System in Oceania. IUCN, Gland, Switzerland and Cambridge UK/UNEP, Nairobi, Kenya. 328 pp.

Davis, S.D., Droop, S.J.M., Gregerson, P., Henson, L., Leon, C.J., Lamlein Villa-Lobos, J., Synge, H. and Zantovska, J. (1986). Plants in Danger: What do we know? IUCN, Gland, Switzerland and Cambridge, UK. 488 pp.

Eaton, P. (1985). Land Tenure and Conservation: Protected Areas in the South Pacific. Report to the South Pacific Commission.

Fai' ai, P and Daschbach, N. (1989). American Samoa. Country Review 3. Fourth South Pacific Conference on Nature Conservation and Protected Areas, Port Vila, Vanuatu, 4-12 September. $10 \mathrm{pp}$.

Government of American Samoa (1975). American Samoa recreation area development plan: 1975-1980. American Samoa Park and Recreation Board, Pago Pago. 52 pp.

National Park Service and American Samoa Government (1988). National Park feasibility study. Draft 01/88. National Park Service and American Samoa Government. 139 pp.

SPREP (1980). American Samoa. Country Report 1. South Pacific Commission, Noumea.

UNEP/IUCN (1988). Coral Reefs of the World. Volume 3. Central and Western Pacific. UNEP Regional Seas Directories and Bibliographies. IUCN, Gland, Switzerland and Cambridge, UK/UNEP, Nairobi, Kenya. 378 pp.

US Department of Commerce (1984). Final environmental impact statement and management plan for the proposed Fagatele Bay National Marine Sanctuary. Sanctuary Programme Division of the Office of Ocean and Coastal Resource Management, National Oceanic and Atmospheric Administration, US Department of Commerce, Washington DC.

Weiting, H., Lukowski, S., Buckingham, N., Schamis, M and Humke, J. (1975). Preserving our natural heritage. Volume 1. Federal activities. The Nature Conservancy and US Man and the Biosphere Program. 323 pp. 


\section{ANNEX \\ Definitions of protected area designations, as legislated, together with authorities responsible for their administration}

\section{Title: Parks and Recreation Act}

Date: 1980

Brief description: There is created the American Samoa parks system. The department shall inventory all properties belonging to the government and with the Governor's approval determine which properties are included in the park system. The department keeps a list of all areas in the park system according to the classification (see "designations"), with correct and accurate descriptions, and provide the Legislature with a current copy of the list (18.0204).

Administrative authority: Department of Parks and Recreation

Designation:

Natural preserves which are to remain unimproved;

Conservation preserves which may be improved for the purpose of making them accessible to the public in a manner consistent with the preservation of their natural features;

Territorial park or community parks which may be improved for the purpose of providing public recreational facilities in a manner consistent with the preservation and enhancement of the natural features;

Territorial recreation facilities or community recreation facilities which may be improved for the purpose of providing public recreation facilities;

Historical and prehistoric objects and sites which are administered in accordance with federal guidelines as set by the Department of the Interior;

Seashore reserves which include underwater land and water areas of the Territory of American Samoa extending from the mean high water line seaward to 10 fathoms is included within the park system and administered by the Director in accordance with 18.0204. 
SUMMARY OF PROTECTED AREAS

\begin{tabular}{llcrc}
\hline $\begin{array}{l}\text { Map } \\
\text { ref. }\end{array}$ & Name of area & $\begin{array}{c}\text { IUCN management } \\
\text { category }\end{array}$ & $\begin{array}{c}\text { Area } \\
\text { (ha) }\end{array}$ & $\begin{array}{c}\text { Year } \\
\text { notified }\end{array}$ \\
\hline & $\begin{array}{l}\text { National Parks } \\
\text { American Samoa National Park* }\end{array}$ & II & 3,725 & 1988 \\
& National Wildlife Refuges & & & \\
2 & Rose Atoll* & I & 653 & 1973 \\
& National Marine Sanctuaries & & & \\
3 & Fagatele Bay* & IV & 64 & 1985 \\
& National Natural Landmarks & & & \\
4 & Anunu'u Island & Unassigned & 123 & 1972 \\
5 & Cape Taputapu & Unassigned & 69 & 1972 \\
6 & Fogama'a Crater & Unassigned & 196 & 1972 \\
7 & Leala Shoreline & Unassigned & 14 & 1972 \\
8 & Matafao Peak & Unassigned & 71 & 1972 \\
9 & Rainmaker Mountain (Mt. Pioa) & Unassigned & 69 & 1972 \\
10 & Vaiava Strait & Unassigned & 142 & 1972 \\
& Archaeological Park & & & \\
11 & American Samoa Archaeological Park & Unassigned & 1 & \\
\hline
\end{tabular}

* Site is described in this directory.

${ }^{+}$Locations of most protected areas are shown in the accompanying map. 


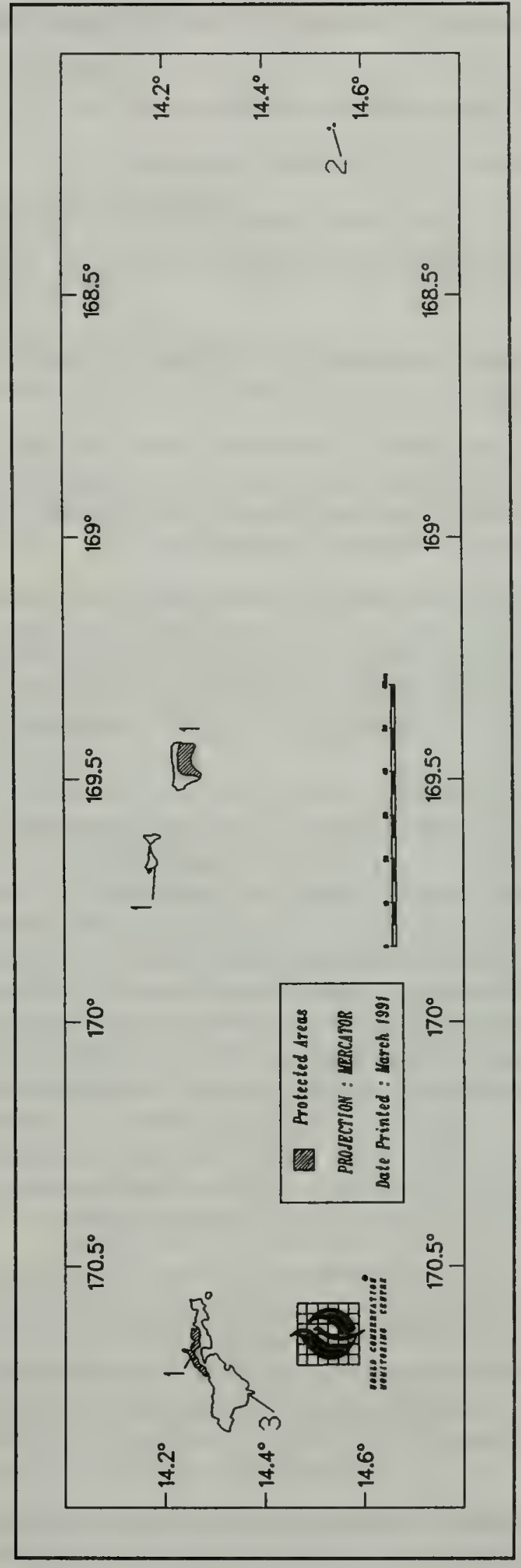

Protected Areas of American Samoa 


\title{
AMERICAN SAMOA NATIONAL PARK
}

\author{
IUCN Management Category II (National Park)
}

Biogeographical Province 5.05.13 (Central Polynesian)

Geographical Location Three units on separate islands, Tutuila, Ta'u and Ofu

Date and History of Establishment Authorised as a national park by the US Congress in October 1988.

Area Ta' $u$ Unit is 2,100ha, Tutuila Unit is 1,200ha and Ofu Unit is 30 ha. About an additional 395ha are ocean.

Land Tenure Waters are territory of American Samoa. Lands are owned by eight separate traditional villages. Currently lease negotiations are underway involving the US Department of the Interior, the High Court of American Samoa, the Governor, and the eight villages to negotiate long-term leases of the lands for national park purposes.

Altitude From below sea level to $966 \mathrm{~m}$ at the summit of Lata Mountain

Physical Features The sea cliffs along the south coast of Ta'u are spectacular. The shoreline along the north coast is highly scenic, containing sheer cliffs, knife-like ridges, and sheltered coves. The Ofu unit has the nicest beach and coral reef in American Samoa.

Climate No specific information

Vegetation The 2,100ha unit on the island of Ta' $u$ is the largest and is mostly undisturbed native rain forest. The rain forest on Ta'u includes coastal, lowland, montane, and cloud forest communities, the latter being the largest such community in American Samoa. At lower elevations littoral forests include fine examples of both Pandanus and Barringtonia subcommunities. Rain forest communities include predominantly Dysoxylum huntii, Syzygium samoense, Calophyllum samoense, Canarium samoense, Canthium merrillii, Planchonella torricellensis, Dysoxylum samoense, and Myristica fatua. Ridge forest communities have dominantly Dysosylum huntii, Myristica hypargyaea, Canarium samoense, Crossostylis biflora, Diospyros samoensis, Planchonella linggenensis, Calophyllum samoense, and Syzygium inophylloides. On Mt Lata the dominant cloud forest plants are S. samoense, Weinmannia affinis, Astronidium pickeringii, Dysoxylum huntii, Fagraea berteriana, S. samarangense and Reynoldsia lanutoensis. The Tutuila unit contains a major expanse of undisturbed native rain forest. The forest here is composed of coastal, lowland, montane, and ridge communities.

Fauna Two flying foxes, Pteropus samoensis (E) and $P$. tonganus (I) are the most conspicuous vertebrates. Perhaps these, as fruit-eating pollinators, affect the composition of the Samoan forests. Birds are less conspicuous, but the park includes an excellent sample of almost the entire native avifauna and the park contains the most significant seabird nesting site on Tutuila. Wattled honey-eater Foulehaio carunculata, cardinal honey-eater Myzomela cardinalis, Samoan and Polynesian starlings Aplonis atrifusca and A. tabuensis, and fruit doves of genus Ptilinopus are common.

Local Human Population The areas within the park boundaries are unpopulated. Nearby villages are native Samoan. 
Visitors and Visitor Facilities Adjacent communities and villages offer accommodation.

Scientific Research and Facilities The Cooperative National Park Resources Studies Unit (CPSU) at the University of Hawaii is conducting both botanical and archaeological research. This research is continuing.

Conservation Management No information

Management Constraints The introduced, noxious weed Koster's curse Clidemi hirta has recently invaded Ta'u Cloud Forest.

Staff At present a project manager is the only staff.

Budget US $\$ 85,000$ is the base budget (1991), and science research budget is about US $\$ 15,000$ (1991)

Local Addresses The project manager lives and works on site.

\section{References}

Amerson, A.B., Jr., Whistler, W.A. and Schwaner, T.D. (1982). Wildlife and wildlife habitat of American Samoa. 2 Vols. US Fish and Wildlife Service, Washington DC.

Coastal Zone Management (1981). Atlas of American Samoa. Development Planning Office, American Samoan Government and University of Hawaii, Honolulu.

Cole, T. (1987). Vegetation Maps of Tutuila, Ofu, Olosega, and Tau. Institute of Pacific Islands Forestry, US Forest Service, Honolulu.

Engbring, J. (1986). Observations of fruit bats in Samoa, with emphasis on the status of the Samoan fruit bat (Pteropus samoensis). Unpublished. US Fish and Wildlife Service, Honolulu.

Engbring, J. (1986). Samoa forest bird survey data. Unpublished. US Fish and Wildlife Service, Honolulu.

Frost, J.O. (1976). Summary Report of Archaeological Investigations on Tutuila Island, American Samoa. New Zealand Archaeological Association Newsletter 19: 30-37.

National Park Service and the American Samoa Government (1988). National park feasibility study, American Samoa. Pacific Area Office, National Park Service, Honolulu. 138 pp.

Whistler, W.A. (1980). The Vegetation of Eastern Samoa. Allertonia, Pacific Tropical Botanical Garden, Kauai, Hawaii.

Date February 1991

\section{FAGATELE BAY NATIONAL MARINE SANCTUARY}

IUCN Management Category IV (Managed Nature Reserve)

Biogeographical Province 5.05.13 (Central Polynesian)

Geographical Location Situated on the south-western shore of Tutuila, about $12 \mathrm{~km}$ south-west of Pago Pago Harbour, the principal township on Tutuila. Access is via the road from Futiga village to the lighthouse on Steps Point at the southern extremity of the Bay. The nearest village 
is Taputimu to the north-west, but there is no track leading to the bay. The northern boundary is defined by the cliff face and by a notional line across the mouth of the bay to the south. Approximately $14^{\circ} 23^{\prime} \mathrm{S}, 170^{\circ} 46^{\prime} \mathrm{W}$

Date and History of Establishment Jointly signed into law by the Governor of the Territory of American Samoa and the Deputy Administrator of the National Oceanic and Atmospheric Administration. Fagatele Bay was designated a marine park on 13 October 1982 by the Department of Parks and Recreation, to be included in the American Samoa park system. Protection was enhanced by the designation of the area as a national marine sanctuary under the provisions of Title III of the 1972 Marine Protection, Research and Sanctuaries Act. Regulations came into force on 31 July 1986, although some authorities state that the date of establishment as a national marine sanctuary was 11 August 1986.

\section{Area 66 ha}

\section{Land Tenure American Samoan government}

\section{Altitude From the mean high water mark to approximately $100 \mathrm{~m}$ depth}

Physical Features The bay was formed in recent geological history when the seaward side of a volcanic crater of Pliocene/early Pleistocene origin was breached and flooded by sea water. The bay is defined by steep cliffs of lithic/vitric volcanic tuff derived from the Vailoatai, Fagatele and Fogama craters. Seumalo Ridge, rising to over $120 \mathrm{~m}$, flanks the western and northern sides of the bay, while the eastern side is bounded by Matautuloa Ridge (up to $60 \mathrm{~m}$ ), culminating in the rocky Steps Point, the southern limit. Soils on these steep slopes are silty clay loams derived from basic tuff and basaltic ash. The nature of the landscape makes the bay inaccessible from the landward side; access is via a dirt trail along Matautuloa Ridge, leading down to the beach at the base of the cliffs. The beach of calcareous sand, mixed with a small proportion of volcanic sand, extends some $10 \mathrm{~m}$ from the shore until it merges with the fringing reef platform of consolidated limestone and encrusting coralline algae. The platform fringes the interior bay shore to varying widths, being widest along the eastern shore. At its limit the reef front drops almost vertically to depths of $1.5 \mathrm{~m}$ to $3 \mathrm{~m}$, subsequently sloping more gradually to depths of $5 \mathrm{~m}$ to $6 \mathrm{~m}$, some $90 \mathrm{~m}$ offshore. Nearly vertical basalt cliffs and faces extend from the surface to as deep as $80 \mathrm{~m}$ along the exposed outer portions of the bay which are characterised by strong currents and surge in the upper portions. There are no permanent streams discharging into the bay and salinity, turbidity and nutrient levels remain constant. Sea water temperatures range between $27^{\circ} \mathrm{C}$ and $28^{\circ} \mathrm{C}$ with little seasonal or diurnal variation; salinity ranges from $35.5 \mathrm{ppt} \mathrm{to} 36 \mathrm{ppt}$. Wave action, normally from the east, is dampened by the encircling reef platform and because the bay faces south-west. Tides are probably similar to Pago Pago Bay where they are diurnal with mean and spring ranges of $0.76 \mathrm{~m}$ and $0.95 \mathrm{~m}$, respectively (USDC, 1984).

Climate American Samoa has a warm, humid tropical climate with a mean annual rainfall of $5080 \mathrm{~mm}$, mainly from December to March, and an annual temperature range of $21^{\circ} \mathrm{C}-32^{\circ} \mathrm{C}$. The islands are exposed to the south-east trade winds, strongest during winter (June to August). They also lie in the southern hurricane belt with hurricane force winds $(240 \mathrm{~km} / \mathrm{hr})$ hitting the islands once every five years or so; Fagatele Bay, however, is protected from the full force of these.

Vegetation The bay is rimmed by undisturbed tropical wet forest surviving on the steep ridges. The sanctuary, however, only extends up to the high water mark and does not include the cliff tops. 
Fauna There is a large flying fox colony of some 2,000 or more individuals, principally comprising Pteropus tonganus (I), on the Seumalo Ridge (N. Daschbach, pers. comm., 1989), although this is not strictly part of the sanctuary. The bay and adjacent waters are important to a group of hump-back whales Megapter a novaeangliae (V), members of the Southern Hemisphere breeding population. The occasional sperm whale Physeter catodon has been sighted offshore, as have Pacific bottlenose dolphin Tursiops truncata and spinner dolphin Stenella sp. Around the bay, the abundant avifauna (both sea and shore birds) use the shore, cliffs and forests for nesting and/or feeding. The 19 bird species recorded in the vicinity of Fagatele Bay include brown booby Sula leucogaster, red-footed booby S. sula, grey-backed tern Sterna lunata, black noddy Anous tenuirostris, brown noddy $A$. stolidus, blue-grey noddy Procelsterna cerulea, great frigate bird Fregata minor, white tern Gygis alba, white-tailed tropic bird $P$ haethon lepturus and turnstone Arenaria interpres. Five species of marine turtle are known to frequent the waters in and around Fagatele Bay, namely green turtle Chelonia mydas (E), hawksbill turtle Eretmochelys imbricata (E), loggerhead Caretta caretta (V), olive Ridley Lepidochelys olivacea (E) and leatherback Dermochelys coriacea $(\mathrm{E})$. The sheltered bay and its associated coral reefs provide valuable habitats for the abundant, species-rich fish fauna. A survey in 1978 (Wass, 1978) recorded 86 species from the Fagatele Bay reef and 114 from the reef platform. Consistently abundant species include damselfish Stegastes albofasciatus, Glyphidodontops cyanea, and G. leucopomus, surgeonfish Acanthurus nigrofuscus and wrass Thalassoma hardwickei. Other conspicuous species include the surgeonfishes Ctenochaetus striatus, Acanthurus lineatus, and A. triostegus, butterflyfish Chaetodon reticulatus, damselfish Glyphidodontops glaucus, adult and juvenile parrotfish Scarus sp., and anemonefish Amphiprion melanopus. Damselfish Plectroglyphidodon dickii and Chromis acares were particularly abundant at the south-eastern tip of the bay. The most conspicuous coral species found along the eastern reef platform are Pocillopora verrucosa, Favia sp., Galaxea sp., Goniastrea sp., Acropora humilis, Porites lutea and the soft coral Palythoa sp.; predominant algae include Cheilosporum sp., Bryopsis sp. and Halimeda sp. In all, some 172 species of coral have been identified from the area. The Draft Environmental Impact Statement (1983) provides checklists of fish and coral species collected from Fagatele Bay (USDC, 1984).

\section{Cultural Heritage No information}

Local Human Population Old maps indicate two villages, Fagale'a and Fagatele, located along the margins of Fagatele Bay, which have since been abandoned. Today, primary use of the bay includes sport and subsistence fishing by villagers who live above the bay. Land access is controlled by these villagers via their traditional land tenure system. Gleaning, principally of shellfish, such as giant clam Tridacna sp. and algae Dictyota sp., Laurencia sp. and Ulva sp. from the nearshore reef areas, and pole and line fishing, are the major subsistence activities, while rod and reel fishing are the dominant sportfishing activities. The most common species caught include butterfly fish Chaetodon spp., surgeonfish Acanthurus spp., goatfish Parapeneus and snappers Lutjanus. In 1988 less than 20 people were regularly involved in these activities (Thomas, 1988).

Visitors and Visitor Facilities None at present; the management plan recommends improved access, provision of mooring buoys and the development of an interpretative centre as necessary measures to encourage tourism. It is anticipated that most visitors will come by boat from Leone, which would give the park authority greater control (Eaton, 1985).

Scientific Research and Facilities The marine biota was extensively surveyed in 1978 by a team from Aquatic Farms and AECOS. The crown-of-thorns starfish Acanthaster planci 
population has been studied during the devastating population explosion in 1978 (Marine Environmental Research Inc., 1978).

The Sanctuary Program of NOAA has funded a long-term resource survey of the bay to track the recovery of the coral population from the crown-of-thorns starfish outbreak. In addition, fish populations are surveyed and an invertebrate study has also been carried out. Developed by the University of Guam, under contract to the National Oceanic and Atmospheric Administration and the Development Planning and Tourism Office, the survey is conducted every three years (Fai' ai and Daschbach, 1989). A study to gather baseline population data was completed in 1985 (Birkeland et al., in press) and the reefs were due to be re-surveyed in 1988 (UNEP/IUCN, 1988). Research on coral re-colonisation and changes in the composition and structure of inshore fish communities is underway. The management plan includes a detailed research programme under the coordination of a Fagatele Bay Research Committee. There are no facilities at present; the management plan recommends improved access and the provision of a boat for research teams. Future research requirements are described in USDC (1984), and range from broad surveys to monitoring of crown of thorns starfish.

Conservation Value The pristine nature of the bay provides ideal conditions for the study of coral regeneration following crown-of-thorns starfish predation. The sanctuary has a number of invertebrates which serve as important subsistence food sources. Subsistence fishing and recreational activities are both important in the area (USDC, 1984).

Conservation Management Protected under the provisions of Title III of the Marine Protection, Research and Sanctuaries Act, 1972, regulations prohibit activities which threaten the bay's resources, such as dredging and the discharge of pollutants; traditional uses, such as fishing and recreation, are permitted. Detailed management measures are presented in the final environmental impact statement (USDC, 1984), although many of the proposals have subsequently been superseded and may no longer apply. Major aims are to protect Fagatele Bay; expand public awareness; expand scientific understanding of marine ecosystems; allow uses of the sanctuary that are compatible with the first three aims; and to give highest priority to subsistence and public recreational uses. The area is divided into two zones: an outer zone in which subsistence fishing is permitted, and an inner core zone which is a strict nature reserve. The Sanctuary Programs Division of NOAA is responsible for overall administration and programme implementation.

An education programme was scheduled for implementation from 1988. Stage I of the programme (1988 and 1989) will focus on identifying the sanctuary to the public and disseminating that information through the development of a marine science curriculum in local schools, public extension programmes and touring exhibitions. Stage II (1990-1993) will expand on Stage I to include areas outside the sanctuary, emphasising the cultural and historical aspects of the bay and similar areas throughout the Pacific (Thomas, 1988).

Management Constraints Human impact on the bay has been minimal due to its inaccessibility. Increasing visitor pressure could have an adverse impact on the reefs if not regulated. In late 1978 and early 1979 a population explosion of crown-of-thorns starfish devastated the coral reefs around Tutuila, including $90 \%$ of those found in Fagatele Bay. Recent surveys indicate that the coral cover is recovering (Fai'ai and Daschbach, 1989). In general, human impact has been minimal, and the bay is considered one of the least disturbed areas on Tutuila, although dynamite fishing has occurred in recent years. 
Staff A coordinator (manager) was appointed in 1988, and the sanctuary programme was due to appoint a ranger during 1990 (N. Daschbach, pers. comm., 1989).

Budget US\$ 82,500 for $1986-89$; US $\$ 90,000$ for 1990

Local Addresses Fagatele Bay National Marine Sanctuary, PO Box 4318, Pago Pago (under the co-administration of NOAA and the American Samoa Government)

\section{References}

Aquatic Farm and AECOS (1980). American Samoa coral reef inventory. US Army Corps of Engineers, Honolulu District. Prepared for Development Planning Office, American Samoa Government. (Unseen)

Fai'ai, P and Daschbach, N. (1989). Country Review 3. American Samoa. Fourth South Pacific Conference on Nature Conservation and Protected Areas, Port Vila, Vanuatu, 4-12 September. 10 pp.

National Oceanic and Atmospheric Administration (1985). Fagatele Bay (American Samoa) designated a national marine sanctuary. US Department of Commerce News. April 29, 1985.

US Department of Commerce (1984). Final environmental impact statement and management plan for the proposed Fagatele Bay National Marine Sanctuary. Sanctuary Programme Division of the Office of Ocean and Coastal Resource Management, National Oceanic and Atmospheric Administration, US Department of Commerce, Washington DC. 107 pp.

US Department of Commerce (1983). Draft environmental impact statement and management plan for the proposed Fagatele Bay National Marine Sanctuary. Sanctuary Programme Division of the Office of Ocean and Coastal Resource Management, National Oceanic and Atmospheric Administration, US Department of Commerce, Washington DC.

Marine Environment Research Inc. (1978). Observations concerning the infestation of the island of Tutuila, American Samoa, by the crown-of-thorns starfish. Preliminary report submitted to the Government of American Samoa. 4 pp. and maps. Unpublished.

Thomas, W.J. (1988). Fagatele Bay: a sanctuary in Samoa. Oceanus 31: 18-24

UNEP/IUCN (1988). Coral Reefs of the World. Volume 3. Central and Western Pacific. UNEP Regional Seas Directories and Bibliographies. IUCN, Gland, Switzerland and Cambridge, UK/UNEP, Nairobi, Kenya. 378 pp.

Wass, R.C. (1978). Fagatele Bay reef front and flat: list of species recorded along reef front on September 25, 1978 and along reef flats on February 15, 1978. Office of Marine Resources, American Samoa Government. Unpublished.

Date June 1985, reviewed October 1989

\section{ROSE ATOLL NATIONAL WILDLIFE REFUGE}

\section{IUCN Management Category IV (Managed Nature Reserve)}

\section{Biogeographical Province 5.05 .13 (Hawaiian)}

Geographical Location 241.5km east-south-east of Pago Pago Harbour, Tutuila Island, American Samoa. The boundary is defined by the extreme low waterline outside the perimeter 
of the reef except at the entrance channel, where the boundary is a line extended between the extreme low water lines on each side of the entrance channel. $14^{\circ} 32^{\prime}-14^{\circ} 34^{\prime} \mathrm{S}, 168^{\circ} 08^{\prime}-168^{\circ} 10^{\prime} \mathrm{W}$

Date and History of Establishment 5 July 1973. Originally reserved in the 1960s as an "Island for Science" under the International Biological Programme.

Area $650 \mathrm{ha}$. Rose Island is $7.29 \mathrm{ha}$ with a $1 \mathrm{~km}$ shoreline; Sand Island is $0.81 \mathrm{ha}$ with a $0.5 \mathrm{~km}$ shoreline.

\section{Land Tenure US Federal government}

Altitude Rose Island rises to $3.1 \mathrm{~m}$ above sea level and Sand Island to $5.2 \mathrm{~m}$ above sea level. The lagoon is 7-8 fathoms deep.

Physical Features Rose Atoll was formed in the late Pleistocene on a volcanic basement and consists of two low sandy islands on a coralline algae reef that nearly encloses a $2,000 \mathrm{~m}$ wide lagoon. A single channel $1.8 \mathrm{~m}$ to $15 \mathrm{~m}$ deep links the lagoon to the sea. The emerged reef remnants indicate about a $1.5 \mathrm{~m}$ drop in sea level since they were formed. The surface of Sand Island and the base part of Rose Island are apparently composed of unaltered or slightly altered limestone debris, largely algal in origin, which is considered to be a Fusi soil type. The soil within the Pisonia grove on Rose Island is quite distinct, comprising a rich humus of considerable depth in the south, overlying intermediate horizons and calcium carbonate bedrock. Other features include reef fronts, reef flats, lagoon pinnacles and sandy lagoon floors. No surface fresh water is present (Amerson et al., 1982).

Climate Information specific to Rose Atoll is not available. The general climate for the country is characterised by mean monthly temperatures of $18^{\circ} \mathrm{C}$, no winter season and abundant rainfall that exceeds annual evaporation (Amerson et al., 1982).

Vegetation Rose Island, the only vegetated island in the atoll, has the least and simplest vegetation of any island in American Samoa. The flora consists of only seven species and two plant communities, namely sand strand and littoral forest. The littoral forest is the best example of a Pisonia grandis subcommunity in American Samoa, where it forms dominant dense stands of trees up to $21 \mathrm{~m}$ high. The density averages 16.1 trees per $100 \mathrm{sq} . \mathrm{m}$ with no ground cover. A certain amount of dieback was noted in the early 1970 s but this had been reversed by 1976 . There are scattered Messerschmidia argentea trees to the north. The sand strand vegetation is dominated by Boerhavia tetrandra and Portulaca lutea. The simple floral composition may be the result of the unusually high concentrations of water-soluble salts in the soil (Amerson, 1982).

Fauna Some 97\% of the total seabird population of American Samoa is resident on Rose Atoll. Sooty tern Sterna fuscata, confined to Rose Atoll, comprises more than $85 \%$ of the entire seabird population of American Samoa. In total 20 species of birds have been recorded; 13 are native resident breeders ( 12 seabirds and one marsh bird) and 7 are migrants ( 6 shore birds and 1 land bird). The large nesting colonies of seabirds consist of great frigate Fregata minor and lesser frigate bird $F$. ariel, red-footed booby Sula sula, brown booby $S$. leucogaster and blue-faced booby $S$. dactylatra, red-tailed tropicbird Phaeton rubricauda, white tern Gygis alba, sooty tem Sterna fuscata, black-naped tern Sterna sumatrana and grey-backed tern S. lunata, and brown booby Anous stolidus and black noddy A.tenuirostris. Reef heron Egretta sacra nest in the hollowed bases of Pisonia trees (Amerson et al., 1982). Migratory shore birds include American golden plover Pluvialis dominica, bristle-thighed curlew Numenius tahitiensis (R), wandering tattler Heteroscelus incanus, ruddy turnstone Arenaria interpres and sanderling Calidris alba. White-tailed tropicbird Phaethon lepturus and long-tailed New Zealand cuckoo have also been 
recorded (US-FWS, n.d.). The only terrestrial mammal is Polynesian rat Rattus exulans, living primarily in the Pisonia forest and the Messerschmidia shrubs. Only four species of reptile are known, with two geckoes from Rose Island. Hawksbill turtle Eretmochelys imbricata (E) and green turtle Chelonia mydas (E) nest on both islands. Over 100 fish species have been recorded (Wass, n.d. a and b). The lagoon fish fauna is similar to that of the rest of the Samoan Islands, although there is a lack of damselfish species and biomass within the lagoon, and relatively few herbivorous fish. The abundance of carnivorous fish is high, possibly due to a lack of fishing pressure. The fish fauna of the reef front has a low diversity compared with other reef fronts around Tutuila. Surveys in early 1987 indicated little change in the reef fish community over the previous six or seven years (Itano, 1987). Giant clam Tridacna maxima $(\mathrm{K})$ is present throughout the shallow areas of the lagoon; in 1980 about 10\% of the population was dead (Wass, n.d. c). There is an abundant and diverse coral fauna which is briefly described in UNEP/IUCN (1988).

Cultural Heritage Rose Atoll was discovered and named by Louis de Freycint on 21 October 1819. The first recorded landing was made by the US Exploring Expedition under Commander Charles Wilkes aboard the Vincennes in October 1839 (US-FWS, n.d.).

Local Human Population There is no resident population and the atoll has never been inhabited.

Visitors and Visitor Facilities There are no facilities. The number of visitors permitted to camp on either island is regulated to a maximum of six on Rose Island and two on Sand Island. Group size is limited to a maximum of ten individuals during the day on Rose Island and six on Sand Island. Access requires a boat chartered from Pago Pago (Wass, 1989).

Scientific Research and Facilities Limited presently to annual resource surveys by US Fish and Wildlife Service and American Samoan Government personnel, and a study on giant clams to determine a management strategy. These surveys include coverage of both the outer reef and lagoon as well as of the terrestrial biota of the islands. The atoll has considerable scientific and educational value and has been visited by school teachers from the American Samoan Department of Education (UNEP/IUCN, 1988). A summary of information on Rose Atoll is given by Sachet (1954).

Conservation Value The refuge was established to preserve the native land and marine fauna and flora for scientific study, environmental education, and to protect aesthetic values (US-FWS, n.d.).

Conservation Management It is prohibited for any person to hunt any bird of any kind, or take eggs, unless specifically authorised by the Territorial Government and the refuge manager. Turtles are strictly protected, the hawksbill turtle additionally enjoying protection under the provisions of the 1973 Endangered Species Act. A public use policy statement stipulates a number of prohibited activities, as follows: all activities conducted within the refuge must be coordinated through the refuge manager and generally require the issue of a special use permit. Such permits are only issued for activities beneficial to fish and wildlife resources and the management of the refuge. Fishing is permitted within the refuge but the catch must be consumed on site or released, and not transported for personal consumption or sale. No Tridacna clams may be collected without a permit, and no waste, oil or pollutants may be dumped, spilled or pumped within the refuge. Particular care must be taken to prevent the accidental introduction of flora or fauna and camping on the beaches is prohibited during the October to November green turtle nesting season.

The atoll is managed cooperatively by the US Fish and Wildlife Service and the American Samoan Govemment (US-FWS, 1985). In 1976 staff members of the Office of Marine Resources 
of the Government of American Samoa were designated as US Fish and Wildlife Service game wardens; this action was taken to control entry to Rose Atoll. The atoll is entirely zoned as a strict natural area.

Management Constraints The atoll is very largely undisturbed except for a concrete marker and a US Fish and Wildlife Service refuge sign. Coconut Cocos nucifera were introduced in 1900 , although they have not thrived and do not pose a threat to the native flora (Amerson et al., 1982). Introduced Polynesian rat Rattus exulans feed on seeds, bird eggs and perhaps birds and their young. Their population was estimated at 200-300 in 1975-78. There is little direct evidence of rat predation on birds, their young or on hatchling turtles. Indeed, observations show that four species of shorebird are largely responsible for most egg damage (Amerson et al., 1982).

\section{Staff None}

Budget Approximately US $\$ 527,000$ for refuge complex administration, protection, natural science studies, interpretation and maintenance budgeted for fiscal year 1981.

Local Addresses Hawaiian Islands and Pacific Islands National Wildlife Refuge Complex, PO Box 50167, Honolulu, HI 96850, USA

\section{References}

Amerson, A.B., Whistler, W.A., and Schwaner, T.D. (1982). Wildlife and wildlife habitat of American Samoa. I. Environment and ecology. US Department of the Interior Fish and Wildlife Service, Washington, DC.

Anon (n.d.). Rose Atoll National Wildlife Refuge, American Samoa. US Department of the Interior, Fish and Wildlife Service. 1 pp.

Itano, D. (1987). Rose Atoll trip -1-87. Unpublished report. 7 pp.

Sachet, M.H. (1954). A summary of information on Rose Atoll. Atoll Research Bulletin 29.

UNEP/IUCN (1988). Coral Reefs of the World. Volume 3. Central and Western Pacific. UNEP Regional Seas Directories and Bibliographies. IUCN, Gland, Switzerland and Cambridge, UK/UNEP, Nairobi, Kenya. 378 pp.

US-FWS (n.d.). Rose Atoll National Wildlife Refuge: American Samoa. US Fish and Wildife Service, Honolulu, Hawaii. 1 pp.

US-FWS (1985). Hawaiian and Pacific Island National Wildlife Refuges. Brochure. US Fish and Wildlife Service, Honolulu, Hawaii. 1 pp.

Wass, R.C. (n.d. a). The fishes of Rose Atoll - supplement I. Unpublished report. 11 pp.

Wass, R.C. (n.d. b). The fishes of Rose Atoll. Unpublished report. 10 pp.

Wass, R.C. (n.d. c). The Tridacna clams of Rose Atoll. Unpublished report. (Unseen).

Date June 1985, reviewed October 1989 


\section{USA - GUAM}

Area 541 sq. km (marine area 218,000 sq. km)

Population 120,000 (1990 estimate)

Natural increase: No information

GNP US\$ 19,197 per capita (USA)

Policy and Legislation Guam's constitutional status is that of an unincorporated territory of the United States of America; military authorities control about one-third of the island.

The policy on natural resources is that areas important for recreation, and critical marine and wildlife habitats, "shall be protected through policies and programmes affecting such resources" (Anon., 1985). Areas managed by the Government of Guam are protected by the provisions of Public Law No. 12-209 as either natural preserves or as conservation reserves. Natural preserves are intended to remain unimproved, while conservation reserves may be managed for the purpose of making them accessible to the public "in a manner consistent with the perpetuation of their natural features". Multiple-use management or recreation areas (national historic parks and seashore parks) are created to protect outstanding marine life, terrestrial wildlife, oceanic resources, scenery and cultural heritage, including landscapes resulting from World War II (Anon., 1985). New protected areas of Government of Guam ownership are added by legislative or administrative action of the Department of Parks and Recreation.

The Federal Government also administers a number of ecological reserve areas (research natural areas), which were established on 13 March 1984 by the Chief of Naval Operations, United States Navy as physical or biological units in which current natural conditions are maintained. There is no direct legislative protection afforded to such areas, which are established and managed by virtue of administrative procedures of the appropriate land-holding agency. The US Air Force has also established a natural area, in 1973, and is responsible for its management. In addition, Federal Public Law No. 95-348 (1978) created War in the Pacific National Historical Park.

Other relevant legislation specific to conservation in Guam includes the Forestry and Conservation Laws, Territorial Seashore Act, as well as a number of US federal legislative acts. There are several relevant Executive Orders signed by the Governor of Guam, including one on the Protection of Wetlands (Anon., 1985) and Executive Order No 87-36, which established Anao Conservation Area.

International Activities At the international level, the United States has entered into a number of obligations and cooperative agreements related to conservation. It is party to the Convention concerning the Protection of the World Cultural and Natural Heritage (World Heritage Convention) which it accepted on 7 December 1973. The United States became a contracting party to the Convention on Wetlands of International Importance especially as Waterfowl Habitat (Ramsar Convention) on 18 December 1986, although no sites in Guam are included in the List of Wetlands of International Importance established under the terms of the Convention. The United States participates in the Unesco Man and the Biosphere Programme. To date, 46 biosphere reserves have been declared as part of the international biosphere reserve network, but none is located in Guam.

The Convention on the Conservation of Nature in the South Pacific (1976) has been neither signed nor ratified. Known as the Apia Convention, it entered into force during 1990. The 
Convention is coordinated by the South Pacific Commission and represents the first attempt within the region to cooperate on environmental matters. Among other measures, it encourages the creation of protected areas to preserve indigenous flora and fauna.

The United States is party to the South Pacific Regional Environment Programme (SPREP) and the 1986 Convention for the Protection of the Natural Resources and Environment of the South Pacific Region (SPREP Convention) has been signed (25 November 1986) but not ratified. The convention entered into force during August 1990. Article 14 calls upon the parties to take all appropriate measures to protect rare or fragile ecosystems and threatened or endangered flora and fauna through the establishment of protected areas and the regulation of activities likely to have an adverse effect on the species, ecosystems and biological processes being protected. However, as this provision only applies to the Convention area, which by definition is open ocean, it is most likely to assist with the establishment of marine reserves and the conservation of marine species.

Administration and Management The Department of Parks and Recreation is responsible for the Guam Territorial Park System, which includes three protected areas (Guam Territorial Seashore Park, Masso River Reservoir Area and Anao Conservation Area).

The development and management of Guam Territorial Seashore Park is divided among several agencies: the Department of Parks and Recreation is responsible for coordination, planning, facility maintenance, outdoor recreation, historic preservation and scenic resources; the Department of Agriculture is responsible for wildlife, marine resources, forestry, fire prevention and soil resources; the Department of Land Management is responsible for leases and land registration and the Guam Environmental Protection Agency (GEPA) is responsible for water, air pollution and solid waste disposal (Anon., 1985). The Division of Forestry and Soil Resources has responsibility for development, management and protection of forests and watershed resource lands, whilst the US National Park Service is responsible for the management and development of National Park Service areas which are federal protected lands. Federal protected areas are also administered by the US Navy and US Air Force (Anon., 1985).

Systems Reviews Guam is the westernmost territory of the United States and has the finest deep water harbour between Hawaii and the Philippines. With its strategic location and harbour, it can be expected to assume a growing importance for American military and trade activities in the western Pacific (Anon., 1986).

Guam is also the largest and southernmost island of the Marianas Archipelago in the Pacific Ocean, and has been ranked as one of the most important islands for conservation in the South Pacific (Dahl, 1986). Rain forest originally covered most of the island but much has been logged and cleared for development. The mixed forests on old volcanic soils have been completely destroyed, whilst ravine forests survive along river valleys and on some volcanic and limestone hillslopes. There are also still some small areas of mangrove (Davis et al., 1986). Extensive urban development around the island, clearance of land for tourism-related facilities and centuries of slash and bum agriculture have also been responsible for the destruction of natural vegetation cover (Maragos, 1985; Dahl, 1986). Burning of vegetation is also a major issue, particularly in the south where ensuing erosion exacerbates the problem. Guam has the highest incidence of wildfire arson in the US. Other fires are deliberately set for refuse disposal, game flushing and to stimulate grass regrowth to attract game. Public laws 18-29 and 19-34 Section 28 specifically address the problem of fires and their prevention (Anon., 1989) but enforcement is weak. 
Most coral reefs are fringing, although there are two barrier reef lagoons, namely Apra Harbour, which is now extensively modified, and Cocos Lagoon in the south-west. These, and other reefs, are discussed in more detail in UNEP/IUCN (1988). The principal threats to coral reefs are dredging and sedimentation, fertiliser run-off, thermal and other types of water pollution.

The introduced brown tree snake Boiga irregularis has been implicated in the widespread and severe decline of native bird species, a number of which are now restricted to the northern part of Guam (Arnett, 1983; Carey, 1988). Consequently, some of the most important areas for conservation are the northern cliffs and north-western plateau habitats.

The biggest threat to the environment is unregulated development, most of which is geared towards tourism and its related infrastructure. Guam is presently undergoing a heavy construction phase, almost all of which is funded by capital originating from outside the territory. There is some concern amongst those public agencies with responsibilities for environmental issues that this expansion is damaging natural resources. Permits are required for earthmoving and tree felling and mandatory mitigative measures may be imposed by the Government, but rarely enforced (SPREP, 1989). Furthermore, various "development", "master" and "management" plans have been developed for all or part of Guam, and several of these have included provision for nature conservation (SPREP, 1985a). However, none of these is followed and most are an exercise in paperwork (J.E. Miculka, pers. comm., 1990).

An action strategy for the development of protected areas in the South Pacific Region (SPREP, 1985b), developed by field managers in the region at the technical session of the Third South Pacific National Parks and Reserves Conference, provides a work programme to implement conservation and protected areas objectives. Priority recommendations for Guam are: to establish the Hilaan area as a protected area; to conduct a multimedia public education programme on the need for further protected areas; to develop tourism programmes to give emphasis to parks and protected areas; to complete a survey of proposed protected areas; and to facilitate the exchange of management and resources information, particularly with the Northern Marianas. All these measures have been initiated to some degree, although very little progress has been achieved (D. Lotz, pers. comm., 1990).

\section{Addresses}

Department of Parks and Recreation, 490 Chalan Palasyo Road, Agana Heights, Guam 96919 US National Park Service, War in the Pacific NHP, Marine Drive, Asan, PO Eox FA, Agana, Guam 96910

Guam Aquatic and Resource Wildlife Division, Fish and Wildlife Service, PO Box 23367, GAMF, Guam MI 96921

Department of the Navy, US Naval Station, FPO San Francisco 96630-100

Department of the Air Force, Headquarters 633D, Air Base Wing (PACAF), APO San Francisco 96334-5000

\section{References}

Anon. (1986). Guam Annual Economic Review, Guam Department of Commerce. (Unseen). Amett, G.R. (1983). Proposed endangered status for seven birds and two mammals from the Mariana Islands. Federal Register 48 (230): 53729-53733.

Carey, J. (1988). Massacre on Guam. National Wildlife 26(5): 13-15.

Dahl, A.L. (1986). Review of the Protected Areas System in Oceania. IUCN, Gland, Switzerland and Cambridge, UK/UNEP, Nairobi, Kenya. 328 pp. 
Davis, S.D., Droop, S.J.M., Gregerson, P., Henson, L., Leon, C.J., Lamlein Villa-Lobos, J., Synge, H. and Zantovska, J. (1986). Plants in Danger: What do we know? IUCN, Gland, Switzerland and Cambridge, UK. 488 pp.

Maragos, J.E. (1985). Coastal resources development and management in the US Pacific Islands. Report to US Congress Office of Technology Assessment. Unpublished. $130 \mathrm{pp}$.

Randall, R.H. and Holloman, J. (1974). Coastal Survey of Guam. University of Guam Marine Technical Report 14. 404 pp.

SPREP (1980). Country Report 6: Guam. South Pacific Commission, Noumea.

SPREP (1985a). Guam. In: Thomas, P.E.J. (Ed.), Report of the Third South Pacific National Parks and Reserves Conference. Volume III. Country reviews. South Pacific Commission, Noumea, New Caledonia. Pp. 93-114.

SPREP (1985b). Action strategy for protected areas in the South Pacific Region. South Pacific Commission, Noumea, New Caledonia. 24 pp.

SPREP (1989). Guam. Paper presented at the Fourth South Pacific Conference on Nature Conservation and Protected Areas, Port Vila, Vanuatu, 4-12 September. 5 pp.

UNEP/IUCN (1988). Coral Reefs of the World. Volume 3. Central and Western Pacific. UNEP Regional Seas Directories and Bibliographies. IUCN, Gland, Switzerland and Cambridge, UK/UNEP, Nairobi, Kenya. 378 pp.

\section{ANNEX \\ Definitions of protected area designations, as legislated, together with authorities responsible for their administration}

Title: Public Law No. 12-209

Date: No information

Brief description: Provides for the establishment of protected areas by the Government of Guam

Administrative authority: Department of Parks and Recreation

Designations:

Natural preserve

Conservation reserve

Territorial park

Community park

Recreational facilities (= national historic park, seashore park)

\section{Title: Public Law No. 95-348}

Date: 18 August 1978 
Brief description: Provided for the establishment of the War in the Pacific National Historical Park

Administrative authority: US National Park Service

Designations: War in the Pacific National Historical Park

\section{Title: Public Law No. 16-62}

Date: 9 February 1982

Brief description: An act to amend sections 26003(g), 26007, 26009(b), to add Articles VI, VII, VIII and IX of Chapter IV, Title XIII all of Government Code, relative to forestry and conservation programs of the Department of Agriculture.

Administrative authority: Department of Parks and Recreation

\section{Designations:}

Conservation reserve The Department, in cooperation with the Department of Parks and Recreation, shall control and manage lands and water areas that have been set aside by the government of Guam as conservation reserves. Such control and management shall have as its objectives, the wise use of the soil, water, plants and animals of the reserves. Consistent with this objective, the Director, with the concurrence of the Director of the Department of Parks and Recreation, may establish and enforce rules for economic use. 
SUMMARY OF PROTECTED AREAS

Map $^{\dagger}$ Name of area
ref.
IUCN management category

Area

Year

ref.

Ecological Reserve Areas

1 Haputo*

2 Orote Peninsula*

IV

IV

102

1984

Natural Reserves

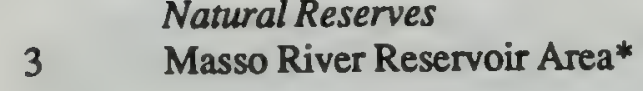

IV

67

1976

Natural Areas

4 Pati Point*

IV

112

1973

Conservation Reserves

5 Anao*

IV

6 Bolanos (Chalan Palii)

VIII

\section{Cotal}

VIII

223

$8 \quad$ Schroeder

9 Y-Piga

VIII

552

VIII

45

Territorial Seashore Parks

10 Guam Territorial Seashore Park*

VIII

6,135

1978

National Historic Parks

11 War in the Pacific*

V

779

1978

*Site is described in this directory.

${ }^{\dagger}$ Locations of most protected areas are shown in the accompanying map. 


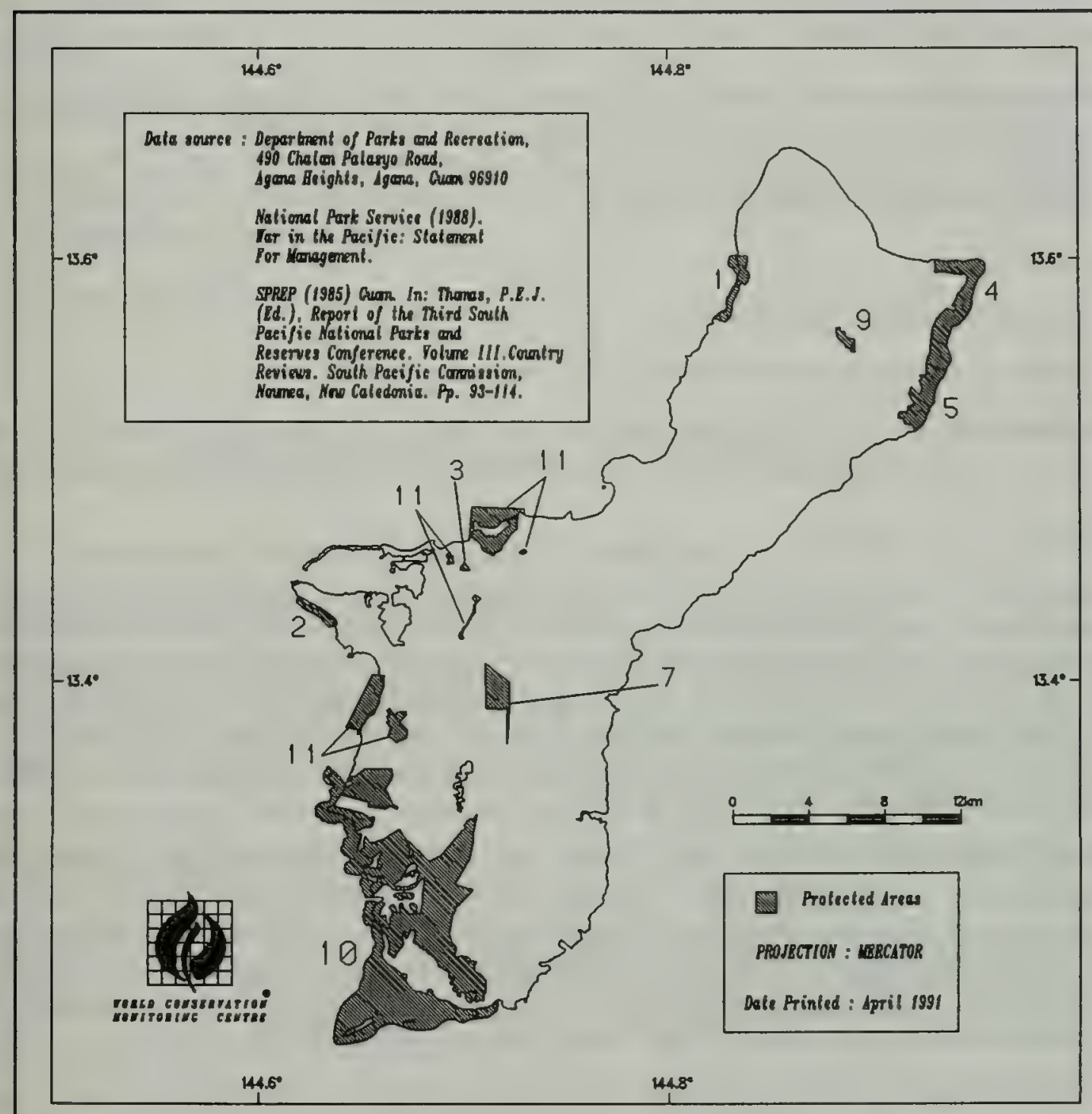

Protected Areas of Guam 


\section{ANAO CONSERVATION RESERVE}

\section{IUCN Management Category IV (Managed Nature Reserve)}

Biogeographical Province 5.02.13 (Micronesian)

Geographical Location Located in north-west Guam in the Municipality of Yigo. Pati Point Natural Area is adjacent to the north. Approximately $13^{\circ} 32^{\prime} \mathrm{N}, 144^{\circ} 56^{\prime} \mathrm{E}$

Date and History of Establishment 1953

Area 263ha

\section{Land Tenure Government of Guam}

Altitude Rises from sea level to $161 \mathrm{~m}$

Physical Features The reserve rises from the eastern boundary at the coast to $161 \mathrm{~m}$ above sea level at the top of the rugged limestone plateau cliffs. A coral reef abuts the ocean (SPREP, 1985).

Climate No information

Vegetation Vegetation communities comprise beach strand and limestone forest. Prominent species in the beach strand are coconut palm Cocos nucifera, ironwood Casuarina equisetifolia, nigas Pemphis acidula, beach morning glory Ipomoea pes-caprae, nanaso Scaerola taccada, and beach sunflower Wedelia biflora. Species in the limestone forest include federico Cycas circinalis, screw pine Pandanus fragrans, gulos Cyhometra ramiflora, fagot Neisosperma oppositifolia, kahlao Phymatodes scolopendria, ifil Intsia bijuga, and the scarce and locally threatened Seriathes nelsonii (SPREP, 1985).

Fauna Mammals include Guam deer Cervus sp. and Marianas fruit bat Pteropus mariannus (E). Birds present include Guam rail Gallirallus owstoni (E), Micronesian kingfisher Halcyon cinnamomina, Marianas fruit dove Ptilinopus roseicapilla (R), white-throated ground dove Gallicolumba xanthoura, Guam flycatcher Myiagra freycineti (R), bridled white-eye Zosterops conspicillata, cardinal honey-eater Myzomela cardinalis and Marianas crow Corvus kubaryi (R). Notable reptiles include monitor lizard Varanus indicus (SPREP, 1985).

Cultural Heritage Contains the site of the old Chamorro village of Mati. Remains include black midden areas, rock shelters and pottery sherds (SPREP., 1985).

Local Human Population No information

Visitors and Visitor Facilities There is one hiking trail (D. Lotz, pers. comm., 1990).

Scientific Research and Facilities None at present

Conservation Value No information

Conservation Management The area is managed jointly by the Department of Parks and Recreation and the Department of Agriculture to make the area accessible to the public (currently by foot trail) while preserving the natural features (SPREP, 1985).

Management Constraints Illegal hunting, fishing and cutting of trees (SPREP, 1985). 
Staff None exclusively for the reserve

Budget None exclusively for the reserve

Local Addresses Department of Parks and Recreation, 490 Chalan Palasyo Road, Agana Heights, Guam 96919

\section{References}

SPREP (1985). Guam. In: Thomas, P.E.J. (Ed.), Report of the Third South Pacific National Parks and Reserves Conference. Volume III. Country reviews. South Pacific Commission, Noumea, New Caledonia. Pp. 95-96.

Date December 1989

\section{GUAM TERRITORIAL SEASHORE PARK}

\section{IUCN Management Category VII (Multiple Use Management Area)}

Biogeographical Province 5.02.13 (Micronesian)

Geographical Location The park covers an extensive but irregularly patterned area in the south-west of Guam, with park areas interspersed with non-park private land. It includes a contiguous stretch of coastline from Anae Island and Patch Reef, $1 \mathrm{~km}$ off shore south of Nimitz Beach Park in the west, southwards to include twenty-two acres (8.9ha) of Cocos Island and all of the Lagoon, and east to include a portion of Ajayan Bay, just north of Manell Channel. The area includes Cetti Bay on the south-west coast between Sella and Fouha bays (UNEP/IUCN, 1988). $13^{\circ} 13^{\prime}-13^{\circ} 25^{\prime} \mathrm{N}, 144^{\circ} 38^{\prime}-144^{\circ} 44^{\prime} \mathrm{E}$

Date and History of Establishment Guam Territorial Seashore Park was established on 12 December 1978 under Executive Order No. 78-42, and is designed to protect the wildlife, marine life and other oceanic resources and natural environment of south-west Guam. Some portions have been protected since 1953.

Area The site covers 3,596ha of land and 2,539ha of coast and sea.

Land Tenure Government of Guam. Some areas are claimed by individuals and others are leased. Cocos Lagoon and one-third of Cocos Island are owned by the Government of Guam; the remaining two-thirds of the island (not within the park) is privately owned.

Altitude $-18.3 \mathrm{~m}$ to $396 \mathrm{~m}$

Physical Features The southern half of the island is largely volcanic in origin, comprising a series of hills reaching up to nearly $400 \mathrm{~m}$ and extending along the west side of the island. The general physical character of the area is determined by volcanic activity modified by limestone deposits and subsequently cut by erosion. The land area is divisible into three major types dissected volcanic uplands, the interior basin, and the coastal lowlands and valley floors. The coastal areas are of two zonations - the south-west coast and the Cocos Lagoon to Ajayan Bay area. Anae Island is the only one of the eight islets on the south-west coast which is not associated 
with a fringing coral reef. The western and northern sides of the island and patch reefs slope steeply to a $30 \mathrm{~m}$-deep terrace, while the eastern and southern sides consist of a gently sloping terrace $3 \mathrm{~m}-8 \mathrm{~m}$ deep. In these protected waters, large coral mounds, pinnacles and ridges, $6 \mathrm{~m}-8 \mathrm{~m}$ high, are separated by sandy floored channels (UNEP/IUCN, 1988). Cetti Bay, described by Randall and Holloman (1974), is surrounded by steep slopes and sandy beaches. The shoreline consists of rocky volcanic headlands with steep shorelines, bordered by low-lying narrow limestone terraces. Silt content is high and visibility low in the inner bay, but visibility is good in other areas.

Cocos Barrier Reef and Lagoon comprises a triangular barrier reef (7.2 sq. km), lagoon and associated islands. The area has been divided into three biotopes. The terrestrial biotope includes Cocos Island and a small sand islet at its eastern end, Babe Island, with the landward border along Cocos Lagoon. This consists of a narrow fringing reef, an intertidal zone dotted with mangrove patches and seagrasses. A second biotope consists of the deep Mamaon and Manell Channels and a third includes the lagoon, barrier reef-flat platform and fringing reef-flat platforms. The barrier reefs are nearly $5 \mathrm{~km}$ long on the north-west side, $5-6 \mathrm{~km}$ long on the south (UNEP/IUCN, 1988).

The fringing reef platform bordering most of the south-east shoreline is completely cut by the Ajayan River, forming a small estuary with moderate alluvial silt deposition at the river mouth. A small islet, Agrigan Island, is located on the south-west reef flat. The channel is characterised by progressively steeper fringing reef walls seaward to approximately $18 \mathrm{~m}$ in depth. The floor of the channel grades from a silt-mud zone to sand approximately midway out. Water visibility improves seaward. The reef flats are wide and largely covered by seagrass beds. Coral cover on the reefs of Cocos Barrier Reef and Lagoon is variably dense, based on differing degrees of reef-flat exposure. In general, there is an increase in coral cover and diversity from the seaward side to the lagoon side (UNEP/IUCN, 1988).

Climate Tropical warm and humid throughout the year. Two well-defined seasons occur: a dry season from January to May and a wet season from July to October. Annual mean temperature for 1981 was $25.9^{\circ} \mathrm{C}$. The coolest months are January, February and March and the warmest months are May and June. Mean annual rainfall is $2286 \mathrm{~mm}$.

Vegetation The area encompassed by the park includes almost every major type of habitat found on Guam and is representative of all the southern islands of the Marianas. The southern half of the island has several vegetational zones. The volcanic upland savanna grasslands are dominated by swordgrass Miscanthus floridulus and scattered Casuarina trees, along with Pennisetum polystachyon, Lycopodium carnum and the threatened tree fern Cyathea lunulata (Anon., 1985). This eroded savanna habitat is thought to be the result of repeated burning. The forested ravines, river valleys and forest patches on the limestone caps of volcanic uplands are characterised by betel palm Areca catechu but include a variety of trees, such as banyans Ficus benghalensis, screw-pine Pandanus kirkii and breadfruit Artocarpus altilis, with a lush undergrowth component. Apart from a couple of mangrove areas, the coast is largely dominated by coconut Cocus nucifera which sometimes extends up the river valleys. Associated species include Messerachnidia argentea, Scaevola taccada and Ipomoea pes-caprae (Anon., 1985). The mangrove swamp is situated between Merizo and the Suyafe River and has Rhizophora, Bruguiera and Lumnitzera components. The coastal area is important for its seagrass Enhalus acoroides concentrations which are to be found off the northern end, to the south of Taleyfac Bay and again near the Ajayan river. Some 90 species of marine plants have been recorded (Eldredge, 1979; UNEP/IUCN, 1988). 
Fauna The majority of the native land birds are confined to the north of the island, but some are found in the park. Cocos Island has number of nesting seabirds including white tern Gygis alba, brown noddy Anous stolidus, Micronesian starling Aplonis opaca and Pacific reef heron Egretta sacra all of which are rare or no longer breed on the mainland due to predation by the introduced brown tree snake Boiga irregularis. The island also harbours several species of skink and geckoes that do not occur elsewhere in Guam (G. Wiles, pers. comm., 1990). Other species may include Vanikoro swiftlet Collocalia vanikorensis, white-tailed tropic bird Phaeton lepturus, brown booby Sula leucogaster and reef heron Demiguetta sacra (Anon., 1985; UNEP/IUCN, 1988). Marianas fruit bat Pteropus mariannus (V) apparently occurs in the area (Anon., 1985). The most important conservation areas of the site are on the coast and in particular around Cocos Lagoon. This is a very rich marine system due to its high diversity and wide range of habitats. The coral communities are scattered throughout the length of the south-west reef flat and are usually restricted to holes, depressions and margins. Cocos Lagoon contains one of the most diverse coral communities on Guam (dominated by Porites) but within the lagoon their distribution is patchy. Some 159 species of coral have been found, 58 species of gastropods, 49 species of bivalves and 40 species of echinoderms. In the lagoon itself some 267 species of fish have been identified out of a total of $\mathbf{2 7 6}$ for southern Guam. Hawksbill turtle Eretmochelys imbricata (E) and green turtle Chelonia mydas (E) have been observed and the latter breeds. Porpoises are regularly seen but dugong Dugong dugon (V) was last sighted in 1974 (UNEP/IUCN, 1988).

Cultural Heritage The park is rich in prehistoric cultural resources. There are numerous ruins of forts and stone bridges dating from the Spanish period, as well as World War Two relics, such as Japanese Zero aircraft (Anon., 1985).

Local Human Population Three villages exist adjacent to the park with a total population in 1980 of 895 people (Anon., 1985). The local economy is based on tourism, agriculture and employment by the state (D. Lotz, pers. comm., 1990).

Visitors and Visitor Facilities There are plans for a full range of interpretive facilities and under the General Development Plan there are moves to promote recreational use in accordance with the Land Classification Plan. There are also plans for intertidal reef flat nature trails and a management plan is proposed for the park in accordance with the appropriate recreation category. Overnight accommodation is being established in a major resort development on Cocos Island. At present there are three boat launching sites, with the main site being Merizo Pier Park. Cocos Lagoon is used for organised (Marianas Yacht Club) and individual water sports including both motor and sail boat races, diving, snorkelling, water-skiing and fishing (UNEP/IUCN, 1988).

Scientific Research and Facilities Several marine biota studies have been carried out in the Nimitz Channel, the Taleyfac Bay region, at Sella Bay, Fouha Bay, Umatac and Toguan Bay. Shellfish and sea urchins studies were conducted in 1978 and the Division of Aquatic Wildlife Resources carries out inshore creek censuses and periodic offshore aerial surveillance programmes. Two artificial reefs have been constructed to investigate improved lagoon management techniques (UNEP/IUCN, 1988).

\section{Conservation Value No specific information}

Conservation Management Hunting, shelling, fishing, ranching, boating and outdoor recreation activities are permitted. The Guam Environmental Protection Agency water quality rating for most of this area is " $\mathrm{A}$ ", recreational, but for Anae Island and Patch Reef and for Cetti Bay is "AA", conservation. There are three Natural Landmarks within the Park: Faha Point, Mt 
Lamlam and Facpi Point (UNEP/IUCN, 1988). The area between Facpi Point and Fort Santo Angel and Cocos Lagoon separately have been proposed as national marine sanctuaries under the Coastal Zone Management Act (D. Lotz, pers. comm., 1987). The Master Plan was adopted in 1979 and encourages multiple use (Anon., 1985). The US Army Corps of Engineers (1983) has reviewed planning and the management of the entire area. The Department of Parks and Recreation is responsible for coordination, planning, facility maintenance, outdoor recreation, historic preservation and scenic resources. The Department of Agriculture is responsible for leases and land registration. The Guam Environmental Protection Agency is responsible for water and air pollution and solid waste. All agencies have active programs in the park in their area of responsibility (Anon., 1985). Governmental lands are generally semi-natural without management, whilst private areas are scattered and sparsely populated and include old plantations and agricultural holdings.

Stojkovich (1977, quoted in UNEP/IUCN, 1988) gives a list of recommendations for the Cocos Lagoon area which include prohibiting fishing, coral harvesting and shell collecting within the proposed sanctuary except by special permit; the GEPA water quality classification to be changed from " $A$ " recreation to "AA" conservation; the establishment of an upper limit on the number and type of point source discharges into Mamaon and Manell Channels; recreational activities to be retained but strictly controlled; the establishment of an upper limit on the number of transport boats and persons using the area at any given time; the establishment of the entire Cocos area as a marine underwater park with trails and basic information on the geology, physiography and biota; the placement of artificial reefs and fish traps for scientific and maricultural purposes to be allowed with issue of a special permit; and strict litter laws to be implemented especially for waste cans (UNEP/IUCN, 1988). Stojkovich also recommended that Ajayan Bay, Anae Island, and Cetti Bay be established as natural sanctuaries in which no coral harvesting be allowed; that fishing be allowed only by special permit; that swimming, snorkelling and SCUBA diving activities be retained; that special care be taken to preserve the seagrass beds and that the adjacent wetlands be included in any preservation plan. Mooring buoys should be established and underwater trails developed. A number of these recommendations have been taken care of in the course of developing the park (UNEP/IUCN, 1988).

Management Constraints There have been large-scale introductions of flora (300 species), avifauna (7 species) and mammals (5 species). The accidentally-introduced brown tree snake Boiga irregularis is a major suspect in the drastic decline of the native fauna. Other introduced fauna include feral cats, dogs, pigs, rats and a south-east Asian elk. The sponge Terpios was overgrowing corals at Anae Island at a rapid rate in the early 1970 s and its growth rate was monitored. The increasing popularity of the Merizo coast and of Cocos Island, as a full-time fishing and tourist operation, could be a threat. Shell populations have been depleted by collectors, especially popular species such as Cassis cornuta. There is some illegal fishing with dynamite and bleach (Anon., 1985). However, there was little change between 1975 and 1982 although there had been a substantial increase in tourism in the area (UNEP/IUCN, 1988). There have also been major pollution and litter problems, as well as major threats from agricultural encroachment (SPREP, 1985).

Staff One park manager and two ground workers (D. Lotz, pers. comm., 1990)

Budget US\$ 71,133 for the fiscal year 1990 (D. Lotz, pers. comm., 1990)

Local Addresses Department of Parks and Recreation, 490 Chalan Palasyo Road, Agana Heights, Guam 96919 


\section{References}

Anon. (1967). A Master Plan for Guam National Seashore. US Department of Interior. National Park Service.

Eldredge, L.G. (1979). Marine biological resources within the Guam seashore study area and the War in the Pacific National Historical Park. University of Guam Marine Laboratory. Technical Report No. 57.

Jenkins, J.M. (1983). The Native Forest Birds of Guam. Ornithological Monographs No. 31 . The American Ornithologists' Union, Washington DC.

Randall, R.H. and Holloman, J. (1974). Coastal survey of Guam. University of Guam Marine Laboratory Marine Technical Report 14. 404 pp. (Unseen).

SPREP (1985). Guam. In: Thomas, P.E.J. (Ed.), Report of the Third South Pacific National Parks and Reserves Conference. Volume III. Country reviews. South Pacific Commission, Noumea, New Caledonia. Pp. 93-114.

UNEP/IUCN (1988). Coral Reefs of the World. Volume 3. Central and Western Pacific. UNEP Regional Seas Directories and Bibliographies. IUCN, Gland, Switzerland and Cambridge, UK/UNEP, Nairobi, Kenya. 378 pp.

Wheeler, M.E. and Aguon, C.R. (1978). The Current Status and distribution of the Marianas fruit bat on Guam. Aquatic and Wildlife Resources Division Technical Report No. 1.

Date August 1987, revised December 1989, February 1990

\section{HAPUTO ECOLOGICAL RESERVE AREA}

\section{IUCN Management Category IV (Managed Nature Reserve)}

\section{Biogeographical Province 5.02.13 (Micronesian)}

Geographical Location Located in the Naval Communication Area Master Station, in the Finegayan area of Dededo municipality, approximately $8 \mathrm{~km}$ north of the town of Dededo, on the north-west coast of Guam. Approximately $13^{\circ} 35^{\prime} \mathrm{N}, 144^{\circ} 50^{\prime} \mathrm{E}$

Date and History of Establishment Established by the Chief of Naval Operations, United States Navy on 13 March 1984. Authority for the establishment of the area is drawn from HR 6502 (National Heritage Policy Act 1979); FR Vol.40, No. 38 (Federal Committee on Ecological Reserves); 36 CFR 251.23 (Experimental areas and research natural areas); OPNAVINST 5090.1, Chapter 15, paragraph 15304 (5/26/83) - Ecological Reserves; and NAVFAC P-73, Real Estate Procedural Manual, Chapter 17, pp. 14-15 - Ecological Reserves (NFEC, 1986). A legal description and geographical definition is given in NFEC (1986).

Area $102 \mathrm{ha}$, of which $73 \mathrm{ha}$ are land and $29 \mathrm{ha}$ are water

Land Tenure The entire area is owned by the United States Navy.

Altitude From sea level to $122 \mathrm{~m}$

Physical Features The offshore double reef and the adjacent coastline abutting the coral reef constitutes the marine area. The shoreline consists of rocky limestone cliffs with two sandy beach coves. Haputo Beach lies in a small embayment, bordered by cut benches and rocky slopes on 
both the north and south sides, and is described by Randall and Holloman (1974). Double Reef consists of a narrow fringing reef and adjacent patch reef (Pugua) about $350 \mathrm{~m}$ off shore. Freshwater springs are abundant on the reef flat. Inland, the topography rapidly rises to the top of the limestone cliffs (SPREP, 1985).

\section{Climate No information}

Vegetation The offshore area is covered by sand and limestone rock with a wide variety of corals and algae. On the land, limestone forest predominates with coconut palm Cocos nucifera, screw pine Pandanus fragrans, hibiscus Hibiscus tiliaceus, chopa Mannea oderata, bamboo Bamba vulgaris, limeberry Triphasia trifolia, fish-kill tree Barringtonia asiatica, and federico Cycas circinalis (SPREP, 1985). The reserve is a well-preserved example of the vegetation type that formerly occurred extensively throughout the island (NFEC, 1986). Algal cover is also rich and diverse. Further details are given in UNEP/IUCN (1988).

Fauna The area supports Marianas flying fox Pteropus mariannus (E), although possibly only for feeding purposes, and Guam deer Cervus unicolor mariannus NFEC (1986). Land bird populations were very low in 1986, but sea birds are better represented (NFEC, 1986). Species include cardinal honey-eater Myzomela cardinalis, Marianas crow Corvus kubaryi, Micronesian kingfisher Halcyon cinnamomina and white-throated ground dove Gallicolumba xanthonura (SPREP, 1985). Brown tree snake Boiga irregularis, implicated in the widespread decline of certain native birds, is probably present. The inshore reef area supports healthy and diverse populations of reef community fish and associated invertebrates. Double Reef, included within the reserve, is one of Guam's few remaining examples of leeward fringing reef in good condition, and provides a nursery for species of subsistence and commercial fishery value (NFEC, 1986). The honeycomb structure of the outer reef flat at Double Reef and Haputo Beach has led to a diverse and very abundant fish fauna, with 108 species recorded at the former and 21 at the latter (Stojkovich, 1977).

Cultural Heritage The area contains archaeological remains of a Chamorro settlement including a well, midden concentrations and rock shelters. The area also includes a World War Two site, Tweed's Cave, where the United States Navy radioman George Tweed hid from the Japanese (SPREP, 1985).

Local Human Population The naval station has a population of 3,358 (SPREP, 1985).

Visitors and Visitor Facilities The area is very popular for SCUBA diving, fishing and photography (Stojkovich, 1977).

Scientific Research and Facilities Studies have included Stojkovich (1977). There are no facilities at present (SPREP, 1985).

Conservation Value The reserve was established as one of several mitigation measures which the US Navy proposed in order to obtain approval from various Federal and Govemment of Guam agencies for the construction of an ammunition wharf at Adotgan Point in outer Apra Harbour. The reserve was also established to protect two separate biological units. The terrestrial unit supports a remnant of native limestone forest and high cliffs which have the potential to provide important habitat for native birds. The marine unit contains an excellent example of a pristine coral community (NFEC, 1986).

Conservation Management A federal ecological reserve is defined as a physical or biological unit in which current natural conditions are maintained insofar as possible. These conditions are 
ordinarily achieved by allowing natural physical processes to prevail without human intervention. As a general rule such reserves should show no evidence of interference by man during the previous 50 years.

Management responsibility ultimately rests with the Commanding Officer, Guam US Naval Station, although the Naval Facilities Engineering Command (Pacific Division), US Fish and Wildlife Service, National Marine Fisheries Services, and the Division of Aquatic and Wildlife Resources of the Department of Agriculture also have various management roles (NFEC, 1986). Management recommendations (NFEC, 1986) include compilation of inventories of birds, other terrestrial fauna, flora, marine resources and historic sites. The reserve is subject to strict control, with entry by permit only. Permitted activities include recreational fishing, shell collecting and non-consumptive uses such as snorkelling and bird-watching. Scientific research is subject to formal authorisation by the Commanding Officer, US Naval Station, Guam (NFEC, 1986).

Management Constraints No information

Staff None

Budget The funding of management activities is the responsibility of the Commanding Officer, Naval Communications Area Master Station (NFEC, 1986).

Local Addresses Commanding Officer, Naval Communications Area Master Station, Western Pacific, FPO San Francisco, CA 96630, USA

\section{References}

NFEC (1986). Management plan for the Haputo Peninsula Ecological Reserve Area. Naval Facilities Engineering Command. 12 pp.

Randall, R.H. and Holloman, J. (1974). Coastal survey of Guam. University of Guam Marine Laboratory Marine Technical Report 14. 404 pp. (Unseen)

SPREP (1985). Guam. In: Thomas, P.E.J. (Ed.), Report of the Third South Pacific National Parks and Reserves Conference. Volume III. Country reviews. South Pacific Commission, Noumea, New Caledonia. Pp. 93-114.

Stojkovich, J.O. (1977). Survey and Species Inventory of Representative Pristine Marine Communities on Guam. Guam Coastal Management Program Technical Reports, Agana. (Unseen).

UNEP/IUCN (1988). Coral Reefs of the World. Volume 3. Central and Western Pacific. UNEP Regional Seas Directories and Bibliographies. IUCN, Gland, Switzerland and Cambridge, UK/UNEP, Nairobi, Kenya. 378 pp.

Date December 1989, revised February 1990

\section{MASSO RIVER RESERVOIR AREA}

IUCN Management Category IV (Managed Nature Reserve)

Biogeographical Province 5.02.13 (Micronesian) 
Geographical Location Located within the US Naval Station, Piti. Approximately $13^{\circ} 27^{\prime} \mathrm{N}, 144^{\circ} 41^{\prime} \mathrm{E}$

Date and History of Establishment 14 January 1976 by a cooperative agreement between the Government of Guam and the US Navy for the conservation and management of fish and wildlife resources (D. Lotz, pers. comm., 1990).

\section{Area $67 \mathrm{ha}$}

\section{Land Tenure United States Navy}

Altitude Ranges from $10 \mathrm{~m}$ above sea level at the north-western boundary to $76 \mathrm{~m}$ in the south-east (SPREP, 1985).

Physical Features Masso River Reservoir Area has variable terrain. The park contains three basic physical features: a partially modified savannah community; a watershed system of two streams flowing into Masso Reservoir, and Masso Reservoir which was built in the early 1900s as a potable water resource. The reservoir dike extends $100 \mathrm{~m}$, raising the water level by $1.3 \mathrm{~m}$. The dike is of concrete construction, with coral backfilling adjoining a steel sluice gate for water run-off (SPREP, 1985).

Climate Data for the period 1945-1982 from Agana indicate a mean annual temperature of $30^{\circ} \mathrm{C}$, mean annual precipitation of $2249 \mathrm{~mm}$, mean relative humidity of $72-86 \%$ and generally easterly prevailing winds. The rainy season normally begins in July and continues until November. Tropical storms are frequent during this period, occasionally increasing in intensity to become typhoons. January to May constitutes the dry season, and June and December are transitional.

Vegetation Aquatic vegetation found within the ponding area is dominated by the reed Phragmites karka in wet areas, and by Leucaena leucocephala on dry ground. Other principal trees in the area include hibiscus Hibiscus tiliaceus, screw pine Pandanus fragrans, African tulip Spathodea campanulata, ironwood Casuarina equitsetifolia, camachile Pithecellobium dulce, and coconut palm Cocos nucifera (SPREP, 1985).

Fauna Aquatic organisms found in the park area and its feeder streams are eels Anguilla mormorata and A. bicolor, Chonophorus guamemsis, Microsicydium elegans, and Sicypeterus macrostetholepis, an eleotrid Eleotris fusca, shrimps Atya sp., Cordina sp., and Macrobrodhium las, tadpoles of Bufo marinas, and a variety of insect larvae and small invertebrates. In addition to aquatic organisms, there are wild pig Sus scrofa and a variety of small rodents (SPREP, 1985).

Cultural Heritage The remnants of Masso Reservoir may have historical significance, since it is one of the earliest known US Naval engineering structures The Masso area was also a primary source of potable water in the early 1900s to the surrounding vicinity (SPREP, 1985).

Local Human Population Piti Village, where Masso River Reservoir area is situated, has a population of 2,866 (SPREP, 1985).

Visitors and Visitor Facilities No information

Scientific Research and Facilities Publications include the Department of Agriculture's "Aquatic and Wildlife Resources Annual Report Fiscal Year 1976 to 1982", Agana, Guam (SPREP, 1985). 
Conservation Value Valued for the conservation and management of fish and wildlife resources.

Conservation Management The park area is not presently incorporated in a master plan. However, development and management are distributed among various agencies. The Department of Parks and Recreation is responsible for coordination, planning and facility maintenance. The Department of Agriculture is responsible for promulgation of the fishing rules and regulations (SPREP, 1985).

Management Constraints Include illegal fishing (D. Lotz, pers. comm., 1990)

Staff None

Budget None

Local Addresses Department of Parks and Recreation, 490 Chalan Palasyo Road, Agana Heights, Guam 96919

\section{References}

SPREP (1985). Guam. In: Thomas, P.E.J. (Ed.), Report of the Third South Pacific National Parks and Reserves Conference. Volume III. Country reviews. South Pacific Commission, Noumea, New Caledonia. Pp. 103-104.

Date December 1989, revised February 1990

\section{OROTE PENINSULA ECOLOGICAL RESERVE AREA}

\section{IUCN Management Category IV (Managed Nature Reserve)}

Biogeographical Province 5.02.13 (Micronesian)

Geographical Location South-west tip of Orote Peninsula, in the Santa Rita municipality, approximately $0.6 \mathrm{~km}$ north-north-west of Apuntua Point, in western central Guam. The boundary, which follows the cliff edge on the landward side and the 20 fathom $(18.3 \mathrm{~m})$ depth contour to seaward, is unmarked, and, in view of the inaccessible cliff area and the extremely rugged shore, it is recommended that no attempt be made to identify the reserve more clearly (NFEC, 1986). Approximately $13^{\circ} 26^{\prime} \mathrm{N}, 144^{\circ} 38^{\prime} \mathrm{E}$

Date and History of Establishment Established by the Chief of Naval Operations, United States Navy on 13 March 1984.

Area $66 \mathrm{ha}$, of which $12.1 \mathrm{ha}$ is land and $53.8 \mathrm{ha}$ is sea

Land Tenure United States Navy

Altitude Ranges from a depth of $-18.3 \mathrm{~m}$ offshore to $61 \mathrm{~m}$.

Physical Features The terrestrial unit extends from the upper cliff line boundary to the mean low water line and includes the limestone cliff face. The marine unit, comprising a submerged 
limestone terrace, originates at the mean low water mark and extends to the 20 fathom (18.3m) depth contour (US-FWS, 1988). The limestones drop vertically to the first submarine terrace at $15-20 \mathrm{~m}$ depth, which is $20-45 \mathrm{~m}$ wide. A second submarine cliff drops to a second terrace at about $80 \mathrm{~m}$. The submerged terraces have tunnels and caves (Stojkovich, 1977)

Climate Data for the period 1945-1982 from Agana indicate a mean annual temperature of $30^{\circ} \mathrm{C}$, mean annual precipitation of $2249 \mathrm{~mm}$, mean relative humidity of $72-86 \%$ and generally easterly prevailing winds. The wettest months are July to October, and August to November is characterised by a higher than average incidence of tropical cyclones.

Vegetation The beach strand community is composed of nigas Pemphis acidula and nanaso Scaevola taccada (SPREP, 1985). The terrestrial unit supports marginal stands of remnant native limestone forest, varying from dense to sparse vegetative cover with little or no soil accumulation. Specimens of Leucaena leucocephala observed in 1986 along the top of the Orote cliff appeared to be dead in 1988, although closer examination revealed considerable re-growth. A plant species list is provided in US-FWS (1986).

Fauna Five bird species were recorded in 1986 (US-FWS, 1986), viz. brown noddy Anous stolidus, Philippine turtle dove Streptopelia bitorquata, wandering tatler Heteroscelus incanus, great frigatebird Fregata minor and short-tailed shearwater Puffinus tenuirostris, but only the first three species were observed in 1988 (US-FWS, 1988). Species seen flying above the reserve included black francolin Francolinus francolinus, whimbrel Numenius phaeopus, lesser golden-plover Pluvialis dominica, Philippine turtle-dove, black drongo Dicrurus macrocercus and Eurasian tree sparrow Passer montanus. With the exception of the turtle dove, none is expected to make use of the reserve (US-FWS, 1988). Common tern Sterna hirundo has also been reported (SPREP, 1985).

Results of both the 1986 and 1988 surveys (US-FWS, 1986 and 1988) failed to detect the presence of small mammals. Evidence from the 1940s and 1950s suggests that such taxa have been abundant. Fruit bats are represented on Guam by a single species, Marianas fruit bat Pteropus mariannus $(E)$, restricted to a single colony on the north coast, but there is no evidence of their presence in the reserve.

Reptiles and amphibians include house gecko Hemidactylus frenatus and mourning gecko Lepidodactylus lugubris, abundant four-toed skink Carlia fusca and relatively uncommon blue-tailed skink Emoia werneri. Monitor lizard Varanus indicus is present but not common. Only one amphibian is known, giant toad Bufo marinus. There is some suggestion that snake populations are increasing on Orote Peninsula. Brown tree snake Boiga irregularis, implicated in the widespread decline of certain native birds, has not been recorded in the reserve for a number of years (US-FWS, 1988).

A total of 227 marine fish species was recorded in 1986 (US-FWS, 1986) but only 116 in 1988 (US-FWS, 1988), although there has been little qualitative change in the health of the fish community. The discrepancy may be due to mistaken identification, less experienced staff, fewer transects and samples and natural variation in abundance. The most common families in both surveys were wrasses Labridae and damselfishes Pomacentridae, with 12 species, respectively. Other well represented families include triggerfish Balistidae, surgeonfish Acanthuridae and squirrelfish Holocentridae, each with seven species; and butterflyfish Chaetodontidae, jack Carangidae and goatfish Mullidae, each with five species. The most abundant species in both surveys were damselfish Chrysiptera leucopomus and Pomachromis guamensis and goby Pogonoculius zebra (US-FWS, 1988). Species lists for marine algae and fauna recorded in the 
area are given in Stojkovich (1977). There is a relatively undisturbed coral and algal community in the submerged area (NFEC, 1986). The upper slope and most of the terrace floor consists of scattered small Pocillopora colonies. In more protected habitats around fallen blocks and larger rubble, a much richer coral community is evident. Coral Pachyclavularia violacea was observed in 1977 (Stojkovich, 1977). Results of a recent survey (US-FWS, 1988) indicate little or no damage to coral colonies from typhoon storm damage, dynamite fishing or anchors.

\section{Cultural Heritage None}

Local Human Population The Naval Station has a population of 5,633 (SPREP, 1985).

\section{Visitors and Visitor Facilities No information}

Scientific Research and Facilities Studies have included those by Stojkovich (1977) and US-FWS $(1986,1988)$. A summary account is given in SPREP (1985). There are no facilities at present (SPREP, 1985).

Conservation Value The reserve was established to protect two separate biological units. The terrestrial unit supports a remnant of native limestone forest and cliffs which have the potential to provide important habitat for native birds. The marine unit contains an excellent example of a pristine coral community (NFEC, 1986).

Conservation Management A federal ecological reserve is defined as a physical or biological unit in which current natural conditions are maintained insofar as possible. This is achieved by allowing natural physical processes to prevail. As a general rule such reserves should show no evidence of interference by man during the previous 50 years.

The reserve was established as one of several mitigation measures which the US Navy proposed in order to obtain approval from various Federal and Government of Guam agencies for the construction of an ammunition wharf at Adotgan Point in outer Apra Harbour. Authority for the establishment of the area is drawn from HR 6502 (National Heritage Policy Act 1979); FR Vol.40, No. 38 (Federal Committee on Ecological Reserves); 36 CFR 251.23 (Experimental areas and research natural areas); OPNAVINST 5090.1, Chapter 15, paragraph 15304 (5/26/83) - Ecological Reserves; and NAVFAC P-73, Real Estate Procedural Manual, Chapter 17, pp 14-15 - Ecological Reserves (NFEC, 1986). A legal description and geographical definition is given in NFEC (1986).

A management plan has been prepared (NFEC, 1986) and responsibility ultimately rests with the Commanding Officer, Guam US Naval Station, although the Naval Facilities Engineering Command (Pacific Division), US Fish and Wildlife Service, National Marine Fisheries Services and the Division of Aquatic and Wildlife Resources of the Department of Agriculture (DAWR) also have various management roles (NFEC, 1986). Management recommendations (NFEC, 1986) include compilation of inventories of birds, other terrestrial fauna, flora, marine resources and historic sites. The reserve is subject to strict control, with entry by permit only. Permitted activities include recreational fishing, shell collecting and non-consumptive uses such as snorkelling and bird-watching. Scientific research is subject to formal authorisation by the Commanding Officer, US Naval Station, Guam (NFEC, 1986).

The original management and monitoring recommendations included annual crown-of-thorns starfish Acanthaster planci infestation monitoring and quantitative surveys of coral and fish communities. However, it has been suggested that a five-year cycle may be more cost effective, 
and the establishment of a cooperative agreement between the Navy and the DAWR for routine monitoring of marine resources within the reserve is recommended (US-FWS, 1988).

Management activities for the marine unit recommended in the US-FWS 1986 survey remain valid, and include restricted collecting of live coral and invertebrates; increased patrolling and banning of certain fishing techniques; prevention of excessive anchor damage; development of interpretive material for all ERAs; halting the use of Apuntua Point beach as a dumping site; and restricting dumping within the reserve. The terrestrial unit is biologically very simple and only requires the prevention of disturbance as a management measure. Recommended management includes the protection of the brown noddy colony, a survey of a former Navy dump, brown tree snake control, provision of interpretation material and periodic sampling of terrestrial fauna (US-FWS, 1988).

Management Constraints The reserve is of inadequate size to protect the land area (SPREP, 1985). A survey in 1988 (US-FWS, 1988) confirmed earlier findings (US-FWS, 1986) that crown-of-thorns starfish is present but only at the level of one or two individuals. There is evidence to suggest that local fishermen may have removed individual young clams Tridacna spp. from the north of the reserve. A beach nearby is being used to dump rubbish, soil etc. which has lead to reduced water clarity in its immediate vicinity.

\section{Staff None}

Budget The funding of management activities is the responsibility of the Commanding Officer, Naval Communications Area Master Station (NFEC, 1986).

Local Addresses Commanding Officer, US Naval Station, Guam (NAVSTA Guam, San Francisco, CA 96630, USA)

\section{References}

NFEC (1986). Management plan for the Orote Peninsula Ecological Reserve Area. Naval Facilities Engineering Command. 11 pp.

SPREP (1985). Guam. In: Thomas, P.E.J. (Ed.), Report of the Third South Pacific National Parks and Reserves Conference. Volume III. Country reviews. South Pacific Commission, Noumea, New Caledonia. Pp. 101-102.

Stojkovich, J.O. (1977). Survey and Species Inventory of Representative Pristine Marine Communities on Guam. Guam Coastal Management Program Technical Reports, Agana. (Unseen).

US-FWS (1986). Fish and wildlife resources of the Orote Ecological Reserve Area. Unpublished report prepared for the Department of the Navy by the US Fish and Wildlife Service. $60 \mathrm{pp}$. (Unseen).

US-FWS (1988). Fish and wildlife resources of the Orote Ecological Reserve Area, US Naval Station, Guam (NAVSTA). First biennial resurvey June and August 1988. US-Fish and Wildlife Service, Honolulu. Unpublished. 16 pp.

Date December 1989, revised February 1990, December 1990 


\section{PATI POINT NATURAL AREA}

\section{IUCN Management Category IV (Managed Nature Reserve)}

\section{Biogeographical Province 5.02.13 (Micronesian)}

Geographical Location Located on the far north-east of Guam and forming a coastal fringe of the North Field section of Andersen Air Force Base (AFB). The site extends southwards down the east coast as far as Anao Point, which marks the south-eastern boundary of Andersen AFB. Anao Conservation Reserve is adjacent to the south. Approximately $13^{\circ} 32^{\prime} \mathrm{N}, 144^{\circ} 56^{\prime} \mathrm{E}$

Date and History of Establishment 24 May 1973. Established by administrative action of the Commander of the US Eighth Air Force, Andersen Air Force Base.

Area 112ha

\section{Land Tenure United States Air Force}

\section{Altitude From sea level to $183 \mathrm{~m}$ on Pati Point}

Physical Features Comprises a rugged limestone cliff and coral reef abutting the ocean (SPREP, 1985). Randall and Holloman (1974) describe the geology, hydrology and physiography of the area. The north coast consists of rugged limestone cliffs bordering intermittent long stretches of beach with a wide reef flat platform and convex algal ridge. There is heavy surf and strong rip currents especially near the larger surge channels and near Ritidian Point, beyond the western boundary. Northern Guam comprises a high, porous limestone plateau. Consequently, rainfall percolates rapidly through the thin soils and into the bedrock and there are no surface streams.

Climate Data for the period 1945-1982 from Agana indicate a mean annual temperature of $30^{\circ} \mathrm{C}$, mean annual precipitation of $2249 \mathrm{~mm}$, mean relative humidity of $72-86 \%$ and generally easterly prevailing winds. Data from Andersen AFB indicate a mean annual temperature of $26^{\circ} \mathrm{C}$ and a mean annual rainfall of $2343 \mathrm{~mm}$. The rainy season normally begins in July and continues until November. Tropical storms are frequent during this period, occasionally increasing in intensity to become typhoons. January to May constitutes the dry season, and June and December are transitional.

Vegetation Vegetation communities comprise beach strand and limestone forest. Large trees include nunu Ficus prolixa, Merrilliodendron megacarpum, Pisonia grandis, wild seeded breadfruit Artocarpus mariannensis, joga Eleocarpus joga, thought to be a food source for Marianas fruit bat, faia Tristeropsis obtusangula and ifil Intsia bijuga, Guam's official tree. Medium-sized trees include fago Ochrosia oppositifolia and agkag Pandanus fragrans, both thought to be fruit bat food trees, paipai Guamia mariannae, fadang Cycas circinalis, pago Hibiscus tiliaceus, pengua Macaranga thompsonii, mapunao Aglaia mariannensis. Species forming the undergrowth include Piper guahamense, and epiphytic Bikkia mariannensis, Asplenium nidas, Ophioglossum pendulum and orchids including Taeniophyllum mariannense. Prominent species in the beach strand are nigas Pemphis acidula, nanaso Scaevola taccada, Messerschmidia argentea, in addition to coconut palm Cocos nucifera, ironwood Casuarina equisetifolia, beach morning glory Ipomoea pes-caprae and beach sunflower Wedelia biflora (H. Hirsh, pers. comm., 1990).

Fauna Mammals include Guam deer Cervus mariannus (C. unicolor), and Marianas flying fox Pteropus mariannus (E), for which Pati Point is the most important roosting site on the island 
(G. Wiles, pers. comm., 1990). Approximately 500 individuals are present in the colony which is monitored on a more than weekly basis (H. Hirsh, pers. comm., 1990).

A number of bird species have been recorded in the vicinity of the reserve, or on Andersen AFB, including Guam rail Gallirallus owstoni (E), last seen on Andersen AFB in 1986 and now thought to be extinct in the wild, but the subject of a captive breeding and re-introduction programme; Guam flycatcher Myiagra freycineti (E), formerly abundant but not recorded on Andersen AFB since 1984; bridled white-eye Zosterops conspicillata, declined from 2,000 individuals in 1981 but not seen in the area since 1983 and now thought to be extinct; cardinal honey-eater Myzomela cardinalis, restricted to the area and not observed since 1986; Vanikoro swiftlet Aerodramus vanikorensis, recorded from a single cave on Andersen AFB; Marianas crow Corvus kubaryi, with up to 50 individuals in the north of the air base; rufous-fronted fantail Rhipidura rufifrons, last observed in 1984 and probably now extinct; Marianas fruit dove Ptilinopus roseicapillus (R), last observed in 1985 and possibly now extinct; white-throated ground dove Gallicolumba xanthonura, last observed on 1 January 1986; Micronesian starling Aplonis opaca, which has declined rapidly but is occasionally seen on Andersen AFB; and cardinal honeyeater Myzomela cardinalis, last sighted in 1986 (H. Hirsh, pers. comm., 1990).

Noteworthy reptiles include monitor lizard Varanus indicus (SPREP, 1985) and introduced brown tree snake Boiga irregularis, a species that has been implicated in the widespread decline of native bird species (H. Hirsh, pers. comm., 1990).

A summary description of the reef communities is given in UNEP/IUCN (1988). Chaetodontid, pomacentrid, acanthurid and balistid fish are abundant in the moat area of the reef. Fish are also abundant in the holes, overhangs and crevices of the terrace and slope. Larger game fish and grey sharks have been recorded and hawksbill turtle Eretmochelys imbricata (E) has been seen in deeper slope waters and used to nest on Ritidian Beach, outside the reserve (Pritchard, 1981). Species lists for marine fauna and flora are given in Stojkovich (1977).

Cultural Heritage Archaeological records suggest that Guam was first occupied around 3,500 years ago by peoples from eastern Melanesia; western contact was made by the Spanish in 1521 . An archaeological survey during 1965-66 identified numerous sites, including stone platforms in the Pati Point area. During World War Two, Guam was captured from the Japanese, after which the US Army Corps built and maintained three air bases on the island. On 7 October 1949 two of these, North Field and Northwest Field, were re-designated as Andersen Air Force Base in honour of Brigadier General James Roy Andersen, who served as the Chief of Staff for Headquarters, Pacific Ocean Area from 1944 until his death in 1946.

Local Human Population Andersen Air Force Base had a population of 4,183 during financial year 1990-91 (H. Hirsh, pers. comm., 1990).

\section{Visitors and Visitor Facilities No information}

Scientific Research and Facilities Guam Division of Aquatic and Wildlife Resources and the University of Guam

Conservation Value Guam's avifauna has been severely depleted in the last 10-20 years and many species are now restricted to the north of the island. Although possible reasons for the decline include habitat destruction, avian disease, and the use of pesticides (Arnett, 1983), it is most probable that the introduced brown tree snake is responsible (Carey, 1988). Pati Point Natural Area protects typical Artocarpus forest on cliffs and terraces and thus may provide habitat 
for a number of threatened and endemic species. The reserve is also one the last strongholds of Marianas fruit bat.

Conservation Management Andersen AFB, of which the reserve is a part, is managed in accordance with numerous Department of Defence directives, Air Force Regulations, Public Laws, Territorial Laws, provisions of the National Environmental Policy Act and the 1988-1992 Andersen AFB Fish and Wildlife Management Plan. The normal operations of the base have no detrimental impact on the reserve. The base commander has administrative responsibility for the area, with full authority to make rules and to place restrictions on the use of the area.

Management Constraints The biological value of the site is threatened by brown tree snake.

Staff Comprises one environmental protection specialist and one natural resources planner, operating from the Civil Engineering Squadron.

Budget No information

Local Addresses Base Commander, 633 Air Base Wing, Andersen Air Force Base, Guam 96334

\title{
References
}

Amett, G.R. (1983). Proposed endangered status for seven birds and two mammals from the Mariana Islands. Federal Register 48 (230): 53729-53733.

Carey, J. (1988). Massacre on Guam. National Wildlife 26(5): 13-15.

Pritchard, P.C.H. (1981). Marine turtles of Micronesia. In: Bjorndal, K.A. (Ed.), Biology and conservation of sea turtles. Smithsonian Institution Press, Washington, DC. Pp. 263-274.

Randall, R.H. and Holloman, J. (1974). Coastal survey of Guam. University of Guam Marine Laboratory Technical Report 14. 404 pp. (Unseen).

SPREP (1985). Guam. In: Thomas, P.E.J. (Ed.), Report of the Third South Pacific National Parks and Reserves Conference. Volume III. Country reviews. South Pacific Commission, Noumea, New Caledonia. Pp. 97-98.

Stojkovich, J.O. (1977). Survey and species inventory of representative pristine marine communities on Guam. Guam Coastal Management Program Technical Reports, Agana. (Unseen).

UNEP/IUCN (1988). Coral Reefs of the World. Volume 3. Central and Western Pacific. UNEP Regional Seas Directories and Bibliographies. IUCN, Gland, Switzerland and Cambridge, UK/UNEP, Nairobi, Kenya. 378 pp.

Date December 1989, revised February 1990, December 1990

\section{WAR IN THE PACIFIC NATIONAL HISTORICAL PARK}

\author{
IUCN Management Category V (Protected Landscape)
}

Biogeographical Province 5.02.13 (Micronesian)

Geographical Location The park lies on the westward side of the island of Guam, by the Philippine sea. It comprises several units, including two discontinuous shoreline sections: the 
Asan Unit (Adelup Point west to Gapan Islet) and the Agat Unit (Rizal Beach south to Bangi and Alutom Islands), and several discrete inland units. $13^{\circ} 13^{\prime}-13^{\circ} 22^{\prime} \mathrm{N}, 144^{\circ} 38^{\prime}-144^{\circ} 44^{\prime} \mathrm{E}$

Date and History of Establishment Established by the US National Park Service on 18 August 1978 under Federal Public Law 95-348 as a "multiple-use management area". The legislation authorises the inclusion of the reef areas of Agat and Asan.

Area 779ha

Land Tenure US Federal Government (326ha); Government of Guam (353ha); private property (96ha) and unknown (3.2ha). The land protection plan (NPS, 1984) recommends that privately owned lands within the park be acquired.

\section{Altitude Approximately $65 \mathrm{~m}$ below sea level to $313 \mathrm{~m}$ (Mt Tenjo-Mt Chacao range)}

Physical Features The seven physically separate units comprise Asan Beach Unit, Asan Inland Unit, Fonte Plateau Unit, Piti Unit, Mt Chachao/Mt Tenjo Unit, Agat Unit and Mt Alifan Unit and include sand beaches, offshore reefs, rugged hills and mountain crests (SPREP, 1985). Includes the reef areas of Agat and Asan which encompass the shore and reef flats. These units range from $52 \mathrm{~m}$ to $978 \mathrm{~m}$ in width and have a substrate of a combination of scattered sand, gravel, coral-algal rubble and boulders. The intertidal beaches give way to low limestone cliffs with occasional volcanic headlands. There are some small offshore islands and raised pinnacle limestone rocks. Sections of the shoreline have been altered with artificial structures such as sea walls and sewage outlets (Randall, 1977 quoted in UNEP/IUCN, 1988; Eldredge, 1979).

Climate Tropical, warm and humid throughout the year. Two well-defined seasons occur: a dry season from January to May and a wet season from July to October. Mean annual temperature for 1981 was $25.9^{\circ} \mathrm{C}$. Coolest months are January, February and March, the warmest months May and June. Mean annual rainfall is $2286 \mathrm{~mm}$.

Vegetation There are scattered patches of seagrass Enhalus acoroides, which becomes the dominant marine vegetation in places. Some 43 species of marine plant have been recorded. The sandy beach vegetation is dominated by coconut palm Cocos nucifera, whilst the other areas consist either of modified limestone forest containing breadfruit Artocarpus mariannensis, lemonberry Triphasia tritolion and banyan Ficus prolixa, or open savanna vegetation dominated by grasses Miscanthus floridulus and Pennisetum polystachyon along with ground orchid Spathoglottis plicata, club moss Lypodium cernum and savanna fern Dicranopteris lincaris (SPREP, 1985).

Fauna Coral communities dominate the inner reef formations but vary widely in distribution, and are composed of a moderate number of coral species. Only a few corals are to be found on the outer reef. However, in total, some 140 species have been identified in the Agat area. Studies have recorded 75 species of gastropod, 18 species of bivalves, 45 species of echinoderms and 26 fish species on the coastline (Anon., 1985; Eldredge, 1979).

Cultural Heritage Guam's recapture is an example of island defence and invasion which characterised World War Two operation in the Pacific theatre. The park comprises invasion beaches used in the recapture of Guam and the hills which overlook them. The assault of Guam by US forces in July 1944 was part of the crucial Marianas campaign against Japan's inner defence perimeter. A major theme of the park is the bravery and sacrifices made by all Pacific Island residents, by those who defended as well as those who attacked the islands, and by those who fought on, over, and under the Pacific waters during World War Two (NPS, 1988a). The 
park contains Japanese defensive fortifications including pill boxes, coastal defence guns, military equipment, foxholes and trench works. The two beaches preserved are the assault beaches of the American invasion of 21 July 1944 (SPREP, 1985). There are underwater historic features in the Asan and Agat areas associated with the Pacific Theatre of World War Two (J.E. Miculka, pers. comm., 1990). A description of the major World War Two sites is given by Thompson (1985).

Local Human Population There are four villages adjacent to the park which had a total population of 6,000 in 1990 (J.E. Miculka, pers. comm., 1990). Land use of the park is divided between preservation, agriculture, residential use and commercial activities (Anon., 1985).

Visitors and Visitor Facilities The park comprises seven units, but only small areas of these are open to the public, namely Asan Point in the Asan Beach Unit and Apaca Point and Gaan Point in the Agat Unit. The T. Stell Newman visitor information centre is located on the beach side of Marine Drive in the Asan Beach Unit. Opened in 1982 it includes static displays and audio-visual presentations. Four wayside exhibits were installed at the Asan Beach Unit and at Gaan Point in the Agat Unit. The total number of visitors during FY 1989 was 57,287, of which $50 \%$ were Guamanian, and 38\% were Japanese (Anon., 1990). Facilities include numerous snorkel and scuba diving areas in the Asan Beach and Agit Unit areas, along with fishing and boating. There are also parking areas and numerous scenic points. The World War Two relicts are well marked (Anon., 1985).

Scientific Research and Facilities The Division of Aquatic and Wildlife Resources (Department of Agriculture) has conducted inshore reef research in the Asan Unit. Other surveys have been undertaken by the Department of Biology, University of Guam (Raulerson, 1979). An underwater cultural resource survey is underway (J.E. Miculka, pers. comm., 1990). There is a library with more than 500 volumes, including archival material, approximately 800 photographs and slides and some 800 artifacts. The Arizona Memorial Museum Association cooperates with the park (Anon., 1990).

Conservation Value The purpose of the park is defined in Section 6(a) of Public Law 95-348 as "to commemorate the bravery and sacrifice of those participating in the campaigns of the Pacific theatre of World War II and to conserve and interpret outstanding natural, scenic, and historic values and objects on the island of Guam for the benefit and enjoyment of present and future generations".

Conservation Management The National Historic Preservation Act (1966), as amended and supplemented by Executive Order 11593, placed all national park operations under the procedures of the Advisory Council on Historic Preservation. The entire park is on the National Register of Historic Places, and six sites are individually listed on the register. The general management plan for the park has been approved and implemented (NPS, 1983) and a more recent management statement has been compiled (NPS, 1988b). Conservation management is specified as being to preserve important natural features such as native plant communities and stream and marine bed environments for public use and enjoyment. Shelling, fishing, boating and outdoor recreation activities are permitted (SPREP, 1985). The primary interpretive theme of the park is to interpret the nature and sequence of the Pacific War, the nature, sequence and logistics of the battle for Guam, within the broader Pacific War context, the rôle of the US-NPS, and the natural history of Guam (Anon., 1990). A fire management plan has been compiled (NPS, 1989), the central theme of which is to maintain the vegetation as it appeared prior to the devastating bombardments that preceded the US invasion. The park has a programme to acquire private land (SPREP, 1985). 
Management Constraints There are some problems from fishing with bleach and dynamite (Anon., 1985). Sections of the shoreline have been altered by sea walls and sewage outfalls. Agat Bay is moderately heavily developed (Randall, 1978). Other problems include grassland fires, poaching, illegal dumping (SPREP, 1985), and resort development and related activities with its effect on park resources (J.E. Miculka, pers. comm., 1990). More than 64 tonnes of unexploded munitions remain within the park's offshore areas, and some of the historic structures, such as defensive bunkers, are potentially hazardous (Anon., 1990).

Staff Five permanent members including a superintendent, chief ranger, park ranger and maintenance and administration staff (J.E. Miculka, pers. comm., 1990). Other employees are hired on a limited term contract (SPREP, 1985).

Budget US\$225,000 for the fiscal year 1990 (J.E. Miculka, pers. comm., 1990)

Local Addresses Park Superintendent, War in the Pacific National Historical Park, PO Box FA, Agana, Guam 96910

\section{References}

Anon. (1990). War in the Pacific National Historical Park: statement for interpretation 1990. Unpublished. $12 \mathrm{pp}$.

Eldredge, L.G. (1979). Marine biological resources within the Guam seashore study area and the War in the Pacific National Historical Park. University of Guam Marine Laboratory. Technical Report No. 57.

Miculka, J.E. (1985). Underwater Resource Survey. Report

NPS (n.d.). War in the Pacific National Historic Park, Guam. National Park Service, US Department of the Interior. Leaflet. 2 pp.

NPS (1983). Environmental Assessment General Management Plan: War in the Pacific National Historical Park. National Park Service, US Department of the Interior.

NPS (1983b). General Management Plan: War in the Pacific National Historical Park. US Department of the Interior.

NPS (1986). Natural Cultural Resource Protection Plan 1984-86.

NPS (1984). War in the Pacific: Land Protection Plan. National Park Service, US Department of the Interior. $58 \mathrm{pp}$.

NPS (1988a). War in the Pacific National Historic Park: statement for management. National Park Service, US Department of the Interior. $50 \mathrm{pp}$.

NPS (1988b). War in the Pacific National Historical Park: statement for management. National Park Service, US Department of the Interior. $50 \mathrm{pp}$.

Raulerson, L. (1979). Terrestrial and freshwater organisms within the limnology and hydrology of the Guam seashore study area and the War in the Pacific National Historical Park. Department of Biology, University of Guam.

SPREP (1985). Guam. In: Thomas, P.E.J. (Ed.), Report of the Third South Pacific National Parks and Reserves Conference. Volume III. Country reviews. South Pacific Commission, Noumea, New Caledonia. Pp. 93-114.

Thompson, E. N. (1985). Historic resource study: War in the Pacific National Historic Park, Guam. National Park Service, US Department of the Interior. $189 \mathrm{pp}$.

UNEP/IUCN (1988). Coral Reefs of the World. Volume 3. Central and Western Pacific. UNEP Regional Seas Directories and Bibliographies. IUCN, Gland, Switzerland and Cambridge, UK/UNEP, Nairobi, Kenya. 378 pp.

Date August 1987, revised December 1989, February 1990 


\section{USA - HAWAII}

Area 16,760 sq. $\mathrm{km}$ (land area)

Population $1,062,000(1986)$

Natural increase: No information

GNP No information

Policy and Legislation Legislation exists at both the State and Federal levels. The major texts covering protected areas include the Federal Land Policy and Management Act of 1976 (which requires the inventory, assessment and planning of all federal lands); the Fish and Wildlife Act of 1956; the Coastal Zone Management Act of 1972; the Endangered Species Act of 1973 (streamlined in 1982 and supplemented in 1983 by the International Environment Protection Act); the National Policy Act of 1969; and the Fish and Wildlife Improvement Act of 1978. More specific acts of the US Congress which affect the conservation of areas include the Wilderness Act (16 USC 1131), Water Resources Planning Act of 1965 (42 USC 1962), Concessions Policy Act of 1965 (16 USC 20), and the Solid Waste Disposal Act of 20 October 1965 (PL 89-272). Other acts include the Marine Protection, Research and Sanctuaries Act which authorises the Secretary of Commerce to designate ocean waters as marine sanctuaries. In the case of wetland protection, the main legislative provisions are the Migratory Bird Conservation Act of 1929, the Migratory Bird Hunting and Conservation Stamp Act of 1934, the Pittman-Robertson Act of 1937 and the Land and Water Conservation Fund Act of 1965. Regulations published by the Department of Agriculture in 1983 called for the maintenance of habitats in order to sustain viable populations of flora and fauna. The controlling legislation for the activities of the Fish and Wildlife Service is the Fish and Wildlife Coordination Act of 1958 (16 USC 1531) (a supplement to the $1956 \mathrm{Act}$ ) and a number of international treaties.

The State of Hawaii controls land by three principal means: the Land Use Law, the Hawaii Environmental Impact Statement Law and the Coastal Zone Management Act. The Land Use Law provides for the creation of a Land Use Commission which has classified some $46 \%$ of land area as conservation area, the use of which is cortrolled by the governing Board of the Department of Land and Natural Resources (the Land Board). Land with a Conservation District classification includes national and state parks, lands with a slope of more than 20 degrees or more, land in existing forestry or water reserves, and marine waters and offshore islands. In reality, only lands within the Protective "P" Subzone of the Conservation District are protected for "conservation" reasons, for example all north-western Hawaiian islands with the exception of Midway Atoll (Callies, 1989).

The first modern conservation measures in Hawaii were taken in 1903 when the US Forestry Service established a professional forestry programme. The early focus was on soil and water conservation rather than natural habitats and included removal of feral cattle from forest areas and the establishment of fenced forest reserves. Nevertheless, these measures are believed to have been critical in helping to preserves much of the biological diversity found today (Holt, 1989).

The establishment of national parks in Hawaii was the earliest major project expressly for habitat conservation (Holt, 1989). Hawaii National Park was created on 1 August 1916 by Act of the US Congress (39 Stat. 432) and consisted of two units each on different islands; one on Hawaii Island and the other on Maui Island. The area of the park was more than doubled as a result of Congressional authorization in 1922 (45 Stat. 503), in 1928 (45 Stat. 424) and in 1938 
(52 Stat. 781). The 'Ola'a Forest Tract was donated in 1951 and 1953 (Executive Order \#1640). The park was split into Hawaii Volcanoes National Park (on Hawaii Island) and Haleakala National Park (on Maui Island) in 1961 (75 Stat. 577). Hawaii Volcanoes National Park is protected under 16 USC 1 (National Park Service Organic Act) and under the terms establishing the park as set out in 16 USC 395b, and under several sections of 16 USC 391-396a, which specifically pertain to Haleakala.

The Hawaii Natural Area Reserves System was established under the provisions of Hawaii Revised Statute s. 195-1 et seq. in 1970, to "preserve in perpetuity specific land and water areas which support communities, as relatively unmodified as possible, of the natural flora and fauna, as well as geological sites of Hawaii".

Marine life conservation districts are created by administrative authority of the Division of Fish and Game of the Department of Land and Natural Resources, and are established under the provisions of Hawaii Revised Statute s.190-1. The same Division takes responsibility for state wildlife sanctuaries, also established by administrative action.

International Activities The US ratified the Convention on Wetlands of International Importance especially as Waterfowl Habitats (Ramsar Convention) on 18 December 1986, although no sites have yet been listed in Hawaii. The Convention concerning the Protection of the World Cultural and Natural Heritage (World Heritage Convention) was ratified on 7 December 1973 and Hawaii Volcanoes National Parks was inscribed on the World Heritage List in 1987. The US is also party to the Unesco Man and the Biosphere Programme, and Hawaii Islands Biosphere Reserve, comprising Haleakala and Hawaii Volcanoes national parks, has been accepted as part of the international biosphere network.

The Convention on the Conservation of Nature in the South Pacific has been neither signed nor ratified. Known as the Apia Convention, it entered into force during 1990. The Convention is coordinated by the South Pacific Commission and represents the first attempt within the region to cooperate on environmental matters. among other measures, it encourages the creation of protected areas to preserve indigenous flora and fauna.

The United States is party to the South Pacific Regional Environment Programme, and the 1986 Convention for the Protection of the Natural Resources and Environment of the South Pacific Region (SPREP Convention) has been signed (25 November 1986) but not yet ratified. The Convention entered into force during August 1990. Article 14 calls upon the parties to take all appropriate measures to protect rare or fragile ecosystems and threatened or endangered flora and fauna through the establishment of protected areas and the regulation of activities likely to have an adverse effect on the species, ecosystems and biological processes being protected. However, as this provision only applies to the Convention area, which by definition is open ocean, it is most likely to assist with the establishment of marine reserves and the conservation of marine resources.

Administration and Management The National Park Service (NPS) was established by the Act of 25 August 1916 (39 Stat. 535) under the Federal Department of the Interior. National parks and other categories of lands within the national park system are established by individual acts of Congress, except national monuments which can be created by the President on Federal lands, by proclamation under the authority of the Antiquities Act of 8 June 1906. The Service manages Hawaii Volcanoes National Park and Haleakala National Park to preserve outstanding scenic, geological, and biological values, and to ensure their availability for public use and 
enjoyment to the extent compatible with resource preservation. NPS historic areas have different primary management goals, although natural resource conservation is required.

The responsibility for management and administration of the public lands of the state of Hawaii rests with the Board of Land and Natural Resources, appointed by the Governor. Actions of the Board are carried out by the Department of Land and Natural Resources' six divisions: Land Management, Conveyances, Forestry, Fish and Game, State Parks, Outdoor Recreation and Historic Sites, and Water and Land Development (HRS s.171-3). The Division of State Parks, Outdoor Recreation and Historic Sites carries the responsibilities for preserving state parks "in their natural condition so far as may be consistent with their use and safety", while making improvements for the use and enjoyment of the public. The Division of Fish and Game, amongst other responsibilities, manages marine life conservation districts, wildlife refuges and bird sanctuaries under authority granted by law through regulations of the Board of Land and Natural Resources. The Division also acts in advisory capacity to the State Natural Area Reserves Systems Commission. The Division of Forestry manages the State's forest resources in a series of forest reserves, under the principle of multiple use, namely: protection and management of water resources; forest recreation; forest management, including timbering, fire and pest control and reforestation; grazing; and protection and conservation of wildlife habitat and natural forest ecosystems. In the area of flora and fauna preservation, the goal of the Forestry Division is to "protect and preserves unique native plant and animal species, and examples of relatively unmodified native forest ecosystems for their productive value to science, education and the cultural or scientific enrichment or satisfaction of future generations".

The Natural Area Reserves System Commission, appointed by the Governor of Hawaii, and part of the Hawaii Department of Land and Natural Resources, the major state land management agency, recommends, to the Department and the Governor, areas for inclusion; recommends policies on controls and uses of areas within the system; advises on preservation of natural areas; and develops ways to extend and strengthen established natural areas. The Governor must approve the nominations by Executive Order. Once an area is included in the system, removal, except through trade for another area, is also through Executive Order. Natural area reserves are selected on the basis of diversity, rarity and viability (TNCH and DFW, 1989).

The Fish and Wildlife Service administers the National Wildlife Refuge System, including Hawaiian Islands NWR, which, according to statute, aims to preserve and manage the habitats of waterfowl, threatened species, big game and other fauna and flora.

The Nature Conservancy of Hawaii (TNCH) was founded in 1980 as an affiliate of a nation-wide, non-profit conservation organisation which had its beginnings in 1917 and is the leading non-governmental organisation in the field of nature conservation in Hawaii. The mission of both the national and Hawaii groups is "to find, protect, and maintain the best examples of communities and ecosystems, and endangered species in the natural world". Through conventional real estate negotiations and innovative practices such as "conservation easements" (paying landowners for allowing use of their land for conservation), TNCH has acquired, and is continuing to acquire, key natural areas. TNCH makes extensive use of volunteer workers, and includes a Board of Trustees (largely comprising influential business people) and a Scientific Advisory Committee, comprising University, State, private and Federal scientists. TNCH has developed the Hawaii Heritage Program (HHP), a sophisticated inventory and database to optimise the selection of further acquisitions (Stone and Holt, 1987; Newman, 1989).

Systems Reviews The Hawaiian Archipelago is the longest and most isolated chain of tropical islands in the world, stretching about $2,300 \mathrm{~km}$ from Hawaii in the south-east to Kure Atoll in 


\section{IUCN Directory of Protected Areas in Oceania}

the north-west. Considerable geophysical evidence suggests that the entire chain formed as a result of tectonic motion of the Pacific plate over a relatively stationary hotspot in the mantle of the earth. Hawaii, the youngest island at about 0.8 million years old, is situated over the hotspot and contains the most active volcano in the world, Kilauea, included within Hawaii Volcanoes National Park. Steady crustal movement is transporting each island land mass north-westwards, eventually breaking connection with the hotspot. As a result, the islands to the north-west of Hawaii become progressively older and more effected by subsidence and erosion. All of the islands north-west of Gardner Pinnacles, the last island in the chain with subaerial basalts, are either atolls, coral islands or reefs and shoals of limestone construction. Midway Atoll, the second to last island in the chain, has been dated at $27+/-0.6$ million years old. Beyond Kure Atoll the chain continues as a series of drowned atolls or seamounts which extend all the way to Kamchatka (UNEP/IUCN, 1988).

The geography of the Hawaiian Islands is complex. Those islands to the south-east are the summits of some of the largest mountains in the world, measured from their bases, Mauna Loa extending some $9,756 \mathrm{~m}$. Some of the older high islands are deeply eroded with spectacular river valleys such as Waipio Valley in Hawaii, Iao Valley on Maui and Halawa Valley on Molokai. All of these are heavily vegetated with many endemic species of flora and fauna. A rise in sea level of approximately $130 \mathrm{~m}$ during the Holocene has created many bays and estuaries in the drowned heads of river valley systems, particularly on the older islands. The islands to the north-west are much simpler because they are low rocky islets or coral islands at sea level. The climate is mainly tropical but approaches sub-tropical in the extreme north-west. Mild temperatures, moderate humidity and persistent north-easterly tradewinds are typical, whilst rainfall patterns that can vary from very heavy to very light, mainly influenced by altitude, have encouraged the development of a wide variety of terrestrial ecosystems (UNEP/IUCN, 1988).

The native vegetation of Hawaii varies greatly according to altitude, prevailing moisture and substrate. The most recent classification of Hawaiian natural communities recognises nearly 100 native vegetation types categorised in a hierarchy of elevation, moisture and physiognomy. Within these types are numerous island-specific or region-specific associations: an extremely rich array of vegetation types occurs within a very limited geographic area. Major vegetation formations include forests and woodlands, shrublands, grasslands (including savannas, tussock grasslands, and sedge-dominated associations), herblands, and pioneer associations on lava and cinder substrates (IUCN, 1991).

Forest formations include subalpine, montane and lowland, extending from sea level to above $3,000 \mathrm{~m}$ on the slopes of the region's highest mountain. Coastal forests are found on one of the north-western Hawaiian Islands, an offshore islet near Molokai, and other main islands of Kaua'i, O'hau, Moloka'i, Maui and Hawaii. Lowland forest occurs below $1,000 \mathrm{~m}$ on Kaua'i, O'hau, Moloka'i, Maui, Lana'i and Hawaii. Historically such forests were present on the islands of Ni'ihau and Kaho'olawe, but these were lost to development or displaced by alien species. Montane forests are found between 1,000 and $2,000 \mathrm{~m}$ and are dry to mesic on leeward slopes and mesic to wet on windward slopes. Montane forests are well developed on Kaua'i, Moloka'i, Maui and Hawaii. On the islands of Lana' $i$ and $O$ 'hau, the highest forests are similar to montane wet forests on higher islands, but these forests occupy limited area and include lowland elements. Subalpine forests are known only from the two largest and geologically youngest islands: Maui and Hawaii. Shrubland formations are also found, ranging in altitude from sea level to sub-alpine. Most types are in dry and mesic settings that limit forest formations, or on cliffs or slopes too steep to support trees. Eleven native Hawaiian grassland types, including sedge-dominated associations are found in coastal, lowland, montane and subalpine regions. Hawaiian herblands 
are also found across the full altitudinal range. Pioneer vegetation is well developed in the active and recent volcanic settings of the islands of Maui and Hawaii.

In spite of their low diversity, coral reefs are well developed. Their community structure, succession and development throughout the archipelago has been reviewed by Grigg (1983). Reefs are best developed on leeward (south and south-western) coasts or in bays sheltered from wave action. These include many sites along the Kona Coast and Kealakekua Bay on Hawaii, Molokini "lagoon", the south-east coast of Molokai, Hanauma Bay and some reefs near Barbers Point on Ohau, and the lagoons of the north-western Hawaiian Islands, including Midway and Kure (UNEP/IUCN, 1988). Other important coastal ecosystems include marshes, streams and stream-mouth estuaries, lagoons and beaches.

The Hawaiian biota is characterised by both a high diversity and endemism, caused by 40 million years of isolation and adaptive radiation. The native flora is estimated at some 1,000-1,500 species, whilst arthropods number 6,500-10,000 and native bird species about 100. However, extinction, or the threat of extinction, is also characteristic, and although Hawaii possesses only some $0.2 \%$ of the land mass, and $14.3 \%$ of the native birds and plants of the United States, it contains $27.8 \%$ of the threatened birds and plants and $72.1 \%$ of extinct birds and plants (DLNR, n.d.). Nine endemic bird species have populations of less than 50 individuals and at least 57 bird species have become extinct, most in the last 200 years. Ayensu and DeFilipps (1978) list 646 candidate "endangered" species, 197 candidate "threatened" and 270 presumed extinct plant species, subspecies and varieties in the Hawaiian islands, which together comprise some $50 \%$ of the total indigenous flora. This is largely due to the impact of introduced flora and fauna and introductions can be traced back to the arrival of Polynesians around AD400, who were accompanied by domestic pigs, jungle fowl, dogs, Polynesian rats and various stowaway geckoes, skinks and snails. The Polynesians also actively cultivated the land and as much as $80 \%$ of the lowland forest was drastically effected. European visitors, from 1778 onwards, introduced goats (1778), cattle and sheep (1793), horses (1803), axis deer (1867), European pigs and more recently pronghorn antelope, mouflon sheep, brush-tailed rock wallaby, Rocky Mountain mule deer and Columbian black-tailed deer (Degener and Degener, 1961) as well as numerous plants. At least 111 new plant arrivals are recorded between 1778 and 1839 and in total there are some 4,500 exotic plants throughout the islands (Berger, 1975), although only some $2 \%$ of these are serious invaders of native ecosystems (Stone and Loope, 1987). As many as 16 insects are accidentally introduced annually (Beardsley, 1962). The most severe documented impacts have been caused by feral goats, through grazing on species that have evolved in the absence of such pressure, and pigs, by encouraging the dispersal of exotic plant species and the direct effect of their digging activities (Atkinson, 1977; Stone and Loope, 1987). One specific example of the impact of introduced species is the severe damage to the fragile ecosystem of Laysan Island by rabbits; as a direct result of this, several endemic terrestrial birds became extinct, namely Laysan millerbird Acrocephalus familiaris familiaris, Laysan honeycreeper Himatione sanguinea freethi, and Laysan rail Porzana palmeri (Anon., 1985)

Terrestrial protected areas management priorities almost invariably include programmes to control non-native species, and activities including fencing, live- and kill-trapping, baiting and snaring. Programmes to eliminate exotic flora have been developed, including the use of selective herbicides. The prospects for long-term survival of native species within protected areas depends on the intensity of long-term management. There is evidence that native flora will survive if pigs and goats are held in check, and that native birds in turn will survive if sufficient habitat remains, as will native invertebrates, although exotic ants, rats and mongooses will have to be controlled 
(Stone and Loope, 1987). It is also common practice to allow hunting by members of the public, and hunting is frequently carried out by managers of protected areas.

Both national parks were established principally on the basis of their geological interest and while they also contain significant biological resources they do not protect the entire range of habitat for native taxa (R. Kam, pers. comm., 1991). Thus the acquisitions and easements of The Nature Conservancy of Hawaii, the State Natural Areas Reserve System, forest reserves and the national wildlife refuge are key elements in the conservation of biological diversity. The Natural Areas Reserves System currently covers 20 sites which were selected on the basis of biological diversity and relatively undamaged natural conditions. Holt (1989) discusses the effectiveness with which both State and Federal protected areas achieve conservation goals, and also provides a definition of protected natural area which demands lasting legal protection from destructive uses and an active management programme. State forest reserves and conservation districts are judged not to meet the definition; State natural area reserves, sanctuaries and Alaka'i Wilderness Preserve meet the definition in general as do the preserves of The Nature Conservancy; National parks, and the national wildlife refuges are deemed to have effective legal protection and the most comprehensive management programmes of any class of protected area in the State. The existing network, which includes Federal, State and private protected areas, is considered to protect 46 of the 180 natural communities recognised by The Nature Conservancy. Some 88 community types which lie outside the current network are regarded as being in critical need of protection. Holt (1989) makes three recommendations for the further development of the protected areas network: the protection of critically imperilled natural communities must be ensured; active management must be established in existing areas; and conservation techniques for island ecosystems must be developed.

Demand on land around protected areas is increasing, removing buffering areas and reducing still further the extent of near-native ecosystems. Other threats include geothermal and other energy developments, hunting and recreational uses, ranching, agriculture and timber management, housing and heavy industry (Stone and Loope, 1987).

\section{Addresses}

National Park Service, Pacific Area Office, 300 Ala Moana Boulevard, Box 50165, Room 6305, Honolulu, HI 96850

Fish and Wildlife Service, National Wildlife Refuge Complex, 300 Ala Moana Boulevard, PO Box 50167, Room 5302, Honolulu, HI 96850

The Nature Conservancy of Hawaii, 1116 Smith Street, Suite 201, Honolulu, HI 96817 (Tel: 808 537 4508; FAX: 808545 2019)

Department of Land and Natural Resources, 1151 Punchbowl Street, Honolulu

\section{References}

Anon. (1985). Plan approved for three songbirds of the northwestern Hawaiian Islands. Endangered Species Technical Bulletin 10 (2): 8-10

Atkinson, I.A.E. (1977). A reassessment of factors, particularly Rattus rattus L., influencing the decline of endemic forest birds in the Hawaiian Islands. Pacific Science 31(2): 109-113. Ayensu, E.S. and DEFilipps, R.A. (1978). Endangered and threatened plants of the United States. Smithsonian Institution and World Wildlife Fund-US, Washington. 403 pp.

Berger, A.J. (1975). Hawaii: a dubious distinction. Defenders 50(6): 491-496. 
Callies, D.L. (1989). Land use planning and priorities in Hawaii. In: Stone, C.P. and Stone, D.B. (Eds.), Conservation biology in Hawaii. University of Hawaii Cooperative National Park Resources Study Unit, Honolulu. Pp. 163-167.

Degener, O. and Degener, I. (1961). Green Hawaii: past, present and future of an island flora. Pacific Discovery 14(5): 14-17.

DLNR (n.d.). Preserving Hawaii's natural treasures: Hawaii's natural area reserves system. Department of Land and Natural Resources, Honolulu. Brochure.

Davis, S.D., Droop, S.J.M., Gregerson, P., Henson. L., Lamlein Villa-Lobos, J., Synge, H. and Zantovska, J. (1986). Plants in Danger: What do we know? IUCN, Gland, Switzerland and Cambridge, UK. 488 pp.

Grigg, R.W. (1983). Community structure, succession and development of coral reefs in Hawaii. Marine Ecology Programme Series 11:1-14

Holt, A. (1989). Protection of natural habitats. In: Stone, C.P. and Stone, D.B. (Eds), Conservation biology in Hawaii. University of Hawaii Cooperative National Park Resources Study Unit, Honolulu. Pp. 168-174.

The Nature Conservancy of Hawaii and Division of Forestry and Wildlife (1989). State of Hawaii, Natural Areas Reserves Systems: Biological Resources and Management Priorities. Summary Report. 26 pp.

Newman, A. (1989). Biological databases for preserve selection. In: Stone, C.P. and Stone, D.B. (Eds.), Conservation biology in Hawaii. University of Hawaii Cooperative National Park Resources Study Unit, Honolulu. Pp. 154-157.

Stone, C.P. and Holt, R.A. (1987). Managing the invasions of alien ungulates and plants in Hawaii's natural areas. Unpublished report. $23 \mathrm{pp}$.

Stone, C.P. and Loope, L.L. (1987). Reducing negative effects of introduced animals on native biotas in Hawaii: what is being done, what needs doing, and the role of the national parks. Environmental Conservation 14(3): 245-258.

UNEP/IUCN (1988). Coral Reefs of the World. Volume 3. Central and Western Pacific. UNEP Regional Seas Directories and Bibliographies. IUCN, Gland, Switzerland and Cambridge, UK/UNEP, Nairobi, Kenya. 378 pp.

Date March 1991

\section{ANNEX 1}

Definitions of protected area designations, as legislated, together with authorities responsible for their administration

Title (English): Rules regulating Wildlife Sanctuaries, Department of Land and Natural Resources, Title 13, Subtitle 15 Forestry and Wildlife, Part 2 Wildlife, Chapter 125

Date: No information

Brief description: To conserve, manage and protect indigenous wildlife in sanctuaries Administrative authority: Board of Land and Natural Resources 


\section{Designations:}

Wildlife sanctuaries The following activities are prohibited except for agents of the Board and except as authorised by the Board or its authorised representative: to remove, disturb, injure, kill, or possess any form of plant or wildlife; to possess or use any firearm, bow and arrow, or any other weapon, trap, snare, poison, or any device designed to take, capture or kill wildlife; to discharge any weapon on or into a wildlife sanctuary; to possess any explosives or fireworks; to introduce any form of plant or animal life; to start or maintain a fire; to camp or erect any structure; to enter into any area posted "No Trespassing Area"; to remove, damage, or disturb any notice, sign, marker, fence, or structure; to dump, drain, or leave any litter, toxic material, or other waste material except in trash receptacles or areas designated for the deposit of refuse; to enter or remain upon any surface water area; to park, land, or operate any air, water, or land vehicle except on roads and in areas designated for such use.

\section{Title (English): Rules regulating activities within Natural Area Reserves, Department of Land and Natural Resources, Title 13, Subtitle 9, Chapter 209, Natural Area Reserves System}

Date: No information

Brief description: Regulates and prohibits activities within natural area reserves, including provisions for excepted-use activities by permit and penalties for violation of the regulation.

Administrative authority: Board of Land and Natural Resources

Designations:

Natural area reserve Those State lands that have been designated as part of the Hawaii natural area reserves system by the Department pursuant to Section 195-4, Hawaii Revised Statutes

- Permitted activities include hiking, nature study and bedroll camping without a tent or other temporary structure. Hunting is a permitted activity pursuant to hunting rules of the department.

- It is prohibited: to remove, injure, or kill any form of plant or animal life, except game mammals and birds hunted according to Department rules; to introduce any form of plant or animal life, except dogs when permitted by hunting rules of the Department; to remove, damage, or disturb any historic or prehistoric remains; to remove, damage, or disturb any notice, marker, or structure; to engage in any construction or improvement; to engage in any camping activity that involves the erecting of a tent or other temporary structure; to start or maintain a fire; to litter, or to deposit refuse or any other substance; to operate any motorised or unmotorised land vehicle or air conveyance of any shape or form in any area, including roads or trails, not designated for its use; to operate any motorised water vehicle of any shape or form in freshwater environments, including bogs, ponds and streams, or marine waters, except as otherwise provided in the boating rules of the Department of Transportation, State of Hawaii; to enter into, place any vessel or material in or on, or otherwise disturb a lake or pond. 


\section{Map $^{\dagger}$ Name of araa \\ ref.}

\section{IUCN management category}

Area

(ha)
Year notified

Biosphere Reserves

1 Hawaii Islands (comprises Haleakala and Hawaii Volcanoes national parks)*

IX

99,545

1980

World Heritage Sites

2 Hawaii Volcanoes National Park*

$\mathrm{X}$

92,964

1987

National Parks

3 Haleakala*

II

11,728

1916

4 Hawaii Volcanoes*

II $\quad 91,960$

1916

Preserves of The Nature Conservancy of Hawaii

$\begin{array}{ll}5 & \text { Honouliuli* } \\ 6 & \text { 'Ihi'ihilauakea* } \\ 7 & \text { Kaluahonu* } \\ 8 & \text { Kamakou* } \\ 9 & \text { Kanepu'u* }\end{array}$

Private

Private

Private

Private

Private

10 Kapunakea*

11 Maui Lava Tubes*

Private

Private

12 Mo'omomi*

13 Pelekunu*

Private

Private

Pu'u Kukui Watershed Management Area*

Private

Private

$\begin{array}{rr}1,495 & 1990 \\ 12 & 1987 \\ 86 & 1982 \\ 1,123 & 1982 \\ 187 & 1990 \\ 486 & 1990 \\ 43 & 1987 \\ 372 & 1988 \\ 2,332 & 1987 \\ 3,239 & 1988 \\ 2,117 & 1983\end{array}$

Marine Life Conservation Districts

16 Hanauma Bay

IV

IV

41

1967

17 Honolua-Mokuleia Bay

18 Kealakakua Bay

19 Lapakahi

20 Manele-Hulopoe

IV

128

1978

1969

59

1979

IV

IV

125

1976

1981

IV

IV

1983

22 Pupukea

23 Wailea Bay

14

1985

Natural Reserves

24 Ahihi-Kinau

IV

1973

National Wildlife Refuges

25 Hakalau

IV

IV

16,706

1985

Hanalei

IV

393

1972

27 Hawaiian Islands (8 sites)*

103,068

1945

IV

97

1973

29

IV

$31 \quad$ Kilauea Point

IV

65

1974 
Map $^{\dagger}$ Name of area

ref.
IUCN management category

Unassigned

IV

Unassigned

Unassigned

Unassigned

IV

IV

1,763

IV

IV

IV

IV

IV

IV

IV

IV

IV

IV

IV

IV

IV

IV

IV

IV

IV

IV

II

II

V

828

3,036

1,275

5

6,772

2,260

662

3,196

10,344

1,577

445

662

266

538

4,901

4,106

259

2,714

4,343

470

73

Unassigned

Unassigned

Unassigned

Unassigned

Unassigned

Unassigned

Unassigned

Unassigned

49

\section{8}

3

Year notified

1988 
Map $^{\dagger}$ Name of area

ref.

IUCN management

Area

(ha)

Year category notified

$\begin{array}{ll}68 & \text { Kokee } \\ 69 & \text { MacKenzie } \\ 70 & \text { Mauna Kea } \\ 71 & \text { Na Pali } \\ 72 & \text { Old Kona Airport } \\ 73 & \text { Palaau } \\ 74 & \text { Polihale } \\ 75 & \text { Sacred Falls } \\ 76 & \text { Sand Island } \\ 77 & \text { Wahiawa } \\ 78 & \text { Waianapanapa } \\ 79 & \text { Wailua River } \\ 80 & \text { Wailuku River } \\ 81 & \text { Waimea Canyon }\end{array}$

Unassigned

1,738

Unassigned

5

Unassigned

203

Unassigned

2,600

Unassigned

48

Unassigned

96

Unassigned

57

Unassigned

549

Unassigned

34

Unassigned

27

Unassigned

49

Unassigned

451

Unassigned

33

Unassigned

746

\section{State Wildlife Sanctuaries}

82 Hawaii State (39 islets)

83 Kure Atoll

I 58

* Site is described in this directory.

${ }^{\dagger}$ Locations of most protected areas are shown in the accompanying map. 


\section{IUCN Directory of Protected Areas in Oceania}

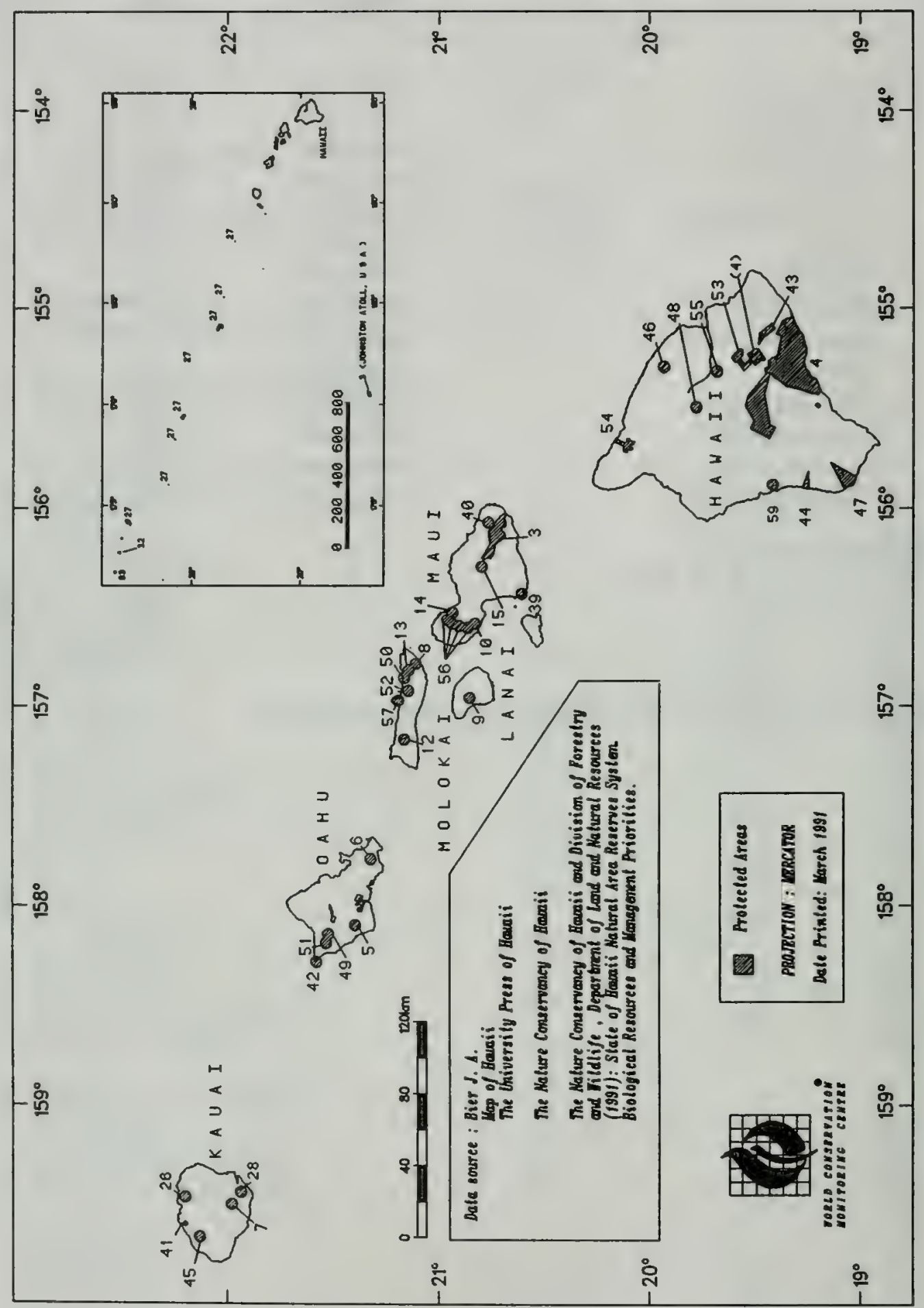

Protected Areas of Hawaii 


\section{HALEAKALA NATIONAL PARK}

\section{IUCN Management Category II (National Park); IX (Biosphere Reserve)}

\section{Biogeographical Province 5.03 .13 (Hawaiian)}

Geographical Location Maui County in the eastern portion of Maui Island, State of Hawaii. 2039'-2047'N, 15602'-15616'W.

Date and History of Establishment Legal status since 1916 when authorised as part of Hawaii National Park under Act of United States Congress (39 Stat. 432). Separated from Hawaii Volcanoes National Park in 1960 and given full national park status in 1981 (75 Stat. 577). Accepted as a biosphere reserve in 1980, together with Hawaii Volcanoes National Park.

Area 11,462 ha with biosphere reserve status which applies only to all park land above the $366 \mathrm{~m}$ contour line. National park area is 11,605 ha.

Land Tenure Federal 97.8\%; private 2.2\%. The Federal government has exclusive jurisdiction over all lands within the park boundaries.

\section{Altitude $0-3,055 \mathrm{~m}$}

Physical Features The park extends from the summit of Mount Haleakala, south-eastward to the coast. The $900 \mathrm{~m}$ deep "crater" is a water-carved depression resulting from erosion by two major streams, which has subsequently been partly filled by later lava flows and numerous cinder cones. The topography of the crater, which is $43 \mathrm{~km}$ in circumference, consists of vents, lava tubes and flows, basaltic dikes, and rock, stone and cinder deserts. There is no evidence of major eruptions in the last 1,200 years, but in 1790 two minor flows at lower elevations appear to have altered the coastline outside the park. Kipahulu Valley is located on Haleakala's eastern flank. As with the crater, it was formed by stream erosion and partly refilled by lava flows, which helped to produce the distinctive $152 \mathrm{~m}$ escarpment which divides the area lengthwise. It is characterised by a large number of small gulches; exceptionally poor vertical drainage; bogs; and deadfall 'ohi'a, making this valley one of the most impenetrable and inhospitable areas in the State.

Climate Subjected to the north-east trades for $70 \%$ of the time, the climate ranges with altitude from tropical humid to alpine desert with the mean annual rainfall ranging from 250 to $1000 \mathrm{~mm}$; the mean temperature ranges from $0 \mathrm{C}$ to $20 \mathrm{C}$. Rain and fog occur all year round.

Vegetation At least nine ecosystems are found in the park, ranging from small enclaves of only a few hectares to major expanses on the mountain; each comprises its own unique plant and animal communities. The western slope of Mount Haleakala above $2,833 \mathrm{~m}$, and most of the central and western end of the crater, supports an alpine desert vegetation, including the threatened Haleakala silversword Argroxiphium sandwicense. Across the crater on the ridges above Paliku two native Deschampsia grassland communities occur. They are noteworthy in that one of them represents the highest elevational and least disturbed tussock ecosystem in the State and it is the only grassland of its kind in the United States. It includes several endemic species, some of which are threatened. Immediately below the Deschampsia grasslands a narrow band of alpine shrub-scrub vegetation acts as a buffer between the open summits and the 'ohi'a rain forest. Dominant shrub genera of these upper slopes and crater include Styphelia, Vaccinium, Coprosma, and Sophora. The Hana 'ohi' a rain forest of the north and east slopes stretches from around $610 \mathrm{~m}$ up to the trade wind inversion at about $2,074 \mathrm{~m}$. Although much of this habitat lies 
outside the park boundaries, an important segment is found within the north central corner of the park. This area, with its extremely dense rain forests, high rainfall and precipitous gulches, represents one of the most inaccessible and consequently most pristine forests in the State and is the habitat of many rare plants. Below $1,220 \mathrm{~m}$ the Kipahulu Valley rain forest is characterised by a koa Acacia koa canopy, with tree ferns, 'ohi' $a$, and many other native plants forming the understorey. Kipahulu Valley is one of the richest botanical regions in Hawaii, with genera such a Metrosideros and Cheirodendron. As in the Hana rain forest, this area contains many uncommon plant species. In the "Waianapanapa" of the Hana rain forest, and to a lesser extent in Kipahulu Valley, there are a number of bogs and several ponds; one of these being one of only two natural lakes in Hawaii. Between this feature and the Deschampsia grasslands is Flattop $\mathrm{Bog}$, at nearly $2,316 \mathrm{~m}$ the highest altitude bog in Hawaii. These bog areas are believed to contain valuable pollen records. Nearby is critical habitat for the rare greensword Argroxiphium virescens, a relative of the silversword. Of the two species originally found here, one is thought to be extinct as a result of early grazing activities. The Kaupo area supports remnant dryland forest of Pleomele and Planchonella. Threatened Santalum haleakalae and Geranium arboreum are found on the north-west slopes.

Fauna Native fauna are limited to birds, insects and a few aquatic organisms present in the streams of Kipahulu. Threatened birds include Maui akepa Loxops coccinea ochracea (recently sighted for the first time in 30 years), Hawaiian goose or nene Brania sandvicensis (V), Maui parrotbill Pseudonestor xanthophrys, crested honeycreeper Palmeria dolei, Maui nukupu'u Hemignathus lucidus affinus, dark-rumped petrel or uao Pterodroma phaeopygia sandwichensis (limited to small breeding populations on Haleakala and to a much lesser extent on the islands of Hawaii and Lanai) and po'o uli Melamprosops phaeosoma. Other endemic birds are 'i'iwi Vestiaria coccinea, Maui 'amakihi Loxops virens wilsoni, 'apapane Himatione sanguinea, Maui creeper Loxops maculatas newtoni, and pueo Asio flammeus sandwichensis. Indigenous birds include white-tailed tropic bird Phaethon lepturus dorotheae and golden plover Pluvialis dominica. The diverse speciation of the invertebrate fauna represents a highly valuable evolutionary resource. Numerous endemic insects are found, over $20 \%$ of them unique to Mount Haleakala. There are many rare Drosophila flies found only in the Paliku area and Kipahulu Valley, including the largest Drosophila in the world and the rare freshwater lizard goby Lentipes concolor. The alpine desert area has flightless forms of 25 insect species. An unusual predatory caterpillar is also found. Common freshwater fauna include 'o'opu (a small goby-like fish), 'opae (a small shrimp), and hihiwai (a freshwater limpet).

Cultural Heritage The cultural heritage of the park is very rich and has been recognised by listing all of Crater District on the National Register of Historic Places as Crater Historic District. In addition, the lower portion of Kipahulu District has been determined eligible for the National Register as Kipahulu Historic District. Nevertheless, the cultural resources of the park have only been partially inventoried and evaluated.

\section{Local Human Population No information}

Visitors and Visitor Facilities Two visitor centres and two public campgrounds.

Scientific Research and Facilities A National Park Service scientist has been resident in the park since 1980. Since 1973, the Cooperative National Park Resources Studies Unit (CPSU) at the University of Hawaii has produced numerous technical reports concerning the components of the park's ecosystems; this research is continuing. The University of Washington CPSU has conducted biological studies on two endangered birds, dark-rumped petrel and nene. The US Fish and Wildlife Service is analysing data from a survey of endangered birds on Haleakala. 
Independent research projects are being conducted on several general or endemic plant species including Argyroxiphium, Dubautia, and Tetramolopium. Research is oriented towards study of the high degree of endemicity, adaptive radiation genetics and evolutionary trends. There is a small research laboratory facility with office space and an adjoining dormitory for visiting researchers.

\section{Conservation Value No specific information}

Conservation Management Since 1916 protected under 16 USC National Park Service Organic Act, also under terms establishing the park as set out in 16 USC 395b, and under several sections of 16 USC 391-396a which specifically pertain to Haleakala. Section 394 states that "The regulations promulgated shall provide for the preservation from injury of all timber, birds, mineral deposits, and natural curiosities or wonders within said park, and their retention in their natural condition as nearly as possible", while Section 395c states that "All hunting or the killing, wounding, or capturing at any time of any wild bird or animal, except dangerous when it is necessary to prevent them from destroying human lives or inflicting personal injury, is prohibited within the limits of said park in any other way than by hook and line, and then only at such seasons and in such times and manner as may be directed by the Secretary of the Interior."

Much of the Kipahulu Valley is closed to public entry, access being limited to scientific research and for purposes of resource management. The Kipahulu Coastal Area is not connected by roads to the Haleakala Crater.

The park is divided into five management areas: General Outdoor Recreation Area, 280ha; Natural Environment Area, 1,363ha; Outstanding Natural Area, 4,690ha; Primitive Area 4,712ha; and Historical and Cultural Sites, 1ha. It also contains Kipahulu and Crater Historic District, totalling 7,263ha, and the designated Haleakala Wilderness of $10,028 \mathrm{ha}$; these areas overlap for the most part.

Management Constraints Man and introduced feral pigs Sus scrofa, and, in the past, goats, cattle and horses, have had a serious impact on the mountain area, altering the native ecosystems through the destruction of the native biota and accelerated erosion. This has allowed exotic vegetation to establish itself in many areas of the park. Invading species include guava Psidium cattleyanum, kikuyu grass Pennisetum clandestinum, Yorkshire fog Holcus lanatus, and Maui pamakani Eupatorium adenophorum. Active management in progress will largely remove introduced goats within the next few years. Native fauna have also been affected through predation by such exotic species as rats, mongoose, mice, feral cats and dogs, vespid wasps and Argentine ants. The native Deschampsia grasslands are ravaged by feral pigs and goats but are also heavily used by nene Branta sandvicensis.

Staff There are 16 permanent and full-time employees and 12-20 seasonal employees.

Budget Approximately US\$1,491,000 were budgeted for 1991 with an additional US\$150,000 for scientific research, and US\$ 300,000 for project specific biological resource management.

Local Addresses Superintendent, Haleakala National Park, P O Box 369, Makawao, Maui, HI 96768

\section{References}

Beardsley, J. (1980). Haleakala National Park Crater District resources basic inventory: insect. Cooperative National Park Resources Studies Unit Report No. 31. University of Hawaii. 
Carlquist, S. (1970). Hawaii, a natural history. American Museum of Natural History. 463 pp. Conant, S. and Stemmermann, M. (1979). Haleakala National Park Crater District Resources Basic Inventory: Birds. Cooperative National Park Resources Studies Unit Report No. 26. University of Hawaii.

Degner, O. (Rev. 1975). Plants of Hawaii national parks. Braun-Brunfield Inc. 312 pp.

Herat, T., Higashino, P.K. and Smith, C.W. (1981). Haleakala National Park Crater District resources basic inventory: ferns and fern allies. Cooperative National Park Resources Studies Unit Report No. 39. University of Hawaii.

Higashino, P. K., Cuddihy, L.W., Anderson, S.J. and Stone, C.P. (1988). Bryophytes and vascular plants of Kipahulu Valley, Haleakala National Park. Cooperative National Park Resources Studies Unit Report No. 65. University of Hawaii.

Hoe, W. J. 1979. Haleakala National Park Crater District resources basic inventory: mosses. Cooperative National Park Resources Studies Unit Report No. 25. University of Hawaii.

Jacoby, J. D. 1989. Vegetation maps of the upland plant communities on the Islands of Hawaii, Maui, Molokai and Lanai. Cooperative National Park Resources Studies Unit Report No. 68. University of Hawaii.

MacDonald, G. A. and Abbott, A.T. (1970). Volcanoes in the Sea: The Geology of Hawaii. University of Hawaii Press. 440 pp.

Smith, C. W., Williams, J.E. and Asherman, K.E. (1985). Vegetation map and resource management recommendations for Kipahulu Valley (below 700 meters), Haleakala National Park. Cooperative National Park Resources Studies Unit Report No. 53. University of Hawaii.

Stemmermann, L., Smith, C.W. and Hoe, W.J. (1979). Haleakala National Park Crater District resources basic inventory: 1967-77. Cooperative National Park Resources Studies Unit Report No. 24. University of Hawaii.

Stemmermann, L., Higashino, P.K. and Smith, C.W. (1981). Haleakala National Park Crater District resources basic inventory: conifers and flowering plants. Cooperative National Park Resources Studies Unit Report No. 38. University of Hawaii.

Whiteaker, L. D. (1980). Vegetation map - Haleakala National Park. Cooperative National Park Resources Studies Unit Report No. 35. University of Hawaii.

Date 1982, revised August 1986, February 1991

\section{HAWAIIAN ISLANDS NATIONAL WILDLIFE REFUGE}

\section{Iucn Management Category IV (Managed Nature Reserve)}

\section{Biogeographical Province 5.03.13 (Hawaiian)}

Geographical Location Extends from Nihoa Island to Pearl and Hermes Reef; a gently arching north-west extension of the main Hawaiian Islands. The reserve includes the northemmost coral reefs in the Pacific Ocean. $23^{\circ} 04^{\prime}-27^{\circ} 50^{\prime} \mathrm{N}, 161^{\circ} 55^{\prime}-175^{\circ} 50^{\prime} \mathrm{W}$

Date and History of Establishment 1966. The refuge was first protected in 1909 as the Hawaiian Islands Bird Reservation. In 1940 the area was re-designated the Hawaiian Islands National Wildlife Refuge and in 1966 it became part of the National Wildlife Refuge System.

Area Total area of $123,159 \mathrm{ha}$, comprising $716 \mathrm{ha}$ land and $122,443 \mathrm{ha}$ marine 


\section{Land Tenure Federal Government}

Altitude Nihoa Island, $277 \mathrm{~m}$; Pearl and Hermes reef, 4m. Lagoon depths: Pearl and Hermes Reef and French Frigate Shoals, variable to $30 \mathrm{~m}$.

Physical Features Includes all emergent rocky islands, sandy islets and major atoll lagoons between the Nihoa Island and Pearl and Hermes Reef in the north-western portion of the Hawaiian Archipelago. Travelling northwards, the eroded remains change from elevated volcanic islands to low atolls of sandy islands, or sandy islands with extensive shallow fringing reefs. A more detailed summary description is given in UNEP/IUCN (1988).

Vegetation Various grasses, for example Eragrostis predominate, with strand vegetation, such as beach morning glory Ipomoea, and inland sandy soil species, such as beach heliotrope Messerschmidia sp., Boerhavia sp., purslane Porkulaca lutea and puncture vine Tribulus cistoides. There is an endemic species of palm on Nihoa Island.

Fauna This group of islands is important for the variety of threatened species which survive here, namely Hawaiian monk seal Monachus schauinslandi (E), Nihoa millerbird Acrocephalus familiaris kingi (V) and Laysan duck Anas laysanensis (R). Short-tailed albatross Diomedea albatrus (R), various cetaceans and green turtle Chelonia mydas $(\mathrm{E})$ visit the islands. They are also a major breeding area for tropical north Pacific seabirds including Laysan albatross Diomedia immutabilis and black-footed albatross $D$. nigripes, blue-grey noddy Procelsterna cerulea, common noddy Anous stolidus, white-capped noddy A. minutus, three species of booby Sula spp., three tems Sterna spp., various shearwaters $P$ uffinus spp., petrels and frigate bird Fregata sp. The islands and reefs support a diverse marine flora and fauna, including 600 fish species and a variety of corals and other invertebrates. The community structure and species composition of corals in the refuge have been documented by Grigg (1983). In general the coral fauna is impoverished (43 species) relative to the Indo-West Pacific but most species are found off all islands.

Cultural Heritage Remains of prehistoric occupation by early Polynesians are protected on Nihoa and Necker islands.

\section{Visitors and Visitor Facilities No information}

Scientific Research and Facilities There has been scientific study in the islands since 1902, and a summary of past and present activities is given in UNEP/IUCN (1988). There are no facilities, but the former Coast Guard LORAN Station is used as base camp.

Conservation Value No specific information

Conservation Management The refuge is currently under the strict supervision of the US-Fish and Wildlife Service. In addition to its national designation the site is also protected as a state wildlife refuge, and the surrounding waters are designated as a marine fisheries management area by the Division of Aquatic Resources. Zoned for strict natural areas, but proposed as wilderness. The refuge includes the Pearl and Hermes Reef Natural Area, Laysan Island Natural Area, Lisianski Island Natural Area, Necker Island Natural Area, and Nihoa Island Natural Area. The National Marine Fisheries Service has designated critical habitat for the Hawaiian monk seal to include all waters from the $18.3 \mathrm{~m}$ depth contour to the vegetation line on all islands and reefs except Maro Reef (UNEP/IUCN, 1988). 
Management Constraints Previous commercial guano mining resulted in introduction of exotic species that caused the extinction of Laysan rail, Laysan honey creeper and Laysan millerbird; the decline of the endangered monk seal is also possibly related to human disturbance. The former Coast Guard LORAN Station at French Frigate Shoals is an intrusion.

Staff Three seasonal employees covering Tern Island and French Frigate Shoals and one permanent full-time employee in the Honolulu office

Budget Approximately US\$ 527,000 for refuge complex administration, protection, natural science studies, interpretation and maintenance (1981)

Local Addresses Hawaiian Island and Pacific Island National Wildlife Refuge Complex, US-Fish and Wildlife Service, PO Box 50167, Honolulu, HI 96850, USA

\section{References}

Bryan, E.H. Jr. (n.d.). The North-western Hawaiian Islands, an annotated bibliography. US-FWS, Honolulu. 150 pp.

Grigg, R.W. (1983). Community structure, succession and development of coral reefs in Hawaii. Marine Ecology Programme Series 11: 1-14

UNEP/IUCN (1988). Coral Reefs of the World. Volume 3. Central and Western Pacific. UNEP Regional Seas Directories and Bibliographies. IUCN, Gland, Switzerland and Cambridge, UK/UNEP, Nairobi. Kenya. 378 pp.

US-FWS (1985). Hawaiian and Pacific Islands National Wildlife Refuges. Illustrated Brochure.

Date 1981, reviewed March 1991

\section{HAWAII VOLCANOES NATIONAL PARK}

\section{IUCN Management Category II (National Park); IX (Biosphere Reserve)}

Biogeographical Province 5.03.13 (Hawaiian)

Geographical Location Lies in the south-east part of the island of Hawaii (Big Island), the easternmost island of the State of Hawaii, and includes the summit and south-east slope of Mauna Loa and the summit and south-western, southern, and south-eastern slopes of the Kilauea Volcano. The core of the park lies at $19^{\circ} 11^{\prime}-19^{\circ} 33^{\prime} \mathrm{N}, 155^{\circ} 01^{\prime}-155^{\circ} 39^{\prime} \mathrm{W}$; the 'Ola'a Forest Tract, to the north-east is centred on $19^{\circ} 29^{\prime} \mathrm{N}, 155^{\circ} 15^{\prime} \mathrm{W}$.

Date and History of Establishment Hawaii National Park was created on 1 August 1916 by Act of the US Congress (39 Stat. 432) and consisted of two units each on different islands, one on Hawaii Island and the other on Maui Island. The area of the park was more than doubled as a result of Congressional authorization in 1922 (45 Stat. 503), in 1928 (45 Stat. 424) and in 1938 (52 Stat. 781). The 'Ola'a Forest Tract was donated in 1951 and 1953 (Executive Order \#1640). However, because the tract is not contiguous to the main body of the park, it is not considered to be within the same legal entity. The park was split into Hawaii Volcanoes National Park (on Hawaii Island) and Haleakala National Park (on Maui Island) in 1961 (75 Stat. 577). Hawaii Volcanoes and Haleakala national parks were accepted as Unesco MAB biosphere reserves in 
1980, and combined to form one cluster, Hawaiian Islands Biosphere Reserve in April 1983. Inscribed on the Unesco World Heritage List in 1987.

Area In June 1987 the national park area was recorded as 92,964 ha. The biosphere reserve designation covers $99,545 \mathrm{ha}$.

Land Tenure The park was created from federally-owned land donated by the State of Hawaii, while the Congressional Act of 1930 (46 Stat. 227) gave exclusive legal jurisdiction to the Federal government. The Act of 1920 (41 Stat. 452) authorised the acquisition of privately owned land and rights of way. The owner is the United States Department of the Interior, Washington, DC and protective custody remains with the National Park Service. The 'Ola'a Forest Tract, being separated from the core by parcels of private land, is, according to Executive Order \#1640, not technically part of the national park. A land exchange, authorised by Congress and now in process, will add 2,300ha to the national park. This covers the private land tract. The 'Ola'a Forest Tract is now apparently out of private ownership.

Altitude From sea level to $4,170 \mathrm{~m}$

Physical Features The park extends from the southern coast to the summit calderas of Kilauea and Mauna Loa volcanoes. Mauna Loa is a massive, flat-domed shield volcano built by lava flow layers and is considered to be the best example of its type in the world. It extends from $6,096 \mathrm{~m}$ below sea level to $4,103 \mathrm{~m}$ above. These are among the world's most active volcanoes and exhibit constantly changing features especially from the two principal rift zones featuring extensive recent flows. Since 1969 new flows have spread to $78 \mathrm{sq}$. $\mathrm{km}$. of the park and added more than 81 ha of new land to the island. This activity continues. An unusual feature in the park is an area which has sunk $3.4 \mathrm{~m}$ into the sea as a result of an earthquake several years ago. The Halemaumau fire pit was a continuously active lava lake into the early 1900s and others existed along the East Rift. Eruptive activity, which began in January 1983 in the East Rift Zone, continues at frequent intervals and has produced extensive new lava flows and a $300 \mathrm{~m}$ high cinder cone.

Climate The weather is dominated by north-east trade winds. Windward mid-slopes receive a mean annual rainfall of $3810 \mathrm{~mm}$, and leeward areas receive only $10 \%$ of that amount. Such extremes of annual average precipitation produces dramatic climatic and life-zone gradients. Annual average temperatures range from $22 \mathrm{C}$ at sea level to $7 \mathrm{C}$ at $3,400 \mathrm{~m}$. The summit of Mauna Loa is cooler still.

Vegetation The park contains a high diversity of plant communities with striking life-form and physiognomic differences. Doty and Mueller-Dombois (1966) have identified 23 distinct vegetation types in five major ecological zones, varying from rain forest to desert scrub and coastal strand to alpine. The spectrum of environments occurring in the tropics, from persistently wet to seasonably wet, to dry is found in Hawaii, and account for the vegetative diversity. The range of environments results from temperature and moisture gradients associated with elevation and exposure differences. Volcanism enhances vegetative diversity, resulting in a mosaic of successional and climax stages in all park environments.

Endemism rates in flowering plants are extraordinarily high (95\%) because of geographic isolation. Characteristic of islands, the flora is impoverished relative to continental areas, with greatest diversity in rain forest and lowest diversity in desert or alpine scrub. Similar to other islands, ferns constitute a significant portion of the native flora, with tree fern-dominated rain forest reaching its highest development in Hawaii in and adjacent to the park. With imperfect isolation mechanisms and active speciation, species lines within many genera are difficult to draw, presenting challenges for evolutionary biologists and systematists in Hawaii. 
Introduced plants, stimulated and dispersed by introduced ungulates, have invaded all plant communities. The park's flora contains nearly twice as many non-native flowering plants as native ones. Although some plant communities, especially those below $600 \mathrm{~m}$, have been significantly impacted by introduced plants, others, particularly those above $1,500 \mathrm{~m}$, are essentially native. A significant portion of the park's flora is threatened by ungulates, introduced plants and wildfire. There are 41 candidate endangered species, with an additional 40 species considered to be rare, comprising $30 \%$ of the flowering plant flora of the park. Although several introduced plant species threaten to seriously disrupt native plant communities, control programmes are underway throughout the park for 41 localised species and in selected areas for five widespread species.

Fauna Animal life is characterised by paucity of forms and by scarcity of native species. Except for a single species of bat Lasiurus cinereus semotus, native mammalian forms are absent. Little is known to date about invertebrate forms. Aquatic animals abound in the coastal water beyond the park's $48 \mathrm{~km}$ coast boundary. Avian forms present interesting and significant examples of adaptive radiation and of extinction. Most endemic avian species are rare or endangered. Species which are formally listed in the US include Hawaiian goose, nene Branta sandvicensis (V), a terrestrial non-migratory goose; Hawaiian hawk, 'io Buteo solitarius; four honeycreepers, 'akepa Loxops coccinea; 'akiapola'au Hemignathus wilsoni; o'u Psittirostra psittacea; and Hawaiian creeper Oreomystis mana; Hawaiian dark-rumped petrel Pterodroma phaeopygia sandwichensis, and short-eared owl, pueo Asio flammeus sandwichersis. Other endemic species include Hawaiian thrush, omao Phaeornis obscurus; and four honeycreepers, 'apapane Himatione sanguinea; 'elepaio Chasiempis sandwichensis, 'amakihi Hemignathus virens; and 'i'iwi Vestiaria coccinea. Introduced pigs, cats, mongooses, dogs, birds, and innumerable invertebrates have colonised parts of the park environment.

Cultural Heritage The park is rich in remains $(88,654 \mathrm{ha}$ are included in Puna-Ka'u Historic District) and particularly so along the coast with native villages, heiaus (temples), graves, paved trails, canoe landings, petroglyphs, shelter caves, agricultural areas and two major archaeological sites: Waha'ula Heiau ruins (constructed in 1275) and the Pu'u Loa Petroglyph Field, at $0.2 \mathrm{ha}$ being the largest concentration of "rock carvings" in the park and representing early Hawaiian culture. Following the arrival of Captain James Cook in 1778-79, Christian influences started in or around 1823, with churches and schools built and the introduction of cattle, goat, and pulu (tree-fern product) harvesting and the encouragement of visitors. Extensive ruins of stone structures dating back to the time of $\mathrm{Pa}^{\prime} \mathrm{ao}$ (a high priest) in 1275 are present.

\section{Local Human Population No information}

Visitors and Visitor Facilities Mauna Loa was first climbed in 1794 and, as a result of descriptions written in 1823, Kilauea Volcano had become a tourist attraction by 1840 . The first Volcano House was constructed in 1866 and successive structures were built in 1877, 1893, and 1941 to serve volcano watching visitors. The 1877 construction is now used as the Volcano Art Centre; the 1941 construction is the park's only hotel. Present day facilities include the Volcano House and two campgrounds. Hiking and fishing are two of the major activities.

Scientific Research and Facilities The park was previously used as a natural arboretum and a centre for developing both native plant and tree nurseries and native seed sources, but the present policy is for a reduction in threats from non-native elements and unaided natural processes, and in fact there has been intensive study of native recolonisation and successions following eruptions. The next three five-year research programmes will concentrate on the integration of herbicidal and other control methods, long-term monitoring of effects on native plant species 
(and alien communities) and new herbicidal testing. There is a volcanic geological research programme, directed by the US Geological Survey scientists based at the Hawaiian Volcano Observatory (founded in 1912 on the rim of the Kilauea Caldera) and, as a result of work done at the observatory over many years, Mauna Loa and Kilauea are the most studied and best understood volcanoes in the world. The observatory has trained most of the volcanic scientists in the world and developed research techniques that are now standard procedure. Research conducted here has contributed to understanding of island building through volcanic processes. The US Fish and Wildlife Service, the US Forest Service, and the National Park Service are studying endangered birds, and there is a proposal to translocate the 'akiapola'au into the koa-'ohi'a forest of the Mauna Loa section of the park. The University of Hawaii, together with park staff, is studying exotic plants and animals and methods of their reduction and the restoration of native species and many of the International Biological Program island ecosystem studies were based here. The park maintains six weather stations which measure air temperature, rainfall, wind speed, wind direction, and relative humidity, and six other stations covering rainfall. There are programmes for the monitoring of feral goat, feral pig, and native Hawaiian goose movement through the use of radio transmission collars and radio telemetry. Birds are reared and released from pens outside the park, a programme undertaken in cooperation with the Hawaii Department of Land and Natural Resources. In addition, there are several vegetation plots with transects and three quality monitoring stations.

Conservation Value The park is managed to preserve its outstanding scenic, geological, and biological values and to ensure its availability for public use and enjoyment.

Conservation Management Hawaii Volcanoes National Park is protected under 16 USC 1 (National Park Service Organic Act) and under the terms establishing the park as set out in 16 USC $395 \mathrm{~b}$, and under several sections of 16 USC $391-396 \mathrm{a}$ which specifically pertain to Haleakala. Section 394 states that "The regulations promulgated shall provide for the preservation from injury of all timber, birds, mineral deposits, and natural curiosities or wonders within said park, and their retention in their natural condition as nearly as possible," while Section 395 c states that "All hunting or the killing, wounding, or capturing at any time of any wild bird or animal, except dangerous when it is necessary to prevent them from destroying human lives or inflicting personal injury, is prohibited within the limits of said park in any other way than by hook and line, and then only at such seasons and in such times and manner as may be directed by the Secretary of the Interior."

The construction of goat and pig fencing, control of feral pigs in newly fenced units and the maintenance of these structures are the top three management priorities. Feral pig control is conducted in $140 \mathrm{ha}$ to $1,900 \mathrm{ha}$ fenced units. The other important management goal is controlling non-native species and active management to reduce negative effects of invasions by feral ungulates and alien plants, especially in relatively intact ecosystems. Widespread alien species control is, however, restricted by current or expected staffing and funding levels. A modest plant control research programme has produced safe, cost-effective herbicidal control methods for five alien species in near-native ecosystems. For administrative purposes the park is divided into two segments; the summits and parts of the flanks of volcanoes Mauna Loa and Kilauea covering 84,033ha; and the 'Ola'a Forest Tract, containing 3,907ha, the latter separated from the major sector by several small parcels of private land, although a land exchange has been authorised by Congress and is in progress. The tract is managed for conservation and its protection status is enhanced under the auspices of the Department of Natural Resources. Act of Congress formally designated 57\% as Wilderness lands (P L 95-625). The park is divided into three land use zones: primary use zone for concentrated visitor use, interpretive programmes such as the Crater Rim 
Summit loop drive, the Chain of Craters Road corridor, and the Waha'ula Visitor Center areas; wilderness threshold zone, comprising a self-guiding nature area used almost exclusively by local island residents and off-island visitors who rent vehicles; and backcountry zone, the largest and least used zone. There is a special emphasis on the delineation, study and management of special ecological areas. These are areas largely intact, representing important ecosystems, containing rare and/or diverse components, and are manageable and of educational potential. Taking of wild pigs (and goats) by local residents is permitted and control methods, including fencing, baiting, trapping, snaring and hunting, have resulted in improved conditions in a 4,000 ha area of the park. There are mammal control efforts in the petrel colonies in the park. Threats from geothermal development on adjacent lands and the intrusiveness of helicopter overflights have been reduced through political pressure. The 'Ola'a Forest Tract is owned by and is under the protective custody of the National Park Service although it is not legally part of the national park itself.

Management Constraints Direct removal or alteration of native forest for sugar and pineapple plantations, ranching and logging, has altered the native biota of the forest habitats, particularly at low and middle elevations of the Hawaiian Islands. These have been most impacted and the prospects for restoration are least encouraging. However, other areas are recovering and studies show that exotics can be controlled and biological integrity restored. Ranching activities and the introduction of species such as pig Sus scrofa (4,000 at a density of 30-50 pigs per sq. km.) and goat Capra hircus have been largely eliminated from the park's lowlands by fencing park boundaries, construction of barrier fences and by organising hunts (previously 15,000-20,000 now 10 individuals within marked areas and a total of 100 animals residing in the park). The presence of mongoose Herpestes auropunctatus has had serious biological consequences, including destruction of native ecosystems and widespread extinction of endemic species. Pox and malaria disease reservoirs in domestic birds is an added threat. Pockets of standing water, created by the wallowing of feral pigs, provide breeding places for mosquitoes and result in serious avian malaria. Approximately 475 non-native plant species occur in the park and at least 40 of these are known to invade native ecosystems. The spread of non-native plant species is also attributed to dispersion by feral pigs, and to cohort die-back in which large areas of dead trees are subject to invasion by alien species, a situation particular to 'ohi'a. Non-native species (on the islands as a whole) outnumber native species by two to one. Mongooses, cats, dogs, and several species of alien birds and insects continue to disrupt native ecosystems. Argentine ant Iridomyrmex humilis is a pest (especially around human settlements) and is spreading in native ecosystems. All eleven major ecological zones in the park have alien plant problems. Those species currently being controlled in special ecological areas include Psidium cattleianum, Hedychium gardnerianum, Linociera ligustrina, and Tropaeolum majus. Other ubiquitous aliens include Pennisetum setaceum and Myrica faya. The effect of the presence of Kilauea Military Camp is unknown. The park boundaries were drawn primarily to include recent lava flows and the summits of the volcanoes, hence only including a limited area of potential species diversity.

Staff In 1987 there were 10 permanent staff on resource management/research and about 20 permanent less than full time, 39 seasonal and 50 members from the Young Adult Conservation Corps (YACC). Individual positions include management ecologist, chief park interpreter, research scientist, and Pacific area archaeologist.

Budget The park received an annual base budget of US\$2.5 million in 1991. Additional biological research programme was about US $\$ 500,000$ (1990) and cultural research programme was US $\$ 110,000$ (1990).

Local Addresses Superintendent, Hawaii Volcanoes National Park, PO Box 52, Hawaii National Park, HI 96718 


\section{References}

Anon. (1970). Hawaii Volcanoes National Park Master Plan. US Department of the Interior, National Park Service, revised 1973.

Anon. (1973). Hawaii Volcanoes National Park, Hawaii, Natural Resources Management Plan and Program. Revised/updated in 1978, 1980, annually since 1982 with latest version, March 1985.

Anon. (1984). Hawaii Volcanoes National Park, Hawaii, Natural Resources Management Program. November 1984 update. An Addendum to the Natural Resources Management Plan.

Carlquist, S. (1980). Hawaii: A Natural History. Lawai, Kauai, Hawaii: Pacific Tropical Botanical Garden, Honolulu. 463 pp.

Cuddihy, L.W. and Stone, C.P. (1990). Alteration of native hawaiian vegetation; effects of humans, their activities and introduction. University of Hawaii Cooperative National Park Resources Studies Unit. 138 pp.

Degner, O.M. (1973). Plants of Hawaii National Park. Braun-Brumfield, Inc., Ann Arbor, Michigan.

Doty, M. S. and Mueller-Dombois, D. (1966). Atlas Bioecological Studies at Hawaii Volcanoes National Park. Hawaii Botanical Science Paper No. 2. University of Hawaii, Honolulu. 507 pp. Jacoby, J.D. (1989). Vegetation maps of the upland plant communities of the Islands of Hawaii, Maui, Molokai, and Lanai. University of Hawaii Cooperative National Park Resources Studies Unit.

MacDonald, G.A. and Abbott, A.T. and Peterson, F.L. (1983). Volcanoes in the Seas: The Geology of Hawaii. Second Edition. University of Hawaii Press, Hawaii. 400 pp.

Stone, C.P. and Holt, R.A. (1987). Managing the invasions of alien ungulates and plants in Hawaii's natural areas.Unpublished report. 23 pp.

Stone, D.P. and Keith, J.O. (1987). Control of feral ungulates and small mammals in Hawaii's national parks: research and management. In: Richards, C.G.J. and Ku, J.Y. (Eds), Control of mammal pests. Supplement 1. Tropical Pest Management 32: 277-287.

Smart, C.D. (1965). The Archaeological Resources of Hawaii Volcanoes National Park. Department of Anthropology, Bernice P. Bishop Museum. 112 pp.

Smathers, G.A. and Mueller-Dombois, D. (1973). Invasion and Recovery of Vegetation After a Volcanic Eruption in Hawaii. National Park Service Scientific Monograph Series No. 3. US National Park Service, Washington DC.

Date 1980, updated 1991

\section{KALAUPAPA NATIONAL HISTORICAL PARK}

IUCN Management Category V (Protected Landscape)

Biogeographical Province 5.03.13 (Hawaiian)

Geographical Location Includes the entire Kalaupapa Peninsula and adjoining cliffs of the north shore of Molokai, Hawaii. Approximately $21^{\circ} 11^{\prime} \mathrm{N}, 157^{\circ} 10^{\prime} \mathrm{W}$ 
Date and History of Establishment Established on 22 December 1980 as a national historical park by the US Congress on lands owned by the State of Hawaii (although a large parcel of the state land is also "Hawaiian Homes Lands" for native Hawaiians).

Altitude Below sea level to $1,287 \mathrm{~m}$

Area 4,300ha land, and about 810 ha water

Land Tenure 10 ha federal in fee; 30 ha private; the rest is the State of Hawaii (of which about 500 ha is Hawaiian Homes Land)

Physical Features Within the park is the entire Kalaupapa Peninsula, a small shield volcano built against the base of the Molokai's great north shore sea cliff. Within the park are those portions of the sea cliff that abut the peninsula, a few sea stacks, three stream valleys penetrating the sea cliff, and the adjoining sea habitats.

\section{Climate No information}

Vegetation The entire area has a long period of intense human use; hence, little natural habitats remain. Fine remnants of native vegetation systems remain in an upland near the head of Waikolu Valley (and is part of the State of Hawaii Natural Area Reserve System), and all along the ocean strand.

Fauna Unfortunately, now fairly large populations of feral pigs, goats, axis deer, and cattle (all introduced) dominate the landscape and the vegetation composition. Although technical solutions exist to the problem, the complex jurisdictions foreclose serious attempts to correct the matter on a broad scale.

Cultural Heritage The entire site is on the National Register of Historic Places. More than 200 National Register historic structures remain, including Father Damien's Church. Extensive prehistoric Hawaiian sites are found throughout the park.

Local Population There are about 90 remaining Hansen's Disease patients, and a State Department of Health staff of 30 who still reside at Kalaupapa Settlement within the park.

Visitors And Visitor Facilities There are no visitor facilities at present. For the life of the remaining Hansen's Disease patients, the number of visitors to the park is limited to 100 per day.

Scientific Research And Facilities The Cooperative National Park Resources Studies Unit (CPSU) at the University of Hawaii has produced numerous technical reports concerning the components of the park's ecosystems. This research is continuing.

Conservation Value Principally cultural

Conservation Management All the lands within park boundaries are under the jurisdiction of the State of Hawaii Director of Health as a Hansen's Disease (Leprosy) Settlement. The national park operates on a long-term "cooperative agreement" with the State Director of Health to continue the Settlement for the life of the last present patients and to concurrently begin operating it as a national historical park. There are currently active negotiations between the Hawaii Homes Commission and the National Park Service for the park to lease the Hawaiian Homes Lands within the park. Although unclear, this legal protection is working in practice.

Through cooperative agreements and contracts, Kalaupapa is jointly administered, by the State of Hawaii Department of Health for patient medical matters, and by the National Park Service 
relating to park and historic preservation matters. No new patients are assigned to Kalaupapa. Over time, administration of the area will shift to the National Park Service.

Management Constraints No information

Staff The staff consists of a superintendent, four permanent, and five seasonal employees. The staff is expanding in numbers.

Budget The base operating budget in FY 1991 is US $\$ 959,000$.

Local Addresses National Park Service, Pacific Area Office, 300 Ala Moana Boulevard, Room 6305, Box 50165, Honolulu, HI 96850

\section{References}

Asherman, K.E., Crummerr, J.M. and Lau, J.Q.C. (1990). A Botanical Reconnaissance of Kalaupapa National Historical Park, November 17-December 5, 1989. Draft. 30 pp.

Linney, G. and Funk, E. (1986). Botanical Survey of Kauhako Crater, Kalaupapa National Historical Park. Cooperative National Park Resources Studies Unit. University of Hawaii. Draft report, miméo. $22 \mathrm{pp}$.

National Park Service (1984). Cultural Resources Management Plan, Kalaupapa National Historical Park. Kalaupapa National Historical Park. Miméo. 85 pp.

Soulliere, L. E. and Law, H.G. (1977). Building Inventory, Kalaupapa. Western Regional Office, National Park Service. 3 Vols.

Date February 1991

\section{KALOKO-HONOKOHAU NATIONAL HISTORICAL PARK}

IUCN Management Category V (Protected Landscape)

Biogeographical Province 5.03.13 (Hawaiian)

Geographical Location On the west shore of the Island of Hawaii at about $19^{\circ} 42^{\prime} \mathrm{N}$ and $156^{\circ} 5^{\prime} \mathrm{W}$

Date and History of Establishment Established as a national historical park by Public Law 92-346 on 11 July 1972

Area About 266ha land and 204ha water

Land Tenure All but about 10 ha are in either Federal or State ownership.

Altitude From below sea level to about $29 \mathrm{~m}$ above mean high tide

Physical Features The park comprises low lava flows along the sea at the warm, dry side of Hawaii. There are three pre-historic man-made fish ponds here, and hundreds of associated archaeological features.

Climate No information 
Vegetation Except for the native and typical strand vegetation, nearly all other plant communities are alien.

Fauna The ponds, particularly Aimakapa, are exceptional water and shore bird habitats. Two endangered birds, Hawaiian coot Fulica alai and Hawaiian stilt Himantopus mexicanus knudseni, nest here in abundance.

Cultural Heritage The entire park is a designated a national historic landmark and is on the National Register of Historic Places. It is noted for its great number of archaeological sites associated with the fishponds.

Local Human Population The park is in the city of Kailua-Kona, a place of ethnic mix and diversity.

Visitors And Visitor Facilities It is a day-use area. A variety of accommodations and services is available nearby at Kailua-Kona.

Scientific Research And Facilities The Cooperative National Park Resources Studies Unit (CPSU) at the University of Hawaii has produced numerous technical reports concerning the components of the park's ecosystems. This research is continuing.

Conservation Value The park is noted for its great number of archaeological sites associated with the fishponds.

Conservation Management No information

Management Constraints No information

Staff A local superintendent with four permanent and about five seasonal staff.

Budget Annual base operations appropriation in 1991 was US\$296,000. Additionally, about US $\$ 70,000$ a year is spent on biological research and resource management.

\section{References}

Honokohau Study Advisory Commission (1974). Kaloko Honokohau. National Park Service. US Department of the Interior. $85 \mathrm{pp}$.

National Park Service (1990). Resource Management Plan. Kaloko-Honokohau National Historical Park. 103 pp.

Date February 1991

\section{PU'UHONUA O HONAUNAU NATIONAL HISTORICAL PARK (FORMERLY THE CITY OF REFUGE NATIONAL HISTORICAL PARK)}

IUCN Management Category V (Protected Landscape)

Biogeographical Province 5.03.13 (Hawaiian) 
Geographical Location Pu'uhonua o Hononaunau lies on the western slope of Mauna Loa, on the south shore of Honaunau Bay of western Hawaii island (County of Hawaii). Approximately $19^{\circ} 26^{\prime} \mathrm{N}, 155^{\circ} 55^{\prime} \mathrm{W}$.

Date And History Of Establishment The site was set aside as a national historical park by Congress on 1 July 1961 (City of Refuge National Historical Park) and renamed Pu'uhonua o Honaunau National Historical Park on 10 November 1978.

\section{Area 73 ha}

\section{Land Tenure Federal Govermment}

\section{Altitude Sea level}

Physical Features The park consists of a generally flat coastal area comprising lava formations, predominantly pahoehoe and a'a types, with occasional pockets of soil material. The shoreline is flat with many small inlets and patches of sand, rubble, and fringing coral reefs (Anon., 1981).

Climate The average annual temperature is $31^{\circ} \mathrm{C}$ and the minimum is $18^{\circ} \mathrm{C}$, with a diurnal range of $6^{\circ} \mathrm{C}$. The mean annual rainfall is $508 \mathrm{~mm}$, with a rainy season from May to September and hurricane season from June-December. Storms move through the area more frequently from December to February, bringing high seas, wind and rain from the west and south. Tsunami (tidal waves) occur infrequently in the Kona Coast.

Vegetation The coastal vegetation of Honaunau Bay is predominantly xerophytic scrub with some trees, characterised by ekoa Leucaena leucocephala thicket and uncleared opiuma/ekoa scrub forest. Common plants are passion flower Passiflora sp., morning glory Ipomoea sp., sword fern Nephrolepis sp., garden spurge Euphorbia hirta, Madagascar periwinkle Catharanthus roseus and klu Acacia farnesiana. The grass present is mostly red top Rhynchelytrum repens, noni Morinda citrifolia, hala Pandanus odoratissimus and kou Cordia subcordata. Sedge Fimbristylis cymosa grows in pockets in the pahoehoe lava close to the sea, and another sedge, 'ahu'awa Cyperus sp., grows around the brackish pools. The dominant grass is Bermuda grass Cynodon dectylon (Yen, 1971; Anon., 1981).

Fauna Introduced mammals are plentiful, with mongoose Herpestes griseus, house mouse Mus musculus, black rat Rattus rattus, and brown rat $R$. norvegicus. Birds present are the kolea or Pacific golden plover Pluvialis dominica, 'akekeke or ruddy turnstone Arenaria interpres and the less abundant ulili or wandering tattler Heteroscelus incanus. Common but introduced birds are turtle dove Streptopelia sp. and Brazilian cardinal Caryothraustes sp. Three species of geckoes and three species of skinks are known from the park.

Of a total of 609 insect species recorded for the Kona district, only 150 species have been collected here (72 species are considered native). The ant species Pheidole megacophala is abundant and has caused the destruction of countless endemic species, especially beetles. The little silk-spinning embiid has been sighted in the park and is common in the drier lowlands. Leafhoppers collected in the park are endemic. Only one species of the many native damselflies has been collected at Honaunau. This species is common and often found from sea level up to the native forest on the hill slopes. Except for an endemic species of wood borer, all 23 species of beetles from the park area are non native. Cockroaches, flies and termites thrive in the warm, humid climate.

Cultural Heritage The prime cultural features of the park include the Pu'uhonua sanctuary building, the temple of Hale o Keawe and Ki'ilae village. The park encompasses a restored 
traditional Hawaiian village and the spiritual sanctuary where defeated warriors or people who had broken sacred laws could be absolved and allowed a fresh start in the community. The Ki'ilae village was completely abandoned in 1926.

Local Human Population The nearby village is still inhabited by indigenous Hawaiians who continue to practise traditional crafts and skills such as weaving mats and night fishing.

Visitors And Visitor Facilities There are 350,000 visitors annually. The heaviest period of use is usually mid-day and the pattern is generally an orientation talk, a pre-arranged tour of the palace grounds, demonstrations of traditional Hawaiian activities and visits to Hale o Keawe and the Place of Refuge. There are three visitor centres, museums, and horse trails.

Scientific Research and Facilities A Cooperative National Park Resources Studies Unit with assistance from the University of Hawaii, Manoa campus, conducts some research. Researchers at Mauka Botanical Gardens develop and grow native Hawaiian plants for re-introduction into the park.

Conservation Values The park has been established to "preserve through public ownership and as part of the American national park system the historical ruins as well as other nearby prehistoric features"

Conservation Management With the aim to return the landscape to its late 18th century appearance, the authorities have embarked on a limited programme to clear exotic plants from around the ruins. By the early 1980s 23ha of land had been cleared of exotic plants such as ekoa Leucaena glauca, opiuma Pithecellobium dulce, christmasberry Schinus terenthifolia, and kiawe Prosopis pallida.

Administration of the park is coordinated by the National Park Service and the US Department of the Interior. The park authorities work in close association with the Waimea Hawaiian Civic Club and the Hawaii Natural History Association.

Management Constraints No information

Staff In 1990 there were ten permanent full-time staff and five permanent part-time staff.

Budget US\$ 601,000 budgeted for fiscal year 1991

Local Addresses Superintendent, Pu'uhonua o Honaunau NHP, P O Box 129, Honaunau, Kona, HI 96726 (also administers Pu'ukohola Heiau National Historic Site)

\section{References}

Bryan, E.H., Wentworth, C.K., Greenwell, A., Neal, M.C., Suehiro, A. and Kay, A. (1957). The natural and cultural history of Honaunau. Bernice P. Bishop Museum, Honolulu, Hawaii. $221 \mathrm{pp}$.

Emory, K. P., Stokes, J.F.G., Barrere, D.B., and Kelly, M.A. (1957). The Natural and Cultural History of Honaunau, Kona, Hawaii. Volume Two. The Cultural History of Honaunau. Bernice P. Bishop Museum, Honolulu, Hawaii. 247 pp.

Yen, D.C. (1971). An ethnobotanical survey of the National Parks at Honaunau and Kalapana on the Island of Hawaii, and Kipahulu, Maui. Bernice P. Bishop Museum, Honolulu, Hawaii. 26 pp.

Date August 1987, revised February 1991 


\section{STATE NATURAL AREA RESERVES:}

Summary Information

Source: State of Hawaii, Natural Area Reserves System, Biological Resources and Management Priorities, Appendices (1989)

\section{AHIHI-KINAU}

$\begin{array}{ll}\text { Island } & \text { Maui } \\ \text { Size } & \text { 501ha land, 327ha marine } \\ \text { Altitude } & \text { Below sea level-152m } \\ \text { Year established } & \text { 1973 }\end{array}$

Description Set on the most recent historic lava flow on Maui, Ahihi-Kinau contains anchialine pools with a high diversity of rare Hawaiian shrimps, and a unique lava tube community that provides habitat for native Hawailan cave animals. The marine portion is not characterised here. Natural communities comprise high salinity lava anchialine pool, MeionetalHawaiioscia lowland lava tube, 'Akulikuli coastal dry herbland, Cacenomobius coastal mesic boulder beach, low salinity lava anchialine pool and pioneer vegetation on lava. There are 21 native plant taxa, and 14 native animal taxa.

Management Preserving the integrity of anchialine pools is a major management focus. The main threats to pools are non-native plants on pool margins, excessive algal mat formation, introduced fish or invertebrates, and bathing or swimming in the pools. Recommended management includes erecting new signs to inform people of the unique nature of the pools and the need to protect them, controlling and monitoring invasive weeds such as sour bush and mangrove, and removal and monitoring of non-native fish such as mosquito-fish or tilapia. Lava tubes will not be made accessible to the general public. Guidelines for scientific work in the lava tubes should be established. Much of the reserve's vegetation is non-native dominated.

\section{HANAWI}

$\begin{array}{ll}\text { Island } & \text { Maui } \\ \text { Size } & 3,036 \mathrm{ha} \\ \text { Altitude } & 610 \mathrm{~m}-2,286 \mathrm{~m}\end{array}$

Year established 1986

Description This reserve extends into subalpine zones of East Maui and includes a rare subalpine grassland, as well as shrublands and montane wet forests. These forests are valuable watershed, contain rare plants, and provide essential habitat for the state's largest concentration of rare and endangered Hawaiian birds. Natural communities comprise Deschampsia nubigena subalpine mesic grassland, 'Akala montane wet shrubland, Carex alligata montane wet grassland, Hawaiian intermittent stream, Koa/'Ohi'a lowland wet forest, mixed ferm/mixed shrub montane wet cliff, 'Ohi'a/'Olapa montane wet forest, 'Ohi'a/mixed shrub montane wet forest, 'Ohi'a/Uluhe montane wet forest, 'Ohi'a/Uluhe lowland wet forest, Pukiawe subalpine dry shrubland and Uluhe lowland wet shrubland. There are 15 native plant taxa and one native animal taxa. 
Management The top priority for management is feral pig control. Barrier fences are recommended to create $623 \mathrm{ha}$ of controlled management units in the upper part of the reserve. An intensive programme of snaring and hunting is recommended for these units. Public and staff hunting is planned for the rest of the reserve. Monitoring is recommended for pig control and to track special resources, such as endangered birds, including the Po'ouli. Another aspect of management is tracking potential weed threats and identifying necessary action such as removal of blackberry from the Puu Alaea area. Also recommended is an increased public education programme.

\section{HONO O NA PALI}

$\begin{array}{ll}\text { Island } & \text { Kauai } \\ \text { Size } & 1,275 \mathrm{ha} \\ \text { Altitude } & \text { Near sea level-1,280m } \\ \text { Year established } & 1983\end{array}$

Description Streams and forested valleys of the Na Pali cliffs feed from a remote plateau. The reserve includes two rare communities (a bog and a stream), as well as representative coastal, lowland and montane communities. Rare plants and a possible nesting site for Hawaiian dark-rumped petrel are also known from this reserve. Natural communities comprise Hawaiian continuous perennial stream, 'Ohi'a mixed montane bog, Hala coastal mesic forest, Hawaiian intermittent stream, Kawelu coastal dry grassland, Kawelu lowland mesic grassland, Lama/'Ohi'a lowland mesic forest, 'Ohi'a/mixed shrub montane wet forest, 'Ohi'a/'Olapa montane wet forest, 'Ohi'a/Uluhe montane wet forest and Uluhe lowland wet shrubland. There are 214 native plant taxa and 14 native animal taxa.

Management Feral goats are the major threat to the lower elevations while pigs constitute the greatest threat to the upland plateau. Goat and pig control is recommended. Short fences may be required in the lower unit to limit goat movements. A goat exclosure is recommended to assess their impact on native vegetation. Priority weed management is recommended, especially for Clidemia, blackberry, firebush, and banana poka. Monitoring programmes are recommended to assess ungulate and weed control and native species affected. Public education and volunteer work activities are feasible along the Kalalau trail.

\section{KAENA POINT}

$\begin{array}{ll}\text { Island } & \text { Oahu } \\ \text { Size } & 5 \mathrm{ha} \\ \text { Altitude } & \text { Sea level-6m }\end{array}$

Year established 1983

Description This small reserve includes coastal communities on the western-most point of Oahu, and provides habitat for rare coastal plants. Natural communities comprise Naupaka mixed coastal dry shrubland, Cacenomobius coastal mesic boulder beach, 'Ilima mixed coastal dry shrubland and Naupaka coastal dry shrubland. There are 50 native plant taxa and 9 native animal taxa. 
Management A barrier has been established to exclude off-road vehicles, which have damaged the dune ecosystem. Monitoring will be necessary to maintain the barrier, evaluate regeneration of native communities, and control target weeds. Not all weeds can be removed, especially in non-native dominated areas, but the most intact areas should be kept weed free. The 'ohai Sesbania tomentosa population needs monitoring. Other proposed management includes interpretive signs, fure control and community volunteer programmes.

\section{KAHAUALEA}

$\begin{array}{ll}\text { Island } & \text { Hawaii } \\ \text { Size } & 6,772 \mathrm{ha} \\ \text { Altitude } & 518 \mathrm{~m}-1,067 \mathrm{~m}\end{array}$

Year established 1987

Description Kahaualea includes representatives of pioneer vegetation on lava flows, lowland rain forest and mesic forest in the Puna District. It includes the largest known populations of a federally endangered fern Adenophorus periens, as well as the currently active flows of the Puu Oo vent. Natural communities comprise 'Ohi'a/Hapu'u lowland wet forest, 'Ohi'a/Hapu'u montane wet forest, 'Ohi' a lowland mesic forest, 'Ohi' a/Uluhe lowland wet forest, 'Ohi'a/Uluhe montane wet forest, pioneer vegetation on lava. There are one native plant taxa and seven native animal taxa.

Management Feral pigs and cattle are high priority management concerns. Public and staff hunting should be increased. Programmes to control ungulates may include enhanced access via new trails, and fencing around key management areas. Stepped up control of marijuana and prosecution of growers is recommended to allow hunters and the public safe access to the reserve. A maintained trail to Puu Oo is recommended. Target weeds include Clidemia, golden Himalayan raspberry, palm grass, Tibouchina, and strawberry guava. Systematic monitoring will be needed to assess needs and effectiveness of a pig and weed control programme.

\section{KIPAHOEHOE}

$\begin{array}{ll}\text { Island } & \text { Hawaii } \\ \text { Size } & 2,260 \text { ha } \\ \text { Altitude } & \text { Near sea level-1,676m } \\ \text { Year established } & 1983\end{array}$

Description A narrow piece of land running down the south-west slopes of Mauna Loa in the district of South Kona, Kipahoehoe includes a rare lowland grassland, as well as mesic and wet forests of 'ohi'a and koa. Recent volcanic flows run through the reserve, leaving a variety of different aged communities. Natural communities comprise Pili lowland dry grassland, Fimbristylis coastal dry grassland, Koa/'Ohi'a montane wet forest, 'Ohi'a lowland dry forest, 'Ohi'a/Uluhe montane wet forest, 'Ohi'a lowland mesic forest, pioneer vegetation on lava, uncharacterised lowland lava tube and uncharacterised montane lava tube. There are 117 native plant taxa and 8 native animal taxa.

Management Feral pigs and goats constitute the most severe threats to this reserve. Management will consist of fencing management units, snaring, staff hunting in key units and increased public 
hunting in others. To increase public hunting, a programme of better access through easements, trails and special hunts are recommended. Systematic monitoring will assess changes in ungulate damage, recovery of native vegetation and status of rare plants. Management of priority weeds such as fountain grass can be part of a public education and volunteer programme.

\section{KUIA}

$\begin{array}{ll}\text { Island } & \text { Kauai } \\ \text { Size } & 662 \mathrm{ha} \\ \text { Altitude } & 671 \mathrm{~m}-1,189 \mathrm{~m} \\ \text { Year established } & 1981\end{array}$

Description The mesic forests of north-eastern Kokee contain a large number of native tree species, including a rare red-flowered Hawaiian tree cotton. Natural communities comprise Kauai diverse lowland mesic forest, Koa/'Ohi' a mixed montane mesic forest, 'A'ali'i lowland dry shrubland, Koa/'Ohi' a lowland mesic forest and 'Ohi'a/Uluhe montane wet forest. There are 160 native plant taxa and 9 native animal taxa.

Management Goats and deer are damaging the lowland forests while pigs constitute the biggest threat to upland forests. No fencing or snaring is practical at this time. Instead, a programme of increased public and staff hunting is recommended. Other management recommendations include increased access, an open hunting season within the reserve, and removing bag limits for hunting in the reserve. Priority weeds can be removed from areas of fairly intact native forest only. Target weeds are banana poka, lantana, blackberry, firebush, karaka nut, silk oak, and strawberry guava. Stakeout and prosecution of marijuana growers are recommended to curtail incipient growing activities.

\section{LAUPAHOEHOE}

$\begin{array}{ll}\text { Island } & \text { Hawaii } \\ \text { Size } & 3,196 \mathrm{ha} \\ \text { Altitude } & 579 \mathrm{~m}-1,420 \mathrm{~m} \\ \text { Year established } & 1983\end{array}$

Description On the slopes of windward Mauna Kea, Laupahoehoe includes examples of wet montane forests of 'ohi' $a$ and koa. The poorly drained portions contain wet grasslands and small montane lakes. Numerous streams run through the reserve. Natural communities comprise $C a r e x$ alligata montane wet grassland, Hawaiian intermittent stream, Hawaiian montane lake, Koa/'Ohi'a montane wet forest, Mamaki lowland wet shrubland, 'Ohi'a/Hapu'u lowland wet forest, 'Ohi'a/Uluhe lowland wet forest, Uluhe lowland wet shrubland. There are 140 native plant taxa and 9 native animal taxa.

Management Feral pigs constitute the most severe management threat. Recommended action will begin with increased public hunting through enhanced access roads and trails. Special hunts and an active deputy hunter programme should enhance staff hunting efforts for pig reduction. In a second phase, snaring in the more remote areas should keep pig populations low. Priority weeds targeted for removal include Clidemia, blackberry, golden Himalayan raspberry, and palm grass. Emergent Ficus rubiginosa trees should be girdled. Systematic monitoring will track 
changes in pig populations and key weeds. Public education and a volunteer support group are also recommended.

\section{MANUKA}

$\begin{array}{ll}\text { Island } & \text { Hawaii } \\ \text { Size } & 10,344 \mathrm{ha} \\ \text { Altitude } & \text { Near sea level-1,684m } \\ \text { Year established } & 1983\end{array}$

Description On the flank of leeward Mauna Loa in South Kona, Manuka encompasses a wide range of habitats. These include subalpine shrublands and forests, mesic montane kipuka forests, wet montane forests, lowland mesic forests and lowland dry forests. Recent lava flows add a variety of pioneer vegetation types, as well as uncharacterised and unsurveyed lava tubes. Concentrations of the Hawaiian hoary bat occur in the area. A rare lowland grassland and anchialine pools are included as well. Natural communities comprise Koa/'Ohi'a mixed montane mesic forest, high salinity lava anchialine pool, Pili lowland dry grassland, 'A'ali'i lowland dry shrubland, Fimbristylis coastal dry grassland, 'Ilima coastal dry shrubland, Lama lowland dry forest, Lama/'Ohi'a lowland mesic forest, low salinity lava anchialine pool, 'Ohi'a lowland dry forest, 'Ohi'a lowland mesic forest, 'Ohi'a montane mesic forest, 'Ohi'a subalpine dry forest, pioneer vegetation on lava, Pukiawe subalpine dry shrubland, ?uncharacterised lowland lava tube, and uncharacterised montane lava tube. There are 187 native plant taxa and 7 native animal taxa.

Management Staff control of feral pigs at higher elevations and of goats at lower elevations will be aided by new trails planned for the reserve. Priority weeds include fountain grass, cat's claw, banana poka, and Passiflora suberosa. Maintaining the current marijuana control programme is recommended. Ilegal harvesting of native hardwoods from the reserve should be halted through stepped up enforcement. Systematic monitoring of ungulate and weed control is needed. The impact of non-native plant species spreading from Manuka State Park should be studied. Guppies in anchialine pools should be removed as soon as possible.

\section{MAUNA KEA ICE AGE}

$\begin{array}{ll}\text { Island } & \text { Hawaii } \\ \text { Size } & 1,577 \mathrm{ha} \\ \text { Altitude } & 3,048 \mathrm{~m}-4,097 \mathrm{~m}\end{array}$

Year established 1981

Description Sparsely vegetated cinder and lava deserts on the southern summit flank of Mauna Kea include two rare communities: an invertebrate-dominated aeolian desert and the state's only alpine lake. Important archaeological and geological features are also present. Natural communities comprise Hawaiian alpine aeolian desert, Hawaiian alpine lake, 'Ohi'a subalpine dry forest and Pukiawe subalpine dry shrubland. There are four native plant taxa, and two native animal taxa. 
Management Managers will need to monitor vehicular trespass, litter and chemical leakage from nearby buildings, and disturbances associated with continued expansion of summit astronomical facilities.

\section{MOUNT KAALA}

$\begin{array}{ll}\text { Island } & \text { Oahu } \\ \text { Size } & 445 \mathrm{ha} \\ \text { Altitude } & 366 \mathrm{~m}-1,219 \mathrm{~m}\end{array}$

Year established 1981

Description Several wet and mesic shrubland and forest communities typical of the central Waianae Mountains are found on the wet, flat summit and northern valleys of Mt. Kaala. Among them are two rare lowland forest communities. Rare plants and snails are also known from the reserve. Natural communities comprise Lonomea lowland dry forest, Oahu diverse lowland mesic forest, 'A'ali'i lowland dry shrubland, Hawaiian intermittent stream, Koa/'Ohi'a lowland mesic forest, Mamaki lowland wet shrubland, mixed fern/mixed shrub montane wet cliff, 'Ohi' a/mixed shrub montane wet forest, 'Ohi'a montane wet shrubland, 'Ohi'a/'Olapa montane wet forest, 'Ohi'a/Uluhe montane wet forest and Uluhe lowland wet shrubland. There are 208 native plant taxa, and 11 native animal taxa.

Management Feral pigs are a problem in gulches and upper flats. Public and staff hunting will be increased. Fences are recommended for the summit plateau unit. A management trail is recommended along the lower contour and easier access to the area via permits is needed. Stray cattle should be removed from the reserve by ranch personnel. More surveying is recommended to identify the most intact areas of lowland mesic and dry native forests and only in these areas are weeds to be removed and kept under control. Target weeds include blackberry, Clidemia, toon, and Christmas berry. No weed control is recommended for areas dominated by non-native vegetation.

\section{OLOKUI}

$\begin{array}{ll}\text { Island } & \text { Molokai } \\ \text { Size } & 656 \mathrm{ha} \\ \text { Altitude } & \text { Near sea level-1,403m }\end{array}$

Year established 1985

Description An isolated plateau set between two of Molokai's largest and most undisturbed streams. A pre-dawn infra-red helicopter survey confirmed that the plateau of Olokui remains one of the few rain forest areas in the state still free from feral ungulates. It is exceptionally intact as a result, providing examples of native communities and essential forest bird habitat. Rare snails were observed during a 1989 survey. Natural communities comprise Hawaiian intermittent stream, Hawaiian mixed shrub coastal dry cliff, Kawelu coastal dry grassland, Lama/'Ohi'a lowland mesic forest, mixed fern/mixed shrub montane wet cliff, 'Ohi'a/mixed shrub montane wet forest, 'Ohi'a/'Olapa montane wet forest, 'Ohi'a/Uluhe lowland wet forest, 'Ohi'a/Uluhe montane wet forest and Uluhe lowland wet shrubland. There are 150 native plant taxa, and nine native animal taxa. 
Management No feral ungulates have been detected from the summit, which is astoundingly pristine. Management will concentrate on keeping ungulates from reaching the summit area. Short fences placed in critical locations are recommended for potential access ridges. Human access trails to the summit from lower areas should be prohibited. Restricting access will prevent people from spreading weed seeds. Some monitoring will be needed to keep track of noxious weeds and ungulates. Aerial hunting is recommended to immediately reduce animal populations in both Wailau and Pelekunu valleys.

\section{PAHOLE}

$\begin{array}{ll}\text { Island } & \text { Oahu } \\ \text { Size } & 266 \mathrm{ha} \\ \text { Altitude } & 335 \mathrm{~m}-792 \mathrm{~m} \\ \text { Year established } & 1981\end{array}$

Description A rare dry forest and a rare mesic forest occur in Pahole Valley in the Northern Waianae Mountains, famous for its botanical richness. In the native communities are many rare plants and endangered tree snails. Natural communities comprise Lonomea lowland dry forest, Oahu diverse mesic forest, 'A'ali'i lowland dry shrubland, Koa/'Ohi'a lowland mesic forest, 'Ohi' a/Uluhe lowland mesic forest, and Hawaiian intermittent stream. Native plants comprise 168 taxa, and native animals 10 taxa.

Management Feral pig control is recommended. Weed control is the highest priority in this reserve. Weeds are widespread and only the most intact pockets of native forest or rare native species will receive weed control. Weeds such as Christmas berry, Lantana, and various non-native trees and grasses are targeted. An education and volunteer programme is recommended to provide the labour needed to protect and manage key management units. Predation on endangered tree snails by rats and the non-native snail Euglandina should be monitored.

\section{PUU ALII}

$\begin{array}{ll}\text { Island } & \text { Molokai } \\ \text { Size } & 538 \mathrm{ha} \\ \text { Altitude } & 762 \mathrm{~m}-1,287 \mathrm{~m}\end{array}$

Year established 1985

Description A representative portion of the Molokai summit, Puu Alii lies between Pelekunu and Waikolu valleys. Its wet plateau is good forest bird habitat and an important part of Molokai's watershed. Natural communities comprise Hawaiian intermittent stream, mixed fern/mixed shrub montane wet cliff, 'Ohi' a/mixed shrub montane wet forest, 'Ohi'a montane wet shrubland, 'Ohi' a/'Olapa montane wet forest, 'Ohi' a/Uluhe lowland wet forest, 'Ohi'a/Uluhe montane wet forest and Uluhe lowland wet shrubland. There are 157 native plant taxa, 10 native animal taxa.

Management Feral pigs and goats represent the biggest threat to the integrity of this remote reserve. Recommended management action calls for fencing to divide the reserve into two units. Snaring and hunting by staff hunters are recommended on both sides of the fence. Goat hunting will be concentrated on the drier ridges and slopes. New management trails and two shelters are 
also recommended. Monitoring will be needed to maintain fences, assess ungulate control, locate target weeds, and check status of rare species.

\section{PUU MAKAALA}

$\begin{array}{ll}\text { Island } & \text { Hawaii } \\ \text { Size } & 4,901 \mathrm{ha} \\ \text { Altitude } & 914 \mathrm{~m}-1,682 \mathrm{~m}\end{array}$

Year established 1981

Description The wet koa and 'ohi'a forests of this reserve on the north-east flank of Mauna Loa are important habitat for some of Hawaii's rarest birds, as well as several rare plants. A montane wet grassland occurs in the poorly drained portions of the reserve. Natural communities comprise Carex alligata montane wet grassland, Koa/'Ohi'a montane wet forest and 'Ohi'a/Hapu'u montane wet forest. There are 176 native plant taxa and 9 native animal taxa.

Management Feral pig control is the highest management priority. Barrier fences are recommended to create five management units. Staff hunting and snaring within certain units will be needed and continued public hunting outside those units is essential. Maintenance of the fences and monitoring pig control is proposed. Also recommended is removal and monitoring of weeds targeted for control. These priority weeds include yellow Himalayan raspberry, blackberry, Clidemia, and firebush. Public education and a volunteer programme are also recommended.

\section{PUU O UMI}

$\begin{array}{ll}\text { Island } & \text { Hawaii } \\ \text { Size } & 4,106 \mathrm{ha} \\ \text { Altitude } & \text { Sea level-1,603m }\end{array}$

Year established 1987

Description This reserve includes the wet summit lands of the Kohala Mountains, with two rare kinds of montane bog surrounded by 'ohi'a forests, shrublands and grassland. The reserve extends downslope to the Kohala sea cliffs and a coastal dry grassland there. Rare plants are known from the bogs and forests. The steep cliffs of Waipio and Waimanu valleys form part of the reserve boundary. Numerous streams run through the area. The reserve is an important watershed for the region. Natural communities comprise mixed sedge and grass montane bog, 'Ohi'a mixed montane bog, Carex alligata montane wet grassland, Hawaiian intermittent stream, Kawelu coastal dry grassland, mixed fern/mixed shrub montane wet cliff, Naupaka coastal dry shrubland, 'Ohi'a/mixed shrub montane wet forest, 'Ohi'a montane wet shrubland, 'Ohi' a/'Olapa montane wet forest, 'Ohi' a/Uluhe lowland wet forest, 'Ohi' a/Uluhe montane wet forest and Uluhe lowland wet shrubland. There are 124 native plants taxa and seven native animal taxa.

Management Pig control via fencing, snaring, hunting by staff, and public hunting is needed. Managers will improve access, enhance trail systems, and establish shelters and helipads. Fenced management units will be monitored for pig damage, native vegetation recovery, and status of 
rare species. Targeted priority weed species include broomsedge, gingers, palm grass, blackberry, and banana poka. Also recommended is a public education and volunteer programme.

\section{WAIAKEA 1942 LAVA FLOW}

$\begin{array}{ll}\text { Island } & \text { Hawaii } \\ \text { Size } & 259 \mathrm{ha} \\ \text { Altitude } & 908 \mathrm{~m}-1,036 \mathrm{~m}\end{array}$

Year established 1974

Description A recent lava flow being recolonised by young 'ohi'a forest dominates this reserve, providing good opportunities for the study of revegetation on lava flows. Natural communities comprise 'Ohi'a/Uluhe montane wet forest and pioneer vegetation on lava flow. No data on native plants and animals are available.

Management No management plans have been drafted for this reserve. Key threats have not been confirmed, but weeds that typically compete with native species on pioneer lava substrates may compromise the quality of this reserve.

\section{WEST MAUI (Honokowai Section)}

$\begin{array}{ll}\text { Island } & \text { Maui } \\ \text { Size } & 304 \mathrm{ha} \\ \text { Altitude } & 762 \mathrm{~m}-1,764 \mathrm{~m}\end{array}$

Year established 1986

Description One of four sections that make up West Maui Natural Area Reserve, the Honokowai Section is on the wet upper northern slopes of the West Maui Mountains. The native communities include two kinds of rare bogs, as well as wet forests, shrublands and a montane lake. This section has watershed value and includes many rare plants. Natural communities comprise mixed sedge and grass montane bog, 'Ohi'a mixed montane bog, Hawaiian intermittent stream, Hawaiian montane Lake, Mamaki lowland wet shrubland, mixed fern/mixed shrub montane wet cliff, 'Ohi'a/mixed shrub montane wet forest, 'Ohi'a/'Olapa montane wet forest, 'Ohi'a/Uluhe lowland wet forest, 'Ohi'a montane wet shrubland and Uluhe lowland wet shrubland. There are 15 native plant taxa, and 9 native animal taxa.

Management Feral pig impact is the top management concern in this section. Strategic fencing, staff hunting, and a snaring programme are recommended. Fence maintenance and ungulate control monitoring will be needed. Priority weeds such as blackberry and Tibouchina need removal and monitoring. A public education and volunteer programme may be established.

\section{WEST MAUI (Kahakuloa Section)}

$\begin{array}{ll}\text { Island } & \text { Maui } \\ \text { Size } & 1,326 \mathrm{ha} \\ \text { Altitude } & 305 \mathrm{~m}-1,366 \mathrm{~m} \\ \text { Year established } & 1986\end{array}$


Description One of four sections of West Maui Natural Area Reserve, the Kahakuloa Section lies on wet, windward slopes of the West Maui Mountains. The plateau of Eke Crater is still undisturbed by feral ungulates. This section includes the upper reaches of two perennial streams, and includes a rare montane bog surrounded by 'ohi' a wet forests. This section also has watershed value and includes many rare plants. Natural communities comprise Hawaiian continuous perennial stream, 'Ohi'a mixed montane bog, Hawaiian intermittent stream, Hawaiian montane Lake, Mamaki lowland wet shrubland, mixed fern/mixed shrub montane wet cliff, 'Ohi' a/mixed shrub montane wet forest, 'Ohi'a montane wet shrubland, 'Ohi'a/'Olapa montane wet forest, 'Ohi'a/Uluhe lowland wet forest and Uluhe lowland wet shrubland. There are 15 native plant taxa and 9 native animal taxa.

Management Feral pigs are the major threats to this section. Short fence sections have been constructed to block ungulates from Mt Eke but other sections of fence are still needed. Pig removal by snaring and hunting both inside and outside the fences seems a feasible strategy, but fence maintenance and pig control monitoring are needed to assess results. Better access for public hunting is needed for the lower elevation areas. Priority weeds such as Clidemia and Tibouchina are targeted for management. An increased programme of public education and volunteer help is recommended.

\section{WEST MAUI (Lihau Section)}

$\begin{array}{ll}\text { Island } & \text { Maui } \\ \text { Size } & 389 \mathrm{ha} \\ \text { Altitude } & 305 \mathrm{~m}-1,279 \mathrm{~m}\end{array}$

Year established 1986

Description The driest of the four sections of West Maui Natural Area Reserve, Lihau is a steep-sloped volcanic remnant that extends from dry leeward lowlands to a wet summit with cliffs on all sides. The 1988 survey indicated that the summit of Lihau remains ungulate-free. A rare grassland and shrubland occur near the lower boundaries of the reserve, and many rare plants are known from Lihau, including the federally endangered plant Gouania hillebrandii. Natural communities comprise Ko'oko'olau lowland dry shrubland, Pili lowland dry grassland, 'A'ali'i lowland dry shrubland, mixed fern/mixed shrub montane wet cliff, 'Ohi' $a /$ mixed shrub montane wet forest, 'Ohi'a lowland mesic shrubland, 'Ohi'a/'Olapa montane wet forest and 'Ohi'a/Uluhe lowland mesic forest. There are 15 native plant taxa, and 9 native animal taxa.

Management No ungulates occur at the summit of Lihau and many areas appear pristine. Much of the upper elevation areas are weed free. Recommended management includes monitoring of priority weeds, especially those present in the lower elevation areas. No fencing is recommended. Fire pre-suppression measures are recommended because of the potential for dry season fires.

\section{WEST MAUI (Panaewa Section)}

$\begin{array}{ll}\text { Island } & \text { Maui } \\ \text { Size } & 695 \mathrm{ha} \\ \text { Altitude } & 472 \mathrm{~m}-1,591 \mathrm{~m} \\ \text { Year established } & 1986\end{array}$


Description One of four sections of West Maui Natural Area Reserve, Panaewa includes a rare montane bog, as well as representative 'ohi'a forests and shrublands. This section also includes rare plants. Natural communities comprise 'Ohi'a mixed montane bog, Hawaiian intermittent stream, Mamaki lowland wet shrubland, mixed fern/mixed shrub montane wet cliff, 'Ohi' a/mixed shrub montane wet forest, 'Ohi' a montane wet shrubland, 'Ohi'a/'Olapa montane wet forest and 'Ohi' a/Uluhe lowland wet forest. There are 15 native plant taxa and 9 total native animal taxa.

Management Few ungulates currently exist in this section and much of the upper area is relatively pristine. No fencing is recommended, but staff control of ungulates is needed. Priority weeds such as Tibouchia need control. Monitoring will be necessary to locate priority weeds and remove them where found.

\section{PRESERVES OF THE NATURE CONSERVANCY OF HAWAII: Summary Information}

Source: Preserves of The Nature Conservancy of Hawaii, 1991

\section{HONOULIULI PRESERVE}

$\begin{array}{ll}\text { Island } & \text { O'ahu } \\ \text { Size } & 1,495 \mathrm{ha} \\ \text { Altitude } & 366 \mathrm{~m}-945 \mathrm{~m}\end{array}$

Year established 1990

Description Located on the south-east slope of the Waianae Mountains, Honouliuli Preserve is home to more than 45 rare plant and animal species, and contains some of the last remaining habitat on O'ahu for native forest birds. It protects three extremely rare Hawaiian plants, and several species of land snails, two of which are endangered. Natural communities comprise Kawelu lowland mesic grassland, Koa/'Ohi'a lowland mesic forest, Mamaki lowland wet shrubland, $O$ 'ahu diverse lowland mesic forest, 'Ohi'a lowland wet forest, 'Ohi'a lowland mesic forest, 'Ohi'a lowland mesic shrubland, 'Ohi' a/Uluhe lowland wet forest and Lonomea lowland dry forest. There are nine native communities, more than 100 plant species, and six upland bird species.

Management Historic feral cattle and goat damage was followed by invasion by aggressive alien plants. Management plans call for active weed control, restoration of rare lowland forest types, protection of rare plants and endangered snails, and maintenance of intact native vegetation.

\section{'IHI'IHILAUAKEA PRESERVE}

$\begin{array}{ll}\text { Island } & \text { O'ahu } \\ \text { Size } & 12 \mathrm{ha} \\ \text { Altitude } & 61 \mathrm{~m} \\ \text { Year } & 1987\end{array}$


Description Located in a shallow crater on the dry south-east coastline above Hanauma Bay, this preserve is a cooperative effort by The Nature Conservancy, the Hawaiian Botanical Society, and the City and County of Honolulu to protect a one-of-a-kind vernal pool with anhydrobiotic aquatic crustaceans, and a rare fern, 'ihi'ihilauakea Marsilea villosa. Staff and volunteers organise work parties on the preserve, which also serves as a site for public education programmes. Natural communities comprise Ihilauakea lowland dry herbland and vernal pool. There is one rare native community, approximately 12 native plant species. The number and status of aquatic invertebrates uncertain.

Management Management plans call for protection of the site from off-road vehicle traffic, as well as control of alien plants invading the Marsilea mats. Protection of the aquatic invertebrates will be passive: use of chemical control of weeds will be minimised to avoid possible water contamination.

\section{KALUAHONU PRESERVE}

$\begin{array}{ll}\text { Island } & \text { Kaua'i } \\ \text { Size } & 86 \mathrm{ha} \\ \text { Altitude } & 183 \mathrm{~m}-457 \mathrm{~m} \\ \text { Year } & 1982\end{array}$

Description The preserve was established through a lease agreement with Grove Farm Company. It protects the largest privately-owned nesting colony of the threatened Newell's shearwater or 'a'o Puffinus newelli (V), a native seabird. Natural communities include Ohi'a/Uluhe lowland wet forest and Uluhe lowland wet shrubland. There are two native communities, and an estimated more than 50 native plant species. No animal survey has yet been conducted.

Management The preserve is managed by Kaua'i volunteers with TNC staff supervision, in cooperation with state wildlife biologists. It is closed to the public to protect the nesting seabirds.

\section{KAMAKOU PRESERVE}

$\begin{array}{ll}\text { Island } & \text { Moloka'i } \\ \text { Size } & 1,123 \mathrm{ha} \\ \text { Altitude } & 762 \mathrm{~m}-1,382 \mathrm{~m} \\ \text { Year } & 1982\end{array}$

Description Established through a perpetual conservation easement from Moloka'i Ranch Ltd. The preserve protects native rain forest, shrublands, and bogs near the summit of the island, and is habitat for five native forest birds (including the endangered Moloka'i thrush, oloma'o), and several rare plant species. In Kamakou's remote native rain forests and shrublands live several hundred species of plants, insects, and land snails found only in Hawaii. The preserve is also a key watershed for Moloka'i. Natural communities comprise mixed fern/mixed shrub montane wet cliffs, 'Ohi'a/'Olapa montane wet forest, 'Ohi' a/mixed shrub montane wet forest, 'Ohi'a mixed montane bog, 'Ohi'a/Uluhe lowland wet forest, 'Ohi'a lowland mesic shrubland and Uluhe lowland wet shrubland. There are more than 350 native plant taxa. The native animals have not yet been fully catalogued, but includes threatened forest birds, and rare land snails. 
Management Kamakou is managed by TNC staff in cooperation with the state Division of Forestry and Wildlife. Portions of the preserve with maintained roads and trails are open to the public.

\section{KANEPU'U PRESERVE}

$\begin{array}{ll}\text { Island } & \text { Lana'i } \\ \text { Size } & 187 \mathrm{ha} \\ \text { Altitude } & 500 \mathrm{~m}-518 \mathrm{~m} \\ \text { Year } & 1990\end{array}$

Description Established via a perpetual conservation easement from Castle and Cooke Inc., Kanepu'u is the last significant remnant of a once-vast tropical dry forest on Lana'i. Such forests, composed of rich assemblages of tree species, once covered most of the dry and mesic Hawaiian lowlands, but have been almost entirely destroyed by fire and grazing statewide. Natural communities comprise Olopua/Lama lowland dry forest. There is one rare native community. The native plant species not yet catalogued. The native animals have also not yet been catalogued, but 'ua'u Pterodroma phaeopygia sandwichensis, a threatened native seabird, may occur.

Management TNC will attempt to restore the Kanepu'u dry forest through fencing (to protect the remnants from feral deer) and replanting of native trees, and will establish public access to the preserve.

\section{KAPUNAKEA PRESERVE}

$\begin{array}{ll}\text { Island } & \text { Maui } \\ \text { Size } & 486 \mathrm{ha} \\ \text { Altitude } & 488 \mathrm{~m}-1,706 \mathrm{~m} \\ \text { Year } & 1990\end{array}$

Description Kapunakea Preserve in the West Maui Mountains above Kaanapali protects at least 25 different types of rare Hawaiian plants, animals, and natural communities, including land snails, native forest birds, many rare plants, and pristine Hawaiian montane bogs. Kapunakea is an important link in the protection of more than 5,263ha of summit rain forests, the source of West Maui's fresh water. The preserve is not yet open to the public. Natural communities comprise 'A'ali'i lowland dry shrubland, Hawaiian intermittent stream, Lama/'Ohi'a lowland mesic forest, Mamaki lowland wet shrubland, mixed fern/shrub montane wet cliff, 'Ohi'a lowland mesic forest, 'Ohi'a lowland mesic shrubland, 'Ohi'a mixed montane bog, 'Ohi'a/mixed shrub montane wet forest, 'Ohi'a/'Olapa montane wet forest and 'Ohi'a/Uluhe lowland wet forest. Native plants have not yet been catalogued, there are few birds, and the invertebrates are not fully censused.

Management Feral ungulates and alien plants threaten native communities. Preventative weed control and fencing to exclude feral ungulates is recommended. 
MAUI LAVA TUBES PRESERVE

$\begin{array}{ll}\text { Island } & \text { Maui } \\ \text { Size } & 43 \text { ha } \\ \text { Altitude } & \text { Not available (see Management) } \\ \text { Year } & 1987\end{array}$

Description This preserve, established through a perpetual conservation easement with the landowner, protects one of Hawaii's finest known lava tube ecosystems and the uniquely adapted cave insects that occur only at this site. The ecosystem is so fragile that the preserve's location cannot be publicised. Research here promises important new insights into Hawaiian cave species adaptation and evolution. Natural communities comprise Thaumatogryllus/Cacenomobius Lowland Lava Tube. Approximately 30 native plant species and several extremely rare cave invertebrates occur.

Management Maui Lava Tubes Preserve is managed by TNC staff in cooperation with the land owner. The lead management concerns are disturbance of native surface vegetation via invasion by alien plants, and disturbance of the caves by human entry. To protect the cave, its location and elevation are not made available.

\section{MO'OMOMI PRESERVE}

$\begin{array}{ll}\text { Island } & \text { Moloka'i } \\ \text { Size } & 372 \mathrm{ha} \\ \text { Altitude } & \text { Sea level-198m } \\ \text { Year } & 1988\end{array}$

Description On the north-west coast of Moloka'i, the preserve was established through fee purchase from Moloka'i Ranch Ltd. It protects the finest coastal dune ecosystem in the main Hawaiian Islands. Its wind-swept dunes shelter five globally threatened plant species. Green turtle Chelonia mydas (E) nests here and TNC hopes sea birds will recolonise the area. The dunes also protect important research sites for Hawaiian prehistory, paleontology and geology. Natural communities comprise 'Aki'aki coastal dry grassland, 'Ilima coastal dry shrubland, Naupaka coastal dry shrubland, Nehe coastal dry shrubland and Tetramolopium rockii coastal dry shrubland. There are approximately 36 native plant species.

Management The preserve is managed by TNC staff. The leading management concerns are disturbance to sea turtle nesting grounds, protection of fragile dune vegetation from vehicular disturbance, and control of aggressive alien plants.

\section{PELEKUNU PRESERVE}

$\begin{array}{ll}\text { Island } & \text { Moloka'i } \\ \text { Size } & 2,332 \mathrm{ha} \\ \text { Altitude } & \text { Sea level-1,514m } \\ \text { Year } & 1987\end{array}$


Description Established through fee purchase from Moloka'i Ranch Ltd. Located on Moloka'i's rugged north coast, the preserve is accessible only on foot or by boat. The valley's remoteness has protected its lowland forests, sea cliffs, and one of Hawaii's last remaining free-flowing streams. For safety reasons, public access to the preserve is limited. Natural communities comprise Hala coastal mesic forest, Hawaiian intermittent stream, Hawaiian continuous perennial stream, Hawaiian mixed shrub coastal dry cliff, Hawaiian mixed shrub lowland dry cliff, Kawelu coastal dry grassland, Lama/'Ohi'a lowland mesic forest, 'Ohi'a/Uluhe lowland wet forest and 'Ohi'a/Hapu'u montane wet forest. There are nine native communities and ca. 180 native plant species. The native animals have not been fully catalogued, but include rare forest birds, land snails, stream fish and invertebrates.

Management Pelekunu is managed by TNC staff. The lead management concerns are the control of alien stream animals, and aggressive alien plants. Balancing protection of rare taxa with traditional uses of the valley is another management issue.

\section{PU'U KUKUI WATERSHED MANAGEMENT AREA}

$\begin{array}{ll}\text { Island } & \text { Maui } \\ \text { Size } & 3,239 \mathrm{ha} \\ \text { Altitude } & 427 \mathrm{~m}-1,764 \mathrm{~m} \\ \text { Year } & 1988\end{array}$

Description Pu'u Kukui Watershed Management Area is a cooperative effort of Maui Land and Pineapple Company, and The Nature Conservancy of Hawaii, to protect the Company's upland forest and shrublands as vital watershed and habitat for hundreds of endemic species of plants and animals. At the request of the land owner, the watershed management area is closed to the public. Natural communities comprise 'A'ali'i lowland dry shrubland, Hawaiian continuous perennial stream, Hawaiian intermittent stream, Koa/'Ohi'a lowland mesic forest, Lama/'Ohi'a lowland mesic forest, Mamaki lowland wet shrubland, mixed fern/shrub montane wet cliff, 'Ohi'a mixed montane bog, 'Ohi'a montane wet shrubland, 'Ohi'a/Uluhe lowland wet forest, 'Ohi' a/mixed shrub montane wet forest, 'Ohi'a lowland mesic shrubland, 'Ohi' a/Olapa montane wet forest and Uluhe lowland wet shrubland. There are more than 250 native plant species. The native animals have not been fully catalogued, but includes few forest birds, five species of rare land snails, aquatic fauna and many invertebrates.

Management Feral pigs and alien weeds are the two most important threats to the integrity and long-term survival of the native watershed forest. An aggressive pig fencing and control programme is being undertaken, accompanied by weed monitoring and control.

\section{WAIKAMOI PRESERVE}

$\begin{array}{ll}\text { Island } & \text { Maui } \\ \text { Size } & 2,117 \mathrm{ha} \\ \text { Altitude } & 1,341 \mathrm{~m}-2,438 \mathrm{~m} \\ \text { Year } & 1983\end{array}$

Description The preserve, on the north slopes of Haleakala Volcano, was established through a perpetual conservation easement from Haleakala Ranch Company. It protects native forest and 
shrubland, providing essential watershed protection for East Maui, and is habitat for 12 Hawaiian birds, several of which are threatened, and numerous other native species. Entry permits are required to visit this remote, rugged area. Natural communities comprise 'Akala montane wet shrubland, Carex montane wet grassland, Deschampsia subalpine mesic grassland, Koa/'Ohi'a montane wet forest, Mamane subalpine dry forest, mixed fern/shrub montane wet cliffs, 'Ohi'a/mixed shrub montane wet forest, 'Ohi'a/'Olapa montane wet forest, 'Ohi'a/Uluhe montane wet forest, 'Ohi'a subalpine mesic forest, pioneer vegetation on lava flows, Pukiawe subalpine dry shrubland and Uluhe lowland wet shrubland. There are more than 200 native plant taxa and native animals. Invertebrates have not yet been catalogued.

Management Maintenance of habitat for rare and threatened birds is the primary management goal. The key threats are feral ungulates, specifically goats at higher elevations, and pigs throughout the preserve. Invasion by aggressive alien plants is a problem in certain portions of the preserve, and plant control programmes are also ongoing. 


\section{VANUATU}

Area 12,189 sq. $\mathrm{km}$

Population $151,000(1988)$

Natural increase: $4.2 \%$ (urban) and $3.1 \%$ (rural)

(World Bank, 1990)

(Dahl, 1986 and IUCN, 1988)

GNP US\$ 820 per capita (1988) (World Bank, 1990)

Policy and Legislation The post-independence Constitution devotes a chapter to land issues, and provides the basis upon which all legislation and policy concerning land tenure in Vanuatu rests. The salient points are that: all land in the Republic belongs to the indigenous custom owners and their descendants; the rules of custom form the basis of ownership and use of land; only indigenous citizens who have acquired land in accordance with a recognised system of land tenure may have perpetual land ownership; and government may own land in the public interest (Nalo et al., 1987). Most land is thus in customary ownership and there is little likelihood of Government acquiring land for protected areas. Such areas would have to be leased or managed jointly by the government and custom owners (M.R. Chambers, pers. comm., 1989). Declaration of a site as public land could well meet with opposition from custom owners, and could involve expensive compensation (Nalo et al., 1987).

The issue of land tenure must be seen in the light of customary practice, or strong traditions concerning land. Although there are certain nationwide principles, such as the important distinction between use rights and ownership rights, the system is highly fragmented and different practices may apply amongst the approximately 40 different language groups in the country. Land tenure, customary tenure, protected areas and conservation are discussed further by Nalo et al. (1987) and with particular reference to the establishment of Erromango Kauri Reserve (Barrance, 1989).

Environmental conservation is embodied in the Constitution, which states in Article 7(d) that every person is obliged "to protect Vanuatu and to safeguard the national wealth, resources and environment in the interests of the present generation and of future generations". Two of the six objectives of the Second National Development Plan (1987-1991) specifically address the attainment of sustainable development. Thus, the third objective is to "increase productive utilization of the country's natural resource base as a means of generating viable and sustained economic growth", and the sixth is to "ensure that Vanuatu's unique environmental and cultural heritage is not damaged in the process of economic development and change".

Legislation for the establishment of national parks and reserves and the protection of land and water is generally lacking (Nalo et al., 1987). Laws on Vanuatu which were enacted prior to independence were made by the Resident Commissioners under the provisions of the Anglo-French Protocol of 1914. Some of these are still in force and several include conservation measures. The Forestry Joint Regulation (No. 30 of 1964) provides for the establishment of forest areas, forest lands, and forest reserves (although none have been established), and is incidentally also used for the protection of wrecks. The intention of this legislation is to ensure that forest resources are protected and developed in accordance with good forestry principles.

Under Forestry Act No. 14 (1982), the Director of Forests is authorised to enter into forest plantation agreements with owners to assist reafforestation or to protect threatened forests. Such areas are subject to state control, and clearance without a permit is prohibited. Agreements may 
be formulated in order to prevent soil erosion, preserve the ecology of an area, conserve land of particular scenic, cultural, historic or national interest, or for recreational use by the public (Sloth, 1988).

Other environmental legislation includes the Fisheries Act No. 37 (1982) which provides for the declaration of marine reserves (Section 20) within which no living organism, sand, coral or part of a wreck may be taken or removed.

Improved legislation for national parks and reserves was under consideration in 1989 (Leaver and Spriggs, 1989) and a number of potential protected areas have been identified. The National Conservation Strategy prospectus (IUCN, 1988) states that a project to review the legislation concerning conservation and environment has been implemented, with the object of making recommendations for modifications or additions to existing laws. One major piece of legislation needed is a heritage conservation act that would provide for both cultural and natural conservation. The act should provide mechanisms whereby custom leaders and land owners could have sites and objects of special importance registered for protection under the act. Ownership and management would rest with the custom owners, but with the additional support of the law for their protection and specified penalties for the violation of that protection.

The contribution made by traditional custom and practice towards protected areas and resource conservation is significant. For example, seasonal custom taboos are applied in certain coastal waters for the conservation of dugong, fish and turtle (SPREP, 1989). During colonial times land in Vanuatu was registered under freehold titles and were mainly held by non-indigenous interests. Land held by the French, British and Condominium governments prior to independence was vested in the Vanuatu government for the benefit of the Republic, under Land Reform Regulation No. 31 of 1980. A significant number of these land parcels comprised long distances of coastal land about $100 \mathrm{~m}$ wide. Much of this land has been returned to customary owners, but some has been retained for the establishment of protected areas. The Land Reform Regulation also empowers the Minister responsible for lands to declare any land to be public. This is only done on the advice of the Council of Ministers and after consultation with customary owners. Following requests by the Local Government Council, proposals to declare parts of Espiritu Santo as public land for recreational purposes have been made.

International Activities Vanuatu is not yet party to any of the international conventions or programmes that directly promote the conservation of natural areas, namely the Convention concerning the Protection of the World Cultural and Natural Heritage (World Heritage Convention), Unesco Man and the Biosphere Programme and the Convention on Wetlands of International Importance especially as Waterfowl Habitat (Ramsar Convention).

The Convention on the Conservation of Nature in the South Pacific (1976) has been neither signed nor ratified. Known as the Apia Convention, it entered into force during 1990. The Convention is coordinated by the South Pacific Commission and represents the first attempt within the region to cooperate on environmental matters. Among other measures, it encourages the creation of protected areas to preserve indigenous flora and fauna.

Although Vanuatu is party to the South Pacific Regional Environment Programme (SPREP), the 1986 Convention for the Protection of the Natural Resources and Environment of the South Pacific Region (SPREP Convention) has not yet been signed or ratified. The Convention entered into force during August 1990. Article 14 calls upon the parties to take all appropriate measures to protect rare or fragile ecosystems and threatened or endangered flora and fauna through the establishment of protected areas and the regulation of activities likely to have an adverse effect 
on the species, ecosystems and biological processes being protected. However, as this provision only applies to the Convention area, which by definition is open ocean, it is most likely to assist with the establishment of marine reserves and the conservation of marine species.

Other international and regional conventions concerning environmental protection to which Vanuatu is party are reviewed by Venkatesh et al. (1983).

Administration and Management The Department of Forestry of the Ministry of Agriculture, Forestry and Fisheries is responsible for the implementation of the Forestry Act No. 14 of 1982. The Department of Fisheries of the same Ministry is responsible for the Fisheries Act No. 37 of 1982 , and is consequently responsible for marine reserves, whilst the Ministry is charged with generally overseeing issues concerned with environment and conservation. The administrative status of currently gazetted recreational reserves rests with a local government council, although the legal basis for this is not clear.

In September 1986 an Environment Unit was established in the Ministry of Lands, Geology and Rural Water Supply, with responsibility for coordinating environmental and conservation issues. The Environment Unit essentially has a single objective: to develop policies and programmes such that natural resources are managed so that they are not severely degraded by development activities. Major projects include preparation of a national conservation strategy and comprehensive environmental legislation; resource surveys of fringing reefs, freshwaters, Espiritu Santo Island and biological, geological, scenic and cultural heritage sites; dugong surveys; and surveys of estuarine crocodiles of Vanua Lava (Chambers and Bani, 1987 and 1989). The Environment Unit will also be made responsible for the management of any parks and reserves gazetted in the future (SPREP, 1989).

The protected areas system is too small and fails to protect most ecosystems. Existing protected areas are threatened by inadequate management, whilst the options for selecting new protected areas must be declining with time. There is an increasingly urgent need to gazette a protected area on Erromango as there have been recent (1988/1989) proposals to log parts of the remaining kauri stands. Approval has been given for major logging schemes for parts of Malekula despite opposition from Government advisors and technical staff from the Environment, Forestry, Finance, Culture and Labour departments (M.R. Chambers, pers. comm., 1989).

Systems Reviews The Republic of Vanuatu, formerly the Anglo-French Condominium of the New Hebrides, consists of the central and southern part of an archipelago which forms one of the numerous seismic arcs found in the Western Pacific. The Santa Cruz Islands, politically part of the Solomon Islands, constitute the northern part of the archipelago (UNEP/IUCN, 1988).

The archipelago of about 80 islands forms a bifurcating chain; the larger islands are found in the west and are made up of extinct volcanoes covered with fossil or modern coral reefs. The island arc is young and associated with considerable volcanic and seismic activity (Cheney, 1987). The islands are mountainous by Pacific standards, many island interiors being uninhabited (Anon., 1989a), and Tabwemasana Peak on Espiritu Santo attains $1,879 \mathrm{~m}$. Brief summaries of the physical characteristics are given by Douglas (1969) and UNEP/IUCN (1988) for most of the islands.

Some 9,000 sq. km, $74 \%$ of total land area, is under natural vegetation (Neill, 1987). Principal formations are tropical lowland evergreen rain forest, small areas of broadleaved deciduous forest, closed conifer forest, montane rain forest between $1,000 \mathrm{~m}$ and $1,500 \mathrm{~m}$; cloud forest above $1,500 \mathrm{~m}$, extensive coastal forest, swamp forest on Efate; and scattered mangrove forests covering 
between 2,500 and 3,500ha, of which 2,000ha occur on Malakula (Beveridge, 1975; David, 1985; Davis et al., 1986).

Although lowland formations have largely been cleared and replaced by anthropogenic vegetation, forest remains the dominant landscape element on most islands. Surveys conducted in the mid-1960s indicate that some $180 \mathrm{sq} . \mathrm{km}$ of Erromango were occupied by closed climax forest, including $50 \mathrm{sq.} \mathrm{km}$ of kauri pine stands (Johnson, 1981). According to Quantin's (1976) maps, high forests are restricted on most of the islands, especially those that are densely populated (Pentecost, Aoba, Tanna and Shepherd) or have active volcanoes (Ambrym). However, the low montane forests are generally well preserved, and occupy large areas; dense, secondary woody formations, often with a thicket Hibiscus community, are extensive.

Forest resources are poor compared with neighbouring countries, due to geological activity, geographic isolation, hurricanes and shifting agriculture. It is estimated that current exploitable, natural forest resources will supply domestic needs for at least 20 years. Logging of indigenous forest has been sporadic, wasteful, largely unprofitable and concentrated on Efate, Espiritu Santo, Erromango, Aneityum and, to a lesser extent, Malekula and Hui. On Erromango, intensive exploitation of kauri pine commenced in 1967. Here, the risk of wind damage to residual vegetation, invasion by weed species and land slips has subsequently increased (Beveridge, 1975), and major stands have been reduced to a single tract. However, a ban on the export of whole logs was due to be in place by 1990 . Similarly, a sandalwood export moratorium is to be imposed by 1992 .

Coral reefs occur throughout the archipelago, encircling some islands, but discontinuous around active or recently active land masses such as Espiritu Santo, Malakula and Ambrym. Summaries of vegetation and coral reefs on most islands are given by Douglas (1969) and UNEP/IUCN (1988), respectively. Details given in UNEP/IUCN (1988) includes particular reference to the reefs of President Coolidge and Million Dollar Point Reserve and Reef Island.

In general, Vanuatu's environment is relatively undisturbed (Chambers and Bani, 1987), due to low population densities (about 10 per sq. $\mathrm{km}$ in rural areas), and the limited degree of development (M.R. Chambers, pers. comm., 1989). Nevertheless, this could change due to the high rate of human population increase and the high proportion ( $85 \%$ ) of the population engaged in slash-and-burn agriculture and subsistence reef fishing. Further, the concentration of the population in coastal districts, coupled with a reduced fallow period in the slash-and-burn cycle, has led to soil erosion (Anon., 1989). A broad-ranging discussion of environment, resources and development is given by Baines (1981), covering topics such as tenure, population, administration, financial costs and aspects of natural resources including forests, mangroves, reefs, minerals, wildlife etc. Large-scale agricultural developments are leading to environmental problems, principally accelerated by forest clearance, soil erosion through poor pasture management and increasingly heavy use of pesticides and herbicides (IUCN, 1988).

Protected areas are currently restricted to President Coolidge and Million Dollar Point Reserve, which only includes marine components, and four recreational reserves. The area within the system amounts to less than $0.1 \%$ of the total national area, and much of that is accounted for by President Coolidge Reserve.

Dahl (1980) lists 37 habitats, including several forest types, scrub, marsh, grassland, volcanic desert, freshwater and littoral features and various reef formations. With the exception of fringing reefs, none of these is effectively protected. 
An Action Strategy for Protected Areas in the South Pacific Region (SPREP, 1985) has been prepared. The principal goals of the strategy cover conservation education, conservation policy development, establishment of protected areas, effective protected area management and regional and international cooperation. Priority recommendations for Vanuatu are as follows: develop a national conservation strategy; establish a kauri reserve on Erromango Island; establish recreational reserves on Espiritu Santo.

The development of a national conservation strategy was delayed by a lack of funds, but has since been financed with funds from Australia, channelled through SPREP. An outline draft National Parks Act has been compiled (Leaver and Spriggs, 1989), although it is not known if this will be integrated into the national conservation strategy or implemented in any other way. Negotiations are underway with landowners on the island of Erromango to secure a long-term lease for the proposed 500ha Kauri Reserve (L. Bule, pers. comm., 1990). SPREP has funded an inter-departmental team to carry out a survey of three potential protected areas on Ambrym, Efate and Malakula and it is hoped that these, along with the proposed site on Erromango, will form the nucleus of a protected areas system (Anon., 1989).

Dahl (1980) has recommended that the protected areas network be consolidated through the establishment of reserves to protect examples of major forest types, grasslands, swamps, lakes and marine habitats; forest reserves on each of the main islands for vegetation and birds, such as 2,000ha of forest in southern Erromango and 2,000-3,000ha in central Efate; a cloud forest reserve on Espiritu Santo, which would be of value for the conservation of Santo mountain starling (Hay, 1986); and reserves along the north-west coast of Malekula or Santo, where reefs were elevated over $6 \mathrm{~m}$ in 1965. Less specific recommendations are made by Dahl (1986) and include establishing a major protected area on Espiritu Santo, smaller reserves at least on Tanna, Aneityum and Erromango, a recreation and tourism reserve on Efate, and protection of saltwater crocodiles on Vanua Lava (Dahl, 1986).

\section{Addresses}

\section{Recreational Reserves}

Department of Lands, Ministry of Lands, Geology and Rural Water Supply, Private Mail Bag 007, Port Vila

Environmental Unit, Ministry of Lands, Geology and Rural Water Supply, Private Mail Bag 007, Port Vila

Department of Local Government, Ministry of Home Affairs, Private Mail Bag 036, Port Vila

\section{Marine Parks}

Department of Fisheries, Ministry of Agriculture, Forestry and Fisheries, Private Mail Bag 064, Port Vila

Forestry Reserves

Department of Forestry, Ministry of Agriculture, Forestry and Fisheries, Private Mail Bag 064, Port Vila

\section{References}

Anon. (1989). Progress with the action strategy for protected areas in the South Pacific. Information Paper 3. Fourth South Pacific Conference on Nature Conservation and Protected Areas. Port Vila, Vanuatu, 4-12 September. 19 pp. 
Baines, G.B.K. (1981). Environmental resources and development in Vanuatu. Report to the Government of Vanuatu with support of UNDAT (United Nations Development Advisory Team for the Pacific). Unpublished. $26 \mathrm{pp}$.

Barrance, A.J. (1989). Erromango kauri reserve - a case study in environmental protection on customary land. Case Study No. 7. Fourth South Pacific Conference on Nature Conservation and Protected Areas, Port Vila, Vanuatu, 4-12 September. 6 pp.

Beveridge, A.E. (1975). Kauri forests in the New Hebrides. Philosophical Transactions of the Royal Society of London B 272: 369-383.

Chambers, M.R. and Bani, E. (1987). Wildlife and heritage conservation in Vanuatu. Resources development and environment. ESCAP, Port Vila, Vanuatu. Pp. 124-133.

Chambers, M.R. and Bani, E. (1989). Vanuatu - safe haven for the dugong. The Pilot. September. Pp. 13-14

Cheney, C. (1987). Geology and the environment. In: Chambers, M.R. and Bani, E., Resources development and environment. ESCAP, Port Vila, Vanuatu. Pp. 1-16.

Dahl, A.L. (1980). Regional ecosystem survey of the South Pacific Area. SPC/IUCN Technical Paper 179. South Pacific Commission, Noumea, New Caledonia. 99 pp.

Dahl, A.L. (1986). Review of the Protected Areas System in Oceania. IUCN, Gland, Switzerland and Cambridge, UK/UNEP, Nairobi, Kenya. 328 pp.

David, G. (1985). Les mangroves de Vanuatu: 2ème partie, présentation générale. Naika 19: 13-16.

Davis, S.D., Droop, S.J.M., Gregerson, P., Henson, L., Leon, C.J., Lamlein Villa-Lobos, J., Synge, H. and Zantovska, J. (1986). Plants in Danger: What do we know? IUCN, Gland, Switzerland and Cambridge, UK. 488 pp.

Douglas, G. (1969). Draft checklist of Pacific Oceanic Islands. Micronesica 5: 327-463.

Hay, R. (1986). Bird conservation in the Pacific. ICBP Study Report No. 7. International Council for Bird Preservation, Cambridge, UK. 102 pp.

IUCN (1988). National Conservation Strategy: Vanuatu. Phase I: Prospectus. IUCN, Gland, Switzerland. $39 \mathrm{pp}$.

Johnson, M.S. (1971). New Hebrides Condominium, Erromango forest inventory. Land Resources Study No. 10. Overseas Development Administration, Land Resources Division, Surbiton, UK. 91 pp.

Leaver, B. and Spriggs, M. Erromango kauri reserve. Working Paper No. 1. TCP/VAN/6755. FAO, Rome. 28 pp.

Nalo, C., Hunt, L. and Boote, D. (1977). Land tenure in Vanuatu today. In: Chambers, M.R. and Bani, E., Resources development and environment., ESCAP, Port Vila, Vanuatu. Pp. 78-92.

Neill, P. (1987). Forestry resources and policies in Vanuatu. In: Chambers, M.R. and Bani, E., Resources development and environment. ESCAP, Port Vila, Vanuatu. Pp. 59-62.

Quantin, P. (1976). Archipel des Nouvelles Hébrides: sols et quelques données du milieu naturel, Santo. Office de la Recherche Scientifique et Technique de Outre-Mer, Paris. 37 pp.

Schmid, M. (1978). The Melanesian forest ecosystem (New Caledonia, New Hebrides, Fiji Islands and Solomon Islands. In: Unesco/UNEP/FAO, Tropical forest ecosystems. Unesco, Paris. Pp. 654-683.

Sloth, B. (1988). Nature legislation and nature conservation as part of tourism development in the island Pacific. Pacific Regional Tourism Development Programme. Tourism Council of the South Pacific, Suva, Fiji. 82 pp.

SPREP (1985). Action strategy for protected areas in the South Pacific Region. South Pacific Commission, Noumea, New Caledonia. 24 pp.

SPREP (1989). Vanuatu. Paper presented at the Fourth South Pacific Conference on Nature Conservation and Protected Areas, Port Vila, Vanuatu, 4-12 September. 6 pp. 
UNEP/IUCN (1988). Coral Reefs of the World. Volume 3. Central and Western Pacific. UNEP Regional Seas Directories and Bibliographies. IUCN, Gland, Switzerland and Cambridge, UK/UNEP, Nairobi, Kenya. 378 pp.

Venkatesh, S, Va'ai, S. and Pulea, M. (1983). An overview of environmental protection legislation in the South Pacific countries. SPREP Topic Review No. 13. South Pacific Commission, Noumea, New Caledonia. 63 pp.

World Bank (1990). World Tables. 1989-90 Edition. The John Hopkins University Press, Baltimore. $646 \mathrm{pp}$.

\section{ANNEX \\ Definitions of protected area designations, as legislated, together with authorities responsible for their administration}

\section{Title: The Forestry Joint Regulation (No. 30)}

Date: 1964

Brief description: Enacted prior to independence under the provisions of the Anglo-French Protocol of 1914.

Administrative authority: Director of Forests

Designation:

Forest areas

Forest lands

Forest reserves

Title: Forestry Act No. 14

Date: 1982

Brief description: The Director of Forests is authorised to enter into forest plantation agreements with owners to assist reafforestation or to protect threatened forests. Such areas are subject to state control and clearance without a permit is prohibited. Agreements may be formulated in order to prevent soil erosion, preserve the ecology of an area, conserve land of particular scenic, cultural, historic or national interest, or for recreational use by the public.

Administrative authority: Director of Forests

Designation: No information

Title: Fisheries Act No. 37

Date: 1982

Brief description: Provides, inter alia, for the declaration of marine reserves (Section 20). Administrative authority: Department of Fisheries 
IUCN Directory of Protected Areas in Oceania

Designation:

Marine reserves No living organism, sand, coral or part of a wreck may be taken or removed.

SUMMARY OF PROTECTED AREAS

\begin{tabular}{llccc}
\hline $\begin{array}{l}\text { Map } \\
\text { ref. }\end{array}$ & Name of area & $\begin{array}{c}\text { IUCN management } \\
\text { category }\end{array}$ & $\begin{array}{c}\text { Area } \\
\text { (ha) }\end{array}$ & $\begin{array}{c}\text { Year } \\
\text { notified }\end{array}$ \\
\hline & $\begin{array}{l}\text { Reserves } \\
\text { Naomebaravu-Malo* }\end{array}$ & Unassigned & 11 & 1984 \\
2 & $\begin{array}{l}\text { President Coolidge and Million } \\
\text { Dollar Point* } \\
\text { Whitesands* }\end{array}$ & Unassigned & 100 & 1983 \\
3 & Unassigned & 39 & 1984 \\
4 & $\begin{array}{l}\text { Recreation Parks } \\
\text { Aore* } \\
\text { Bucaro Aore* }\end{array}$ & Unassigned & 37 & 1984 \\
& Proposed & Unassigned & 20 & 1984 \\
& Erromango kauri reserve & Proposed & $(500)$ & \\
\hline
\end{tabular}

* Site is described in this directory.

${ }^{1}$ Locations of most protected areas are shown in the accompanying map. 


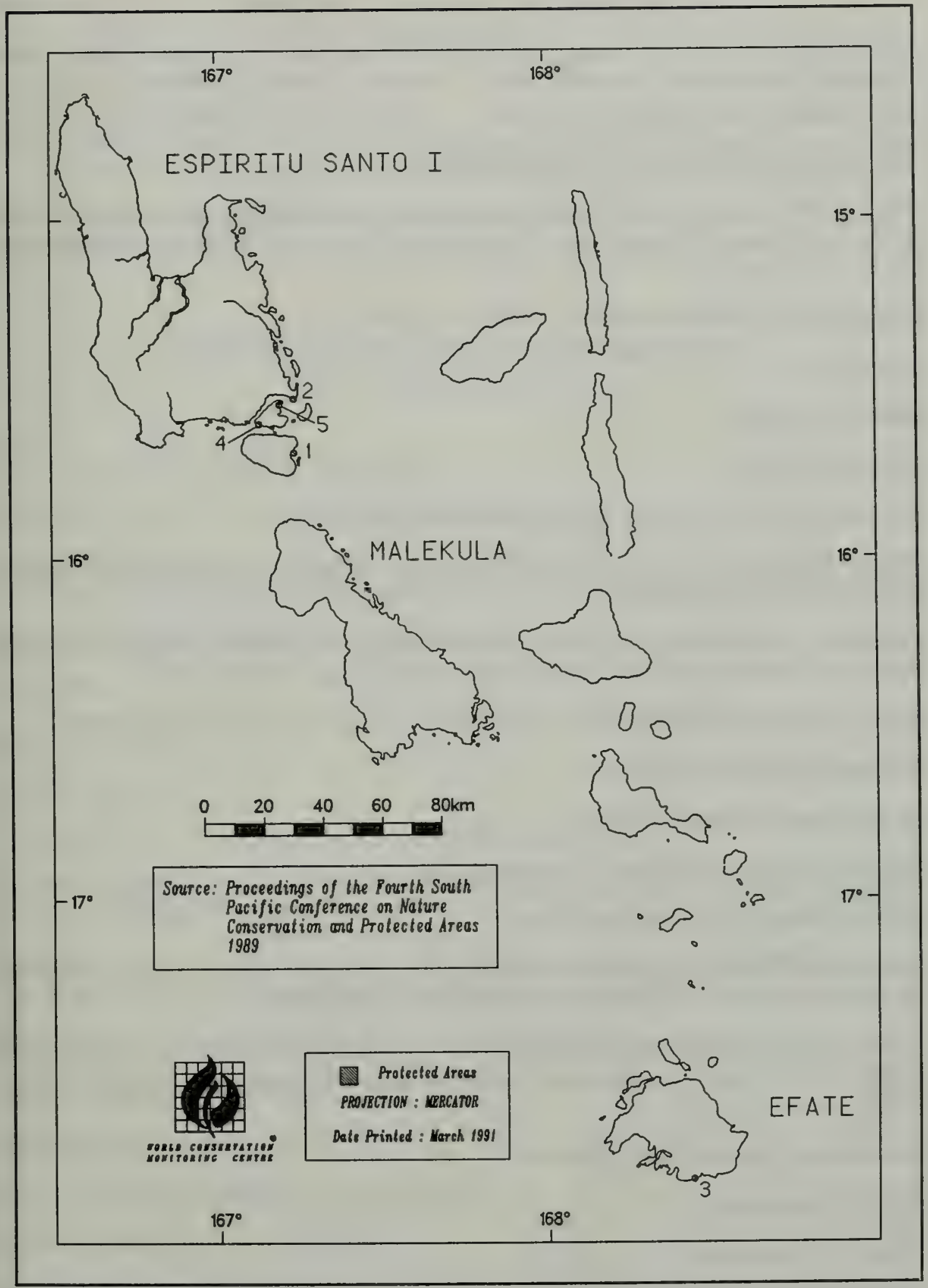

Protected Areas of Vanuatu 


\section{AORE RECREATIONAL RESERVE (Title No. 414)}

\section{IUCN Management Category Unassigned}

Biogeographical Province 5.07.13 (East Melanesian)

Geographical Location Located on the south-west coast of Aore Island which, in turn, lies $1 \mathrm{~km}$ off the south coast of Espiritu Santo. Luganville is $11 \mathrm{~km}$ to the north-east. Approximately $167^{\circ} 07^{\prime} \mathrm{E}, 15^{\circ} 36^{\prime} \mathrm{S}$

Date and History of Establishment 20 September 1984

Area 37 ha

\section{Land Tenure State}

Altitude Sea-level

Physical Features Comprises coral formations with sandy beaches.

Climate Annual rainfall varies between $2500 \mathrm{~mm}$ and $4000 \mathrm{~mm}$ and temperatures range from $18^{\circ} \mathrm{C}$ to $33^{\circ} \mathrm{C}$ (SPREP, 1985).

Vegetation Common coastal trees include Barringtonia sp., Calophyllum sp. and Terminalia sp., with epiphytic ferns and orchids. Strand vegetation also occurs (SPREP, 1985).

Fauna Current knowledge indicates that only common species occur (SPREP, 1985).

Cultural Heritage None known

Local Human Population None

Visitors and Visitor Facilities No information

Scientific Research and Facilities None

Conservation Value The site has been designated as a recreational reserve (SPREP, 1989), with complete protection of vegetation and natural environment intended.

Conservation Management Enactment and enforcement of local bye-laws is undertaken to prohibit litter, damage to vegetation and the construction of unauthorised buildings (SPREP, 1989).

\section{Management Constraints No information}

Staff No information

Budget No information

Local Addresses Secretary, Santo/Malo Local Government Council, PO Box 239, Luganville 


\section{References}

SPREP (1985). Vanuatu. In: Thomas, P.E.J. (Ed.), Report of the Third South Pacific National Parks and Reserves Conference. Volume III. Country reviews. South Pacific Commission, Noumea, New Caledonia. Pp. 217-228.

SPREP (1989). Vanuatu. Paper presented at the Fourth South Pacific Conference on Nature Conservation and Protected Areas, Port Vila, Vanuatu, 4-12 September. 10 pp.

Date November 1988, updated July 1989, February 1990

\section{BUCARO AORE RECREATIONAL RESERVE (Title Nos. 386 and 388)}

\section{IUCN Management Category Unassigned}

Biogeographical Province 5.07.13 (East Melanesian)

Geographical Location Located on north-east Aore Island which, in turn, lies $1 \mathrm{~km}$ off the south coast of Espiritu Santo. Luganville is $4 \mathrm{~km}$ to the north-west. Approximately $167^{\circ} 13^{\prime} \mathrm{E}, 15^{\circ} 33^{\prime} \mathrm{S}$

Date and History of Establishment 20 September 1984

Area $20 \mathrm{ha}$

Land Tenure State

Altitude Sea-level

Physical Features Comprises coral formations with sandy beaches.

Climate Annual rainfall varies between $2500 \mathrm{~mm}$ and $4000 \mathrm{~mm}$ and temperatures range from $18^{\circ} \mathrm{C}$ to $33^{\circ} \mathrm{C}$ (SPREP, 1985).

Vegetation Common coastal trees include Barringtonia sp., Calophyllum sp. and Terminalia sp., with epiphytic ferns and orchids. Strand vegetation also occurs (SPREP, 1985).

Fauna Current knowledge indicates that only common species occur (SPREP, 1985).

Cultural Heritage None known

Local Human Population None

Visitors and Visitor Facilities No information

Scientific Research and Facilities None

Conservation Value The site has been designated as a recreational reserve (SPREP, 1985), with complete protection of vegetation and natural environment intended. 
Conservation Management Enactment and enforcement of local bye-laws is undertaken to prohibit litter, damage to vegetation and the construction of unauthorised buildings (SPREP, 1989).

Management Constraints No information

Staff None

Budget None

Local Addresses Secretary, Santo/Malo Local Government Council, P O Box 239, Luganville

\section{References}

SPREP (1985). Vanuatu. In: Thomas, P.E.J. (Ed.), Report of the Third South Pacific National Parks and Reserves Conference. Volume III. Country reviews. South Pacific Commission, Noumea, New Caledonia. Pp. 217-228.

SPREP (1989). Vanuatu. Paper presented at the Fourth South Pacific Conference on Nature Conservation and Protected Areas, Port Vila, Vanuatu, 4-12 September. 10 pp.

Date November 1988, updated July 1989, February 1990

\section{NAOMEBARAVU-MALO RECREATIONAL RESERVE} (Title No. 830)

\section{IUCN Management Category Unassigned}

Biogeographical Province 5.07.13 (East Melanesian)

Geographical Location Located on eastern Malo Island, which lies $3 \mathrm{~km}$ south of Espiritu Santo. Luganville is $19 \mathrm{~km}$ to the north-west. Approximately $167^{\circ} 15^{\prime} \mathrm{E}, 15^{\circ} 44^{\prime} \mathrm{S}$

Date and History of Establishment 20 September 1984

Area 11 ha

\section{Land Tenure State}

Altitude Sea-level

Physical Features Comprises coral formations with sandy beaches.

Climate Annual rainfall varies between $2500 \mathrm{~mm}$ and $4000 \mathrm{~mm}$ and temperatures range from $18^{\circ} \mathrm{C}$ to $33^{\circ} \mathrm{C}$ (SPREP, 1985).

Vegetation Common coastal trees include Barringtonia sp., Calophyllum sp. and Terminalia sp., with epiphytic ferns and orchids. Strand vegetation also occurs (SPREP, 1985).

Fauna Current knowledge indicates that only common species occur (SPREP, 1985).

Cultural Heritage None known 
Local Human Population None

Visitors and Visitor Facilities No information

Scientific Research and Facilities None

Conservation Value The site has been designated as a recreational reserve (SPREP, 1985), with complete protection of vegetation and natural environment intended.

Conservation Management Enactment and enforcement of local bye-laws is undertaken to prohibit litter, damage to vegetation and the construction of unauthorised buildings (SPREP, 1989).

Management Constraints No information

Staff None

Budget None

Local Addresses Santo/Malo Local Government Council, P O Box 239, Luganville

\section{References}

SPREP (1985). Vanuatu. In: Thomas, P.E.J. (Ed.), Report of the Third South Pacific National Parks and Reserves Conference. Volume III. Country reviews. South Pacific Commission, Noumea, New Caledonia. Pp. 217-228.

SPREP (1989). Vanuatu. Paper presented at the Fourth South Pacific Conference on Nature Conservation and Protected Areas, Port Vila, Vanuatu, 4-12 September. 10 pp.

Date November 1988, updated July 1989, February 1990

\section{PRESIDENT COOLIDGE AND MILLION DOLLAR POINT RESERVE}

\section{IUCN Management Category Unassigned}

Biogeographical Province 5.07.13 (East Melanesian)

Geographical Location Situated off southern Espiritu Santo, approximately $6 \mathrm{~km}$ east of Luganville and seaward of the highest water mark of spring tides. The boundary is delimited by a line from the "white rock", in position $15^{\circ} 31^{\prime} \mathrm{S}, 167^{\circ} 13^{\prime} \mathrm{E}$, extending $180^{\circ}$ true for 0.3 nautical miles $(556 \mathrm{~m})$, then $090^{\circ}$ true for one nautical mile $(1,853 \mathrm{~m})$ and then $000^{\circ}$ true to the shore.

Date and History of Establishment Declared a marine reserve on 18 December 1983 by the Minister of Land and Natural Resources, under the Fisheries Act (1982) for the complete protection of all marine life and the wreck and all its contents (SPREP, 1989).

Area Approximately 100ha

Land Tenure Part state-owned and part customary land 
Altitude Ranges from the highest spring-tide water mark to $73 \mathrm{~m}$ below sea level (UNEP/IUCN, 1988).

Physical Features Includes the wreck of the American wartime troopship President Coolidge, which sank in 1942, and the area known as Million Dollar Point (Crossland, 1984). The wreck, over $198 \mathrm{~m}$ long and $24.4 \mathrm{~m}$ wide, forms an artificial reef in an otherwise barren area. The stern of the President Coolidge lies in 73m of water (SPREP, 1985). There is a shallow reef within the reserve (A. Power, in litt., 1987).

Climate Mean monthly temperatures in Luganville range from $23^{\circ} \mathrm{C}$ in August to $26.5^{\circ} \mathrm{C}$ in February. Mean monthly minimum and maximum temperatures are $20^{\circ} \mathrm{C}$ in July and $29.7^{\circ} \mathrm{C}$ in February, respectively. Mean annual rainfall at Luganville is $3216 \mathrm{~mm}$. There is no marked dry season, although maximum and minimum monthly mean rainfall varies between $450 \mathrm{~mm}$ in March and $160 \mathrm{~mm}$ in June, respectively (Giovanelli, 1966).

\section{Vegetation No information}

Fauna The wreck, which is well covered by coral, supports a population of thousands of reef fish. The largest are two habituated groupers Promicrops lanceolatus. Individual fish, including angelfish and small cod, are known to have inhabited the wreck for at least 10 years. Grey sharks Carcharhinus sp., approximately $1.8 \mathrm{~m}$ long, are frequently seen. Female Carcharhinus sp. and hammerheads (family Sphyrnidae) congregate in May for breeding. Hawksbill turtle Eretmochelys imbricata (E) occur, as do a very large number and variety of fish in the shallower areas. These include an habituated $1.8 \mathrm{~m}$ moray eel Gymnothorax flavomarginatus (A. Power, in litt., 1987).

\section{Cultural Heritage No information}

\section{Local Human Population Not applicable}

Visitors and Visitor Facilities The reserve is the main tourist attraction of Espiritu Santo. Santo Dive Tours conduct dives in the reserve (A. Power, in litt., 1987).

Scientific Research and Facilities No scientific studies to date

\section{Conservation Value No specific information}

Conservation Management Under the 1982 Fisheries Act, marine organisms may not be removed and it is prohibited to fish, take or destroy coral, dredge sand or gravel, disturb the natural habitat or take or destroy any wreck or part thereof (Crossland, 1984).

Management Constraints The shallow reef was extensively damaged by Hurricane Nigel in 1985 and regeneration of hard corals has been very slow. Some fish poaching occurs, including spearfishing and fishing with nylon lines from boats at night. The latter is believed responsible for elimination of most of a shoal of tame snapper Lutjanus argentimaculatus. Yachts moor directly over the wreck and unsupervised diving occurs. Divers from visiting yachts remove artefacts and corals, mainly gorgonians, black coral and red Distichopora violacea (SPREP, 1985; A. Power, in litt., 1987); prevention is hampered by staff shortages. Some semi-commercial black coral and gorgonian collection by local divers occurred during 1975-1980 (Crossland, 1984; A. Power in litt., 1987).

Staff Occasional coverage by Department of Fisheries staff (SPREP, 1985) 
Budget None (SPC, 1985)

Local Addresses Secretary, Santo/Malo Local Government Council, P O Box 239, Luganville

\section{References}

Crossland, J. (1984). Vanuatu's First Marine Reserve. Naika (Journal of the Vanuatu Natural Science Society) 14:2-3.

Giovanelli, J.L. (1966). Dix années d'observations météorologiques aux Nouvelles Hébrides. Service météorologique, Nouvelle Calédonie, Noumea. 81 pp. (Unseen).

Lee, K.E. (1975). A discussion on the results of the 1971 Royal Society-Percy Sladen expedition to the New Hebrides: introductory remarks. Philosophical Transactions of the Royal Society B 272: 269-276.

SPREP (1985). Vanuatu. In: Thomas, P.E.J. (Ed.), Report of the Third South Pacific National Parks and Reserves Conference. Report. Volume III. Country reviews. South Pacific Commission, Noumea, New Caledonia. Pp. 217-228.

SPREP (1989). Vanuatu. Paper presented at the Fourth South Pacific Conference on Nature Conservation and Protected Areas, Port Vila, Vanuatu, 4-12 September. 10 pp.

UNEP/IUCN (1988). Coral Reefs of the World. Volume 3: Central and Western Pacific. UNEP Regional Seas Directories and Bibliographies. IUCN, Gland, Switzerland and Cambridge, UK/UNEP, Nairobi, Kenya. 378 pp

Date June 1985, reviewed November 1988, updated July 1989, February 1990

\section{WHITESANDS RECREATIONAL RESERVE (Title No. 1258)}

IUCN Management Category Unassigned

Biogeographical Province 5.07.13 (East Melanesian)

Geographical Location Located on the southern coast of Efate Island, $15 \mathrm{~km}$ south-east of Port Vila. Approximately $165^{\circ} 25^{\prime} \mathrm{E}, 18^{\circ} 12^{\prime} \mathrm{S}$

Date and History of Establishment 27 December 1984

Area $39 \mathrm{ha}$

Land Tenure State

Altitude Sea-level

Physical Features Comprises coral formations with sandy beaches.

Climate Annual rainfall varies between $2500 \mathrm{~mm}$ and $4000 \mathrm{~mm}$ and temperatures range from $18^{\circ} \mathrm{C}$ to $33^{\circ} \mathrm{C}$ (SPREP, 1985 ).

Vegetation Common coastal trees include Barringtonia sp., Calophyllum sp. and Terminalia sp., with epiphytic ferns and orchids. Strand vegetation also occurs (SPREP, 1985). 
Fauna Current knowledge indicates that only common species occur (SPREP, 1985).

Cultural Heritage None known

Local Human Population None

Visitors and Visitor Facilities No information

Scientific Research and Facilities None

Conservation Value The site has been designated as a recreational reserve (SPREP, 1985), with complete protection of vegetation and natural environment intended.

Conservation Management Enactment and enforcement of local bye-laws is undertaken to prohibit litter, damage to vegetation and the construction of unauthorised buildings (SPREP, 1989).

Management Constraints No information

Staff No information

Budget No information

Local Addresses Secretary, Efate Local Government Council, P O Box 239, Port Vila

\section{References}

SPREP (1985). Vanuatu. In: Thomas, P.E.J. (Ed.), Report of the Third South Pacific National Parks and Reserves Conference. Report. Volume III. Country reviews. South Pacific Commission, Noumea, New Caledonia. Pp. 217-228.

SPREP (1989). Vanuatu. Paper presented at the Fourth South Pacific Conference on Nature Conservation and Protected Areas, Port Vila, Vanuatu, 4-12 September. 10 pp.

Date November 1988, updated July 1989, February 1990 


\section{WESTERN SAMOA}

Area 2,830 sq. $\mathrm{km}$ land area in an Exclusive Economic Zone of $680,000 \mathrm{sq} . \mathrm{km}$

Population 168,000 (1988) (World Bank, 1990) Natural increase: 0.7\% (SPREP, 1989a)

GNP US\$ 610 per capita (1988) (World Bank, 1990)

Policy and Legislation The Fifth Development Plan (1985-87) stated, inter alia, that the protection of the environment and conservation of natural resources was a principal national goal, although overriding priority was to be given to an increase in production, particularly for export (Firth and Darby, 1988). The Constitution (1960) stipulates that "all land in Western Samoa is either customary land, private freehold, or public land". The relative proportions of these different types of tenure are customary land ( $80.5 \%$ of land area), private freehold $(3.7 \%)$, Western Samoa Trust Estates Corporation (4.5\%) and public government land (11.3\%) (Eaton, 1985). All land below the high water mark is defined as public land (Pearsall, 1988). The Constitution also states that customary land may only be acquired compulsorily for public purposes. Customary land may be leased for an authorised purpose if the lease is in accordance with Samoan custom and usage, the desires and interests of the owners, or the public interest (Eaton, 1985).

Legislation which enables Government to acquire customary land includes the Taking of Lands Act (1964) and Article 102 of the Constitution. The first gives the Government the power to obtain land for public purposes by negotiation or compulsory processes, although the latter is rarely used. The 1964 Act could be used as a legal instrument for obtaining land for parks and reserves (Tiavolo, 1985) and has provision for land to be taken to protect catchment areas, especially where agricultural development is a threat (Venkatesh et al., 1983).

The principal current legislation for the establishment of protected areas is the 1974 National Parks and Reserves Act. Section 4 enables the Head of State, acting on the advice of the Cabinet, to declare any public land to be a national park, provided it is not set aside for any other public purpose and is not less than $607.5 \mathrm{ha}$ (1,500 acres), except in the case of an island. As defined in Section 5, every national park shall be preserved in perpetuity for the benefit and enjoyment of the people of Western Samoa and shall be administered so that: it is preserved as far as practical in its natural state; flora and fauna are preserved as far as possible; its value as a soil, water and forest conservation area is maintained; and, subject to a number of provisos, the public has freedom of access. Section 6 provides for the establishment of nature reserves within which either named species are protected, or all taxa within a specified area are protected. Access may be restricted, except where a nature reserve is declared in a marine area, in which case customary fishing rights remain unaffected. Sections 7,8 and 9 , respectively, make provision for the establishment of recreation reserves, historic reserves, and reserves for other purposes. A site fully gazetted under the Act can only be degazetted by Parliament. The principal weakness of the 1974 Act is that it only enables national parks and reserves to be established on public land. There is no legal mechanism for establishing areas on customary land. For example, a recently established reserve in Falealupo District, comprising 1,200ha of pristine lowland rain forest, has no legal basis (E. Bishop, pers. comm., 1988). Environmental and conservation legislation is currently being reviewed, and the amendment of the National Parks and Reserves Act has again been recommended with an expectation that it may be completed by the end of 1991 (I. Reti, pers. comm., 1991). 
Habitat protection is also provided for under the 1959 Agricultural, Forests and Fisheries Ordinance and the 1967 Forests Act. These enable the Forestry Division within the Department of Agriculture, Forests and Fisheries to "conserve, protect, and develop the resources of the country especially soil, water and forest" and to establish forest reserves for water, soil and climate protection and a sustained timber harvest. The Forests Act allows for protection of forest and water catchment areas as "protected land". Large areas of indigenous forest have been designated as protection forests, although in practice logging has continued (Firth and Darby, 1988).

Other legislation which incorporates measures relating to protected areas includes the 1965 Water Act, under which watersheds and riparian vegetation may be protected.

A summary review of legislation covering aspects of environmental protection, planning and tourism is given in Firth and Darby (1988).

At the present time, no protected area in Western Samoa receives full legal protection. It is a legal requirement that all proposed protected areas are surveyed and that the proposed boundary, with a written submission, be presented to the Land Board in the Ministry of Lands. Public comment is duly invited, and, if this is positive, the proposal is submitted to the Head of State for signature. Subsequently, the Ministry of Lands will amend its land use maps to indicate a protected area. This process has not yet been completed in any instance. The lack of due process fails to invoke the full legal protection of the available legislation, and other Government departments are technically at liberty to propose and implement changes in land use within nominal protected areas (E. Bishop, pers. comm., 1989).

International Activities Westem Samoa is not yet party to any of the international conventions or programmes that directly promote the conservation of natural areas, namely the Convention concerning the Protection of the World Cultural and Natural Heritage (World Heritage Convention), the Unesco Man and the Biosphere Programme and the Convention on Wetlands of International Importance especially as Waterfowl Habitat (Ramsar Convention).

At a regional level, Western Samoa has signed (12 June 1976) and ratified (20 July 1990) the Convention on the Conservation of Nature in the South Pacific, 1976. Known as the Apia Convention, it entered into force during 1990. The Convention is coordinated by the South Pacific Commission and represents the first attempt within the region to cooperate on environmental matters. Among other measures, it encourages the creation of protected areas to preserve indigenous flora and fauna.

Western Samoa is also party to the South Pacific Regional Environment Programme (SPREP) and has signed (25 November 1986) and ratified (19 July 1990) the Convention for the Protection of the Natural Resources and Environment of the South Pacific Region, 1986 (SPREP Convention). The convention entered into force during August 1990. Article 14 calls upon the parties to take all appropriate measures to protect rare or fragile ecosystems and threatened or endangered flora and fauna through the establishment of protected areas and the regulation of activities likely to have an adverse effect on the species, ecosystems and biological processes being protected. However, as this provision only applies to the Convention area, which by definition is open ocean, it is most likely to assist with the establishment of marine reserves and the conservation of marine species.

Other international and regional conventions concerning environmental protection to which Western Samoa is party are reviewed by Venkatesh et al. (1983). 
Administration and Management The National Parks and Reserves Act (1974) is currently administered by the Department of Agriculture, Forests and Fisheries, although the Department of Lands and Environment undertakes all responsibilities (I. Reti, pers. comm., 1991). The Assistant Director for Forests and Conservation has the overall responsibility for forestry and national parks (I. Reti, pers. comm., 1989). Management aims are to: establish examples of each type of reserve, ensuring that as many of the different types of vegetation and wildlife as possible are conserved; improve and develop appropriate facilities, to enable the full enjoyment and appreciation of the reserves; and promote public awareness, understanding and appreciation of these areas. Government departments were being restructured during 1989 and it was intended that the National Parks and Reserves Section would be transferred from its current ministry to the Ministry of Lands on 1 January 1990 (E. Bishop, pers. comm., 1990).

The National Parks and Reserves section operating budget was reduced in real terms by $93 \%$ between 1979 and 1987, while staff numbers were reduced by $42 \%$ in the same period. This trend is now being reversed and the 1988 budget was 28,000 WS Tala (US $\$ 14,000$ ), twice that of 1987 . The 1989 budget was 56,000 WS Tala, the proposed 1990 budget was WS Tala 104,000. Similarly, staff numbers have increased and were proposed to increase from 19 in 1988 to 27 in 1990. Most of these funds were to pay for additional labourers at O' Le Pupu Pu'e National Park, installation of a water pipe in Vailima Botanical Garden and the preparation of a poster depicting Samoan birds (E. Bishop, pers. comm., 1988). Staff levels and annual budgets previously reached a peak of 30 staff in 1981 and a budget of 66,300 WS Tala in 1979, a period during which substantial external financial and management assistance was available (SPREP, 1985b). The Department of Lands and Environment has four staff (1991) and a current six-month budget of WS Tala 87,610 .

A Division of Environment and Conservation has been established within the Department of Lands and Environment. Its principal function is the provision of advice on: policies influencing the management of natural and physical resources; impact of private or public development; means of ensuring public participation in environmental planning and policy formulation; the control and management of hazardous substances; establishment and naming of national parks; control of pollution of air, water and land and the control of litter, and research and training relevant to these functions (I. Reti, pers. comm., 1991).

Systems Reviews Western Samoa, lying between $13^{\circ}-15^{\circ} \mathrm{S}$ and $171^{\circ}-173^{\circ} \mathrm{W}$, is situated approximately $1,000 \mathrm{~km}$ north-east of Fiji and a similar distance north-north-east of Tonga, and includes nine islands, the largest being Savai'i $(1,709 \mathrm{sq} . \mathrm{km})$ and Upolu $(1,118 \mathrm{sq} . \mathrm{km})$. The biologically related, but politically distinct, American Samoa lies some $100 \mathrm{~km}$ to the east.

Most of the original lowland tropical forest on Savai'i and Upolu has been cleared or highly modified. Only two major forested areas, on customary land, persist, namely Tafua and Mt Silisili on Savai'i (E. Bishop, pers. comm. 1988). Figures given by Firth and Darby (1988) indicate that approximately $1,500 \mathrm{sq}$. $\mathrm{km}$ remain forested, comprising $550 \mathrm{sq} . \mathrm{km}$ of protection forest or proposed national parks and reserves, and $950 \mathrm{sq} . \mathrm{km}$ of commercial forest. However, no firm commitment has been made to the environmental protection role of protection forests and there is virtually no primary forest remaining (Firth and Darby, 1988). Montane forests are less damaged and still contain a rich endemic flora. Cloud forests, montane lava flow scrub and montane meadows are found in the upland regions. The Aleipata Islands include a number of littoral communities, as well as Diospyros coastal forests and Dysoxylum lowland forests, which are otherwise rare in Western Samoa (Whistler, 1983; Davis et al., 1986). Mangroves cover less than 1,000ha (Bell, 1985). 
Forest resources, particularly lowland and sub-montane formations, are threatened by both agricultural encroachment and commercial logging (Pearsall, 1988). In 1977 responsibility for parks and reserves was transferred to a department which included indigenous forest logging amongst its primary responsibilities and the momentum of an initially dynamic protected areas programme was lost. Within a few years, most of the remaining lowland and foothill forest in Savai' $i$ and Upolu had been destroyed (Firth and Darby, 1988). A recent development has been the risk of timber concessions being sold for cash remuneration, particularly on Savai'i. The destruction of lowland rain forest is largely complete, and regions of higher elevations are threatened by governmental road construction, followed by clearing of large areas in order to expand plantations or to facilitate cattle farming; commercial logging activities by Australian and Japanese concerns, formerly engaged in selective felling but currently clear felling; and uncontrolled clear felling by local families on village-owned land (Beichle and Maelzer, 1985). The cutting and in-filling of mangroves has been largely uncontrolled (Bell, 1985). Although the 1976 Forestry Act provides for the exploitation of forests on a sustained yield basis, the criteria for this to be judged by, for example, annual allowable cut, have never been established and there is a risk that the bulk of indigenous timber resources may be exhausted by as soon as 1995 (Firth and Darby, 1988).

Coastal and peripheral woodlands have been heavily disturbed by cultivation and lower slopes around main settlements are cultivated. Approximately $20 \%$ of Savai'i is cultivated, whilst the largest cultivated areas on Upolu are along the north coast around Apia and Satapuala (Douglas, 1969). The coastal district has long been settled and soils around villages have been exhausted (Firth and Darby, 1988). A process of land tenure conversion is underway, from the traditional (and legally constituted) system to a de facto system of private control and virtual ownership by converting land to agriculture.

Western Samoa's current park and reserve system consists of one national park and five reserves. A little over $1 \%$ of the land area is protected, but O Le Pupu Pu'e National Park alone accounts for $95 \%$ of the protected area. The system's growth years were 1978-79, when one national park and three reserves were established. O Le Pupu Pu'e National Park is a key area within the Samoa, Wallis and Futuna biogeographic province identified by Dahl (1980). Dahl (1980) identifies a number of habitats as occurring in Western Samoa, including varieties of lowland rain forest, montane rain forest, cloud, riverine, swamp, mangrove and atol//beach forest, scrub, grassland, freshwater marsh, rock desert, lakes and streams, and a variety of littoral, coastal and marine habitats, including reefs and lagoons. A significant number are protected within O Le Pupu Pu'e, namely four lowland rain forest formations, three montane rain forest formations, cloud and swamp forest, Pandanus sp. littoral scrub, crater meadow, crater marsh, caves and rocky coast (Dahl, 1980). It also protects populations of all the major forest bird species of Upolu, including tooth-billed pigeon Didunculus strigirostris and ma'o Gymnomyza samoensis (Hay, 1986). Nevertheless, a similar reserve is required on Savai' $i$, in view of deforestation at the western end of the island (Hay, 1986). Two sites, one incorporating coastal forest at Tafua, south-east Savai'i, and another on the slopes of Mt Silisili up to the summit, have been proposed as protected areas (Holloway and Floyd, 1975) and would preserve the greatest range of habitats (Hay, 1986). These two sites still support lowland rain forest, but are in the process of being cleared and are on customary land, thus precluding their designation as national parks or reserves under current legislation (E. Bishop, pers. comm., 1988). A coastal reserve is particularly important, as are examples of the high altitude habitats of the island. Such reserves would assist in and may ensure the protection of species such as Samoan white-eye, tooth-billed pigeon and ma'o, possibly Samoan wood-rail if its existence is re-confirmed, and other endemic Samoan species (Hay, 1986). A recent development has been the agreement between a private group from the USA and 
villagers in the Falealupo District in Savai' $i$, whereby some 1,200 ha of lowland rain forest is protected in return for financial assistance and restricted exploitation rights (SPREP, 1989). However, as the site is on customary land it will not be possible to gazette the site under the provisions of existing legislation. It is not known if this arrangement has any basis in protected areas legislation.

An Action Strategy for Protected Areas in the South Pacific Region (SPREP, 1985a) has been prepared. The principal goals of the strategy cover conservation education, conservation policy development, establishment of protected areas, protected area management and regional and international cooperation. Priority recommendations for Western Samoa are as follows: develop a national conservation strategy; investigate the remaining traditional marine fishing rights; train researchers and managers in the marine field; assess conservation status and availability of reef and lagoon areas; include environmental concerns in education systems; establish an Environmental Management Unit responsible for environmental assessment, liaison, environmental education, legislation and environmental reporting; map all national ecosystems; make an inventory of flora and fauna, particularly threatened species; prepare management plans for all protected areas; develop a national environmental public awareness campaign to be implemented through schools, mass media and Pulenu'us; set aside areas which include ecosystems not covered by existing parks and reserves; complete a review of marine resources; and send the Superintendent of Parks and Reserves to the 1987 Parks Management Training Course in New Zealand.

Regional progress on the implementation of the action strategy has been reviewed (SPREP, 1987 and 1989b). Western Samoa has participated in a sub-regional course in coastal resource management and planning, emphasising the role of protected areas. A SPREP project to assess the potential environmental impact of tourism, with emphasis on the protection of critical habitats, species and potential protected areas, has been completed (Firth and Darby, 1988). An ecosystem survey was scheduled to commence in 1989 , using aerial photographs taken during 1987 (Pearsall, 1989). This is intended to identify a representative system of natural areas. In conjunction with the Land Use Resource Programme of the Ministry of Lands, it will provide a powerful resource planning and management tool (Anon., 1989). The compilation of management plans for each of the five reserves and updating that for O Le Pupu Pu'e was planned 1988-90 (E. Bishop, pers. comm., 1988). An Asian Development Bank funded project on land use planning commenced in 1989 (I. Reti, pers. comm., 1989).

A major UNDAT survey in the mid-1970s (Holloway and Floyd, 1975) identified 6 potential national parks, 24 nature reserves, 11 historical sites and 7 archaeological sites. Of these, O Le Pupu Pu'e, Palolo Deep Marine Reserve and Mount Vaea have been gazetted. Recommended sites considered to be of particular value include Mt Silisili and Tafua (Hay, 1986). However, the proposed areas occur on customary land and gazettement under the current 1974 legislation is precluded. Three methods of protecting the areas were mooted: government purchase of the land, which would only be possible with outside financial assistance; leasing, which might not provide the necessary security of tenure; and the dedication of customary land (Holloway and Floyd, 1975). Dahl's (1980) proposed reserves reiterate those of Holloway and Floyd (1975), with the addition of a recommended reserve type aimed at protection of Palolo worm Eunice viridis (K). Dahl (1986) identifies as highest priority the protection of a major park in central Savai'i, possibly also including a sample of lowland forest. Protection of both land and marine areas in the Aleipata Islands should also be considered and a survey of the latter site has been completed (Andrews and Holthus, 1989). 
The preparation and adoption of a national conservation strategy is recommended by Firth and Darby (1988) to ensure the sustainable exploitation of natural resources, a call reiterated in SPREP (1989a). Strengthening the national parks and reserves systems is perhaps more urgent, and should be addressed as a high priority. This would principally entail; amending the 1974 National Parks and Reserves Act, such that reserves may be established on customary land (not necessarily with government ownership), provision of adequate funding, the establishment of some 30 protected areas, the principal one being Mount Silisili National Park on Savai'i, and the imposition of a moratorium on any further logging in Tafua Forest (Firth and Darby, 1988).

Despite repeated recommendations for the establishment of protected areas, especially Mount Silisili and the Aleipata Islands, there has been no progress in gazetting either site. Nevertheless, the establishment of the Division of Environment and Conservation, increased funding and the adoption of the Lands and Environment Act 1989 indicate a greater willingness on the behalf of government to give the environment equal priority with other pressing issues (I. Reti, pers. comm., 1991).

\section{Addresses}

National Parks and Reserves, Department of Agriculture, Forests and Fisheries, PO Box L1874, Apia

Division of Environment and Conservation, Department of Lands and Environment, PO Private Bag, Apia

\section{References}

Andrews, G.J. and Holthus, P.F. (1989). Marine environment survey: proposed Aleipata Islands National Park, Western Samoa. South Pacific Commission, Noumea, New Caledonia. $67 \mathrm{pp}$.

Beichle, U. and Maelzer, M. (1985). A conservation programme for Western Samoa. ICBP Technical Publication No. 4. International Council for Bird Preservation, Cambridge, UK. Pp. 1-3.

Bell, L.A.J. (1985). Coastal zone management in Western Samoa. In: Thomas, P.E.J. (Ed.), Report of the Third South Pacific National Parks and Reserves Conference. Volume II. South Pacific Commission, Noumea, New Caldenonia. Pp. 57-73.

Dahl, A.L. (1980). Regional ecosystem surveys of the South Pacific Area. SPC/UCN Technical Paper 179. South Pacific Commission, Noumea, New Caledonia. 99 pp.

Dahl, A.L. (1986). Review of the Protected Areas System in Oceania. IUCN, Gland, Switzerland and Cambridge, UK/UNEP, Nairobi, Kenya. 328 pp.

Davis, S.D., Droop, S.J.M., Gregerson, P., Henson, L., Leon, C.J., Lamlein Villa-Lobos, J., Synge, H. and Zantovska, J. (1986). Plants in Danger: What do we know? IUCN, Gland, Switzerland and Cambridge, UK. 488 pp.

Douglas, G. (1969). Draft checklist of Pacific Oceanic Islands. Micronesica 5: 327-463.

Eaton, P. (1985). Land tenure and conservation: protected areas in the South Pacific. SPREP Topic Review No. 17. South Pacific Commission, Noumea, New Caledonia. 103 pp.

Firth, N. and Darby, d'E.C. (1988). Environmental planning for tourism in Western Samoa. A report to the Government of Western Samoa and the South Pacific Regional Environment Programme. KRTA Limited, Auckland, New Zealand. 124 pp.

Hay, R. (1986). Bird conservation in the Pacific. ICBP Study Report No. 7. International Council for Bird Preservation, Cambridge, UK. 102 pp. 
Holloway, C.W. and Floyd, C.H. (1975). A national parks system for Western Samoa. United Nations Development Advisory Team for the South Pacific (UNDAT), Suva, Fiji. 71 pp.

Pearsall, S.H. (1988). Western Samoa. Country Report. The Nature Conservancy, Honolulu, Hawaii. Unpublished report. 75 pp.

Pearsall, S.H. (1989). A system of representative natural areas for Western Samoa. Case Study 29. Fourth South Pacific Conference on Nature Conservation and Protected Areas, Port Vila, Vanuatu, 4-12 September. $12 \mathrm{pp}$.

SPREP (1985a). Action strategy for protected areas in the South Pacific Region. South Pacific Commission, Noumea, New Caledonia. 24 pp.

SPREP (1985b). Westem Samoa. In: Thomas, P.E.J. (Ed.), Report of the Third South Pacific National Parks and Reserves Conference. Volume III. Country reviews. South Pacific Commission, Noumea, New Caledonia. Pp. 232-269.

SPREP (1987). SPREP makes considerable progress with implementation of action strategy for protected areas. Environment Newsletter. South Pacific Regional Environment Programme. July-September. Pp. 15-22.

SPREP (1989a). Western Samoa. Paper presented at the Fourth South Pacific Conference on Nature Conservation and Protected Areas, Port Vila, Vanuatu, 4-12 September. 13 pp.

SPREP (1989b). Progress with the Action Strategy for protected areas in the South Pacific Region. Information Paper 3. Fourth South Pacific Conference on Nature Conservation and Protected Areas, Port Vila, Vanuatu, 4-12 September. 19 pp.

Tiavolo, A. (1985). Land tenure system in Western Samoa. South Pacific Commission, Noumea, New Caledonia. Unpublished report. 3 pp.

Trotman, I.G. (1979). Western Samoa launches a national park program. Parks 3(4): 5-8.

Venkatesh, S., Va'ai, S. and Pulea, M. (1983). An overview of environmental protection legislation in the South Pacific countries. South Pacific Commission, Noumea, New Caledonia. $63 \mathrm{pp}$.

Whistler, W.A. (1983). Vegetation and flora of the Aleipata Islands, Western Samoa. Pacific Science 37(3): 227-249. (Unseen)

World Bank (1990). World Tables. 1989-90 Edition. The John Hopkins University, Baltimore. $646 \mathrm{pp}$.

\section{ANNEX \\ Definitions of protected area designations, as legislated, together with authorities responsible for their administration}

\section{Title: National Parks and Reserves Act}

Date: 30 December 1974

Brief description: Provides for the establishment, preservation and administration of national parks and reserves for the benefit of the people of Western Samoa.

Administrative authority: As stated in the Act: Department of Lands and Survey, Minister of Lands (National Parks and Reserves, Ministry of Agriculture, Forestry and Fisheries) 
Designation:

National park As defined in Section 5, every national park shall be preserved in perpetuity for the benefit and enjoyment of the people of Western Samoa and shall be administered so that: it is preserved as far as practical in its natural state; flora and fauna are preserved as far as possible; its value as a soil, water and forest conservation area is maintained; and, subject to a number of provisos, the public has freedom of access.

Nature reserves Within which either specified species of flora and fauna are protected, or all taxa within a specified area are protected. Access may be restricted, except where a nature reserve is declared in a marine area, in which case customary fishing rights remain unaffected.

\section{Recreation reserves (S.7)}

Historic reserves (S.8)

Reserves for other purposes (S.9)

NB: A site fully gazetted under the Act can only be degazetted by Parliament. The principal weakness of the 1974 Act is that it only enables national parks and reserves to be established on public land.

\section{Title: Forests Act}

Date: 1967

Brief description: Consolidates the law relating to conservation, protection and development of natural resources, especially soil, water and forests.

Administrative authority: Department of Agriculture, Forests and Fisheries

Designation:

State forests on customary or freehold land

\section{Protected forestry}

Historic, cultural and archaeological sites

NB Source: Firth and Darby (1988); original act not seen 
SUMMARY OF PROTECTED AREAS

\begin{tabular}{lccc}
\hline $\begin{array}{l}\text { Map } \\
\text { ref. }\end{array}$ & IUCN management area \\
category & $\begin{array}{r}\text { Area } \\
\text { (ha) }\end{array}$ & $\begin{array}{r}\text { Year } \\
\text { notified }\end{array}$ \\
\hline
\end{tabular}

National Parks

1 O Le Pupu Pu'e*

Unassigned $\quad 2,857$

1978

Historic and Nature Reserve

2 Tusitala (comprises 3 parts as follows)* Mount Vaea Scenic Reserve Stevenson's Historic Site Vailima Botanic Garden

Unassigned Unassigned Unassigned Unassigned

$\begin{array}{rr}64 & 1958 \\ 51 & 1958 \\ 1 & 1958 \\ 12 & 1978\end{array}$

$\begin{array}{ll} & \text { Reserves } \\ 3 & \text { Palolo Deep* } \\ 4 & \text { Togitogiga Recreation } \\ & \text { Unclassified }\end{array}$

$5 \quad$ Falealupo Forest

$$
\text { IV }
$$

Private

1,215

1989

\section{Proposed}

Cape Puava Forest

Nu'usafe'e Island $R$

Aleipata and Nu'utele Islands MP

Aganoa Beach

Aopo

Apolimafou Wetlands

Fuipisia/Sopo'aga Gorge

Fusi-Tafitaola Reef

Lake Lanoto'o

Lake Mafane Upland Forest

Lake Olomaga

Lata Forest

Leanamoea Beach

Matautu Lowland Swamp Forest

Mount Silisili

Msngaloa Swamp Forest

Nu'utele Islands

Pata Mangroves

Sa'anapu Mangroves

Salamumu

Sato'alepai Mangroves

Satuimalufilufi-Fuailolo'o Reef

Tafua

Taupou's Grave Lava

Tiavi /gorge and Falls

Proposed

Proposed

Proposed

Proposed

Proposed

Proposed

Proposed

Proposed

Proposed

Proposed

Proposed

Proposed

Proposed

Proposed

Proposed

Proposed

Proposed

Proposed

Proposed

Proposed

Proposed

Proposed

Proposed

Proposed

Proposed 
IUCN Directory of Protected Areas in Oceania

\begin{tabular}{|c|c|c|c|c|}
\hline $\begin{array}{l}\text { Map }^{\dagger} \\
\text { ref. }\end{array}$ & Name of area & $\begin{array}{l}\text { IUCN management } \\
\text { category }\end{array}$ & $\begin{array}{r}\text { Area } \\
\text { (ha) }\end{array}$ & $\begin{array}{c}\text { Year } \\
\text { notified }\end{array}$ \\
\hline & Tufutafoe Swamp & Proposed & (40) & \\
\hline & Vaipu Wetlands & Proposed & $(120)$ & \\
\hline
\end{tabular}

* Site is described in this directory.

${ }^{\dagger}$ Locations of most protected areas are shown in the accompanying map. 


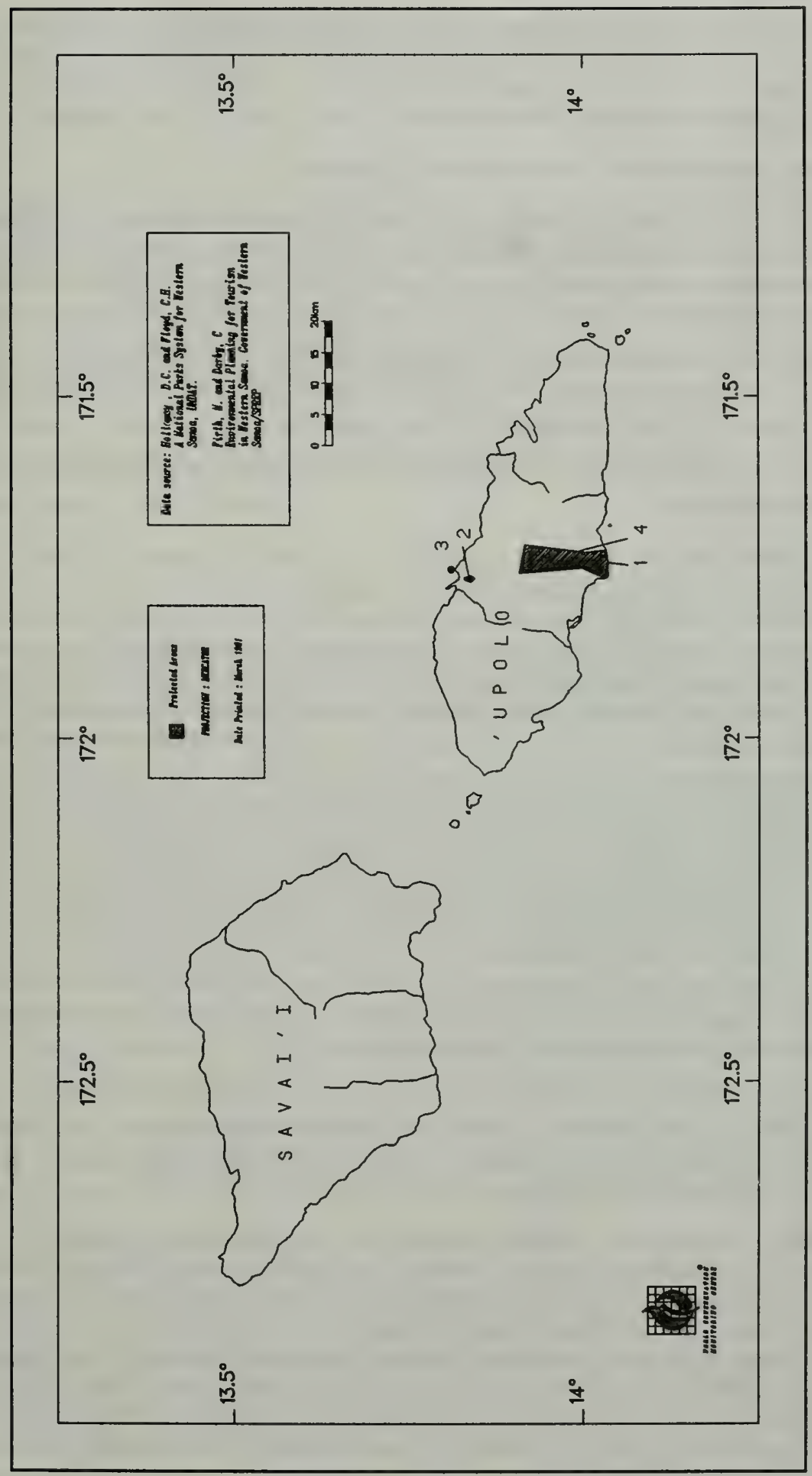

Protected Areas of Western Samoa 


\section{O LE PUPU PU'E NATIONAL PARK}

\section{IUCN Management Category Unassigned}

\section{Biogeographical Province 5.05.13 (Central Polynesian)}

Geographical Location Situated in southern central 'Upolu Island in Atua and Taumasaga Districts. Approximately $26 \mathrm{~km}$ south of Apia (SPREP, 1985). The park is bounded by government land to the east, north-east, north, north-west and south-west, and customary lands to the east and south-east (Eaton, 1985). $13^{\circ} 55^{\prime}-14^{\circ} 02^{\prime} \mathrm{S}, 171^{\circ} 42^{\prime}-171^{\circ} 45^{\prime} \mathrm{W}$

Date and History of Establishment The boundary has been delimited under Court Order 220 (1976), but the park has not been gazetted under the provisions of the 1974 National Parks and Reserves Act (E. Bishop, pers. comm, 1989).

Area 2,857ha. Adjacent marine areas are not included. Togitogiga Recreation Reserve (3ha) is contiguous to the east.

\section{Land Tenure State}

\section{Altitude Sea level to $1,075 \mathrm{~m}$}

Physical Features The park consists of a strip of land $1.5-6 \mathrm{~km}$ wide, descending from a central watershed to eroded basaltic cliffs approximately $10 \mathrm{~m}$ high (Mossman and Berg, 1981). The broad highland plateau is punctuated by volcanic cones and craters, including Mt Le Pu'e in the north-west, a remnant of the Salani volcanics, and is cut by several steep valleys. The terrain dips southward at approximately $8^{\circ}$ from the highland plateau to a plain about $300 \mathrm{~m}$ above sea level (SPREP, 1985). The partially subterranean Afuiva River drains the northern central area. Geologically, the island dates back to the Fagaloa Volcanics some three million years ago. Approximately one million years ago lava from the Salani Volcanics covered much of the older Fagaloa formation. More recently, 3,000 years ago, the Pu'apu'a Volcanics formed a wide lava fan in the southern lowlands which has since eroded to form coastal cliffs (Eaton, 1985). Pe'ape'a Cave, a partially collapsed $1,800 \mathrm{~m}$-long lava tube (Trotman, 1979), is located near the centre of the park. Soils principally comprise weathered basalt and are generally poorly developed and prone to erosion. Ten different types have been identified, of which only one, present in isolated patches, is suitable for agriculture (Mossman and Berg, 1981).

Climate Mean temperature range is $22^{\circ} \mathrm{C}-32^{\circ} \mathrm{C}$, depending upon altitude and time of year. Mean annual rainfall is about $3500 \mathrm{~mm}$ at highest altitudes and mean annual humidity for the island is 83\% (Tioa, 1979). There is a marked dry season between May and August, in contrast to December to March which is hot, wet and windy (UNEP/IUCN, 1988).

Vegetation Three main vegetation communities are distinguished. Pahoehoe lava of the Pu'apu'a Volcanics remain bare near the coast, but there is a littoral scrub belt, sheared by salt winds (Trotman, 1979). The littoral vegetation comprises four communities, Lepturus rock stand, Scaevola littoral scrub, Pandanus littoral forest and Calophyllum littoral forest (SPREP, 1985). Further inland is lowland forest comprising four communities, namely Tava lowland forest, Manalava foothill forest, Mafoa foothill forest and Maotamea montane forest (SPREP, 1985). At higher altitudes montane swamp forest predominates with tree and ground ferns, lichens and epiphytes abundant. Species prominent at lower elevations persist and may even be locally common (Trotman, 1979). 
Fauna Indigenous mammals are restricted to three bat species, all of which occur within the park. These are Samoan flying fox Pteropus samoensis (E), Insular flying fox $P$. tonganus (I) and sheath-tailed bat Emballonura semicaudata, which resides in the Pe'ape'a lava tube. The only other mammals are introduced Polynesian rat Rattus exulans and pig Sus scrofa (SPREP, 1985).

Forty-two bird species have been recorded, including twelve endemic to Western Samoa; three of these occur only on 'Upolu Island (Mossman and Berg, 1981). Endemics include tooth-billed pigeon Didunculus strigirostris (V) and Samoan starling Aplonis atrifusca, whilst the scarce ma'o Gymnomyza samoensis, endemic to Western and American Samoa, is also present. The five most abundant species are cardinal honey-eater Myzomela cardinalis, Pacific pigeon Ducula pacifica, wattled honey-eater Foulehaio carunculata and white-rumped swiftlet Collocalia spodiopygia, which inhabits Pe'ape'a Cave (SPREP, 1985).

Four reptiles are present: snake-eyed skink Ablephorus boutonii, azure-tailed skink Emoia cyanura, Samoan skink E. samoensis and an unidentified skink (SPREP, 1985).

\section{Cultural Heritage No information}

Local Human Population A number of small villages are located near the park on the south coast road (SPREP, 1985). Government land to the north-west has been allocated to various villages (Eaton, 1985). Customary land lies to the south-east, a government cattle farm to the east, and an area of state reafforestation and a quarry at Togitogiga lie to the south-west, the latter being used occasionally. There are numerous small plantations within the park boundary, mostly scattered peripherally, and four private dwellings are in the vicinity of Togitogiga Recreation Reserve (Mossman and Berg, 1981).

Visitors and Visitor Facilities The park is not well known and receives few visitors (Mossman and Berg, 1981). A road runs from Apia through the park and to the coast. An information centre is located at park headquarters in Togitogiga Recreation Reserve (Mossman and Berg, 1981). Nature trails, including a rough track to Pe'ape'a Cave, have been laid out and are being improved (Dasmann, 1980). A trail along the coastal cliffs was established in 1980, running through littoral scrub and Pandanus forest. Approximately 150 visitors used this and the Pe'ape'a trail in 1988 (E. Bishop, pers. comm., 1988).

Scientific Research and Facilities Eaton (1985) considered land use and tenure at O Le Pupu Pu'e in a study undertaken for the South Pacific Regional Environment Programme. Other research includes surveys of the flora, fauna and geology (Ollier et al., 1972).

Conservation Value The site is valued because it holds nearly the whole range of forest types found on 'Upolu (Mossman and Berg, 1981). The lowland forest is a remnant of an extensive tract which covered the south coast of Upolu prior to its clearance (Trotman, 1979).

Conservation Management Under the current legal arrangement, the Ministry of Lands is not entitled to designate a separate land-use classification for the park. Any government department wishing to use the land may do so, on the condition that an application is accepted by the government. However, since the park was established there have been no such applications (E. Bishop, pers. comm., 1988). The park is administered from the headquarters at Togitogiga Scenic Reserve. A management plan has been produced (Mossman and Berg, 1981); objectives include preservation, education and controlled use of the area by the public. Policies have been established to: protect the park from detrimental activities; provide for management with an emphasis on relevant research; and confine public use to sites already developed (Mossman and 
Berg, 1981). Support has been provided through IUCN/WWF-New Zealand Project 1650. Zoning is addressed by Trotman (1979) who recommends a simple system comprising an upland wilderness area and an area of more intensive use around the information centre. An updated management plan is expected to be produced within the next two years (E. Bishop, pers. comm., 1988).

Management Constraints The Land Board (Ministry of Lands) submitted the proposed boundary to public scrutiny in the early 1980s. Members of a village neighbouring the site objected to the location of the boundary and, because the issue was never resolved, the legal gazettement of the park has been stalled ever since. Ownership claims are also maintained over about half of the park by local people (E. Bishop, pers. comm., 1989). Indiscriminate firewood collection, logging and shooting, particularly of birds, threaten the park (Beichle and Maelzer, 1985). Rapid growth of weed species makes maintenance of tracks and picnic areas difficult (Dasmann, 1980). Forest clearance and agricultural encroachment have occurred in the south-east and in areas contiguous to cultivated land outside the park. Prosecution is difficult, however, because the boundary is not marked (Mossman and Berg, 1981). Approximately 4ha of park land adjacent to the main road have been felled during a coastal electrification scheme (E. Bishop, pers. comm., 1989).

Staff A caretaker and ten workers maintain the park and adjacent recreation reserve (SPREP, 1985).

Budget No specific funds are allocated to the park. Expenditure is met from the total national park and reserves budget, WS Tala 28,000 (US $\$ 14,000$ ) in 1988. This was expected to double in 1989, with a significant proportion being assigned to increasing the level of staffing in the park (E. Bishop, pers. comm., 1988). Financial assistance has been received for various projects; for example, WWF provided US\$14,000 in 1979 to fund an expatriate ranger to develop the park (Dasmann, 1980).

Local Addresses National Parks and Reserves Section, Forestry Division, Ministry of Agriculture, Forests and Fisheries, P O Box L1874, Apia

\section{References}

Beichle, U. and Maelzer, M. (1985). A conservation programme for Western Samoa. ICBP Technical Publication No. 4. International Council for Bird preservation, Cambridge, UK. Pp. 297-299.

Dahl, A.L. (1978). Report on assistance to Western Samoa with national parks and conservation. South Pacific Commission, Noumea, New Caledonia. 27 pp.

Dasmann, D. (1980). World Wildlife Yearbook 1979/1980. WWF, Gland, Switzerland. Pp. 96-97. Eaton, P. (1985). Land tenure and conservation: protected areas in the South Pacific. SPREP Topic Review No. 17. South Pacific Commission, Noumea, New Caledonia. 103 pp.

Holloway, C.W. and Floyd, C.H. (1975). A national parks system for Western Samoa. UNDAT, Suva, Fiji. 68 pp.

Mossman, R. and Berg, P. (1981). Management plan for the O Le Pupu-Pu'e National Park. Directorate of Agriculture and Forests, Apia. $27 \mathrm{pp}$.

Ollier, C.D., Whistler, W.A. and Amerson, A.B. (1972). O Le Pupu-Pu' e National Park, Samoa. Volume 1. United Nations Advisory Team, Suva. (Unseen)

Orenstein, R.I. (1979). Notes on the ma'o (Gymnomyza samuensis), a rare Samoan honeyeater. Notornis 26:181-184. 
SPREP (1985). Western Samoa. In: Thomas, P.E.J. (Ed.), Report of the Third South Pacific National Parks and Reserves Conference. Volume III. Country reviews. South Pacific Commission, Noumea, New Caledonia. Pp. 232-269.

Trotman, I.G. (1979). A national park program. Tigerpaper 4:11-14.

UNEP/IUCN (1988). Coral Reefs of the World. Volume 3. Central and Western Pacific. UNEP Regional Seas Directories and Bibliographies. IUCN, Gland, Switzerland and Cambridge, UK/UNEP, Nairobi, Kenya. 378 pp.

Date June 1988

\section{PALOLO DEEP MARINE RESERVE}

\section{IUCN Management Category IV (Managed Nature Reserve)}

Biogeographical Province 5.05.13 (Central Polynesian)

Geographical Location Located approximately $1.6 \mathrm{~km}$ north-east of Apia, in Vaimanga West Subdistrict, Tuamasaga District, on the north coast of 'Upolu. The reserve includes part of the surrounding reef to the north and south and extends $500 \mathrm{~m}$ east of the fringing reef (Bell, 1985).

Date and History of Establishment 5 December 1979. Gazetted under the provisions of Section 9 of the 1974 National Parks and Reserves Act.

Area $22 \mathrm{ha}$

Land Tenure State ownership of the seabed, ocean and land below the high water mark, the remainder comprising customary land.

Altitude Ranges from $0-1 \mathrm{~m}$ above sea level to a depth of approximately $10 \mathrm{~m}$.

Physical Features Palolo Deep is a hole about $200 \mathrm{~m}$ in diameter and $10 \mathrm{~m}$ deep within a fold in the fringing reef which surrounds Pilot Point. There is a small sand beach on the shore extending onto the reef flat which is dotted with small basalt rocks. On the seaward side of the deep there is a talus slope of sand and coral debris thrown over the reef (SPREP, 1985). The fore-reef slope and extensive submarine terraces have rich coral cover (Dahl, 1978).

Climate The mean daily temperature is $27^{\circ} \mathrm{C}$, with a range of $22^{\circ} \mathrm{C}$ to $30^{\circ} \mathrm{C}$. The mean annual rainfall is $2870 \mathrm{~mm}$, of which $1900 \mathrm{~mm}$ falls during October to March. Ocean temperatures range from $24^{\circ} \mathrm{C}$ to $30^{\circ} \mathrm{C}$ (SPREP, 1985).

Vegetation The $10 \mathrm{~m}$ wide access strip has a banana tree overstorey with various ornamental shrubs as an understorey. A large pulu tree is located near the reserve entrance (SPREP, 1985).

Fauna The reserve is named after the palolo worm Eunice viridis $(\mathrm{K})$, although it is now rarely found in the locality. There are many corals and abundant fish and invertebrates such as sea urchins, sea cucumbers, parrotfish, clownfish, pipefish, starfish, lionfish and possibly stonefish (SPREP, 1985).

Cultural Heritage No significant cultural heritage (SPREP, 1985). 
Local Human Population Palolo Deep is situated within the city of Apia, a collection of about 60 villages with a total population of 35,000 (SPREP, 1985). Matautu Village is contiguous to the south.

Visitors and Visitor Facilities During 1988 there were approximately 1,500 visitors, of whom $65 \%$ were tourists, the remainder being residents. An entrance fee of $1.00 \mathrm{Tala}$ (US\$ 0.50 ) is charged (E. Bishop, pers. comm., 1989). Access to the site is via a $10 \mathrm{~m}$-wide strip that skirts around nearby government-owned buildings. Accommodation for visitors is available in Apia. Tourist brochures have been produced but were inadequately distributed (Johannes, 1982). The customary owner supplements his income by hiring snorkelling equipment and selling refreshments from a small store (T. Uli, pers. comm., 1987).

Scientific Research and Facilities In the early 1970s, a rudimentary monitoring programme of Palolo Deep was carried out by the Regional Ecologist of the South Pacific Commission (Hunter, 1977), but this has not been continued. The origin of the Deep is not clear, but it has been suggested that a freshwater spring occurred there, preventing coral growth (SPREP, 1985).

Conservation Value The site was identified as being of special interest in the 1970s (Holloway and Floyd, 1975) because it was already being used for wildlife viewing and because of its proximity to Apia.

Conservation Management According to Firth and Darby (1988), the reserve was started as a private venture by a Samoan family, and serves as a precedent to demonstrate the potential for customary resource users to earn a cash income by conserving wildlife resources in their natural state. The current legal status of the reserve does not prohibit any government department from applying for a change in land use (E. Bishop, pers. comm., 1989). An underwater nature trail was planned in 1978 (Dahl, 1978), established in the early 1980s (Dahl, 1980) and redeveloped in 1985 with assistance from New Zealand. By 1987 the trail signs were no longer present. A management plan was due to be compiled during $1988-89$ (E. Bishop, pers. comm., 1988). The definition of marine reserve is not clear, and in many respects the reserves is a de facto recreational reserve (Bell, 1989).

Management Constraints The site is affected by pollution, siltation and by problems with urchins and crown-of-thorns starfish Acanthaster planci. Underwater visibility declined between 1970 and 1977 as a result of sedimentation, considered to be due to large-scale reclamation for an hotel complex in the vicinity (Hunter, 1977). The proximity of the reserve to Apia Harbour increases its vulnerability. In 1982, the area was being fished illegally, probably at night (Johannes, 1982). There is reported to be some coral collection (UNEP/IUCN, 1988). Trained management personnel are lacking and a lack of funds for the National Parks and Reserves Section has meant that the development of the Deep is not a high priority (T. Uli, pers. comm., 1987).

Staff The owner is paid a government wage, and a caretaker is employed to guard the site at night (E. Bishop, pers. comm., 1989).

Budget No budget is allocated specifically to the reserve. The National Parks and Reserves Section budget for 1988 was 28,000 WS Tala (US\$ 14,000) and the proposed 1990 budget was 104,000 WS Tala.

Local Addresses National Parks and Reserves, Department of Agriculture, Forests and Fisheries, PO Box L1874, Apia 


\section{References}

Bell, L.A.J. (1985). Coastal zone management in Western Samoa. In: Thomas, P.E.J. (Ed.), Report of the Third South Pacific National Parks and Reserves Conference. Selected key issue and case study papers. South Pacific Commission, Noumea, New Caledonia. Pp. 57-73.

Bell, L.A.J. (1989). Marine conservation: present status in Western Samoa. In: SPREP, Report of the workshop on customary tenure, traditional resource management and nature conservation, Noumea, 28 March-1 April. South Pacific Commission, Noumea. Pp. 87-94.

Dahl, A.L. (1978). Report on assistance to Western Samoa with national parks and conservation. South Pacific Commission, Noumea, New Caledonia. 28 pp.

Dahl, A.L. (1980). Regional ecosystem surveys of the South Pacific Area. IUCN/SPCTechnical Paper 179. South Pacific Commission, Noumea, New Caledonia. 99 pp.

Firth, N. and Darby, E.C. (1988). Environmental planning for tourism in Western Samoa. A report to the Government of Western Samoa and the South Pacific Regional Environment Programme. KRTA Limited, Auckland, New Zealand. 124 pp.

Holloway, C.W. and Floyd, C.H. (1975). A national parks system for Western Samoa. United Nations Development Advisory Team for the South Pacific (UNDAT). 71 pp.

Hunter, A.P. (1977). Country Report. Western Samoa. In: Collected Abstracts and Papers of the International Conference on Marine Parks and Reserves, Tokyo, Japan, May 1975. The Sabiura Marine Park Research Station, Kushimoto, Japan. (Unseen)

Johannes, R.E. (1982). Reef and lagoon management in Western Samoa. Unpublished report. South Pacific Regional Environment Programme.

SPREP (1985). Western Samoa. In: Thomas, P.E.J. (Ed.), Report of the Third South Pacific National Parks and Reserves Conference. Volume III. Country reviews. South Pacific Commission, Noumea, New Caledonia. Pp. 232-269.

UNEP/IUCN (1988). Coral Reefs of the World. Volume 3. Central and Western Pacific. UNEP Regional Seas Directories and Bibliographies. IUCN, Gland, Switzerland and Cambridge, UK/UNEP, Nairobi, Kenya. 378 pp.

Date July 1989

\section{TUSITALA HISTORIC AND NATURE RESERVE (COMPRISING MOUNT VAEA SCENIC RESERVE, STEVENSON (TUSITALA) MEMORIAL RESERVE AND VAILIMA BOTANIC GARDEN)}

\section{IUCN Management Category Unassigned}

Biogengraphical Province 5.05.13 (Central Polynesian)

Geographical Location Located in northern 'Upolu island, in Vaimanga West Subdistrict, Taumasaga District and on the eastern slopes and summit of Mt Vaea. The protected area is at the end of Ala o le Alofa Road and lies $4 \mathrm{~km}$ inland from Apia. Stevenson Memorial Reserve lies at the approximate centre of Mt Vaea Scenic Reserve, whilst Vailima Botanic Garden is contiguous to the south-east. Approximately $5^{\circ} 04^{\prime} \mathrm{N}, 75^{\circ} 57^{\prime} \mathrm{W}$ 
Date and History of Establishment Originally gazetted on 22 September 1958 as Mount Vaea Scenic Reserve and Stevenson Memorial Reserve, then redesignated and expanded on 11 October 1978, under the 1974 National Parks and Reserves Act, to include Vailima Botanic Garden. The site is still marked on Ministry of Lands maps as government land, not national park or reserve. Consequently, the reserve does not enjoy the full protection available under the 1974 Act (E. Bishop, pers. comm., 1989).

Area Mount Vaea Scenic Reserve 51 ha; Stevenson Memorial Reserve 0.5ha; Vailima Botanic Garden 12ha

\section{Land Tenure State}

\section{Altitude $180-400 \mathrm{~m}$}

Physical Features Mt Vaea is a small remnant of a two million year old volcano, emerging through younger volcanoes (Kear, 1967; SPREP, 1985) and forming a prominent hill overlooking the national capital, Apia. The reserve consists entirely of the oldest rock found in Western Samoa: the Fagaloa Volcanics. There are dense lava flows, and lava flows which contained a large amount of gas during formation. The latter erodes readily, forming the two waterfalls on Vailima Stream and shallow, stony soils (SPREP, 1985). The Botanic Garden has a gentle, northerly aspect and is bounded to the north by Vailima Stream.

Climate The mean daily temperature is $27^{\circ} \mathrm{C}$, with a range of $22^{\circ} \mathrm{C}$ to $30^{\circ} \mathrm{C}$. The mean annual rainfall is $2870 \mathrm{~mm}$, of which $1900 \mathrm{~mm}$ falls during October to March (SPREP, 1985).

Vegetation Forest covers about three-quarters of Mt Vaea Scenic Reserve. The original forest cover has been disturbed and may be classified into three general categories. Plantations were established along Vailima Stream, principally to protect the watershed after severe storm damage in 1963 (Trotman, 1979). Predominant species include Cedrella odorata, Albizia chinensis, A. falcataria, Castilloa elastica, Funtumia elastica, Pinus sp., Eucalyptus sp. and Securinega flexuosa. Secondary forest, dominated by mature species adapted to germination and growth in sunny, disturbed areas covers most of Mt Vaea Scenic Reserve. Early stages of secondary forest host Pipturus argenteus, Kleinhovia hospita, Homalanthus nutans and Hibiscus tiliaceus. Later stages of secondary forest include Rhus taitensis, Alphitonia zizyphoides, Bischofia javanica, Macaranga stipulosa, Cananga adorata, Myristica fatua and tree ferns of the genus Cyathea. Foothill rain forest is found as small patches of native species within secondary forest. No single species is dominant, although Myristica, Palaquiumstehlinii, Syzygium ionphylloides, Canarium samoense, Barringtonia samoensis and Pometia pinnata are all represented (SPREP, 1985). Vegetation within Stevenson Memorial Reserve includes lopa, gatae, Asi and breadfruit, in addition to open areas around the memorial. Vailima Botanic Garden includes many species of trees, ornamental shrubs, in addition to native and exotic food crops, planted for demonstration purposes. The garden also includes a cocoa plantation and a forestry trial area (Anon., n.d.).

Fauna Birds commonly seen include wattled honey-eater Foulehaio carunculata, Samoan starling Aplonis atrifusca, white-rumped swiftlet Collocalia spodiopygia, triller Lalage sharpei, Samoan fantail Rhipidura nebulosa and red-vented bulbul Pycnonotus cafer. Flying fox Pteropus sp. are present. Reptiles are represented by black skink, Samoan skink and Polynesian gecko (SPREP, 1985).

Cultural Heritage Stevenson Memorial Reserve includes the tomb of the author Robert Louis Stevenson, who spent his last years on the island. His former home is now the residence of the 
Head of State. The reserve entrance road, Alao le Loto Alofa (Road of the Loving Hearts) was constructed in Stevenson's honour, following his involvement in local politics (Anon., n.d.).

Local Human Population The nearest major population centre is Apia, with a population of some 35,000. The reserves are located just west of a string of small Samoan villages fronting on Tiavi Road (East Cross Island Road). A few small plantations are interspersed to provide food for villagers. The Head of State's residence is immediately south of the reserve entrance road (SPREP, 1985).

Visitors and Visitor Facilities The area is well-used, with activities ranging from hiking to swimming and picnicking. The annual number of visitors is not known and access is free by road from Apia. In 1979 there were more than 150 visitors each month (Trotman, 1979). Two trails lead to Stevenson's tomb, one of which traverses the west side of Mount Vaea (E. Bishop, pers. comm., 1989)

Scientific Research and Facilities There are forestry trials at Vailima Botanic Garlen (Anon., n.d.).

Conservation Value The area has been established to safeguard the scenery and countryside around Robert Louis Stevenson's home and tomb, as well as to serve as an important recreation area for the residents of Apia.

Conservation Management The current legal status does not prohibit any government department from applying for a change in land-use (E. Bishop, pers. comm., 1989). Management plans for each of the three sites are due to be compiled within the next three years. Management objectives have included establishing, by December 1989, displays of native Samoan plants in the botanical garden, including ornamentals, crops, medicinal species and trees, and the provision of appropriate staff training (E. Bishop, pers. comm., 1988).

Management Constraints The botanical garden was overrun by bush during the 1980s due to a lack of staff for maintenance work. Much of this was cleared during 1987-89. Local people have established plantations in the reserve, although these have been removed (E. Bishop, pers. comm., 1989).

Staff A caretaker, with two labourers, has responsibility for all three sites (SPREP, 1985).

Budget No budget is specifically allocated to the reserves. The National Parks and Reserves Section had a 1988 budget of 28,000 WS Tala (US\$ 14,000) and a projected 1990 budget of 104,000 WS Tala.

Local Addresses National Parks and Reserves Section, Forestry Division, Ministry of Agriculture, Forestry and Fisheries, PO Box L1874, Apia

\section{References}

Anon. (n.d.). Mt. Vaea Scenic Reserve, Vailima Botanic Garden, Stevenson Memorial Reserve. Pamphlet printed by the National Parks and Reserves Section, Forestry Division, Ministry of Agriculture, Forestry and Fisheries.

Kear, D. (1967). Geological notes on Western Samoa. New Zealand Journal of Geology and Geophysics 10(6): 1446-1451. 
SPREP (1985). Western Samoa. In: Thomas, P.E.J. (Ed.), Report of the Third South Pacific National Parks and Reserves Conference. Volume III. Country reviews. South Pacific Commission, Noumea, New Caledonia. Pp. 232-269.

Trotman, I.G. (1979). Western Samoa launches a national park program. Parks 3(4): 5-8.

Date August 1987, reviewed January 1989, February 1990 


\section{OTHER PACIFIC ISLANDS}

SUMMARY OF PROTECTED AREAS

\begin{tabular}{|c|c|c|c|c|}
\hline $\begin{array}{l}\text { Map }^{\dagger} \\
\text { ref. }\end{array}$ & Name of area & $\begin{array}{l}\text { IUCN management } \\
\text { category }\end{array}$ & $\begin{array}{r}\text { Area } \\
\text { (ha) }\end{array}$ & $\begin{array}{c}\text { Year } \\
\text { notified }\end{array}$ \\
\hline
\end{tabular}

\section{AUSTRALIA}

International designation: World Heritage Site
1 Lord Howe Island Group
(Permanent Preserve)*
II/X

1176

1982

CHILE

\section{National Park}

2 Rapa Nui*

II

6800

1935

NEW ZEALAND

Nature Reserve
Kermadec Islands*
UK PITCAIRN - Henderson Island

International designation: World Heritage Site

4 Henderson Island*

$\mathrm{X}$

3,700

1988

USA - Minor Outlying Islands

$\begin{array}{llrrr}5 & \text { National Wildlife Refuges } & & \\ 6 & \text { Baker Island* } & \text { I } & 12,843 & 1974 \\ 6 & \text { Howland Island* } & \text { I } & 13,173 & 1974 \\ 7 & \text { Jarvis Island* } & \text { I } & 15,183 & 1974 \\ 8 & \text { Johnston Atoll* } & \text { Unassigned } & 12,995 & 1926\end{array}$

*Site is described in this directory.

${ }^{\dagger}$ Locations are shown in the accompanying map. 


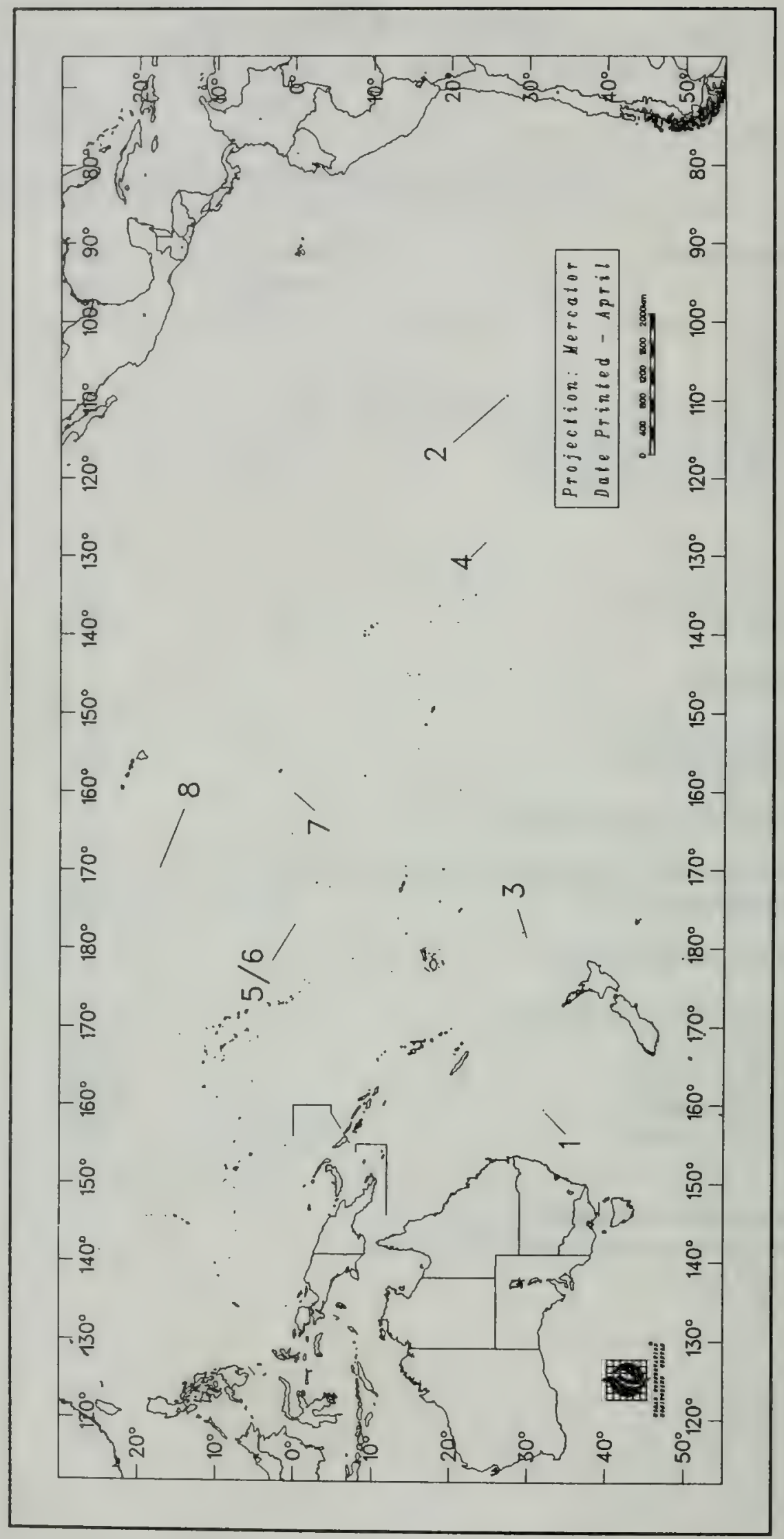

Protected Areas of other Pacific Islands 


\title{
AUSTRALIA \\ Lord Howe Island Group (permanent Preserve)
}

\author{
IUCN Management Category II (National Park) \\ X (World Heritage Site; criteria i, ii, iii, iv)
}

Biogeographical Province 5.06.13 (New Caledonian)

Geographical Location Located in the South Pacific Ocean, 700km north-east of Sydney and included administratively in New South Wales. The preserve includes some $75 \%$ of the land area of Lord Howe Island and all of the offshore islands and rocks of significant size in the region. These include the Admiralty Group (immediately to the north-east of Lord Howe Island); Mutton Bird and Sail Rock (just east of the central part of Lord Howe Island); Blackburn (Rabbit) Island (in the lagoon on the western side of Lord Howe Island); Gower Island (just off the southern tip of Lord Howe Island); and Ball's Pyramid (25km south-east of Lord Howe Island), together with a number of small islands and rocks. The seaward boundary follows the mean high water mark and consequently excludes all littoral and marine areas (Davey, 1986). A detailed description of the boundary is given in Schedule 1 of the 1981 Lord Howe Island (Amendment) Act. $31^{\circ} 30^{\prime}-31^{\circ} 50^{\prime} \mathrm{S}, 159^{\circ} 00^{\prime}-159^{\circ} 17^{\prime} \mathrm{E}$

Date and History of Establishment The preserve was established on 1 January 1982 under Section 19A of the Lord Howe Island (Amendment) Act, 1981. The Lord Howe Island Board was originally constituted under Section 4(1) of the Lond Howe Island Act, 1953. The entire island region was inscribed on the Unesco World Heritage List in 1982.

Area Approximately 1,176ha. The World Heritage site includes the whole island region, covering approximately $1,540 \mathrm{ha}$ of land area.

Land Tenure State Government of New South Wales. All permanent private occupation is on leasehold from the government subject to various conditions (ANPWS, 1981).

Altitude Sea level to $875 \mathrm{~m}$ (Mount Gower)

Physical Features The main island of Lord Howe measures $10 \mathrm{~km}$ from north to south and is little more than $2 \mathrm{~km}$ in width. It roughly describes a crescent, enclosing a coral reef lagoon on its south-western side. The island's topography is dominated by the southerly Mount Gower $(875 \mathrm{~m})$ and Mount Lidgbird $(777 \mathrm{~m})$. Steep cliffs rise several hundred metres to form the seaward flanks of Mount Gower. Only a narrow isthmus of lowland country in the north-central part of the island is habitable. The northern tip consists of steep hillsides culminating in extensive sea cliffs against the northern coastline. Scattered around the main island are several groups of smaller islands and rocks. The most distant of these is a group of small islets and rock stacks around the $650 \mathrm{~m}$ pinnacle of Balls Pyramid, $25 \mathrm{~km}$ to the south-east of Lord Howe.

Lord Howe Island is the eroded remnant of a large shield volcano which erupted from the sea floor intermittently for about 500,000 years, 6.5 to 7 million years ago in the late Miocene (McDougall et al., 1981). The island group represents the exposed peaks of a large volcanic seamount which is about $65 \mathrm{~km}$ long and $24 \mathrm{~km}$ wide and which rises from ocean depths of over $1,800 \mathrm{~m}$. The Lord Howe seamount is near the southern end of a chain of such seamounts, mostly below sea level, extending for over $1,000 \mathrm{~km}$. These mark the successive movement of the Australian tectonic plate over a "hotspot" within the upper mantle below. Four separate series of volcanic rocks are recognised on the main island group, the oldest being exposed in the Admiralty 
Group and on the north-eastern tip of Lord Howe. These include tuffs, breccia and basalts, with widespread intrusion of basaltic dykes, and are overlain by progressively younger units to the south. The youngest volcanic rock is Mt Lidgbird basalt, which is present in lava flows up to $30 \mathrm{~m}$ thick. Sedimentary aeolian calcarenite or dune limestone characterise the lowland parts of the main island (Davey, 1986).

The dominant landforming process on Lord Howe since the last of the volcanic eruptions has been marine erosion, which has cut and maintained major cliffs. Slope failure and accumulation of talus at the foot of some cliffs, especially in the south, have modified their original shape. Local variations in lithology are the major determinant of the shape of the irregular rocky coastline and of the small residual islands and rock stacks. There are numerous resistant projecting points and sea caves (Davey, 1986).

Subsequent erosion means that the present islands occupy only one-fortieth of the original area. Lord Howe Island has sedimentary deposits of Pleistocene and Holocene ages, including cross-bedded calcarenite with intercalated soil horizons, lagoonal deposits, a single sand dune, and alluvium. The island supports the southernmost true coral reef in the world, which is of Pleistocene to Recent age and differs considerably from more northerly warm water reefs. It is unique in being a transition between the algal and coral reef, due to fluctuations of hot and cold water around the island. The entire island group has remarkable volcanic exposures not known elsewhere, with slightly weathered exposed volcanics showing a great variety of upper mantle and oceanic type basalts. Ball's Pyramid represents the nearly complete stage in the destruction of a volcanic island. The intercalated soil horizons have yielded important palaeontological data, with interesting fossil finds such as the shells of land snail Placostylus and the terrestrial giant horned turtle Meiolania platyceps, which probably became extinct more than 20,000 years ago. A fossil bat skull, uncovered in 1972, has been described as a new species Nyctophilus howensis; it may have persisted into modern times. Significant landforms in the preserve are listed in Davey (1986).

Climate Climate is humid subtropical with a mean temperature of $16^{\circ} \mathrm{C}$ in August and $23^{\circ} \mathrm{C}$ in February. Both diurnal and seasonal temperature range is about $7^{\circ} \mathrm{C}$. A temperature of $0^{\circ} \mathrm{C}$ has been recorded on the summit of Mount Gower. Mean annual rainfall in the lowlands is almost $1700 \mathrm{~mm}$, with a pronounced maximum in winter and a mean rainfall of $100 \mathrm{~mm}$ in February. The highest annual rainfall recorded in the lowlands is $2870 \mathrm{~mm}$, with a minimum of $1000 \mathrm{~mm}$. The southerly part of Lord Howe Island is generally wetter due to orographic effects. Relative humidity is high at 75-78\% and wind levels average 13 knots in August, 9-10 knots in January and March. Climatic data and summaries are available in Anon. (1969), Gentilli (1971) and Pickard (1983).

Vegetation A wide variety of vegetation types has been described for the islands, with the diversity corresponding with the range of habitats, viz. lowland, montane, valleys, ridges and areas exposed to the maritime influence. Variable exposure to wind and penetration of salt spray appear to be the main determinants of vegetation occurrence, structure and floristics. Lord Howe Island is almost unique among small Pacific Ocean islands in that its mountains have sufficient altitude for the development of true cloud forest on their summits.

Twenty-five vegetation associations in twenty alliances have been identified (Pickard, 1983). Fourteen of these associations have endemic species as their dominant components. The slopes of the northern hills are dominated mostly by Drypetes/Cryptocaria rain forest, with Howea forsterana palm forest on the flats behind North Bay and H. belmoreana palm forest in the narrower gullies running down towards Old Settlement Beach. Melaleuca/Cassinia scrubs and 
Cyperus and Poa grasslands occur on the exposed slopes of Mount Eliza and along the crest of the sea cliffs on the northern coast. The southern mountains are covered with a more variable suite of rain forest and palm associations, often with Pandanus along drainage lines, and with scrub and cliff associations in the more exposed parts and along the coastline. There are small occurrences of Poa grassland on Mutton Bird Point (on the east coast) and King Point (at the southern tip). The upper slopes of mounts Gower and Lidgbird include areas of forest dominated by another of the endemic palms, Hedyscepe canterburyana. The very humid summit plateau on Gower and the summit ridge on Lidgbird consist of structurally distinct gnarled mossy forest (Davey, 1986).

There are 219 native species of vascular plants on the island, including 74 endemics. Sixteen of these are considered rare, endangered or vulnerable. There are four endemic palm species in three endemic genera. There are also two other endemic genera in the families Asteraceae and Gesneriaceae. Other endemic species are widely scattered among families. Endemism is particularly noticeable among ferns and in the families Asteraceae, Myrsinaceae, Myrtaceae and Rubiaceae. There are 48 species of indigenous pteriodphytes (including 19 endemic ferns) belonging to 32 genera, and 180 species of angiosperms ( 56 endemics) in 149 genera. A further four species are represented by endemic subspecies or varieties; there are no gymnosperms. Some of the endemics suggest recent speciation, and many have confusing origins, such as the three endemic palm genera Howea, Hedyscope and Lepidorrhachis, and also Dietes sp., the three congeners of which are endemic to southern Africa and which has seeds with apparently only short range dispersal capacity. Other noteworthy endemics are Dendrobium moorei and Bubbia howeana. Many species are threatened or have restricted distribution on the island; there is only one known plant of non-endemic Pandanus pedunculatus, and Chionochloa conspicua ssp. nov. (Poaceae) is an endemic known only from one clump on Mount Lidgbird.

The vegetation has affinities with sub-tropical and temperate rain forests, and 129 plant genera are shared with Australia, 102 with New Caledonia and only 75 with New Zealand. There are 160 naturalised, introduced plant species, mostly, but not exclusively, in the lowland settlement area. Weed species of the greatest immediate concern within the preserve are bone seed (biton bush) and kikuyu grass. Many other species are potentially serious problems (Davey, 1986).

Fauna A small population of little cave eptesicus Eptesicus sagittula still occurs. No other indigenous native mammals are known. Introduced species, however, include mouse Mus musculus and rats, feral cat Felis domestica, goat Capra hircus and, formerly, pig Sus domestica.

There are at least 129 native and introduced bird species, mostly vagrants, with 27 breeding regularly. A partial species list is given in Davey (1986). Lord Howe is now the only known breeding ground for providence petrel Pterodroma solandri, although it also probably breeds on Ball's Pyramid. Fleshy-footed shearwater Puffinus carneipes hullianus breeds in substantial numbers on Lord Howe, with possibly half the world's population present. Other important species breeding within the preserve include Kermadec pstrel Pterodroma neglecta, black-winged petrel $P$. nigripennis, wedge-tailed shearwater $P$ uffinus pacificus, little shearwater $P$. assimilis, white-bellied storm petrel Fregetta grallaria, masked booby Sula dactylatra, red-tailed tropic bird Phaeton rubricauda in greater concentrations than probably anywhere else in the world. Sooty tern Sterna fuscata, noddy Anous stolidus and grey ternlet Procelsterna cerula. Several migratory wader species are regular visitors to the island, principally double-banded dotterel Charadrius bicinctus, eastern golden plover Pluvialis dominica, turnstone Arenaria interpres, whimbrel Numenius phaeopus and bar-tailed godwit Limosa lapponica. Four endemic birds are present. Lord Howe Island woodhen Tricholimnas sylvestris, reduced to some 26 individuals in 1975, has been successfully bred in captivity and now numbers 
around 200. The other endemic land birds are silver-eye Zosterops tephropleura, Lord Howe Island golden whistler Pachycephala pectoralis contempta, both reasonably abundant, and the scarce Lord Howe Island currawong Strepera graculina crissalis (Davey, 1986), with only 20 known pairs (ANPWS, 1981).

The islands support two species of terrestrial reptile, skink Leiolopisma lichenigera and gecko Phyllodactylus guentheri, which are threatened with extinction on the main island but are abundant on other islands in the group. Many of the endemic invertebrates from the moss forest on the summit of Mount Gower have been collected and described. The small terrestrial gastropods (Hydrobiidae) comprise nine species and sixteen subspecies, a greater number of subspecies than those found on the eastern Australian mainland. The terrestrial molluscs have suffered from habitat changes; two colonies of large ground snails Placostylus sp. appear to be maintaining their numbers, though distinct forms seem to have become extinct on other parts of the island. There are five endemic species of flies (Diptera) and a further nine confined to Lord Howe and Norfolk islands. Specimens of Lord Howe Island phasmid Dryococoelus australis (Ex), a large flightless phasmatid thought to be extinct on Lord Howe Island, is known to occur still on Ball's Pyramid. Over 50\% of more than 100 species of spiders recorded for Lord Howe Island are thought to be endemic. One endemic species of leech and ten endemic species of earthworm have also been recorded. The terrestrial and freshwater crustacea are not well known, but include a freshwater crab Halicarcinus lacustris and a freshwater prawn Paratya howensis. Three new genera and 12 new species of terrestrial isopod have been recorded and recently a new species of talitrid amphipod from the top of Mount Gower was described. The waters around Lord Howe Island provide an unusual mixture of temperate and tropical organisms, 477 fish species having been recorded in 107 families of which $4 \%$ are unrecorded elsewhere other than in Norfolk Island-Middleton Reef waters. Lionfish Pterois volitans is protected in the marine waters (ANPWS, 1981).

Cultural Heritage The earliest human discovery of Lord Howe appears to have been in 1788 by the British colonial vessel HMS Supply. There is no recognised evidence of prior Polynesian or Melanesian discovery or settlement. A small permanent settlement was established in the 19th century, subsisting on trade with passing ships. With numerous fluctuations over the years, the settlement slowly expanded and consolidated, developing a distinctive social structure and culture with the passage of time (Davey, 1986). The island is an interesting example of restricted island settlement, although the World Heritage nomination was not made on cultural grounds (ANPWS, 1981).

Local Human Population There is currently a resident population of between 250 and 300 individuals inhabiting the relatively level ground in the central part of the main island. Tourism is the major component of the island economy, followed by public administration and community service. Approximately $10 \%$ of the main island's vegetation has been cleared for agriculture, and another $10 \%$ has been subject to physical disturbance. Commercial activities within the preserve include collection of palm seed, especially Kentia palm Howea forsterana, and cutting of Pandanus foliage for production of baskets and other craft items, subject to control by the Lord Howe Island Board (Davey, 1986).

Visitors and Visitor Facilities Some three or four hundred tourists may be present simultaneously during the summer (Davey, 1986), although neither the annual total number of visitors, nor the revenue derived from tourism is known. The principal means of access to the island for visitors is by light aircraft. There are six licensed guest houses providing full board accommodation and eleven self-contained apartment complexes (Thompson et al., 1987). Walking, often for nature study, bird watching or photography, is the major recreation activity. 
There is an extensive system of walking tracks ramifying throughout the reserve and a guide service is available. Scenic flights are available over the entire island group and several commercial operators offer boat tours. Proposed interpretation and environmental education activities are outlined in the current management plan (Davey, 1986).

Scientific Research and Facilities There has been considerable scientific interest in Lord Howe ever since discovery of the island. A succession of scientific expeditions in the 19th century quickly established the international significance of the island's natural history. In the early 1970s the Australian Museum undertook a terrestrial environmental survey of the island for the Lord Howe Island Board (Recher and Clark, 1974) which included, inter alia, a recommendation to establish an extensive land reserve for the protection of terrestrial flora and fauna. Land use planning studies undertaken for the Board (Ashton, 1974) also recommended the establishment of a substantial reserve on the island. A major research project culminated in the successful captive breeding of Lord Howe Island woodhen in the early to mid-1970s. A research bibliography is given in Davey (1986).

Conservation Value The preserve is valued for exceptional natural beauty, a diversity of landscapes and wide variety of rare flora and fauna.

Conservation Management The affairs, care, control and management of Lord Howe Island, including the smaller islands offshore, are administered by the Lord Howe Island Board. The Lord Howe Island (Amendment) Act, 1981, reconstituted the Board, such that one of its members is an officer of the New South Wales National Parks and Wildlife Service, nominated by the Minister administering the 1974 National Parks and Wildlife Act. Section 15B of the amended Act provides for the preparation of a management plan in respect of the preserve, prepared by the Director of Parks and Wildlife, in terms of Part V of the 1974 Act. The plan is to be approved by the Minister administering the Lord Howe Island Act. The Board has adopted a "land use policy set", based on a model that proposes that the region comprises two components: the settlement area, and the preserve. One of the objectives of the land use policy set is "to ensure that the management plan for the settlement area will complement the future permanent park preserve plan of management and form a plan of management for the island as a whole".

The Lord Howe Island management plan (Davey, 1986) states that the fundamental management objectives are to: maintain the natural land-forming processes; protect significant landforms; maintain natural plant and animal populations; avoid all unnatural disturbances of plant associations and habitats; protect all individuals and the population of each species from unnatural disturbances; eliminate human disturbance; restore disturbed areas; control or eliminate introduced species; preserve outstanding natural scenery and natural character of the preserve; promote appreciation and enjoyment of the preserve; maintain the full range of plant genetic diversity; and make provision for continued livelihood of the local populace. Specific management activities have included the elimination of goats from the Northern Hills, resulting in substantial recovery of the understorey and a severe reduction in the number of feral pigs (Davey, 1986). Funds and labour have been allocated to an intensive effort to control weed infestations and feral animals affecting native vegetation and birds. However, funding and labour constraints have so far only allowed the control, and not elimination, of introduced flora and fauna. The Board is seeking Commonwealth Government funding in order to fully implement the eradication programme (Anon., 1989).

Management Constraints Nine of the fifteen species of land birds recorded when the Island was first discovered are now extinct, of which seven were endemics. Their destruction has been due to hunting, introduction of black rat Rattus rattus, owls and feral cats, or through habitat 
changes caused by introduced goats and pigs. The size of some seabird colonies on the main island has also declined. Endemic land snails are less abundant and confined to isolated colonies although exact details are not known, and the two lizards are very restricted if not extinct on the main island. There are 175 introduced species of plant, although most of these have not invaded the indigenous plant communities. In the lower-lying areas, destruction of native vegetation has been virtually complete where clearings have been made for settlement, grazing and agriculture, and regrowth tends to be of invading weed species, including introduced plants such as guava, bitou bush and asparagus fern. However, adequate samples of intact lowland vegetation remain in less accessible parts of the island, some of them in special flora reserves (ANPWS, 1981).

Staff No information

Budget Approximately $10 \%$ and $20 \%$ of the Board's budget (after wages, on-costs and expenses) has been committed to the eradication of noxious weeds and vertebrate pests, respectively (Anon., 1989).

Local Addresses Lord Howe Island Board, Lands Department Building, 23 Bridge Street, Sydney, NSW 2000; New South Wales National Parks and Wildlife Service, PO Box N189, Grosvenor Street PO, Sydney, NSW 2000

\section{References}

Anon. (1969). Climatic averages Australia temperature, relative humidity and rainfall. Bureau of Meteorology, Melbourne.

Anon. (1974). Australian Natural History 18(2), June. (Entire issue devoted to Lord Howe Island). (Unseen).

Anon. (1989) Information update on the cultural sites inscribed on the World Heritage list: Lord Howe Island Group. Department of the Arts, Sport, the Environment, Tourism and Territories, Canberra. Unpublished. 3 pp.

Ashton, N. (1974). Report to the Lord Howe Island Board on the future land use and land management of Lord Howe Island. Sydney, State Planning Authority of New South Wales. (Unseen).

Australian National Parks and Wildlife Service (1981). Nomination of the Lord Howe Island Group for inclusion in the World Heritage List. New South Wales Government. 30 pp.

Brown, I. (1979). Birds of Ball's Pyramid, Lord Howe Island. Australian Birds 13(3): 41-42. (Unseen).

Davey, A. (1986). Plan of management: Lord Howe Island Permanent Park Preserve. New South Wales National Parks and Wildlife Service, Sydney. 118 pp.

Disney, H.J. and Smithers, C.N. (1972). The distribution of terrestrial and freshwater birds on Lord Howe Island, in comparison with Norfolk Island. The Australian Zoologist 17(1). (Unseen).

Elenius, E. (1979). Lord Howe Island - World Heritage threatened. National Parks Journal 13: 13-14. (Unseen).

Gentilli, J. (1971). Climates of Australia and New Zealand. In: World Survey of Climatology Volume 13. Elsevier, Amsterdam.

McDougall, I., Embleton, B.J.J. and Stone, D.S. (1981). Origin and evolution of Lord Howe Island - South-west Pacific Ocean. Journal of the Geological Society of Australia 28: 156-176. (Unseen).

McKean, John L. (1975). The Bats of Lord Howe Island with the description of a new Nyctophiline bat. Journal of the Australian Mammal Society 1(4): 329-332. (Unseen). 
Miller, B. (1981). Liberate the woodhen, the theme of the '80s. Napawi Staff Newsletter of the National Parks Wildlife Service, NSW (2): 17-19. (Unseen).

Miller, B. and Kingston, T. (1980). Lord Howe Island Woodhen. Endangered Species of New South Wales. National Parks and Wildlife Service. (Unseen).

NPWS (n.d.). Walks and tours: Mount Gower Walk. New South Wales National Parks and Wildlife Service, Sydney. Leaflet. 2 pp.

Pickard, J. (1983). Vegetation of Lord Howe Island. Cunninghamia 1: 133-266. (Unseen)

Pope, E.C. (1960). Australian Museum Magazine 13(7): 207-210. (Unseen).

Rabone, H.R. (1972). Lord Howe Island - Its discovery and early associations 1788-1888. Sydney, Australia. (Unseen).

Recher, H.F. and Clark, S.S. (1974). A biological survey of Lord Howe Island with recommendations for the conservation of the island's wildlife. Biological Conservation 6(4): 263-273. (Unseen).

Recher, H.F. and Clark, S.S. (1974). Environmental survey of Lord Howe Island. A Report to the Lord Howe Island Board. Australian Museum. (Unseen).

Rodd, A.N. (1981). Field Trip 17 Lord Howe Island Handbook, produced for the XIII International Botanical Congress, Sydney. (Unseen).

Standard, J.C. (1963). Geology of Lord Howe Island. Journal and Proceedings of the Royal Society of New South Wales 96: 107-121. (Unseen).

Thompson, D, Bliss, P. and Priest, J. (1987). Lord Howe Island geology. Lord Howe Island Board, Sydney. Brochure.

Waterhouse, D.R. (1976). A new national park in the Pacific. Tigerpaper (3)1.

Date April 1982, reviewed April and November 1989

\section{CHILE \\ Isla de Pascua}

Name Rapa Nui National Park

IUCN Management Category II (National Park)

Biogeographical Province 5.04.13 (Southeastern Polynesia)

Geographical Location On Isla de Pascua (Easter Island), 3,600km from the coast of Chile. Approximately $27^{\circ} 10^{\prime} \mathrm{S}, 109^{\circ} 26^{\prime} \mathrm{W}$

Date and History of Establishment 1935 by Decree 103, Ministry of Lands and Colonization

Area $6,800 \mathrm{ha}$

Land Tenure Government

Altitude $0-300 \mathrm{~m}$

Physical Features The park mainly covers the coastal areas of the island, together with the col between the peaks of Terevaka and Poike. The island is volcanic in origin. Rano Kau peak, also included in the park, is a collapsed cone now in the form of a caldera filled by a freshwater lake; 
the crater of Rano Raruku also contains a lake. There are no perennial freshwater streams. The coastline is very eroded, consisting mainly of high cliffs.

Climate South-east trade winds dominate from October to April, and winds are mixed from March to September. Rainfall is about $1250 \mathrm{~mm}$ each year, with a rainy season in winter. Mean annual water temperatures range from $19^{\circ} \mathrm{C}$ in winter to $24^{\circ} \mathrm{C}$ during summer (UNEP/IUCN, 1988).

Vegetation There are 150 species of plants, 45 of which are indigenous, including three endemic species of grass. Despite the tropical climate, the whole island is now covered mainly by grassland. Sophora toromiro was noteworthy, being the only species of tree or shrub known on the island in historic times, but the species is now generally regarded as extinct in the wild. The major cover of the dense steppe lands is Stipa spp., Nasella spp. and by introduced Sporobulus indicus and Cynodon dactilon. A description of the vegetation is given by Etienne et al. (1982).

Fauna There are four species of terrestrial birds and three of marine birds, including greater frigatebird Fregata minor, red-tailed tropic bird Phaethon rubricauda and Kermadec petrel Pterodroma neglecta. There are no mammals except introduced rodents and carnivores. Two terrestrial reptiles, Lepidodactylus lugubris and Ablepharus boutoui poecilopleurus, occur and three species of marine turtles occasionally visit the park.

Cultural Heritage The archaeological remains are unique and include the particularly noteworthy large statues characteristic of the island.

Local Human Population No information

Visitors and Visitor Facilities Tourism on land is very important on account of the rich cultural resources. To date, visitors have made little use of the marine environment; a dive facility has been installed, but diving is difficult and expensive. Islanders sell corals to dealers on the Chilean mainland and to tourists (UNEP/IUCN, 1988).

Scientific Research and Facilities Research has been very limited, although the cultural resources are important and of great interest. There are no scientific facilities.

Conservation Value Easter Island, with the small rocky islet of Sala y Gomez, is the most isolated island in the Pacific Ocean, and is thus of great importance in the study of biogeographical dispersion and colonisation by marine organisms.

Conservation Management The zoning system comprises intangible, primitive, extensive use, intensive use, service and special use areas. A large proportion of the extensive use zone (second in importance to the intangible zone) conforms to the 1976 Management Plan proposals. A management plan for the park was published with the assistance of FAO in 1976 (CONAF, 1976). The plan details management objectives and zones the park to help develop these objectives. It also gives details on most other aspects relevant to park management.

Management Constraints The island was extensively deforested prior to modem times. Archaeological investigations, erosion and damage caused by visitors are more current problems. There are many introduced species. Islanders do not recognise the Chilean Government's authority to declare their lands a national park and consequently respect few of its rules (UNEP/IUCN, 1988).

Staff No recent information. Park rangers protect and patrol archaeological sites (UNEP/IUCN, 1988). 
Budget No information

Local Addresses Corporación Nacional Forestal, V Región, Viña del Mar, Chile

\section{References}

CONAF (1976). Plan de Manejo del Parque Nacional Rapa Nui. Documento Técnico de Trabajo No. 20. Proyecto FAO/RLAT/TF 199. Corporación Nacional Forestal, Santiago de Chile. Etienne, M., Michea, G. and Diaz, E. (1982). Flora, Vegetación y Potencial Pastoral de Isla de Pascua. Boletin Técnico no. 47, Universidad de Chile Facultad de Ciencias Agrarias, Veterinarias y Forestales, Santiago, Chile.

UNEP/IUCN (1988). Coral Reefs of the World. Volume 1. Atlantic and Eastern Pacific. UNEP Regional Seas Directories and Bibliographies. IUCN, Gland, Switzerland and Cambridge, UK/UNEP, Nairobi, Kenya. 420 pp.

Date June 1981, reformatted and updated February 1990

\section{NEW ZEALAND \\ Raoul Island and Kermadec Group Nature Reserve}

IUCN Management Category I (Strict Nature Reserve)

Biogeographical Province 5.05.13 (Central Polynesian)

Geographical Location $1,000 \mathrm{~km}$ north-east of North Cape. Approximately $29^{\circ} 32^{\prime} \mathrm{S}, 177^{\circ} 18^{\prime} \mathrm{E}$

Date and History of Establishment 1934. Designated as a marine reserve during 1990, coincident with the increase in size.

Area 3,089ha. Enlarged during 1990 to 735,000 ha.

Land Tenure No information

Altitude 0-516m

Physical Features Comprises two large islands, Raoul and Curtis, covering 2,938ha and 306ha, respectively, and 15 small islands and islets of the Kermadec Archipelago. Islands are summits of young, steep-sided volcanic cones, dissected by ungraded streams. Raoul has a large crater with three lakes, one hot and mineralised. Rocks are basalt, basaltic andesite, obsidian gabbro and diorites capped by pumice ash. Soils comprise fertile yellow-brown loam and recent soil from volcanic ash, colluvium and alluvium. Raoul Island has erupted three times since discovery by the French in 1773, the last eruption occurring in 1964.

Climate Mild, subtropical with mean annual rainfall of $1473 \mathrm{~mm}$

Vegetation Coastal vegetation on unstable talus comprises soft brome, iceplant, Jersey cudweed and salt-tolerant herbs. Coastal scrub includes Kermadec ngaio Coprosma petiolata-Cyperus ustulatus. Below $244 \mathrm{~m}$, Kermadec pohutukawa-Kermadec mapou dry forest occurs, and pohutukawa/hutu wet forest at the highest altitudes. There are 23 endemic plant species or subspecies, and 12 threatened plants, as follows: Coprosma acurifolia, Homalanthus polyandrus, 
Pseudopanax arboreus var. kermadecensis, Boehmeria australis var. dealbata, Senecio lautus esperensis, Pisonia brunoniana, Ipomoea pes-caprae brasiliensis, Cook's scurvy grass Rorippa gigantea, Nephrolepis cordifolia, Macrothelypteris torresiana, Christella dentata. Endemic Hebe breviracemosa survives as a single specimen in the wild, with a number of plants in cultivation.

Fauna Thirty-five bird species have been reported from the islands, and twenty are known to breed, including Kermadec petrel Pterodroma neglecta, white-necked petrel $\boldsymbol{P}$. externa, black-winged petrel $P$. nigripennis, wedge-tailed shearwater $P$ uffinus pacificus and sooty tem Sterna fuscata. Anthropod fauna is poor and fragmentary (Anon., 1984; W. Murray, pers. comm., 1990). Some 112 coastal fish species have been recorded in the Kermadecs, with three being endemic to the islands. A feature of the marine ecology of particular interest is the lack of coral reefs, even though reef building corals are common. The sub-tidal habitat is, therefore, a part-tropical, part-temperate transitional habitat. This complex of different elements is uncommon, and possibly unique worldwide (Anon., 1987).

Cultural Heritage Maori legends tell of Rangitahua, at which canoes called on the long voyage to New Zealand. Since the Maoris are thought to have come from the general region of the Society Islands, it is likely that the Kermadecs, particularly Raoul Islands, were a stopping place on the way to New Zealand.

Some history of early whaling is known, although no actual onshore whaling occurred. There may have been many attempts to colonise Raoul Island since approximately 1940 (W. Murray, pers. comm., 1990).

\section{Local Human Population None}

\section{Visitors and Visitor Facilities None}

Scientific Research and Facilities Research is undertaken by specialised scientific officers under the jurisdiction of the Department of Conservation. Conservation officers based on Raoul Island monitor the temperature of the lakes, keep seismological recordings, take air samples for analysis and compile daily meteorological reports (W. Murray, pers. comm., 1990).

\section{Conservation Value No information}

Conservation Management An eradication scheme is being undertaken to control noxious plants such as mysore thom Caesalpinia decapetala, African olive Olea africana, purple guava Psidium littorale and Mauritius hemp Furcraea foetida.

Management Constraints Goats had been introduced to Macauley and Raoul islands by 1836 and have posed a serious threat to the flora and fauna. However, goats have now been eradicated. Cat and Norwegian rat Rattus norvegicus are present on Raoul. Polynesian rat $R$. exulans exists on Raoul and Macauley islands. Endemic species on Raoul Island are now endangered by rats and cats (W. Murray, pers. comm., 1990).

Staff Four conservation officers are stationed on Raoul Island.

\section{Budget No information}

Local Addresses Department of Conservation, Auckland Conservancy Office, Private Bag No. 8, Newton, Auckland, New Zealand 


\section{References}

Anon. (1984). Register of Protected Natural Areas in New Zealand. Department of Lands and Survey, Wellington. $457 \mathrm{pp}$.

Anon. (1987). Kermadec Islands Marine Reserve proposal. SPREP Environment Newsletter. April-June. P. 8.

Date March 1990, updated January 1991

\section{UK \\ Pitcairn Islands - Henderson Island}

Name Henderson Island

IUCN Management Category X (World Heritage)

Biogeographical Province 5.04.13 (Southeastern Polynesian)

Geographical Location Henderson Island is the largest island in the Pitcairn Island group, one of the remotest groups of islands in the South Pacific, with no major landmass within a 5,000km radius. The group comprises four islands, with Henderson lying $200 \mathrm{~km}$ east-north-east of Pitcairn, 200km east of Oeno and $360 \mathrm{~km}$ west of Ducie. Only Ducie, and the Chilean islands of Rapa Nui (Easter Island) and Sala y Gomez lie further to the east within Polynesia. Approximately $24^{\circ} 22^{\prime} \mathrm{S}, 128^{\circ} 20^{\prime} \mathrm{W}$

Date and History of Establishment Henderson Island has not been declared a protected area as such, although it receives de facto protection from its isolation, and various restrictions on possession, occupation and transference of lands applied under the Lands and Administration of Estates Ordinance. Some wildlife protection is provided by part IV of the Local Government Regulations. Inscribed on the Unesco World Heritage List in 1988.

Area Land area $3,700 \mathrm{ha}$

Land Tenure The Pitcaim Island group is a Dependent Territory of the United Kingdom, and Henderson is Crown Land.

Altitude Up to a maximum of $33 \mathrm{~m}$

Physical Features Henderson is an elevated coralline limestone ("makatea") island which rises as an isolated conical mound from a depth of about $3,500 \mathrm{~m}$, and is presumably a reef-capped volcano. The surface of the island is in large part reef-rubble interspersed with areas of dissected limestone, surrounded by steep limestone cliffs undercut on all sides except to the north. There are three main beaches, to the north, north-west and north-east. Tidal range at spring tides is probably about $1 \mathrm{~m}$, and tides are semidiumal. The central depression is considered to be an uplifted lagoon. Freshwater is almost completely absent, only occurring as drippings in caves, and as a spring below high tide level in the north (flow and permanence unknown). The geology of the island is summarised by Fosberg et al. (1983), who conclude that the limestones are of late Tertiary age. It is also suggested that much of the inland topography may be karst features. 
There is a fringing reef at least $200 \mathrm{~m}$ wide to the north, north-west and north-east sides of the island, backed by a wide beach (St John and Philipson, 1962). Reefs off the north and north-east beaches are seawardly sloping reef platforms without reef crests, and are not typical fringing reefs. Coral cover is about 5\%, dominated by Pocillopora with Millepora becoming dominant at depths greater than $7 \mathrm{~m}$ (Paulay, 1987). Submassive Acropora colonies are also present on the buttresses and solid substratum (Richmond in litt., 1987). In total, 19 genera and 29 species of coral were collected in 1987 (Paulay, 1987). There are two narrow channels through the reef on the north and north-western coasts (Serpell et al., 1983).

Climate Henderson lies in the south-east trades and probably has a mean annual rainfall of around $1500 \mathrm{~mm}$. No meteorological records are available.

Vegetation The vegetation of the island has not been modified to any significant extent, and most of the surface of the island is densely vegetated with tangled scrub and scrub forest $5 \mathrm{~m}-10 \mathrm{~m}$ tall. The central part of the depression is more sparsely covered. The flora is described by St John and Philipson (1962), Fosberg et al. (1983) and Flenley et al. (1987). The island has a high degree of endemicity for its size; out of a total of 51 native flowering plant taxa, ten are endemic. The tallest trees are screw-pine Pandanus tectorius, and other trees include the endemics Santalum hendersonense, Myrsine hoskae, Celtis paniculata var. viridis, and two endemic varieties of Bidens hendersonensis. The last-named species is of particular botanical interest as a woody member of a mainly herbaceous genus, and also because of its isolation from related genera within the Compositae.

Fauna Fauna recorded from the island are listed in Fosberg et al. (1983), and variously commented on by other visitors. There are no native species of land mammal. All four of the island's land birds are endemic, comprising flightless Henderson rail Nesophylax ater, Stephen's lorikeet Vini stepheni (R), Henderson fruit dove Ptilinopus insularis, and Henderson warbler Acrocephalus vaughani taiti. Very little information is available on either the ecology or the status of these four birds. Fifteen seabirds have been recorded, at least nine of which are thought to breed on the island (Williams, 1960; Boume and David, 1983); Murphy's petrel Pterodroma ultima, phoenix petrel $P$. alba, herald petrel $P$. arminjoniana, Kermadec petrel $P$. neglecta, shearwater Puffinus pacificus, masked booby Sula dactylatra, red-tailed tropicbird Phaethon rubicauda, brown noddy Anous stolida, blue-grey noddy Procelsterna caerulea, and fairy tem Gygis alba. Bourne and David (1983) provide a species list with detailed annotation. Other terrestrial species are also poorly recorded and understood (including lizards and skinks as well as invertebrates), and it is likely that the invertebrate fauna is much larger, including several more endemics. For example, a new species of hawk-moth has recently been identified.

Various records of the marine and littoral fauna have been made by Paulay (1987), and by Broodbakker (in litt., 1981; 1987) and Richmond (in litt., 1987), and a list of marine molluscs recorded from Henderson is given in Fosberg et al. (1983). Species of particular note include coconut crab Birgus latro (R) (identified from remains collected in 1987), at least two coenobite species (one of which was found to be the commonest crustacean on the island in 1987), and spiny lobster Panulirus penicillatus (CT). Green turtle Chelonia mydas (E) occasionally nests on the island (Fosberg et al., 1983). Collections of marine molluscs and sponges and of as yet unidentified caridean shrimps (mostly Alpheids, probably comprising 5-8 species), were made in 1987. There is a diverse echinoderm fauna. An unidentified holothurian is common on the northern reef flats, and an echinoid Heterocentrotus sp. (possibly $\boldsymbol{H}$. trigonarius) is locally abundant on the sloping marginal reefs and shallow reef flat of the northern beach. Fish are sparse, with Caranx lugubris being the most common and obvious species. A more comprehensive account of the corals is given in UNEP/IUCN (1988). 
Cultural Heritage The history of the island, which has been uninhabited apart from occasional visitors, is described in Fosberg et al. (1983). Recently discovered archaeological remains suggest that Henderson was colonised by Polynesians between the 12 th and 15 th centuries (Sinoto, 1983), but their impact would appear to have been slight, although there is some disagreement over this (Steadman and Olson, 1985; Bourne and David, 1986).

Local Human Population The island is visited by Pitcaim islanders once or twice each year, chiefly to cut "miro" Thespesia populnea and tao from which carvings are made for sale to visitors to Pitcairn, and sandalwood Santalum hendersonense.

Visitors and Visitor Facilities Cruise ships visit occasionally (M. de L. Brooke, pers. comn., 1990).

Scientific Research and Facilities Fosberg et al. (1983) summarise scientific expeditions to the island, of which the two most important were the Whitney South Sea Expedition in 1922 and the Mangarevan Expedition of 1934. They also summarise the published information, and provide nearly 100 references. The island was visited by Operation Raleigh in spring 1987 and by an expedition from the Smithsonian Institution in the same year.

Conservation Value Henderson is the world's best remaining example of an elevated coral atoll ecosystem and is thought to be of outstanding value in this regard (Fosberg and Sachet, 1983). It remains in an undisturbed state, largely as a result of its remoteness, and its inhospitable nature. It has suffered little from human modification, and few introduced species exist so the biota has escaped the fate of similar species on other oceanic islands.

Conservation Management Access to Henderson requires a licence issued by the Governor following approval by the Pitcairn Island Council (Foreign and Commonwealth Office, 1988). However, the island has no formal conservation status and there is no specific body charged with conservation. There is no management plan for the island, and no active management, although the Foreign and Commonwealth Office (1988) suggests that little management would be required beyond the possible removal of exotic species.

Management Constraints Goats and pigs were introduced to the island early in the century, but have fortunately not survived (and the keeping of goats on Henderson is now prohibited). Introduced rats are still present, although this is Polynesian rat Rattus exulans, rather than black or brown rat. The terrestrial vegetation is still largely pristine, with very few exotics, although there are two substantial coconut groves at the principal landing sites (Paulay, 1987), and Cordyline terminalis and Aleurites moluccana have also been deliberately introduced, and Achyranthes aspera accidentally.

In 1982/1983 the island was potentially under severe threat as a result of a proposal by a wealthy American to build a house, landing facilities and airstrip (Fosberg and Sachet, 1983). A resolution at the 15th Pacific Science Congress in 1983 urged the British Government not to permit the proposed development before a detailed biological survey had been carried out and an assessment of the impacts made. The proposal was opposed by scientific and conservation bodies who petitioned the British Government to deny permission to carry out these plans (Serpell et al., 1983). This they subsequently did and the island was successfully nominated for inclusion in the World Heritage List in 1988. Had such plans gone ahead, the terrestrial fauna and flora would undoubtedly have been severely damaged, with likely resulting impacts on the reefs (Serpell et al., 1983).

\section{Staff None}




\section{Budget None}

Local Addresses Pitcaim Island Council, although ultimate authority rests with the Governor, c/o British High Commission, PO Box 1812, Wellington, New Zealand

\section{References}

Bourne, W.R.P. and David, A.C.F. (1983). Henderson Island, Central South Pacific, and its birds. Notornis 30: 233-252.

Bourne, W.R.P. and David, A.C.D. (1986). Henderson Island. Letter to Nature 322: 302.

Flenley, J., Parkes, A. and Johnson, M. (1987). Vegetation survey of Henderson Island. Unpublished report to Operation Raleigh, London.

Foreign and Commonwealth Office (1988). Nomination of Henderson Island for inclusion in the World Heritage List. Submitted by The Secretary of State for Foreign and Commonwealth Affairs, United Kingdom. Prepared by S. Oldfield. Produced by the Nature Conservancy Council. $21 \mathrm{pp}$.

Fosberg, F.R. (1984). Henderson Island saved. Environmental Conservation 11(2): 183-184.

Fosberg, F.R. and Sachet, M.-H. (1983). Henderson Island threatened. Environmental Conservation 10(2): 171-173.

Fosberg, F.R., Sachet, M.-H. and Stoddart, D.R. (1983). Henderson Island (south-eastem Polynesia): summary of current knowledge. Atoll Research Bulletin $272.53 \mathrm{pp}$.

Oldfield, S. (1987). Fragments of Paradise. Pisces Publications, Oxford. 192 pp.

Paulay, G. (1987). Comments on the Pitcairn Islands. Unpublished report. 2 pp.

St John, H. and Philipson, W.R. (1962). An account of the flora of Henderson Island, South Pacific Ocean. Transactions of the Royal Society of New Zealand 1: 175-194.

Serpell, J., Collar, N., Davis, S. and Wells, S. (1983). Submission to the Foreign and Commonwealth Office on the future conservation of Henderson Island in the Pitcairn Group. Unpublished Report, WWF-UK, IUCN, ICBP. This report has 24 letters annexed to it in support of the report's conclusions that settlement on the island would be inappropriate.

Sinoto, Y.S. (1983). Analysis of Polynesian migrations based on archaeological assessments. J. Soc. Océanistes 39: 57-67.

Steadman, D.W. and Olson, S.L. (1985). Bird remains from an archaeological site on Henderson Island, South Pacific: Man-caused extinctions on an "uninhabited" island. Proceedings of the National Academy of Science, USA 82: 6191-6195.

UNEP/IUCN (1988). Coral Reefs of the World. Volume 3. Central and Western Pacific. UNEP Regional Seas Directories and Bibliographies. IUCN, Gland, Switzerland and Cambridge, UK/UNEP, Nairobi, Kenya. 378 pp.

Williams, G.R. (1960). The birds of the Pitcairn Islands, Central Pacific Ocean. Ibis 102: 58-70.

Date Revised April 1988, May 1990

USA

Outlying Islands

Name Baker Island National Wildlife Refuge

IUCN Management Category IV (Managed Nature Reserve) 
Biogeographical Province 5.02.13 (Micronesian)

Geographical Location 2,657 km south-west of Honolulu and $500 \mathrm{~km}$ north-west of the Phoenix Islands, close to Howland Island. Approximately $0^{\circ} 13^{\prime} \mathrm{N}, 176^{\circ} 29^{\prime} \mathrm{W}$

Date and History of Establishment July 1974

Area 11,583ha comprising $124 \mathrm{ha}$ land and $11,459 \mathrm{ha}$ reef

Land Tenure Federal Government

Altitude Estimated at 5-8m

Physical Features A low-lying oval-shaped island. There is no fresh water on the island.

Climate Very low rainfall and fairly steady winds

Vegetation Mainly low grasses, sparse low brush, and prostrate herbs and vines. Species include Sida sp. and purslane Portulaca lutea, the vine-like Triumfetta procumbems, Boerhavia diffusa, puncture vine Tribulus cistoides and grass Digitaria pacifica.

Fauna Eleven migratory seabirds and four migratory shorebirds have been identified. An estimated 7,000 birds of six species were observed nesting in 1973. These include sooty tem Sterna fuscata, blue-faced booby Sula dactylatra brown and red-footed booby $S$. sula and lesser frigate birds Fregatta ariel. Green turtle Chelonia mydas (E) has been observed inshore. A diverse fringing coral reef surrounds the island.

Cultural Heritage No information

Local Human Population The island was colonised in 1935, then occupied by American troops during World War Two, when an airstrip was constructed. Since then it has been uninhabited.

Visitors and Visitor Facilities No information

Scientific Research and Facilities Occasional wildlife monitoring trips are made by the US Fish and Wildlife Service. There are no facilities.

Conservation Value No information

Conservation Management In 1986 the US Army Corps of Engineers sponsored a survey and complete clean-up of oil and fuel on the island. Some 400 of the 3,400 barrels on the island contained oil or fuel which was burned in situ, and the drums were turned onto their sides to prevent sea birds falling into them. Cat eradication programmes have apparently been successful (USACE, 1987).

Management Constraints Guano mining occurred in the late 1800 s. Birds were nearly eradicated during the war but are now recovering.

\section{Staff None}

Budget Approximately US $\$ 527,000$ for refuge complex administration, protection, natural science studies, interpretation and maintenance budgeted for fiscal year 1981.

Local Addresses Hawaiian Islands and Pacific Islands National Wildlife Refuge Complex, US Fish and Wildlife Service, PO Box 50167, Honolulu, HI 96850, USA 


\section{References}

Bryan, E.H. Jr. (1942). American Polynesia and the Hawaiian Chain. Elepaio, the Journal of the Hawaii Audubon Society. Tongg Publishing Co. $253 \mathrm{pp}$.

USACE (1987). Defense restoration account inventory project report: Baker Island National Wildlife Refuge, Baker Island. Project No. H09HI000700, Ft. Shafter, Honolulu. (Unseen).

Date 1981, updated 1991

\section{Howland Island National Wildlife Refuge}

\section{IUCN Management Category IV (Managed Nature Reserve)}

Biogeographical Province 5.02.13 (Micronesian)

Geographical Location $2,657 \mathrm{~km}$ south-west of Honolulu and $500 \mathrm{~km}$ north-west of the Phoenix Islands close to Baker Island. Approximately $0^{\circ} 48^{\prime} \mathrm{S}, 176^{\circ} 38^{\prime} \mathrm{W}$

Date and History of Establishment July 1974.

Area $11,823 \mathrm{ha}$, comprising $89 \mathrm{ha}$ land and $11,734 \mathrm{ha}$ reef

Land Tenure Federal government

\section{Altitude 4-5m}

Physical Features A low-lying elongated island oriented in a north-south direction. It is approximately $2.4 \mathrm{~km}$ long, by $0.3 \mathrm{~km}$ wide. The substrate is of sand, coral rubble and flat sheets of guano covered rock and it is surrounded by a $100 \mathrm{~m}$-wide fringing coral reef. There is no fresh water on the island.

Climate Windy and sunny, with low rainfall

Vegetation Almost entirely grasses, prostrate vines or herbs and low shrubs. The principal grass species are Digitaria sp. and Lepturus sp.; vines include puncture vine Tribulus cistoides and Triumfettia procumbens; and herbs include Boerhavia diffusa. Purslane Portulaca sp. is also found.

Fauna An estimated 200,000 sooty tern Sterna fuscata, 6,000 lesser frigate bird Fregata ariel, 1,000 blue-faced booby Sula dactylatra, together with a smaller number of red-footed booby Sula sula, brown booby S. leucogaster and white tern Gygis alba nest here. In addition, blue-grey noddy Procelsterna cerutea, wedge-tailed shearwater Puffinus pacificus, phoenix petrel and white-throated storm petrel Nesofregatta fuliginosa are also present. In total, some 26 species of seabird are known from the island. Threatened green turtle Chelonia mydas $(\mathrm{E})$, together with numerous fish and invertebrate species, inhabits the surrounding coral reef.

Cultural Heritage No information

Local Human Population The island was colonised in 1935 and American troops occupied the island in World War Two. Except for rare visits by scientists and Coast Guard, the island has been uninhabited since the war. An airfield was built in 1937 but is no longer serviceable.

Visitors and Visitor Facilities No information 
Scientific Research and Facilities Isolation presents severe logistical problems, but occasionally scientists visit to monitor the wildlife population. There are no facilities.

Conservation Value No information

Conservation Management A cat eradication programme has been apparently successful. In 1986 the US Army Corps of Engineers turned the 12 or so fuel drums on their side to prevent sea birds falling into them (USACE, 1987).

Management Constraints Feral cats had previously decimated phoenix petrel Pterodrama alba populations, prior to control measures. Guano was mined in the 1800 s. Although present since human occupation, Polynesian rat has not harmed the bird population.

Staff No staff assigned

Budget Approximately US $\$ 527,000$ for refuge complex administration, protection, natural science studies, interpretation, and maintenance budgeted for fiscal year 1981.

Local Addresses Hawaiian Island and Pacific Island National Wildlife Refuge Complex, PO Box 50167, Honolulu, HI 96850, USA

\section{References}

Bryan, E.H., Jr. (1942). American Polynesia and the Hawaiian Chain. Elepaio, the Journal of the Hawaiian Audubon Society. Tongg Publishing Co. 253 pp.

USACE (1987). Defense restoration account inventory project report: Howland Island National Wildlife Refuge, Baker Island. Project No. H09H1000700, Ft. Shafter, Honolulu. (Unseen).

Date 1981, updated 1991

\section{Jarvis Island National Wildlife Refuge}

\section{IUCN Management Category IV (Managed Nature Reserve)}

Biogeographical Province 5.04.13 (South eastem Polynesian)

Geographical Location 2,093km due south of Honolulu, in the Line Islands, about $300 \mathrm{~km}$ south-west of Kiritimati (Christmas Island). Approximately $0^{\circ} 22^{\prime} \mathrm{S}, 160^{\circ} 01^{\prime} \mathrm{W}$

Date and History of Establishment July 1974

Area Total of $15,189 \mathrm{ha}$, comprising $445 \mathrm{ha}$ land, $14,744 \mathrm{ha}$ reef and water

Land Tenure Federal government under jurisdiction of US Department of the Interior

Altitude $6-8 \mathrm{~m}$

Physical Features A low-lying sandy island, $3 \mathrm{~km}$ long and $1.6 \mathrm{~km}$ wide, with a coral-reef rock base. A $100 \mathrm{~m}$ wide shallow fringing coral reef encircles the island. There is no freshwater present on the island.

Climate No specific information 
Vegetation No trees or high bushes. Dominant vegetation consists of prostrate creepers, such as puncture vine Tribulus cistoides and Boerhavia sp., low succulents, Sesuvium portulacastrum and Portulaca lusea, grasses Lepturus repens and low sparse shrubs such as Sida spp. and Abutilon spp.

Fauna Red-footed booby Sula sula, blue-faced booby $S$. dactylatra, lesser frigatebind Fregatta ariel, great frigatebird $F$. minor and sooty tern Sterna fuscata are among the most common of eight nesting seabirds; six other seabird species visit. The threatened green turtle Chelonia mydas (E), and a variety of invertebrates and fish, is present in the surrounding coral reef.

Cultural Heritage No information

Local Human Population Guano was mined between 1857 and 1879. The island was colonised in 1935 but abandoned in World War Two, and is at present uninhabited.

Visitors and Visitor Facilities No information

Scientific Research and Facilities An annual survey of birds, other wildlife and the plant population is made. Other studies were undertaken during International Geophysical Year. There are no facilities.

Conservation Value No information

Conservation Management No information

Management Constraints Feral cats have now been eliminated from the island, but not before they decimated the petrel population.

\section{Staff None}

Budget Approximately US $\$ 527,000$ for refuge complex administration, protection, natural science studies, interpretation and maintenance budgeted for fiscal year 1981.

Local Addresses Hawaiian Island and Pacific Island National Wildlife Refuge Complex, US Fish and Wildlife Service, PO Box 50167, Honolulu, HI 96850, USA

\section{References}

Bryan, E.H., Jr. (1942). American Polynesia and the Hawaiian Chain. Elepaio, the Journal of the Hawaii Audubon Society. Tongg Publishing Co. 253 pp.

Date 1981, reviewed March 1991

\section{Johnston Atoll National Wildlife Refuge}

\section{IUCN Management Category Unassigned}

Biogeographical Province 5.02.13 (Micronesian)

Geographical Location Over 1,320km south-west of Honolulu, between the Hawaiian islands to the north and the Line and Phoenix islands to the south. The nearest island to the atoll is the French Frigate shoals, mid-way along the Hawaiian island chain. $16^{\circ} 41^{\prime}-16^{\circ} 47^{\prime} \mathrm{N}$, $169^{\circ} 24^{\prime}-169^{\circ} 34^{\prime} \mathrm{W}$ 
Date and History of Establishment Created a Federal bird refuge in 1926 under a Presidential Executive Order to protect the vast population of breeding seabirds, and has since been placed under the jurisdiction of the military authorities.

Area 13,252ha; comprising 13,000ha marine and 252ha terrestrial (Johnston Island, 231 ha; Sand Island, 9ha; and the artificial islands of Akau, 7ha; and Hikina, 5ha)

Land Tenure US Federal Government; under the jurisdiction of a joint military task force, except for Sand Island which is administered as a LORAN station by the US Coast Guand (Amerson and Shelton, 1976). The islands have been under military jurisdiction (initially US Navy and subsequently US Air Force) since 1936, with the Defence Nuclear Agency assuming operational control in 1973. The bird refuge is under the Department of the Interior.

Altitude Below sea level to $4.5 \mathrm{~m}$ (Summit Peak on Johnston Island rose to $14 \mathrm{~m}$ before the island was levelled by military engineers).

Physical Features The isolated atoll comprises a coral platform, with over $130 \mathrm{sq} . \mathrm{km}$ submerged under less than $30 \mathrm{~m}$; a marginal reef, only exposed at low tide extends for $14 \mathrm{~km}$ along the north-west margin. The platform is supported on a submerged mountain (of the Hawaiian or Christmas Ridges) of volcanic origins. Johnston and Sand islands lie on a small, shallow ridge extending west-east from the western end of the marginal reef and enclosing a lagoon some 3-9m deep. Military occupation and construction during the past forty years has dramatically altered the physiography of the atoll and little of the original habitat remains. Of the four islands, only two are natural, but extensively modified. Of these, Johnston Island is the largest; some four times the size of Sand Island. Both were formed of wind-transported beachrock-sand and gravel, cemented together by calcium carbonate and loose sand. Between 1939 and 1942 Johnston Island was levelled (formerly, it rose to $14 \mathrm{~m}$ at the north-west end) and enlarged to 85ha. An artificial islet was built near Sand Island constructed from coral material dredged from the lagoon when clearing deep ship channels and seaplane landing areas. By 1944 Johnston Island was fully developed as an airforce base, with a runway, buildings and gun emplacements (since removed). Another period of construction work (1963-64) further enlarged Johnston and Sand islands, extended the runway, and produced the totally artificial islands of Akau (North) and Hikina (East) in the lagoon. The present surfaces of Johnston, Akau and Hikina, together with the artificial part of Sand Island, consist of hard packed coral debris, ranging in size from sand to cobble stones. The interior of Sand Island is covered with deep, loose coral sand, bound by grass roots and perforated by burrows of wedge-tailed shearwater, a layer of beachrock is exposed around most of the island perimeter. No freshwater is available on the atoll.

Climate Tropical and marine, with little variation in temperature $\left(26^{\circ} \mathrm{C}\right.$ mean annual temperature; minimum of $16.5^{\circ} \mathrm{C}$ in October and maximum of $31.5^{\circ} \mathrm{C}$ in July/November) or windspeed, but considerable variation in rainfall, both yearly and seasonal. The mean annual rainfall is $663 \mathrm{~mm}$, though extremes of $1085 \mathrm{~mm}$ (1968) and $435 \mathrm{~mm}(1969)$ have been recorded. Rainfall is greatest during the winter months, December to March, when winds are most variable. The easterly trade winds are at their strongest during the summer, April to November.

Vegetation Vegetation on the modified and artificial areas is restricted to sparse lawns, scattered bushes and trees, and sparsely distributed weed species on the least disturbed parts. The interior of Sand Island supports bunch grass.

Fauna There are no native mammals on the islands; of the six recorded, five were introduced by man; house mouse Mus musculus, rat Rattus rattus, domestic dog Canis familiaris, domestic cat $F$ elis domesticus and European rabbit Oryctolagus cuniculus. Hawaiian monk seal Monachus 
schauinslandi (E) migrated from Hawaii and established breeding in the 1960s. The undisturbed area of Sand Island is of major importance for its breeding populations of sooty tern Sterna fuscasa. Red-footed booby Sula sula, brown noddy Anous stolidus, wedge-tailed shearwater $P$ uffinus pacificus and great frigatebird $F$ regata minor breed in significant numbers. Blue-faced booby Sula dactylatra, Laysan albatross Diomedea immutabilis and black-footed albatross $D$. nigripes stopped breeding on the atoll because of the high level of human disturbance; now they are only occasional visitors. In all some 56 species of bird have been recorded. During the breeding season up to 600,000 birds may be present on the atoll. Of the 34 species of waterfowl, marsh and land bird recorded seven are regular migrants, including bristle-thighed curlew Numenius tahitiensis (R), which is threatened in its Alaskan breeding territory. Of the five species of reptile known from the islands all but one, green turtle Chelonia mydas (E), were introduced by man. Some 194 species of fish have been identified from the atoll lagoon. Two of these species have not been collected from anywhere else in the Pacific and are possibly endemic, namely butterfly fish Centropyge nigriocellus and $C$. flammeus. The invertebrate fauna has not been extensively studied with most collections being of the phyla Cnidaria (18 species), Mollusca (58 species), Annelida (12 species), Arthropoda (75 species) and Echinodermata (37 species). A summary description of the coral reefs is given in UNEP/IUCN (1988). Amerson and Shelton (1976) give a checklist for all the major faunal groups.

\section{Cultural Heritage No information}

Local Human Population This uninhabited atoll was discovered in 1796 and claimed by the United States in 1858. It remained uninhabited, except for occasional visits by guano miners, until 1936, when it was developed as a military base. It was an important US Naval base throughout World War Two, after which it was maintained as a lower grade "naval air facility". The atoll was used as a test area during the atmospheric nuclear tests of the 1950s-1962. In the early 1970s the atoll began to be used for the storage of various obsolete chemicals. In 1976 the following groups were based on the atoll, 25 members of the US Coast Guard (maintaining the LORAN transmitter), US Air Force and Navy units, personnel of the Air Force Defence Command Space Systems Command and Pacific Missile Range.

\section{Visitors and Visitor Facilities No information}

Scientific Research and Facilities A number of studies have been carried out on the atoll and these are summarised in Amerson and Shelton (1976) and UNEP/IUCN (1988). The military installations provide some research facilities.

\section{Conservation Value No specific information}

Conservation Management The atoll is divided into three areas operated by different government/military agencies: natural area, under the Department of Interior, US coastguard LORAN station; and a US military toxic chemical storage area. There is no management, although during the nuclear tests of the 1950s elaborate measures were taken to safeguard the bird colonies; a water sprinkler system was set up, smoke pots were placed upwind to act as a shade screen and aerial flares were let off to divert the birds attention from the nuclear flash. In May 1974 the Environmental Protection Agency began to consider how to safely dispose of the hazardous chemicals stored on Johnston Island.

Management Constraints The coral reef, benthic communities and terrestrial habitats are seriously degraded in places and the high level of human disturbance has resulted in at least three species of seabird no longer breeding on the atoll. There has been extensive dredging and sedimentation. It has been a military base since 1934. Most of the buildings and gun 
emplacements installed during World War Two were removed in the 1950 s, but, with its continuing occupation, there are still accommodation facilities, roadways and an elaborate LORAN transmitting structure on Sand Island. Following the atomic tests of the 1950s there has inevitably been some contamination of both terrestrial and marine biotas by radioactive substances, together with leaks of chemicals. The construction work led to extensive modification, both of the terrestrial habitat as well as the marine areas.

The major threat to the environment is the military storage area where various chemicals (herbicides, poisonous gases, etc), left over from recent wars, are kept. An accident in which stored Agent Orange defoliant was spilt has left areas contaminated. Facilities on the Atoll were to be developed for the destruction of some 100,000 chemical warheads (7,000 tons), previously deployed in Europe. There has been concern in the region that these activities may lead to serious environmental impacts (Brown, 1990) although it is not known if they will go ahead. In view of the extensive military activities on the atoll, and the threat posed by the storage and disposal of chemical munitions, no IUCN management category has been assigned.

Staff No information

Budget No information

Local Addresses Hawaiian Island and Pacific Island Wildlife Refuge Complex, US Fish and Wildlife Service, PO Box 50167, Honolulu, HI 96850

\section{References}

Amerson, A.B. and Shelton, P.C. (1976). The natural history of Johnston Atoll, Central Pacific Ocean. Atoll Research Bulletin 192. 385 pp. (Includes a bibliography).

Bugglen, R.G. and Tsuda, R.T. (1966). A preliminary marine algal flora from selected habitats on Johnston Atoll. Technical Report 9: 1-29. Hawaii Institute of Marine Biology.

Brown, P. (1990). Hell fire in the Pacific. The Guardian July 27. Pp. 21.

Bugglen, R.G. and Tsuda, R.T. (1969). A record of benthic marine algae for Johnston Atoll. Atoll Research Bulletin 120: 1-20.

Date 1981, updated 1991 



\section{GEOGRAPHICAL INDEX}

Ahihi-Kinau, 355

American Samoa (USA), 285

American Samoa National Park, 292

Anao Conservation Reserve, 308

Aore Recreational Reserve, 380

Aoupinie Special Fauna Reserve, 67

Amavon Wildlife Sanctuary, 248

Asuncion Island Preserve, 144

Atoll de Taiaro (Reserve Integrale W.A.

Robinson), 51

Bagiai Wildlife Management Area, 182

Baiyer River Sanctuary, 183

Baker Island National Wildlife Refuge, 422

Bikar Atoll, 124

Bimie Island Wildlife Sanctuary, 100

Bokaak (Taongi) Atoll, 127

Bucaro Aore Recreational Park, 381

Cape Wom International Memorial Park, 185

Colo-i-Suva Forest Park, 33

Commonwealth of the Northern Mariana Islands, 139

Cook Islands, 1

Cook Islet Closed Area (Kiritimati WS), 107

Easter Island (Rapa Nui) National Park, 415

Eiao Island Nature Reserve, 53

Faaiti, Parc Naturel Territorial de 55

Fagatele Bay National Marine Sanctuary, 293

Fanga'uta and Fanga Kakau Lagoon, 267

Federated States of Micronesia, 21

Fiji, 25

France - French Polynesia, 45

France - New Caledonia, 59

France - Wallis And Futuna, 89

Garu Wildlife Management Area, 186

Guam (USA), 301

Guam Territorial Seashore Park, 309

Guguan Island Preserve, 146

Ha'atafu Beach Reserve, 271

Hakaumama'o Reef Reserve, 272

Haleakala National Park, 339

Hanawi, 355

Hansa Bay Marine Park, 189

Haputo Ecological Reserve Area, 313

Haute Yate Special Fauna Reserve, 71

Hawaii (USA), 327

Hawaii Volcanoes National Park, 344

Hawaiian Islands National Wildlife Refuge, 342

Henderson Island, 419

Hono O Na Pali, 356

Honouliuli Preserve, 365

Horseshoe Reef Marine Park, 191

Howland Island National Wildlife Refuge, 424

Huvalu Tapu Forest, 136

'Ihi'ihilauakea Preserve, 365

J.H. Garrick Memorial Reserve, 34

Jarvis Island National Wildlife Refuge, 425

Johnston Island National Wildlife Refuge, 426

Kaena Point, 356

Kahaualea, 357

Kakerori Reserve, 10

Kalaupapa National Historical Park, 349

Kaloko-Honokohau National Historical Park, 351

Kaluahonu Preserve, 366

Kamakou Preserve, 366

Kanepu'u Preserve, 367

Kapunakea Preserve, 367

Kermadec Group Nature Reserve, 417

Kingdom of Tonga, 257

Kipahoehoe, 357

Kiribati, 93

Kiritimati Wildlife Sanctuary, 102

Kuia, 358

La Chute de la Madeleine Special Botanical Reserve, 69

Lake Dakataua National Park, 194

Lake Hargy National Park, 195

Lake Lavu Wildlife Management Area, 197

Laupahoehoe, 358

Lea Lea Salt Flats Marine Park, 198

Lepredour Islet Special Fauna Reserve, 73

Lord Howe Island Group, 409

Lou Island Wildlife Management Area, 199

Maitre Islet Fauna and Flora Reserve, 79

Malden Island (Closed Area) Wildlife

Sanctuary, 108

Malinoa Island Park and Reef Reserve, 274

Manuka, 359

Marine Fauna Rotating Reserve, 81 
Marshall Islands, 157

Masso River Reservoir Area Natural Reserve, 315

Maug Island Preserve, 148

Maui Lava Tubes Preserve, 368

Mauna Kea Ice Age, 359

Maza Wildlife Management Area, 200

McAdam National Park, 202

McKean Island Wildlife Sanctuary, 110

Mo'omomi Preserve, 368

Mojirau Wildlife Management Area, 204

Mont Humboldt Special Botanical Reserve, 74

Mont Mou Special Botanical Reserve, 75

Mont Panie Special Botanical Reserve, 77

Montagne des Sources Strict Nature Reserve, 78

Monuafe Island Park and Reef Reserve, 276

Motupore Island Wildlife Management Area, 205

Motu Tabu Closed Area (Kiritimati WS), 107

Motu Upua Closed Area (Kiritimati WS), 108

Mount Gahavisuka Provincial Park, 207

Mount Kaala, 360

Mount Vaea Scenic Reserve, 403

Mount Wilhelm National Park, 209

Nauru, 131

Namanatabu Historic Reserve, 211

Nanuk Island Provincial Park, 213

Naomebaravu-Malo Recreational Reserve, 382

Ndrolowa Wildlife Management Area, 214

New Caledonia (France), 59

Ngaontetaake Closed Area (Kiritimati WS), 107

Ngerukewid Islands Wildlife Reserve, 162

Niue, 135

Northern Mariana Islands, Commonwealth of, 139

North-west Point Closed Area (Kiritimati WS), 108

Nuserang Wildlife Management Area, 216

O Le Pupu Pu'e National Park, 398

Olokui, 360

Orote Peninsula Ecological Reserve Area, 317

Pahole, 361

Palau, 157

Palolo Deep Marine Reserve, 401

Pam Island Special Fauna Reserve, 72
Pangaimotu Reef Reserve, 277

Papua New Guinea, 167

Pati Point Natural Area, 321

Pelekunu Preserve, 368

Phoenix Island (Rawaki) Wildlife Sanctuary, 112

Pokili Wildlife Management Area, 217

President Coolidge and Million Dollar Point Reserve, 383

Pu'u Kukui Watershed Management Area, 369

Pu'uhonua o Honaunau National Historical Park, 352

Puu Alii, 361

Puu Makaala, 362

Puu O Umi, 362

Queen Elizabeth National Park, 250

Ranba Wildlife Management Area, 219

Raoul Island and Kermadec Group Nature Reserve, 417

Rapa Nui (Easter Island) National Park, 415

Republic of Kiribati, 93

Republic of Nauru, 131

Republic of Palau, 157

Republic of the Marshall Islands, 119

Riviere Bleue Territorial Park, 82

Rose Atoll National Wildlife Refuge, 297

Salamaua Peninsula Marine Park, 221

Sarigan Island (de-gazetted), 151

Sawataetae Wildlife Management Area, 223

Sigatoka Sand Dunes National Park and Reserve, 37

Siwi Utame Wildlife Management Area, 225

Solomon Islands, 239

Southern Special Botanical Reserve, 68

Starbuck (Closed Area) Wildlife Sanctuary, 115

Stevenson (Tusitala) Memorial Reserve, 403

Suwarrow Atoll National Park, 12

Takutea Nature Reserve, 16

Talele Islands Nature Reserve, 227

Te Manga Nature Reserve, 18

Thy Territorial Park, 84

Tokelau, 253

Tonda Wildlife Management Area, 228

Tonga, Kingdom of, 257

Tusitala Historic and Nature Reserve, 403

Tuvalu, 281

Uracas Island Preserve, 153

USA - American Samoa, 285 
USA - Guam, 301

USA- Hawaii, 327

Wallis and Futuna (France), 89

Vailima Botanic Garden, 403

Vanuatu, 371

Varirata National Park, 233

Vostock Island Wildlife Sanctuary, 117

Waiakea 1942 Lava Flow, 363

Waigani Swamp Provincial Park, 236

Waikamoi Preserve, 369
War in the Pacific National Historic Park, 323

West Maui (Honokowai section), 363

West Maui (Kahakuloa section), 363

West Maui (Lihau section), 364

West Maui (Panaewa section), 364

Western Samoa, 387

Whitesands Recreational Reserve, 385

Yadua Taba Island Crested Iguana Reserve, 40

Yves Merlet Special Marine Reserve, 86 



\section{TAXONOMIC INDEX}

Ablepharus boutonii, 104, 109, 399

Ablepharus boutonii poecilopleurus, 416

Abutilon, 426

Acacia, 229

Acacia auriculiformis, 199, 229

Acacia farnesiana, 353

Acacia koa, 340

Acanthaster, 295, 295

Acanthaster planci, 5, 272, 295, 319, 401-2

Acanthrophis antarcticus, 231

Acanthurus, 192, 295

Acanthurus leucopareius, 149

Acanthurus lineatus, 149, 295

Acanthurus nigrofuscus, 295

Acanthurus triostegus, 295

Acanthus ilicifolius, 187

Acclypha ribularis, 35

Achyranthes, 51

Achyranthes aspera, 421

Achyranthes canescens, 148

Acridotheres fuscus, 36

Acrocephalus aequinoctialis, 104

Acrocephalus caffer aquilonis, 54

Acrocephalus familiaris familiaris, 331

Acrocephalus familiaris kingi, 343

Acrocephalus vaughani taiti, 420

Acrochordus, 215

Acrophorus leucorhachis, 19

Acropora, 79, 150, 164, 192, 276, 278, 420

Acropora digitifera, 79, 81

Acropora humilis, 81, 295

Acropora palifera, 190, 222, 222, 222

Acrostichum, 268, 268

Acrostichum aureum, 187, 199, 236, 268

Actitis hypoleucos, 248

Adenophorus periens, 357

Adiantum fournieri, 70

Adioryx, 192

Aedes albopictus, 52

Aedes polynesiensis, 52

Aerodramus vanikorensis, 322

Agathis, 71

Agathis lanceolata, 83

Agathis ovata, 70, 83

Aglaia mariannensis, 321

Ailuroedus buccoides, 234

Albizia chinensis, 404
Albizia falcataria, 404

Aleurites moluccana, 421

Alpheus mackayi, 268

Alphitonia zizyphoides, 404

Alpinia oceanica, 187

Alstonia, 229

Altemanthera sessilis, 236

Alyxia elliptica, 10

Amblyornis macgregoriae, 216, 225

Ampelopteris prolifera, 236

Amphiprion melanopus, 295

Amphrion, 271, 278

Anadara maculata, 269

Anas laysanensis, 343

Anas superciliosa, 194, 236, 269

Angiopteris longifolia, 10

Anguilla bicolor, 316

Anguilla mormorata, 316

Anous, 54

Anous minutus, 14, 17, 107, 117, 146, 149, 343

Anous stolidus, 11, 14, 17, 107, 111, 117,

$125,129,144,146,149,153,295,298$,

$311,318,343,411,420,428$

Anous tenuirostris, 295, 298

Anthipathidae, 222

Aplonis, 185

Aplonis atrifusca, 292, 399, 404

Aplonis cinerascens, 11

Aplonis opaca, 144, 146, 149, 153, 311, 322

Aplonis tabuensis, 292

Apus pacificus, 269

Aquila audax, 230

Araucaria columnaris, 86

Araucaria cunninghamii, 202

Araucaria humboldtensis, 75

Araucaria hunsteinii, 202

Araucaria muelleri, 83

Araucaria rulei, 75

Archaster, 268

Ardeotis australis, 230

Areca catechu, 310

Arenaria interpres, 14, 104, 125, 129, 144,

$146,149,153,295,298,353,411$

Argroxiphium, 341

Argroxiphium sandwicense, 339

Argroxiphium virescens, 340 
Arillastrum gummiferum, 70

Aristada, 229

Artemisia salina, 105

Artocarpus, 13, 322

Artocarpus altilis, 310

Artocarpus incisa, 187

Artocarpus mariannensis, 321, 324

Ascarina diffusa, 19

Asio flammeus sandwichensis, 340, 346

Asplenium, 51

Asplenium lunulatum, 19

Asplenium nidus, 13, 148, 153, 321

Astrapia stephaniae, 208, 210, 225

Astronidium pickeringii, 292

Astropecten, 268

Atrina, 269

Atya, 316

Avicennia, 199, 229

Avicennia marina, 199

Baiateana knowlesi, 36

Bambusa vulgaris, 35, 314

Banksia dentata, 229

Banksia marginata, 229

Barringtonia, 292, 380-2, 385

Barringtonia asiatica, 314

Barringtonia samoensis, 404

Barringtonia tetraptera, 230

Bidens, 53, 116

Bidens hendersonensis, 420

Bidens pilosa, 116

Bikkia mariannensis, 321

Birgus latro, 14, 51, 104, 118, 164, 420

Bischofia javanica, 404

Blechnum francii, 70

Blechnum milnei, 35

Blechnum orientale, 35

Blechnum procerum, 19

Boehmeria australis, 418

Boerhavia, 13, 13, 51, 103, 103, 111, 113, $125,128,343,426$

Boerhavia albiflora, 100, 111

Boerhavia diffusa, 423-4

Boerhavia repens, 117, 124, 128

Boerhavia tetrandra, 298

Boiga irregularis, 187, 303, 312, 314, 318, 322

Bolmetapan muricatus, 126

Bombax, 234

Brachiaria reptans, 38

Brachylophus fasciatus, 35, 39
Brachylophus vitiensis, 41

Branta sandvicensis, 340-1, 346

Brasiliensis, 153

Brousonettia papyrifera, 251

Bruguiera, 199, 310

Bruguiera gymnorhyza, 268

Bruguiera parviflora, 187

Bryopsis, 295

Bubbia howeana, 410

Buchanania mollis, 187

Bufo marinus, 35, 188, 226, 231, 316, 318

Bulweria bulwerii, 113, 129

Buteo solitarius, 346

Cacenomobius, 356

Caesalpinia decapetala, 418

Caesio, 192

Calappa hepatica, 268

Calidris acuminata, 194

Calidris alba, 14, 298

Caloenas nicobarica, 164

Calophyllum, 131, 218, 229, 248, 380-2, 385, 398

Calophyllum inophyllum, 38

Calophyllum samoense, 292, 292

Campnosperma, 187

Cananga adorata, 404

Canarium samoense, 292, 292, 404

Canavalia, 148

Canavalia maritima, 38

Candoia aspera, 215

Candoia bibroni, 35, 39, 41

Candoia carinata, 164, 187

Canis familiaris, 220, 427

Canthium barbatum, 10

Canthium merrillii, 292

Capparis cordifolia, 149, 149

Capra, 41

Capra hircus, 348, 411

Capsicum, 148

Caranx, 192

Caranx lugubris, 420

Carcharchinus, 384

Carcharchinus amblyrhynchos, 129

Carcharchinus archarchinus, 192

Carcharchinus spallanzoni, 192

Carcinus brevimana, 14

Carcinus perlata, 14

Carcinus rugosa, 14

Cardisoma, 14

Cardisoma carnifex, 104 
Cardisoma hirtepes, 164

Caretta caretta, 295

Carex, 370

Carex alligata, 355, 358, 362

Carlia fusca, 318

Caryothraustes, 353

Cassinia, 410

Cassiopea, 269

Cassis cornuta, 312

Cassytha, 13, 51, 103

Cassytha filiformis, 103

Castanopsis, 234

Castanopsis acuminatissima, 202, 208

Castilloa elastica, 404

Casuarina, 41, 140, 184-5, 213, 248, 259, 310

Casuarina equisetifolia, 38, 41, 308, 316, 321

Casuarius, 184, 204, 208

Casuarius bennetti, 187, 203, 225, 234

Casuarius casuarius, 231

Catharanthus roseus, 353

Caulerpa, 15, 128, 128, 190

Caulerpa ashmeadii, 268

Caulerpa racemosa, 268

Caulerpa serratula, 268

Cecropia palmata, 20

Cedrella odorata, 404

Celtis, 234

Celtis paniculata, 420

Centropyge flammeus, 428

Centropyge nigriocellus, 428

Ceonobita, 109

Ceratophyllum demersum, 236

Ceratopteris thalictroides, 236

Ceriops, 229

Ceriops tagal, 199

Cervus, 308

Cervus mariannus, 321

Cervus timorensis rusa, 230

Cervus unicolor, 321

Cervus unicolor mariannus, 314

Chaetodon, 192, 271, 278, 295

Chaetodon reticulatus, 295

Chara corallina, 194

Chara fibrosa, 194

Chara globularis, 194

Charadrius bicinctus, 411

Charadrius dubius, 224

Charadrius leschenaultii, 194, 224

Charadrius mongolus, 194, 224

Charmosyna amabilis, 36
Chasiempis sandwichensis, 346

Cheilodipterus, 192

Cheilosporum, 295

Cheirodendron, 340

Chelonia depressa, 187

Chelonia mydas, 14, 100, 104, 109, 113, 116, $118,125,164,187,190,215,220,249$, $295,299,311,343,368,420,423-4,426$, 428

Chionochloa conspicua, 410

Chlamydera cerviniventris, 234

Chlamydosaurus kingi, 231

Chlidonias hybridus, 236

Chlidonias niger, 237

Chloris barbata, 199

Chloris cheesemanii, 19

Chonophorus guamemsis, 316

Chorizandra cymbaria, 70

Chorodesmis, 268

Christella dentata, 418

Chromis acares, 295

Chromis caerulea, 149

Chromis caerulens, 278

Chrysalidocarpus lutescens, 185

Chrysiptera leucopomus, 318

Cicinnurus magnificus, 184, 234

Circus approximans, 41

Cladina, 70

Cladonia, 70

Cladophora, 268

Clidemia, 357-8, 360, 362

Clidemia hirta, 35, 293

Cloezia aquarum, 70

Clytorhynchus nigrogularis, 36

Cnemophilus macgregorii, 210

Cocos, 13, 125, 131

Cocos nucifera, 51, 54, 103, 124, 148-9, 163 , $182,185,213,220,300,308,310,314$, $316,321,324$

Codakia divergens, 51

Coenobita perlata, 104, 111, 129

Collocalia spodiopygia, 399, 404

Collocalia vanikorensis, 311

Colluricincla tenebrosa, 164

Colubrina, 13

Colubrina asiatica, 149, 153

Commersonia bartramia, 35

Conus pulicarius, 269

Coprosma, 339

Coprosma actuifolia, 417 
Coprosma laevigata, 10

Coprosma petiolata, 417

Cordia, 13, 248, 254, 278

Cordia lutea, 53

Cordia subcordata, 116, 149, 353

Cordina, 316

Cordyline terminalis, 421

Corvus, 213

Corvus kubaryi, 308, 314, 322

Corypha, 230

Costularia fragilis, 70

Costularia xyridioides, 70

Cracticus mentalis, 234

Crassocephala crepidioides, 35

Craterocelis nigrorufa, 234

Crinum asiatica, 148-9

Crocethia alba, 129

Crocodylus, 220, 236

Crocodylus novaeguineae, 194, 197, 231

Crocodylus porosus, 164, 194, 197, 224, 231, 249

Crossostylis biflora, 292

Cryptoblepharus, 226

Cryptoblepharus boutonii, 42

Cryptoblepharus boutonii poecilopleurus, 129

Cryptocaria, 410

Crytodactylus, 226

Ctenochaetus striatus, 149, 295

Culcita straminea, 35

Cuscuta campestris, 103

Cyathea, 404

Cyathea affinis, 19

Cyathea alata, 35

Cyathea hornei, 35

Cyathea lunulata, 310

Cycas circinalis, 308, 314, 321

Cyclosorus interruptus, 236

Cyhometra ramiflora, 308

Cymbiola rossiniana, 86

Cynodon dactylon, 353, 416

Cypeomorus, 269

Cyperus, 259, 353, 411

Cyperus javanica, 149, 149

Cyperus platystylis, 230, 236

Cyperus ustulatus, 417

Cypraea annulus, 269

Cypraea moneta, 269

Cypraea tigris, 269

Cypraea vitellus, 269
Cyprinus carpio, 236

Cyrtandra lillianae, 19

Cyrtandra rarotongensis, 10

Dacelo leachii, 230

Dacelo tyro, 231

Dacrycarpus, 210

Dacrydium araucarioides, 83

Dacrydium guillauminii, 70

Dactylopsila trivirgata, 208

Danaus hamata, 215

Dasia smaragdina, 187

Dasyurus albopuncatus, 208

Decapoda, 201

Degeneria vitiensis, 35

Demiguetta sacra, 311

Dendrobium moorei, 410

Dendrocygna arcuata, 194, 236

Dendrolagus, 208

Dendrolaphis lineolatus, 164

Dendronephthya, 192

Dermochelys coriacea, 187, 220, 295

Deschampsia, 339, 339-41, 369-70

Deschampsia nubigena, 355

Desmodium heterophylla, 35

Diadema setosum, 268

Dicramopteris linearis, 35,324

Dicrurus macrocercus, 318

Dictyota, 295

Didunculus strigirostris, 390,399

Dietes, 410

Digitaria, 51, 424

Digitaria mariannensis, 149

Digitaria pacifica, 111, 423

Dillenia alata, 229, 229, 229

Dillenia biflora, 35

Diomedea albatrus, 343

Diomedea immutabilis, 343,428

Diomedea nigripes, 343, 428

Diospyros, 389

Diospyros samoensis, 292

Diplastrea heliopora, 150

Dipteris conjugita, 35

Dischidia, 233

Discodeles, 188

Distichopora violacea, 384

Dobsonia, 215

Dobsonia praedatrix, 187

Dorcopsis hageni, 225

Dorcopsis veterum, 230

Dorcopsulus, 208 
Dorcopsulus vanheurni, 234

Dracontomelon, 187

Drosera, 230

Drosophila, 340, 340

Dryococoelus australis, 412

Dryopteris fatuhivensis, 19

Drypetes, 410

Dubautia, 341

Ducula bicolor, 185

Ducula oceanica, 164

Ducula pacifica, 11, 399

Ducula pickeringii, 215

Dugong dugon, 164, 182, 187, 190, 200-1, 311

Dysoxylum, 389

Dysoxylum huntii, 292

Dysoxylum richii, 38

Dysoxylum samoense, 292

Echinogorgia, 192

Echinopora, 192

Echymipera, 187

Echymipera kalabu, 184

Eclectus roratus, 225

Egretta picata, 236

Egretta sacra, 14, 17, 41, 125, 129, 149, 190, $269,298,311$

Elaeocarpus tonganus, 10

Elapho glossum, 19

Elapho savaiense, 19

Eleocarpus joga, 321

Eleocharis dulcis, 236

Eleotris fusca, 316

Elmerillia, 184

Elmerillia tsiampacca, 203

Emballonura, 164, 187

Emballonura semicaudata, 149, 399

Emoia callistica, 187

Emoia concolor, 35, 41

Emoia cyanogaster, 215

Emoia cyanura, 35, 42, 118, 187, 399

Emoia parkeri, 35

Emoia samoensis, 399

Emoia trossula, 41

Emoia werneri, 318

Emydura, 231

Enhalus acoroides, 206, 310, 324

Epimachus fastuosus, 225

Epimachus meyeri, 208, 225

Epinephelus, 192, 192
Eptesicus sagittula, 411

Eragrostis, 343

Eragrostis xerophila, 53

Eremophylla, 227

Eretmochelys imbricata, 149, 164, 187, 220 , $249,295,299,311,322,384$

Eriachne, 229

Eriocaulon, 70

Eriochloe procera, 199

Erithalis polygama, 51

Erythrina, 144, 146, 234

Erythrura kleinschmidti, 36

Esacus magnirostris, 213, 224

Eucalyptus, 171, 206, 229, 233, 404

Eucalyptus deglupta, 184

Eucalyptus tereticomis, 233

Eudynamis taitensis, 11, 14, 17

Eugenia reinwardtiana, 163

Euglandia, 361

Eunice viridis, 401

Euodia, 10

Eupatorium adenophorum, 341

Euphorbia hirta, 353

Euphorbia ramosissima, 51

Eurya, 210

Euxiphipops, 192

Evodia crassiramis, 187

Evodia elleryane, 184

Excoecaria agallocha, 268

Exocarpus pseudocasuarina, 70

Fagraea berteriana, 10, 292

Favia, 150, 192, 295

Felis catus, 427

Felis domesticus, 35, 41, 411

Ficus, 146, 234

Ficus benghalensis, 310

Ficus obliqua, 268

Ficus prolixa, 321, 324

Ficus ribiginosa, 358

Ficus smithii, 35

Ficus storckii, 35

Ficus vitiensis, 35

Fimbristylis, 13, 357, 359

Fimbristylis cymosa, 149, 353

Fitchia speciosa, 10

Flindersia pimenteliana, 203

Foulehaio carunculata, 292, 399, 404

Fragum unedo, 269

Francolinus francolinus, 318 
Fregata, 190, 343

Fregata ariel, 14, 104, 109, 111, 113, 117, $269,298,423-4,426$

Fregeta grallaria, 411

Fregata minor, 14, 17, 54, 104, 107, 117, 125, $128,146,149,153,295,298,318,416$, 426,428

Freycinetia wilderi, 10

Fulica alai, 352

Fungia, 192

Funtumia elastica, 404

Furcraea foetida, 418

Gafrarium pectinatum, 51

Gafrarium tunidum, 269

Gahnia novocaledonensis, 70

Galaxea, 295

Galaxias, 70

Galaxias neocaledonicus, 70

Gallicolumba rubescens, 54

Gallicolumba xanthonura, 146, 149, 308, 314,322

Gallinula tenebrosa, 236

Gallirallus owstoni, 308, 322

Gallus gallus, 54

Gandenia aubryi, 70

Garimia myrtifolia, 35

Gamotia cheesemanii, 19

Gecarcoidea lalandii, 164

Gecko vittatus, 187

Gehyra mutilata, 104

Gehyra oceanica, 42

Gelidiopsis intricata, 149

Geograpsus grayii, 104, 111

Geranium arboreum, 340

Girroneira celtidifolia, 35

Gleichenia, 3, 208

Glyphidodontops cyanea, 295

Glyphidodontops glaucus, 295

Glyphidodontops leucopomus, 295

Gnetum, 184

Goniastrea, 295

Goniastrea retiformis, 150

Goniopora, 192

Gonocephalus, 226

Gonystylus punctatus, 35

Gossypium hirsutum, 148

Gouania hillebrandii, 364

Goura, 204

Gracilaria, 268

Grammitis hookeri, 19
Grapsidae, 14

Gretum gnemon, 187

Grevillea glauca, 229, 229

Grus rubicunda, 230

Guamia mariannae, 321

Guettarda, 13, 254, 278

Guettarda speciosa, 51

Gulubia microcarpa, 35

Gulubia palauensis, 163,163

Gygis alba, 11, 14, 17, 54, 107, 107, 117, 125, $129,144,146,149,153,295,298,311$, 420,424

Gygis alba microrhynca, 54

Gymnomyza aubryana, 83

Gymnomyza samoensis, 390, 399

Gymnostoma deplancheanum, 69

Gymnothorax flavomarginatus, 192, 384

Gymnothorax javanicus, 129

Halcyon chloris, 144, 149, 153

Halcyon cinnamomina, 308, 314

Haliaeetus leucogaster, 190

Haliaeetus sanfordi, 248

Haliastur indus, 248

Halicarcinus lacustris, 412

Halimeda, 295

Halimeda discoidea, 268

Halodule, 268

Halophilia ovalis, 268

Hanguana malayana, 236

Harpyopsis novaeguineae, 203, 210, 231

Hawaiioscia, 355

Hebe breviracemosa, 418

Hedychium gardnerianum, 348

Hedyotis, 148

Hedyscepe, 410

Hedyscepe canterburyana, 411

Heliopora coerulea, 150

Heliotrope, 17

Heliotropium, 103, 103, 108

Heliotropium anomalum, 103

Hemidactylus frenatus, 318

Hemignathus lucidus affinus, 340

Hemignathus virens, 346

Hemignathus wilsoni, 346

Hemiscyllium ocellatum, 192

Hernandia sonora, 149

Herpestes auropunctatus, 35, 41, 348

Herpestes griseus, 353

Herpolitha, 192

Heterocentrotus, 420 
Heterocentrotus trigonarius, 420

Heteroscelus brevipes, 149, 194

Heteroscelus incanus, 14, 17, 104, 118, 125, $129,149,298,338,353$

Hibiscus, 13, 144, 227, 374

Hibiscus tiliaceus, 10, 38, 53, 148, 268, 268, $276,278,314,316,321,404$

Himantopus leucocephalus, 194, 224, 236

Himantopus mexicanus knudseni, 352

Himatione sanguinea, 340, 346

Himatione sanguinea freethi, 331

Hippopus hippopus, 126, 129

Hipposideros galeritus, 187

Hirunda tahitica, 269

Holcus lanatus, 341

Holocentrus, 271, 278

Holothuria atra, 51, 268

Holothuria edulis, 268

Holothuria impatiens, 268

Holothuria leucospilota, 268

Homalanthus nutans, 404

Homalanthus polyandrus, 417

Homalium acuminatum, 10

Homalium kanaliense, 70

Homoeostrichus flabellatus, 149

Homstedtia lycostoma, 187

Howea, 410

Howea belmoreana, 410

Howea forsterana, 410, 412

Hydnophora, 192

Hydrocharis dubia, 236

Hymenachne acutigluma, 236

Hymenachne pseudointerrupta, 230

Hymenophyllum involucratum, 19

Hyomys goliath, 225

Hyptis pectinata, 35, 149

Imperata, 229, 229, 229-30

Imperata cylindrica, 199, 230, 233

Intsia bijuga, 163, 308, 321

Ipomoea, 116, 343, 353

Ipomoea aquatica, 236

Ipomoea brasiliensis, 38,38

Ipomoea pes-caprae, 148-9, 308, 310, 321

Ipomoea pes-caprae brasiliensis, 418

Irediparra gallinacea, 236

Iridomyrmex humilis, 348

Ischaemum polystachyum, 236

Ixora bracteata, 10

Jania capillacea, 149

Katsuwonus pelamis, 192
Kleinhovia hospita, 404

Kyphosus cinarascens, 149

Lalage sharpei, 404

Lambis lambis, 269

Lantana, 361

Lantana camara, 10

Lasiurus cinereus semotus, 346

Lates calcifer, 231

Laticauda colubrina, 164, 192, 269

Laurencia, 295

Laurencia succisa, 149

Leea indica, 187

Leersia hexandra, 236

Leiolopisma lichenigera, 412

Lemna perpusila, 194

Lentipes concolor, 340

Lepidium, 51

Lepidochelys olivacea, 295

Lepidodactylus lugubris, 104, 109, 111, 318, 416

Lepidorrhachis, 410

Leptiora, 192

Leptoria phrygia, 81

Lepturus, 13, 100, 103, 113, 125, 128, 398, 424

Lepturus gasparricensis, 128

Lepturus pilgerianus, 111,113

Lepturus repens, 103, 116, 124, 128, 128, 426

Lethrinus, 270

Leucaena glauca, 354

Leucaena leucocephala, $38,316,318,353$

Liasis, 226

Liasis papuensis, 234

Libocedrus, 210

Libocedrus yateensis, 83

Limosa lapponica, 269, 411

Linckia laevigata, 268

Linociera ligustrina, 348

Liparis clypeolum, 19

Lithocarpus rufovillosus, 208

Lithothamnion, 128

Litsea, 187

Lobophora variegata, 149

Lobophyllia, 150

Loecenia, 53

Lonchura castaneothorax, 54

Lonchura nevermanni, 231

Lorentzimys nouhuysi, 225

Loria loriae, 208

Lorius lory, 225 


\section{Loxops coccinea, 346}

Loxops coccinea ochracea, 340

Loxops maculatas newtoni, 340

Loxops virens wilsoni, 340

Lucina, 269

Ludwigia adscendens, 236

Ludwigia hyssopifolia, 236

Ludwigia octovalvis, 35, 194, 236

Lumnitzera, 310

Lumnitzera lottorea, 268

Lutjanus, 192, 270, 295

Lutjanus argentimaculatus, 384

Lutjanus bohar, 126

Lutjanus fulvus, 129

Lutjanus gibbus, 126

Lycopodium cernum, 35, 310, 324

Lysiosquilla, 268

Macaranga stipulosa, 404

Macaranga thompsonii, 321

Macrobrodhium las, 316

Macroglossus, 187

Macropiper latifolia, 10

Macropus agilis, 230

Macrothelypteris torresiana, 418

Mallomys argentata, 225

Mallomys hercules, 225

Mallomys rothschildi, 225

Malurus alboscapulatus, 237

Mangifera, 229

Mangifera inocarpoides, 229, 229

Mannea oderata, 314

Manucodia comrii, 224

Marsilea crenata, 236

Marsilea villosa, 366

Megacrex inepta, 231

Megalurus albolimbatus, 231

Megapodius, 190, 197, 220

Megapodius eremita, 187

Megapodius freycinet, 218, 218, 248

Megapodius laperouse, 146, 149, 152, 154, 164

Megaptera novaeangliae, 295

Meiolania platyceps, 410

Meioneta, 355

Melaleuca, 74, 229, 229, 229, 229, 229, 229, 229-30, 233, 410

Melaleuca brongnartii, 70

Melaleuca cajaputi, 229

Melaleuca gnidioides, 70

Melaleuca quinquenervia, 85
Melaleuca viridiflora, 229-30

Melamprosops phaeosoma, 340

Melidectes princeps, 210

Melidetes belfordi, 225

Melochia compacta, 149

Melomys fellowsi, 225

Melomys hageni, 225

Melomys levipes, 225

Melomys rufescens, 184

Melonycteris melanops, 187

Merrilliodendron megacarpum, 321

Meryta pauciflora, 10

Messerschmidia, 17, 103, 108, 299, 343

Messerschmidia argentea, 103, 298, 310, 321

Metapenaeus ensis, 268, 270

Metrosideros, 340

Metrosideros collina, 10

Metroxylon sagu, 171, 187, 212, 214

Miconia calvescens, 56

Microeca papuana, 225

Micromelum pubescens, 187

Micropsitta meeki, 215

Microsicydium elegans, 316

Mikania micrantha, 19, 35

Millepora, 420

Millepora platyphylla, 150

Milvus migrans, 182

Mimosa pudica, 35

Miscanthus, 140, 208

Miscanthus floribundus, 35

Miscanthus floridulus, 149, 153, 310, 324

Monachus schauinslandi, 343, 427

Monarcha infleix, 215

Monochoria hastata, 236

Monocodia atra, 234

Monocodia chalybata, 234

Montipora, 192

Morinda, 146

Morinda citrifolia, 51, 148, 153, 353

Morphopsis meeki, 208

Mucuna novoguineensis, 184

Mugil cephalus, 270

Murexia longicaudata, 184

Mus musculus, 109, 353, 411, 427

Myiagra erythrops, 164

Myiagra freycineti, 308, 322

Myiagra rubecula, 234

Myoporum, 51

Myrica faya, 348

Myripristis, 192 
Myristica, 187, 187, 234, 404

Myristica castaneifolia, 35

Myristica fatua, 292, 404

Myristica hypargyaea, 292

Myrsine hoskae, 420

Myzomela cardinalis, $292,308,314,322$, 322, 399

Myzomela rubrata, 144, 146, 149, 153

Nageia minor, 70

Najas indica, 236

Najas tenuifolia, 194

Nasella, 416

Naso lituratus, 149

Nectarinia, 213

Neisosperma, 144, 146

Neisosperma oppositifolia, 149, 308

Nelumbo, 230

Neocallitropsis pancheri, $70,70,70$

Neoveitchia storckii, 35

Nepenthes, 230

Nephrolepis, 140, 353

Nephrolepis biserrata, 194

Nephrolepis cordifolia, 418

Nephrolepis hirsutula, 136

Nerita plicata, 269

Nerita undata, 269

Nesofregatta albigularis, 104, 107, 111, 113

Nesofregatta fuliginosa, 424

Nesophylax ater, 420

Nothofagus, 225

Numenius americanus, 248

Numenius minutus, 230

Numenius phaeopus, 248, 318, 411

Numenius tahitiensis, 14, 17, 104, 118, 125 , $129,298,428$

Nyctophilus howensis, 410

Nymphaea, 230

Nymphaea dictyophlebia, 236

Nymphaea pubescens, 236

Nymphoides indica, 236

Nypa fruticans, 187, 187, 199

Oceanodroma matsudairae, 144, 149

Ochrosia oppositifolia, 321

Ocypode, 14, 104

Ogmodon vitianus, 35

Olea africana, 418

Olearia, 210

Omalanthus nutans, 19

Operculina ventricosa, 149

Ophioglossum pendulum, 321
Orectolobus dasypogon, 192

Oreochromis mossambicus, 236

Oreomystis mana, 346

Oreophryne brachypus, 188

Ornithoptera chimaera, 208

Ornithoptera priamus, 215

Oryctes rhinoceros, 254

Oryctolagus cuniculus, 113,427

Oryza, 230

Otus podarginus, 164

Oxalis gagneorum, 53

Oxyuranus scutellatus, 231

Pachycare flavogrisea, 234

Pachycephala pectoralis contempta, 412

Pachycephala rufiventris, 234

Pachyclavularia violacea, 319

Palaquium stehlinii, 404

Palmeria dolei, 340

Palythoa, 295

Pancheria communis, 70

Pandanus, 13, 17, 17, 38, 38, 51, 131, 144, $146,171,184,208,218,230,248,268$, $268,292,390,398-9,411-2$

Pandanus fragrans, 308, 314, 316, 321

Pandanus kirkii, 310

Pandanus maximum, 38, 38

Pandanus odoratissimus, 353

Pandanus pedunculatus, 410

Pandanus tectorius, 53, 124, 124, 148, 420

Pandion haliaetus, 86, 248

Panicum, 230

Panicum maximum, 38

Panulirus, 104, 215

Panulirus penicillatus, 420

Papilio aegeus, 215

Papilio ulysses, 215

Papuacedrus, 210

Paradisaea guilielmi, 216

Paradisaea minor, 184

Paradisaea raggiana, 184, 231, 234

Parahalomitra, 192

Parahydromys asper, 184

Parapeneus, 295

Parasitaxis ustus, 78,83

Paratya howensis, 412

Parinari, 229

Parotia lawesii, 208

Parthenos sylvia, 215

Parupeneus, 192

Paspalum conjugatum, 19 
Passer montanus, 318

Passiflora, 353

Passiflora suberosa, 359

Pecten, 269

Pemphis, 13, 13

Pemphis acidula, 51, 308, 318, 321

Penaeus semisulcatus, 270

Penaeus sensculcatus, 268

Pennisetum clandestinum, 341

Pennisetum polystachyon, 310, 324

Pennisetum setaceum, 348

Pentacarya anoniala, 51

Perca, 201

Periglypta, 269

Periophthalmus, 269

Peroryctes, 208, 225, 234

Peroryctes raffrayanus, 184

Petaurus, 187

Petaurus australis, 225

Petaurus breviceps, 225

Peterodroma arminjoniana, 20

Petesia camosa, 51

Phaeomis obscurus, 346

Phaethon lepturus, $11,125,144,146,149$, $153,295,298,311$

Phaethon lepturus dorotheae, 340

Phathon rubricauda, 14, 17, 104, 107, 125, $129,146,149,153,298,411,416,420$

Phalacrocorax melanoleucos, 194

Phalanger, 182, 187, 197, 208, 220, 224

Phalanger maculatus, 215

Phalaropus lobatus, 194

Pheidole megacophala, 353

Phigys solitarius, 36

Philemon albitorques, 215

Phragmites karka, 230, 230, 236, 316

Phyllanthus, 144

Phyllanthus amarus, 149

Phyllanthus marianus, 149

Phyllodactylus guentheri, 412

Phymatodes, 19

Phymatodes scolopendria, 153, 308

Phymatosorus, 13

Physeter catodon, 295

Pinctada maculata, 51

Pinctada margaritifera, 14, 126, 269

Pinctada maxima, 15

Pinus, 404

Piper aduncum, 35

Piper guahamense, 321
Pipturus argenteus, 148, 153, 404

Pisonia, 13, 17, 117, 124, 124, 124, 124-5, $248,254,298,298-9$

Pisonia brunoniana, 418

Pisonia grandis, 53, 53, 103, 107-8, 117 , $124-6,128,148-9,298,321$

Pistia stratoites, 236

Pithecellobium dulce, 316, 354

Pitta sordida, 225

Pitta superba, 215

Pittosporum, 210

Pittosporum arborescens, 10

Placostylus, 410, 412

Planchonella, 340

Planchonella linggenensis, 292

Planchonella torricellensis, 292

Platygyra daedalea, 81

Platymantis papuensis, 188

Platymantis vitiensis, 35

Plectorhynchus, 192

Plectroglyphidodon dickii, 295

Pleomele, 340

Pluchea indica, 199

Pluvialis, 17

Pluvialis dominica, 14, 104, 118, 125, 129 , $146,149,194,224,269,298,318,353$, 411

Pluvialis dominica fulva, 340

Poa, 411

Pocillopora, 81, 150, 192, 319, 420

Pocillopora damicomis, 79

Pocillopora verrucosa, 79, 295

Podargus, 225

Podocarpus, 71

Pogonoculius zebra, 318

Polygonum barbatum, 236

Polypodium, 51

Polypodium scolopendria, 148

Polyscias, 187

Polysiphonia, 149

Pomacentrus melanopterus, 149

Pomachromis guamensis, 318

Pomarea dimidiata, 4, 10

Pomarea iphis fluxa, 54

Pometia pinnata, 251, 404

Pometia tomentosa, 187, 203

Porites, 164, 192, 222, 254, 269, 311

Porites lobata, 51

Porites lutea, 81, 150, 295

Porphyrio porphyrio, 236 
Portulaca, 53, 103, 103, 113, 125, 128, 149, 424

Portulaca lutea, $100,103,111,113,116$, $124-5,128,298,343,423,426$

Portulaca oleracea, 103

Porzana palmeri, 331

Procelsterna cerulea, 100, 104, 107, 109, 111 , 295, 343, 411, 420, 424

Promicrops lanceolatus, 384

Prosopsis pallida, 354

Pseudechis papuans, 231

Pseudocheirus, 225

Pseudocheirus albertisi, 225

Pseudocheirus mayeri, 225

Pseudonestor xanthophrys, 340

Pseudopanax arboreus, 418

Pseudophegopteris, 19

Pseudoraphis spinescens, 230, 230

Psidium cattleianum, 10, 348, 341

Psidium guayava, 10

Psidium littorale, 418

Psilotum, 51

Psittirostra psittacea, 346

Pteridophora alberti, 208

Pteris quadriaurita, 148

Pterodroma alba, 104, 107-8, 420, 425

Pterodroma arminjoniana, 420

Pterodroma externa, 418

Pterodroma neglecta, 411, 416, 418, 420

Pterodroma nigripennis, 411, 418

Pterodroma phaeopygia sandwichensis, 340 , 346,367

Pterodroma solandri, 411

Pterodroma ultima, 420

Pterois volitans, 412

Pteropus, 11, 154, 404

Pteropus admiraltatum, 215

Pteropus macrotis, 187

Pteropus mariannus, 144, 146, 149, 308, 311, $314,318,321$

Pteropus samoensis, 35, 292, 399

Pteropus tonganus, 35, 41, 292, 295, 399

Ptilinopus, 292

Ptilinopus aurantiifrons, 237

Ptilinopus insularis, 420

Ptilinopus pelewensis, 164

Ptilinopus rarotongensis, 11

Ptilinopus roseicapilla, 308, 322

Ptiloris magnificus, 234

Puffinus, 343
Puffinus assimilis, 411

Puffinus carneipes hullianus, 411

Puffinus l'herminieri, 111, 113

Puffinus nativitatis, 104, 107-8, 113, 129

Puffinus newelli, 366

Puffinus pacificus, 104, 107, 113, 144, 149, $411,418,420,424,428$

Puffinus tenuirostris, 318

Pycnonotus cafer, 36, 404

Quercus, 184

Ramalina, 51

Rana novaebritannae, 188

Rattus exulans, 14,41,54, 100, 103, 109,111, $116,117,125,129,145,147,299-300$, $399,418,421$

Rattus leucopus, 225

Rattus norvegicus, 154, 348, 353, 418

Rattus rattus, $103,129,225,348,353,413$, 427

Rattus verecundus, 225

Reynoldsia lanutoensis, 292

Rhipidura lepida, 164

Rhipidura nebulosa, 404

Rhipidura rufifrons, 322

Rhipidura semirubra, 215

Rhizophora, 199, 229, 278, 310

Rhizophora mucronata, 163, 187

Rhizophora samoensis, 268, 268

Rhizophora stylosa, 268

Rhododendron, 210

Rhus taitensis, 404

Rhynchelytrum repens, 353

Rhynchospora corymbosa, 153

Rhynochetos jubatus, 83

Rhyticeros plicatus, 197

Rorippa gigantea, 418

Rousettus amplexicaudatus, 187

Sagittaria platyphylla, 236

Salvinia molesta, 236, 236-7

Santalum haleakalae, 340

Santalum hendersonense, 420-1

Sarcocephalus coadunata, 229-30

Sargassum, 79

Saurauia, 208

Scaevola, 13, 17, 103, 108, 128, 227, 254, 398

Scaevola sericea, 124, 128, 128

Scaevola taccada, 38, 103, 148, 153, 308, $310,318,321$

Scarus, 295

Scaveola, 51 
Schefflera, 210

Schinus terenthifolia, 354

Schizaea dichotoma, 70

Schizaea laevigata, 70

Schoenus, 230

Schoenus brevifolius, 70

Scirpus grossus, 236

Scirpus nodosus, 19

Sclerotheca viridiflora, 10, 19

Scolopsis, 192

Scorpaenopsis, 192

Scylla serrata, 268

Securinega flexuosa, 404

Sehima nervosum, 233

Senecio lautus esperensis, 418

Sephemomorphus elegantulum, 188

Sepia apana, 215

Seriathes nelsonii, 308

Seriatopora, 192

Sericomis arfakianus, 234

Sericornis nouhuysi, 225

Sesuvium, 113, 113, 113

Sesuvium portulacastrum, $100,103,111$, $113,117,199,426$

Sicypeterus macrostetholepis, 316

Sida, 103, 113, 113, 128, 128, 128, 423, 426

Sida fallax, 100, 103, 108, 111, 113, 116, 128

Siganus, 192

Sinularia, 192

Solanum torvum, 35

Sonneratia, 199

Sonneratia alba, 187, 199

Sophora, 339

Sophora toromiro, 416

Spathodea campanulata, 35, 316

Spathoglottis plicata, 324

Sphyraena barracuda, 192

Sphyma lewini, 192

Spinifex hirsutus, 38

Spirodela polyrhiza, 236

Sporobolus indicus, 416

Sporobolus virginicus, 199

Squilla, 268

Stegastes albofasciatus, 295

Stenella, 215, 295

Stenotaphrum micranthum, 149

Sterna, 248, 343

Sterna bergii, 14, 194, 269
Sterna fuscata, 14, 54, 104, 107-9, 113, 116, $118,125,129,144,146,149,298,298$, $411,418,423-4,426,428$

Sterna hirundo, 318

Sterna lunata, 104, 109, 111, 146, 295, 298

Sterna nareis, 269

Sterna sumatrana, 14, 298

Stichopus chloronotus, 268

Stichopus variegatus, 268

Stiltia isabella, 224

Stipa, 416

Strepera graculina crissalis, 412

Streptopelia, 353

Streptopelia bitorquata, 318

Stromatopteris moniliformis, 70

Strombus gibberulus, 269

Sturnus vulgaris, 237

Stylophora, 192

Styphelia, 339

Styphelia longistyles, 70

Stypopodium hawaiiensis, 149

Sula, 54, 343

Sula dactylatra, 14, 17, 100, 104, 109, 113, $117,125,149,153,298,411,420,423-4$, 426,428

Sula leucogaster, 14, 17, 100, 109, 117, 125, $128,144,146,149,153,295,298,311$, 424

Sula sula, $14,17,107,109,117,125,128$, $146,149,153,295,298,423-4,426,428$

Suriana, 17, 51, 103, 108

Suriana maritima, 103

Sus, 225

Sus domestica, 411

Sus scrofa, 35, 41, 54, 182, 187, 197, 208, $220,224,234,316,341,348,399$

Swietenia mahogoni, 33

Synoga lysicephala, 229

Syringodium, 164

Syzygium, 229

Syzygium effusum, 35

Syzygium inophylloides, 292, 404

Syzygium richii, 38

Syzygium samarangense, 292

Syzygium samoense, 292, 292

Tachybaptus novaehollandiae, 236

Tachybaptus ruficollis, 194

Tachyglossus aculeatus, 230

Taeniophyllum mariannense, 321 
Tanysiptera hydrocharis, 231

Tarenna leiloba, 70

Tasmannia, 210

Tecticornia cincrea, 199

Tekoulina, 20

Tellina, 269

Terminalia, 144, 146, 203, 229, 234, 380-2, 385

Terminalia catappa, 148-9

Terpios, 312

Tetramolopium, 341

Tetramolopium rockii, 368

Thalamita prymna, 268

Thalasseus bergii, 107

Thalassoma hardwickei, 295

Themeda australis, 184, 199, 233

Themeda novoguineensis, 199

Thespesia, 278

Thespesia populnea, 421

Thespia populnea, 53

Thylogale, 187

Thylogale stigmatica, 225, 230

Tibouchina, 357

Tolypiocladia glomerulata, 149

Tournefortia, 51, 124, 124-5, 125, 128, 128, $128,128,254$

Tournefortia argentea, 124, 128

Toxopnuestes pileolus, 268

Trema orientalis, 149

Triaenodon obesus, 192

Tribulus, 103, 111, 116

Tribulus cistoides, $111,111,116,343,423-4$, 426

Tricholimnas sylvestris, 411

Trichomanes, 19

Trichomanes digitatum, 19

Tricostularia, 230

Tricostularia guillauminii, 70

Tridacna, 15, 254, 295, 299, 320

Tridacna gigas, 129

Tridacna maxima, 14, 51, 126, 129, 271, 273 , 275-6, 278, 299

Tridacna squamosa, 129, 271, 273, 278

Tringa hypoleucos, 194

Tringa totanus, 237

Triphasia trifolia, 314, 324

Tripnuestes gratilla, 268

Tristania, 229, 229, 229, 229

Tristania suaveolens, 229
Tristeropsis obstusangula, 321

Triumfetta, 13, 124

Triumfetta procumbens, $113,124,423-4$

Trochus, 126

Trochus niloticus, 15

Tropaeolum majus, 348

Tubastrea, 192

Turbinaria, 79, 128, 192

Tursiops truncata, 295

Typha orientalis, 236

Tyto alba, 41

Uca, 14

Uca lactea, 269

Ulva, 295

Uromys neobritannicus, 187

Urtica, 51

Usnea, 233

Utricularia, 70, 70

Utricularia aurea, 230

Vaccinium, 210, 339

Vaccinium cereum, 19

Vanellus miles, 236

Varanus, 231

Varanus indicus, 308, 318, 322

Vavaea amicorum, 41

Vernonia cinerea, 149

Vestiaria coccinea, 340, 346

Vini kuhlii, 104

Vini stepheni, 420

Vitex, 229, 234

Vitex coffasus, 251

Vitex negundo, 148

Vitex trifoliata, 38

Wedelia biflora, 149, 153, 308, 321

Weinmannia affinis, 292

Weinmannia samoensis, 10

Xanthostemon, 229, 229

Xanthostemon aurantiacum, 70

Xylocarpus, 268

Xylocarpus granatum, 268

Xylopia pacifica, 35

Xylosma gracile, 10

Xyris neocaledonica, 70

Xyris pancheri, 70

Zingiber zerumbet, 19

Zosterops conspicillata, 308, 322

Zosterops finschii, 164

Zosterops tephropleura, 412

Zoysia matrella, 149 

This book is part of

THE IUCN CONSERVATION LIBRARY

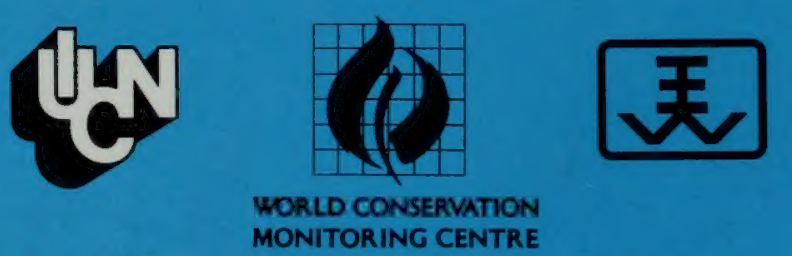

For a free copy of the complete catalogue please write to: IUCN Publications Services Unit 219c Huntingdon Road, Cambridge, CB3 ODL, UK

17. Communications Unit,

W. Whont-Blanc, $\mathrm{CH}-1196$ Gland, Switzerland (1) 